\title{
2007 Annual Report
}

\section{Summer Research Institute Interfacial and Condensed Phase Chemical Physics}

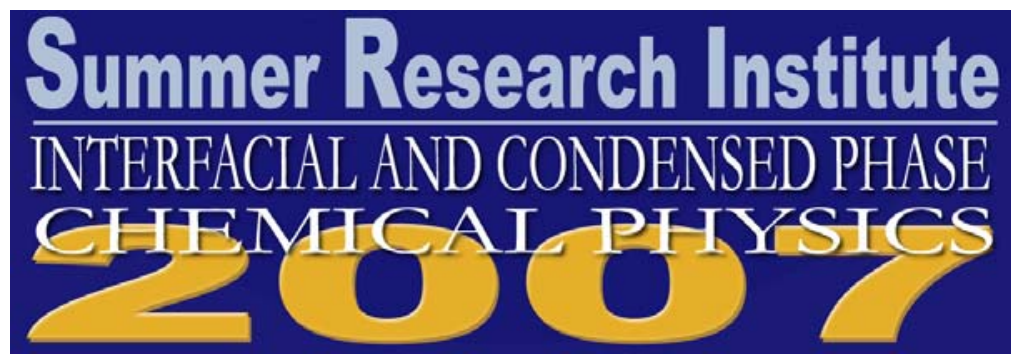




\title{
DISCLAIMER
}

This report was prepared as an account of work sponsored by an agency of the United States Government. Neither the United States Government nor any agency thereof, nor Battelle Memorial Institute, nor any of their employees, makes any warranty, express or implied, or assumes any legal liability or responsibility for the accuracy, completeness, or usefulness of any information, apparatus, product, or process disclosed, or represents that its use would not infringe privately owned rights. Reference herein to any specific commercial product, process, or service by trade name, trademark, manufacturer, or otherwise does not necessarily constitute or imply its endorsement, recommendation, or favoring by the United States Government or any agency thereof, or Battelle Memorial Institute. The views and opinions of authors expressed herein do not necessarily state or reflect those of the United States Government or any agency thereof.

\author{
PACIFIC NORTHWEST NATIONAL LABORATORY \\ operated by \\ BATTELLE \\ for the \\ UNITED STATES DEPARTMENT OF ENERGY \\ under Contract DE-AC06-76RL01830
}

Printed in the United States of America

$$
\begin{aligned}
& \text { Available to DOE and DOE contractors from the } \\
& \text { Office of Scientific and Technical Information, } \\
& \text { P.O. Box 62, Oak Ridge, TN 37831-0062; } \\
& \text { ph: (865) 576-8401 } \\
& \text { fax: (865) 576-5728 } \\
& \text { email: reports@adonis.osti.gov }
\end{aligned}
$$

\footnotetext{
Available to the public from the National Technical Information Service, U.S. Department of Commerce, 5285 Port Royal Rd., Springfield, VA 22161 ph: (800) 553-6847 fax: (703) 605-6900

email: orders@ntis.fedworld.gov

online ordering: http://www.ntis.gov/ordering.htm
} 
Kenneth M. Beck

Coordinator

ICPCPSRI

(509) 376-9152

Email: cpsi.pnl.gov

Website: http://www.pnl.gov/si 


\section{Annual Report}

\section{Summer Research Institute Interfacial and Condensed Phase Chemical Physics}

October 2007

Prepared for

the U.S. Department of Energy under Contract DE-AC06-76RL01830 
PNNL-17069

\section{Executive Summary}

The Pacific Northwest National Laboratory (PNNL) hosted its fourth annual Summer Research Institute in Interfacial and Condensed Phase Chemical Physics from April through September 2007. During this time, 21 PNNL scientists hosted 23 participants from 20 different universities. Of the 23 participants, 20 were graduate students, 1 was a postdoctoral fellow, and 2 were university faculty members. 


\section{Table of Contents}

\begin{tabular}{l|l} 
Executive Summary & iii
\end{tabular}

\begin{tabular}{l|l} 
Contents & V
\end{tabular}

\begin{tabular}{l|l} 
Acknowledgments & 1
\end{tabular}

\begin{tabular}{l|l|} 
Summary & 3
\end{tabular}

\begin{tabular}{l|l} 
Participants and the Institute Structure & 5
\end{tabular}

$\begin{array}{ll}\text { Benefits } & 14\end{array}$

New in FY07

Measures of Success

\begin{tabular}{l|l} 
Participant Survey & 28
\end{tabular}

\begin{tabular}{l|l|} 
Technical Reports & 31
\end{tabular}

Minta C. Akin, Charles Mullins, Greg Kimmel 33

"Suppression of $\mathrm{O}_{2}$ by $\mathrm{CH}_{3} \mathrm{OH}$ "

Adam P. Bateman, Sergey Nizkorodov, Alex Laskin $\quad 53$

"Solvent effects on secondary organic aerosol particles using high resolution mass spectrometry"

Jeremy P. Cain, Hai Wang, Alex Laskin

"Sampling and Heterogeneous Kinetics of Soot from a Flat Flame Burner"

Sara E. Chamberlin, Carol Hirschmugl, Scott Chambers

" $\mathrm{TiO}_{2}$ Anatase(001) : Initial Steps Towards Surface Structure"

Justin W. Cleary, Robert Peale, Ken Beck

"Optimization and Characterization of Gold Black"

Mawanana H Channa R De Silva, Zhiping Zheng, Jun Li

"Theoretical Investigation of Lanthanide(III) $\beta$-diketonates with p,p'-disubstituted bipyridine and phenanthroline type ligands"

Shiyu Du, Joseph Francisco, Greg Schenter

"Many-Body Decomposition of the Binding Energies for $\mathrm{OH} .\left(\mathrm{H}_{2} \mathrm{O}\right)_{2}$ and $\mathrm{OH} .\left(\mathrm{H}_{2} \mathrm{O}\right)_{3}$ Complexes"

Jinlong Gong, Charles Mullins, Zdenek Dohnalek, 
PNNL-17069

Shilpi Gupta, Shalini Prasad, Suntharampillai Thevuthasan

"Sol-gel synthesis of ceria and Yb, Y, Sm and Gd doped ceria"

Prof. Michael R. Hartman, Nancy Hess

"A Quasielastic Neutron Scattering Investigation of the Reorientational Motions of [NH4]+ and [BH4]- Tetrahedra in Ammonium Borohydride"

Win Maw Hlaing Oo, Matthew McCluskey, Lax Saraf

"Ion Beam and Surface Analysis of Conductivity Suppressed Mn Doped ZnO Thin Films Grown by MOCVD"

Adrienne C. Lukaski, Mark Barteau, Chuck Peden

"Fundamental Studies of NOx Adsorbers"

Jacqueline L. Milhans, Hamid Garmestani, Xin Sun

"Modeling of the Effective Elastic and Thermal Properties of

Glass-Ceramic Solid Oxide Fuel Cell Seal Materials"

Leonard Nyadong, Facundo Fernandez, Julia Laskin

"Surface Induced Dissociation of Multiply Charged Peptides in a Fourier

Transform Ion Cyclotron Resonance Mass Spectrometer: Effect of Target

Orientation"

Zachery W. Oestreicher, Zucai Suo, Brian Lower

175

"Using AFM to Study Biological Processes on a Single-Molecules Level"

Saida Y. Ortiz, Matthew Espe, Sarah Burton

"Interface Studies of CdS Nanoparticle/Polymer Composites"

Narendra Singh Parmar, Mark Kuzyk, Lai-Sheng Wang

"The study of gold nanocluster with thiolate ligands using electrospray ionization and photoelectron spectroscopy"

Florian Sieker, Martin Zacharias, T.P. Straatsma

"Analysis of MHC class I peptide dissociation by molecular dynamics simulation"

Aaron Thurber, Alex Punnoose, Ponnusamy Nachimuthu

"Dopant Concentration and Incorporation in Doped Metal Oxide Powders Studied with XPS"

Nicholas S. Wigginton, Michael Hochella, Kevin M. Rosso

"Measuring Electron Transfer Across the Nanoscale Space Between Bacterial Cytochromes and Oxide Surfaces" 
PNNL-17069

Xiang Xia, Yanwen Zhang

"Micro-structural and optical properties of $\mathrm{Sn}$ and $\mathrm{SnO}_{2}$ nanoparticles in $\mathrm{Al}_{2} \mathrm{O}_{3}$ by ion implantation and annealing"

Prof. Zhongqing Yu, Theva Thevuthasan

"Conductivity Studies in Oriented Samaria-Doped Ceria Thin Films Grown by Oxygen-plasma-assisted Molecular Beam Epitaxy"

Prof. Zhongqing Yu, Theva Thevuthasan

"Growth and Structure of Epitaxial $\mathrm{Ce}_{0.8} \mathrm{Sm}_{0.2} \mathrm{O}_{1.9}$ by Oxygen-plasma-assisted Molecular Beam Epitaxy"

Peter A. Zink, Uday Pal, Dr. Subhash C. Singhal

"Study of Calcium Doped Lanthanum Ferrite in Single-Step Co-Fired Solid Oxide Fuel Cells"

Appendix

Participant Survey 


\section{Acknowledgments}

This year's scientific oversight committee consisted of Dr. Bruce Kay, Dr. Michel Dupuis, and Dr. Kenneth Beck from Pacific Northwest National Laboratory. Assistance was also rendered by Dr. R. Scott Smith, FSD. Ms. Nikki Avery was our administrator and fullfilled the key role in ensuring the Summer Research Institute ran smoothly.. Ms. Cynthia A. Irwin and Ms. Susan M. Finch provided financial and budgetary support.

The institute also acknowledges Ms. Rebecca J. Janosky of PNNL's Science and Engineering Education Office. She handled a myriad of details associated with appointments, including awards, agreements, and disbursements, while dealing with a major reorganization. In addition, the institute wishes to acknowledge Ms. Carol A. Elledge, Ms. Cori C. Blake, Mr. Mark D. Bayless, and Ms. Rose M. Watt for their expertise and timeliness in creating and developing the institute ${ }^{1} \mathrm{~s}$ website, application website, and finalizing the institute ${ }^{1}$ s brochure.

Finally, we wish to acknowledge the U.S. Department of Energy's Office of Basic Energy Sciences from whom we received the guidance to initiate the Summer Research Institute in Interfacial and Condensed Phase Chemical Physics and from whom support was ultimately derived.

The real stars of the Interfacial and Condensed Phase Chemical Physics Research Institute were our participants. The remainder of this document is largely devoted to them.

Dr. Kenneth M. Beck and Coordinator Ms. Nikki B. Avery

October 2007

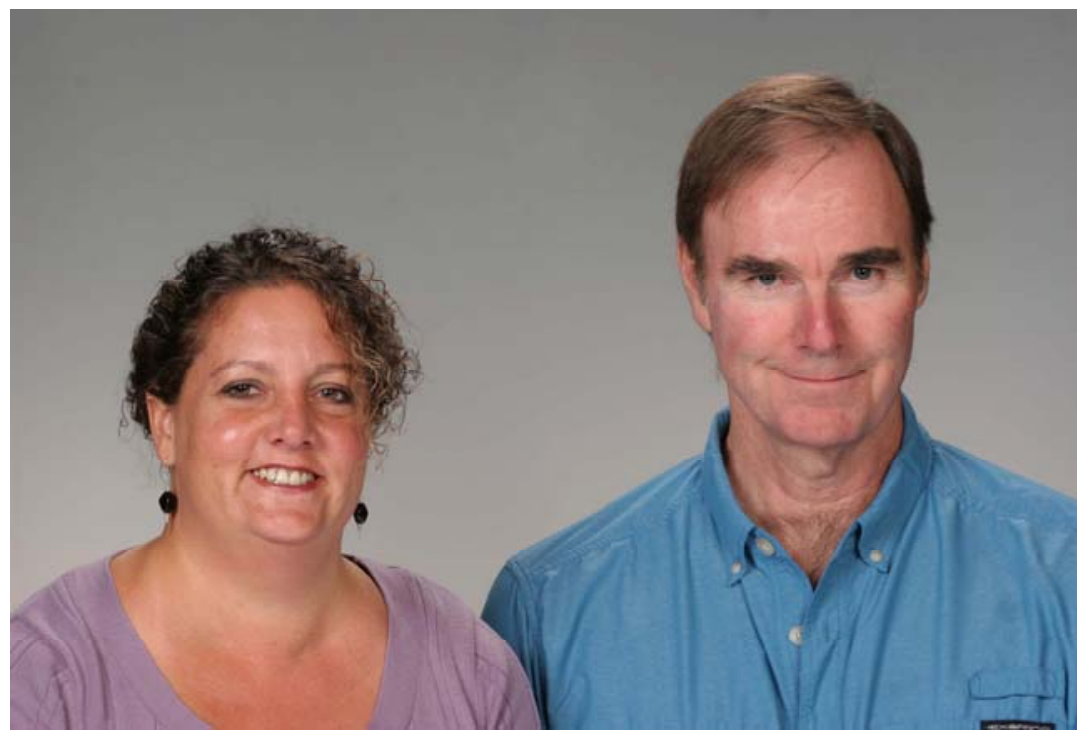


PNNL-17069

\section{Summary}

Pacific Northwest National Laboratory's (PNNL's) Management and Operations Contract with the U.S. Department of Energy (DOE) ${ }^{1}$ Office of Science identified an Office of Basic Energy Sciences (BES) Mission Stretch Goal: "To establish PNNL in a national leadership role in the area of theoretical and experimental condensed phase and interfacial chemical physics research." Successful achievement of a national leadership role will be evidenced by: "Establishment of a summer school (at least two weeks in duration) to educate graduate students and young scientists in state-of-the-art theory, simulation, and experimental measurement, with a total attendance of at least 60 over the contract period."

Interfacial and condensed phase chemical physics is important in nearly every scientific discipline. Technology and engineering in today's world depend to one degree or another on our ability to understand and manipulate condensed phases and interfacial processes.

The guidance from DOE's Office of Science gave PNNL considerable latitude in implementing the Summer Research Institute (SRI) advanced program that focuses on graduate students, postdoctoral fellows, and university faculty. The SRI caters more to graduate students and early career scientists than generally accommodated by PNNL's summer internship programs. The best education people at this level can receive is to actively engage in research that is relevant to their own career development goals. To accomplish this objective, SRI has a different character and puts different requirements on its participants than do either the standard internship programs or other institutes, workshops, etc. Perhaps the best overall description of the institute is a "visiting scientist program for early career researchers." In this spirit, each young scientist's particular program was individually tailored. The descriptions given in this report are generally true for most of the young scientists but may not apply to any particular individual.

\section{Participants and the Institute Structure}

Prospective visitors applied electronically at the Summer Research Institute's website: http://www.pnl.gov/si/. Submission of applications, screening, and correspondence were all handled online. This greatly facilitated the review and screening process as well as recordkeeping. Preliminary screening was handled by the SRI Administrator, in consultation with the Co-ordinator. The Administrator acknowledged receipt of the applications and informed the candidates of any additional information or actions that were necessary to complete the application process. A number of candidates were found to be unsuited to participate in the institute, and they were informed as quickly as that determination could be made. Reasons for rejection included:

- Candidate's area of interest was outside of the scope of the program

- Prospective PNNL hosts were already committed or unavailable

- Candidate was finishing a Master's or PhD degree and did not have a new position

- Candidate failed to finish the application process.

1 Appendix H of Contract Number: DE-AC06-76RL01830, Modification M375. 
Candidates who passed this first series of hurdles and who identified a willing PNNL host were then required to submit a summary of proposed research or activity that they would conduct at PNNL during the summer. Normally, this proposal was prepared with the assistance of both the PNNL host and the candidate's academic advisor (as appropriate). Once the application deadline had passed, all completed applications were reviewed by a PNNL science panel chaired by Dr. Kenneth M. Beck, Co-ordinator of the ICPCPSRI, and consisting of Drs Bruce Kay and Michel Dupuis . All successful candidates received the unanimous approval of the panel. Individual acceptance and rejection letters were prepared and distributed by the Co-ordinator. Table 1 provides some statistics on applications and acceptances.

\begin{tabular}{|l|l|}
\hline Table 1.2007 Participant Numbers \\
\hline Applications and inquiries & 60 \\
\hline Acceptances & 23 \\
\hline Participants & 23 \\
\hline Graduating Seniors & 0 \\
\hline Graduate Students & 20 \\
\hline Postdoctoral Fellows & 1 \\
\hline Junior Faculty & 1 \\
\hline Senior Researchers & 1 \\
\hline US Citizens/Foreign Nationals & $12 / 11$ \\
\hline PNNL Hosts & 21 \\
\hline
\end{tabular}

The application and acceptance procedure requires participation from all concerned parties: the PNNL hosts, the visitors, and the visitors' supervisors at his or her home institution (if applicable). Further, PNNL hosts were expected to provide mentoring for the visitors as well as ensure all necessary resources were available to accomplish the proposed work. The visitors bear the bulk of the application responsibility to come to PNNL for an extended stay. The visitors' supervisors were expected to continue financial support during this visit to PNNL as the SRI only covers travel to and from PNNL and partial living expenses.

Each visitor had a specific program tailored around his or her schedule and research goals. To accommodate individual schedules, the 2007 summer appointments began in late April and the final appointment concluded in September. Before their arrival, each participant was paired with a PNNL host and worked out a research program for the visit. All of this activity was coordinated with the visitor's supervisor. Most often, the visitor was playing a role in a collaboration or prospective collaboration between the PNNL host and his or her supervisor. (For the cases of graduating seniors or faculty members, slightly different procedures apply.) Table 2 lists our visitors, PNNL hosts, and home institution supervisors. Table 3 shows the university statistics. 
Table 2.

Summer Research Institute

Visitors, Academic Advisors, and Hosts

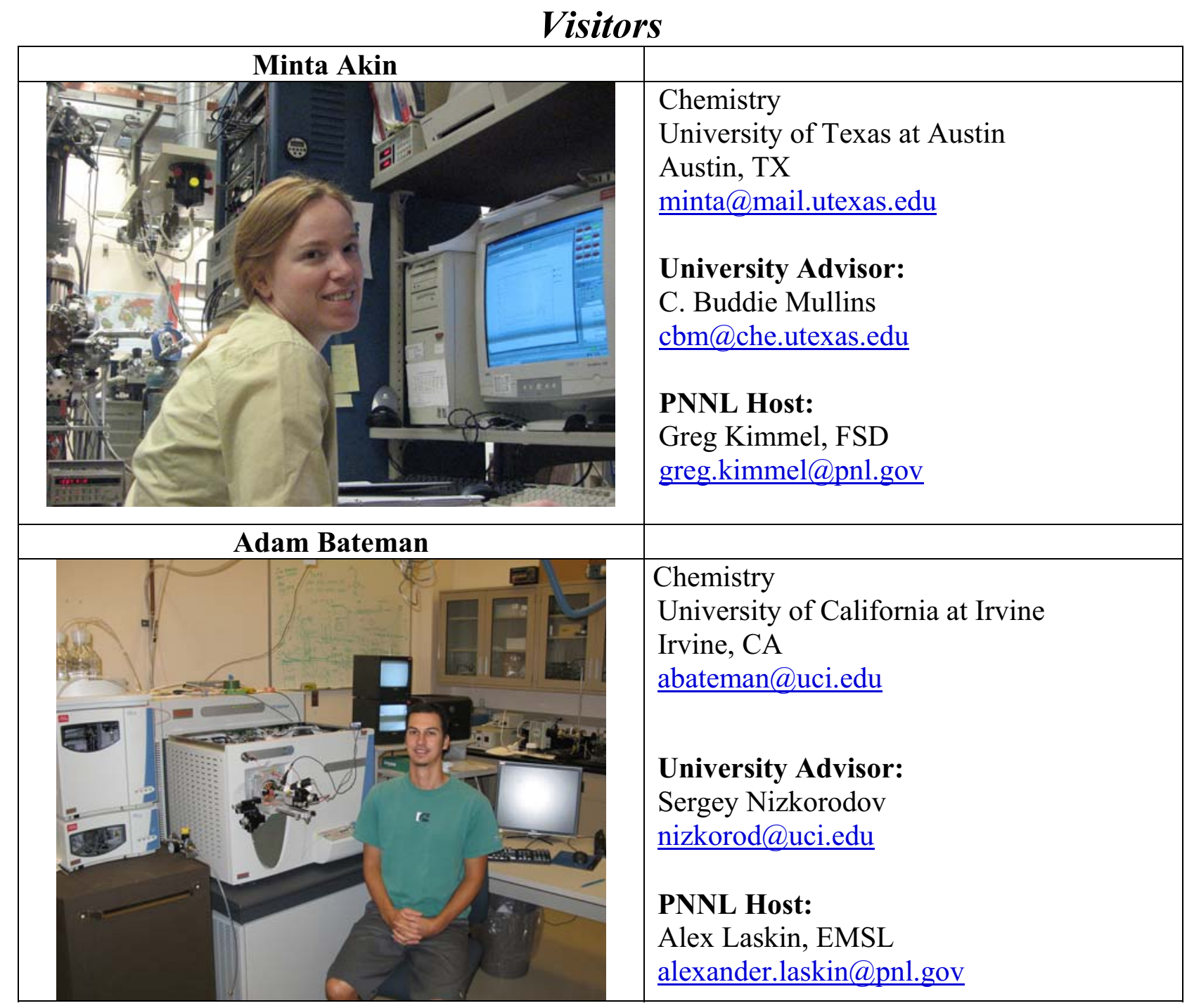




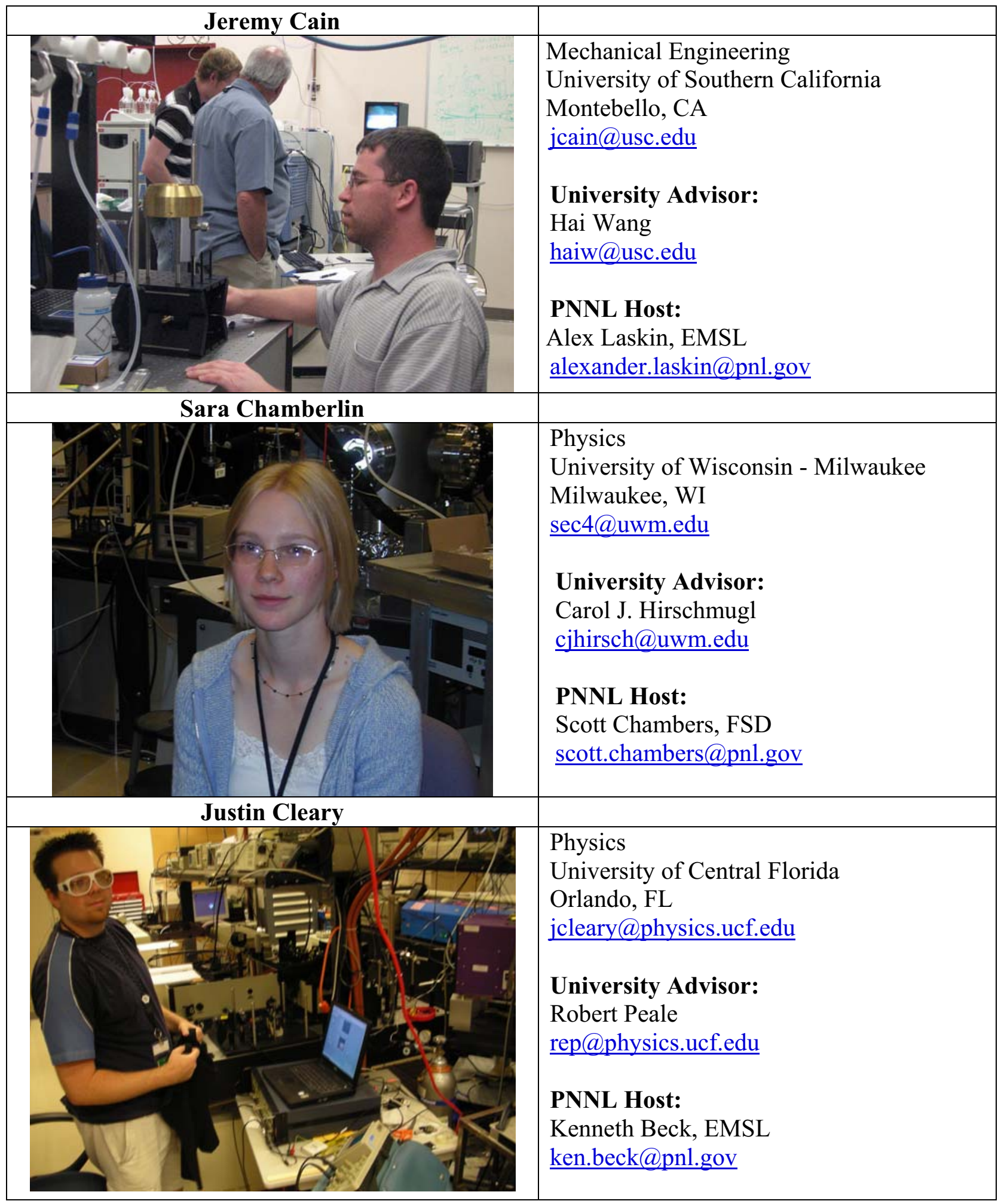




\begin{tabular}{|c|c|}
\hline Mawanana H Channa R De Silva & \\
\hline 8 & $\begin{array}{l}\text { Chemistry } \\
\text { University of Arizona } \\
\text { Tucson, AZ } \\
\text { channa@email.arizona.edu } \\
\text { University Advisor: } \\
\text { Louis René Corrales } \\
\text { lrcorral@email.arizona.edu } \\
\text { PNNL Host: } \\
\text { Jun Li, EMSL } \\
\text { jun.li@pnl.gov }\end{array}$ \\
\hline Du & $\begin{array}{l}\text { Chemistry } \\
\text { Purdue University } \\
\text { West Lafayette, IN } \\
\text { dus@purdue.edu } \\
\\
\text { University Advisor: } \\
\text { Joseph Francisco } \\
\text { jfrancis@purdue.edu } \\
\text { PNNL Host: } \\
\text { Greg Schenter, FSD } \\
\text { greg.schenter@pnl.gov }\end{array}$ \\
\hline 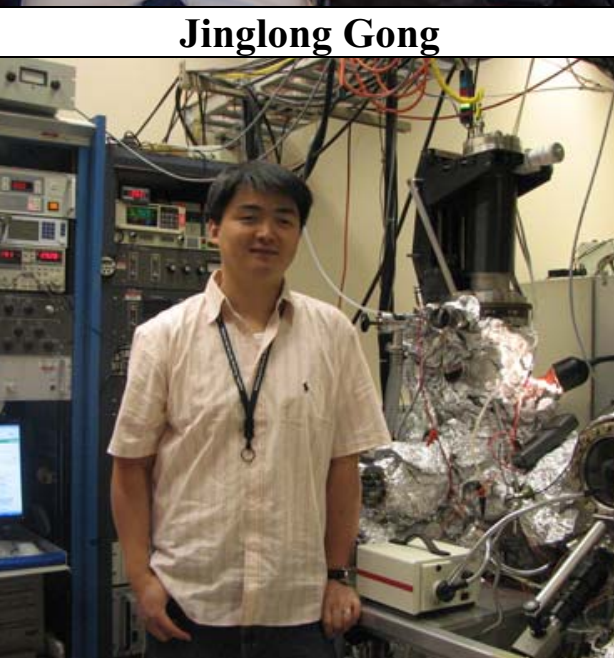 & $\begin{array}{l} \\
\text { Chemical Engineering } \\
\text { University of Texas at Austin } \\
\text { Austin, TX } \\
\text { ilgong@mail.utexas.edu } \\
\text { University Advisor: } \\
\text { C. Buddie Mullins } \\
\text { cbm@.che.utexas.edu } \\
\text { PNNL Host: } \\
\text { Zdenek Dohnalek, FSD } \\
\text { zdenek.dohnalek@pnl.gov }\end{array}$ \\
\hline
\end{tabular}




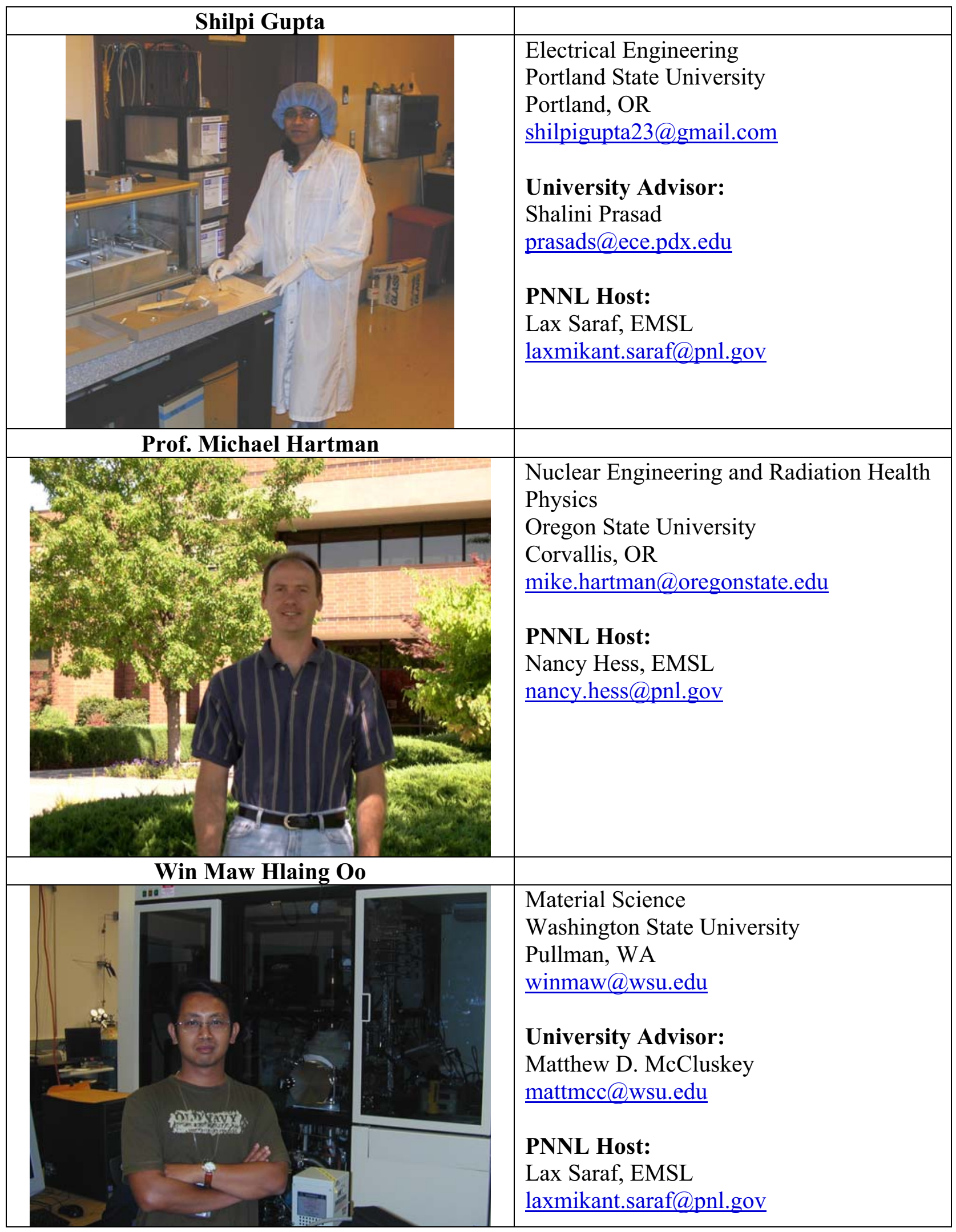




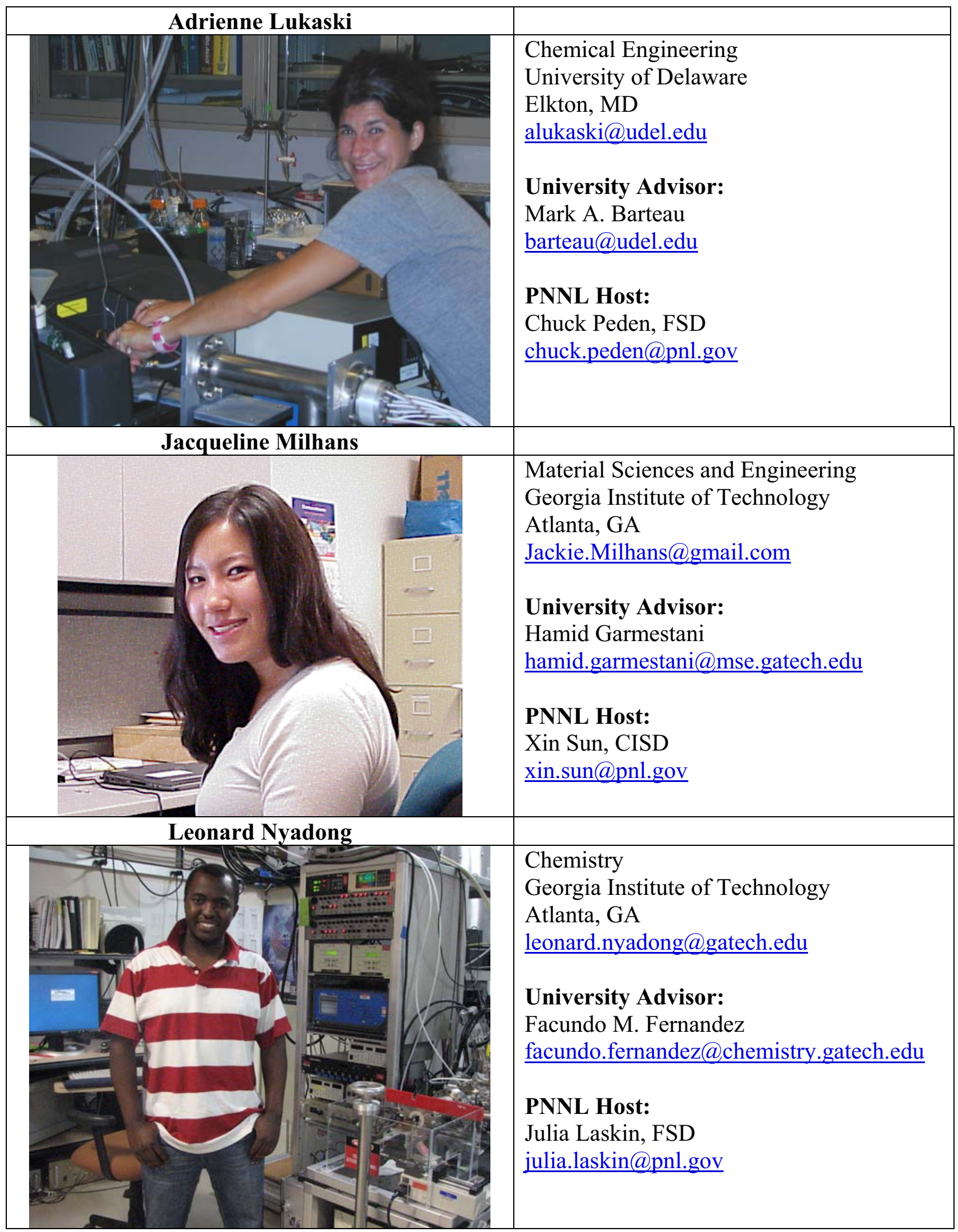




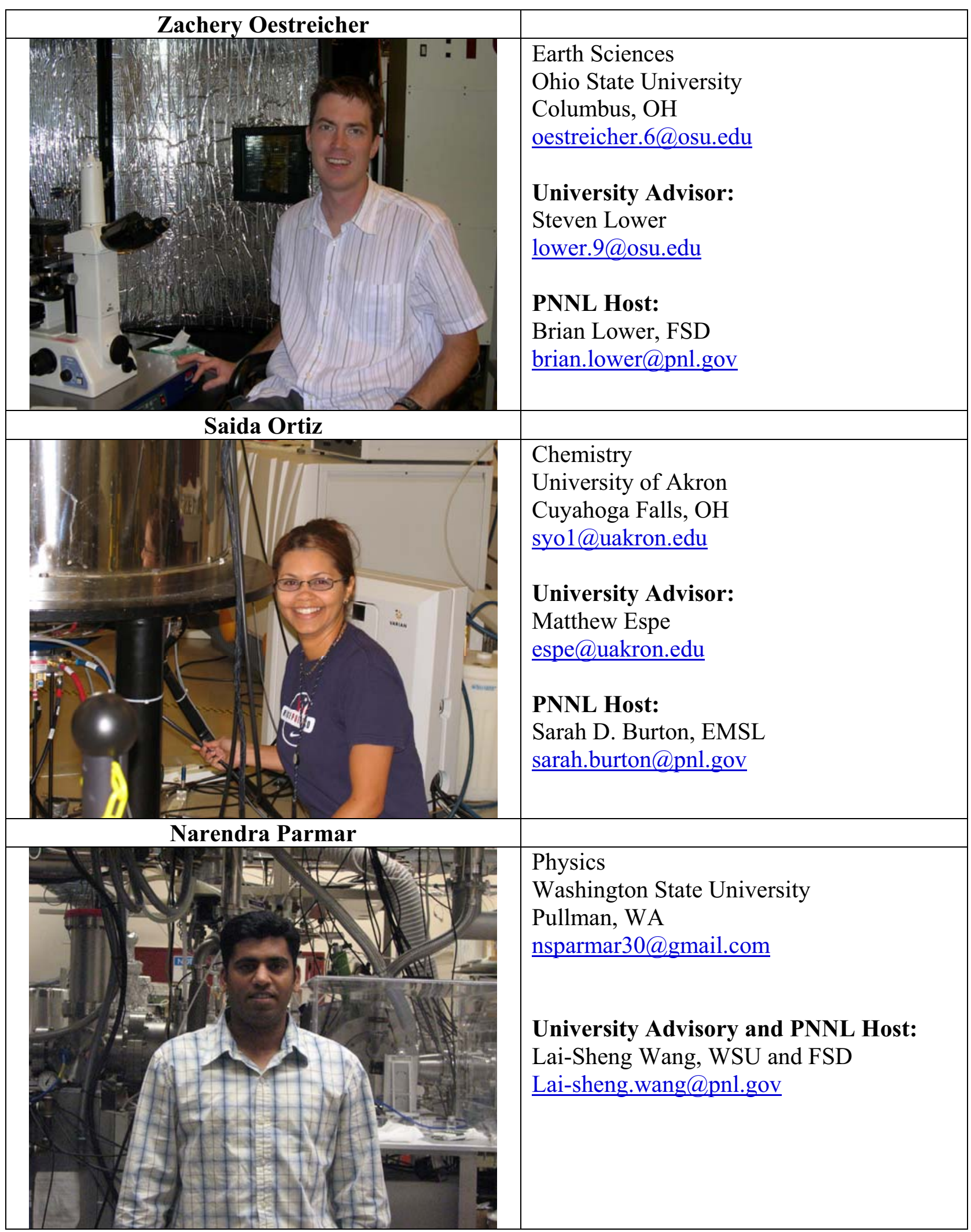




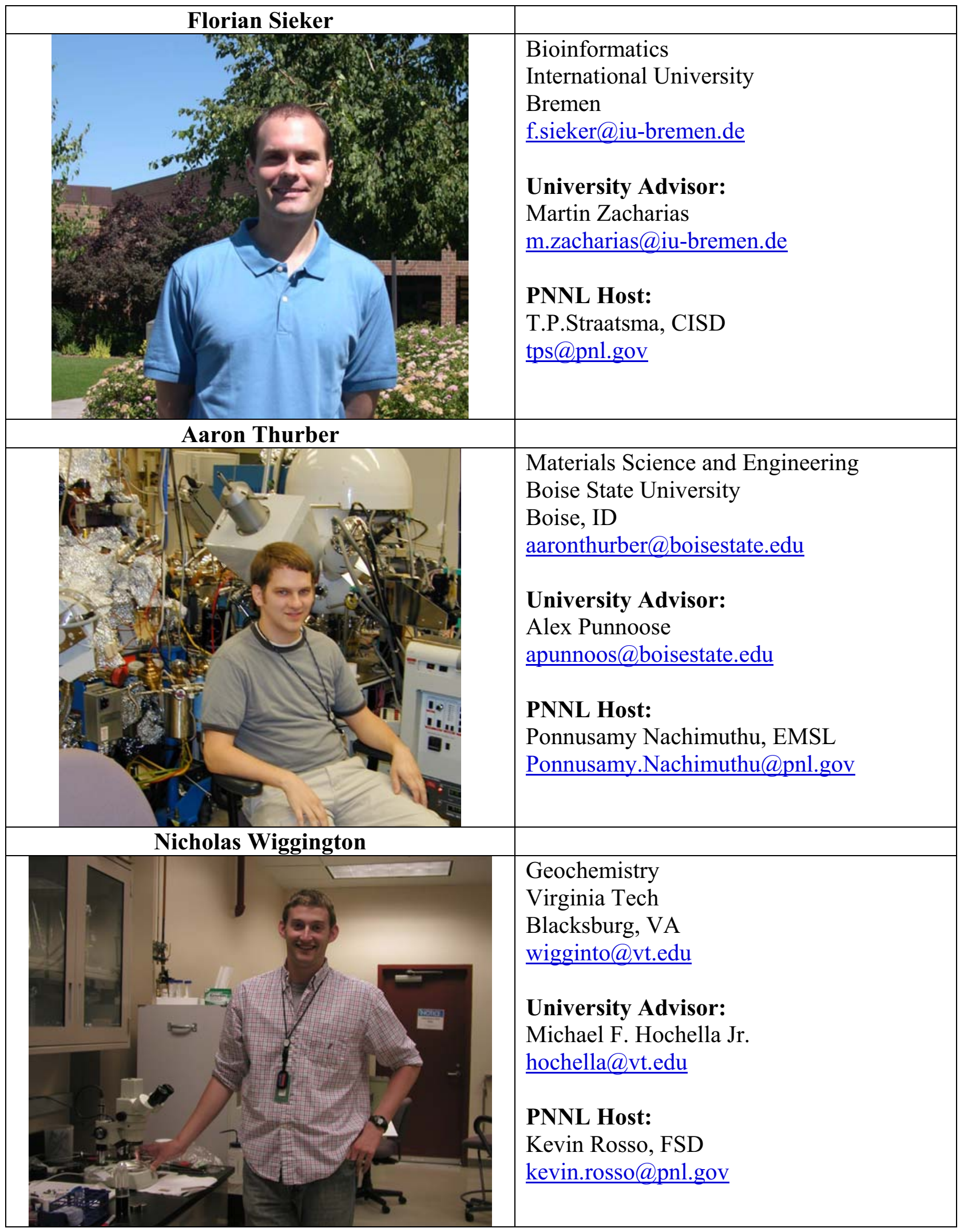




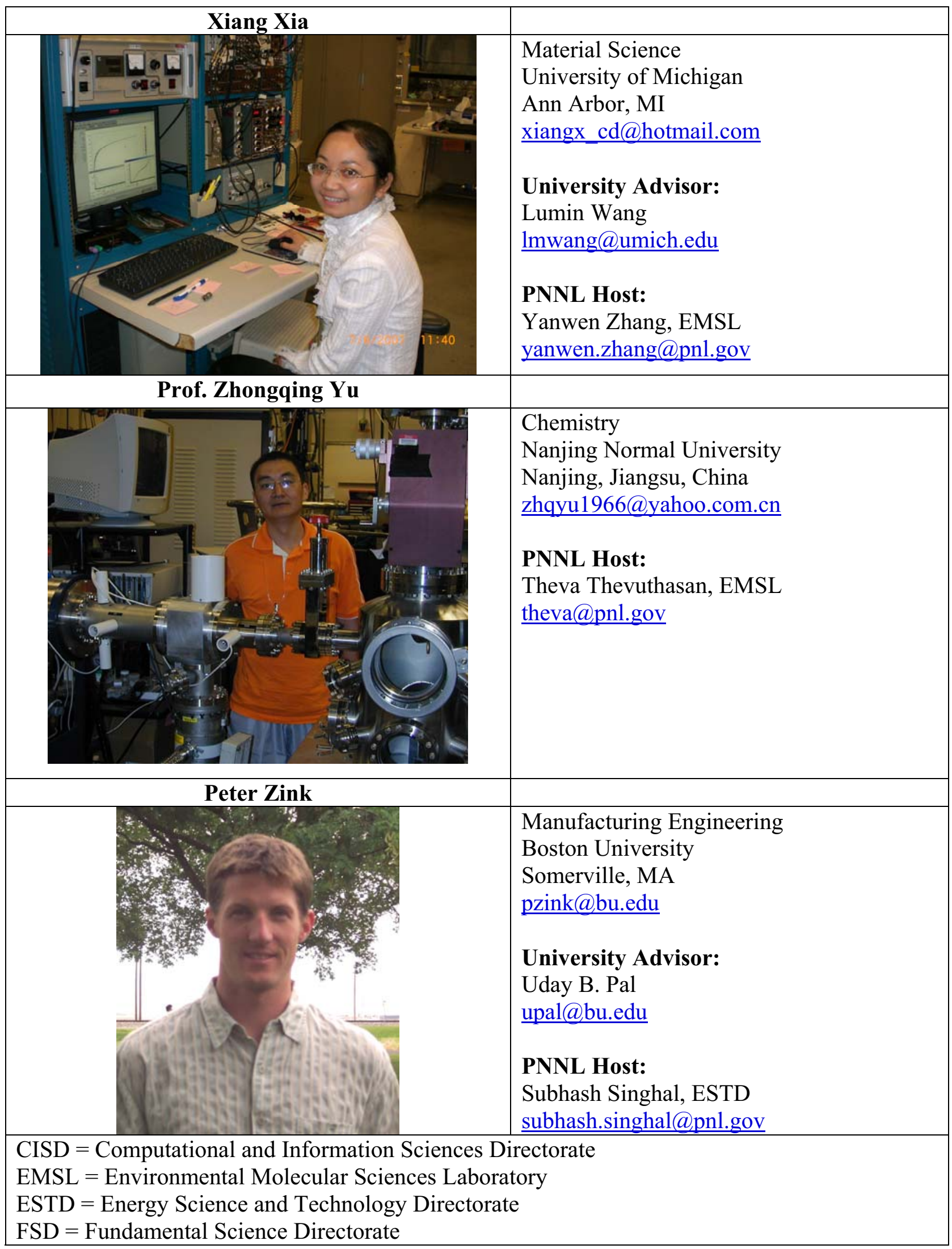


PNNL-17069

\begin{tabular}{|l|l|}
\hline Table 3. 2007 University Statistics & 1 \\
\hline Boise State University & 1 \\
\hline Boston University & 2 \\
\hline Georgia Institute of Technology & 1 \\
\hline International University & 1 \\
\hline Nanjing Normal University & 1 \\
\hline Ohio State University & 1 \\
\hline Oregon State University & 1 \\
\hline Portland State University & 1 \\
\hline Purdue University & 1 \\
\hline University of Akron & 1 \\
\hline University of Arizona & 1 \\
\hline University of California at Irvine & 1 \\
\hline University of Central Florida & 1 \\
\hline University of Delaware & 1 \\
\hline University of Michigan & 1 \\
\hline University of Southern California & 1 \\
\hline University of Texas at Austin & 1 \\
\hline University of Wisconsin - Milwaukee & 1 \\
\hline Virginia Tech & 2 \\
\hline Washington State University & 23 \\
\hline
\end{tabular}


PNNL-17069

\section{Benefits}

As described previously, participation in SRI required a significant investment on the part of all parties involved. The only reason that a young scientist, PNNL host, or academic advisor would be involved is if they believed that their investment would be of benefit. We believe that the institute's structure promoted the likelihood of that success. The visitors were very popular at the laboratory. Their inquisitiveness, creativity, and energy helped stimulate PNNL staff to think in new, creative ways.

\section{New in FY 2007}

For readers familiar with the SRI, most of the procedures and the underlying philosophy are unchanged. However, several important details are new. Some of these changes have been motivated by financial constraints; other changes were driven by new state laws and federal regulations. Finally, in elucidating a definite vision of how the ICPCPSRI might function with the end of direct BES funding encouraging new opportunities have been brought to light that insure its continuation in FY08.

This year, all of the participants came to PNNL with support from their home institutions. SRI can no longer offer "fellowships" or other forms of full support. It is a testimony to the institute's growing reputation, however, that there was no shortage of qualified applicants.

Two of our visitors did not fit into the "graduate student or young scientist" category. Prof. Michael Hartman is an associate professor of chemistry at Oregon State University. Prof. Zhongqing Yu, a professor of chemistry at Nanjing Normal University, specializes in preparation and properties characterization of nanometer-sized oxide materials and magnetic materials. These visitors were sponsored on a "resource available" basis. Their presence here in no way took resources from junior researchers. Except for their more senior status, they otherwise met all of the requirements for participation in the institute.

Lastly, reflecting more clearly the role and responsibility of the position, as well as the direction already set by the Office of Basic Energy Science's Mission Stretch Goal, the title "Director of the ICPCPSRI" has been changed to "Co-ordinator of the ICPCPSRI".

\section{Measures of Success}

This is an educational project within a research enterprise. As such, sustained success becomes apparent only in the following years or decade. However, on a shorter time scale, success can and must also be measured. We can point, for example, to a number of early successes in FY07. First, our applicant pool is growing: we received 60 outstanding applications. Twenty-three of these candidates came to PNNL to participate in the institute. Second, all of the candidates, PNNL mentors, and academic advisors expressed enthusiasm about the institute at the outset and were generally more enthusiastic by the end of the summer appointments. In several cases, plans are being readied for return visits to PNNL, independent of the summer program. Numerous presentations and manuscripts 
are being readied for submission to peer-reviewed journals.

\section{Follow-up}

As of October 2007, 39 papers, listed in Table 4, have been submitted, are in press, or published in the peer-reviewed literature. At least 14 presentations for national or international meetings were also produced-see Table 5. In addition, numerous internal PNNL reports have been generated.

The author lists from 2004 through August 2007 (see Tables 4 and 5) also point to an additional and somewhat unexpected benefit of SRI. Those visitors doing laboratory work in the U.S. Department of Energy's Environmental Molecular Sciences Laboratory (EMSL), a national scientific user facility located at PNNL, were extremely facile in harnessing internal collaborative opportunities and resources. Thus, many of the papers included unanticipated participation by non-host PNNL staff members.

\section{Table 4. Peer Reviewed Publications from 2004 Work through August 2007.}

Alexandrova, A. N. ${ }^{\mathrm{a}}$, Boldyrev, A. I. ${ }^{\mathrm{b}}$, Fu, Y. J., Yang, X., Wang, X. B., \& Wang, L. S. 2004. Structure of the NaxClx+1- $(x=1-4)$ clusters via ab initio genetic algorithm and photoelectron spectroscopy. Journal of Chemical Physics, 121(12): 5709-5719.

Alexandrova, A. N. ${ }^{\mathrm{a}}{ }_{2}$ Boldyrev, A. I. ${ }^{\mathrm{b}}$, Zhai, H. J., \& Wang, L. S. ${ }^{\mathrm{c}}$ 2004. Sigmaaromaticity in clusters of boron, lithium and magnesium. Abstracts of Papers of the American Chemical Society, 227: U1517-U1517.

Alexandrova, A. N. ${ }^{\mathrm{a}}$, Boldyrev, A. I. ${ }^{\mathrm{b}}$, Zhai, H. J., \& Wang, L. S. ${ }^{\mathrm{c}}$ 2005. Photoelectron spectroscopy and ab initio study of the doubly antiaromatic B-6(2-) dianion in the LiB6cluster. Journal of Chemical Physics, 122(5): 8.

Alexandrova, A. N. ${ }^{\mathrm{a}}$, Boldyrev, A. I. ${ }^{\mathrm{b}}$, Zhai, H. J., \& Wang, L. S. ${ }^{\mathrm{c}}$ 2005. Cu3C4-: A new sandwich molecule with two revolving C-2(2-) units. Journal of Physical Chemistry A, 109(4): 562-570.

Alexandrova, A. N. ${ }^{\text {a }}$, Boldyrev, A. I. ${ }^{\text {b }}$, Zhai, H. J., \& Wang, L. S. ${ }^{\mathrm{c}}$ 2006. All-boron aromatic clusters as potential new inorganic ligands and building blocks in chemistry. Coordination Chemistry Reviews, 250(21-22): 2811-2866.

Zubarev, D. Y., Alexandrova, A. N. ${ }^{\mathrm{a}}$, Boldyrev, A. I. ${ }^{\mathrm{b}}$, Cui, L. F., Li, X., \& Wang, L. S. ${ }^{\text {c }}$ 2006. On the structure and chemical bonding of Si-6(2-) and Si-6(2-) in NaSi6- upon $\mathrm{Na}+$ coordination. Journal of Chemical Physics, 124(12): 13.

Gologan, B., Green, J. R. ${ }^{\text {a }, ~ A l v a r e z, ~ J . ~}{ }^{\text {a }}$, Laskin, J. ${ }^{\text {c }}$, \& Cooks, R. G. ${ }^{\text {b } 2005 . ~ I o n / s u r f a c e ~}$ reactions and ion soft-landing. Physical Chemistry Chemical Physics, 7(7): 1490-1500.

$\underline{\text { Alvarez, J. }}{ }^{\text {a }}$ Cooks, R. G. ${ }^{b}$, Barlow, S. E., Gaspar, D. J., Futrell, J. H., \& Laskin, J. ${ }^{\text {c }}$ 2005. Preparation and in situ characterization of surfaces using soft landing in a Fourier transform ion cyclotron resonance mass spectrometer. Analytical Chemistry, 77(11): 3452-3460.

Alvarez, J. ${ }^{\mathrm{a}}$, Futrell, J. H., \& Laskin, J. ${ }^{\mathrm{c}}$ 2006. Soft-landing of peptides onto selfassembled monolayer surfaces. Journal of Physical Chemistry A, 110(4): 1678-1687. Laskin, J. ${ }^{\text { }}$, Wang, O., Hadjar, O., Futrell, J. H., Alvarez, J. ${ }^{\text {a }}$, \& Cooks, R. G. ${ }^{\text {b }} 2007$. 
Table 4. Peer Reviewed Publications from 2004 Work through August 2007. Charge Retention by Peptide Ions Soft-Landed onto Self-Assembled Monolayer Surfaces International Journal of Mass Spectrometry 265(1): 237-243.

Bera, D. ${ }_{2}{ }_{2}$ Kuchibhatla, S. ${ }^{\text {a }}$, S, A., Saraf, L. V., Wang, C., Shutthanandan, V., McCready, D. E., Engelhard, M., Marina, O. A., Baer, D. R. ${ }^{\text {c }}$, Seal, S. ${ }^{\text {b }}$, and Thevuthasan, S. 2007. Growth and characterization of highly oriented gadolinia-doped ceria (111) thin films on zirconia (111)/sapphire (0001) substrates. Thin Solid Films. In Press.

Korshin, G. V. ${ }^{\mathrm{b}}$, Chang, H. S. ${ }^{\mathrm{a}}$, Wang, Z. M. ${ }^{\mathrm{c}}$, \& Zachara, J. M. 2005. Speciation of uranyl adsorbed on gibbsite: A time-resolved laser-induced fluorescence spectroscopic study. Geochimica Et Cosmochimica Acta, 69(10): A619-A619.

Chang, H. S. ${ }^{\text {a }}, \underline{\text { Korshin, G. V. }}{ }^{\text {b }}$, Wang, Z. M. ${ }^{\text {c }}$, \& Zachara, J. M. 2006. Adsorption of uranyl on gibbsite: A time-resolved laser-induced fluorescence spectroscopy study. Environmental Science \& Technology, 40(4): 1244-1249.

Chang, H. S. a , Shutthanandan, V., Singhal, S. C., \& Ramanathan, S. 2007. In situ ion scattering and $x$-ray photoelectron spectroscopy studies of stability and nanoscale oxidation of single crystal (100) InAs. Applied Physics Letters, 90(20): 3.

Chang, H. S. ${ }^{\text {a }}$., Shutthanandan, V., Singhal, S. C., \& Ramanathan, S. 2007. On the stability and oxidation of single crystal (100) InAs surfaces. Journal of the Electrochemical Society. Submitted.

Chang, H. S. ${ }^{\text {a }}$., Shutthanandan, V., Singhal, S. C., \& Ramanathan, S. 2007. In situ studies on stoichiometry and structure of thin film yttria-stabilized zirconia under thermal processing. Materials Research Society. San Francisco, CA.

Du, Y. ${ }^{\text {a }}$, Atha, S., Hull, R., Groves, J. F. ${ }^{\text {b Lyubinetsky, I. }}{ }^{\text {c }}$ \& B Baer, D. R. 2004. Focusedion-beam directed self-assembly of Cu2O islands on SrTiO3(100). Applied Physics Letters, 84(25): 5213-5215.

Du, Y. ${ }^{\text {a }}$, Groves, J. F. ${ }^{\text {b }}$, L Lyubinetsky, I. ${ }^{\text {c }}$, \& Baer, D. R. 2006. Formation of Cu2O quantum dots on SrTiO3 (100): Self-assembly and directed self-assembly. Journal of Applied Physics, 100(9).

Deskins, N., Langell, M., Dupuis, M., Lyubinetsky, I. ${ }^{\text {c }}, \underline{\text { Du, Y. }}{ }^{\text {a }}$, \& Henderson, M. 2007. Unique Hydrogen Configuration on TiO2(110) upon Carboxylic Acid Dissociation 2007 AIChE Annual Meeting, Salt Lake City, UT

Elliott, B. $^{\mathrm{a}}$, Boldyrev, A. I. $^{\mathrm{b}}$, Alexandrova, A. N. ${ }^{\mathrm{a}}$, Zhai, H. J., Yang, X., Wang, X. B., \& Wang, L. S. ${ }^{c}$ 2005. Oxygen rich species: Areas of growth and advancement. Abstracts of Papers of the American Chemical Society, 229: U769-U769.

Elliott, B. M. ${ }^{\text {a }}$, Koyle, E., Boldyrev, A. I. ${ }^{\text {b }}$, Wang, X. B., \& Wang, L. S. ${ }^{\text {c }} 2005 . M X 3-$ superhalogens $(M=B e, M g, C a ; X=C l, B r):$ A photoelectron spectroscopic and ab initio theoretical study. Journal of Physical Chemistry A, 109(50): 11560-11567.

Lagutschenkov, A. ${ }^{\text {a }}$, Fanourgakis, G. S., Niedner-Schatteburg, G. ${ }^{b}$, \& Xantheas, S. S. ${ }^{\text {c }}$ 2005. The spectroscopic signature of the "all-surface" to "internally solvated" structural transition in water clusters in the $n=17-21$ size regime. Journal of Chemical Physics 122(19): 194310-194311 - 194310-194319.

Xantheas, S. S. ${ }^{\text {c }}$, Fanourgakis, G. S., Kowalski, K., Lagutschenkov, A. ${ }^{\text {a }}$, \& Niedner-

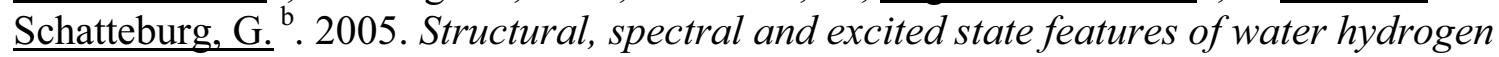
bonding networks: Results of ab-initio calculations and interaction potentials. Abstracts of Papers of the American Chemical Society, 229: U706-U707. 
Table 4. Peer Reviewed Publications from 2004 Work through August 2007. Pankewitz, T., Lagutschenkov, A. ${ }^{\mathrm{a}}$, Niedner-Schatteburg, G. ${ }_{2}$ Xantheas, S. S. ${ }^{\mathrm{c}}$, \& Lee, Y. T. 2007. Infrared spectrum of $\mathrm{NH} 4+(\mathrm{H} 2 \mathrm{O})$ : Evidence for mode specific fragmentation. Journal of Chemical Physics, 126(7).

Joly, A. G. ${ }^{\text {c }}$, Williams, J. R., Chambers, S. A., Xiong, G., Hess, W. P., \& Laman, D. M. ${ }^{\text {a }}$ 2006. Carrier dynamics in alpha-Fe2O3 (0001) thin films and single crystals probed by femtosecond transient absorption and reflectivity. Journal of Applied Physics, 99(5). Heinisch, H. L. ${ }^{\text {c }}$, Gao, F., Kurtz, R. J., \& Le, E. A. ${ }^{\text {a }}$ 2006. Interaction of helium atoms with edge dislocations in alpha-Fe. Journal of Nuclear Materials, 351(1-3): 141-148.

Ou, F. S. ${ }^{\text {, }}$ Saraf, L. V., \& Baer, D. R. 2006. Patterned regions of porous silicon through trapped hydrogen bubbles. Applied Physics Letters, 88(14).

Ou, F. S. ${ }^{\text {a }}$, Saraf, L. V. ${ }^{\text {c }}$, \& Baer, D. R. 2006. Site-Specific Formation of Nanoporous Silicon on Micro-fabricated Silicon Surfaces In Mater. Res. Soc. Symp. Proc. Vol. 829. Lloyd, J. A. ${ }^{\text {a }}$, Spraggins, J. M. ${ }^{\text {a }}$, \& Johnston, M. V. ${ }^{\mathrm{b}}$ 2006. Peptide ozonolysis: Product structures and relative reactivities for oxidation of tyrosine and histidine residues. Journal of the American Society for Mass Spectrometry, 17(9): 1289-1298.

Tait, S. L. ${ }^{\mathrm{a}}$, Dohnalek, Z. ${ }^{\mathrm{c}}$, Campbell, C. T. ${ }^{\mathrm{b}}$, \& Kay, B. D. 2005. Methane adsorption and dissociation and oxygen adsorption and reaction with $C O$ on Pd nanoparticles on $\mathrm{MgO}(100)$ and on Pd(111). Surface Science, 591(1-3): 90-107.

Tait, S. L. $^{\mathrm{a}}$, Dohnalek, Z. ${ }^{\mathrm{c}}$, Campbell, C. T. ${ }^{\mathrm{b}}$, \& Kay, B. D. 2005. n-Alkanes on $\mathrm{MgO}(100)$. I. Coverage-dependent desorption kinetics of n-butane. Journal of Chemical Physics, 122(16).

Tait, S. L. $^{\mathrm{a}}$, Dohnalek, Z. ${ }^{\mathrm{c}}$, Campbell, C. T. ${ }^{\mathrm{b}}$, \& Kay, B. D. 2005. n-Alkanes on $\mathrm{MgO}(100)$. II. Chain length dependence of kinetic desorption parameters for small $n$ alkanes. Journal of Chemical Physics, 122(16).

Tait, S. L. ${ }^{\mathrm{a}}$, Dohnalek, Z. ${ }^{\mathrm{c}}$, Campbell, C. T. ${ }^{\mathrm{b}}$, \& Kay, B. D. 2006. n-alkanes on Pt(111) and on C(0001)/Pt(111): Chain length dependence of kinetic desorption parameters. Journal of Chemical Physics, 125(23).

Wang, Y. ${ }^{a}$, Zhang, L. G., Fan, Y., Luo, J., McCready, D. E., Wang, C. M. ${ }^{\text {c }}$, \& An, L. A. ${ }^{\mathrm{b}}$ 2005. Synthesis, Characterization, and Optical Properties of Pristine and Doped Yttrium Aluminum Garnet Nanopowders. J. American Ceramic Society 88(2): 284-286.

Wang, Y. G. ${ }^{\text {a }}$, An, L. A. ${ }^{\text {b }}$, Fan, Y., Zhang, L. G., Burton, S., \& Gan, Z. H. 2005. Oxidation of polymer-derived SiAlCN ceramics. J. American Ceramic Society, 88(11): 3075-3080.

Wang, Y. ${ }^{\mathrm{a}}$, Wang, C. M. ${ }^{\mathrm{c}}$, \& Yang, B. 2006. Synthesis of P(MMA-b-MAA) amphiphilic block copolymer and its self-organization behavior in solvent. Chemical Journal of Chinese Universities-Chinese, 27(4): 758-760.

Wang, Y. G. ${ }^{a}$, Fan, Y., Zhang, L. G., Zhang, W. G., \& An, L. A. ${ }^{\text {b } 2006 . ~ P o l y m e r-~}$ derived SiAlCN ceramics resist oxidation at 1400 degrees $C$. Scripta Materialia, 55(4): 295-297.

Wang, Y. G. ${ }^{\text {a }}$, Fei, W. F., \& An, L. A. ${ }^{\text {b }}$ 2006. Oxidation/corrosion of polymer-derived SiAlCN ceramics in water vapor. J. American Ceramic Society, 89(3): 1079-1082.

Liu, Y., Yang, Z. ${ }^{\mathrm{a}}$, Dessiaterik, Y., Gassman, P., Wang, H. ${ }^{\mathrm{b}}$, \& Laskin, A. ${ }^{\mathrm{c}} 2007$. Hygroscopic Behavior of Substrate Deposited Particles Studied by Micro FTIR Spectroscopy and Complementary Methods of Particle Analysis. Analytical Chemistry. Submitted. 
${ }^{\mathrm{a}}$ Participant; ${ }^{\mathrm{b}}$ Mentor; ${ }^{\mathrm{c}} \mathrm{PNNL}$ Host

Table 5. Presentations/Conference Papers from 2004 Work though August 2007. Laskin, J. $^{\mathrm{c}}$, Alvarez, J. ${ }^{\mathrm{a}}$, Cooks, R. G. ${ }^{\mathrm{b}}$, Futrell, J. H., \& Barlow, S. E. 2005. Collisions of Peptide Ions with Surfaces Studied Using FT-ICR MS. Presented at the 53rd ASMS Conference on Mass Spectrometry in San Antonio, TX.

Laskin, J. ${ }^{\text {c }}$, Hadjar, O., Wang, P., Futrell, J. H., Alvarez, J. ${ }^{\text {a Green, J. R. }}{ }^{\text {a }}$, \& Cooks, R. G. ${ }^{b}$. 2006. Soft Landing of Peptide Ions on Surfaces. Presented by Julia Laskin (Invited Speaker) at Isolated Biomolecules and Biomolecular Interactions (IBBI), Trest Castle, Czech Republic on May 10, 2006.

Wang, Z. ${ }^{\mathrm{c}}$, Zachara, J. M., Chang, H. ${ }^{\mathrm{a}}{ }_{2}$ Korshin, G. V. ${ }^{\mathrm{b}}$, Senko, J., Burgos, W. D., \& Wan, J. 2007. Cryogenic Laser-induced Time-resolved Fluorescence Spectroscopy Studies of Uranium Adsorbed at Minerals and Soil Sediments. Abstract submitted to 234nd ACS National Meeting, Boston, MA.

Du, Y. ${ }^{a}$, Lyubinetsky, I. ${ }^{\mathrm{c}}$, Baer, D. R., \& Groves, J. F. ${ }^{\mathrm{b}}$ 2007. Template guided selfassembly of metal oxide quantum dots. Abstract submitted to 54th American Vacuum Society, Seattle, WA.

Lyubinetsky, I. ${ }^{\mathrm{c}}$ Vestergaard, E., Du, Y. ${ }^{\mathrm{a}}$, \& Henderson, M. 2007. Direct STM Observation of TMAA Adsorption and Photodecomposition on TiO2(110). Abstract submitted to IVC-17/ICSS-13 and ICN+T'2007, Stockholm, Sweden.

Fanourgakis, G. S., Lagutschenkov, A. ${ }^{\mathrm{a}}$, Niedner-Schatteburg, G. ${ }^{\mathrm{b}}, \&$ Xantheas, S. S. ${ }^{\mathrm{c}}$ 2005. Structural and spectral features of size selected water clusters in the $n=7-21$ regime: Results from electronic structure calculations and empirical potentials Presented by Sotiris Xantheas (Invited Speaker) at Symposium on Size Selected Clusters, Brand, Austria on February 28, 2005.

Fanourgakis, G. S., L Lagutschenkov, A. ${ }^{\text {a }}$, Kowalski, K., Niedner-Schatteburg, G. ${ }^{\text {, } ~ \& ~}$ Xantheas, S. S. ${ }^{\mathrm{c}}$ 2005. Structural, spectral and excited state features of water hydrogen bonding networks: Results of ab-initio calculations and interaction potentials Presented by Sotiris S. Xantheas (Invited Speaker) at American Chemical Society, San Diego, CA on March 13, 2005.

Lagutschenkov, A., Fanourgakis, G. S., Niedner-Schatteburg, G. ${ }^{b}, \&$ Xantheas, S. S. 2005. The Spectroscopic Signature of the "All-Surface" to "Internally Solvated"

Structural Transition in Water Clusters in the $n=17-21$ Size Regime. Presented by Sotiris s. Xantheas (Invited Speaker) at EMSI International Workshop on Ions and Molecules at Aqueous Interfaces, Prague, Czech Republic on June 27, 2005.

Joly, A. G. ${ }^{\text {c }}$, Hess, W. P., Xiong, G., Laman, D. M. ${ }^{\text {, }}$, Williams, J. R., \& Chambers, S. A. 2005. Carrier Lifetimes and Dynamics in Epitaxial Grown Fe2O3/Cr2O3 Thin Films Measured by Femtosecond Transient Reflectivity and Absorption Presented by Gang Xiong (Invited Speaker) at APS Meeting, Los Angeles, CA on March 21, 2005.

Ou, F. S. ${ }^{\mathrm{a}}$, Saraf, L. V. ${ }^{\mathrm{c}}$, \& Baer, D. R. 2004. Site-Specific Formation of Nanoporous Silicon on Micro-fabricated Silicon Surfaces. Presented by Fung Suong Ou at MRS 2004 Fall Meeting, Boston, MA on December 1, 2004.

Ou, F. S. ${ }^{\mathrm{a}}$, Saraf, L. V. ${ }^{\mathrm{c}}$, Baer, D. R., Wang, Z., \& Engelhard, M. 2004. Use of Hydrogen Reactivity During Chemical Etching to Achieve Site-Specific Nano-Porosity. Presented by Don Baer at Micro Nano Breakthrough Conference, Portland, OR on July 28, 2004.

Ou, F. S. ${ }^{\text {a }}$ Saraf, L. V. ${ }^{\mathrm{c}}$, \& Baer, D. R. 2006. Site-specific Formation of Nanoporous 


\section{Table 5. Presentations/Conference Papers from 2004 Work though August 2007.}

Silicon on Micro-fabricated Silicon Surfaces. Paper presented at the Materials Research Society Symposium.

Spraggins, J. M. ${ }^{\mathrm{a}}$, Laskin, J. $^{\mathrm{c}} \underline{\text { \& Johnston, M. V. }} .{ }^{\mathrm{b}}$ 2005. Ozonated Peptides: Insight Into Structure and Fragmentation Energetics Using SID FT-ICR MS. Presented at the 53rd ASMS Conference on Mass Spectrometry in San Antonio, TX on June 08, 2005.

Liu, Y., Yang, Z. ${ }^{\text {, }}$, Gassman, P., Wang, H. ${ }^{\text {, }}$ \& Laskin, A. ${ }^{\mathrm{c}}$ 2007. Probing Hygroscopic Properties of Atmospheric Particles Using Complementary Methods of Micro FTIR Spectroscopy and Micro Analyses. Presented by Yong Liu at AAAR 2007 Meeting, Reno, NV on September 27, 2007.

${ }^{a}$ Participant; ${ }^{b}$ Mentor; ${ }^{c}$ PNNL Host

\section{Follow-up}

Work from the summer of 2005 has already produced 14 refereed publications as well as 2 submitted and 2 in process (Table 6) and 15 presentations (Table 7). There is every reason to expect this number to rise substantially in fiscal year 2008 .

In FY2006, we noted that Mr. Anoop M. Mayampurath had been offered employment at PNNL. In FY2007, he has become a very productive and respected member of the EMSL's Instrument Development Laboratory.

Table 6. Peer Reviewed Publications from 2005 Work through August 2007. Laskin, J. $^{\mathrm{c}}$, Futrell, J. H., \& $\underline{\mathrm{Chu}, \text { I. }^{\mathrm{a}}}$ 2007. Is Dissociation of Peptide Radical Cations an Ergodic Process? Journal of the American Chemical Society 129(31): 9598-9599.

$\underline{\text { Laskin, J. }}^{\mathrm{c}}$, Yang, Z., Lam, C., \& $\underline{\mathrm{Chu}, \mathrm{I}^{\mathrm{a}}}$ 2007. Charge-Remote Fragmentation of OddElectron Peptide Ions Analytical Chemistry. In Process.

Fister, T. ${ }^{\mathrm{a}}$, Vila, F., Seidler, G. ${ }^{\mathrm{b}}$, Svec, L., Linehan, J. C. ${ }^{\mathrm{c}}$, \& Cross, J. 2007. The Local Electronic Structure of Dicarba-closo-dodecaboranes C2B10H12. Journal of the American Chemical Society. In Process.

Gologan, B., Green, J. R. ${ }^{\text {a }}$, Alvarez, J. ${ }^{\text {a }}$ Laskin, J. ${ }^{\text {c }}$, \& Cooks, R. G. ${ }^{b}$ 2005. Ion/surface reactions and ion soft-landing. Physical Chemistry Chemical Physics, 7(7): 1490-1500.

Bera, D. ${ }_{2}^{\text {a Kuchibhatla, S. }}{ }^{\text {a }}$, S, A., Saraf, L. V., Wang, C., Shutthanandan, V., McCready, D. E., Engelhard, M., Marina, O. A., Baer, D. R. ${ }^{\text {c }}$, Seal, S. ${ }^{\mathrm{b}}$, \& Thevuthasan, S. 2007. Growth and characterization of highly oriented gadolinia-doped ceria (111) thin films on zirconia (111)/sapphire (0001) substrates_Thin Solid Films. In Press.

Gutowska, A., Li, L. Y., Shin, Y. S., Wang, C. M. M., Li, X. H. S., Linehan, J. C., Smith, R. S., Kay, B. D., Schmid, B. ${ }^{\text {a }}$, Shaw, W., Gutowski, M., \& Autrey, T. 2005.

Nanoscaffold mediates hydrogen release and the reactivity of ammonia borane. Angewandte Chemie-International Edition, 44(23): 3578-3582.

Hartl, M. A., Daemen, L. L., Autrey, T. ${ }^{\mathrm{c}}$, Linehan, J. C., Hess, N. J., Stowe, A. C., Gutowski, M., Brown, C. M., Mamontov, E., \& Schmid, B. ${ }^{\text {a }}$ 2005. Methyl torsion dynamics in methyl borate: An inelastic neutron scattering study. Abstracts of Papers of the American Chemical Society, 230: U411-U412.

Hess, N. J., Brown, C. M., Daemen, L. L., Mamontov, E., Scott Smith, R., Kay, B. D., 
Table 6. Peer Reviewed Publications from 2005 Work through August 2007. Shaw, W. J., Linehan, J. C., Schmid, B. ${ }^{\text {' }}$, Stowe, A. C., Gutowski, M., \& Autrey, T. 2005. Spectroscopic studies of hydrogen formation from amineborane complexes. Abstracts of Papers of the American Chemical Society, 230: U1651-U1652.

Smith, R. S., Kay, B. D., Li, L. Y., Schmid, B. ${ }^{\text {a }}$, Hess, N. J., Gutowski, M., \& Autrey, T. ${ }^{\text {c }}$ 2005. Mechanistic studies of hydrogen formation from amineborane complexes.

Abstracts of Papers of the American Chemical Society, 229: U858-U858. Presenter: Julia Laskin (Invited Speaker).

Stowe, A. C., Shaw, W. J., Linehan, J. C., Schmid, B. ${ }^{\text {a }}$, \& Autrey, T. ${ }^{\text {c }}$ 2007. In situ solid state B-11 MAS-NMR studies of the thermal decomposition of ammonia borane:

mechanistic studies of the hydrogen release pathways from a solid state hydrogen storage material. Physical Chemistry Chemical Physics, 9(15): 1831-1836.

$\underline{\text { Wei, W. }}_{\text {a }}$, Parker, S. L., Sun, Y. M., White, J. M. ${ }^{\text {b }}$, Xiong, G., Joly, A. G., Beck, K. M., \& Hess, W. P. ${ }^{c}$ 2007. Study of copper diffusion through a ruthenium thin film by photoemission electron microscopy. Applied Physics Letters, 90(11).

Dhamne, A., Xu, W. X., Fookes, B. G., Fan, Y., Zhang, L. G., Burton, S., Hu, J. Z., Ford, J., \& An, L. A. 2005. Polymer-ceramic conversion of liquid polyaluminasilazanes for SiAlCN ceramics. Journal of the American Ceramic Society, 88(9): 2415-2419.

White, J. M. ${ }^{\mathrm{b}}$, Henderson, M., Dohnalek, Z. ${ }^{\mathrm{b}}$, \& Zhang, Z. ${ }^{\mathrm{a}}$ 2006. Surface chemistry on single crystal titania. Abstracts of Papers of the American Chemical Society, 231.

Zhang, Z. ${ }^{\mathrm{a}}$, Bondarchuk, O., Kay, B. D., White, J. M. ${ }^{\mathrm{b}}$, \& Dohnalek, Z. ${ }^{\mathrm{b}}$ 2006. Imaging water dissociation on $\mathrm{TiO} 2(110)$ : Evidence for inequivalent geminate $\mathrm{OH}$ groups. Journal of Physical Chemistry B, 110(43): 21840-21845.

Zhang, Z. R. ${ }^{\text {a }}$, Bondarchuk, O., White, J. M. ${ }^{\text {b }}$, Kay, B. D., \& Dohnalek, Z. ${ }^{\text {b }} 2006$. Imaging adsorbate O-H bond cleavage: Methanol on TiO2(110). Journal of the American Chemical Society, 128(13): 4198-4199.

Zhang, Z. R. ${ }^{\text {a }}$, Bondarchuk, E., Kay, B. D., White, J. M. ${ }^{\text {b }}$, \& Dohnalek, Z. ${ }^{\text {b }}$. 2007. Direct visualization of 2-butanol adsorption and dissociation on TiO2(110). Journal of Physical Chemistry C, 111(7): 3021-3027.

Williams, R., Mancevski, V., McClure, P., Zhang, Z. R. ${ }^{\text {a }}$, Li, S., Dohnalek, Z.. , \& Stevenson, K. J. 2007. Simultaneous Fabrication of Carbon Nanotube Atomic Force Microscopy and Scanning Tunneling Microscopy Tips Via Localized Chemical Vapor Deposition and Nanomanipulation ACS Nano. Submitted.

Zhang, Z. R. ${ }^{a}$, Ge, Q., Li, S., White, J. M. ${ }^{b}$, Kay, B. D., \& Dohnalek, Z. . . 2007. Imaging Intrinsic Diffusion of Bridge-Bonded Oxygen Vacancies on TiO2(110) Science.

Submitted.

${ }^{\mathrm{a}}$ Participant; ${ }^{\mathrm{b}}$ Mentor; ${ }^{\mathrm{c}}$ PNNL Host

Table 7. Presentations/Conference Papers from 2005 Work though August 2007. Futrell, J. H., Laskin, J. ${ }^{\mathrm{c}}$, \& Chu, I. ${ }^{\mathrm{a}}$ 2006. Surface-induced Collisional Activation and Dissociation of Even- and Odd-Electron Peptide Ions. $4^{\text {th }}$ International UPPSALA Conference on ECD/ETD Mass Spectrometry.

Futrell, J. H., Laskin, J. ${ }^{\mathrm{c}}$, \& $\mathrm{Chu}_{\text {I. }}^{\mathrm{a}}{ }^{2006 .}$. Collisional Activation and Dissociation of Even- and Odd-Electron Peptide Cations. Presented by Jean H. Futrell (Invited Speaker) at WSU, Pullman, WA on November 3, 2006.

Futrell, J. H., Laskin, J. ${ }^{\mathrm{c}}$, \& $\underline{\mathrm{Chu}, \mathrm{I}^{\mathrm{a}}}{ }^{2006 .}$ Studies in Tandem Mass Spectrometry: 
Table 7. Presentations/Conference Papers from 2005 Work though August 2007. Collisional Activation and Dissociation of Even- and Odd-Electron Peptide Cations. Presented by Jean H. Futrell (Invited Speaker) at WSU, Pullman, WA on November 3, 2006.

Lam, C. ${ }^{\mathrm{a}}$, Orlova, G., Laskin, J. ${ }^{\mathrm{c}}, \&$ Chu, I. ${ }^{\mathrm{a}}$ 2006. Facile Generation and

Characterization of Cationic Radical Peptides: Ligand Effect and Peptide Structures Presented by Julia Laskin at ASMS Conference on Mass Spectroscopy, Seattle, WA on May 29, 2006.

Laskin, J. $^{\mathrm{c}}$, Lam, C. ${ }^{\text {a }}$, Yang, Z., \& Chu, I. ${ }^{\mathrm{a}}$ 2006. Surface-Induced Dissociation of Peptide Radical Cations Presented by Julia Laskin (Invited Speaker) at 4th International UPPSALA, Hong Kong, Hong Kong on December 13, 2006.

Laskin, J. $^{\mathrm{c}}$, Yang, Z., Lam, C. ${ }^{\mathrm{a}}$, \& Chu, I. ${ }^{\mathrm{a}}$ 2007. Energetics and Dynamics of Electron Transfer and Proton Transfer in Dissociation of Metal 111 (Salen)-Peptide Complexes in the Gas-Phase. Presented by Julia Laskin at 55th ASMS Conference on Mass Spectrometry, Indianapolis, IN on June 6, 2007.

Futrell, J. H., Yang, Z., Laskin, J. ${ }^{\mathrm{c}}$, \& Chu, I. ${ }^{\mathrm{a}}$ 2007. Collisional Activation and Dissociation of Even- and Odd-electron Peptide Ion. submitted to 25th Informal Meeting on Mass Spectrometry, Nyiregyhaza-Sosto, Hungary.

Dyer, M. ${ }^{\mathrm{a}}$, El-Azab, A. ${ }^{c}$, \& Gao, F. ${ }^{c}$ 2006. Interfacial Structure and Point Defects in Ceria/Zirconia Superlattices. MRS Fall 2006, Symposium AA.

Laskin, J. ${ }^{\mathrm{c}}$, Hadjar, O., Wang, P., Futrell, J. H., Alvarez, J. ${ }^{\mathrm{a}}$ Green, J. R. ${ }^{\text {a }}$, \& Cooks, R. G. ${ }^{b}$. 2006. Soft Landing of Peptide Ions on Surfaces. Presented by Julia Laskin (Invited Speaker) at Isolated Biomolecules and Biomolecular Interactions (IBBI), Trest Castle, Czech Republic on May 10, 2006.

Hadjar, O., Dessiaterik, Y., Futrell, J. H., Lea, A., Green, J. R. ${ }^{\text {a }}$, Cooks, R. G. ${ }^{\text {b }}$, \& Laskin, $\mathrm{J}^{\mathrm{c}}{ }^{2}$ 2006. Design and Performance of a Novel Instrument for Soft-Landing of

Biomolecular Ions on Surfaces. Presented by Omar Hadjar at ASMS Conference on Mass Spectrometry, Seattle, WA on May 30, 2006.

Zhang, Z. ${ }^{\mathrm{a}}$, Kay, B. D., Ge, Q., White, J. M. ${ }^{\mathrm{b}}$, \& Dohnalek, Z. ${ }^{\mathrm{c}}$. 2006. Diffusion of Bridge-Bonded Oxygen Vacancies on TiO2(110) Presented by Zhenrong Zhang at AVS 53rd International Symposium and Exhibition, San Francisco, CA on November 13, 2006.

Zhang, Z. ${ }^{\mathrm{a}}$, Bondarchuk, O., White, J. M. ${ }^{\mathrm{b}}$, Kay, B. D., \& Dohnalek, Z. ${ }^{\mathrm{c}}$. 2006. H2O Dissociation and Proton Diffusion on TiO2(110) Presented by Zhenrong Zhang at American Vacuum Society Conference, San Francisco, CA on November 14, 2006.

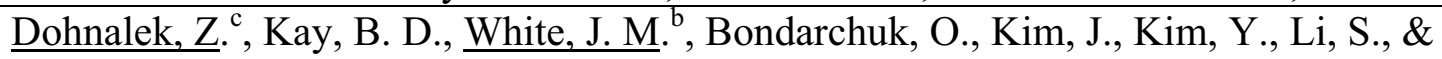
Zhang, Z. ${ }^{\mathrm{a}}$ 2007. Structure and Catalytic Activity of Model Oxide Systems. Presented by Zdenek Dohnalek (Invited Speaker) at DOE BES Catalysis Contractors' Meeting, Washington DC, on May 24, 2007.

Zhang, Z. ${ }^{\text {a }}$, Li, S., Ge, Q., Kay, B. D., White, J. M. ${ }^{\text {b }, ~ \& ~ D o h n a l e k, ~ Z . ~}{ }^{\text {c }}$ 2007. Diffusion of Bridge-Bonded Oxygen Vacancies and Hydrogen on TiO2(110). Presented by Zhenrong Zhang; Gordon Research Conference on Dynamics at Surfaces, Andover, NH on August $16,2007$.

Zhang, Z. ${ }^{\mathrm{a}}, \mathrm{Li}, \mathrm{S}$, , White, J. M. ${ }^{\mathrm{b}}$, \& Dohnalek, Z. ${ }^{\mathrm{c}}$ 2007. Defect and Adsorbate Dynamics on TiO2(110). Presented by Zdenek Dohnalek (Invited Speaker) at University of California, Santa Barbara, Santa Barbara, CA on September 26, 2007. 
Table 7. Presentations/Conference Papers from 2005 Work though August 2007. Zhang, Z. ${ }^{\mathrm{a}}$, Kay, B. D., Ge, Q., White, J. M. ${ }^{\mathrm{b}}$, \& Dohnalek, Z. ${ }^{\mathrm{c}}$ 2007. Diffusion of BridgeBonded Oxygen Vacancies on TiO2(110). Presented by Zhenrong, Zhang at National AVS Conference, Seattle, WA on October 16, 2007.

${ }^{\mathrm{a} P a r t i c i p a n t ;}{ }^{b}$ Mentor; ${ }^{\mathrm{C}} \mathrm{PNNL}$ Host

\section{Follow-up}

Work from the summer of 2006 has already produced 11 peer-reviewed publications as well as 14 submitted (Table 8) and 22 presentations (Table 9).

\section{Table 8. Peer Reviewed Publications from 2006 Work through August 2007.}

Liu, Y., Cain, J. P. ${ }^{a}$, Wang, H. ${ }^{b}$, \& Laskin, A. ${ }^{c}$ 2007. Kinetic Study of Heterogeneous Reactions of Deliquesced NaCI Particles with Gaseous HNO3 Using Particle-onSubstrate Stagnation Flow Reactor Approach. Journal of Physical Chemistry A. Submitted.

Liu, Y., Gibson, E. R., Cain, J. P. ${ }^{\mathrm{a}}$, Wang, H. ${ }^{\mathrm{b}}$, Grassian, V. H., \& Laskin, A. ${ }^{\mathrm{c}} 2007$. Kinetics of Heterogeneous Reaction of CaCO3 Particles with Gaseous HNO3 Over a Wide Range of Humidity Journal of Physical Chemistry A. Submitted.

Zelenyuk, A. ${ }^{c}$, Imre, D., \& Cuadra-Rodriguez, L. A. ${ }^{\text {a }}$ 2006. Evaporation of water from particles in the aerodynamic lens inlet: An experimental study. Analytical Chemistry, 78(19): 6942-6947.

Du, S. ${ }^{a}$, Francisco, J. S. ${ }^{\text {b }}$, Schenter, G. K. ${ }^{\text {c }}$, Iordanov, T. D., Garrett, B. C., Dupuis, M., \& Li, J. 2006. The OH Radical-H2O Molecular Interaction Potential. Journal of Chemical Physics 124(224318 (15)).

Du, S. ${ }^{\mathrm{a}}$, Francisco, J. S. ${ }^{\mathrm{b}}$, Schenter, G. K. ${ }^{\mathrm{c}}$, \& Garrett, B. C. 2007. Ab initio and analytical intermolecular potential for ClO-H2O Journal of Chemical Physics, 126(11): 146-155.

Du, S. ${ }^{\mathrm{a}}$, Francisco, J. S. ${ }^{\mathrm{b}}$, Schenter, G. K. ${ }^{\mathrm{c}}$, \& Garrett, B. C. 2007. Many-Body Decomposition of the Binding Energies for $\mathrm{OH}_{2}(\mathrm{H} 2 \mathrm{O}) 2$ and $\mathrm{OH}_{2}(\mathrm{H} 2 \mathrm{O}) 3$ Complexes. Journal of Chemical Physics. Submitted.

Dutta, D. ${ }^{\mathrm{a}}$, Sundaram, S. K. ${ }^{\mathrm{c}}$, Riley, B. J., Fifield, L. S., Jacobs, J. M. K. G. A., Moudgil, B. M. ${ }^{\mathrm{b}}$, \& Weber, T. J. 2007. Adsorbed Proteins Influence the Biological Activity and Molecular Targeting of Nanomaterials. Toxicological Sciences. Submitted.

Zhang, Y. ${ }^{\mathrm{c}}$, Milbrath, B. D., Weber, W. J., Elfman, M. ${ }^{\mathrm{a}}$, \& Whitlow, H. J. 2007. Radiation detector resolution over a continuous energy range. Applied Physics Letters, 91(09): 1-3.

Zhang, Y. ${ }^{\mathrm{c}}$, Elfman, M. ${ }^{\mathrm{a}}$, \& Weber, W. J. 2007. A Fast Analysis Technique to Evaluate Scintillation Response. IEEE Transactions on Nuclear Science. Submitted.

Lins Neto, R. D. ${ }^{\mathrm{c}}$, Vorpagel, E. R., Guglielmi, M. ${ }^{\mathrm{a}}$, \& Straatsma, T. 2007. Characterization of Uranyl Uptake by the Rough Lipopolysaccharide Membrane of Pseudomonas aeruginosa. Geochimica et Cosmochimica Acta. Submitted.

Doran, J. C., Fast, J. D., Barnard, J. C., Laskin, A. ${ }^{\text {, }}$, Dessiaterik, Y., Gilles, M. K. ${ }^{\text {, }}$ \& Hopkins, R. J. ${ }^{\text {a }}$ 2007. Applications of Lagrangian Dispersion Modeling to the Analysis of Changes in the Specific Absorption of Elemental Carbon. Atmospheric Chemistry and Physics. Submitted.

Hopkins, R. J. ${ }^{\text {, }}$ Lewis, K. M., Dessiaterik, Y., Wang, Z., Tivanski, A., Arnott, W. P., 
Table 8. Peer Reviewed Publications from 2006 Work through August 2007. Laskin, A. $^{\mathrm{c}}$, \& Gilles, M. K. ${ }^{\mathrm{b}}$ 2007. Correlating Optical, Chemical and Physical Properties of Biomass Burn Aerosols. Geophysical Research Letters. Submitted. Hopkins, R. J. ${ }^{\text {a }}$, Tivanski, A., Dessiaterik, Y., Tyliszczak, T., Laskin, A. ${ }^{\mathrm{c}}$, \& Gilles, M. K. ${ }^{\mathrm{b}}$ 2007. Chemical Speciation of Sulfur in Marine Cloud Droplets and Particles: 2. Partitioning of Methanesulfonate and Non-Sea Salt Sulfate in Individual Sea Salt Particles. Journal of Geophysical Research. D. (Atmospheres). Submitted.

Hopkins, R. J. ${ }^{\text {a }}$, Tivanski, A., Dessiaterik, Y., Tyliszczak, T., Laskin, A. ${ }^{\text {c }}$, \& Gilles, M. K. ${ }^{\mathrm{b}}$ 2007. Chemical Speciation of Sulfur in Marine Cloud Droplets and Particles: 1. Analysis of Individual Particles from Marine Boundary Layer Over the California Current . Journal of Geophysical Research. D. (Atmospheres). Submitted.

Johnson, K. S., de Foy, B., Zuberi, B., Molina, L. T., Molina, M. J. ${ }^{\text {, }}$, Xie, Y., Laskin, A. ${ }^{\text {, }}$ \& Shutthanandan, V. 2006. Aerosol composition and source apportionment in the Mexico City Metropolitan Area with PIXE/PESA/STIM and multivariate analysis. Atmospheric Chemistry and Physics, 6: 4591-4600.

Salcedo, D., Onasch, T. B., Dzepina, K., Canagaratna, M. R., Zhang, Q., Huffman, A. J., DeCarlo, P., Jayne, J., Mortimer, P., Worsnop, D. R., Kolb, C. E., Johnson, K. S. a, Zuberi, B., Marr, L., Volkamer, R. M., Molina, L. T., Molina, M. J. ${ }^{\text {, }}$, Cardenas, B., Bernabe, R., Marquez, C., Gaffney, J. S., Marley, N. A., Laskin, A. ${ }^{\text {, }}$, Shutthanandan, V., Xie, Y., Brune, W. H., Lesher, R., Shirley, T., \& Jiminez, J. L. 2006. Characterization of Ambient Aerosols in Mexico City during the MCMA-2003 Campaign with Aerosol Mass Spectrometry. Results from the CENICA Supersite. Chemistry and Physics, 6: 925-946. Barnard, J. C., Kassianov, E. L., Ackerman, T. P., Johnson, K. S. ${ }^{\text {, }}$ Zuberi, B., Molina, L. T., \& Molina, M. J. ${ }^{\mathrm{b}}$ 2007. Estimation of a "radiatively correct" black carbon specific absorption during the Mexico City Metropolitan Area (MCMA) 2003 field campaign Atmospheric Chemistry and Physics, 7(6): 1645-1655.

Lane, C. D., Petrik, N. G., Orlando, T. M., \& Kimmel, G. A. 2007. Electron-Stimulated Oxidation of Thin Water Films Adsorbed on TiO2(110). Journal of Physical Chemistry C. Submitted.

Lane, C. D. ${ }^{\mathrm{a}}$, Petrik, N. G. ${ }^{\mathrm{c}}$, Orlando, T. M. ${ }^{\mathrm{b}}$, \& Kimmel, G. A. 2007. Site-Selective Electron-Stimulated Reactions in Water Films on TiO2(110). Journal of Chemical Physics. Submitted.

Zhai, H. J., Wang, L. M., Li, S. D. ${ }^{a}$, \& Wang, L. S. ${ }^{\mathrm{c}}$ 2007. Vibrationally resolved photoelectron spectroscopy of $\mathrm{BO}$ - and $\mathrm{BO} 2-:$ A joint experimental and theoretical study. Journal of Physical Chemistry A, 111(6): 1030-1035.

Zhai, H. J., Wang, L., Li, S. ${ }^{a}$, \& Wang, L. S. ${ }^{c}$ 2007. Boronyls as Key Structural Units in Boron Oxide Clusters: $B(B O) 2$ - and $B(B O) 3$-. Journal of the American Chemical Society. Submitted.

Lloyd, J. A. ${ }^{\mathrm{a}}$, Spraggins, J. M. ${ }^{\mathrm{a}}$, \& Johnston, M. V. ${ }^{\mathrm{b}}$ 2006. Peptide ozonolysis: Product structures and relative reactivities for oxidation of tyrosine and histidine residues. Journal of the American Society for Mass Spectrometry, 17(9): 1289-1298.

$\underline{\text { Saheb, A. H. }}^{\mathrm{a}}$, Smith, J. A., Jocowicz, M., Janata, J. ${ }^{\mathrm{b}}$, Baer, D. R. ${ }^{\mathrm{c}}$, \& Engelhard, M. H. 2007. Controlling Size of Gold Clusters in Polyaniline from Top Down and from Bottom Up. Journal of Electroanalytical Chemistry. Submitted.

Thomas, J. L. ${ }^{\mathrm{a}}$, Roeselova, M., Dang, L. X. ${ }^{\mathrm{c}}$, \& Tobias, D. J. 2007. Molecular dynamics simulations of the solution-air interface of aqueous sodium nitrate. Journal of Physical 
Table 8. Peer Reviewed Publications from 2006 Work through August 2007.

Chemistry A, 111(16): 3091-3098.

${ }^{a}$ Participant; ${ }^{b}$ Mentor; ${ }^{c}$ PNNL Host

Table 9. Presentations/Conference Papers from 2006 Work though August 2007. Liu, Y., Cain, J. P. ${ }^{\mathrm{a}}$, Wang, H. ${ }^{\mathrm{b}}$, \& Laskin, A. ${ }^{\mathrm{c}}$ 2006. A Kinetic Study of the Heterogeneous Reaction of Deliquesced NaCl Particles with Gaseous HNO3 Using Novel Experimental Approach. Presented by Yong Liu at AGU Meeting, San Francisco, CA on December 12, 2006

Liu, Y., Cain, J. P. ${ }^{\text {a }}$, Wang, H. ${ }^{\mathrm{b}}$, \& Laskin, A. ${ }^{\mathrm{c}}$ 2007. A Kinetic Study of the Heterogeneous Reaction of Deliquesced NaC1 Particles with Gaseous HNO3. Presented by Yong Liu at AAAR 2007 Meeting, Reno, NV on September 25, 2007.

Zelenyuk, A., Cuadra-Rodriguez, L. A. ${ }^{\text {a }}$ Imre, D., Shimpi, S., \& Warey, A. 2006. The Size and Composition of Individual Ultrafine Diesel Emission Particulate from 2007 Diesel Engines with and without after Treatment. Presented by Alla Zelenyuk at DEER 2006, Detroit, MI on August 21, 2006.

Zelenyuk, A. ${ }^{c}$, Cuadra-Rodriguez, L. A. ${ }^{\text {a }}$, Imre, D., Shimpi, S., \& Warey, A. 2006. Comprehensive Characterization of Ultrafine Particulate Emission from 2007 Diesel Engines: PM Size Distribution Loading and Individual Particle Size and Composition. Presented by Alla Zelenyuk at American Geophysical Union Meeting, San Francisco, CA on December 13, 2006.

Zelenyuk, A. ${ }^{\text {c }}$, Cuadra-Rodriguez, L. A. ${ }^{\text {a }}$, Imre, D., Shimpi, S., \& Warey, A. 2007. Comprehensive Characterization of Ultrafine Particulate Emission from 2007 Diesel Engines with Aftertreatment: PM Size Distribution, Loading and Individual Particle Size and Composition. Presented by Alla Zelenyuk at AAAR Meeting, Reno, NV on September 24, 2007.

Zelenyuk, A. ${ }^{\text {, }}$ Imre, D., Cuadra-Rodriguez, L. A. ${ }^{\mathrm{a}}$, \& Ellison, B. 2007. Measurements and Interpretation of the Effect of Soluble Organic Surfactants on the Density, Shape and Water Uptake of Hygroscopic Particles. Presented by Alla Zelenyuk at AAAR Meeting, Reno, NV on September 25, 2007.

Weber, T. J., Sundaram, S. K. ${ }^{\text {c }}$, Riley, B. J., Addleman, R. S., Fifield, L. S., Dutta, D. a , \& Moudgil, B. M. ${ }^{\mathrm{b}}$ 2007. Targeting Nanomaterials to Cell Surface Receptors: Implications for Defining Relevant Modes of Action and Chronic Toxicity. by Tom Weber at Society of Toxicology, Charlotte, NC on March 25, 2007.

Johnson, K. S. ${ }^{\text {a }}$ Gonzalez, R. L. ${ }^{\mathrm{a}}$, Molina, L. T. ${ }^{\mathrm{b}}$, Hopkins, R. J. ${ }^{\mathrm{a}}$, Tivanski, A., Gilles, M. $\underline{\mathrm{K}}^{\mathrm{b}}$, Dessiaterik, Y., \& Laskin, A. ${ }^{\mathrm{c}}$ 2007. Microscopy and Microprobe Studies of Individual Particles Collected During MILAGRO 2006 Study. Presented by Alex Laskin at European Geosciences Union General Assembly 2007, Vienna, Austria on April 18, 2007.

Dessiaterik, Y., Hopkins, R. J. ${ }^{\mathrm{a}}$, Tivanski, A., Berkowitz, C. M., Gilles, M. K. ${ }^{\mathrm{b}}$, \& Laskin, A. ${ }^{\mathrm{c}}$ 2006. Chemical Speciation of Sulfur in Marine Cloud Droplets and Particles: 1. Analysis of Individual Particles Using Complementary Microprobe Methods Presented by Yury Dessiaterik at AGU Fall Meeting, San Francisco, CA on December 13, 2006.

Dessiaterik, Y., Hopkins, R. J. ${ }^{\mathrm{a}}$ Tivanski, A., Gilles, M. K. ${ }^{\mathrm{b}}$, \& Laskin, A. ${ }^{\mathrm{c}} 2006$. 


\section{Table 9. Presentations/Conference Papers from 2006 Work though August 2007.} Partitioning of Methanesulfonate and Non-Sea-Salt Sulfate in Individual Sea Salt Particles Collected at the Pt. Reyes National Seashore by Alex Laskin (Invited Speaker) at AirUCI Workshop, Christchurch, New Zealand on December 11, 2006.

Dessiaterik, Y., Hopkins, R. J. ${ }^{\mathrm{a}}$, Tivanski, A., Gilles, M. K. ${ }^{\mathrm{b}}$, \& Laskin, A. ${ }^{\mathrm{c}} 2007$. Partitioning of Methanesulfonate and Non-Sea-Salt Sulfate in Individual Sea Salt Particles Collected at the Pt. Reyes National Seashore. Presented by Alex Laskin at European Geosciences Union General Assembly 2007, Vienna, Austria on April 19, 2007.

Hopkins, R. J. ${ }^{\mathrm{a}}$, Tivanski, A., Dessiaterik, Y., Gaspar, D. J., Gilles, M. K. ${ }^{\mathrm{b}}$, \& Laskin, A. ${ }^{\mathrm{c}}$ 2006. Analysis of Field Collected Individual Atmospheric Particle Using MultiAnalytical Microprobe Methods. Presented by Yury Dessiaterik at AAAR Meeting, St. Paul, MN on September 13, 2006.

Hopkins, R. J. $^{\text {a }}$, Tivanski, A., Dessiaterik, Y., Laskin, A. ${ }^{\mathrm{c}}$, \& Gilles, M. K. ${ }^{\mathrm{b}} 20006$. Chemical Speciation of Sulfur in Marine Cloud Droplets and Particles: 2. Partitioning of Methanesulfonate and Non-Sea Salt Sulfate in Individual Sea Salt Particles. Presented by Yury Dessiaterik at AGU Fall Meeting, San Francisco, CA on December 13, 2006.

Hopkins, R. J. ${ }^{\text {, }}$, Dessiaterik, Y., Zaveri, R. A., Berkowitz, C. M., Tivanski, A., Gilles, M. $\underline{\mathrm{K}}^{\mathrm{b}}$, \& Laskin, A. ${ }^{\mathrm{c}}$ 2007. Chemical Speciation of Sulfur in Marine Cloud Droplets and Particles: Quantitative Assessment of Methanesulfonate and Non-Sea Salt Sulfate Partitioning in Individual Sea Salt Particles. Presented by Alex Laskin at AAAR 2007 Conference, Reno, NV on September 25, 2007.

$\underline{\text { Hopkins, R. J. }}_{\text {, }}$ Lewis, K. M., Dessiaterik, Y., \& Wang, Z. 2007. Diversity of Biomass Burn Aerosols Based on Fuel. Presented by M. K. Gilles at AAAR 2007 Meeting, Reno, NV on September 26, 2007.

Lam, C. ${ }^{\mathrm{a}}$, Orlova, G., Laskin, J. ${ }^{\mathrm{c}}$, \& Chu, I. ${ }^{\mathrm{a}}$ 2006. Facile Generation and

Characterization of Cationic Radical Peptides: Ligand Effect and Peptide Structures Presented by Julia Laskin.

$\underline{\text { Laskin, J. }}^{\mathrm{c}}$, Lam, C. ${ }^{\mathrm{a}}$, Yang, Z., \& Chu, I. ${ }^{\mathrm{a}}$ 2006. Surface-Induced Dissociation of Peptide Radical Cations Presented by Julia Laskin (Invited Speaker) at 4th International UPPSALA, Hong Kong, Hong Kong on December 13, 2006.

Lee, C. ${ }^{\mathrm{a}}$, Wachsman, E. D., Phillpot, S. R., Devanathan, R. ${ }^{\mathrm{c}}$, \& Sinnott, S. B. ${ }^{\mathrm{b}} 2007$. Chemical Properties of LaFeO3 from First Principles Calculations: Implications for Use as SOFC cathodes. Presented by Chan-Woo Lee at 2007 Gordon Research Conference on Solid State Studies in Ceramics, Andover, NH on August 8, 2007.

Laskin, J. ${ }^{\mathrm{c}}$, Yang, Z., Lam, C. ${ }^{\mathrm{a}}$, \& Chu, I. ${ }^{\mathrm{a}}$ 2007. Energetics and Dynamics of Electron Transfer and Proton Transfer in Dissociation of Metal lll (Salen)-Peptide Complexes in the Gas-Phase. Presented by Julia Laskin at 55th ASMS Conference on Mass Spectrometry, Indianapolis, IN on June 6, 2007.

Laskin, J. ${ }^{\mathrm{c}}$, Yang, Z., \& Lam, C. ${ }^{\mathrm{a}}$ 2007. Surface-Induced Dissociation of Even- and OddElectron Peptide Ions. Presented by Julia Laskin (Invited Speaker) at Gordon Research Conference on Gaseous Ions: Structures, Energetics \& Reactions, Ventura, CA on February 28, 2007.

Petrik, N. G. ${ }^{\mathrm{c}}$, Lane, C. D. ${ }^{\mathrm{a}}$, Orlando, T. M. ${ }^{\mathrm{b}}$, \& Kimmel, G. A. 2007. Electron Stimulated Desorption and Dissociation of Thin Water Films Adsorbed on TiO2(110). Presented by Nick Petrik at ACS International Conference, Boston, MA on August 20, 2007. 
Table 9. Presentations/Conference Papers from 2006 Work though August 2007. $\underline{L i}_{\text {, S. }}^{\text {a }}$, Fu, L., Wang, C. M. ${ }^{\text {c, Lea, S., Arey, B., Engelhard, M., \& Cheng, Z.-Y. }}{ }^{\text {b }} 2006$. Characterization of Microstructure and Composition of Fe-B Nanobars as Biosensor Platform. Paper presented at the MRS Proceedings, Boston, MA.

${ }^{\mathrm{a}}$ Participant; ${ }^{\mathrm{b}}$ Mentor; ${ }^{\mathrm{c}}$ PNNL Host

\section{To Date}

Work from the summer of 2007 has already produced 6 peer-reviewed publications as well as 1 submitted (Table 10) and 4 presentations (Table 11).

\section{Table 10. Peer Reviewed Publications from 2007.}

Punnoose, A. $^{\text {b }}$, Reddy, K. M., Thurber, A. ${ }^{\text {a }}$, Hays, J., \& Engelhard, M. 2007. Novel Magnetic Hydrogen Sensing: A Case Study Using Antiferromagnetic Hematite Nanoparticles. Nanotechnology, 18(16): Art No. 165502.

Thurber, A. ${ }^{\mathrm{a}}$, Hays, J., Reddy, K. M., Shutthanandan, V., \& Punnoose, A. ${ }^{\text {b }} 2007$. Fluorine doping in dilute magnetic semiconductor Sn1-xFexO2. Journal of Materials Science 18(11): 1151-1155.

Wigginton, N. S. ${ }^{\mathrm{a}}$, Rosso, K. M. ${ }^{\mathrm{c}}$, \& Hochella, M. F. ${ }^{\mathrm{b}}$ 2007. Mechanisms of Electron Transfer in Two Decaheme Cytochromes from a Metal-Reducing Bacterium. Journal of Physical Chemistry A, Submitted.

Wigginton, N. S. ${ }^{\mathrm{a}}, \underline{\text { Rosso, K. M. }}{ }^{\mathrm{c}}$, Lower, B. H., Shi, L., \& Hochella, M. F. ${ }^{\mathrm{b}} 2007$. Electron tunneling properties of outer-membrane decaheme cytochromes from Shewanella oneidensis. Geochimica et Cosmochimica Acta, 71(3): 543-555. Goering, J., Kadossov, E., Burghaus, U., Yu, Z. ${ }^{a}$, Thevuthasan, S. ${ }^{c}$, \& Saraf, L. V. 2007. Adsorption of Iso-/n-butane on an Anatase Thin Film: A Molecular Beam Scattering and TDS Study. Catalysis Letters, 116(1-2): 9-14.

Lyubinetsky, I., Yu, Z. ${ }^{\text {, }}$, \& Henderson, M. 2007. Direct Observation of Adsorption Evolution and Bonding Configuration of TMAA on TiO2(110). Journal of Physical Chemistry C 111(11): 4242-4346.

Yu, Z. ${ }^{\text {a }}$, Wang, C. M., Engelhard, M., Nachimuthu, P., McCready, D. E., Lyubinetsky, I., \& Thevuthasan, S. ${ }^{\mathrm{c}}$ 2007. Epitaxial Growth and Microstructure of Cu2O Nanoparticle/thin Films on SrTiO3(100). Nanotechnology 18:Art. No. 115601., 18(115601): doi:10.1088/0957-4484/1018/1011/115601.

Funk, S., Hokkanen, B., Nurkic, T., Goering, J., Kadossov, E., Burghaus, U., A., G., Schmuki, P., Yu, Z. ${ }^{\text {a }}$, Thevuthasan, S. ${ }^{\mathrm{c}}$, \& Saraf, L. V. 2007. Reactivity Screening of Anatase TiO2 Nanotube Arrays and Anatase Thin Films: A Surface Chemistry Point of View. Journal of the American Chemical Society, Submitted.

${ }^{a}$ Participant; ${ }^{b}$ Mentor; ${ }^{c}$ PNNL Host

\section{Table 11. Presentations/Conference Papers from 2007}

Gupta, S. $^{\text {a }}$, Saraf, L. V., Nachimuthu, P., Engelhard, M. H., Shutthanandan, V., Thevuthasan, S., \& Prasad, S. 2007. Ceria Nanomonitors For Trace Oxygen Monitoring In Portable System. Presented by Shilpi Gupta at 2007 Micro Nano Breakthrough Conference Registrations, Portland, OR on September 10, 2007.

Ortiz, S. Y. ${ }^{\mathrm{a}}$, Ziolo, R. F., Burton, S. D. ${ }^{\mathrm{c}}$, \& Espe, M. P. ${ }^{\mathrm{b}}$ 2007. Solid-State NMR studies 


\section{Table 11. Presentations/Conference Papers from 2007}

of CdS Nanoparticles. Presented by Sarah Burton at Rocky Mountain Analytical Conference, Breckenridge, CO on July 23, 2007.

Rosso, K. M. ${ }^{c}$, Skomurshi, F. N., Wander, M. C., Wigginton, N. S. ${ }^{a}$ Kerisit, S. N., \& Yanina, S. 2007. Advances in Mechanistic Understanding of Abiotic and Microbial Electron Transfer Kinetics. Presented by Kevin M. Rosso (Invited Speaker) at 2nd Annual ERSP PI Meeting, Landsdowne, VA on April 17, 2007.

Wigginton, N. S. ${ }^{\mathrm{a}}, \underline{\text { Rosso, K. M. }}{ }^{\mathrm{c}}$, Lower, B. H., Shi, L., \& $\underline{\text { Hochella, M. F. }}{ }^{\mathrm{c}}$ 2007. Singlemolecule STM investigations into the enzymatic reduction of metal-oxides by Shewanella oneidensis. Presented by Nicholas Wigginton (Invited Speaker) at 62nd Annual Meeting of the Northwest Region of the ACS, Boise, ID on June 18, 2007.

${ }^{\mathrm{a}}$ Participant; ${ }^{\mathrm{b}}$ Mentor; ${ }^{\mathrm{c}}$ PNNL Host 
PNNL-17069

\section{Participant Survey}

The questionnaire in the Appendix survey was sent to all of the summer program participants, past and present, (visitors, hosts and advisors). From these, approximately seventy individuals we received thirty-two replies. Exit interviews were attempted with all of the participants. Informal discussions were also conducted with many participants and their PNNL hosts/mentors.

\section{General Impressions}

Overall, the results of our survey and other inquiries produced very similar results to previous years' feedback. That is, most participants - visitors, hosts and home institution supervisors - were more enthusiastic about the program after participating in it than before. Both written and verbal comments indicate that the program should be continued into the indefinite future and suggestions that the program should be expanded in several ways. Praise was universal for the smooth operation of the summer program. Credit for this goes primarily to our administrator, Ms. Nikki Avery. Comments that elicited narrative responses are given in the appendix and arranged according to the role of the respondent - Visitor, Academic Supervisor, PNNL host.

\section{Difficulties}

Most of the difficulties experienced by our visitors fell into two broad categories: those associated with PNNL and those associated with Richland. Lab-level problems and difficulties mostly arise from our participants' unfamiliarity with the national lab work environment and PNNL's own specific features.

In this regard, organizational and personnel shifts within the laboratory were traced to delays in reimbursement for the expenses of a few particpants'. In one case, rent reimbursements were not fully paid until the day a participant left the PNNL and was handed two checks on the way to their airplane. Such crisis' required the direct and personal intervention of both the Co-ordinator and the Administrator.

Other difficulties experienced by our visitors are simply the result of the physical location of the laboratory on the outskirts of Richland, WA. Housing and transportation can be challenging. In an effort to reduce dislocation of particpants, the Administrator reserved a block of rooms at The Guesthouse at PNNL. All were pleased with the accommodations; however it is difficult get from there to local stores without a car.

\section{Future Improvements}

Publicity 
In FY07, we increased our publicity efforts as was done in FY06. It will be important to maintain this effort and expand it if possible in FY08. We continue to appear in the American Chemical Society's list of summer research opportunities.

\section{Participation and Continuity}

Several participants recommended that the program be both expanded and extended pass the FY07 stretch goal year. The past two year's experience with more senior visitors indicates that there is a real need for a program similar to this one to serve that group. As a result, we are focused on a definite vision of the ICPCPSRI as it enter FY08 
PNNL-17069 
PNNL-17069

\section{Technical Reports}

The remainder of this document is devoted to the technical reports provided by each young scientist in SRI in FY2007. Some of these are single paragraph abstracts and, therefore, have rather limited content. Other reports, however, are nearly complete papers. These documents are "as received," apart from minor formatting changes in some cases. We have made no effort to edit or evaluate these reports. Given the limited distribution intended for this report, none of the results in these reports should be considered "published" by virtue of appearing here. 
PNNL-17069 
PNNL-17069

\section{Suppression of $\mathrm{O}_{2}$ by $\mathrm{CH}_{3} \mathrm{OH}$}

Minta Akin and C. Buddie Mullins, University of Texas at Austin Nikolay G. Petrik and Greg A. Kimmel, Pacific Northwest National Laboratory

\section{Introduction}

Most recent work on supercooled thin water films has focused on amorphous solid water (ASW) due that material's importance in multiple fields. Limited work has been done on radiation driven processes in pure ASW, somewhat less work on pure alcohols, and none so far on mixtures of ASW and alcohols. However, such mixes are common in many settings where ASW research has applications, including comets and icy bodies, clouds, cells, and retired reactors. Such mixtures also have applications on a broader scale, by clarifying energy transfer, leading to new synthetic processes, and clarifying mechanisms in water-based reactions. Our understanding of $\mathrm{H}$-bonding networks and mixing at low temperatures needs to be improved by studying such mixtures.

Petrik et al. previously characterized radiation-driven $\mathrm{O}_{2}$ production, proposing the following reaction mechanism:
1. $\mathrm{e}^{-}+\mathrm{H}_{2} \mathrm{O}$ bulk $\rightarrow \mathrm{H}_{2} \mathrm{O}^{+}+2 \mathrm{e}^{-}$
2. $\mathrm{H}_{2} \mathrm{O}^{+}+\mathrm{e}^{-} \rightarrow \mathrm{H}_{2} \mathrm{O}^{*}$ bulk
3. $\mathrm{H}_{2} \mathrm{O}^{*}$ bulk $\rightarrow \mathrm{H}_{2} \mathrm{O}^{*}$ vac
4. $\mathrm{H}_{2} \mathrm{O}^{*}$ vac $\rightarrow \mathrm{H}_{\text {des }}+\mathrm{OH}_{\text {vac }}$
5. $2 \mathrm{OH}_{\text {vac }} \rightarrow \mathrm{H}_{2} \mathrm{O}_{2}$ vac
6. $\mathrm{H}_{2} \mathrm{O}_{2 \text { vac }}+\mathrm{OH}_{\text {vac }} \rightarrow \mathrm{HO}_{2 \text { vac }}+\mathrm{H}_{2} \mathrm{O}$
7. $\mathrm{HO}_{2 \text { vac }}+\mathrm{A} \rightarrow \mathrm{O}_{2}+$ other products

In reaction 7, $\mathrm{A}$ is unknown, and may be another precursor molecule, an exciton, or an impinging electron. In films that had not been previously irradiated (also called "unprocessed" or "raw" films), $\mathrm{O}_{2}$ production grew with time until production was saturated. If the electron beam was stopped after saturation the sample was allowed to "rest" at the same temperature, and the electron beam was restarted, $\mathrm{O}_{2}$ production resumed immediately at its saturation level, regardless of the length of resting time. Using isotopically labeled water $\left(\mathrm{H}_{2}{ }^{16} \mathrm{O}\right.$ and $\left.\mathrm{H}_{2}{ }^{18} \mathrm{O}\right)$, Petrik et al. determined that $\mathrm{O}_{2}$ production was localized at the water-vacuum interface and resulted from an ultimate precursor molecule. This precursor molecule was proposed to be $\mathrm{HO}_{2}$, the result of several intermediate reactions, some of which are thermally driven. The concentration of $\mathrm{HO}_{2}$ and other precursors at saturation was found to be $\sim 0.01$ to 0.03 ML relative to the water coverage (1 ML). 


\section{Methods}

Chamber Set Up

Experiments were done in an ultrahigh vacuum (UHV) chamber, equipped with a closed cycle helium cryostat, low-energy electron gun, quadrupole mass spectrometer, and a molecular beam line. Median base pressure for the system was $\sim 1.1 \mathrm{E}-10$ torr and base temperature was $\sim 22 \mathrm{~K}$. Films were grown on a clean $\mathrm{TiO}_{2}(110)$ crystal approximately 10 $\mathrm{mm}$ in diameter and $0.5 \mathrm{~mm}$ thick. Neon ion sputtering followed by annealing at $850 \mathrm{~K}$ in vacuum cleaned the crystal. The sample is resistively heated, and the temperature measured by a type $\mathrm{K}$ thermocouple spot-welded to the back of the sample.

\section{Deposition and Growth Conditions}

Methanol and water were freeze-pump-thawed prior to use to ensure purity. All films were dosed through beams at normal incidence to the crystal. The films did not cover the entire substrate surface, but were centered on the $\mathrm{TiO}_{2}$ substrate. Water coverage calibration was based on previous calculations.(Petrik, Kavetsky and Kimmel) Direct measurements of methanol saturation coverage on ASW for calibration purposes are difficult due to mixing processes during temperature programmed desorption (TPD). Instead, methanol coverage was calibrated using the integration of the first monolayer peak in the TPD spectra from the bare $\mathrm{TiO}_{2}$ crystal. Based on the relative coverage of water on $\mathrm{TiO}_{2}$, methanol on $\mathrm{TiO}_{2}$, and calculations of methanol on hexagonal ice, one monolayer of methanol on ASW was determined to be three times the exposure needed for one monolayer of methanol on $\mathrm{TiO}_{2}$. The same exposure definition was used for each of the isotopically labeled varieties of methanol used, $\mathrm{CH}_{3} \mathrm{OH}, \mathrm{CD}_{3} \mathrm{OH}$, and $\mathrm{CD}_{3} \mathrm{OD}$, although the calibration was performed only for $\mathrm{CH}_{3} \mathrm{OH}$.

Underlying base water films (in contact with the $\mathrm{TiO}_{2}$ surface) were grown at $80 \mathrm{~K}$, conditions known to produce consistently dense and smooth ASW surfaces. While thermal mixing of water and methanol begins somewhere above $100 \mathrm{~K}$, we saw clear evidence of methanol surfaction at lower temperatures. Surfaction was observed after deposition of upper water layers in "sandwich" experiments, where methanol was buried under several layers of water to isolate it from the vacuum interface. When the deposition temperature was $80 \mathrm{~K}$, the methanol promptly desorbed from the surface in subsequent ESD experiments. Dosing upper layers at $50 \mathrm{~K}$ or less eliminated the prompt appearance of methanol in the following ESD experiments, even if the film was heated to $80 \mathrm{~K}$ from the lower deposition temperature. Heating gently to $80 \mathrm{~K}$ and irradiating did not affect the ESD signal structure compared to irradiation at 50 or $25 \mathrm{~K}$. To eliminate these surfaction effects, all upper films were grown at $80 \mathrm{~K}$ or less, depending on their position in the final film structure. Capping water layers were grown at $50 \mathrm{~K}$ or less to minimize the surfactant properties of methanol. Methanol films were grown at $80 \mathrm{~K}$ or less if on the surface, and at $50 \mathrm{~K}$ or less if in the interior (i.e., in a "sandwich" experiment).

\section{Radiation Conditions}

To eliminate the effects of thermal mixing and focus on radiative mixing and reaction products, all irradiation was performed at $80 \mathrm{~K}$ or colder. Irradiation at $80 \mathrm{~K}$ was done only when the surfactant properties of methanol could be neglected (e.g., pure water films and films with methanol at the vacuum interface). Films were irradiated for 97 
seconds with $100 \mathrm{eV}$ electrons at a current of $2 \mu \mathrm{A}$ using a scan-averaging mode described previously. (Petrik, Kavetsky and Kimmel) The electron beam was incident at $35^{\circ}$ to the sample normal.

\section{Results and Discussion}

\section{Capped films}

$\mathrm{H}_{2}{ }^{18} \mathrm{O}$ was capped by increasing amounts of $\mathrm{CH}_{3} \mathrm{OH}$, up to $0.5 \mathrm{ML}$, and irradiated. We monitored the ${ }^{18} \mathrm{O}_{2}$ signal to measure $\mathrm{O}_{2}$ produced in the water layer during irradiation. Partial isotopic labeling of the water films so that the upper $10 \mathrm{ML}$ are $\mathrm{H}_{2}{ }^{18} \mathrm{O}$ and the bottom $70 \mathrm{ML}$ are $\mathrm{H}_{2}{ }^{16} \mathrm{O}$ confirms that $\mathrm{O}_{2}$ production is concentrated at the surface as it is in pure water films. In this case, the ${ }^{36} \mathrm{O}_{2}$ signal intensity was roughly $70 \%$ that seen from an $80 \mathrm{ML} \mathrm{H}_{2}{ }^{18} \mathrm{O}$ film.

The addition of $\mathrm{CH}_{3} \mathrm{OH}$ to the surface of ASW leads to a delay in the radiationdriven production of $\mathrm{O}_{2}$ from water (Figure 1). For a specified threshold level of $\mathrm{O}_{2}$ production (e.g., a signal intensity of 0.03 a.u.), this delay is linearly dependent on the $\mathrm{CH}_{3} \mathrm{OH}$ dose (Figure 2). The greater the $\mathrm{O}_{2}$ threshold, the longer the delay (steeper slope), indicating that $\mathrm{O}_{2}$ production rates are slowed, and ruling out the possibility that all $\mathrm{CH}_{3} \mathrm{OH}$ and byproducts were eliminated from the system and the remaining $\mathrm{O}_{2}$ comes from a pure water film. When the $\mathrm{O}_{2}$ rate is measured for a given remaining amount of surface methanol, as measured by the methanol desorption, it is not constant. Dosing amounts of methanol greater than $0.5 \mathrm{ML}$ also suppresses $\mathrm{O}_{2}$ production; at amounts greater than about $0.65 \mathrm{ML}$ of $\mathrm{CH}_{3} \mathrm{OH}, \mathrm{O}_{2}$ production does not recover within 97 seconds, the length of the radiation cycle. Integrating the $\mathrm{O}_{2}$ signal over time and plotting its dependence on the initial methanol dose was used to measure $\mathrm{O}_{2}$ suppression. Integration was performed over the first three seconds of irradiation to reflect initial suppression/retardation of early $\mathrm{O}_{2}$ production and to eliminate any radiative mixing effects. Integration was also calculated over the full radiation cycle to reflect total $\mathrm{O}_{2}$ suppression as a function of $\mathrm{CH}_{3} \mathrm{OH}$ dose, including any effects of mixing and $\mathrm{CH}_{3} \mathrm{OH}$ byproducts such as $\mathrm{CH}_{2} \mathrm{O}$. The integration values' dependence on $\mathrm{CH}_{3} \mathrm{OH}$ dose were fitted to an exponential decay where the $1 /$ e constant reflects the amount of methanol needed to reduce the $\mathrm{O}_{2}$ signal. In the initial region, $\mathrm{O}_{2}$ production is quickly suppressed by methanol, roughly $0.05 \mathrm{ML} \mathrm{CH}_{3} \mathrm{OH}$ is sufficient. However, it may appear to be more sensitive to $\mathrm{CH}_{3} \mathrm{OH}$ than it actually is as the signal is very small even when no methanol is dosed. The full cycle is less sensitive, with 0.2-0.3 $\mathrm{ML} \mathrm{CH}_{3} \mathrm{OH}$ needed. This value reflects late stage $\mathrm{O}_{2}$ production as methanol is mixed with the film and removed from the surface, and as $\mathrm{O}_{2}$ production reaches saturation. While $\mathrm{O}_{2}$ production increases as methanol signal decreases, there does not appear to be a threshold $\mathrm{CH}_{3} \mathrm{OH}$ surface concentration above with $\mathrm{O}_{2}$ production is suppressed and below which it recovers.

\section{Sandwiched films}

Films of $\mathrm{n} \mathrm{ML} \mathrm{H}_{2} \mathrm{O}$ over $1 \mathrm{ML} \mathrm{CH}_{3} \mathrm{OH}$ over 120-n $\mathrm{ML} \mathrm{H}_{2} \mathrm{O}$ were grown and irradiated at $50 \mathrm{~K}$. Thinner films of 80 total $\mathrm{ML} \mathrm{H}_{2} \mathrm{O}$ were also grown under the same conditions. In both cases, $\mathrm{O}_{2}$ production resumed as $\mathrm{n}$ reached 10-12 $\mathrm{ML} \mathrm{H}_{2} \mathrm{O}$ (Fig. 4a), and saturated as the capping layer reached $30 \mathrm{ML}$ thickness (Fig 4b). However, saturation levels of $\mathrm{O}_{2}$ production were about $10-20 \%$ lower than $\mathrm{O}_{2}$ production levels in pure water, 
even when $80 \mathrm{ML}$ of water over $1 \mathrm{ML} \mathrm{CH}_{3} \mathrm{OH}$ was compared to $80 \mathrm{ML} \mathrm{H}_{2} \mathrm{O}$ over $\mathrm{TiO}_{2}$ (110). It is clear that the methanol is acting as an internal interface and affects $\mathrm{O}_{2}$ production over long distances.

In sandwich films of $\mathrm{H}_{2}{ }^{16} \mathrm{O}$ over $\mathrm{CH}_{3} \mathrm{OH}$ over $\mathrm{H}_{2}{ }^{16} \mathrm{O}$, the 32 amu signal is a composite of $\mathrm{CH}_{3} \mathrm{OH}$, which begins desorbing immediately after the beam is turned on, and ${ }^{16} \mathrm{O}_{2}$ that forms from $\mathrm{H}_{2}{ }^{16} \mathrm{O}$. In these films, $\mathrm{O}_{2}$ production is observed only at later times and reaches an intensity of $\sim 0.12$ units (Figure $4 \mathrm{a}$ ). To determine the nature of the interface and the $\mathrm{O}_{2}$ source in the interface, labeled sandwiches of $\mathrm{n} \mathrm{ML} \mathrm{H}_{2}{ }^{18} \mathrm{O}$ over $1 \mathrm{ML}$ $\mathrm{CH}_{3} \mathrm{OH}$ over 80-n ML $\mathrm{H}_{2}{ }^{16} \mathrm{O}$ were grown at $25 \mathrm{~K}$ and irradiated at $50 \mathrm{~K}$. The 32,34 , and 36 amu signals were monitored to measure the $\mathrm{CH}_{3} \mathrm{OH} /{ }^{16} \mathrm{O}_{2},{ }^{16} \mathrm{O}^{18} \mathrm{O}$, and ${ }^{18} \mathrm{O}_{2}$ desorption rates respectively. The 32 amu signals from these isotopically labeled sandwiches show prompt desorption characteristic of $\mathrm{CH}_{3} \mathrm{OH}$ desorption at low capping thicknesses. In contrast to the non-labeled films, the $32 \mathrm{amu}$ signal is near zero at higher capping thicknesses (10 ML H${ }_{2}^{18} \mathrm{O}$ or more, Figure 5). Any ${ }^{16} \mathrm{O}_{2}$ that is produced in the water layer trapped beneath the buried $\mathrm{CH}_{3} \mathrm{OH}$ does not appear in the signal, even at shallow depths where the bottom layer is within the penetration depth of the electrons. The ${ }^{16} \mathrm{O}^{18} \mathrm{O}$ signal shows a slow increase characteristic of $\mathrm{O}_{2}$ production in pure water, but even at its greatest intensity (for a $30 \mathrm{ML} \mathrm{H}_{2}{ }^{18} \mathrm{O}$ layer), the signal is $\leq 5 \%$ of the ${ }^{18} \mathrm{O}_{2}$ signal intensity for the same film (Figure 6). This minor signal indicates that very little mixing of oxygen isotopes occurs between water and methanol or $\mathrm{H}_{2}{ }^{18} \mathrm{O}$ and $\mathrm{H}_{2}{ }^{16} \mathrm{O}$, and that there is minimal transfer of labeled water through the $\mathrm{CH}_{3} \mathrm{OH}$ layer. Meanwhile, the ${ }^{18} \mathrm{O}_{2}$ signal grows with increasing amounts of $\mathrm{H}_{2}{ }^{18} \mathrm{O}$ as expected for $\mathrm{O}_{2}$ production to a saturation intensity of $\sim 0.12$ units (Figure 7 ), equal to that seen in the non-isotopically labeled film (Figure 4a). Saturation of $\mathrm{O}_{2}$ production occurs at about the same depth in both films, $\sim 20$ $30 \mathrm{ML}$. The absence of the ${ }^{16} \mathrm{O}_{2}$ and ${ }^{16} \mathrm{O}^{18} \mathrm{O}$ signals, combined with the ${ }^{18} \mathrm{O}_{2}$ signal observed, indicates that all of the observed $\mathrm{O}_{2}$ is generated in the top portion of the film. Methanol is acting as an internal interface in much the same way that $\mathrm{Pt}$ or $\mathrm{TiO}_{2}$ acts as one; the ${ }^{18} \mathrm{O}_{2}$ signal is similar to that seen from dosing similar quantities of water on the bare $\mathrm{TiO}_{2}$ substrate. The combination of these signals also suggests that $\mathrm{CH}_{3} \mathrm{OH}$ is an effective barrier to either the movement of $\mathrm{O}_{2}$ produced in the bottom portion of the sandwich, or to the production of $\mathrm{O}_{2}$ in these lower layers, possibly as a result of exciton trapping or side reactions. Experiments where the methanol/water interface was increased by growing films with more thin layers of methanol also suggest that the desorption products are from only the upper layer, and that lower methanol/water interfaces have little impact on $\mathrm{O}_{2}$ production.

To determine the amount of $\mathrm{CH}_{3} \mathrm{OH}$ needed to form this interface, $\mathrm{O}_{2}$ production levels were measured from $6 \mathrm{ML} \mathrm{H}_{2} \mathrm{O}$ over n $\mathrm{ML} \mathrm{CH} \mathrm{CH}_{3} \mathrm{OH}$ over $80 \mathrm{ML} \mathrm{H}_{2} \mathrm{O} . \mathrm{O}_{2}$ production was suppressed $\sim 50 \%$ by $0.1 \mathrm{ML} \mathrm{CH}_{3} \mathrm{OH}$, and was near full suppression when dosed with $0.5 \mathrm{ML} \mathrm{CH} \mathrm{CH}_{3} \mathrm{OH}$ (Figure 8). If $\mathrm{O}_{2}$ or excited $\mathrm{H}_{2}{ }^{16} \mathrm{O}$ produced below the $\mathrm{CH}_{3} \mathrm{OH}$ layer is being physically blocked by the presence of $\mathrm{CH}_{3} \mathrm{OH}$, this effect cannot be due to a separate continuous phase of methanol acting as an opaque film, as it occurs even at very low coverages. Blocking could be the result of long-range disruptions or restructuring of the H-bonding network near the methanol/water interface to prevent excited water from moving to the vacuum interface, or, more probably, of efficient electron or exciton trapping that would prevent any excited bulk $\mathrm{H}_{2}{ }^{16} \mathrm{O}$ from being formed. 
PNNL-17069

\section{Pre-irradiated films}

To determine if methanol was destroying existing precursors, interrupting reactions with existing precursors, or preventing new precursors from forming, we performed a series of experiments using pre-irradiated water films. In these experiments, a thick pure water layer was deposited and irradiated at $80 \mathrm{~K}$ to saturate the $\mathrm{O}_{2}$ precursor population. The saturation concentrations of the $\mathrm{O}_{2}$ precursors $\mathrm{H}_{2} \mathrm{O}_{2}$ and $\mathrm{HO}_{2}$ were previously estimated to be $\sim 0.01-0.03 \mathrm{ML}$, and the $\mathrm{OH}$ concentrations were estimated to be lower. Petrik et al. showed that such films are stable over time at temperatures $\leq 80 \mathrm{~K}$. When the sample was irradiated a second time after resting, $\mathrm{O}_{2}$ production in these pure water films resumed immediately at or near the saturation level of the first irradiation cycle.

In our experiments, we added a thin $(0.01$ to $0.5 \mathrm{ML})$ capping layer of methanol to the processed water film as it rested, and then resumed irradiation. The addition of $\mathrm{CH}_{3} \mathrm{OH}$ led to a significant drop in the "prompt" portion of the $\mathrm{O}_{2}$ signal, which results from reactions of existing precursors (Figure 9), and a boost in the prompt $\mathrm{CO}$ signal as methanol reacted on the precursor-laden film. Fitting the integrated prompt signals to an exponential decay indicates that only 0.1-0.2 $\mathrm{ML} \mathrm{CH}_{3} \mathrm{OH}$ is needed to quench the prompt response; $0.01 \mathrm{ML} \mathrm{CH}_{3} \mathrm{OH}$ suppresses the prompt portion of the response by $20 \%$. The effectiveness of this low $\mathrm{CH}_{3} \mathrm{OH}$ coverage on $\mathrm{O}_{2}$ production, combined with the low $\mathrm{O}_{2}$ precursor concentration, suggests that the quenching effects of $\mathrm{CH}_{3} \mathrm{OH}$ are long-range and not due to direct reaction with a precursor molecule. Nor are these effects due to some sort of physical blocking by the added monolayer; if compared with water, methanol is a much more effective suppressant.

Increasing the methanol dose has less effect per $\mathrm{CH}_{3} \mathrm{OH}$, and the quenching process appears to saturate (dark and light blue traces, Figure 9), rather than completely stop rapid $\mathrm{O}_{2}$ production. Prompt $\mathrm{O}_{2}$ signals are similar for $0.2,0.25$, and $0.5 \mathrm{ML} \mathrm{CH}_{3} \mathrm{OH}$. Preliminary results suggest that even at methanol coverages of $2 \mathrm{ML}$, prompt $\mathrm{O}_{2}$ production is still measurable, at $\sim 15 \%$ of $\mathrm{O}_{2}$ production in pure water. However, at coverages greater than $0.5 \mathrm{ML} \mathrm{CH}_{3} \mathrm{OH}$, the suppression of $\mathrm{O}_{2}$ shows a linear correlation with $\mathrm{CH}_{3} \mathrm{OH}$ coverage, rather than an exponential one. This change in correlation suggests that we must consider two processes in the suppression of prompt $\mathrm{O}_{2}$. The first process, which occurs at low coverages $\left(<0.25 \mathrm{ML} \mathrm{CH}_{3} \mathrm{OH}\right)$, is the result of long-range effects that interrupt some part of the reaction chain. For example, $\mathrm{CH}_{3} \mathrm{OH}$ could react with an exciton in step 7, preventing $\mathrm{HO}_{2}$ from forming $\mathrm{O}_{2}$. The remaining $\mathrm{O}_{2}$ production could be explained by some $\mathrm{HO}_{2}$ reacting with an impinging electron instead of an exciton, suggesting that step 7 should be labeled as step $7 \mathrm{a}$ and $7 \mathrm{~b}$. Alternately, $\mathrm{CH}_{3} \mathrm{OH}$ could interrupt the formation of $\mathrm{H}_{2} \mathrm{O}^{*}$, which would then stop production of $\mathrm{OH}$ and $\mathrm{H}_{2} \mathrm{O}_{2}$, leaving $\mathrm{HO}_{2}$ to be consumed in prompt $\mathrm{O}_{2}$ production. This alternative requires that preexisting $\mathrm{OH}$ and $\mathrm{H}_{2} \mathrm{O}_{2}$ fully convert to $\mathrm{HO}_{2}$ within the first second of irradiation to explain $\mathrm{O}_{2}$ signals at this first data point. The second process dominates at higher coverages $\left(>0.25 \mathrm{ML} \mathrm{CH}_{3} \mathrm{OH}\right)$ and is less sensitive to methanol concentration. It may be the result of additional methanol now acting as a physical barrier, preventing any remaining precursors from moving to the surface to react and desorb.

We also consider the recovery of $\mathrm{O}_{2}$ production at later times in these capped preirradiated films. As in the capped raw films, increased methanol doses lead to a longer recovery time for $\mathrm{O}_{2}$ production, indicating that the $\mathrm{O}_{2}$ precursor population must be 
reestablished. However, in the preirradiated films recovery appears to take longer than in the equivalent raw film (compare 0.5 ML coverages in Figure 1 and Figure 9). Fitting the $\mathrm{O}_{2}$ signal to the methanol signal indicates that less than $0.007 \mathrm{ML} \mathrm{CH}_{3} \mathrm{OH}$ remains on the surface before $\mathrm{O}_{2}$ production recovers (Figure 10). The slower recovery dependent on the elimination of methanol from the film suggests that a precursor deficiency is created by the presence of methanol, perhaps through $\mathrm{OH}$ or exciton scavenging. Another possibility is that the increased reactions of methanol with $\mathrm{O}_{2}$ precursors generate methanol byproducts that also suppress $\mathrm{O}_{2}$ production. The $\mathrm{O}_{2}$ recovery strongly depends on the surface methanol concentration and $\mathrm{O}_{2}$ production does not resume until nearly all the methanol is gone.

To eliminate the possibility that methanol directly reacts with $\mathrm{O}_{2}$ precursors such as $\mathrm{OH}$ and $\mathrm{H}_{2} \mathrm{O}_{2}$ in the film, three experiments using layers of water as a physical barrier were performed (Figure 11). In each experiment, $80 \mathrm{ML} \mathrm{H}_{2}{ }^{18} \mathrm{O}$ was deposited and irradiated at $80 \mathrm{~K}$ to saturate the precursor concentration at the $\mathrm{H}_{2}{ }^{18} \mathrm{O}$ surface. In experiment $\mathrm{A}$, the processed film was then covered with $\mathrm{n}$ ML unprocessed $\mathrm{H}_{2}{ }^{16} \mathrm{O}$ at $50 \mathrm{~K}$. In experiment $\mathrm{B}$, the processed film was covered by $\mathrm{n}$ ML unprocessed $\mathrm{H}_{2}{ }^{16} \mathrm{O}$ and then 0.5 $\mathrm{ML} \mathrm{CH}_{3} \mathrm{OH}$ at $50 \mathrm{~K}$, to place a physical barrier between the precursor concentration and the methanol/water interface. In experiment $\mathrm{C}$, the processed film was covered first by 0.5 ML $\mathrm{CH}_{3} \mathrm{OH}$ and then by $\mathrm{n}$ ML unprocessed $\mathrm{H}_{2}{ }^{16} \mathrm{O}$ at $50 \mathrm{~K}$, so that precursors and methanol are in contact. Each film was irradiated a second time at $50 \mathrm{~K}$ and the ${ }^{18} \mathrm{O}_{2}$ signal was measured. Film A, water only, shows the expected trend that less ${ }^{18} \mathrm{O}_{2}$ desorbs from the films with thicker capping layers. Films B and C are nearly identical, indicating that methanol does not have to be at the precursor interface and does not react with the $\mathrm{O}_{2}$ precursors $\mathrm{OH}, \mathrm{H}_{2} \mathrm{O}_{2}$, and $\mathrm{HO}_{2}$. The only difference in films $\mathrm{B}$ and $\mathrm{C}$ occurs at very late times, when the recovering $\mathrm{O}_{2}$ signal is slightly smaller in the film where methanol and $\mathrm{OH} / \mathrm{H}_{2} \mathrm{O}_{2} / \mathrm{HO}_{2}$ precursors are in direct contact. However, the addition of the methanol in films $\mathrm{B}$ and $\mathrm{C}$ greatly reduces the peak $\mathrm{O}_{2}$ production signal and delays $\mathrm{O}_{2}$ production recovery compared to film A.

Clarification of the mechanism comes from data on water desorption (Figure 12). Water must be excited to desorb, but the addition of methanol decreases the water desorption signal, indicating that fewer excited water molecules form. Methanol suppresses $\mathrm{H}_{2} \mathrm{O}$ desorption less strongly than $\mathrm{O}_{2}$ production, with an exponential factor of $\sim 0.5 \mathrm{ML} \mathrm{CH}_{3} \mathrm{OH}$. The relative weakness of exciton suppression compared to $\mathrm{O}_{2}$ suppression is likely the result of the large bulk water reservoir and higher rate of exciton formation per electron. Methanol also shows long-range effects on the suppression of exciton formation. A single monolayer of methanol in a water-methanol-water sandwich will suppress the desorption of water, even if buried under 20-30 $\mathrm{ML} \mathrm{H}_{2} \mathrm{O}$, when fewer electrons should be reaching the water/methanol interface. This suggests that methanol is affecting the formation (and possibly movement) of excitons in the bulk water film.

\section{Conclusions}

Methanol is an effective suppressant of $\mathrm{O}_{2}$ production from water during irradiation. $\mathrm{CH}_{3} \mathrm{OH}$ added to the surface of an unprocessed water film delays $\mathrm{O}_{2}$ production, with $\sim 0.2 \mathrm{ML} \mathrm{CH}_{3} \mathrm{OH}$ sufficient to reduce $\mathrm{O}_{2}$ production by $\sim 63 \%$. While lower methanol doses correlate with an increased $\mathrm{O}_{2}$ production rate, there is no threshold 
at which $\mathrm{O}_{2}$ production promptly recovers. Instead, the $\mathrm{O}_{2}$ begins to recover as methanol is simultaneously desorbed, mixed with water, and reacted, resulting in a decreased $\mathrm{O}_{2}$ production rate relative to that in pure water. Because methanol desorbs at the same rate regardless of the amount of methanol dosed, the delays in $\mathrm{O}_{2}$ production seen at later irradiation times are due to mixing that may disrupt the $\mathrm{H}_{2} \mathrm{O}$ structure, or secondary products, such as $\mathrm{H}_{2} \mathrm{CO}$.

No $\mathrm{O}_{2}$ signal from water dosed under a methanol monolayer was detectable in isotopically labeled "sandwich" films, indicating that methanol acts as an internal interface. Experiments found that doses of greater than $\sim 0.7 \mathrm{ML} \mathrm{CH}_{3} \mathrm{OH}$ are sufficient to make the interface opaque to lower water layers and prevent any detectable $\mathrm{O}_{2}$ signal from these layers. All of the detected $\mathrm{O}_{2}$ was generated in water dosed on top of methanol and was very similar to the signal seen from water dosed on the bare $\mathrm{TiO}_{2}$ substrate. Methanol demonstrated a long-range suppression of $\mathrm{O}_{2}$ from these films, with 10-12 ML H2O needed before $\mathrm{O}_{2}$ production would resume, and thicker layers needed to approximate the $\mathrm{O}_{2}$ production levels in pure water. This suppression demonstrates that methanol does not act by physically blocking $\mathrm{O}_{2}$ from desorbing or to a separate continuous phase of methanol.

In processed films, similar results were found: increased amounts of methanol led to decreased $\mathrm{O}_{2}$ signal. In these films, prompt $\mathrm{O}_{2}$ production is reduced by $0.1-0.2 \mathrm{ML}$ $\mathrm{CH}_{3} \mathrm{OH}$, but saturates when about half of the $\mathrm{O}_{2}$ signal remains. This saturation indicates that two processes are at work in $\mathrm{O}_{2}$ production that are not equally affected by methanol's presence. Methanol may react faster on preirradiated films, producing a boost in the $\mathrm{CO}$ signal as the $\mathrm{O}_{2}$ signal is reduced, and preventing $\mathrm{O}_{2}$ production from resuming until all methanol is removed from the film. The mechanism by which $\mathrm{O}_{2}$ production is quenched does not require methanol to react with $\mathrm{O}_{2}$ precursors $\mathrm{OH}, \mathrm{H}_{2} \mathrm{O}_{2}$, or $\mathrm{HO}_{2}$. Placing the methanol in direct contact with such precursors leads to only a small enhancement of $\mathrm{O}_{2}$ suppression at later irradiation times. Methanol suppresses $\mathrm{O}_{2}$ production over long ranges, and with spacer layers of water to act as a barrier, indicating that methanol interferes with exciton production/electron capture in water, or in the ability of the excitons to move to the vacuum interface to react further. The reduction in desorbing water signal with the addition of small quantities of methanol indicates that fewer excited water molecules are present at the surface. The water signal increases as methanol is buried, moving the methanol/water interface further from the region of greatest electron capture and indicating that excitons are moving to the surface again, suggesting that interference with exciton production/electron capture is more likely. However, while it is clear that methanol disrupts the formation of excitons, the mechanism of this interference, especially when methanol is buried, is yet to be determined. 
26 July 2007

36amu MeOH on ASW.qpc

$\mathrm{n} \mathrm{ML} \mathrm{CH} 3 \mathrm{OH}$ on $80 \mathrm{ML}$ raw $\mathrm{H}_{2}{ }^{18} \mathrm{O}$

Deposited and irradiated at $80 \mathrm{~K}$. Irradiation was for 100 cycles with $100 \mathrm{eV}$ electrons at $\sim 2 \mathrm{uA}$.

Measuring the suppression ability of methanol on unprocessed water.

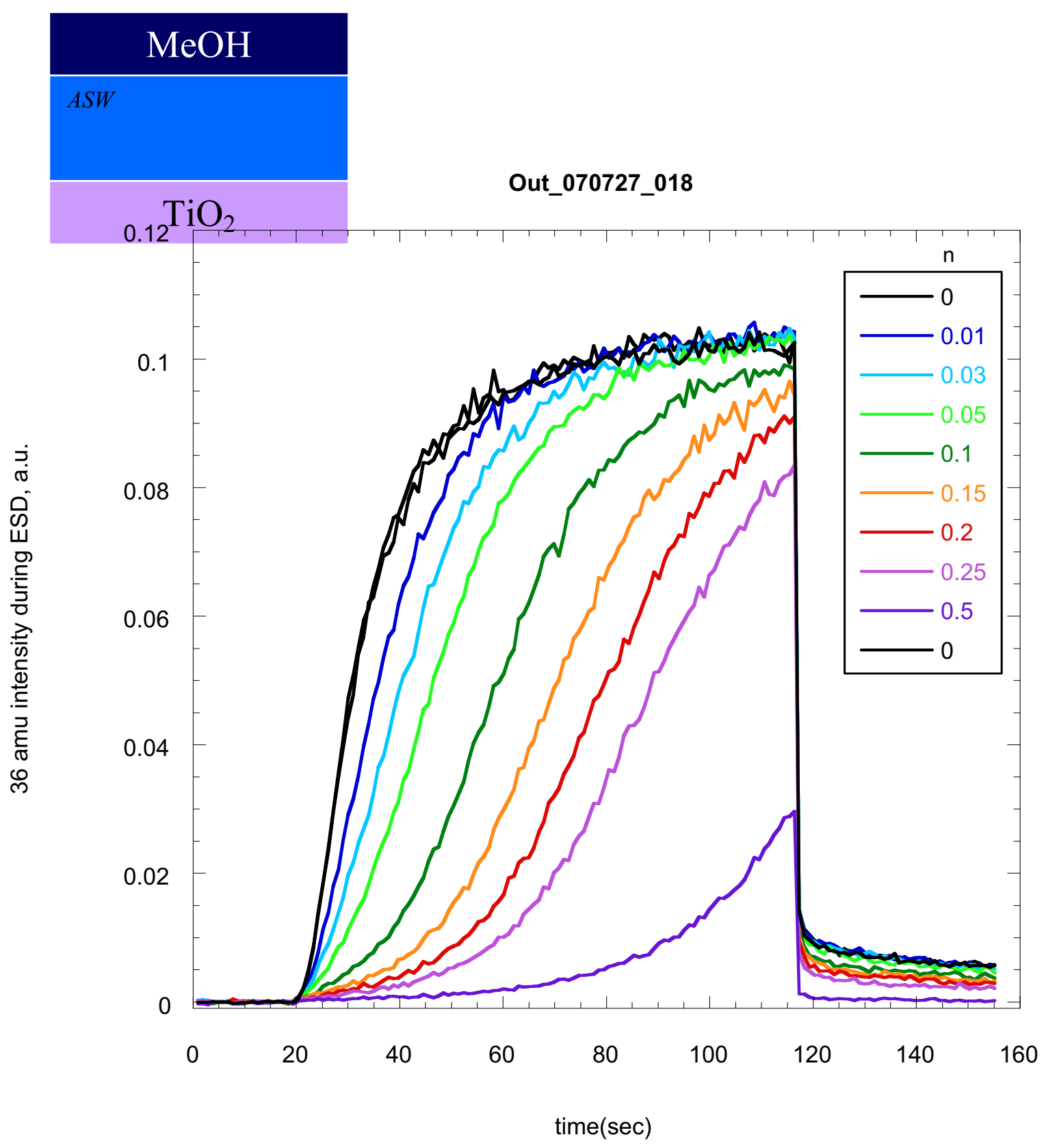

Figure 1: Suppression of $\mathrm{O}_{2}$ production by $\mathrm{CH}_{3} \mathrm{OH}$ capping layer. 
Figure 2: Time delay in $\mathbf{O 2}$ production caused by methanol.

26 July 2007

36amu time delay by $\mathrm{MeOH} . q p c$

n ML CH3OH deposited on $80 \mathrm{ML} \mathrm{H}_{2}{ }^{18} \mathrm{O}$ at $80 \mathrm{~K}$.

Irradiated at $80 \mathrm{~K}$ for 100 cycles using $100 \mathrm{eV}$ electrons at $\sim 2 \mathrm{uA}$.

Measured the time it took for the $36 \mathrm{amu}$ signal to reach a specified signal intensity to find how much $\mathrm{CH} 3 \mathrm{OH}$ delayed $\mathrm{O} 2$ production. The specificed signal levels were determined by the intensity of 0.5 and $0.25 \mathrm{ML} \mathrm{CH} 3 \mathrm{OH} / 80 \mathrm{ML}$ ASW just before the beam was turned off. Final intensity of $0.5 \mathrm{ML} \mathrm{CH} 3 \mathrm{OH} / 80 \mathrm{ML}$ ASW is 0.0296 , final intensity of $0.25 \mathrm{ML} \mathrm{CH} 3 \mathrm{OH} / 80 \mathrm{ML}$ ASW is 0.0834 .

$\longrightarrow$ Time at $Y$ value $=.02961761$

Data 38

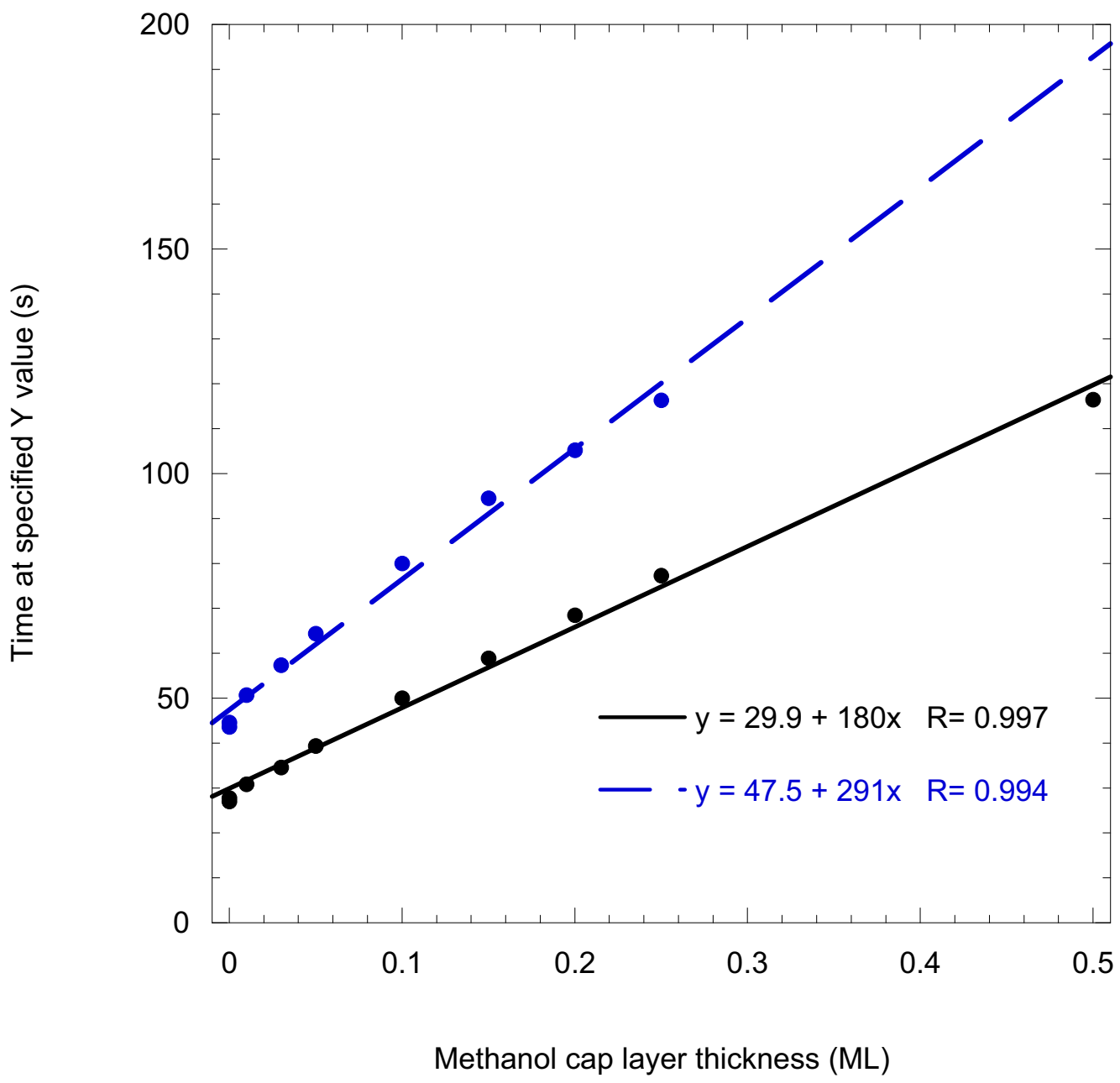


26 July 2007

kin 36amu MeOH cap.qpc

$\mathrm{n} \mathrm{ML} \mathrm{CH} 3 \mathrm{OH}$ over $80 \mathrm{ML} \mathrm{H}_{2}{ }^{18} \mathrm{O}$ deposited at $80 \mathrm{~K}$.

Irradiated at $80 \mathrm{~K}$ for 100 cycles, $100 \mathrm{eV}, \sim 2 \mathrm{uA}$.

Signals were integrated for first three seconds of irradiation to reflect initial suppression of $\mathrm{O} 2$ by $\mathrm{CH} 3 \mathrm{OH}$ prior to mixing. Signals were integrated over the entire irradiation process to reflect total $\mathrm{O} 2$ suppression as a function of $\mathrm{CH} 3 \mathrm{OH}$ deposited, including any radiative mixing effects.
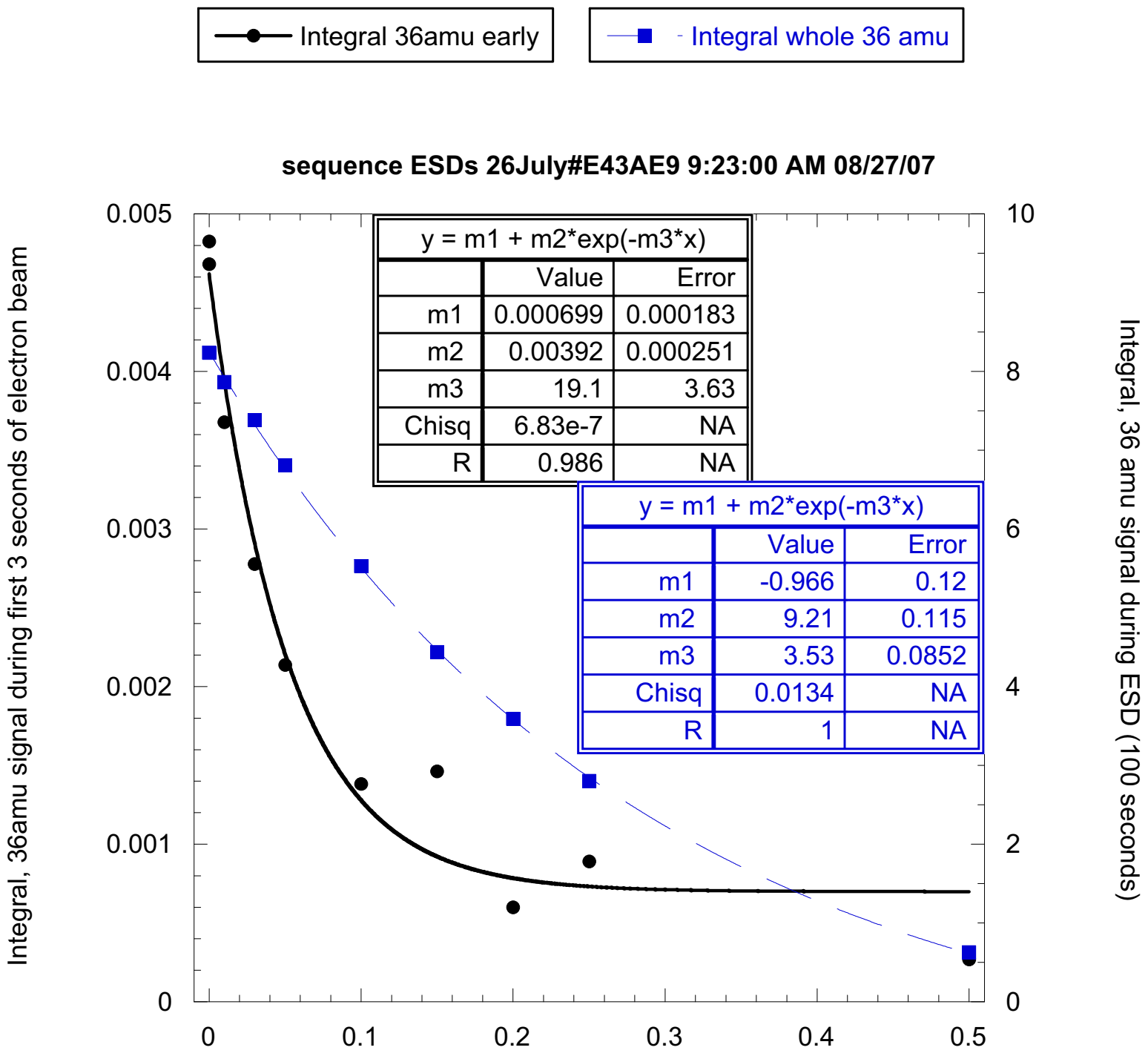

methanol cap layer thickness $(\mathrm{ML})$

Figure 3: Suppression kinetics 

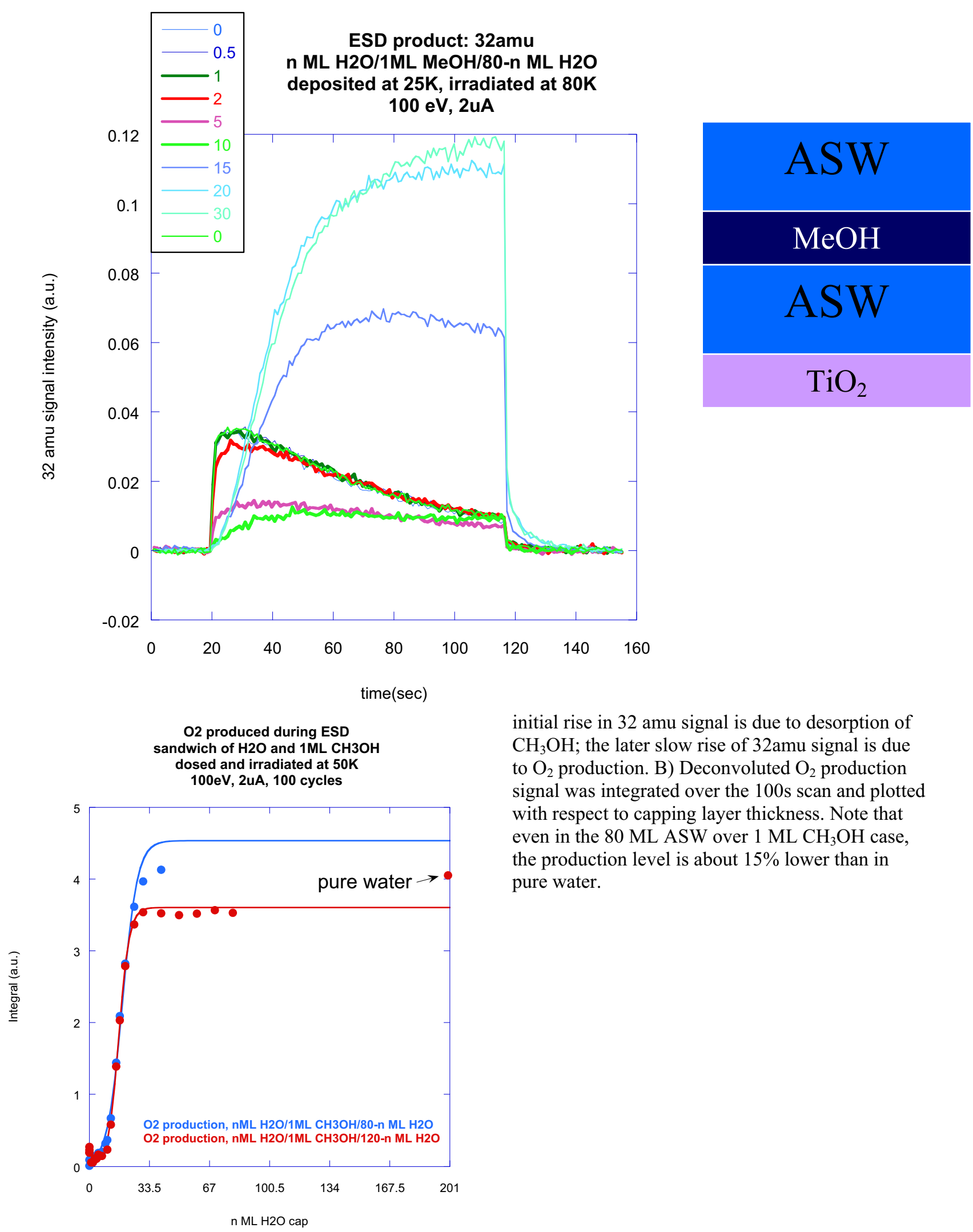

initial rise in $32 \mathrm{amu}$ signal is due to desorption of $\mathrm{CH}_{3} \mathrm{OH}$; the later slow rise of 32amu signal is due to $\mathrm{O}_{2}$ production. $\mathrm{B}$ ) Deconvoluted $\mathrm{O}_{2}$ production signal was integrated over the 100 s scan and plotted with respect to capping layer thickness. Note that even in the $80 \mathrm{ML}$ ASW over $1 \mathrm{ML} \mathrm{CH}_{3} \mathrm{OH}$ case, the production level is about $15 \%$ lower than in pure water.

Figure 4: A) 32amu signal during ESD (top figure). The 
12 June 2007 32amu ESD H2O18 1ML MeOH.qpc

$\mathrm{n} \mathrm{ML} \mathrm{H2O18/1} \mathrm{ML} \mathrm{CH3OH/80-n} \mathrm{ML} \mathrm{H2O16} \mathrm{deposited} \mathrm{at} 25 \mathrm{~K}$, irradiated at $80 \mathrm{~K}$ for 100 cycles, $100 \mathrm{eV}, 2 \mathrm{uA}$

Monitoring mass 32 , which can be the result of $\mathrm{CH} 3 \mathrm{OH}$ desorption, generally seen in the prompt portion of the signal immediately after the beam is turned on, or the result of $\mathrm{O} 2$ forming from $\mathrm{H} 2 \mathrm{O} 16$. $\mathrm{O} 2$

production in the presence of $\mathrm{CH} 3 \mathrm{OH}$ in other films was only observed at later times. This graph shows the desorption of $\mathrm{CH} 3 \mathrm{OH}$ clearly, but no appreciable 32 amu signal is observed at later times. This absence, in combination with the late 36 amu signal seen in this film, suggests that $\mathrm{CH} 3 \mathrm{OH}$ blocks the formation/desorption of $\mathrm{O} 2$ formed from the bottom, $\mathrm{H} 2 \mathrm{O} 16$,

layer. In this way, $\mathrm{CH} 3 \mathrm{OH}$ is acting as an internal interface in much the same way that $\mathrm{Pt}$ or $\mathrm{TiO} 2$ acts as an interface: the upper layers can interact with the $\mathrm{CH} 3 \mathrm{OH}$ but the lower layers appear to be totally blocked. Suggests that $\mathrm{MeOH}$ is an effective barrier to $\mathrm{O} 2$ production from the lower layers, possibly as the result of efficient exciton trapping or side reactions.

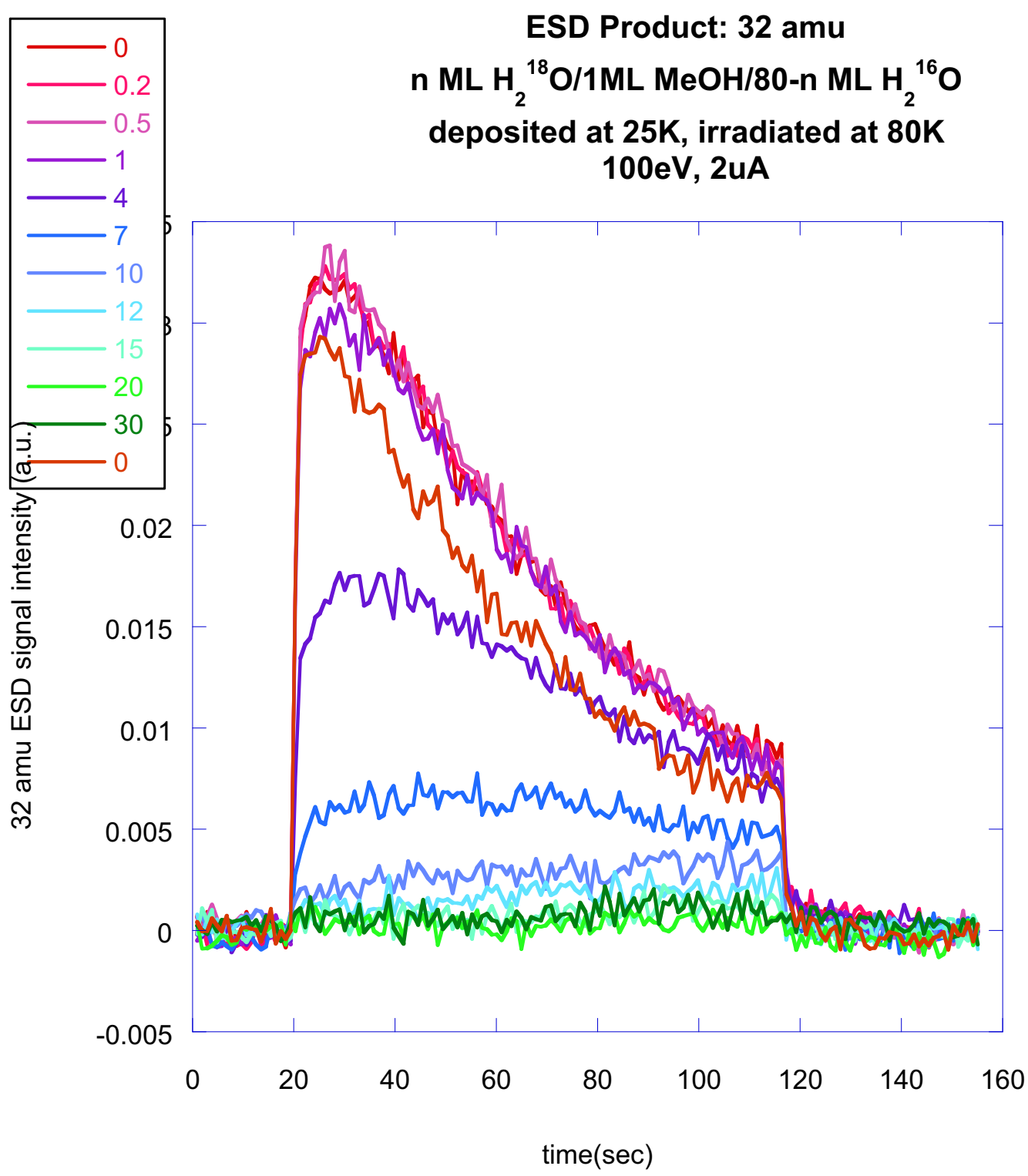

Figure 5 
14 June 2007

34amu ESD H2O18 1ML MeOH.qpc

ESD Product: 34 amu

n ML H ${ }_{2}^{18} \mathrm{O} / 1 \mathrm{ML} \mathrm{MeOH} / 80-\mathrm{n} \mathrm{ML} \mathrm{H}{ }_{2}{ }^{16} \mathrm{O}$

deposited at $25 \mathrm{~K}$, irradiated at $80 \mathrm{~K}$

$100 \mathrm{eV}, 2 \mathrm{uA}$

Measuring the mixing of oxygen from methanol/bottom water layer and capping layer of $\mathrm{H} 2 \mathrm{O} 18$.

Mixing increases with thicker water films, as expected, but is minimal for all thicknesses.

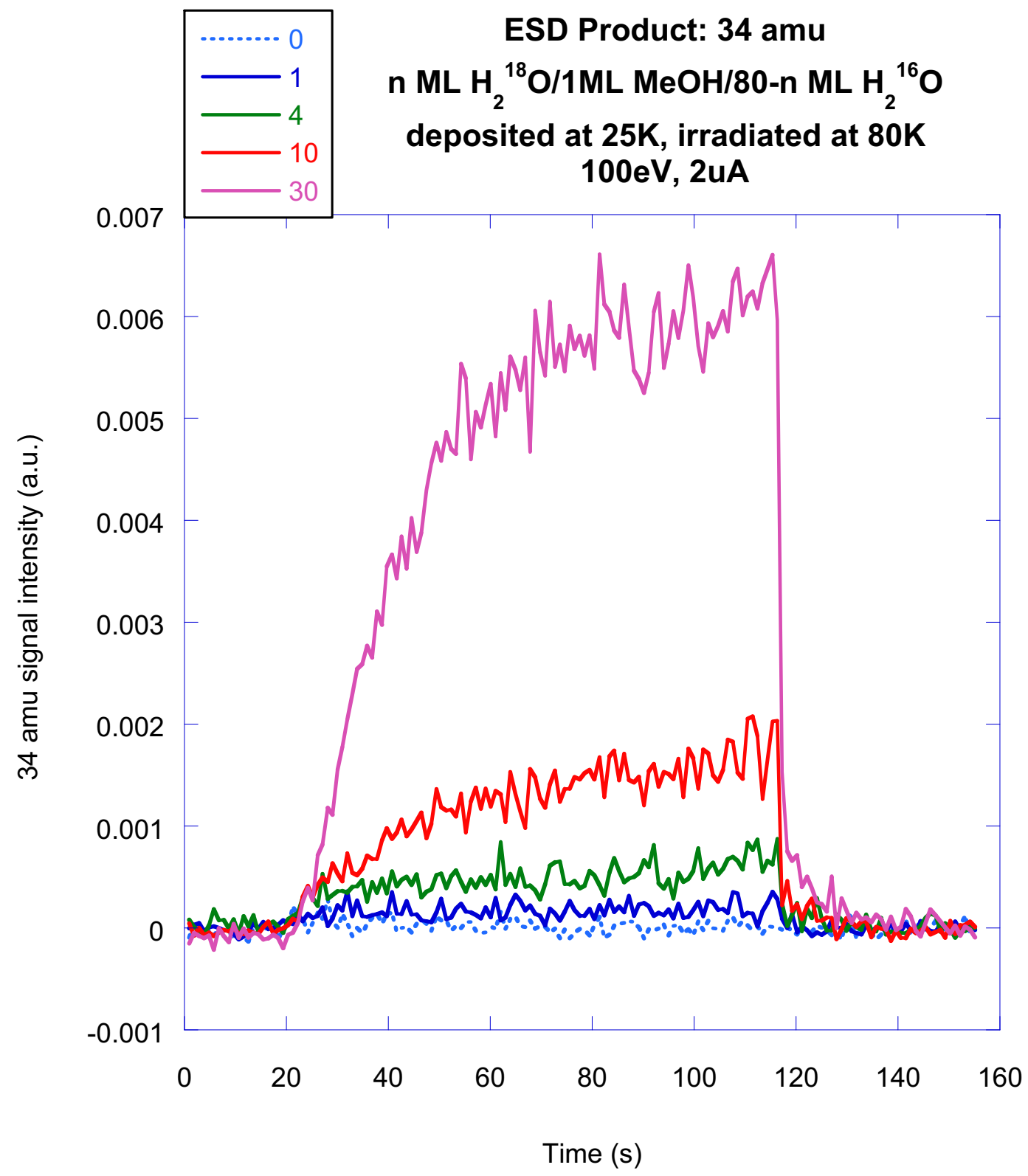

Figure 6 
12 June 2007

O2 production from cap layer of water over methanol: evidence of long-range suppression of $\mathrm{O} 2$ production by $\mathrm{CH} 3 \mathrm{OH}$.

n ML H2O18/1 ML CH3OH/80-n ML H2O16. Deposited at 25K, irradiated at 80K, for 100 cycles, $100 \mathrm{eV}, 2 \mathrm{uA}$.

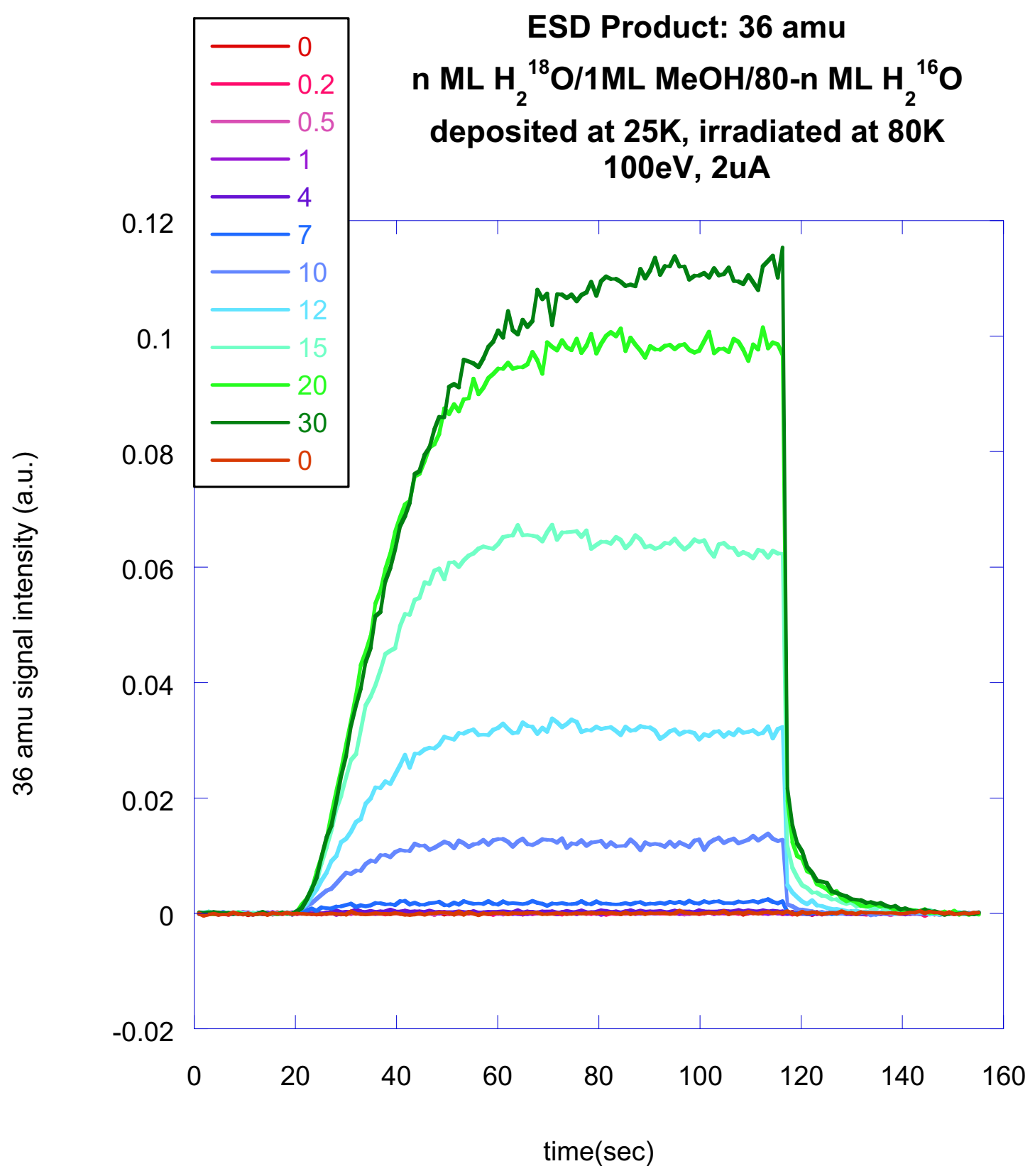

Figure 7 
1 August 2007

dose dep $\mathrm{O} 2$ suppr meoh sndw.qpc

Dose dependence of oxygen suppression by buried methanol.

$6 \mathrm{ML} \mathrm{H} 2 \mathrm{O} / \mathrm{n} \mathrm{ML} \mathrm{CH} 3 \mathrm{OH} / 80 \mathrm{ML} \mathrm{H} 2 \mathrm{O}$

Upper layers dosed at $50 \mathrm{~K} ; 80 \mathrm{ML} \mathrm{H} 2 \mathrm{O}$ dosed at $80 \mathrm{~K}$.

$6 \mathrm{ML}$ ASW

Irradiated at $50 \mathrm{~K}$ for 100 cycles with $100 \mathrm{eV}$ electrons at $2 \mathrm{uA}$ current.

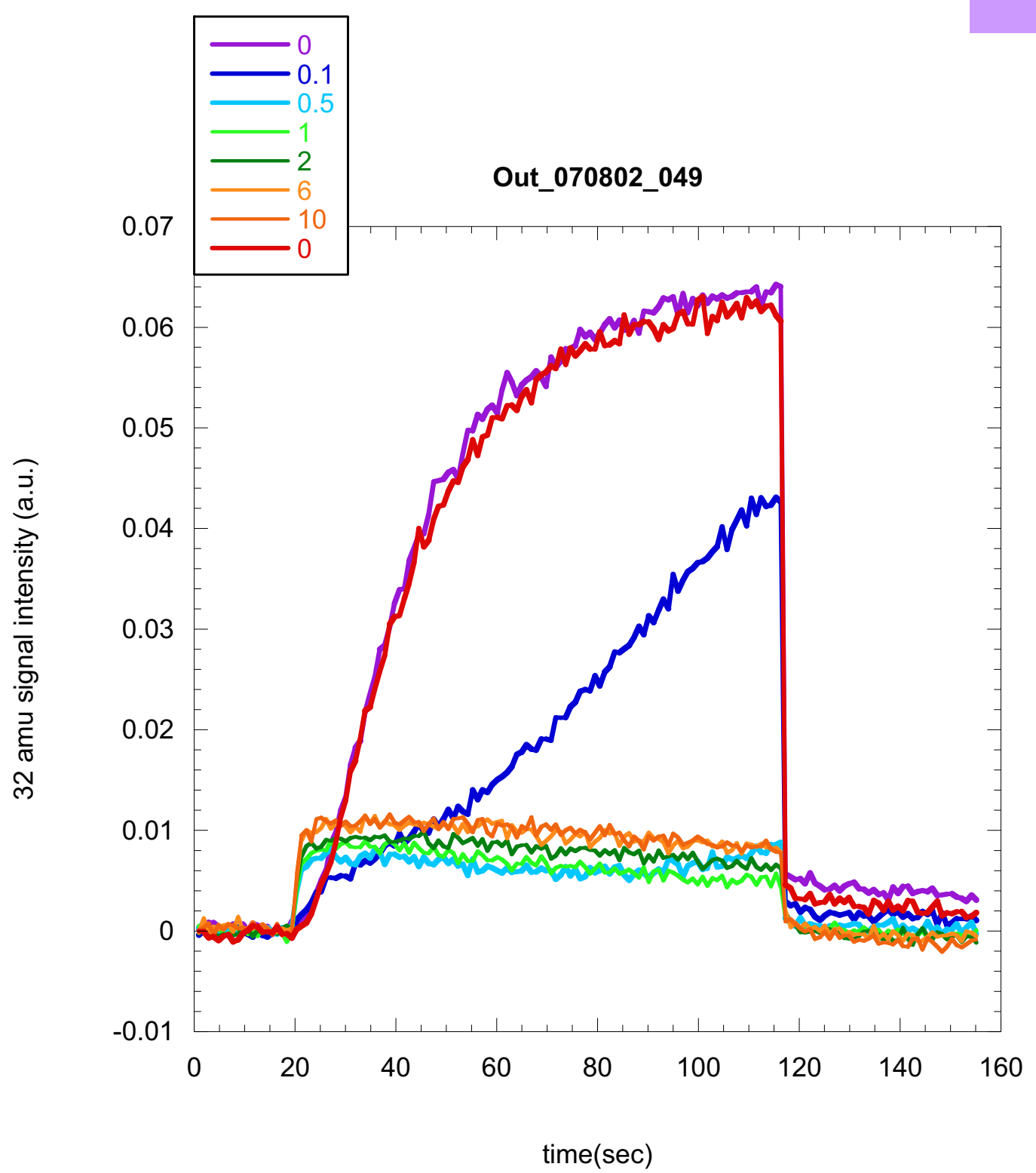

$\mathrm{TiO}_{2}$

Figure 8 
16 July 2007

$1802+\mathrm{nML} \mathrm{MeOH}$ preirr.qpc

Suppression of $\mathrm{O} 2$ precursors by $\mathrm{CH} 3 \mathrm{OH}$ :

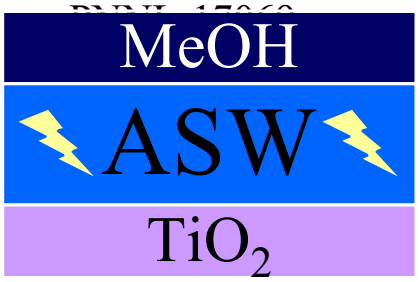

$80 \mathrm{ML} \mathrm{H} 2180$ was dosed and irradiated at $80 \mathrm{~K}$ for 100 cycles, $100 \mathrm{eV}, 2 \mathrm{uA}$.

The preirradiated film was then capped with $\mathrm{n} \mathrm{ML} \mathrm{CH} 3 \mathrm{OH}$, and irradiated again under the same conditions. Without any $\mathrm{MeOH}$ present, the $18 \mathrm{O} 2$ signal (36 amu) returns promptly to its steady state value. The addition of $\mathrm{CH} 3 \mathrm{OH}$ suppresses the prompt production of $\mathrm{O} 2$ as well as the later production of $\mathrm{O} 2$.

\section{ESD product: 36 amu}

${ }^{18} \mathrm{O}_{2}$ production from pre-irradiated films of $\mathrm{H}_{2}^{18} \mathrm{O}$ dosed with $\mathrm{n} \mathrm{ML} \mathrm{CH}_{3} \mathrm{OH}$ Films were dosed and irradiated at $80 \mathrm{~K}, 100$ cycles, $100 \mathrm{eV}, \sim 2 \mathrm{uA}$

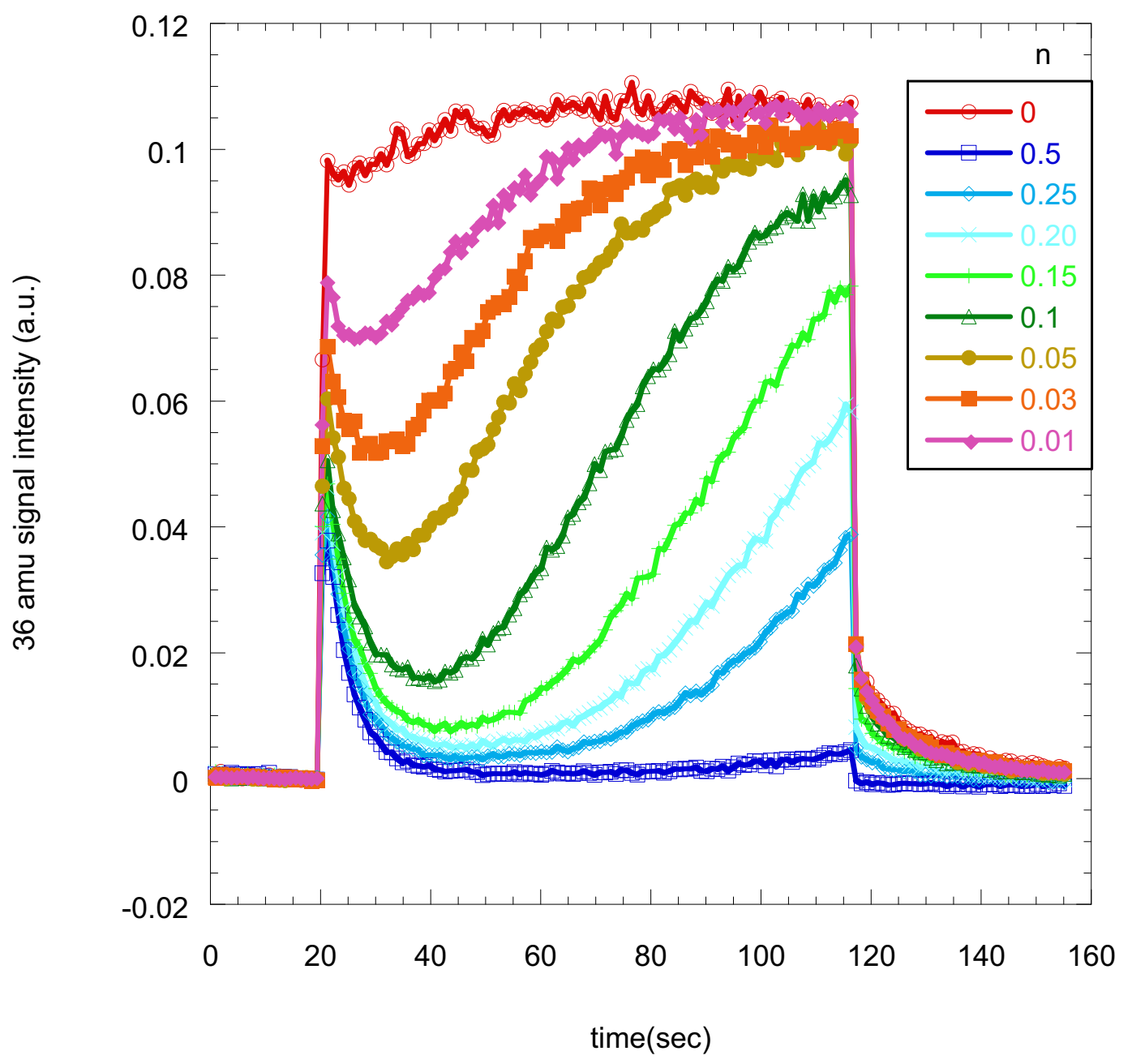

Figure 9: $\mathrm{O2}$ production from capped pre-irradiated $\mathrm{H} 218 \mathrm{O}$ films. 
16 July 2007

preirr $\mathrm{O} 2$ dep $\mathrm{MeOH}$ conc.qpc

$\mathrm{n} \mathrm{ML} \mathrm{CH} 3 \mathrm{OH}$ dosed on $80 \mathrm{ML} \mathrm{H}_{2}^{18} \mathrm{O}$ at $80 \mathrm{~K}$. Irradiated at $80 \mathrm{~K}$ for 100 cycles, $100 \mathrm{eV}, \sim 2 \mathrm{uA}$.

Plotted $18 \mathrm{O} 2$ signal versus $\mathrm{CH} 3 \mathrm{OH}$ signal during $\mathrm{ESD}$ to determine if there was a correlation between the two. Looks like there is. Note that as $\mathrm{CH} 3 \mathrm{OH}$ is removed, the recovery of $\mathrm{O} 2$ converges.

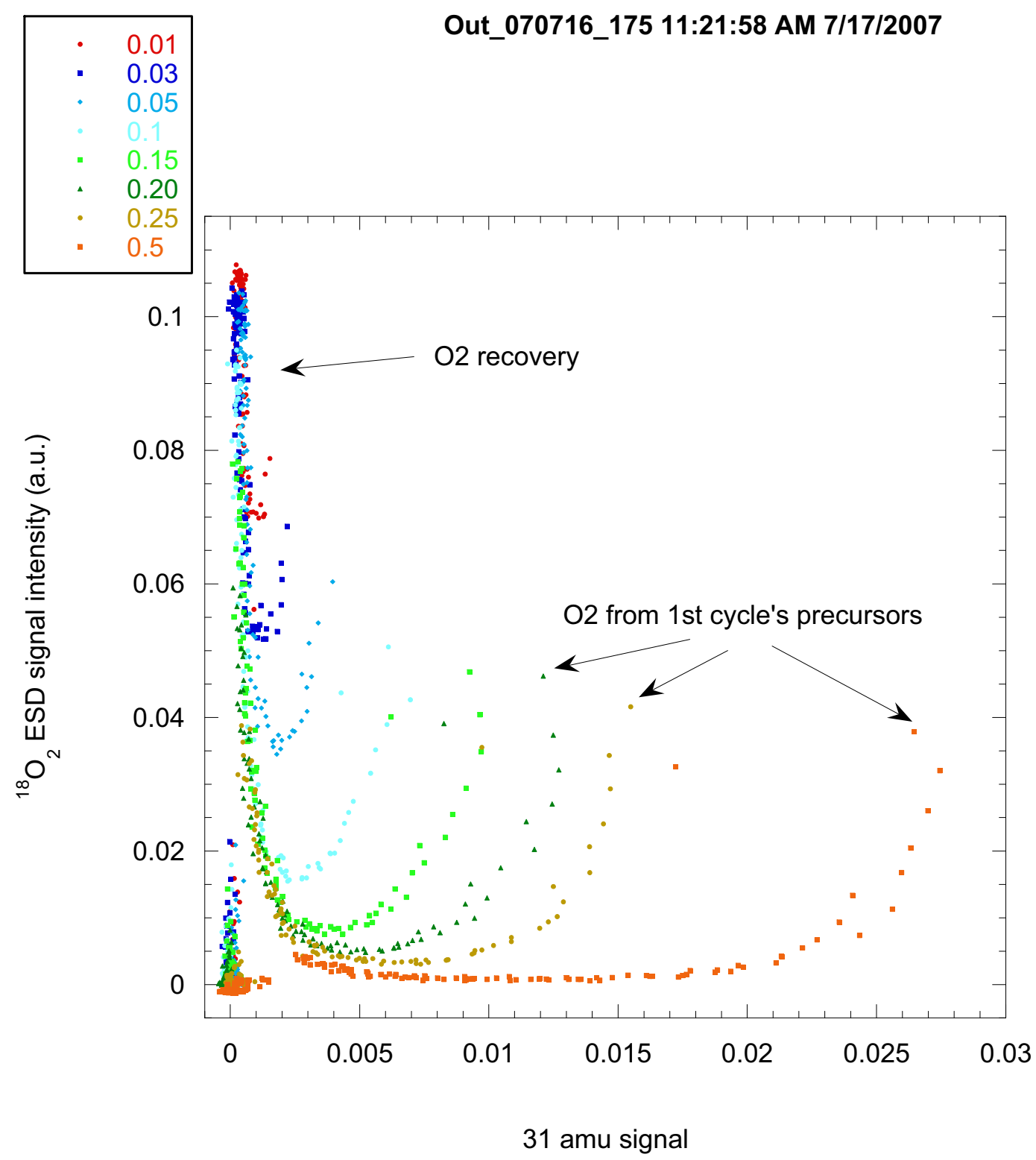

Figure 10: $\mathrm{O} 2$ production dependence on surface $\mathrm{MeOH}$ concentration. 

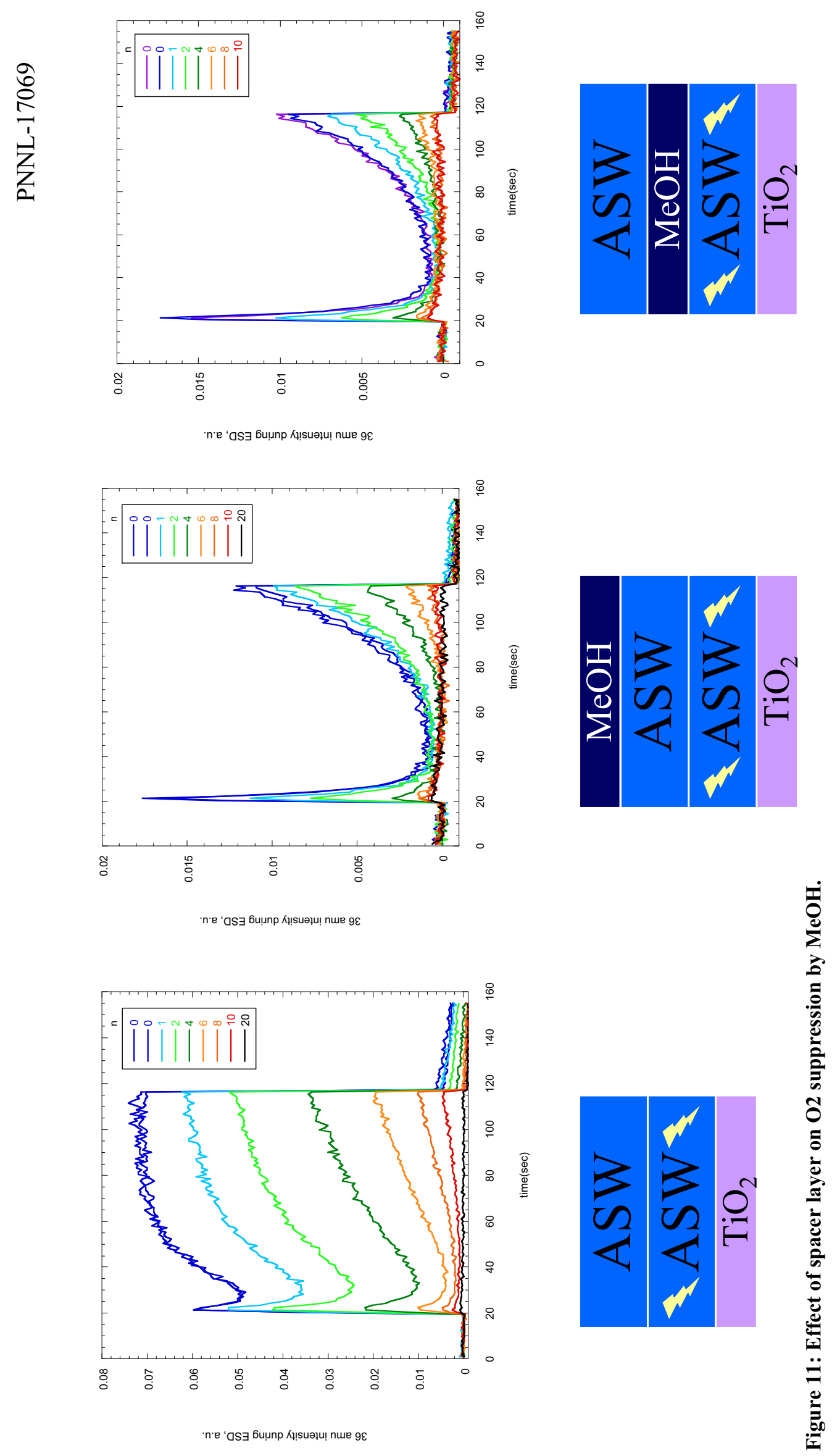
Suppression of water by thin capping layer of $\mathrm{CH} 3 \mathrm{OH}$ :

$\mathrm{n} \mathrm{ML} \mathrm{CH} 3 \mathrm{OH}$ deposited at $80 \mathrm{~K}$ on $80 \mathrm{ML} \mathrm{H} 2 \mathrm{O}$ deposited at $80 \mathrm{~K}$; irradiated at $80 \mathrm{~K}$ for 100 cycles using $100 \mathrm{eV}$ electrons at $\sim 2 \mathrm{uA}$ current. Monitored mass 18 to measure the excitons leading to water desorption:

Compare with 18amu nML MeOHESD 50K, which is the same experiment but with dosing done at $50 \mathrm{~K}$ to determine the effect of dosing temperature on water suppression.
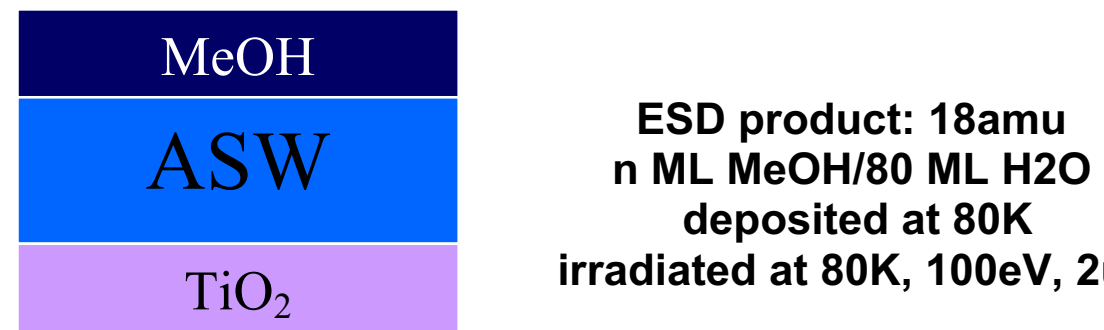

irradiated at $80 \mathrm{~K}, 100 \mathrm{eV}, 2 \mathrm{uA}$

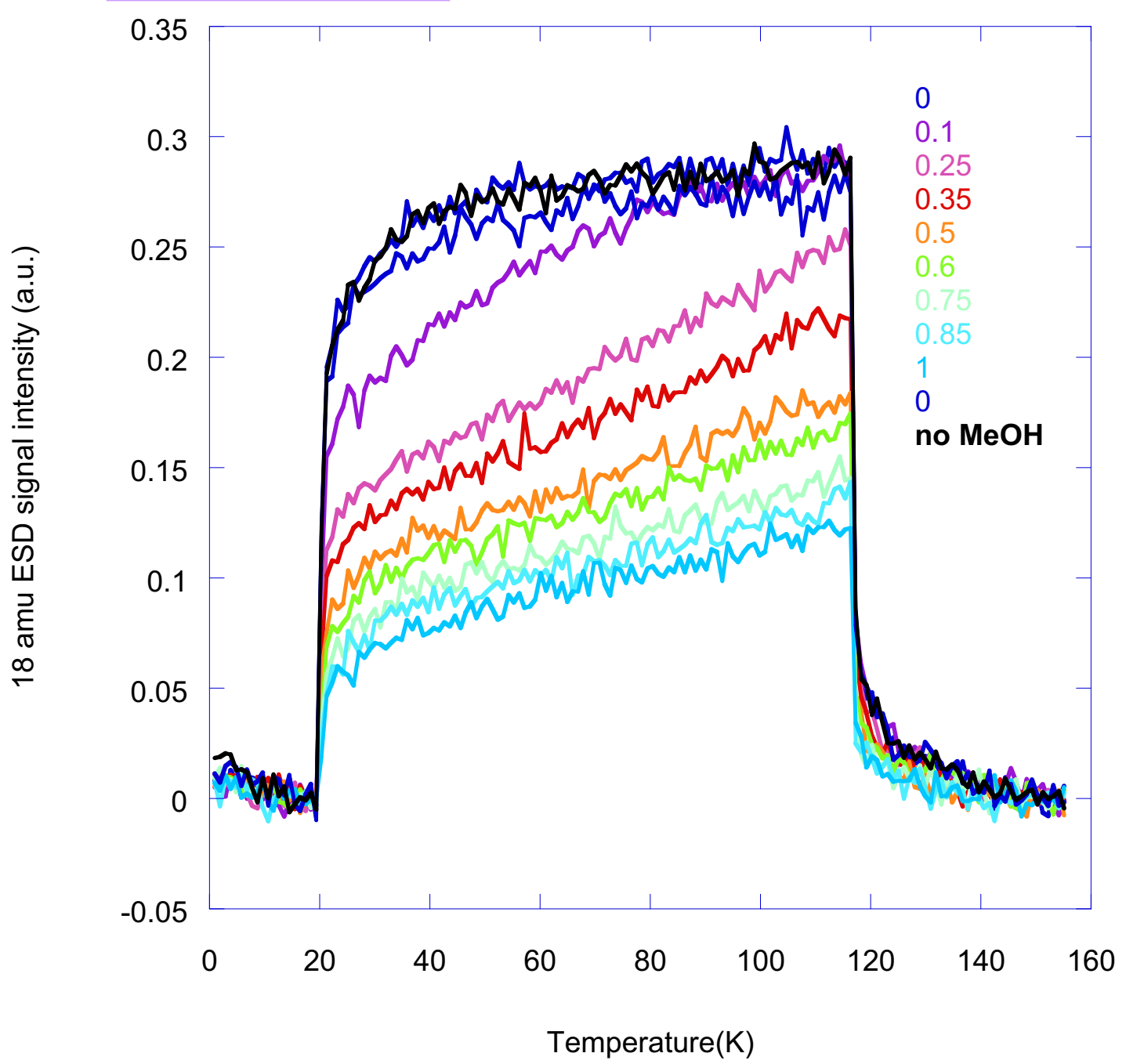

Figure 12: Suppression of water by CH3OH. 
PNNL-17069 
PNNL-17069

\title{
Solvent effects on secondary organic aerosol particles using high resolution mass spectrometry
}

\author{
Adam Bateman (UCI) \\ Dr. Sergey Nizkorodov (UCI) \\ Dr. Alexander Laskin (EMSL)
}

\begin{abstract}
Standard protocols for collecting aerosol particles and analyzing their composition using mass spectrometry often involves extraction of a filtered aerosol sample into a solvent. The solvents of choice for Electrospray Ionization Mass Spectrometry (ESI-MS) have been methanol, water and acetonitrile. As these solvents may be reactive towards organic aerosol species, the extraction process may introduce artifacts in the analysis. This study examined potential dissolution artifacts using pure model chemicals with known functional groups. These model secondary organic aerosol (SOA) particle constituents, were stored in methanol, $\mathrm{d}_{3}$-methanol, acetonitrile and water to investigate the extent of reactions between analyte and solvent molecules resulting in the formation of hemi-acetals, acetals, ketals, esters, and other products.

High resolution electrospray ionization mass spectrometry (HR-ESI-MS) analysis of these mixtures showed that these solvolysis reactions occur on a time scale of days. These reactions showed an increase in the extent and/or rate of reaction with increasing solvent acidity. The reactivity of functional groups was found to be aldehyde $>$ ketone $>$ carboxyl. This study suggests acetonitrile as the optimal solvent for SOA extraction. Furthermore, the sample storage time following the extraction should be minimized, especially if methanol is used for the solvent.
\end{abstract}

\section{Introduction}

Secondary Organic Aerosol (SOA) particles are a complex mixture of organic compounds with low volatility that are formed from reactions between biogenic compounds (limonene, a-pinene, terpenes...) and atmospheric oxidants (ozone, $\mathrm{OH}$ radical, and $\mathrm{NO}_{3}$ radical). In urban areas, volatile exhaust from fossil fuel combustion serves as the main precursor to SOA formation. Model SOA particles can be made in the laboratory by mixing certain VOC (Volatile Organic Compounds) and ozone in a reaction chamber.

Regardless of the SOA source (lab or ambient) they are routinely analyzed by collecting them on filters and extracting soluble components using sonication into the solvent of choice. Recently, HR-MS-ESI has been used to study laboratory generated aerosol particles as well as field aerosol particle samples. These studies have concluded that the chemical composition of SOA particles is very complex, and that SOA species include various multifunctional organic acids, alcohols, peroxides, and carbonyls.

Futhermore, many organic aerosol smaples were found to contain oligomeric compounds produced by polymerization of smaller organic molecules within aerosol particles. Methanol is widely used for SOA extraction due to the advantage of being able to easily electrospray solutions directly after extraction. Unfortunately, methanol, being an alcohol, has the ability to react with carbonyl groups to form hemiacetals, acetals, ketals, and with 
carboxyl groups to form esters. The purpose of this study was to investigate to what extent the aerosol solvent extraction step can produce artifacts in analysis due to the reactions between SOA species and solvent.

\section{Experimental}

Aerosol particles were generated by reacting limonene with $\mathrm{NO}_{3}$ radical in a Teflon bag. $\mathrm{NO}_{3}$ radical was generated from the thermal decomposition of dinitrogen pentoxide $\left(\mathrm{N}_{2} \mathrm{O}_{5}\right)$. The particles were collected on filters and sonicated in either acetonitrile or methanol.

Model solutions were prepared by dissolving pure chemicals in methanol, $\mathrm{d}_{3}$ methanol, acetonitrile, and water at micromolar concentrations. The $\mathrm{pH}$ of solutions was varied by adding glacial acetic acid.

All samples were analyzed using a Thermo-Fisher Orbitrap high resolution mass spectrometer at the Environmental Molecular Science Laboratory (EMSL) at the Pacific Northwest National Laboratory (PNNL), in Richland, WA.

\section{Results}

The key experimental findings can be summarized as follows:

$>$ Direct comparison of the ESI mass-spectra of solutions of succinic acid (SA), pinonic acid (PA), and 1,2-dioxobicyclo[2.2.2] octane-1,4-dicaboxylic acid (DDA) in $\mathrm{d}_{3}$-methanol and methanol, showed that analyte molecules containing a carbonyl group can react with one or two solvent molecules. For example, a new peak appears in the mass-spectrum shifted by $32.0262 \mathrm{~m} / \mathrm{z}$ realative to the parent molecule as a result of an addition of one $\mathrm{CH}_{3} \mathrm{OH}$ molecule (Figure 1). A corresponding peak appears shifted by $35.0447 \mathrm{~m} / \mathrm{z}$ when $\mathrm{CD}_{3} \mathrm{OH}$ is used as solvent proving that it is the solvent that is reacting.

$>$ Addition of one $\mathrm{CH}_{3} \mathrm{OH}$ molecule to an aldehyde or ketone leads to a hemi-acetal or hemi-ketal, respectively (Figure 1). These can react with one additional solvent molecule to form acetals and ketals, respectively. The second reaction further increases the mass by $14.0156 \mathrm{~m} / \mathrm{z}\left(\mathrm{OH}\right.$ group $->\mathrm{OCH}_{3}$ group) in methanol or by 17.0342 (OH group $->\mathrm{OCD}_{3}$ group) in $\mathrm{d}_{3}$-methanol. Both kinds of products were observed in these experiments.<smiles>[R]C([R])=O</smiles>
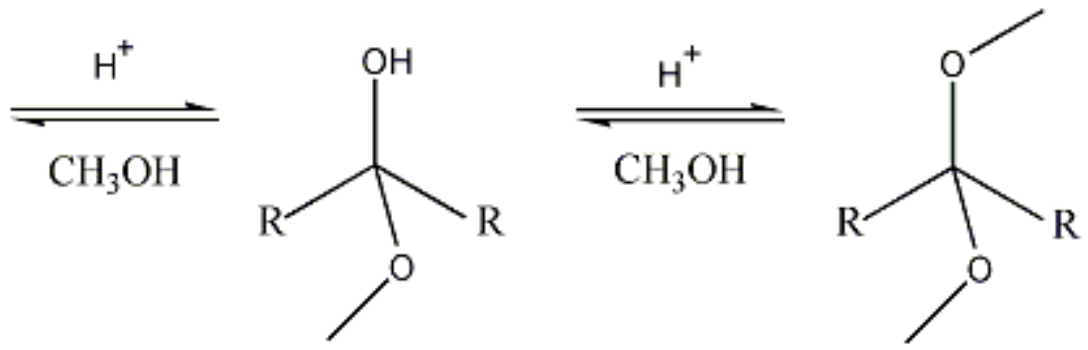

Figure 1. General equation for addition of methanol to carbonyl group. 
The extent and the rate of the reaction were investigated by taking multiple measurements on the same solution over a span of one week. The rate of growth of acetal for succinic acid (SA) increases with acidity, and the equilibrium shown in Figure 1 is not reached even after 160 hours of storage. Formation of ketal from pinonic acid (PA) is similarly accelerated by acids as shown in Figure 3. In both cases the extent of the reaction is relatively small.

$>$ No evidence for reactions between analyte molecules and solvent was observed in acetonitrile.

As a useful tool in determining the structure of SOA constituents, direct comparison between methanol and acetonitrile can provide functional group information. Laboratory generated particles from limonene and $\mathrm{NO}_{3}$ radical were extracted into both acetonitrile and methanol. Figure 4 shows the resulting spectra. A new peak can be clearly seen in the methanol solution that is exactly 32.0264 $\mathrm{m} / \mathrm{z}$ with larger intensity than the parent 191.1045 . This indicates a solvent addition with the parent most likely being an aldehyde.

Acetal Formation vs. Time

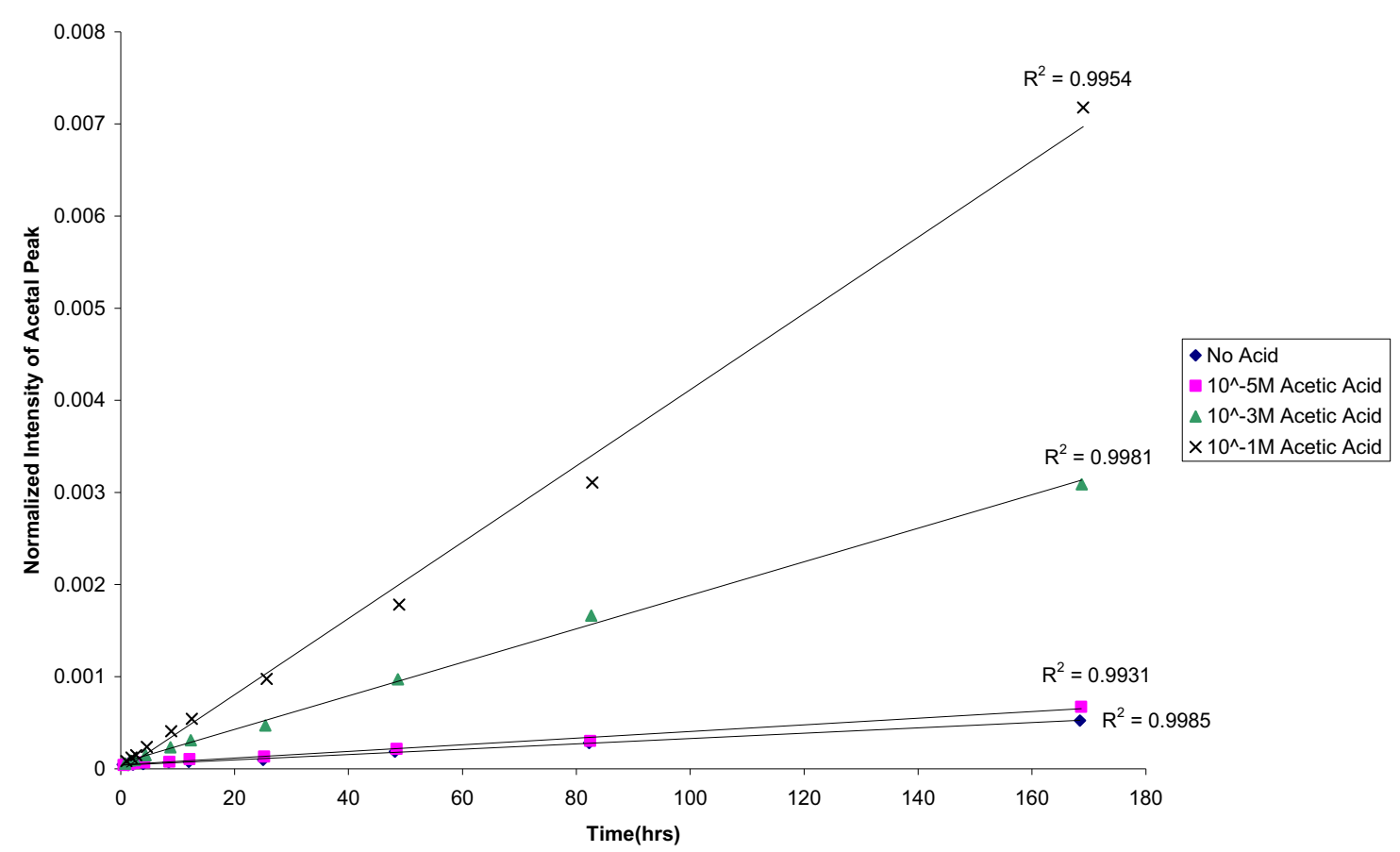

Figure 2. Time-dependent growth of acetal product from a solution of SA in methanol with different levels of acidity. The intensity of the acetal peak in negative mode ESI-MS spectrum is normalized to that of SA parent peak. 
PNNL-17069

Acetal Formation vs. Time

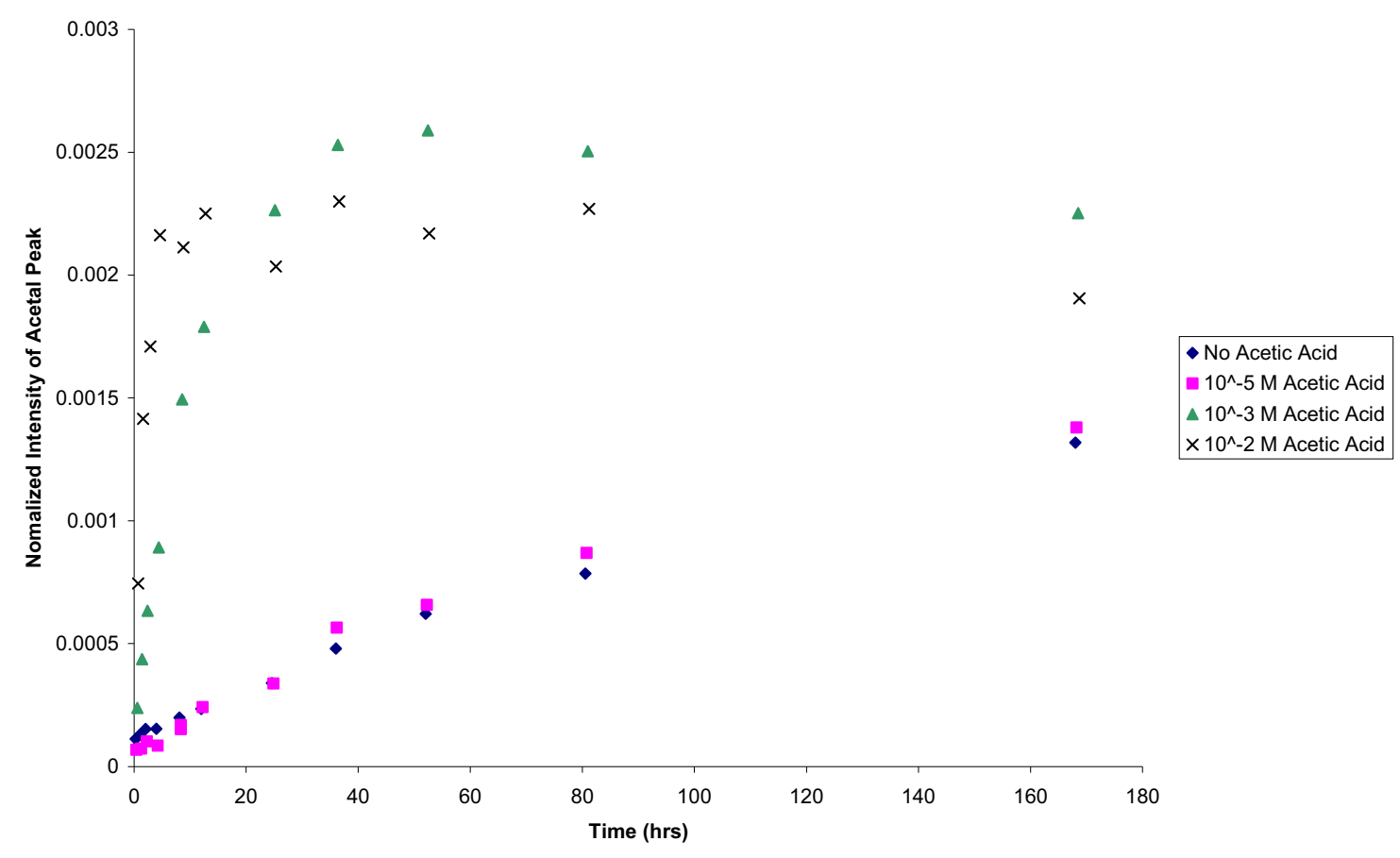

Figure 3. Time-dependent growth of ketal product from a solution of PA in methanol with different levels of acidity. The intensity of the ketal peak in negative mode ESI-MS spectrum is normalized to that of PA parent peak.

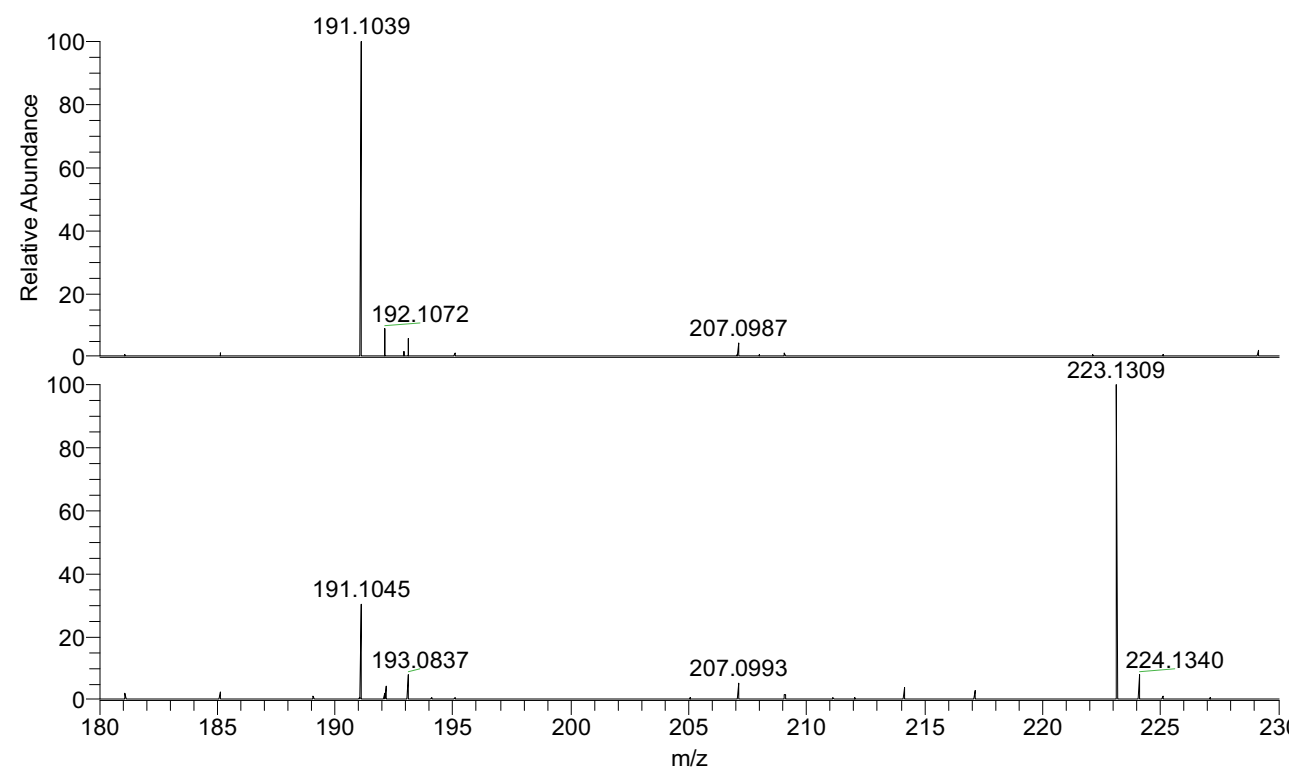

Figure 4. Laboratory generated aerosol dissolved in acetonitrile(top spectra) and methanol(bottom spectra). The new peak at $223.1309 \mathrm{~m} / \mathrm{z}$ represents addition of one solvent molecule. 


\section{Conclusion}

Due to methanol's ability to react with the functional groups found in aerosol particle constituents, it is suggested that SOA samples be extracted using acetonitrile. This solvent has been found to be much less reactive in similar acidic environments. Another important factor is time between extraction and analysis. To avoid solvent reactions, this time should be as short as possible, a few hours to a day. Another suggestion would be to use a buffer solution to maintain $\mathrm{pH}$. Comparison of reactive vs. un-reactive solvents using mass spectrometry can yield useful information for determining structure. 
PNNL-17069 
PNNL-17069

\section{Sampling and Heterogeneous Kinetics of Soot from a Flat Flame Burner Jeremy Cain, Hai Wang - University of Southern California \\ Yong Liu, Alexander Laskin - Pacific Northwest National Laboratory}

Soot is a hydrocarbon particulate produced under fuel rich combustion conditions. It is found throughout the earth's atmosphere due to emissions from power production facilities, automobiles, and aircrafts. Its properties (e.g., carbon-to-hydrogen ratio and hydroscopicity) are highly dependent on the fuel used and contaminants involved (e.g., sulfur and lead containing compounds) and aspects of the combustion process (e.g., temperature and residence time). Soot particles that have a large impact on climate and atmospheric chemistry are emitted from aircrafts. They have a direct effect on climate through light scattering and indirect effects via heterogeneous reactions with reactive trace species prevalent in the atmosphere and cloud formation. The latter two may be investigated using a flat flame burner.

Throughout the course of the summer, an experiment was built to aid in the investigation of soot's indirect atmospheric effects. The experimental setup is shown in Figure 1. A combustible acetylene/air mixture is burned in a McKinney burner. Spatial gradients in the reacting mixture fuel velocity are avoided through the use of a porous brass disc; thus, a flat flame is produced in which no spatial gradients of fuel decomposition exist. A surrounding sheath flow of argon prevents soot oxidation with the surrounding environment. The soot is sampled from the flame through a 125 micron diameter hole in a $1 / 4$ " stainless steel probe. As Figure 2 shows, the size of particles sampled is highly dependent on the height above the flame, as the soot is formed, grows, and agglomerates following the fuel's decomposition at the flame front. The soot is then sent to a heater that increases the carbon-to-hydrogen ratio, $\mathrm{C} / \mathrm{H} \approx 5$ in the flame, to the value characteristic of soot in a jet engine $(\mathrm{C} / \mathrm{H} \approx 13)$. The soot is then deposited onto TEM grids via a multi-orifice uniform discharge impactor (MOUDI). Its reactivity with trace atmospheric gas species, such as $\mathrm{OH}, \mathrm{O}_{3}$, and $\mathrm{HNO}_{3}$, may be determined with a particle-on-substrate stagnation flow reactor (PS-SFR) coupled with ESEM/EDX analysis, a method recently developed at PNNL. The burner fuel delivery system can be easily altered to include sulfur compounds, which are a constituent of jet fuel, and contaminants prevalent in a gas turbine, such as lead from lubricating oil. This will allow for the qualitative and quantitative effects they have on heterogeneous reactivity and hydroscopic behavior to be determined. 


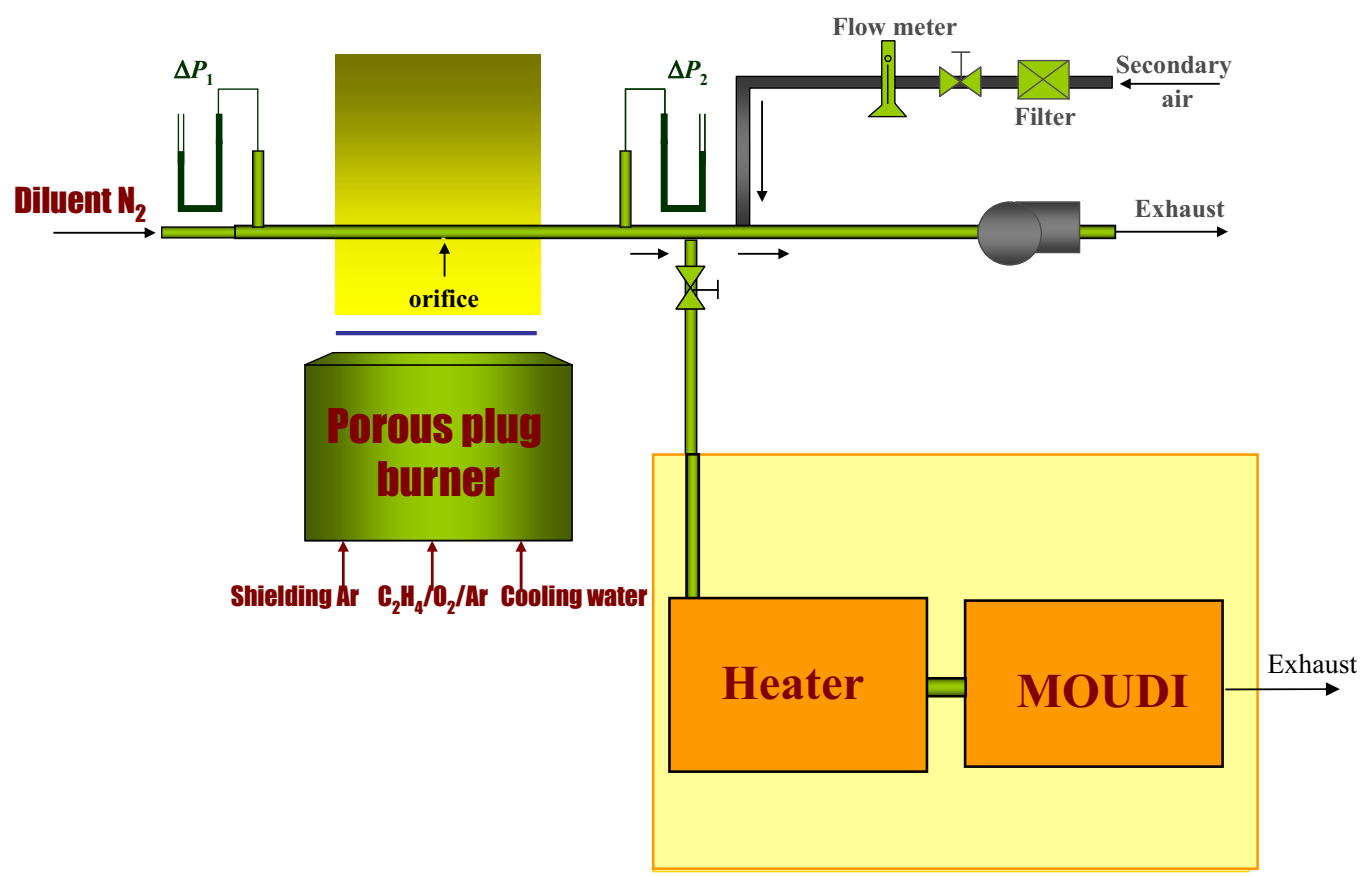

Figure 1 - Schematic of experimental setup
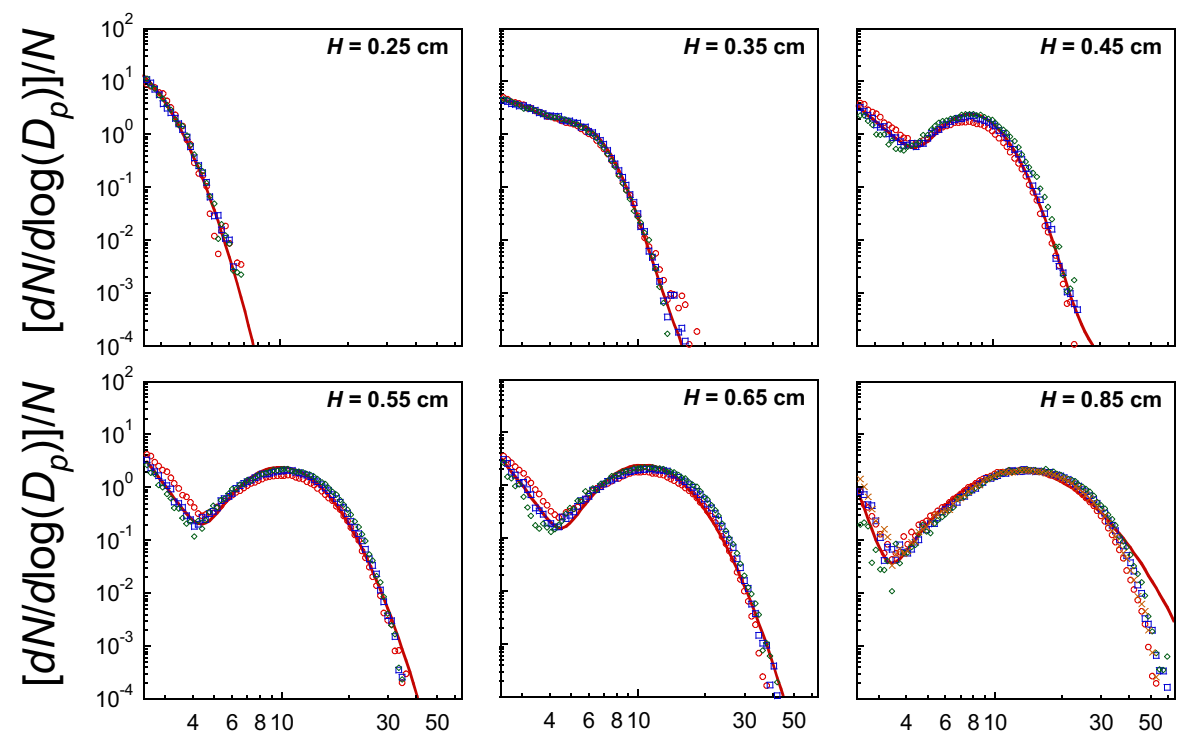

Particle Diameter, $D_{p}(\mathrm{~nm})$

Figure 2 - Plots of particle size distributions for various heights above the burner $(\mathrm{H})$ 


\title{
$\mathrm{TiO}_{2}$ Anatase(001) : Initial Steps Towards Surface Structure
}

\author{
S.E. Chamberlin ${ }^{1}$, T. Kaspar $^{2}$, S.A. Chambers ${ }^{2}$, C.J. Hirschmugl ${ }^{1}$ \\ 1 University of Wisconsin - Milwaukee, Milwaukee, WI 53211 \\ 2 Pacific Northwest National Laboratories, Richland, WA 99354 \\ a $\mathrm{TiO}_{2}$ anatase crystal according to the Wulff construction \\ and calculated surface energies [4].
}

Titanium dioxide $\left(\mathrm{TiO}_{2}\right)$ has received considerable attention due to its technological applications. The anatase surface has not been studied as much as the rutile surface, mainly due to the limited availability of single-crystal samples. However, anatase has been shown to be more important than rutile for several reactions including the photocatalytic formation of $\mathrm{H}_{2}$ and $\mathrm{O}_{2}$ from water [1,2]. A first step in understanding the mechanism of the production of $\mathrm{H}_{2}$ and $\mathrm{O}_{2}$ from water on anatase is to determine the specific surface sites that are available for adsorption and possibly dissociation. It has been found that the (101) surface is the dominant surface exposed on nanosized anatase crystallites, however, (001) and (103) surfaces are exposed as well (Fig. 1) [3]. These minority surfaces may in fact be the dominant source of active sites for the photocatalytic production of $\mathrm{H}_{2}$.

The recent work through the Summer Research Institute included a detailed study of the growth and initial characterization of several anatase thin films. The films were grown by oxygen plasma assisted molecular beam epitaxy (MBE) on Lanthinum aluminate $\left(\mathrm{LaAlO}_{3}\right)$ and Strontium titanate $\left(\mathrm{SrTiO}_{3}\right)$ substrates. Growth was

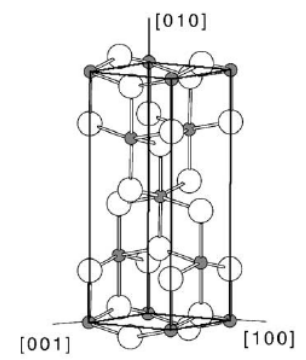

bulk unit cell of anatase

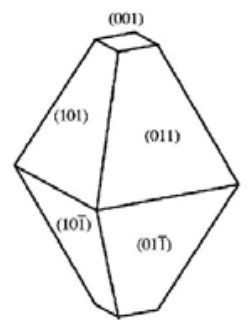

equilibrium shape of a $\mathrm{TiO}_{2}$ anatase crystal

Fig. 1 Bulk unit cell of $\mathrm{TiO}_{2}$ anatase (darker atoms are titanium, lighter atoms are oxygen) and equilibrium shape of monitored and evaluated using Reflection High Energy Electron Diffraction (RHEED). After growth, all surfaces were characterized by Atomic Force Microscopy (AFM).

\section{Anatase / $\mathrm{LaAlO}_{3}(001)$}

$\mathrm{LaAlO}_{3}(001)$ (LAO) has a very low lattice mismatch with anatase $(001)(\sim 0.3 \%)$, making it a strong potential substrate choice. However, its surface is twinned (Fig. 2), making it difficult to determine an average terrace width. Substrate

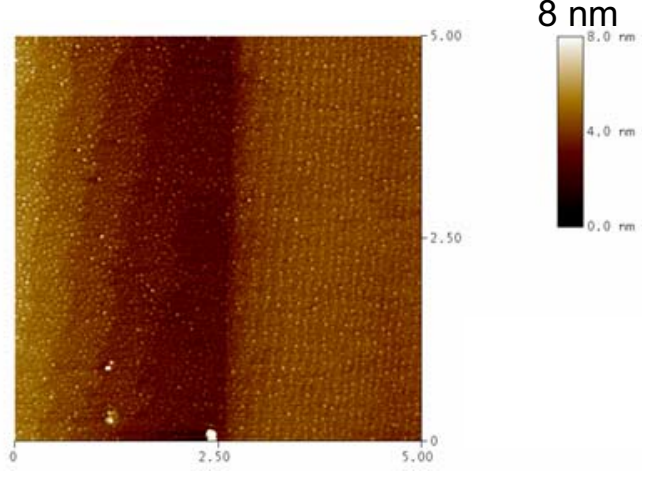

Fig. 2 An example of twinning seen in an AFM image. The terraces on the left side of the image are significantly wider than those on the right.

preparation, growth temperature, and oxygen plasma conditions were the variables explored in order to optimize the growth of the anatase films (i.e. obtain as atomically flat of a film as possible).

\section{a. LAO Substrate Preparation I}

Several substrate preparation techniques were performed in order to obtain a smooth substrate surface before growth. The results of these can be seen in Figure 3. Figure 3(A) shows an LAO substrate annealed at $800{ }^{\circ} \mathrm{C}$ for 8 hours in a tube furnace with a flow of oxygen. Figure 3(D) shows another substrate annealed slightly higher 
and longer at $900{ }^{\circ} \mathrm{C}$ for 12 hours $\left(\mathrm{O}_{2}\right.$ flow $)$. Figure 3(C) shows a substrate that was first treated in boiling de-ionized water for 3 minutes
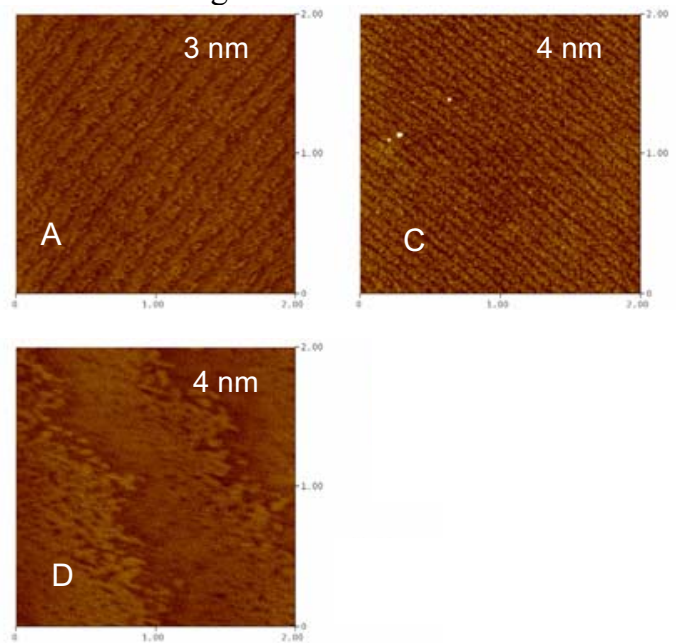

Fig. $32 \mu \mathrm{m} \times 2 \mu \mathrm{m}$ AFM images of LAO (A) $800{ }^{\circ} \mathrm{C} 8 \mathrm{hr} \mathrm{O}_{2}$ flow; (C) Boiling DI $\mathrm{H}_{2} 03 \mathrm{~min}, 800{ }^{\circ} \mathrm{C} 8 \mathrm{hr} \mathrm{O}_{2}$ flow; (D) $900{ }^{\circ} \mathrm{C} 12 \mathrm{hr} \mathrm{O}_{2}$ flow

and then annealed at $800{ }^{\circ} \mathrm{C}$ for 8 hours $\left(\mathrm{O}_{2}\right.$ flow). The roughness of these substrates was determined to be about equal (while terrace size was varied due to twinning).

\section{b. Effect of Growth Temperature}

Approximately $100 \AA$ of anatase was grown on each of the substrates shown in Figure 3. The substrate temperature at which the growth was performed was varied. Figure 4 shows the results. While island growth can be seen on all three films, growing at higher temperatures
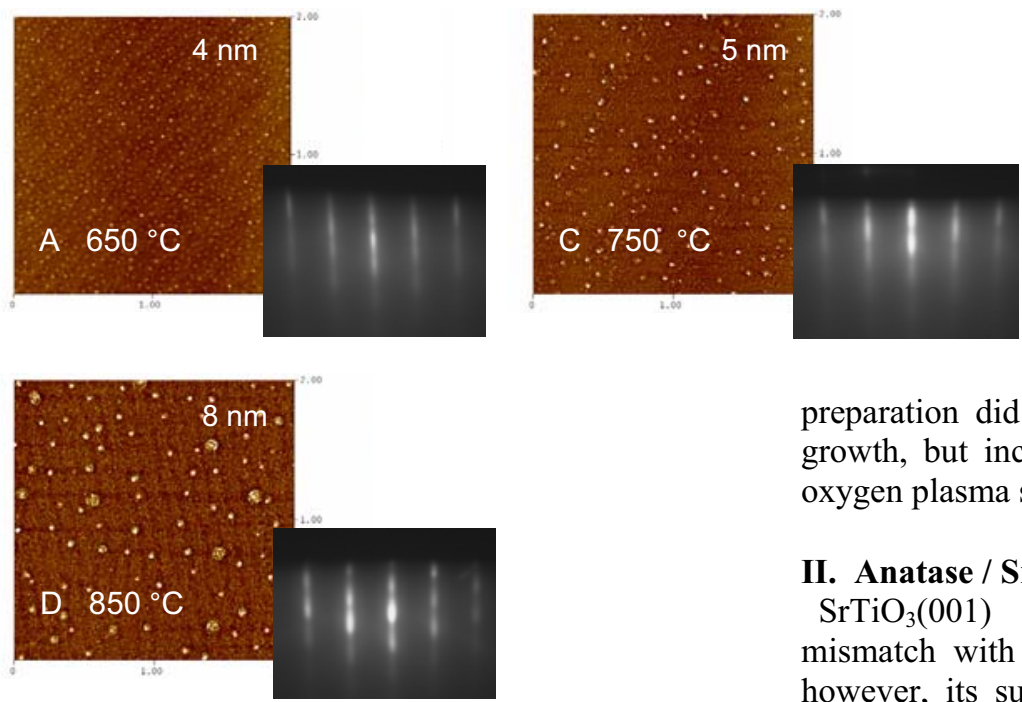

Fig. $42 \mu \mathrm{m} \times 2 \mu \mathrm{m}$ AFM images and RHEED of $\sim 100 \AA$ anatase / LAO (A) growth temperature of $650{ }^{\circ} \mathrm{C}$; (C) 750 ${ }^{\circ} \mathrm{C}$; (D) $850{ }^{\circ} \mathrm{C}$

seems to make this more favorable. Higher temperatures also correlated with larger amplitude oscillations in the (00) RHEED streak during growth, but these oscillations were not sustained for the entire growth, and the postgrowth RHEED streaks are more modulated than those of films grown at lower temperatures.

\section{c. LAO Substrate Preparation II.}

Further investigation into preparation of the LAO substrates proved successful with a very smooth surface achieved after an anneal at $1000{ }^{\circ} \mathrm{C}$ for 12 hours $\left(\mathrm{O}_{2}\right.$ flow) (see Fig. 5).

\section{d. Effect of Oxygen Plasma Conditions}

Substrates prepared such as the one seen in Figure 5 were used for growths under conditions similar to those in Figure 4, but they did not yield flatter films. Another growth parameter to be explored, however, was the oxygen plasma source. In Figure $6(\mathrm{G})$ the results of a growth with the source's power increased and ion trap turned off, as well as an increase in the overall oxygen pressure are shown. Figure 6(H) shows a similar growth with only the source's ion trap turned off. Both growths are of $\sim 100 \AA$ anatase. The prediction had been that a larger oxygen flux during growth would result in a flatter film, but both the RHEED streaks (which are quite modulated) and the AFM (which shows large island formation) indicate that this is not the case.

\section{e. Conclusions}

While LAO's very low lattice mismatch with anatase makes it a promising substrate for growth, the twinning of the substrate surface is most likely an obstacle to atomically flat growth. Substrate preparation did not seem to have an effect on growth, but increasing growth temperature and oxygen plasma settings resulted in rougher films.

\section{Anatase / $\mathrm{SrTiO}_{3}(001)$}

$\mathrm{SrTiO}_{3}(001)$ (STO) has a higher lattice mismatch with anatase(001) than LAO ( 3\%), however, its surface is not twinned like LAO, 
and it is a common substrate choice for anatase growth.
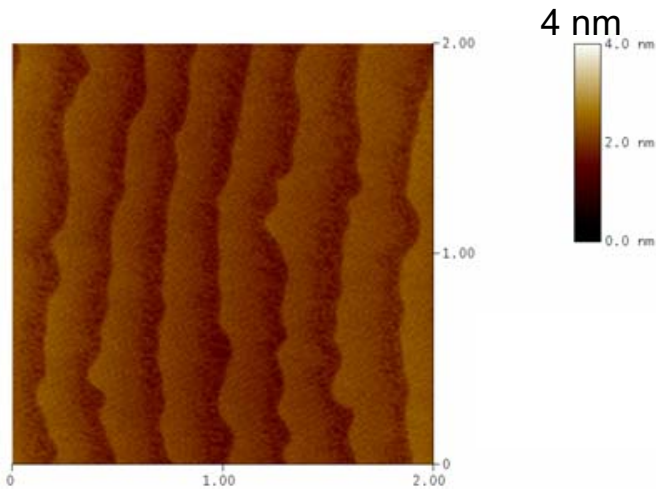

Fig. $52 \mu \mathrm{m} \times 2 \mu \mathrm{m}$ AFM image of LAO after $1000{ }^{\circ} \mathrm{C} 12 \mathrm{hr}$ anneal in $\mathrm{O}_{2}$ flow
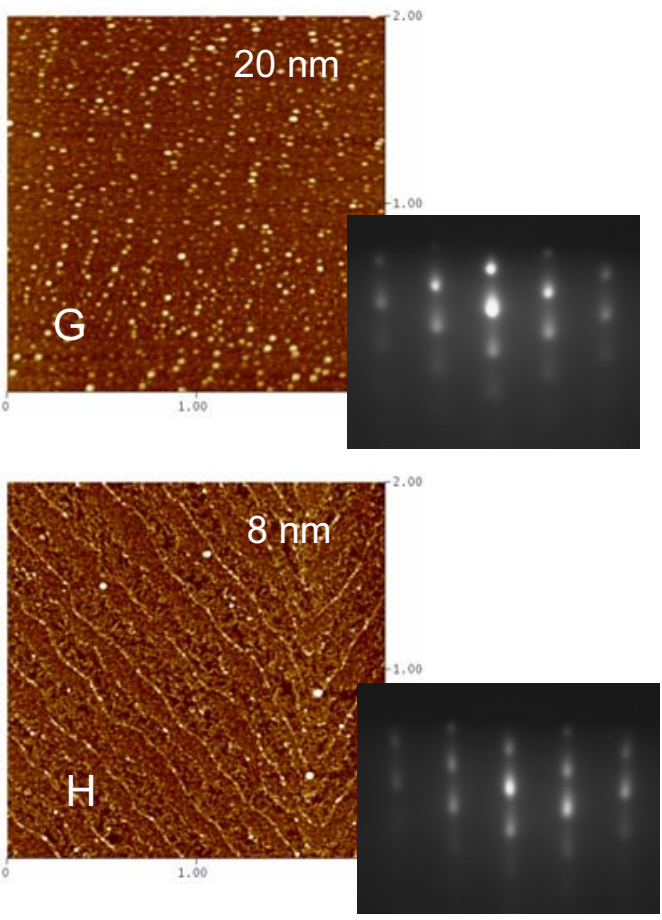

Fig. $62 \mu \mathrm{m} \times 2 \mu \mathrm{m}$ AFM images and RHEED of $\sim 100 \AA$ anatase / LAO (G) oxygen plasma source power increased and ion trap turned off, oxygen pressure in chamber increased; $(\mathrm{H})$ ion trap turned off

\section{a. STO Substrate Preparation}

The STO substrates were ultrasonically cleaned in acetone, isopropanalcohol, and de-ionized water for 5 minutes each, and then treated for 1 minute in a buffered oxide etch. Afterwards, the substrates were annealed at $950{ }^{\circ} \mathrm{C}$ for 2 hours $\left(\mathrm{O}_{2}\right.$ flow $)$. The edges of the terraces were observed to have one-step-height depth holes after this treatment and anneal (see Fig. 7) that were able to mostly diffuse with two subsequent anneals at $950{ }^{\circ} \mathrm{C}$ for 3 hours $\left(\mathrm{O}_{2}\right.$ flow) (see Fig. 8) [5].

\section{b. Effect of Miscut}

Several anatase films were grown on substrates having undergone this treatment and anneal process. The first of these can be seen in Figure 9. Figure 9(L) shows $100 \AA$ anatase grown on a STO substrate annealed for only the initial 2 hours (the holes had not had enough time to diffuse), and Figure 9(M) shows $110 \AA$ anatase grown on a STO substrate that had received the full annealing treatment described above. Both films appear atomically flat, which is supported by the RHEED images, i.e. the streaks are unmodulated, and the $4 \times 1$ reconstruction can clearly be seen. (The $1 \times 1$ construction of anatase is not as stable and tends to reconstruct.) In Figure $9(\mathrm{~N})$ though, the results of trying to grow a thicker film can be seen. $280 \AA$ anatase was grown on another substrate that had received the same full annealing treatment, but this film is not as flat as the first two - larger islands have started to form and the RHEED has become modulated (the $4 \times 1$ reconstruction is still visible, however.) All of these films were grown at 750 ${ }^{\circ} \mathrm{C}$, and the miscut of the substrates was such that the average terrace width seen is $\sim 1 \mu \mathrm{m}$.

A second set of growths can be seen in Figure 10. The substrates were prepared as described above (treatment and full annealing), but because the miscut of these substrates is much lower than that of the previous, the terrace width is too large to allow the holes to diffuse out to the edges in a reasonable amount of annealing time. Two
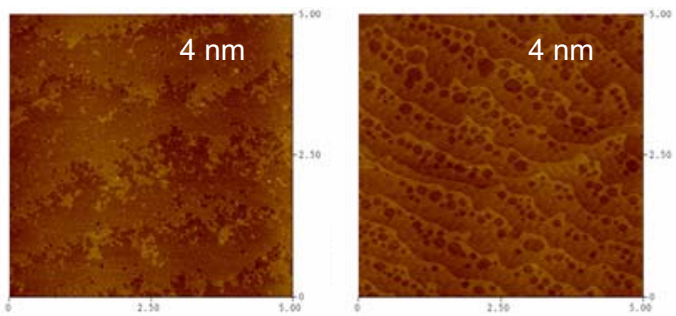

Fig. $75 \mu \mathrm{m} \times 5 \mu \mathrm{m}$ AFM images of STO Left: after 5 min each ultrasonic cleaning in acetone, isopropanalcohol, and de-ionized water and then $1 \mathrm{~min}$ buffered oxide etch; Right: then annealed $950{ }^{\circ} \mathrm{C} 2 \mathrm{hr} \mathrm{O}_{2}$ flow
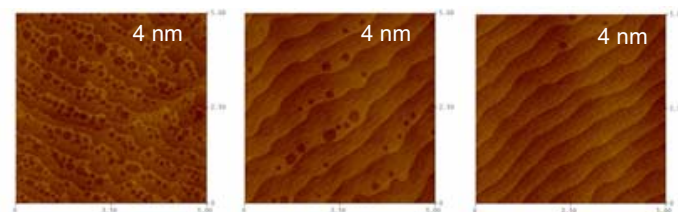

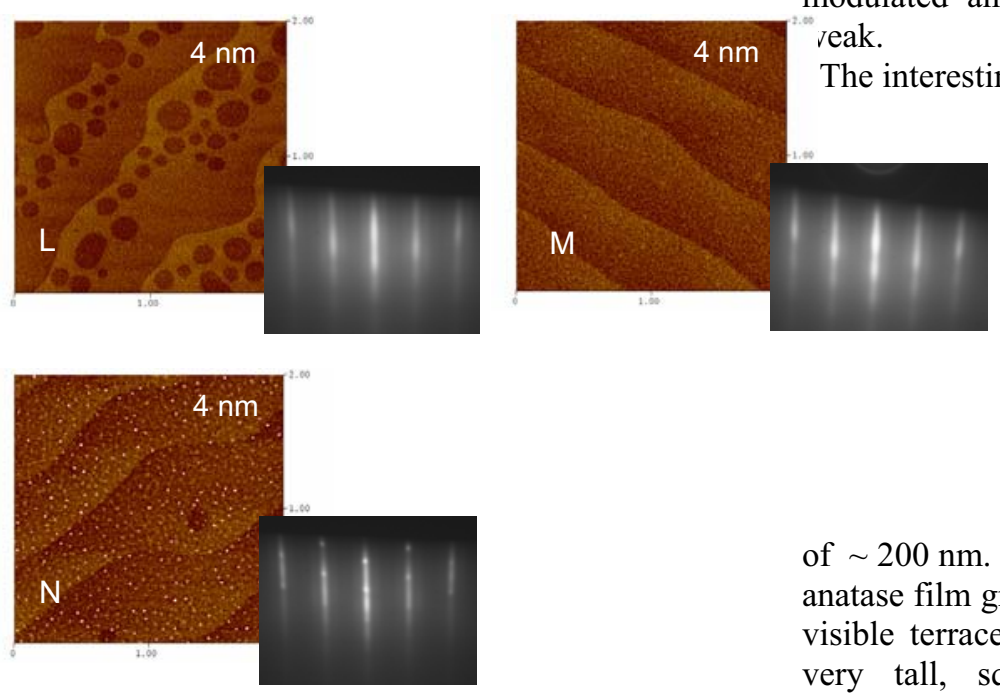

Fig. $92 \mu \mathrm{m} \times 2 \mu \mathrm{m}$ AFM images and RHEED of anatase / STO (L) $100 \AA$; (M) $110 \AA$; (N) $280 \AA$
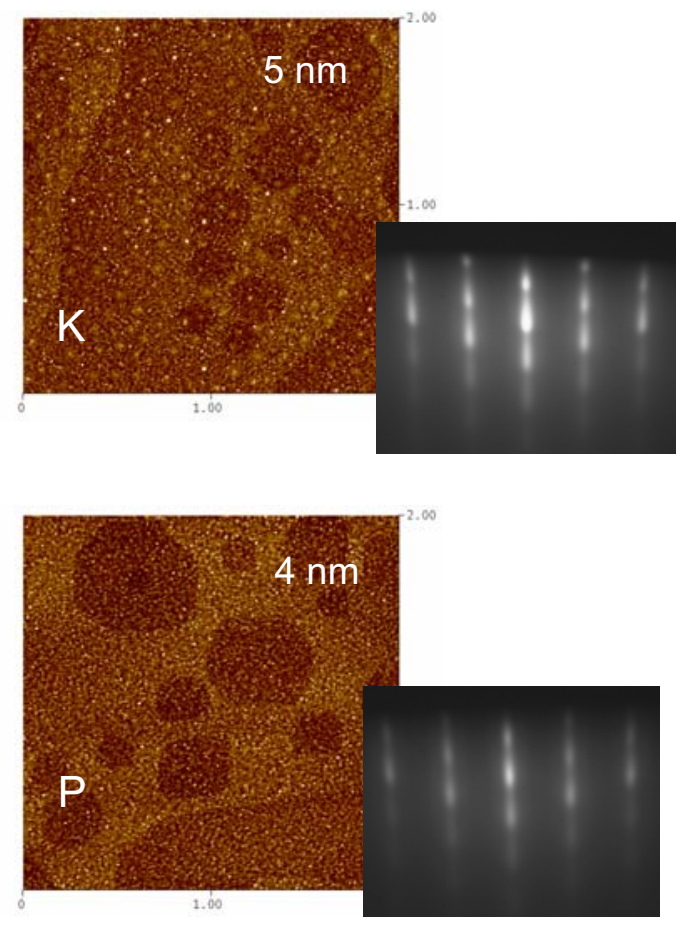

Fig. $102 \mu \mathrm{m} \times 2 \mu \mathrm{m}$ AFM images and RHEED of anatase / STO (K) 150 ̊; (P) $120 \AA$

growths of $\sim 150 \AA$ and $120 \AA$ anatase are shown in Figure 10; both films were grown at $750{ }^{\circ} \mathrm{C}$ and the average terrace width is $\sim 10 \mu \mathrm{m}$. The AFM images show only small island formation on the surface, but the RHEED is quite
Fig. $85 \mu \mathrm{m} \times 5 \mu \mathrm{m}$ AFM images of LAO (A) after treatment and $950{ }^{\circ} \mathrm{C} \quad 2 \mathrm{hr} \mathrm{O}_{2}$ flow; (C) after second anneal at $950{ }^{\circ} \mathrm{C}$ $3 \mathrm{hr} \quad \mathrm{O}_{2}$ flow; (D) after third anneal at $950{ }^{\circ} \mathrm{C} 3 \mathrm{hr} \quad \mathrm{O}_{2}$ flow modulated and the $4 \times 1$ reconstruction is very veak.

The interesting results of a growth on a $0.2 \%$

$\mathrm{Nb}$ :STO substrate are shown in Figure 11. The miscut of the substrate was higher than the other substrates used for growth, as seen in the upper image (after treatment and full annealing), with an average terrace width

of $\sim 200 \mathrm{~nm}$. The lower image shows the $560 \AA$ anatase film grown on this substrate. There is no visible terrace structure, and the surface shows very tall, square pyramidal islands. The RHEED, however, is completely unmodulated and the $4 \times 1$ reconstruction is quite clear, both indicative of a flat, high quality surface. A possible explanation for this is that since only $2.5 \%$ of the surface is covered with the square pyramidal islands, there is enough "flat" space between the islands to give a good RHEED diffraction.

To complete the study of the effect of miscut on the anatase growth, STO substrates with an even higher degree of miscut (average terrace width $850 \AA$ ) were prepared (usual treatment and full anneal). The result of these growths is shown in Figure 12. A successful flat film of $110 \AA$ with a slightly modulated 4x1 RHEED pattern was grown (see Fig. 12(S)), but a thicker film of $200 \AA$ had a very modulated RHEED pattern and the AFM showed an island covered surface with no terrace structure. (Both films grown at 750 ${ }^{\circ} \mathrm{C}$ )

\section{c. Conclusions}

Despite STO's larger lattice mismatch with anatase, it was more successful in flat film growth than LAO. The substrate quality after the described treatment and anneals was good, and atomically flat thin films $(\sim 100 \AA)$ of anatase can consistently be grown. The success of thicker films, however, may be dependent upon substrate miscut/terrace width, i.e. a certain amount of miscut, but not too high, may be necessary.

\section{Future Work}


To fully characterize the growth of anatase, more studies will be done at PNNL exploring the effect of other growth parameters on STO, including substrate temperature and growth rate. The optimal conditions for growth, including those necessary for flat, thick films, will then be

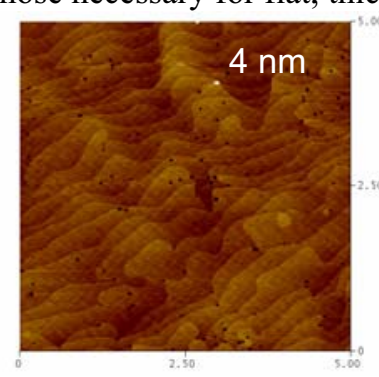

on anatase. The low current DLDLEED will be ideal for studying these systems since the low dose of electrons will not cause significant desorption of oxygen (on the clean anatase surface) or of water adsorbed to the surface.

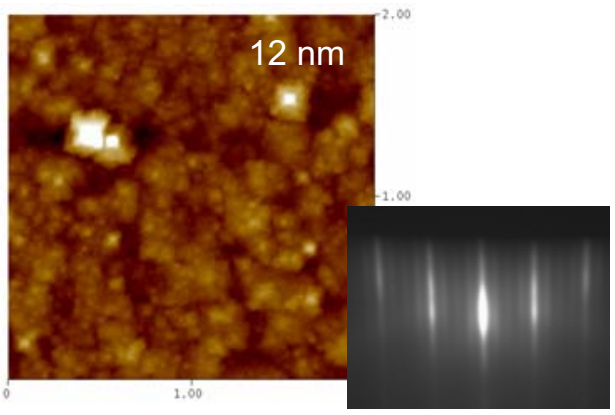

Fig. 11 Upper: $5 \mu \mathrm{m} \times 5 \mu \mathrm{m}$ AFM image of $\mathrm{Nb}: \mathrm{STO}$ substrate; Lower: $2 \mu \mathrm{m} \times 2 \mu \mathrm{m}$ AFM image and RHEED of $560 \AA$ anatase / Nb:STO
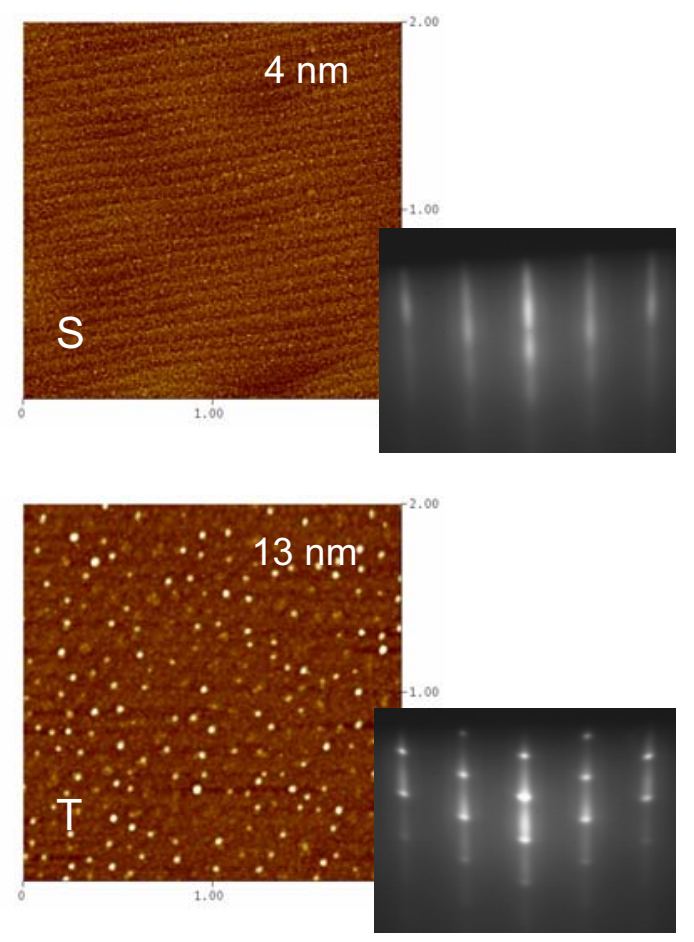

Fig. $122 \mu \mathrm{m} \times 2 \mu \mathrm{m}$ AFM images and RHEED of anatase / STO (S) $100 \AA ;$ (T) $200 \AA$ 
determined. Other interesting results will be the comparison of such films grown by MBE to those grown under optimal conditions by pulsed laser deposition (PLD).

At UW-Milwaukee, work will be done to determine the surface structure of these anatase films by delay line detector (DLD) low energy electron diffraction (LEED) IV curve analysis employing a low current electron gun. DLD-LEED and infrared (IR) spectroscopy will also be used to study the interaction/structure of water

[1] A. L. Linsebigler, G. Lu, and J. T. Yates, Chem. Rev. 95, 735 (1995).

[2] L. Kavan, M. Gratzel, S. E. Gilbert, C. Klemenz, and H. J. Scheel, J. Am. Chem. Soc. 118, 6716 (1996).

[3] J. H. A. Martens, R. Prins, H. Zandbergen, and D. C. Koningsberger, J. Phys. Chem. 92, 1903 (1988).

[4] U. Diebold, Surface Science Reports 48, 53-229 (2003).

[5] G. Koster, G. Rijnders, D.H.A. Blank, H. Rogalla, Physica C 339 215-230 (2000). 


\section{Optimization and Characterization of Gold Black}

Justin Cleary, Robert Peale and

Chris Fredricksen

University of Central Florida

Orlando, Fl
Kenneth Beck, Alan Joly and

and

Wayne Hess

Pacific Northwest National Labs

Richlang, Wa

\section{Introduction}

Gold black is low-density nano-structured gold that strongly absorbs a wide portion of the spectrum from visible to far-infrared. It is created by thermal evaporation in $\sim 1$ Torr ambient of inert gas. Gold black and other metal blacks have been studied as absorbing materials in the infrared since the 1930 's. ${ }^{1-2}$ One goal of this dissertation is to optimize a gold black deposition process for a specific MEMS-based bolometer underdevelopment by Zyberwear, Inc. who is partially supporting the work.

One problem of the gold black is it lacks mechanical robustness. The films are easily damaged. A simple finger swipe or a strong gust of air can remove large amounts of gold black from the substrate. An optimization goal of this project is to develop mechanically robust gold black films on silicon that retain strong IR absorption.

A variety of characterization techniques will be described in the work plan. One feature is the use of surface Plasmon polariton resonance spectroscopy, which is an all-optical technique to determine simultaneously the deposited film thickness and the complex permittivity. The complex permittivity is related to experimental spectral absorption and reflectivity measurements of the gold black film. Application of this technique to gold black films appears to be novel. New physics is anticipated from the analysis of the determined permittivity in terms of various models, although it is too early at this stage to predict what will be discovered. This work is also partially supported by the Air Force Research Laboratory (AFRL) to study SPP's for nano-structured metal films.

This research is currently ongoing at the University of Central Florida (UCF). Preliminary results shown here were collected at UCF or Pacific Northwest National Labs (PNNL). 
PNNL-17069

\section{Theoretical and Experimental}

\section{Gold Black Film Preparation}

The project goal is to develop a lightweight, highly absorbing coating for an innovative MEMS-based thermal infrared detector that absorbs as much IR radiation as possible. With very large absorbance, the gold black film will be able to collect the maximum amount of light in a short time to generate thermal images at a standard frame rate $(\sim 30$ frames per second). The gold black coating absorbs light that would normally be scattered from the pixel surface and transfers the heat to the pixel, maximizing the throughput.

A two level full factorial optimization scheme is being followed. Parameters that possibly could affect gold black film quality will be identified (such as pressure, evaporation current, temperature, etc). For each parameter, two values are chosen to test. A matrix of experiments is set up so that every combination of parameters values in the scheme is completed in random order to avoid systematic errors. From the results of these experiments in conjunction with FTIR absorbance data, the location in parameter space for optimization of the film can be discovered. This will allow the determination of any correlation between parameters. This full factorial scheme is the most statistically sound and economical approach to optimization when the physics that links film quality to the complicated parameter space is not completely understood.

The project will focus initially on films of nano-structured gold metal particles. The samples are prepared by evaporating gold in nitrogen or helium onto glass slides or silicon substrates. The films are sufficiently thin, approximately $50 \mathrm{~nm}$, to allow some transmission of an optical beam. The samples are attached, film-side outward, to the large face of a right-angle or semi-cylindrical prism with an index matching fluid such as glycerine for the optical experiments described below.

A standard bell chamber that is connected to a mechanical and diffusion pump is used in the sample deposition. The bell chamber setup can be seen in figure 1. Samples are mounted on a copper plate, which is attached to a thermoelectric cooler. The thermoelectric cooler is attached to a large copper heat sink with coolant transported through the chamber for lower temperatures. With samples in place and gold ready to evaporate in the boat, the mechanical and diffusion pumps are used on the chamber until the pressure reaches $\sim 10^{-4}$ Torr. Gas (helium or nitrogen) is then allowed to flow in the chamber until the desired pressure is reached, usually on the order of 1 Torr. The thermoelectric cooler is used to cool the samples to $30-40^{\circ} \mathrm{F}$. The evaporations then are completed under various time or current (through the electrodes) conditions. Depositions are many samples have already been completed with specifications for the first five characterized found in table 1. 

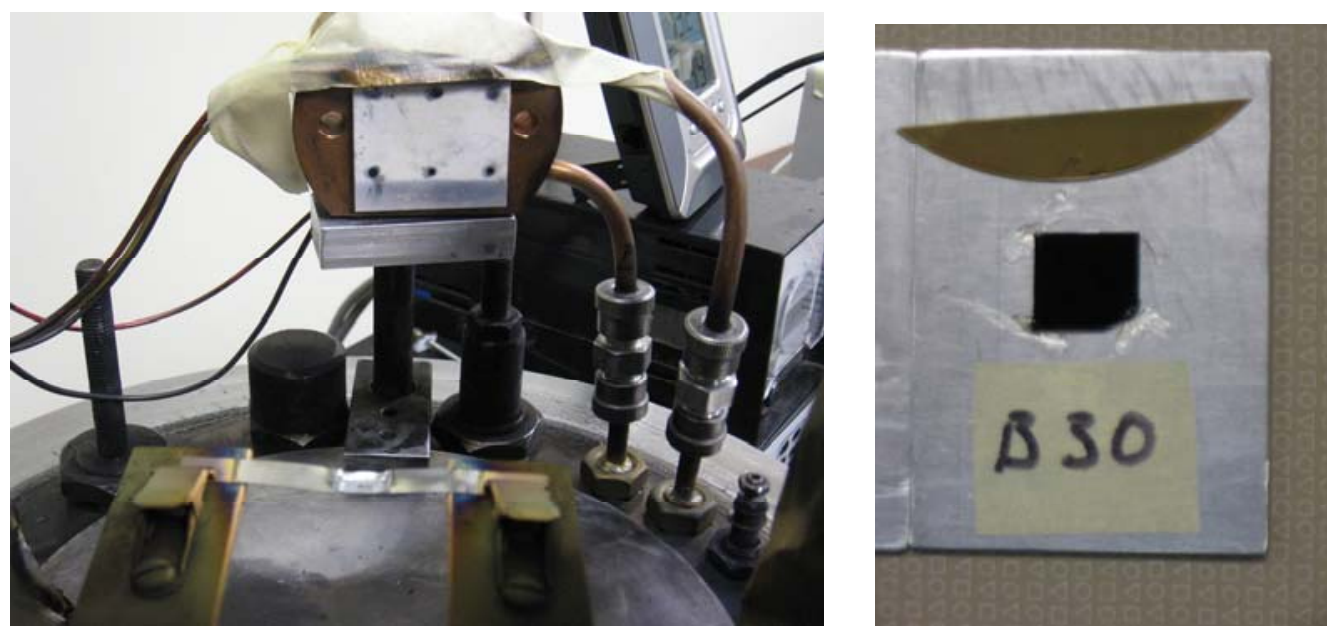

Fig. 1.(left) Bell chamber showing thermoelectric cooler attached to heat sink (top) across from the electrodes and molybdenum boat (bottom). (right) Gold black sample deposited on silicon compared to a standard gold-coated piece of silicon.

Future improvements on the gold black deposition process will be made. A standard deposition monitor will be implemented and used to measure the evaporation rate of gold black and film thickness in real time. Crystal monitors for the deposition monitor will be coated with some material $(\mathrm{Cr}, \mathrm{Ti}$, etc) to attempt to get the gold black to stick better. The effects of various pre and post treatments will also be tested (baking, super glue, epoxy, etc) in attempts to harden the film.

The gold black films are studied and optimized by FTIR spectroscopy, SEM and measurements of surface plasmon polaritons as well as other techniques. Gold black will be evaporated on silicon substrates (used for SEM, FTIR) and glass substrates simultaneously (used for SPP).

Other optimization methods will include weight measurement and temperature dependence while evaporating. Cooling of the substrates is being experimented with currently and initial results indicate that cooling definitely increases the amount of gold black that collects on the substrate. Proper SEM / spectroscopy work needs to be done to be able to determine the effect this has on the properties of the film though. The mass of the substrates will be measured before and after deposition and used to calculate the density of the deposited films. This data, in conjunction with the FTIR data, will determine the correlation between larger absorbance and the density of the film.

\section{Parameters:}

Pressure

Current

Initial Temperature

Evaporation Duration 


\section{Physical Characterization}

Film roughness and metal-particle size distribution will be characterized by scanning electron microscopy. Scanning electron microscopy data is acquired for the gold black samples. Using the data, a better understanding of the surface morphology is found and compared with the absorbance data for the same samples. From the table 1, it was found that sample $\mathrm{D}$ is the most absorbing while sample $\mathrm{E}$ was the $2^{\text {nd }}$ most absorbing. The SEM data in figure 2 shows cloud shaped structures for these two samples. The structures in sample D (the more absorbing film) are about one order of magnitude larger than those in sample E. Samples A-C (lowly absorbing) different structures. From these initial considerations, a correlation could be found between larger cloud-like clusters of gold particles and higher absorption. Regardless of any correlations, SEM will provide a detailed observation of the film morphology.
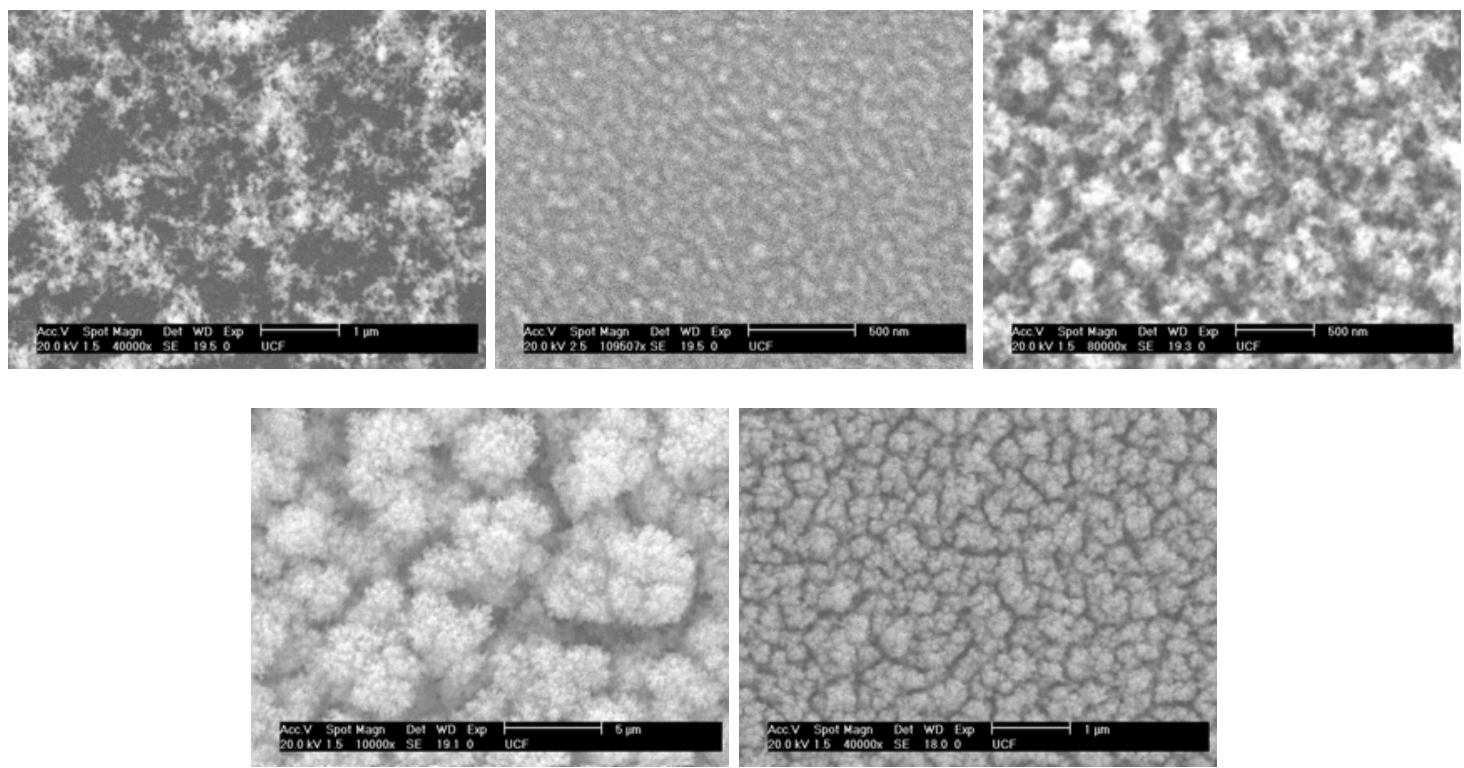

Fig. 2. SEM data for initial gold black samples. Clockwise from top-left corner are samples A through E.

\section{Infrared Spectroscopic Characterization}

Absorption is measured from the near to far-IR using FTIR spectroscopy to better characterize the films created. The transmission and reflectance are measured from near to far-IR using a BOMEM fourier transform interferometer in conjunction with a globar or mercury lamp source, a 4K Bolometer, MCT or DTGS detector and Mylar or $\mathrm{KBr}$ beamsplitter. Gold black samples are mounted onto a machined metallic plate. Transmittance is then measured using a clean silicon substrate as a reference. Reflectance is measured using a gold-coated silicon substrate as a reference reflector. A figure of merit 
for absorbance is then measured by subtracting the transmssion and reflectance from unity.

The first gold black samples completed for this project were completed with the parameters found in table 1. Transmission and Reflectance data in the mid-IR for these samples are presented in figure 3. From the figures it is easily seen that the gold black sample made at the highest pressure here had low transmissitivity but also the largest reflectivity. The most absorbing film of the five (absorbance figure of merit found in table 1 ) is sample D which has, in general, the lowest reflectivity out of the group and the $2^{\text {nd }}$ lowest transmission. The difference between sample E and D (as stated in table 1) is a difference in relative current during evaporation. The empirical absorbance figure of merit used from these gold black samples (and all other samples) is then used in the full factorial scheme. The two parameters in the case of data presented here are pressure of nitrogen in the bell chamber and current used for the deposition. This is an early indication that higher currents and higher pressure during deposition generally help create more absorbing samples. These two parameters will be explored in more detail in reference to absorbance. Other parameters also will be explored in similar two level factorial schemes.
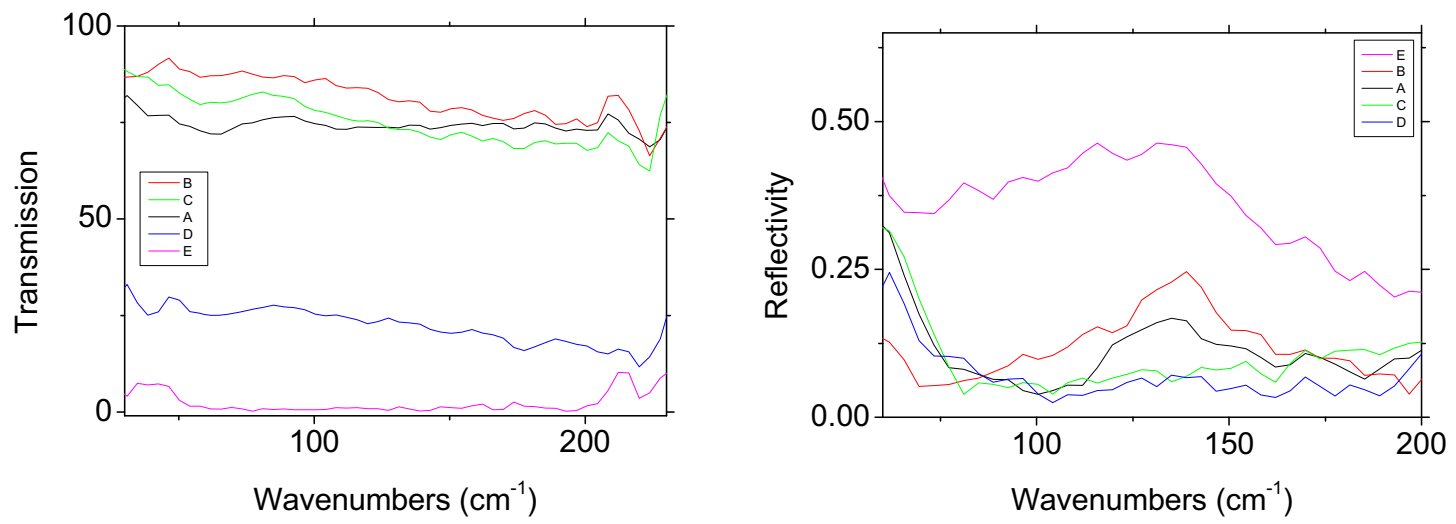

Fig. 3. Transmission and Reflectivity of gold black samples A-E

\begin{tabular}{|ccccc|}
\hline Sample & Pressure (Torr) & Relative Current & FoM @ $100 \mathrm{~cm}^{\wedge}-1$ & FoM @ $400 \mathrm{~cm}^{\wedge}-1$ \\
A & 0.2 & 4.5 & 0.21 & -0.18 \\
B & 0.2 & 3.5 & 0.04 & -0.38 \\
C & 0.5 & 3.5 & 0.15 & -0.42 \\
D & 0.5 & 4.5 & 0.70 & 0.73 \\
E & 0.75 & 4.5 & 0.59 & 0.28 \\
\hline
\end{tabular}

Table 1: Gold black samples A-E deposited with a corresponding pressure of nitrogen in the bell chamber. A figure of merit (FoM) for absorbance, which is meant for comparison purposes only, is calculated as $1-\mathrm{T}$ $-\mathrm{R}$ at wavenumber specified for each sample. Negative values occur because of non-normal incidence in the reflectance measurements. 
PNNL-17069

\section{Surface Plasmon Measurements}

Surface Plasmon Polaritons (SPP) are inhomogeneous electromagnetic plane waves bound to the surface of a conductor. Knowledge of SPP characteristics is of timely and critical interest to the rapidly expanding field of SPP-based "Plasmonics." Practical interest derives from the possibility of nano-scale optoelectronic devices, manipulation of opticalpulse propagation, and concentration of electromagnetic energy for sensing applications.

The properties of SPPs are determined by their frequency-dependent complex wavevector. This may be calculated from the complex permittivity, which is empirically known for fourteen metals. ${ }^{3}$ Numerous reports, from the most recent study ${ }^{4}$ to the earliest, ${ }^{5}$ reveal significant unexplained discrepancies between theory and experiment. These are generally attributed, without analysis or any systematic proof, to surface morphologies, impurities, contamination, and lack of crystallinity for evaporated films. We will investigate surface plasmons generated in low-density nano-structured metal films, which opens a window to systematic study of SPPs on such films as a function of their microstructure. The nano-structure of gold-black affects the electron scattering frequency for currents excited by the SPP. This causes changes to the complex permittivity, which is detectable in the behavior of the SPP. Similarly, metal particle size is expected to effect the measurements due to resonance effects.

SPPs are excited on the nano-structured metal films under conditions of total internal reflection for the optical beam within the prism. In the Kretschmann method, ${ }^{6}$ the prism slows the optical beam so that, at the proper angle of incidence, the in-plane component of the optical wavevector matches that of the surface plasmon at the photon frequency. When a surface plasmon is excited, a sharp drop in the reflected optical power is observed. This experimental resonance at various wavelengths can determine the complex wavevector for the surface plasmons and consequently also determines the complex permittivity of the film. The empirical dispersion relations found here and other cumulative results will be compared to theory and will correlate gold black permittivity with IR and physical properties. This is exploratory research, done first in the visible for convenience (for gold and gold black), even though the spectral range of interest is IR. The visible range is interesting in its own right, and it is this work component that is expected to produce the most interesting physics.

At the current time, gold black films are being evaporated without the use of a deposition monitor. The use of a deposition monitor could give an accurate description of the thickness of the film but this is still being studied as mentioned earlier. By fitting the SPP resonance line shape to theory, the complex permittivity and film thickness are determined simultaneously, in contrast to other optical methods such as ellipsometry, where one or the other needs to be known prior. This technique will prove to be useful over other techniques (ellipsometry and possible others) that require the film thickness to measure 
the complex permittivity or vice versa. Other techniques should be explored however to confirm the results of this experiment.

The optical setup consists of three layers, prism, metal, and air. An example of the system can be seen in figure 4 . With the correct incoming $\mathrm{k}_{\mathrm{x}}$, surface plasmons are excited. This resonance occurs when the incident angle $\theta$ is a certain value that enables coupling of the wavevector $\mathrm{k}_{\mathrm{x}}$ and the $\mathrm{k}$ for SPP propagation. The resonance is defined by equation 1-3. The wavevector for the surface plasmon depends on the complex permittivity of the gold black by eq. 1. Experimentally determining the reflectance as a function of incidence angle in the setup described in figure 4 will enable us to observe the resonance angle for a particular wavelength. By eq. 2, the real part of the wavevector can then be calculated. Using the same system over a variety of wavelengths, the full-width at half-maximum for resonance angle as a function of angular frequency $\left(\Delta \theta_{\text {res }}(\omega)\right)$ can be used to determine the imaginary part of the wavevector by use of eq. 3. Using the real and imaginary parts of the wavevector can then be also used to calculate the complex permittivity using eq. 1 . This method can identify the complex permittivity for metallic samples provided the $\theta_{\text {res }}$ and $\Delta \theta_{\text {res }}(\omega)$ can be accurately measured. The effect of sample morphologies will be revealed by the change in the angular position of the SPP excitation peak and its line shape

$$
\begin{aligned}
& k_{S P P}=\frac{\omega}{c} \sqrt{\frac{\varepsilon_{\text {metal }}}{\varepsilon_{\text {metal }}+1}}=k^{\prime}+i k^{\prime \prime} \\
& k^{\prime}=k_{x}=n_{\text {prism }} \frac{\omega}{c} \sin \left(\vartheta_{\text {res }}\right) \\
& k^{\prime \prime}=\frac{\omega}{c} \Delta \vartheta_{\text {res }} \cos \left(\vartheta_{\text {res }}\right)
\end{aligned}
$$
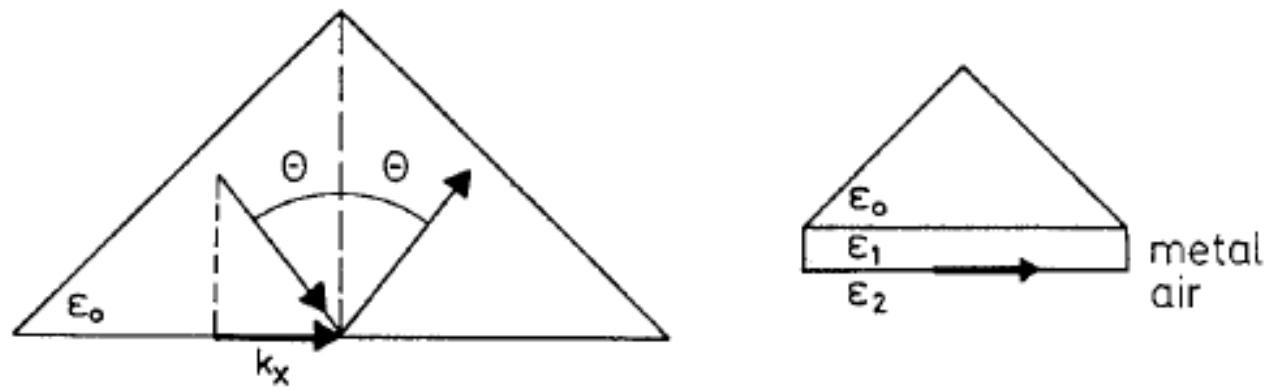

Fig. 4. Diagram of surface plasmon system in the Kretschman method. ${ }^{7}$ Incident light reflects on back interface of prism. With $\theta$ greater than the total internal reflection angle, only a small amount of evanescent waves penetrate into the metal. The waves then excite SPP's on the metal / air interface for a particular $\mathrm{k}_{\mathrm{x}}$ value (picture from Raether ${ }^{7}$ ). 
PNNL-17069

The Fresnel equations for a three-layer system allow one to extract the complex permittivity and thickness of the film from a fit to the resonance spectrum. For a metal film between two transparent dielectrics, the amplitude reflection coefficient is

$$
r=\left(r_{12} e^{-2 i \varphi}+r_{23}\right) /\left(e^{-2 i \varphi}+r_{12} r_{23}\right) \quad,
$$

where for a p-polarized incident beam

$$
\mathrm{r}_{12}=\left(\varepsilon_{2} \mathrm{k}_{0 \mathrm{z}}-\varepsilon_{1} \mathrm{k}_{2 \mathrm{z}}\right) /\left(\varepsilon_{2} \mathrm{k}_{0 \mathrm{z}}+\varepsilon_{1} \mathrm{k}_{2 \mathrm{z}}\right)
$$

and

$$
\mathrm{r}_{23}=\left(\varepsilon_{3} \mathrm{k}_{2 \mathrm{z}}-\varepsilon_{2} \mathrm{k}_{3 \mathrm{z}}\right) /\left(\varepsilon_{3} \mathrm{k}_{2 \mathrm{z}}+\varepsilon_{2} \mathrm{k}_{3 \mathrm{z}}\right)
$$

The change of phase over thickness $h$ of layer 2 is

$$
\varphi=(\omega / \mathrm{c}) h \sqrt{ }\left(\varepsilon_{2}-\varepsilon_{1} \sin ^{2} \theta_{0}\right)
$$

where $\theta_{0}$ is the angle of incidence. In (2) and (3)

$$
\begin{aligned}
& \mathrm{k}_{0 z}=(\omega / \mathrm{c}) \sqrt{ } \varepsilon_{1} \cos \theta_{0} \\
& \mathrm{k}_{2 \mathrm{z}}=(\omega / \mathrm{c}) \sqrt{ }\left(\varepsilon_{2}-\varepsilon_{1} \sin ^{2} \theta_{0}\right)=\varphi_{.} / h \\
& \mathrm{k}_{3 \mathrm{z}}=(\omega / \mathrm{c}) \sqrt{ }\left(\varepsilon_{3}-\varepsilon_{1} \sin ^{2} \theta_{0}\right)
\end{aligned}
$$

Because the metal permittivity $\varepsilon_{2}=\varepsilon_{2}{ }^{\prime}+i \varepsilon_{2}{ }^{\prime}$ is complex, $\mathrm{k}_{2 \mathrm{z}}$ and $\varphi$ are complex, and consequently so are $r_{12}, r_{23}$, and $r$. The reflection coefficient is $\mathrm{R}=\mathrm{rr}^{*}$, which can be plotted as a function of $\theta_{0}$. In our Kretschmann experiment, medium 1 is glass, medium 2 is solid metal or gold black, and medium 3 is air.

Theoretical calculations are completed for SPP resonances (using eqs. 4-10) of a $45 \mathrm{~nm}$ thick gold film on a 1.52 refractive index prism in the Kretschman (fig. 5) using empirical permittivity values. ${ }^{7}$ Simulations require knowledge of film thickness and the complex permittivity as a function of wavelength. Sharpening resonance and shifting to maximum reflected angle is seen as you go to higher wavelengths. At $700 \mathrm{~nm}$, the FWHM is $\sim 1$ degree. Observing experimental SPP resonances at higher wavelengths that visible require the high precision of a stepper motor for the goniometer (to be discussed later). Fig. 6 presents simulations for various thicknesses of gold films at a wavelength of 600 $\mathrm{nm}$. For very thin films, resonances are broad and do not reach as high of reflectance after the resonance. Not until $\sim 40 \mathrm{~nm}$ (or even $50 \mathrm{~nm}$ ) thickness do you see any type of sharp resonance. 


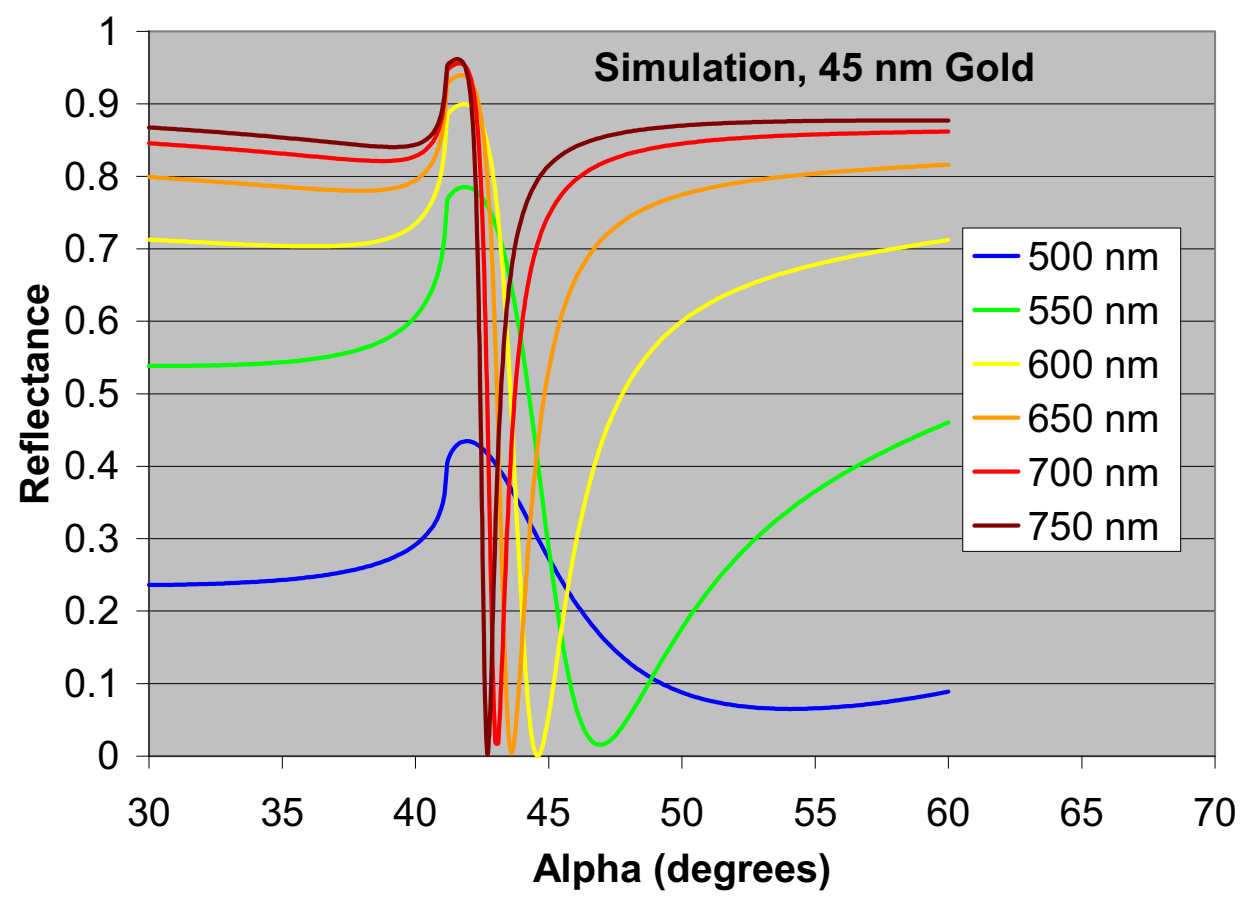

Fig. 5. Theoretical SPP resonances for a $45 \mathrm{~nm}$ thick gold film on a 1.52 refractive index prism as the wavelength is varied.

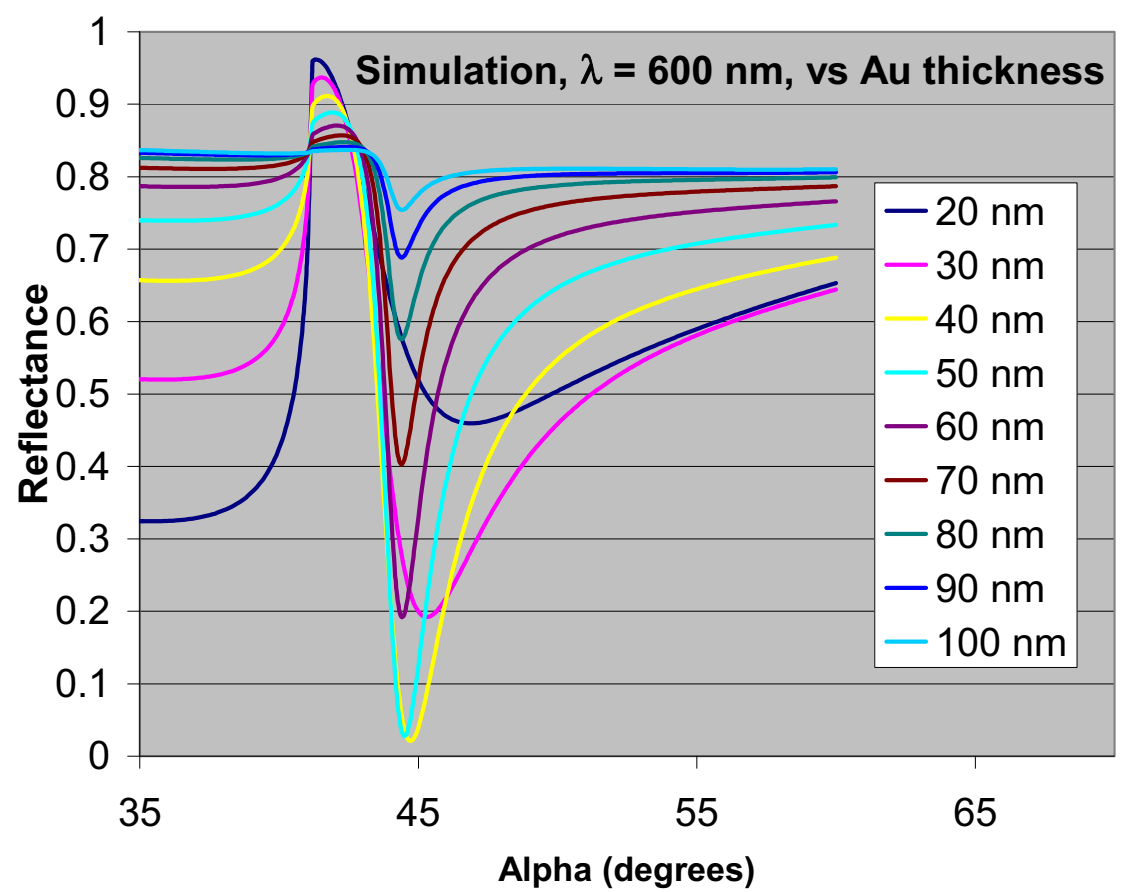

Fig. 6. Theoretical SPP resonances for a wavelength of $600 \mathrm{~nm}$ with a 1.52 refractive index prism as the film thickness is varied.

Preliminary data has been collected using a sophisticated set-up (fig. 7) in conjunction with a prism with a $45 \mathrm{~nm}$ thick layer of gold deposited. Glass substrates with deposited 
gold black films are placed on the back of a prism and the reflectance from the metal film as a function of angle of incidence is measured for a particular wavelength. A high precision stepper-driven goniometer will be used to keep the detector aligned with the reflected optical beam as the prism is rotated with respect to the incident beam. The source will be a high intensity Xe arc lamp used in conjunction with a monochromator (at the University of Central Florida), or Argon and Helium-Neon lasers (at Pacific Northwest National Labs). The chopped reflected signal will be detected by a photomultiplier tube (UCF) or by Si diode (PNNL) and synchronously amplified. A Labview program has been design to control the stepper-motor and simultaneously read the amplified data in real time. The data from the Kretchmann method are in reasonable agreement with values calculated from published empirical permittivity data. The data collected based on the gold film and coressponding real part of the surface plasmon wavevector are presented in figure 8. Experimental data for $45 \mathrm{~nm}$ of gold (fig. 8) follow the general trend of calculated SPP resonances of the same thickness and material (fig.5). Calculations of the real part of the wavevector (by eq.2) follow also calculations using empirical permittivty values $^{7}$ (by eq. 1 ) as seen also in fig. 8 .
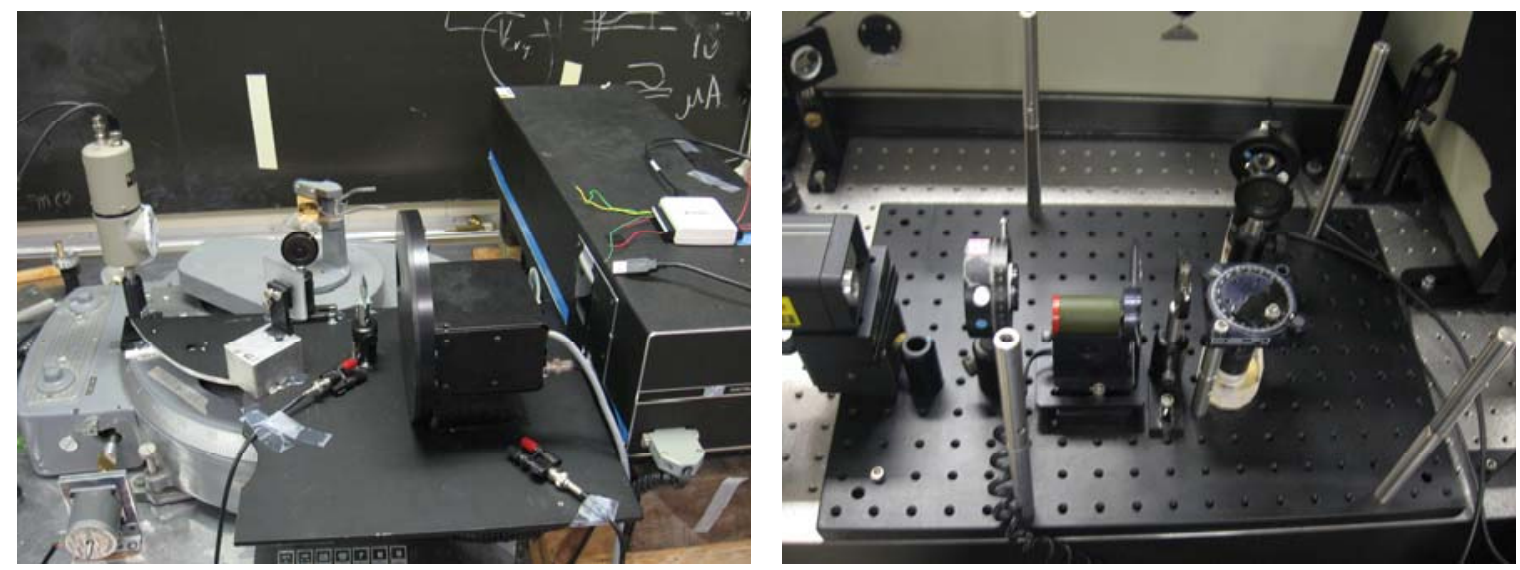

Fig. 7. Setup used for early SPP experiments. (left) Pictured is the goniometer setup used at UCF. On the right had side is a monochromator with a sheet polarizer attached at the output. The beam is chopped and then reflected to the sample (center). The sample reflects the beam to the photomultiplier tube (detector pictured on the far left). Also pictured in the bottom left-hand corner is the motor soon to be used to reach angular precision of up to $1 / 200$ of a degree and on the far-right the labview daq devise used to record data and control the motor. (right) Pictured is the goniometer setup used at PNNL. Laser source originates from the left, passing through a prism polarizer and chopper. An optics dial is used as the goniometer (right) and is manually rotated along with the silicon detector (top). 

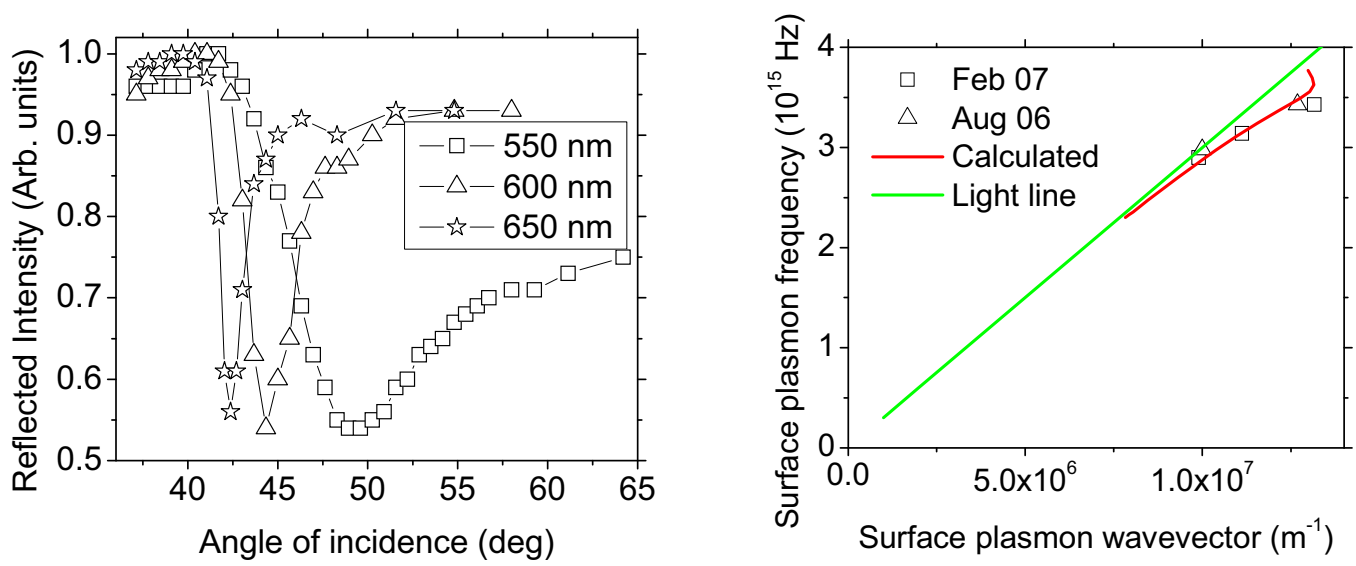

Fig. 8. (left) Surface Plasmon Polariton absorption resonances from Kretschman experiment on smooth gold surface. (right) Surface Plasmon Polariton dispersion curve for smooth gold surface. The open squares are calculated values from published empirical complex permittivity. The solid symbols represent two sets of data collected by the Kretchmann method using a Xe arc lamp and monochromator.

Preliminary data has also been collected with two different gold samples evaporated onto glass slides using a helium-neon laser with each sample mounted to the back of a BK7 prism with glycerine. The thick gold layer is observed to have a narrow resonance while the thin gold layer has a very broad resonance. The thin gold sample is very transparent and is most likely no more than $20 \mathrm{~nm}$ thick. The thick gold sample (data seen in fig. 9) is as reflective as the $45 \mathrm{~nm}$ gold film evaporated on the prism. In comparison with theoretical results at $600 \mathrm{~nm}$ (fig. 6.), thicknesses of $60-70 \mathrm{~nm}$ and less than $20 \mathrm{~nm}$ can be estimated for the thick and thin samples respectively which could be very possibly close to the actual thickness. The data are normalized to the highest reflection value measured so comparisons between R-values cannot be made.

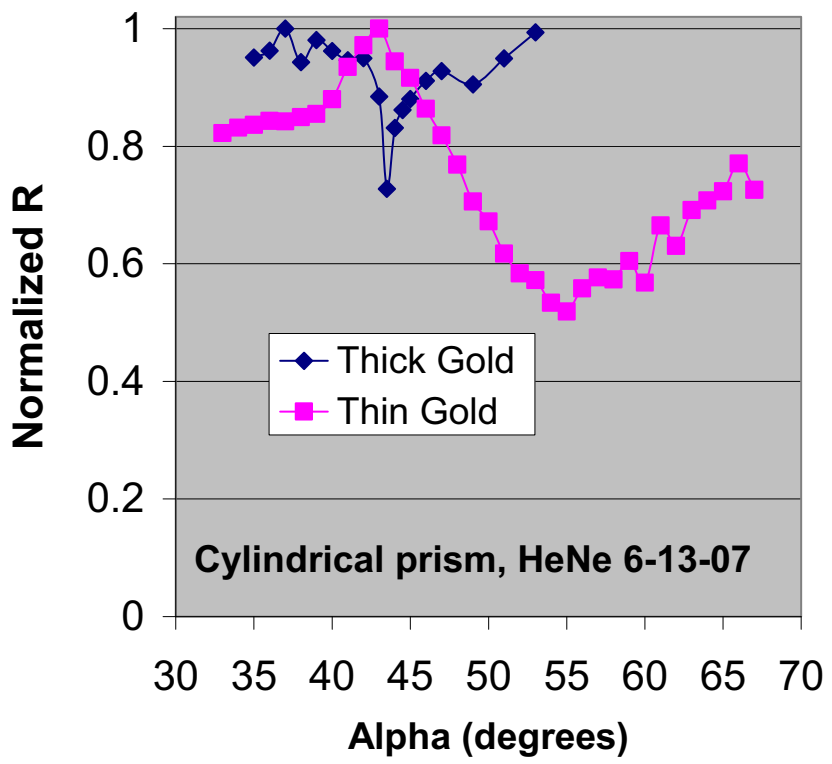

Fig. 9. SPP data collected for a thick and thin gold samples evaporated onto glass slides and mounted onto the same BK7 prism with glycerine. A helium-neon laser was used as a source. 
Data has also been collected on an early gold black sample. Visibly, the gold black coating was dark although uneven. Two different, but visually identical spots were studied. Fig.10 (left) shows a double resonance with peaks at approximately 49 and 53 degrees. The double resonance angles could indicate two distinct film thicknesses regions at the point the light was incident onto the sample. Fig. 10 (right) shows a sharper single resonance at 47 degrees. The narrow resonance of this figure (compared to fig. 10 left) indicates the sample is much thicker at the $2^{\text {nd }}$ spot than the $1^{\text {st }}$ spot. Future work will depend greatly on depositing films with a thickness even to the order of $1 \mathrm{~nm}$ or better.

The effect of sample morphology is revealed by the change in the angular position of the SPP excitation peak and its line shape. The effect of the nanostructure of the gold is to broaden and shift the resonance peak. The SPP resonance spectrum for a gold-black sample in fig. 10 contains a line shape that is clearly wider and the peak occurs at a larger angle than for corresponding optical frequency on smooth gold film (fig. 8-9).
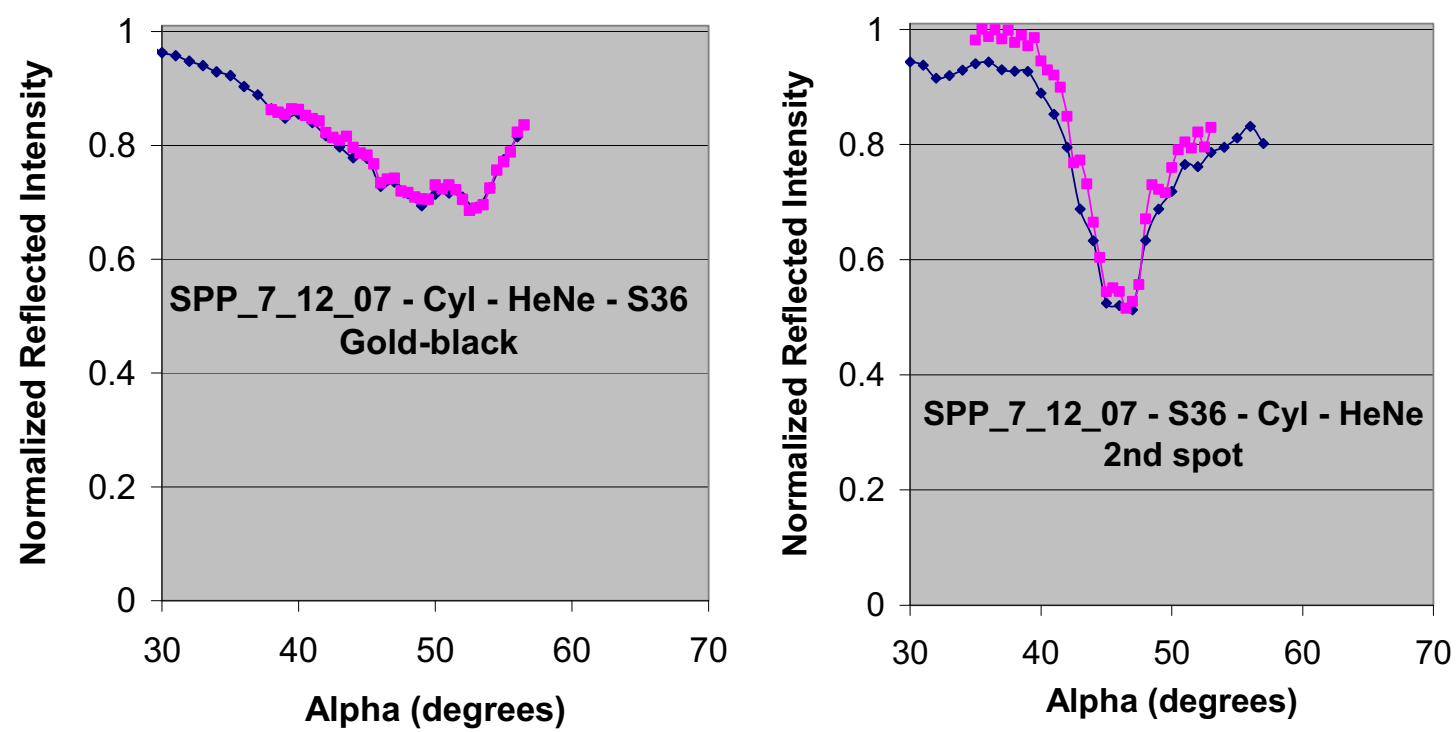

Fig. 10. SPP reflectivity data for gold black evaporated onto a glass slide. The different colored curves are multiple data sets of the same spot on the sample. The deposition was completed with 1 Torr of nitrogen gas in the bell chamber, using only the mechanical pump and no cooling. Note that different spots on the same non-uniform sample give very different resonance line shapes and positions, supporting our hypothesis that SPP spectroscopy is sensitive to film condition.

All current work on gold and gold black films has been in the visible which serves the purpose of experimentation and practice in analysis. Our goal is to also use this method to measure the complex wavevector and permittivity of gold black films in the mid and nearIR. Effort will be made to extend the technique to the longer wavelength region of interest using Alkali Halide prisms and a $\mathrm{CO}_{2}$ laser source provided by AFRL. 
PNNL-17069

\section{Modeling the Permittivity}

A Mathematica program was written to calculate the reflectance $R$ vs. angle of incidence using eqs. 4-10 and use empirical data to complete a two parameter or more least squares fit. Fig. 11 shows the output of the mathematica findfit feature using recent data collected with a gold-coated prism at $650 \mathrm{~nm}$. The nominal prism index was 1.48 and the gold thickness was $50 \mathrm{~nm}$ while the complex permittivity used was $\varepsilon=-11.6+\mathrm{i} 1.2 .^{7}$ The Mathematica code gives a two-parameter fit. The parameter values are satisfyingly close to the nominal values. That the data reaches unity is an artifact of the normalization, which will be corrected in future experiments by measuring a 100\% reflectance reference point. With this correction, and a wider range of angles in the data, the fit may improve. This tool will be able to accurately determine the refractive index of any prism that is used and thickness of gold films (or other films where the complex permittivity is known). For gold black samples with film thickness and the prism refractive index accurately known, a two-parameter fit can easily be used in the same manner to derive the complex permittivity of the film. A three parameter least squares fit will also be able to determine the thickness of the film if unknown (along with the real and imaginary parts of the permittivity). The Fresnel equations (eqs. 4-10) determine every feature of the angular reflectance, including the parts of the curve not belonging to the resonance. This will be a powerful tool in allowing quick and accurate measurements of the complex permittivity and thickness of the gold black films.

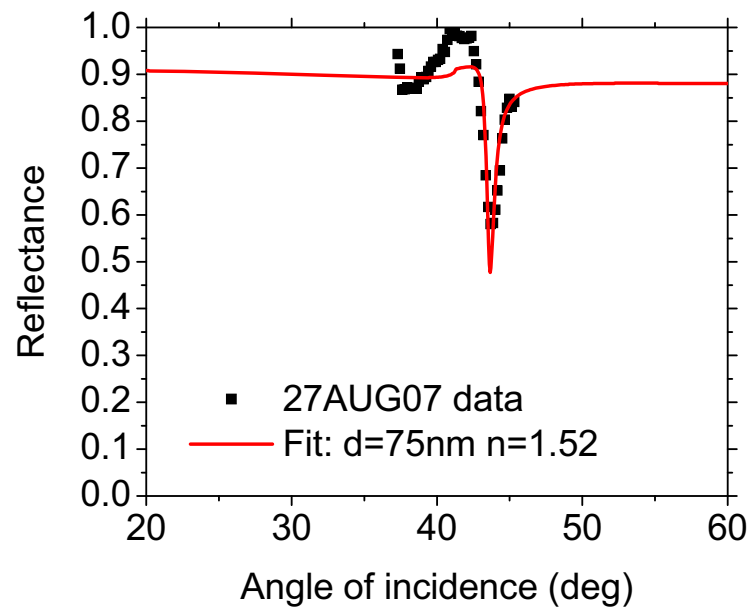

Fig. 11. Two-parameter Mathematica fit to an SPP data set using a gold-coated prism. The fit determines the refractive index of the prism and the thickness of the gold film. Errors occur because the data has been normalized so that the maximum value is unity but will be normalized to a maximum reflectance measurement in the future. This same method will be the main method to calculate the complex permittivity of gold black films. 
Other modeling theories still need to be researched for this project (effective medium theory, Maxwell-Garnett, etc).

\section{Summary}

Gold black is being created by thin film deposition techniques inside a bell chamber with $\sim 1$ torr of ambient gas. The films are being created for high absorption in the IR. A two level full factorial scheme is being used currently for this optimization process. The samples are characterized by weight measurements and SEM (to determine the morphology of the film). Surface Plasmon resonances are used to calculate the real part of the surface plasmon wavevector currently and could be used calculate the complex part in the future. This will allow measurements of the complex permittivity to be made of gold black samples. Mathematica 3 parameter fits of SPP data will be used to also estimate the complex permittivy and the film thickness at the same time. Theoretical modeling of the permittivity of gold black films still needs to be investigated to compare with empirical results.

\section{References}

1. A. H., Pfund, "Bismuth and its applications," Rev. Sci. Instrum. 1, 397-399 (1930).

2. A. H., Pfund, "The optical properties of metallic and crystalline powders," J. Opt. Soc. Am. 23, 375-378 (1933).

3. M. A. Ordal, R. J. Bell, R. W. Alexander, Jr., L. L. Long, and M. R. Querry, "Optical properties of fourteen metals in the infrared and far infrared: $\mathrm{Al}, \mathrm{Co}, \mathrm{Cu}$, Au, Fe, Pb, Mo, Ni, Pd, Pt, Ag, Ti, V, and W," Appl. Optics 24, 4493 (1985).

4. J. T. van Wijngaarden, E. Verhagen, A. Polman, C. E. Ross, H. J. Lezec, and H. A. Atwater, "Direct imaging of propagation and damping of near-resonance surface Plasmon polaritons using cathodoluminescence spectroscopy," Appl. Phys. Lett. 88, 221111 (2006).

5. A. Otto, "Excitation of nonradiative surface plasma waves in silver by the method of frustrated total reflection," Z. Physik 216, 398 (1968).

6. E. Kretschmann, "The determination of the optical constants of metals by excitation of surface plasmons," Z. Physik 241, 313 (1971).

7. H. Raether, "Surface Plasmons on Smooth and Rough Surfaces and on Gratings," Springer Tracts in Modern Physics, 111 (Springer, Berlin, 1986). 


\title{
Theoretical Investigation of Lanthanide(III) $\beta$-diketonates with $p, p$ '- disubstituted bipyridine and phenanthroline type ligands
}

\author{
Channa R. De Silva ${ }^{\mathrm{a}}$, Jun Li ${ }^{\mathrm{b}, *}$, L. René Corrales ${ }^{\mathrm{a}, *}$ \\ ${ }^{a}$ Department of Materials Science and Engineering, University of Arizona, Tucson, AZ 85721 \\ ${ }^{\mathrm{b}}$ W. R. Wiley Environmental Molecular Sciences Laboratory, Pacific Northwest National \\ Laboratory, Richland WA 99352
}

\section{Background and Significance}

Developing and understanding the properties of novel lanthanide complexes used as luminescence components in light emitting devices, bio-immunoassays, and chemical sensors is an exciting and an active area of research.(You et al.; Richardson; Bunzli) A key advantage of lanthanide-centered luminescence complexes lies in their unique energy transfer mechanism where the lanthanide emitting states are populated by energy transfer from the ligand triplet states, which themselves are populated via intersystem crossing from the ligand singlet states.(Kido and Okamoto) Several factors influence the luminescence quantum yield of a particular lanthanide complex that includes the relative singlet and triplet energy levels of the coordinated ligands, the coupling of those ligand energy levels to the emissive state(s) of the lanthanide ion and ligand- and solvent-based vibrational coupling that play a major role in expressing the lanthanide-based luminescence.(de Bettencourt-Dias) Thus, the usefulness of such materials depends critically on their molecular and electronic structures. 
PNNL-17069

Recent quests for novel lanthanide complexes has lead to the design and synthesis of several $\mathrm{Eu}(\mathrm{III})$ and $\mathrm{Tb}(\mathrm{III}) \beta$-diketonate complexes with carefully chosen Lewis-base neutral ligands, specifically $p, p^{\prime}$-disubstituted bipyridine and phenanthroline (Figure 1).(De Silva et al.) UV excitation of these complexes leads to red and green luminescence characteristics of $\mathrm{Eu}(\mathrm{III})$ and $\mathrm{Tb}(\mathrm{III})$ ions, respectively, with impressive quantum yields.

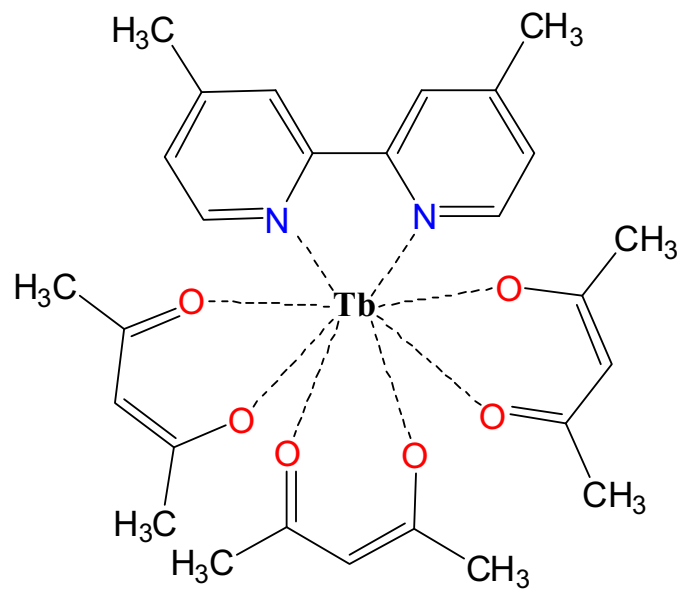

Figure 1. Molecular structure of a $\mathrm{Tb} \beta$-diketonate complex as an example, $\mathrm{Tb}(\mathrm{acac})_{3}(\mathrm{dmdp}):$ acac $=2,4$-pentanedione; $\mathrm{dmdp}=4,4$ '-dimethyl-2,2' '-dipyridyl

However, there is practically no theoretical guidance for the synthesis of lanthanide complexes with improved luminescent properties. Through investigation of existing lanthanide complexes with luminescent properties using state-of-the-art computational chemistry methodologies, important insight on designing efficient energy transfer ligands and highly luminescent lanthanide complexes can be obtained. The purpose of this work is to obtain valuable information regarding the changes in quantum yields observed among these lanthanide complexes composed of different ligand combinations. Few theoretical studies of small lanthanide complexes exist due to the 
PNNL-17069

complexity arising from the high coordination number of the lanthanide center and the larger number of unpaired $f$-electrons present in these systems.(Aiga, Iwanaga and Amano; Guillaumont et al.; Maron and Eisenstein) Therefore it is essential to have both the expertise and the computational resources to do such higher level of calculations. Pacific Northwest National Lab (PNNL) is an ideal environment for this research work due to the availability of the scientific knowledge, the high performance computational capabilities, and that the project fits well within an existing grand challenge program at the MSCF. As a first step to achieving above mentioned goals, theoretical quantum mechanical calculations of $\mathrm{Tb}(\mathrm{acac})_{3}(\mathrm{dmdp})$ were carried out to gain a better understanding of the electronic structure-property relationship and the efficiency of energy transfer processes towards lanthanide emission.

\section{Computational Methods}

All calculations were performed at the level of density functional theory (DFT) using the NWChem(Bylaska) package developed at PNNL. The hybrid B3LYP exchange correlation functional was employed.(Becke; Lee, Yang and Parr) The energy-consistence relativistic effective core potentials (RECPs) developed by the Stuttgart-Dresden group(Dolg, Stoll et al.; Dolg, Stoll et al.; Dolg, Fulde et al.) were used for Tb(III) center. The small-core and large-core RECPs were both used for comparison, where all the electrons on $(4 s 4 p 4 d 4 f, 5 s 5 p 5 d, 6 s 6 p)$ orbitals are explicitly treated in the valence shell in the small-core calculations, while in the large-core calculations the electrons on the $(4 \mathrm{~s} 4 \mathrm{p} 4 \mathrm{~d} 4 \mathrm{f})$ orbitals were all included in the effective core. The RECPs for Tb(III) were used with their optimized valence basis sets supplemented by polarization functions. A 
PNNL-17069

modified version of the NWChem was used for the calculations using large-core RECPs. Standard 6-31G* and 6-311+G* Gaussian basis functions were employed for $\mathrm{C}, \mathrm{H}, \mathrm{N}$, and $\mathrm{O}$ atoms. All these calculations were performed on the massively parallelized computer mpp2 at the Molecular Science Computing Facility located at the Environmental Molecular Science Laboratory, PNNL. The graphical molecular structures and the orbital plots were generated using ECCE (extensible computational chemistry environment) developed at PNNL.

Geometry optimization of the terbium complexes were carried out without symmetry constraints. The excitation energies and the oscillator strengths at the optimized ground state geometries were obtained by time-dependent density functional theory (TDDFT) calculations implemented in NWChem 5.0.

\section{Results and Discussion}

The initial atomic coordinates for the geometry optimization of $\mathrm{Tb}(\mathrm{acac})_{3}(\mathrm{dmdp})$ were generated with a manual built structure and the corresponding X-ray structural coordinates. Two independent calculations were carried out using these two sets of initial coordinates and the optimized structural parameters are very similar to each other.

The calculated geometries of $\mathrm{Tb}(\mathrm{acac})_{3}(\mathrm{dmdp})$ using large- and small-core RECPs were compared to our experimental X-ray crystal structure (Figure 2). In all structures, the coordination sphere consists of six oxygen atoms (from three acac ligands) and two nitrogen atoms (from dmdp ligand) forming an octacoordinated square anti-prism 
geometry. The coordination spheres of the calculated structures resemble that of the experimental structure.

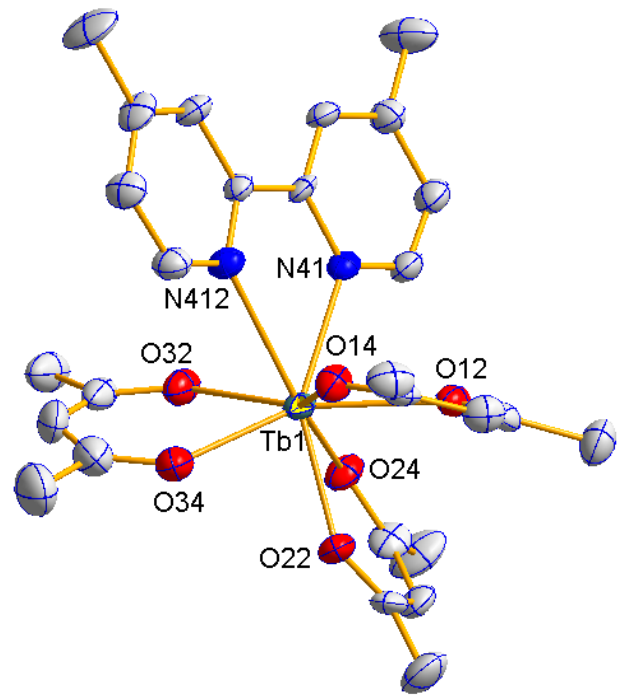

(A)
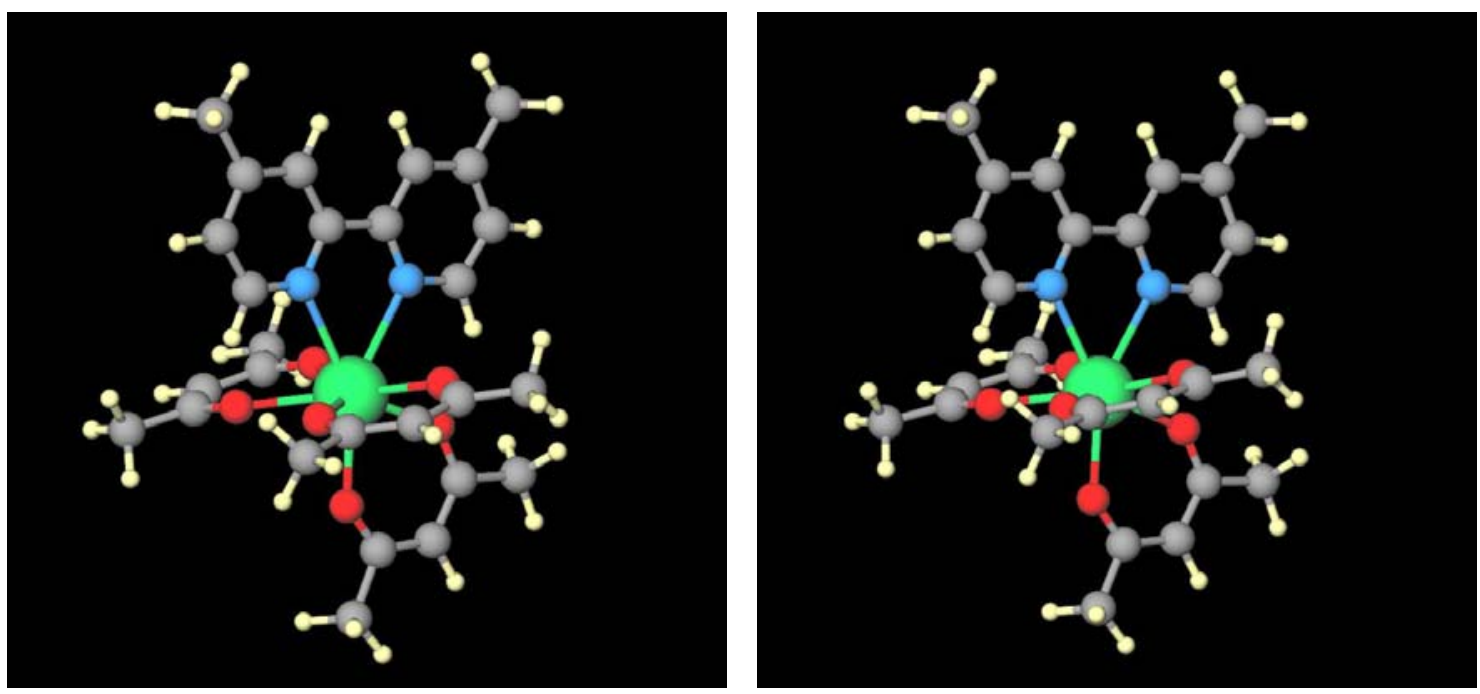

(B)

(C) 
Figure 2. (A) X-ray crystal structure of $\mathrm{Tb}(\mathrm{acac})_{3}(\mathrm{dmdp})$; (Unpublished Results; De Silva C.R. and Zheng, Z. Department of Chemistry, University of Arizona); Optimized molecular geometries using (B) small-core RECPs (Stuttgart 1997) and (C) large-core RECPs (ECP54MWB)

The calculated $\mathrm{Tb}$-ligand bond distances are listed in Table 1 along with the corresponding experimental X-ray structural data. The calculated $\mathrm{Tb}-\mathrm{O}$ bond distances using both small- and large-core RECPs are comparable to the experimental values and are well agreed upon each other. The calculated $\mathrm{Tb}-\mathrm{O}$ bond distance using large-core RECPs $(2.365 \AA)$ and small-core RECPs $(2.344 \AA)$ changes by $0.02 \AA$ and $0.001 \AA$ from the experimental value $(2.345 \AA)$, respectively. However the calculated $\mathrm{Tb}-\mathrm{N}$ bond distances are over estimated by about $0.1 \AA$ in both cases due to the relatively small basis sets used. The experimental average $\mathrm{Tb}-\mathrm{N}$ bond distance is $2.568 \AA$ whereas the calculated values with small- and large-core RECPs are $2.681 \AA$ and $2.648 \AA$, respectively.

Table 1. Experimental and calculated bond lengths of $\mathrm{Tb}(\mathrm{acac})_{3}(\mathrm{dmdp})$

\begin{tabular}{cccc}
\hline & & ECP54MWB & Stuttgart 1997 \\
& & (Large-core) & (Small-core) \\
Bond Label & 2.347 & $6-31 \mathrm{G}^{*}$ & $6-31 \mathrm{G}^{*}$ \\
\hline $\mathrm{Tb}-\mathrm{O}(4)$ & 2.314 & 2.382 & 2.342 \\
$\mathrm{~Tb}-\mathrm{O}(3)$ & 2.318 & 2.314 & 2.358 \\
$\mathrm{~Tb}-\mathrm{O}(2)$ & 2.371 & 2.341 & 2.314 \\
$\mathrm{~Tb}-\mathrm{O}(1)$ & 2.387 & 2.353
\end{tabular}


PNNL-17069

$\begin{array}{cccc}\mathrm{Tb}-\mathrm{O}(5) & 2.386 & 2.383 & 2.341 \\ \mathrm{~Tb}-\mathrm{O}(6) & 2.332 & 2.387 & 2.358 \\ \mathrm{~Tb}-\mathrm{N}(44) & 2.578 & 2.678 & 2.647 \\ \mathrm{~Tb}-\mathrm{N}(43) & 2.557 & 2.684 & 2.649\end{array}$

The closeness of the calculated bond distances with small- and large-core RECPs suggest that the $4 f$ electrons do not participate in the $\mathrm{Tb}-\mathrm{O}$ and $\mathrm{Tb}-\mathrm{N}$ bonding as has previously been shown for Ln-N bonding using smaller lanthanide model complexes $\left[\mathrm{Ln}\left(\mathrm{NH}_{2}\right)_{3}\right.$; where $\left.\mathrm{Ln}=\mathrm{La}-\mathrm{Lu}\right]$.(Maron and Eisenstein) Our calculations further support this idea by comparing these values to the experimental X-ray crystallographic data. Calculated $\mathrm{Tb}-\mathrm{O}$ bond distances with small core RECPs are slightly shorter $(0.02-0.04$ $\AA$ ) than those with large core RECPs. A similar behavior has been observed for the Tb-N bond distances by us and the others. This indicates the requirement of future research to improve the large core RECPs for a better treatment of the core-valence correlation.

TDDFT calculations of $\mathrm{Tb}(\mathrm{acac})_{3}(\mathrm{dmdp})$ using initially optimized ground state geometries were performed with different levels of theory. Different experimental conditions were used to determine the most suitable model for the systems of interest (lanthanide complexes with three $\beta$-diketonate ligands and a bipyridine type neutral ligand) and to test its reliability for future analysis of analogous complexes. It is well known that the energy absorption of these complexes occur via the transitions mainly involving ligand system.(Kido and Okamoto) Therefore TDDFT calculations were performed using large-core RECPs in order to evaluate the excited states for ligand excitations. 
PNNL-17069

The calculated singlet excitation energy levels, their oscillator strengths and the corresponding experimental values are shown in Table 2. The experimental absorption maxima obtained using the UV-Vis spectroscopy compares well with the calculated singlet exited energy levels applying B3LYP exchange-correlation functional and the 6$311+\mathrm{G}^{*}$ basis set.

To interpret the evolution of absorption bands, Kohn-Sham orbitals of $\mathrm{Tb}(\mathrm{acac})_{3}(\mathrm{dmdp})$ were analyzed (Figure 3$)$. The highest occupied molecular orbital (HOMO) mainly involves the negatively charged acac ligand whereas the lowest unoccupied molecular orbital (LUMO) has major contribution from the nitrogen donor neutral ligand (dmdp).

Table 2. Experimental and calculated singlet energy levels of $\mathrm{Tb}(\mathrm{acac})_{3}(\mathrm{dmdp})$

\begin{tabular}{|c|c|c|c|c|}
\hline $\begin{array}{c}\text { Singlet }[\exp ] \\
(\mathrm{nm})\end{array}$ & XC Function & Basis Set & $\begin{array}{c}\text { Singlet [calc] } \\
(\mathrm{nm})\end{array}$ & $\begin{array}{l}\text { Oscillator } \\
\text { Strength }\end{array}$ \\
\hline 283 & B3LYP & 6-31G* & 273 & 0.126 \\
\hline \multirow[t]{5}{*}{251} & & & 250 & 0.208 \\
\hline & B3LYP & $6-311+\mathrm{G}^{*}$ & 284 & 0.107 \\
\hline & & & 250 & 0.319 \\
\hline & PBE0 & $6-311+\mathrm{G}^{*}$ & 276 & 0.119 \\
\hline & & & 249 & 0.419 \\
\hline
\end{tabular}




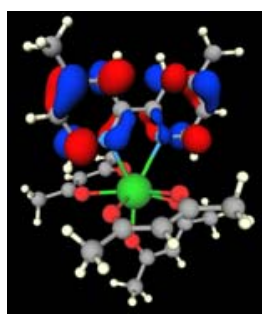

$\mathrm{LUMO}+1$

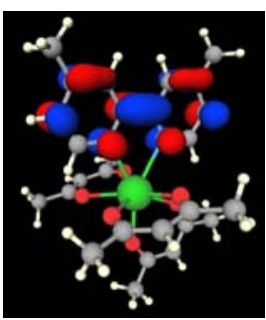

LUMO

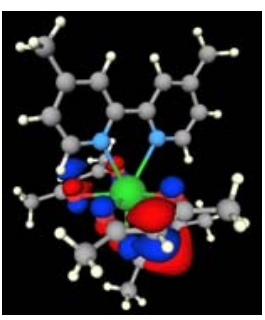

HOMO

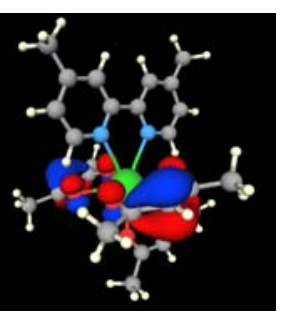

HOMO - 1

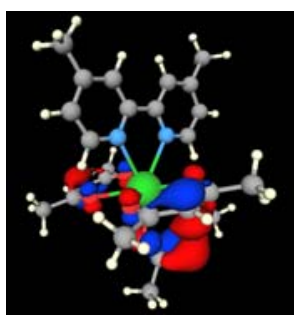

HOMO - 2

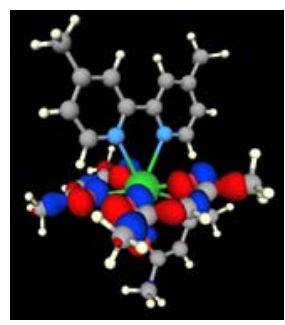

HOMO - 3

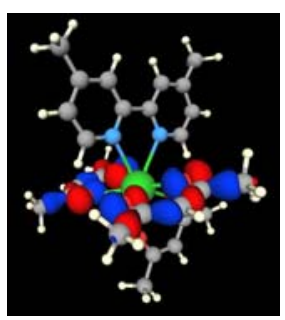

HOMO - 4

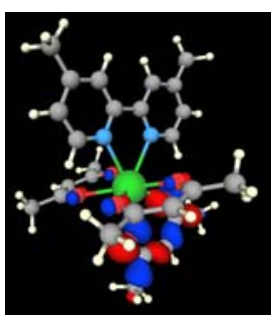

HOMO - 5

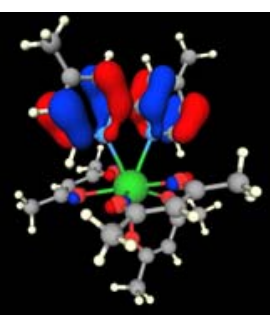

HOMO - 6

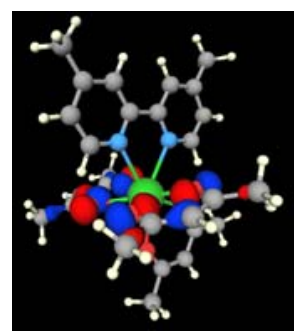

HOMO - 7

Figure 3. 3D isosurfaces of the frontier Kahn-Sham molecular orbitals of $\mathrm{Tb}(\mathrm{acac})_{3}(\mathrm{dmdp})$

The computational results agree with the primary features in the UV-Vis spectrum. The exited state responsible for the maximum absorption can be characterized by two primary transitions; (1) a $\pi$ (HOMO - 6) to $\pi^{*}$ (LUMO) transition within the dmdp neutral 
PNNL-17069

ligand, and (2) a charge transfer type transition from acac (HOMO - 7) ligand to dmdp (LUMO) ligand. Therefore both acac and dmdp ligands are equally important for the energy absorption in $\mathrm{Tb}(\mathrm{acac})_{3}(\mathrm{dmdp})$.

The dependence of the $\mathrm{Tb}(\mathrm{III})$ luminescence quantum yield of $\mathrm{Tb}$-complexes on the triplet state energies is experimentally well documented.(Latva et al.) It is of our interest to theoretically probe the triplet energy levels of such complexes in order to make comparisons and predictions among different lanthanide-ligand systems. As a first step to these goals we have calculated the lowest triplet energy levels of $\mathrm{Tb}(\mathrm{acac})_{3}(\mathrm{dmdp})$ using two different basis sets (Table 3). No significance change in the lowest triplet state energy was observed using $6-31 \mathrm{G}^{*}$ and $6311+\mathrm{G}^{*}$ basis sets. The lowest triple state of $\mathrm{Tb}(\mathrm{acac})_{3}(\mathrm{dmdp})$ can be mainly described by the HOMO and LUMO orbitals. The low quantum yield of the title complex $(0.035)$ may be a result of the relatively low triplet energy level $\left(22582 \mathrm{~cm}^{-1}\right)$ of the complex compared to its ${ }^{5} \mathrm{D}_{4} \mathrm{~Tb}(\mathrm{III})$-emissive state energy $\left(20400 \mathrm{~cm}^{-1}\right)$. This observation is consistence with the fact that experimentally observed quantum yields of Tb-complexes having the lowest triplet level below $22300 \mathrm{~cm}^{-}$ ${ }^{1}$, were much lower due to a back energy transfer from the excited ${ }^{5} \mathrm{D}_{4} \mathrm{~Tb}(\mathrm{III})$ level to the ligand triplet energy level.(Latva et al.) The opportunity provided by this program has initiated a strong collaboration between PNNL and the University of Arizona to further the theoretical study of a series of $\mathrm{Tb} \beta$-diketonate complexes. 
Table 3. Calculated lowest triplet energy level of $\mathrm{Tb}(\mathrm{acac})_{3}(\mathrm{dmdp})$ with different basis sets $\left({ }^{5} \mathrm{D}_{4}\right.$ of $\left.\mathrm{Tb}(\mathrm{III})=20400 \mathrm{~cm}^{-1}\right)$

\begin{tabular}{ccc}
\hline Basis set & Triplet Energy $\left(\mathrm{cm}^{-1}\right)$ & ${ }^{5} \mathrm{D}_{4}-\mathrm{T}\left(\mathrm{cm}^{-1}\right)$ \\
\hline $6-31 \mathrm{G}^{*}$ & 22666.47 & 2266.47 \\
$6311+\mathrm{G}^{*}$ & 22582.11 & 2182.11 \\
\hline
\end{tabular}

\section{References}

1. You, H.; Fang, J.; Xuan, Y.; Ma, D. Mater. Sci. Eng. 2006, B131, 252.

2. Richardson, F. S. Chem. rev. 1982, 82, 541.

3. Bunzli, J. G. Acc. Chem. Res. 2006, 39, 53.

4. Kido, J.; Okamoto, Y. Chem. rev. 2002, 102, 2357.

5. de Bettencourt-Dias, A. Dalton Trans. 2007, 22, 2229.

6. De Silva, C. R.; Maeyer, J. R.; Wang, R.; Nichol, G. S.; Zheng, Z. Inorg. Chim. Acta 2007, 360, 3543.

7. Aiga, F.; Iwanaga, H.; Amano, A. J. Phys. Chem. A 2005, 109, 11312.

8. Guillaumont, D.; Bazin, H.; Benech, J.; Boyer, M.; Mathis, G. Chem. Phys. Chem. 2007, 8, 480.

9. Maron, L.; Eisenstein, O. J. Phys. Chem. A 2000, 104, 7140.

10. Bylaska, E. J., et al, NWChem, A Computational Chemistry Package for Parallel Computers. Pacific Northwest National Laboratory: Richland, WA, 2006; Vol. version 5.0.

11. Becke, A. D. J. Chem. Phys. 1993, 98, 5648.

12. Lee, C.; Yang, W.; Parr, R. G. Phys. Rev. B 1988, 37, 785.

13. Dolg, M.; Stoll, H.; Savin, A.; Preuss, H. Theor. Chim. Acta 1989, 75, 173.

14. Dolg, M.; Stoll, H.; Savin, A.; Preuss, H. Theor. Chim. Acta 1993, 85, 441.

15. Dolg, M.; Fulde, P.; Kuechle, W.; Neumann, C. S.; Stoll, H. I. Chem. Phys. 1991, 94, 3011 .

16. Latva, M.; Takalo, H.; Mukkala, V.; Matachescu, C.; Rodriguez-Ubis, J.; Kankare, J. J. Luminescence 1997, 75, 149. 
PNNL-17069 
PNNL-17069

\title{
Many-Body Decomposition of the Binding Energies for $\mathrm{OH} \cdot\left(\mathrm{H}_{2} \mathrm{O}\right)_{2}$ and $\mathrm{OH} \cdot\left(\mathrm{H}_{2} \mathrm{O}\right)_{3}$ Complexes
}

\author{
Shiyu Du and Joseph S. Francisco \\ Department of Chemistry and Department of Earth and Atmospheric Sciences, Purdue \\ University, West Lafayette, IN 47907-1393 \\ Gregory K. Schenter and Bruce C. Garrett \\ Chemical \& Materials Sciences Division, Pacific Northwest National Laboratory, \\ Richland, WA 99352
}

\begin{abstract}
We use $a b$ initio electronic structure methods to calculate the many-body decomposition of the binding energies of the $\mathrm{OH} \cdot\left(\mathrm{H}_{2} \mathrm{O}\right)_{n}(\mathrm{n}=2,3)$ complexes. We employ MP2 and $\mathrm{CCSD}(\mathrm{T})$ levels of theory with aug-cc-pVDZ and aug-cc-pVTZ basis sets and analyze the significance of the non-pairwise interactions between $\mathrm{OH}$ radical and the surrounding water molecules. We also evaluate the accuracy of our newly developed potential function, the modified Thole-type model (mTTM), for predicting the many-body terms in these complexes. Our analysis of the many-body contributions to the $\mathrm{OH} \cdot\left(\mathrm{H}_{2} \mathrm{O}\right)_{n}$ binding energies clearly shows that they are just as important in the $\mathrm{OH}$ interactions with water as they are for interactions in pure water systems.
\end{abstract}




\section{Introduction}

The hydroxyl radical plays a central role in environmental systems(Seinfeld and Pandis; Wayne; FinlaysonPitts and Pitts; Stumm and Morgan) and in aqueous systems that are subjected to ionizing radiation, ${ }^{5}$ and is one of the most important free radical species in oxidative reactions.(Parsons) Water molecules significantly influence the properties and processes of free radicals. ${ }^{7-12}$ Complexes of $\mathrm{OH}$ with $\mathrm{H}_{2} \mathrm{O}$ have been the subject of many recent experimental ${ }^{13-17}$ and theoretical studies. ${ }^{18-23}$ The reactivity of $\mathrm{OH}$ in aqueous systems is influenced by the structure and energetics of solvation around the radical species and a detailed understanding of the effects of the open shell nature of $\mathrm{OH}$ on solvation structure is lacking. The present paper is a continuation of our previous work( $\mathrm{Du}$ et al.) towards understanding the details of OH-water interactions that control solvation structure, which in turn influences properties such as the absorption spectra and reactive processes. Our previous study focused on developing a detailed understanding of the interaction of $\mathrm{OH}$ with a single water molecule and the development of a new analytical potential function, the modified Thole-type model (mTTM), which is based on the Thole-type model for water-water interactions developed by Burnham, Xantheas and coworkers. ${ }^{24-27}$ In the present work we study interactions of $\mathrm{OH}$ with multiple water molecules and examine the importance of many-body effects in $\mathrm{OH}$-water interactions.

Electronic structure calculations of water clusters provide detailed information about structure and energetics of hydrogen-bonded clusters and there have been numerous studies performed for $\left(\mathrm{H}_{2} \mathrm{O}\right)_{n}$ complexes that have focused on the hydrogen-bonded structures and features of the potential energy surfaces for these clusters. ${ }^{25,28-}$ ${ }^{63}$ Decomposition of the binding energies of water clusters into the various $n$-body interactions has provided a detailed understanding of the importance of many-body interactions in water clusters, ${ }^{64-75}$ and this knowledge has been essential in developing accurate analytical representations of the water potential energy surface. ${ }^{24-}$ ${ }^{27,60,76-79}$ Electronic structure calculations have also been performed for $\mathrm{OH} \cdot\left(\mathrm{H}_{2} \mathrm{O}\right)_{\mathrm{n}}$ complexes, ${ }^{13,18-23,80-84}$ with the major focus of this body of work on determining the bound structures and their energetics. To date, no quantitative investigation of the many body effects for the $\mathrm{OH} \cdot\left(\mathrm{H}_{2} \mathrm{O}\right)_{\mathrm{n}}$ system has been performed, although the significance of many-body effects in $\left(\mathrm{H}_{2} \mathrm{O}\right)_{n}$ strongly suggests that non-pairwise additive interactions may also have important contribution in $\mathrm{OH} \cdot\left(\mathrm{H}_{2} \mathrm{O}\right)_{\mathrm{n}}$ complexes. In addition, the open-shell nature of the $\mathrm{OH}$ radical can also influence the many-body interactions and it is our goal to provide a better understanding of manybody effects in these types of systems. In the current study, we present our analysis of the decomposition of the interaction energy between the $\mathrm{OH}$ radical and water molecules and compare the magnitude with those in the $\left(\mathrm{H}_{2} \mathrm{O}\right)_{n}(\mathrm{n}=2,3)$ complexes reported in previous studies.

\section{Computational Method}

The calculations of the decomposition of the interaction energy are carried using Møller-Plesset perturbation theory(Møller and Plesset) through second order (MP2) and coupled cluster theory including single and double excitations with a perturbation estimation of the triple excitations $[\operatorname{CCSD}(\mathrm{T})] .{ }^{86,87} \mathrm{We}$ adopt the $\operatorname{CCSD}(\mathrm{T})$ level of theory because calculations have shown it to provide high accuracy in previous studies of water clusters and of the $\mathrm{OH} \cdot \mathrm{H}_{2} \mathrm{O}$ complex. ${ }^{17,21,22,25,44,59,63,88}$ We use the family of augmented correlationconsistent basis sets of double zeta quality (aug-cc-pVDZ) and triple zeta quality (aug-cc-pVTZ). ${ }^{89-91}$ In the 
past decade, the use of correlation consistent basis sets in combination with high-level ab initio methods like $\operatorname{CCSD}(\mathrm{T})$ has proven to be a powerful method in determining structures and energetics accurately for a variety of molecules.(Dunning) Because of limitations on sizes of the basis sets, we consider the basis set superposition error (BSSE)(Boys and Bernardi; Liu and McLean) when predicting many-body effects. ${ }^{48,64}$ The BSSE correction can be approximated by the well-known counterpoise method. ${ }^{93,95,96}$

In this work, the prediction of the energy decomposition is performed with the scheme introduced by Hankins et al. \{Hankins, $1970 \# 130\}$ and used in studies of water clusters. ${ }^{64-67}$ Our application of the scheme is similar to Hodges et al. \{Hodges, $1997 \# 20$ \} in which relaxation of the monomers is neglected. In this scheme the energy decomposition is expressed:

$$
E_{n}=\sum_{i=1}^{n} E(i)+\sum_{i=1}^{n-1} \sum_{j>i}^{n} \Delta^{2} E(i j)+\sum_{i=1}^{n-2} \sum_{j>i}^{n-1} \sum_{k>j}^{n} \Delta^{3} E(i j k)+\cdots \cdots
$$

where subscripts $i, j, k$ refer to different molecules in the cluster, $E(i)$ is the total energy of monomer $i$ with the same geometry as in the cluster, and the many body terms are given by

$$
\begin{aligned}
& \Delta^{2} E(i j)=E(i j)-[E(i)+E(j)] \\
& \Delta^{3} E(i j k)=E(i j k)-[E(i)+E(j)+E(k)]-\left[\Delta^{2} E(i j)+\Delta^{2} E(j k)+\Delta^{2} E(i k)\right]
\end{aligned}
$$

The total interaction (or binding) energy is the energy to separate the cluster into non-interacting monomers. As discussed in previous work on water clusters, ${ }^{64-67}$ this interaction energy should take into account relaxation of the monomers from their geometries in the complex to their equilibrium geometries in isolation. This previous work showed that relaxation energies are less than or equal to $1 \mathrm{kcal} / \mathrm{mol}$ in all the cases studied for the water clusters. Although these values are significant and required to accurately compute interaction energies, their neglect does not alter the qualitative understanding of the importance of many-body effects in these systems. In fact, these contributions to the binding energy are less than the changes in binding energies upon inclusion of BSSE corrections. In the current work, we are interested in a qualitative understanding the importance of many-body interactions in $\mathrm{OH}$-water clusters, therefore we neglect the relaxation energies and therefore the interactions energies can be expressed:

$$
\Delta E_{n}=\sum_{i=1}^{n-1} \sum_{j>i}^{n} \Delta^{2} E(i j)+\sum_{i=1}^{n-2} \sum_{j>i}^{n-1} \sum_{k>j}^{n} \Delta^{3} E(i j k)+\cdots \cdots
$$

All the energies are calculated at the complex's geometry and with full basis of the complex according to the counterpoise method. The calculations are performed by the Molpro 2002 program suite.(Werner et al.)

\section{Computational Results and Discussions}

We consider two fixed geometries for each of the $\mathrm{OH} \cdot\left(\mathrm{H}_{2} \mathrm{O}\right)_{2}$ and $\mathrm{OH} \cdot\left(\mathrm{H}_{2} \mathrm{O}\right)_{3}$ complexes. The geometries were chosen to facilitate comparisons of results for these clusters with those for $\left(\mathrm{H}_{2} \mathrm{O}\right)_{n}(n=3,4)$ clusters. The first geometries are cyclic structures in which the $\mathrm{OH}$ radical acts as both a proton acceptor and proton donor. The structures are shown in Figure 1 and are denoted $\mathrm{OH} \cdot\left(\mathrm{H}_{2} \mathrm{O}\right)_{2}\left(\mathrm{da}\right.$,da,da) and $\mathrm{OH} \cdot\left(\mathrm{H}_{2} \mathrm{O}\right)_{3}$ (da,da,da,da), where da 
indicates that the $\mathrm{OH}$ radical or a water molecule acts as both a proton donor and acceptor. The geometries for these structures are the same as those for water trimers and tetramers studied by Xantheas,(Xantheas) with the exception that one of the hydrogen atoms is removed. The second geometries are structures in which the $\mathrm{OH}$ radical acts as a double proton acceptor. The structures are shown in Figure 2 and are denoted $\mathrm{OH} \cdot\left(\mathrm{H}_{2} \mathrm{O}\right)_{2}$ $(\mathrm{d}, \mathrm{aa}, \mathrm{d})$ and $\mathrm{OH} \cdot\left(\mathrm{H}_{2} \mathrm{O}\right)_{3}(\mathrm{dd}, \mathrm{aa}, \mathrm{dd}, \mathrm{aa})$, where "d" or "dd" indicates that a water molecule acts as single or double proton donors and "aa" indicates that the $\mathrm{OH}$ radical or a water molecule acts as a double proton acceptor. Again, the geometries for these structures are the same as those for water clusters studied by Xantheas, ${ }^{65-67}$ with the exception that one of the hydrogen atoms is removed. Although the geometries for the water clusters correspond to equilibrium structures, those for the $\mathrm{OH} \cdot\left(\mathrm{H}_{2} \mathrm{O}\right)_{\mathrm{n}}$ complexes do not. The goal of this work is to understand the many-body effects in the $\mathrm{OH}$-water system and how it compares with those for the water clusters, not on predicting binding energies of the complexes. These geometries are representative of those that may be important in clusters and/or liquids and are therefore relevant to understand how the manybody effects appear for these systems.

\section{Decomposition energies for structures with $\mathrm{OH}$ radical acting as a proton donor and proton acceptor}

Tables $1-2$ show the results of the computations for $\mathrm{OH} \cdot\left(\mathrm{H}_{2} \mathrm{O}\right)_{\mathrm{n}}(\mathrm{n}=2,3)$ complexes for the (da,da,da) and (da,da,da,da) structures. Previous studies of the cyclic water clusters have shown that the differences between binding energies computed with MP2 and CCSD(T) levels of theory are small if the basis sets are the same and BSSE is treated in a consistent manner (e.g., the CP correction is or is not used). For example, differences between MP2 results(Xantheas, Burnham and Harrison) and $\operatorname{CCSD(T)~results~}{ }^{59,63}$ are less than $0.01 \mathrm{kcal} / \mathrm{mol}$ for the dimer and $0.04 \mathrm{kcal} / \mathrm{mol}$ for the trimer when results are extrapolated to the complete basis set limit. The differences between MP2 results(Xantheas, Burnham and Harrison) and $\operatorname{CCSD}(\mathrm{T})$ results(Milet et al.) are about $0.5 \mathrm{kcal} / \mathrm{mol}$ for the aug-cc-pvDZ basis set when BSSE correction is included. It is reasonable then that most previous analyses of many-body effects in water clusters has been performed at the MP2 level of theory. However, the results in Tables 1 and 2 indicate that MP2 is not adequate for calculating the binding energies of the $\mathrm{OH} \cdot\left(\mathrm{H}_{2} \mathrm{O}\right)_{\mathrm{n}}(\mathrm{n}=2,3)$ complexes, where the differences between MP2 and $\mathrm{CCSD}(\mathrm{T})$ are greater than 2 $\mathrm{kcal} / \mathrm{mol}$. For the pair terms, the largest differences between the MP2 and $\operatorname{CCSD}(\mathrm{T})$ results occur for the interactions in which the $\mathrm{OH}$ acts as a proton acceptor. These are interactions 2,3 for $\mathrm{OH} \cdot\left(\mathrm{H}_{2} \mathrm{O}\right)_{2}$ and 3,4 for $\mathrm{OH} \cdot\left(\mathrm{H}_{2} \mathrm{O}\right)_{3}$. For these interactions, the differences between MP2 and $\mathrm{CCSD}(\mathrm{T})$ are about $1.8 \mathrm{kcal} / \mathrm{mol}$, while the differences are typically less than $0.5 \mathrm{kcal} / \mathrm{mol}$ for all the other pair interactions.

Based on the discussion above, MP2 and $\operatorname{CCSD}(\mathrm{T})$ are expected to give similar results for the water clusters. Therefore, it is reasonable to compare the previous decomposition analysis for the water clusters using MP2 results with our new $\mathrm{CCSD}(\mathrm{T})$ results for the $\mathrm{OH} \cdot\left(\mathrm{H}_{2} \mathrm{O}\right)_{\mathrm{n}}$ decomposition energies. The MP2 binding energies for $\left(\mathrm{H}_{2} \mathrm{O}\right)_{3}$ with aug-cc-pVDZ and aug-cc-pVTZ basis sets (including BSSE correction) were reported previously to be 13.86 and $14.96 \mathrm{kcal} / \mathrm{mol}$, respectively.(Xantheas, Burnham and Harrison) These are about 1.2 and $0.8 \mathrm{kcal} / \mathrm{mol}$ higher than the $\mathrm{CCSD}(\mathrm{T})$ results (see Table 1) for $\mathrm{OH} \cdot\left(\mathrm{H}_{2} \mathrm{O}\right)_{2}$ with the same basis sets. These differences in binding energies arise in the 2-body terms. It is interesting that the 3-body terms for both the $\left(\mathrm{H}_{2} \mathrm{O}\right)_{3}$ and $\mathrm{OH} \cdot\left(\mathrm{H}_{2} \mathrm{O}\right)_{2}$ clusters are the same, $-2.5 \mathrm{kcal} / \mathrm{mol}$. The results computed without the BSSE 
correction give higher binding energies for both the water and $\mathrm{OH}$-water clusters, with slightly higher differences between the water and $\mathrm{OH}$-water cluster binding energies of 1.2-1.8 kcal $/ \mathrm{mol}$. The effect of the BSSE correction is primarily on the 2-body interactions, so once again the 3-body terms for the two clusters are about the same and the differences in binding energies between the $\left(\mathrm{H}_{2} \mathrm{O}\right)_{3}$ and $\mathrm{OH} \cdot\left(\mathrm{H}_{2} \mathrm{O}\right)_{2}$ clusters arise from a decrease in the pair interactions for the $\mathrm{OH} \cdot\left(\mathrm{H}_{2} \mathrm{O}\right)_{2}$ cluster relative to the $\left(\mathrm{H}_{2} \mathrm{O}\right)_{3}$ cluster.

The results for the $\mathrm{OH} \cdot\left(\mathrm{H}_{2} \mathrm{O}\right)_{3}$ complex shown in Table 2 are similar to those for the smaller cluster. The major findings are: MP2 is inadequate for computing the energetics of the $\mathrm{OH} \cdot\left(\mathrm{H}_{2} \mathrm{O}\right)_{3}$ cluster, although it provides excellent energetics for $\left(\mathrm{H}_{2} \mathrm{O}\right)_{4}$; the total binding for the $\mathrm{OH} \cdot\left(\mathrm{H}_{2} \mathrm{O}\right)_{3}$ is about 1.5-1.7 kcal/mol lower than in the $\left(\mathrm{H}_{2} \mathrm{O}\right)_{4}$ (which are slightly larger differences than for smaller clusters); the major contributions to these differences in binding energies for the $\mathrm{OH} \cdot\left(\mathrm{H}_{2} \mathrm{O}\right)_{3}$ and $\left(\mathrm{H}_{2} \mathrm{O}\right)_{4}$ clusters are from the 2-body interactions in which the $\mathrm{OH}$ radical acts as a proton acceptor; the total 3-body contributions are in the range -5.7 to -6.2 $\mathrm{kcal} / \mathrm{mol}$ for both clusters; the 4-body terms are about -0.6 to -0.7 in both cases; the effect of the BSSE correction is primarily to decrease the magnitude of the 2-body terms.

Previous calculations of the energy decomposition of cyclic water clusters with (da,da,da) and (da,da,da,da) structures have shown that the three-body terms can contribute up to $14-18 \%$ for the water trimer and $20-26 \%$ for the water tetramer.(Xantheas) We see a slightly higher contribution from the 3-body terms of $15-19 \%$ and $21-27 \%$ in the $\mathrm{OH} \cdot\left(\mathrm{H}_{2} \mathrm{O}\right)_{2}$ and $\mathrm{OH} \cdot\left(\mathrm{H}_{2} \mathrm{O}\right)_{3}$ complexes because of the loss of 2-body interactions, while the 3body interactions stay about the same, relative to the water clusters.

A major difference between the $\mathrm{OH} \cdot\left(\mathrm{H}_{2} \mathrm{O}\right)_{\mathrm{n}}$ and $\left(\mathrm{H}_{2} \mathrm{O}\right)_{\mathrm{n}+1}$ systems is the existence of the singlet occupied orbital for the free radical system leading to a low-lying excited state, which has been observed for the $\mathrm{OH} \cdot \mathrm{H}_{2} \mathrm{O}$ system. ${ }^{19,21}$ The unpaired electron in $\mathrm{OH}$ is localized in a singly occupied $\mathrm{P}$ orbital on the $\mathrm{O}$ atom, which is perpendicular to the $\mathrm{OH}$ bond. The $\mathrm{O}-\mathrm{H}$ moieties forming the cyclic hydrogen-bond structures of $\mathrm{OH} \cdot\left(\mathrm{H}_{2} \mathrm{O}\right)_{2}(\mathrm{da}, \mathrm{da}, \mathrm{da})$ and $\mathrm{OH} \cdot\left(\mathrm{H}_{2} \mathrm{O}\right)_{3}(\mathrm{da}, \mathrm{da}$,da,da) form a nearly planar configuration (see Figure 1$)$. The two states are determined by the orientation of the singly-occupied orbital relative to this plane. To evaluate the many body effects accurately, we compared the energies two states by trying to put the single electron into different 2P orbitals of the $\mathrm{OH}$ radical. Our computational results show that the ground state of these $\mathrm{OH} \cdot\left(\mathrm{H}_{2} \mathrm{O}\right)_{n}$ complexes have the single electron in the $\mathrm{P}$ orbital that is approximately perpendicular to the plane formed by the hydrogen-bonded $\mathrm{O}-\mathrm{H}$ moieties.

\section{Decomposition energies for structures with $\mathrm{OH}$ radical acting as a}

\section{double proton acceptor}

Tables 3 - 4 show the results of the computations for the $\mathrm{OH} \cdot\left(\mathrm{H}_{2} \mathrm{O}\right)_{2}(\mathrm{~d}, \mathrm{aa}, \mathrm{d})$ and $\mathrm{OH} \cdot\left(\mathrm{H}_{2} \mathrm{O}\right)_{2}(\mathrm{dd}$,aa,dd,aa) structures shown in Figure 2. All the results for these structures are with the CCSD(T) level of theory and augcc-pVDZ and aug-cc-pVTZ basis sets. These tables also present new CCSD(T) results for the corresponding water trimer and tetramer structures. Previous calculations on these water structures were performed with MP2/aug-cc-pVDZ level of theory including correction for BSSE. ${ }^{66,67}$ As for the cyclic water structures considered above, the CCSD(T) and MP2 results agree very well. The previous MP2/aug-cc-pVDZ(BSSE) binding energies for $\left(\mathrm{H}_{2} \mathrm{O}\right)_{3}\left(\mathrm{~d}\right.$,aa,d) and $\left(\mathrm{H}_{2} \mathrm{O}\right)_{4}(\mathrm{dd}$,aa,dd,aa) were -7.9 and $-13.9 \mathrm{kcal} / \mathrm{mol}$, (Hodges, Stone 
and Xantheas) in excellent agreement with the CCSD(T) /aug-cc-pVDZ(BSSE) values shown in Tables 3 and 4.

For the $\mathrm{OH} \cdot\left(\mathrm{H}_{2} \mathrm{O}\right)_{2}(\mathrm{~d}, \mathrm{aa}, \mathrm{d})$ and $\mathrm{OH} \cdot\left(\mathrm{H}_{2} \mathrm{O}\right)_{3}(\mathrm{dd}$,aa,dd,aa) structures, the 2-body terms corresponding to hydrogen bonds between $\mathrm{OH}$ and water with $\mathrm{OH}$ acting as the acceptor are about 1.7-1.8 kcal/mol weaker than the corresponding 2-body terms in the water clusters. This weakening of the hydrogen bond with the $\mathrm{OH}$ radical compares to slightly higher values of 2.3-2.4 kcal/mol observed in the $\mathrm{OH} \cdot\left(\mathrm{H}_{2} \mathrm{O}\right)_{2}$ (da,da,da) and $\mathrm{OH} \cdot\left(\mathrm{H}_{2} \mathrm{O}\right)_{3}(\mathrm{da}$,da,da,da) structures. As discussed in the previous section, the 3-body terms were attractive for both the $\mathrm{OH}$-water and water clusters in which each molecule participated as both a proton donor and acceptor, and the magnitude of the 3-body interaction was about the same in the $\mathrm{OH}$-water and water clusters. The results in Tables 3 and 4 show that the 3-body terms are repulsive when the structures include molecules that act as double proton acceptors. In addition, the repulsion for the $\mathrm{OH}$ radical systems is higher by about 1 $\mathrm{kcal} / \mathrm{mol}$ than for the pure water clusters. The 4-body interactions in both the $\mathrm{OH} \cdot\left(\mathrm{H}_{2} \mathrm{O}\right)_{3}$ and $\left(\mathrm{H}_{2} \mathrm{O}\right)_{4}$ clusters are lower for these clusters with double proton acceptors than they were for the clusters discussed in the previous section, although they are small in all cases. An important common point between the $\mathrm{OH}$-water complexes and corresponding water complexes is that the basis set and BSSE corrections show little effect on the many-body terms.

For the water clusters, the 3 -body interactions contribute $-4 \%$ to $-9 \%$ (where a negative number indicates a repulsive interaction) to the total energy, while these values range from $-30 \%$ to $-23 \%$ for the $\mathrm{OH}-$ water clusters. The much larger magnitude in the $\mathrm{OH}$ case is a result of the larger value of the repulsive 3-body interaction in the $\mathrm{OH}$-water clusters and the lower total binding energy because of the weaker (attractive) 2body interactions.

As for the cyclic (da,da,da) and (da,da,da,da) structures, the $\mathrm{OH} \cdot\left(\mathrm{H}_{2} \mathrm{O}\right)_{2}(\mathrm{~d}, \mathrm{aa}, \mathrm{d})$ and $\mathrm{OH} \cdot\left(\mathrm{H}_{2} \mathrm{O}\right)_{3}$ (dd,aa,dd,aa) structures also have low-lying excited states resulting from the unpaired electron in $\mathrm{OH}$, which is localized in a singly occupied $\mathrm{P}$ orbital on the $\mathrm{O}$ atom and is perpendicular to the $\mathrm{OH}$ bond. The $\mathrm{O}-\mathrm{H}$ moieties participating in the hydrogen-bonding in the $\mathrm{OH} \cdot\left(\mathrm{H}_{2} \mathrm{O}\right)_{2}(\mathrm{~d}, \mathrm{aa}, \mathrm{d})$ and $\mathrm{OH} \cdot\left(\mathrm{H}_{2} \mathrm{O}\right)_{3}(\mathrm{dd}, \mathrm{aa}, \mathrm{dd}, \mathrm{aa})$ structures approximately form a plane. The $\mathrm{OH}$ radical lies in a plane that is perpendicular to the plane formed by the $\mathrm{O}$ atoms (see Figure 2). The two states are determined by the orientation of the singly-occupied orbital relative to the plane parallel to the $\mathrm{OH}$ radical. The lowest energy state of these $\mathrm{OH} \cdot\left(\mathrm{H}_{2} \mathrm{O}\right)_{n}$ complexes have the single electron in the $\mathrm{P}$ orbital that is parallel to this plane.

\section{Decomposition energies predicted by the mTTM potential}

We also present evaluations of the many-body decomposition of our newly-developed mTTM model of OHwater interactions(Du et al.) and compare them with the results from $\operatorname{CCSD}(\mathrm{T}) / \mathrm{aug}$-cc-pVTZ calculations including the BSSE correction. Table 6 presents a comparison of decomposition energies for the MTTM model with the CCSD(T)/aug-cc-pVTZ (BSSE) results for all 4 geometries. The two-body terms are well reproduced for geometries near the minima of the dimer potential, but deviate by as much as $1.3 \mathrm{kcal} / \mathrm{mol}$ for other geometries. The total errors in the two-body interactions for the $\mathrm{OH} \cdot\left(\mathrm{H}_{2} \mathrm{O}\right)_{2}(\mathrm{da}$,da,da) and $(\mathrm{d}, \mathrm{aa}, \mathrm{d})$ structures and for the $\mathrm{OH} \cdot\left(\mathrm{H}_{2} \mathrm{O}\right)_{3}(\mathrm{da}, \mathrm{da}, \mathrm{da}, \mathrm{da})$ and $(\mathrm{dd}, \mathrm{aa}, \mathrm{dd}, \mathrm{aa})$ structures are $1.5,1.0,1.2$, and $0.7 \mathrm{kcal} / \mathrm{mol}$, respectively. The magnitude of the three-body interactions are in general underestimated by the MTTM potential, but display the correct qualitative trend, that is they are attractive in the $\mathrm{OH} \cdot\left(\mathrm{H}_{2} \mathrm{O}\right)_{2}$ (da,da,da) and 
$\mathrm{OH} \cdot\left(\mathrm{H}_{2} \mathrm{O}\right)_{3}\left(\mathrm{da}\right.$,da,da,da) and repulsive in the $\mathrm{OH} \cdot\left(\mathrm{H}_{2} \mathrm{O}\right)_{2}\left(\mathrm{~d}\right.$,aa,d) and $\mathrm{OH} \cdot\left(\mathrm{H}_{2} \mathrm{O}\right)_{3}(\mathrm{dd}$,aa,dd,aa) structures. The total errors in the three-body interactions for the $\mathrm{OH} \cdot\left(\mathrm{H}_{2} \mathrm{O}\right)_{2}$ (da,da,da) and $(\mathrm{d}, \mathrm{aa}, \mathrm{d})$ structures and for the $\mathrm{OH} \cdot\left(\mathrm{H}_{2} \mathrm{O}\right)_{3}(\mathrm{da}, \mathrm{da}, \mathrm{da}, \mathrm{da})$ and $(\mathrm{dd}, \mathrm{aa}, \mathrm{dd}, \mathrm{aa})$ structures are $1.3,0.0,3.0$, and $0.7 \mathrm{kcal} / \mathrm{mol}$, respectively. The 4body terms are attractive but their magnitude is underestimated by about $0.3 \mathrm{kcal} / \mathrm{mol}$. Overall the mTTM potential does a reasonable job of reproducing many-body effects, and in particular it does an excellent job of reproducing the qualitative trend that the three-body term is repulsive for configurations in which the $\mathrm{OH}$ radical acts as a double proton acceptor.

\section{Summary and Conclusions}

Our analysis of the many-body contributions to the $\mathrm{OH} \cdot\left(\mathrm{H}_{2} \mathrm{O}\right)_{\mathrm{n}}$ binding energies clearly showed that they are just as important for $\mathrm{OH}$ interactions with water as they are for interactions in pure water systems. We studied the binding energies of $\mathrm{OH} \cdot\left(\mathrm{H}_{2} \mathrm{O}\right)_{n}$ clusters $(\mathrm{n}=2,3)$ in which $\mathrm{OH}$ participates in 2 hydrogen bonds. In one case the $\mathrm{OH}$ radical acts as both a proton donor and a proton acceptor, denoted $(d a)$, and in the other case it acts as a double proton acceptor, denoted $(a a)$. We compared the many-body interaction in these clusters with those in $\left(\mathrm{H}_{2} \mathrm{O}\right)_{n+1}$ clusters, where the geometries of the two systems were the same except for the removal of one of hydrogen atoms in the $\mathrm{OH}$ clusters. Table 5 presents a summary of the relative contributions of the 2-, 3-, and 4-body terms to the binding energies for these clusters. The major conclusions from this work are as follows.

- The total binding energies in the $\mathrm{OH} \cdot\left(\mathrm{H}_{2} \mathrm{O}\right)_{\mathrm{n}}$ clusters are lower than the corresponding $\left(\mathrm{H}_{2} \mathrm{O}\right)_{\mathrm{n}+1}$ clusters by about $1.5 \mathrm{kcal} / \mathrm{mol}$ for the $(d a)$ structures and by over $4 \mathrm{kcal} / \mathrm{mol}$ for the $(a a)$ structures.

- This lowering of the binding energies for the $\mathrm{OH}$ clusters arises primarily from weakening of the 2-body interactions in which the $\mathrm{OH}$ radical acts as a proton acceptor. There is only one such 2-body interaction for the $(d a)$ structures, while there are two for the $(a a)$ structures, accounting for the greater lowering of the binding energies in the $\mathrm{OH}(a a)$ structures.

- The dominant contribution to the many-body effects on the binding energy is from the 3-body terms. The 3-body terms are attractive for the $(d a)$ structures and they are nearly identical in the corresponding $\mathrm{OH}$ and water clusters. The 3-body terms contribute $17 \%$ to $24 \%$ to the binding energy in the $\mathrm{OH}(d a)$ structures. The 3 -body 
terms are repulsive for the $(a a)$ structures and are larger in magnitude by about 1 $\mathrm{kcal} / \mathrm{mol}$ for the $\mathrm{OH}$ clusters compared to the water clusters. The 3-body terms contribute $-23 \%$ to $-30 \%$ to the binding energy of the $\mathrm{OH}(a a)$ structures (a negative contribution indicates a repulsive interaction).

- The 4-body terms are much smaller than the 3-body terms, contributing less than 3\% to the total binding energies for the $\mathrm{OH}$-water clusters.

Compared to interactions in pure water systems, the $\mathrm{OH} \cdot \mathrm{H}_{2} \mathrm{O}$ hydrogen bond when $\mathrm{OH}$ acts as a proton acceptor is weaker and the 3-body interaction have a relatively large repulsive value when $\mathrm{OH}$ acts as a double proton acceptor. Therefore, it will be less probably, compared to pure water systems, to have more than 2 hydrogen bonds (one as a proton donor and one as an acceptor) for $\mathrm{OH}$ in water systems. These findings are consistent with the lower free energy of solvation of $\mathrm{OH}$ in bulk water of about $3.9 \mathrm{kcal} / \mathrm{mol}$ (Autrey et al.) compared to the value of $6.3 \mathrm{kcal} / \mathrm{mol}$ for water.(Ben-Naim and Marcus) A preference for 2 hydrogen bonds also indicates that $\mathrm{OH}$ radical should be surface active, with an increased free energy for staying at the surface of water compared to the bulk, which is consistent with recent simulation studies. ${ }^{101,102}$

\section{ACKNOWLEDGEMENTS}

This work was supported by the Division of Chemical Sciences, Office of Basic Energy Sciences of the U.S. Department of Energy (DOE) and was performed in part using the Molecular Science Computing Facility in the William R. Wiley Environmental Molecular Sciences Laboratory (EMSL) at the Pacific Northwest National Laboratory. The EMSL is funded by the DOE Office of Biological and Environmental Research. Battelle operates Pacific Northwest National Laboratory for DOE. The authors thank Sotiris Xantheas, Jun Li, Tzvetelin Iordanov, and Jun Cui for helpful discussions and assistance. 


\section{REFERENCES}

J. H. Seinfeld and S. N. Pandis, Atmospheric Chemistry and Physics: From Air Pollution to Climate Change, Second ed. (John Wiley \& Sons, New York, 2006).

R. P. Wayne, Chemistry of Atmospheres: An Introduction to the Chemistry of the Atmospheres of Earth, the Planets, and their Satellites, Third ed. (Oxford University Press, Oxford, 2000).

B. J. Finlayson-Pitts and J. N. Pitts, Jr., Chemistry of the Upper and Lower Atmosphere. (Academic Press, San Diego, 1999).

W. Stumm and J. J. Morgan, Aquatic Chemistry: Chemical Equilibria and Rates in Natural Waters, Third ed. (John Wiley \& Sons, Inc., New York, 1995).

B. C. Garrett, D. A. Dixon, D. M. Camaioni, D. M. Chipman, M. A. Johnson, C. D. Jonah, G. A. Kimmel, J. H. Miller, T. N. Rescigno, P. J. Rossky, S. S. Xantheas, S. D. Colson, A. H. Laufer, D. Ray, P. F. Barbara, D. M. Bartels, K. H. Becker, H. Bowen, S. E. Bradforth, I. Carmichael, J. V. Coe, L. R. Corrales, J. P. Cowin, M. Dupuis, K. B. Eisenthal, J. A. Franz, M. S. Gutowski, K. D. Jordan, B. D. Kay, J. A. LaVerne, S. V. Lymar, T. E. Madey, C. W. McCurdy, D. Meisel, S. Mukamel, A. R. Nilsson, T. M. Orlando, N. G. Petrik, S. M. Pimblott, J. R. Rustad, G. K. Schenter, S. J. Singer, A. Tokmakoff, L. S. Wang, C. Wittig, and T. S. Zwier, Chem. Rev. 105, 355 (2005). A. F. Parsons, An Introduction to Free Radical Chemistry. (Blackwell Science Ltd., Oxford, 2000).

V. Vaida, G. J. Frost, L. A. Brown, R. Naaman, and Y. Hurwitz, Ber. Bunsen-Ges. Phys. Chem. Chem. Phys. 99, 371 (1995).

S. Aloisio and J. S. Francisco, Accounts Chem. Res. 33, 825 (2000).

J. C. Hansen and J. S. Francisco, ChemPhysChem 3, 833 (2002).

H. G. Kjaergaard, T. W. Robinson, D. L. Howard, J. S. Daniel, J. E. Headrick, and V. Vaida, J. Phys. Chem. A 107, 10680 (2003).

V. Vaida, H. G. Kjaergaard, and K. J. Feierabend, Int. Rev. Phys. Chem. 22, 203 (2003).

P. G. Sennikov, S. K. Ignatov, and O. Schrems, ChemPhysChem 6, 392 (2005).

P. D. Cooper, H. G. Kjaergaard, V. S. Langford, A. J. McKinley, T. I. Quickenden, and D. P. Schofield, J. Am. Chem. Soc. 125, 6048 (2003).

A. Engdahl, G. Karlstrom, and B. Nelander, J. Chem. Phys. 118, 7797 (2003).

C. S. Brauer, G. Sedo, E. M. Grumstrup, K. R. Leopold, M. D. Marshall, and H. O. Leung, Chem. Phys. Lett. 401, 420 (2005).

M. D. Marshall and M. I. Lester, J. Phys. Chem. B 109, 8400 (2005).

Y. Ohshima, K. Sato, Y. Sumiyoshi, and Y. Endo, J. Am. Chem. Soc. 127, 1108 (2005).

P. C. do Couto, R. C. Guedes, B. J. C. Cabral, and J. A. M. Simoes, J. Chem. Phys. 119, 7344 (2003).

D. P. Schofield and H. G. Kjaergaard, J. Chem. Phys. 120, 6930 (2004).

S. D. Belair, J. S. Francisco, and S. J. Singer, Phys. Rev. A 71 (2005). 
S. Du, J. S. Francisco, G. K. Schenter, T. D. Iordanov, B. C. Garrett, M. Dupuis, and J. Li, J. Chem. Phys. 124, 224318 (2006).

T. D. Crawford, M. L. Abrams, R. A. King, J. R. Lane, D. P. Schofield, and H. G. Kjaergaard, J. Chem. Phys. 125, 204302 (2006).

M. A. Allodi, M. E. Dunn, J. Livada, K. N. Kirschner, and G. C. Shields, J. Phys. Chem. A 110, 13283 (2006).

C. J. Burnham, J. C. Li, S. S. Xantheas, and M. Leslie, J. Chem. Phys. 110, 4566 (1999).

C. J. Burnham and S. S. Xantheas, J. Chem. Phys. 116, 1479 (2002).

S. S. Xantheas, C. J. Burnham, and R. J. Harrison, J. Chem. Phys. 116, 1493 (2002).

C. J. Burnham and S. S. Xantheas, J. Chem. Phys. 116, 1500 (2002).

K. Szalewicz, S. J. Cole, W. Kolos, and R. J. Bartlett, J. Chem. Phys. 89, 3662 (1988).

G. Chalasinski, M. M. Szczesniak, P. Cieplak, and S. Scheiner, J. Chem. Phys. 94, 2873 (1991).

C. J. Marsden, B. J. Smith, J. A. Pople, H. F. Schaefer, and L. Radom, J. Chem. Phys. 95, 1825 (1991).

B. J. Mhin, H. S. Kim, H. S. Kim, C. W. Yoon, and K. S. Kim, Chem. Phys. Lett. 176, 41 (1991).

S. Rybak, B. Jeziorski, and K. Szalewicz, J. Chem. Phys. 95, 6576 (1991).

D. Feller, J. Chem. Phys. 96, 6104 (1992).

K. S. Kim, B. J. Mhin, U. S. Choi, and K. Lee, J. Chem. Phys. 97, 6649 (1992).

O. Mo, M. Yanez, and J. Elguero, J. Chem. Phys. 97, 6628 (1992).

M. Schütz, T. Bürgi, S. Leutwyler, and H. B. Bürgi, J. Chem. Phys. 99, 5228 (1993).

D. J. Wales, J. Am. Chem. Soc. 115, 11180 (1993).

C. J. Tsai and K. D. Jordan, Chem. Phys. Lett. 213, 181 (1993).

S. S. Xantheas and T. H. Dunning, J. Chem. Phys. 99, 8774 (1993).

S. S. Xantheas and T. H. Dunning, J. Chem. Phys. 98, 8037 (1993).

K. Kim, K. D. Jordan, and T. S. Zwier, J. Am. Chem. Soc. 116, 11568 (1994).

B. J. Mhin, J. S. Kim, S. Lee, J. Y. Lee, and K. S. Kim, J. Chem. Phys. 100, 4484 (1994).

J. E. Fowler and H. F. Schaefer, J. Am. Chem. Soc. 117, 446 (1995).

W. Klopper and M. Schütz, Ber. Bunsen-Ges. Phys. Chem. Chem. Phys. 99, 469 (1995).

M. Schutz, W. Klopper, H. P. Luthi, and S. Leutwyler, J. Chem. Phys. 103, 6114 (1995).

M. W. Feyereisen, D. Feller, and D. A. Dixon, J. Phys. Chem. 100, 2993 (1996).

E. M. Mas and K. Szalewicz, J. Chem. Phys. 104, 7606 (1996).

S. S. Xantheas, J. Chem. Phys. 104, 8821 (1996).

E. M. Mas, K. Szalewicz, R. Bukowski, and B. Jeziorski, J. Chem. Phys. 107, 4207 (1997).

J. Kim and K. S. Kim, J. Chem. Phys. 109, 5886 (1998).

J. Kim, D. Majumdar, H. M. Lee, and K. S. Kim, J. Chem. Phys. 110, 9128 (1999).

W. Klopper and H. P. Luthi, Mol. Phys. 96, 559 (1999).

I. M. B. Nielsen, E. T. Seidl, and C. L. Janssen, J. Chem. Phys. 110, 9435 (1999). 
W. Klopper, J. G. C. M. van Duijneveldt-van de Rijdt, and F. B. van Duijneveldt, Phys. Chem. Chem. Phys. 2, 2227 (2000).

H. M. Lee, S. B. Suh, J. Y. Lee, P. Tarakeshwar, and K. S. Kim, J. Chem. Phys. 112, 9759 (2000).

H. M. Lee, S. B. Suh, and K. S. Kim, J. Chem. Phys. 115, 7331 (2001).

H. M. Lee, S. B. Suh, and K. S. Kim, J. Chem. Phys. 114, 10749 (2001).

H. M. Lee, S. B. Suh, J. Y. Lee, P. Tarakeshwar, and K. S. Kim, J. Chem. Phys. 114, $3343(2001)$.

G. S. Tschumper, M. L. Leininger, B. C. Hoffman, E. F. Valeev, H. F. Schaefer, and M. Quack, J. Chem. Phys. 116, 690 (2002).

E. M. Mas, R. Bukowski, and K. Szalewicz, J. Chem. Phys. 118, 4386 (2003).

G. S. Fanourgakis, E. Apra, and S. S. Xantheas, J. Chem. Phys. 121, 2655 (2004).

S. S. Xantheas and E. Apra, J. Chem. Phys. 120, 823 (2004).

J. A. Anderson, K. Crager, L. Fedoroff, and G. S. Tschumper, J. Chem. Phys. 121, 11023 (2004).

S. S. Xantheas, J. Chem. Phys. 100, 7523 (1994).

S. S. Xantheas, Philos. Mag. B 73, 107 (1996).

M. P. Hodges, A. J. Stone, and S. S. Xantheas, J. Phys. Chem. A 101, 9163 (1997).

S. S. Xantheas, Chem. Phys. 258, 225 (2000).

M. J. Elrod and R. J. Saykally, Chem. Rev. 94, 1975 (1994).

W. Chen and M. S. Gordon, J. Phys. Chem. 100, 14316 (1996).

J. K. Gregory and D. C. Clary, J. Phys. Chem. 100, 18014 (1996).

J. M. Pedulla, K. Kim, and K. D. Jordan, Chem. Phys. Lett. 291, 78 (1998).

A. Milet, R. Moszynski, P. E. S. Wormer, and A. van der Avoird, J. Phys. Chem. A 103, 6811 (1999).

R. A. Christie and K. D. Jordan, in Intermolecular Forces and Clusters II, edited by D. J. Wales (Springer, Berlin, 2005), Vol. 116, pp. 27.

J. Cui, H. B. Liu, and K. D. Jordan, J. Phys. Chem. B 110, 18872 (2006).

E. E. Dahlke and D. G. Truhlar, J. Phys. Chem. B 110, 10595 (2006).

C. J. Burnham and S. S. Xantheas, J. Chem. Phys. 116, 5115 (2002).

S. S. Xantheas, in Intermolecular Forces and Clusters II, edited by D. J. Wales (Springer, Berlin, 2005), Vol. 116, pp. 119.

G. S. Fanourgakis and S. S. Xantheas, J. Phys. Chem. A 110, 4100 (2006).

G. C. Groenenboom, E. M. Mas, R. Bukowski, K. Szalewicz, P. E. S. Wormer, and A. van der Avoird, Phys. Rev. Lett. 84, 4072 (2000).

K. S. Kim, H. S. Kim, J. H. Jang, H. S. Kim, B. J. Mhin, Y. M. Xie, and H. F. Schaefer, J. Chem. Phys. 94, 2057 (1991).

Y. M. Xie and H. F. Schaefer, J. Chem. Phys. 98, 8829 (1993).

B. S. Wang, H. Hou, and Y. S. Gu, Chem. Phys. Lett. 303, 96 (1999).

S. Hamad, S. Lago, and J. A. Mejias, J. Phys. Chem. A 106, 9104 (2002). 
Z. Y. Zhou, Y. H. Qu, A. P. Fu, B. N. Du, F. X. He, and H. W. Gao, Int. J. Quantum Chem. 89, 550 (2002). C. Møller and M. S. Plesset, Physical Review 46, 0618 (1934).

J. Gauss, W. J. Lauderdale, J. F. Stanton, J. D. Watts, and R. J. Bartlett, Chem. Phys. Lett. 182, 207 (1991).

J. Gauss, J. F. Stanton, and R. J. Bartlett, J. Chem. Phys. 95, 2623 (1991).

H. Partridge and D. W. Schwenke, J. Chem. Phys. 106, 4618 (1997).

T. H. Dunning, Jr., J. Chem. Phys. 90, 1007 (1989).

R. A. Kendall, T. H. Dunning, Jr., and R. J. Harrison, J. Chem. Phys. 96, 6796 (1992).

A. K. Wilson, T. vanMourik, and T. H. Dunning, Theochem-J. Mol. Struct. 388, 339 (1996).

T. H. Dunning, J. Phys. Chem. A 104, 9062 (2000).

S. F. Boys and F. Bernardi, Mol. Phys. 19, 553 (1970).

B. Liu and A. D. McLean, J. Chem. Phys. 59, 4557 (1973).

G. Chalasinski and M. M. Szczesniak, Chem. Rev. 94, 1723 (1994).

F. B. van Duijneveldt, J. G. C. M. van Duijneveldt-van de Rijdt, and J. H. van Lenthe, Chem. Rev. 94, 1873 (1994).

D. Hankins, J. W. Moskowitz, and F. H. Stillinger, J. Chem. Phys. 53, 4544 (1970).

H.-J. Werner, P. J. Knowles, R. Lindh, F. R. Manby, M. Schütz, P. Celani, T. Korona, G. Rauhut, R. D. Amos, A. Bernhardsson, A. Berning, D. L. Cooper, M. J. O. Deegan, A. J. Dobbyn, F. Eckert, C. Hampel, G. Hetzer, A. W. Lloyd, S. J. McNicholas, W. Meyer, M. E. Mura, A. Nicklass, P. Palmieri, R. Pitzer, U. Schumann, H. Stoll, A. J. Stone, R. Tarroni, and T. Thorsteinsson, MOLPRO (Cardiff, UK, 2006), http://www.molpro.net. T. Autrey, A. K. Brown, D. M. Camaioni, M. Dupuis, N. S. Foster, and A. Getty, J. Am. Chem. Soc. 126, 3680 (2004).

A. Ben-Naim and Y. Marcus, J. Chem. Phys. 81, 2016 (1984).

M. Roeselova, J. Vieceli, L. X. Dang, B. C. Garrett, and D. J. Tobias, J. Am. Chem. Soc. 126, 16308 (2004).

J. Vieceli, M. Roeselova, N. Potter, L. X. Dang, B. C. Garrett, and D. J. Tobias, J. Phys. Chem. B 109, 15876 (2005). 


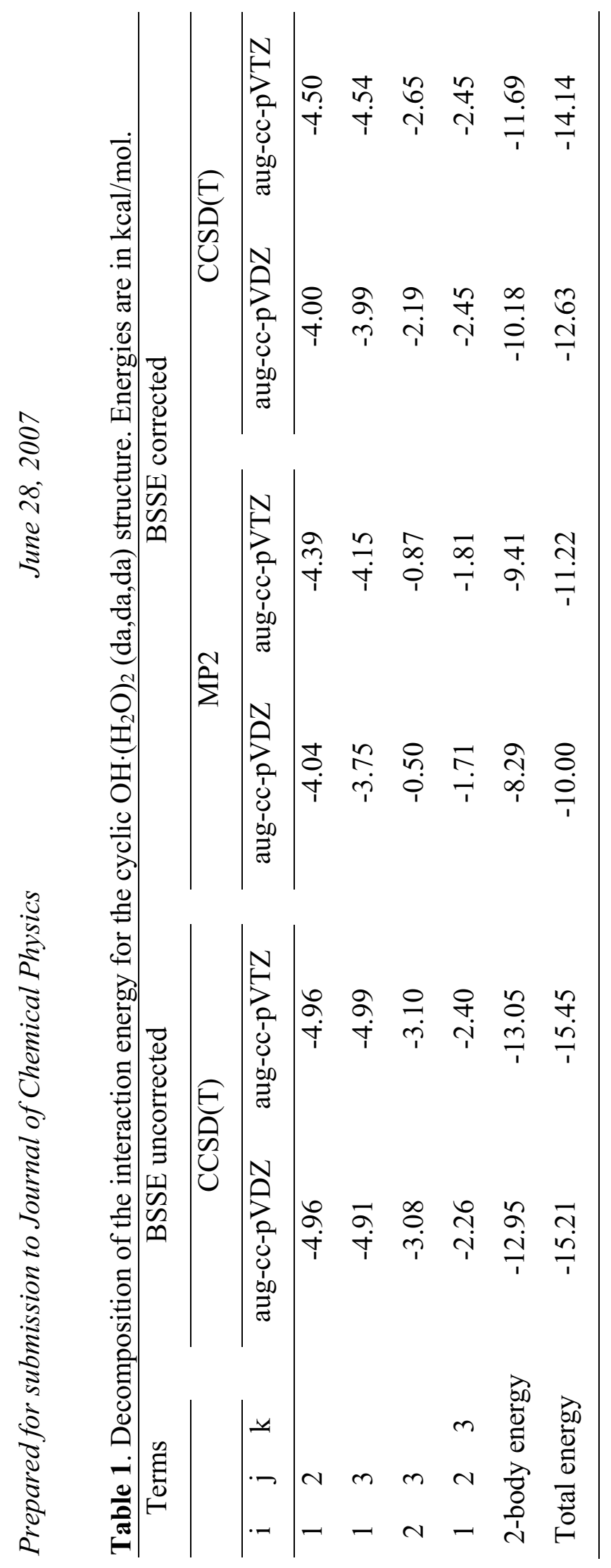


oे
$\frac{1}{3}$
$\bar{z}$
$\frac{1}{2}$

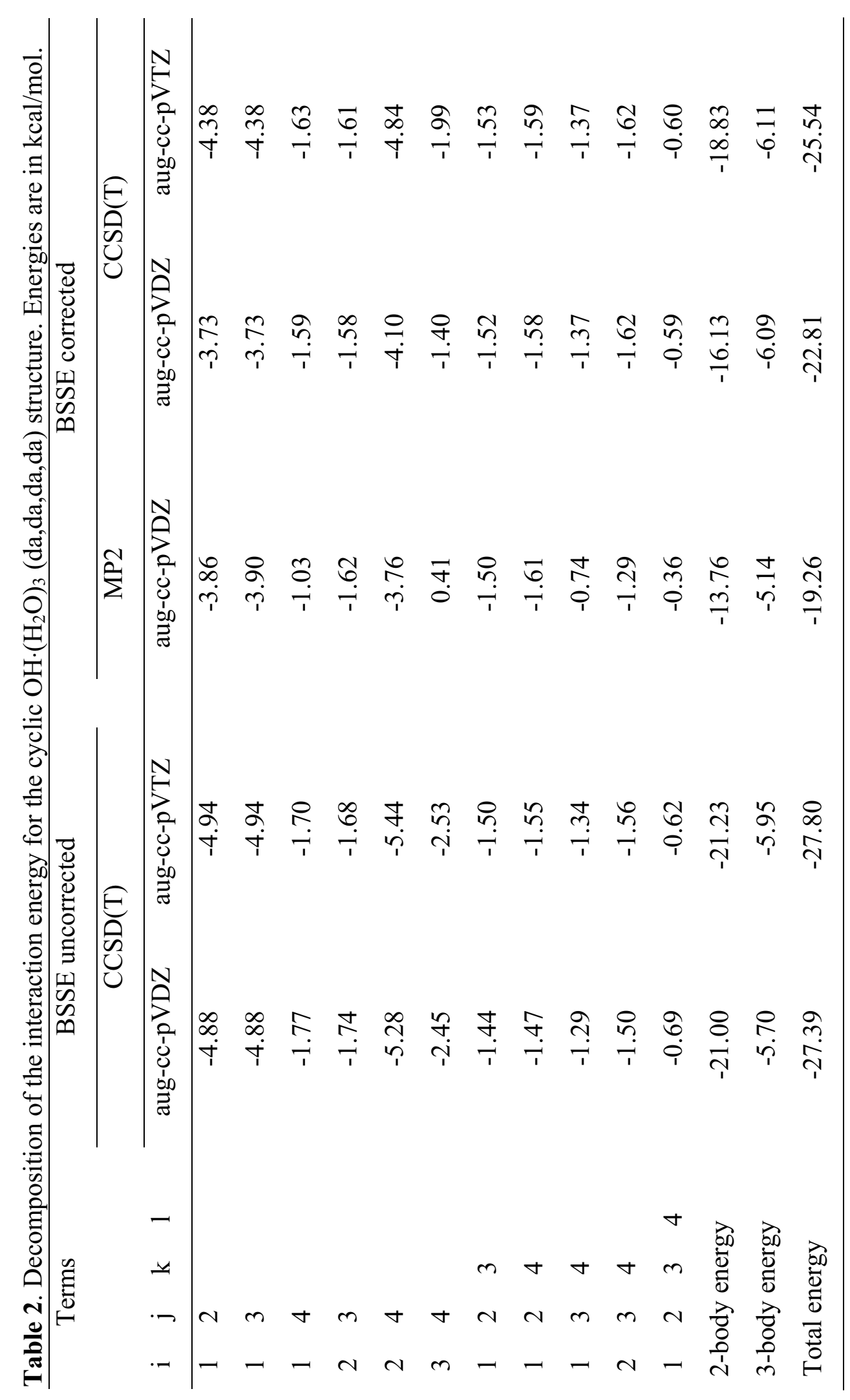




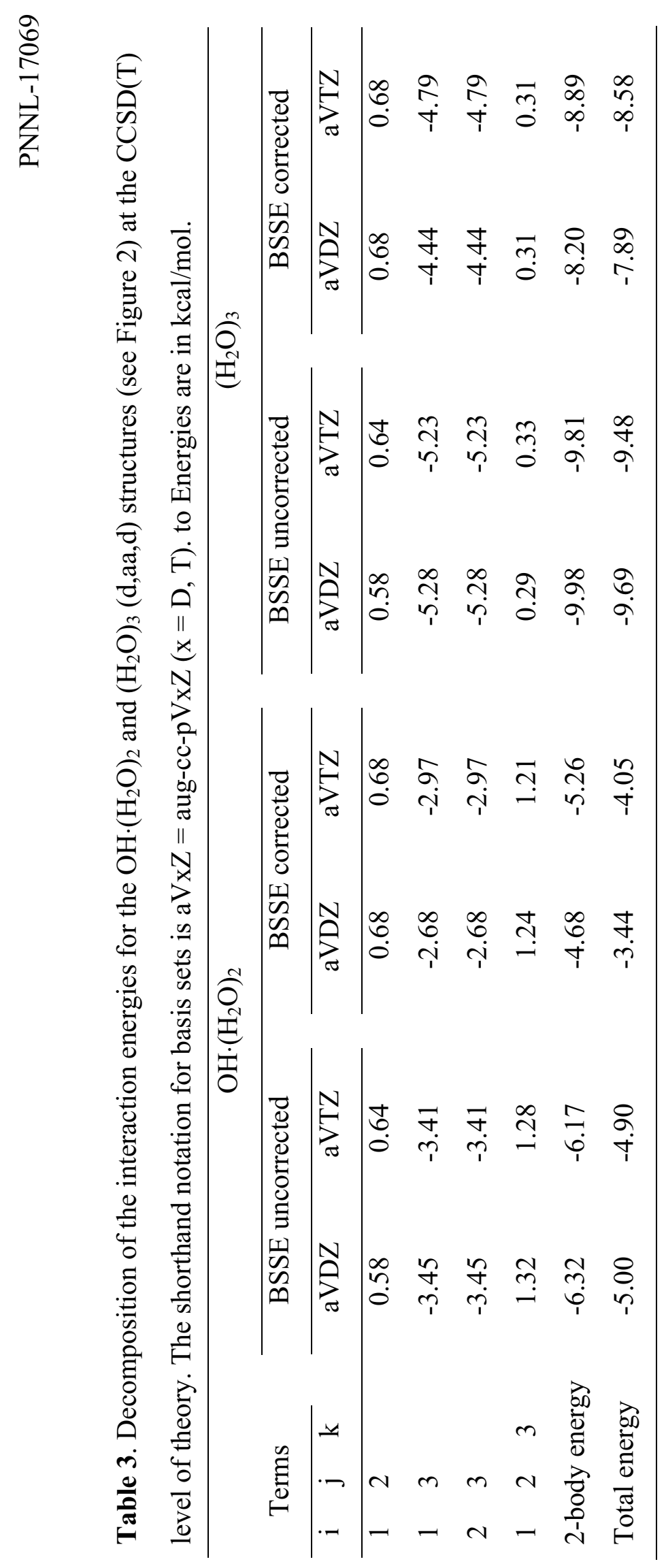




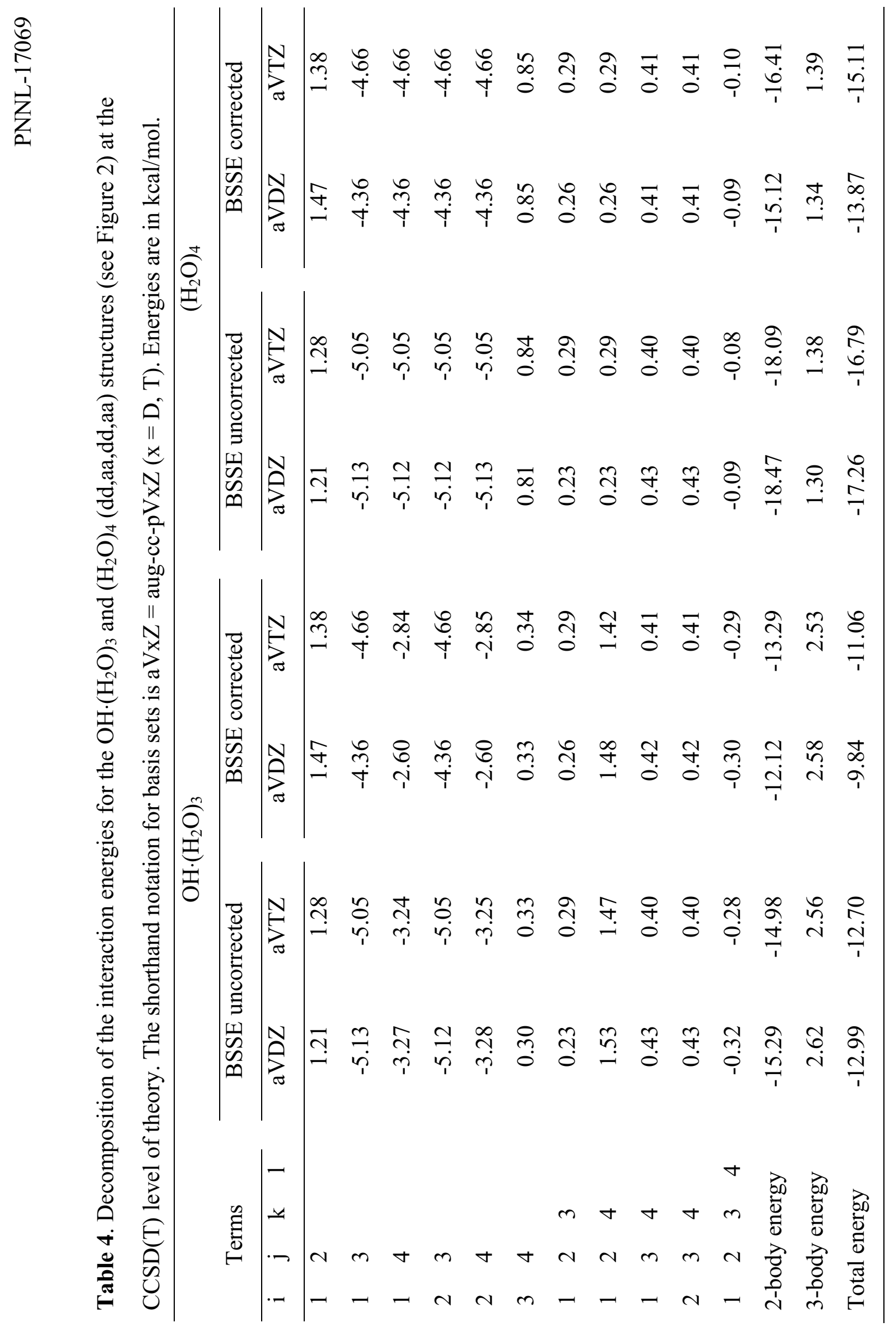




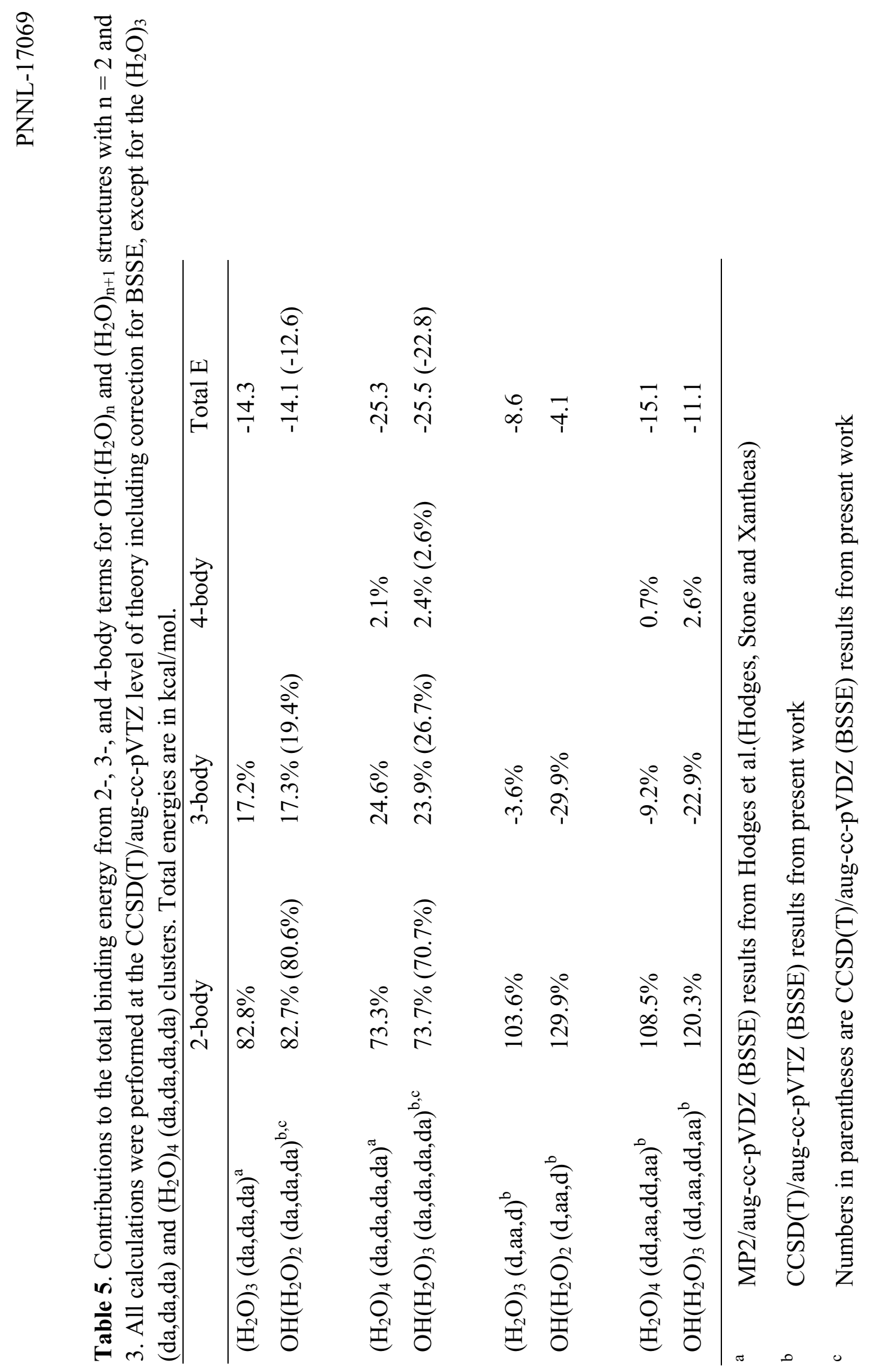




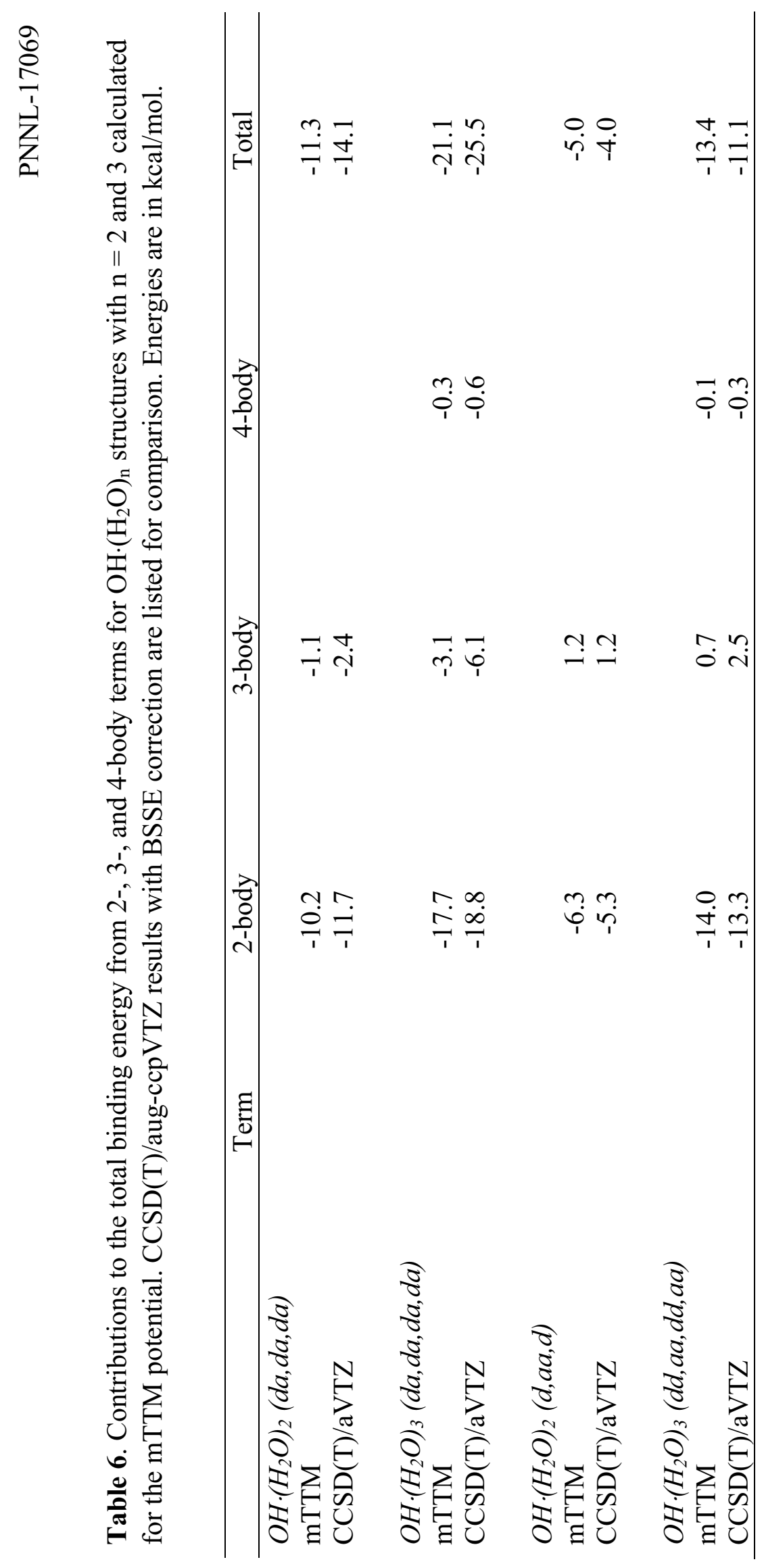



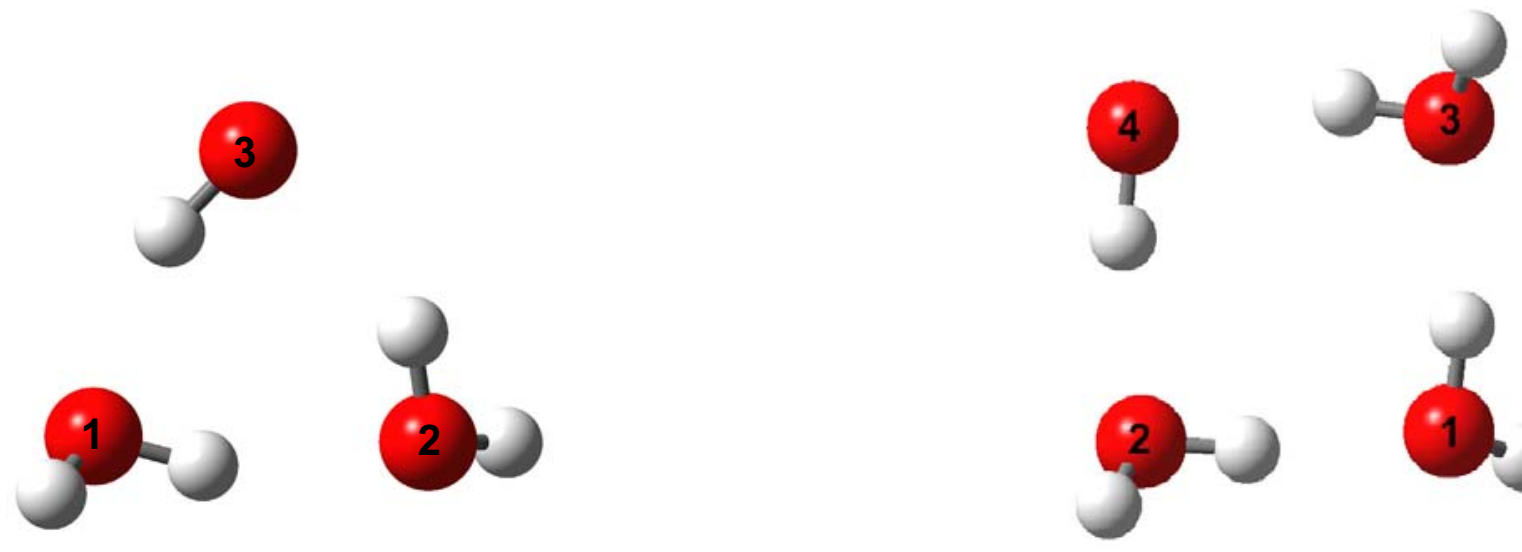

Figure 1. Cyclic structures of $\mathrm{OH} \cdot\left(\mathrm{H}_{2} \mathrm{O}\right)_{2}$ (da,da,da) and $\mathrm{OH} \cdot\left(\mathrm{H}_{2} \mathrm{O}\right)_{3}$ (da,da,da,da). The

$\mathrm{OH}$ molecule is labeled 3 in $\mathrm{OH} \cdot\left(\mathrm{H}_{2} \mathrm{O}\right)_{2}$ and 4 in $\mathrm{OH} \cdot\left(\mathrm{H}_{2} \mathrm{O}\right)_{3}$.
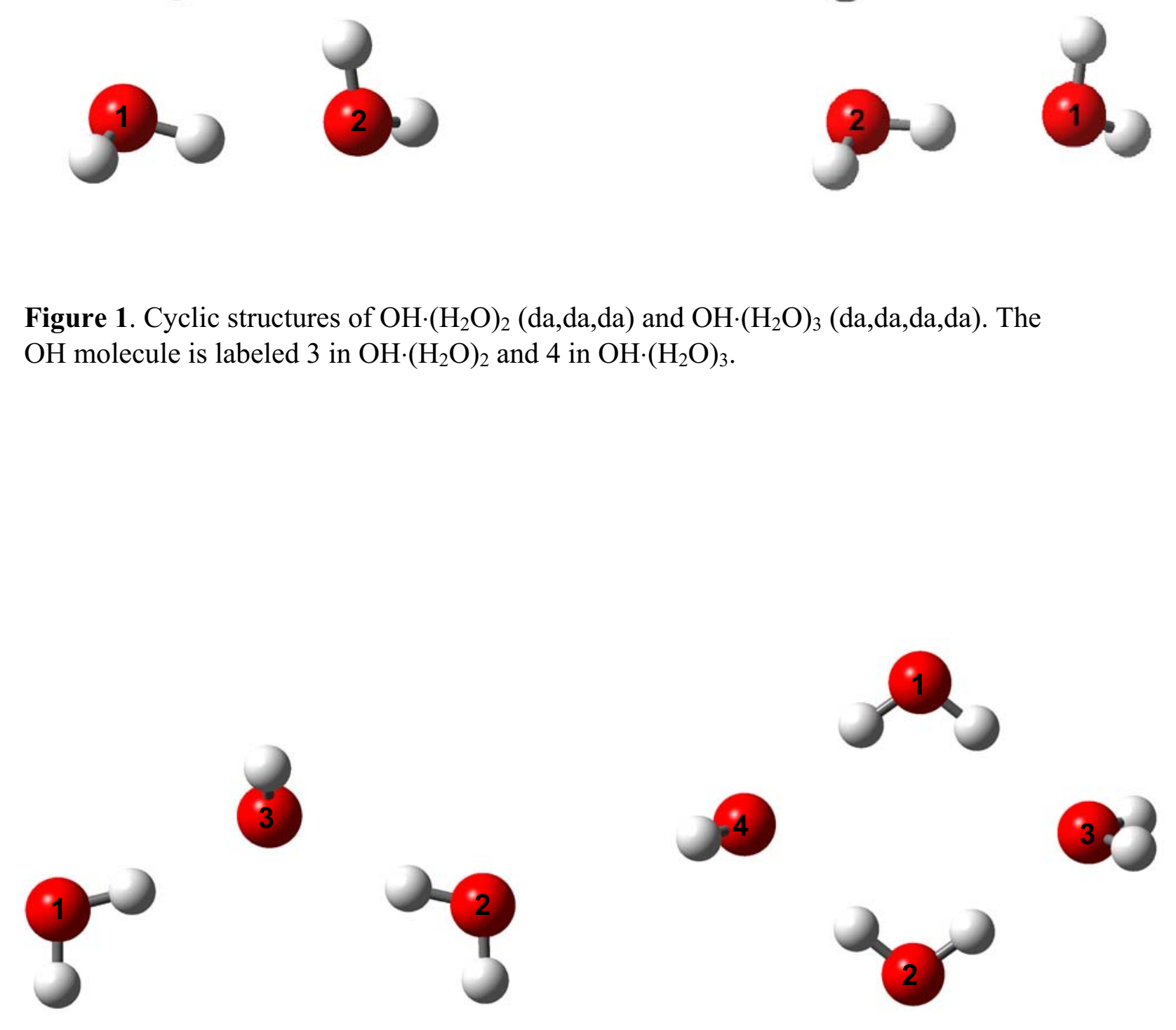

Figure 2. Configurations of $\mathrm{OH} \cdot\left(\mathrm{H}_{2} \mathrm{O}\right)_{2}\left(\mathrm{~d}\right.$,aa,d) and $\mathrm{OH} \cdot\left(\mathrm{H}_{2} \mathrm{O}\right)_{3}(\mathrm{dd}$, aa,dd,aa), with $\mathrm{OH}$ acting as a double hydrogen-bond acceptor. The $\mathrm{OH}$ molecule is labeled 3 in $\mathrm{OH} \cdot\left(\mathrm{H}_{2} \mathrm{O}\right)_{2}$ and 4 in $\mathrm{OH} \cdot\left(\mathrm{H}_{2} \mathrm{O}\right)_{3}$. 
PNNL-17069 


\title{
Direct Observation of 1-Octanol Diffusion on $\mathrm{TiO}_{2}(110)$
}

\author{
Jinlong Gong, ${ }^{a, \uparrow}$ Zhenrong Zhang, ${ }^{b, \uparrow}$ John M. White, ${ }^{b, c+t}$ Bruce D. Kay, ${ }^{b}$ C. Buddie \\ Mullins, ${ }^{a}$ and Zdenek Dohnálek ${ }^{c^{*}}$
}

${ }^{a}$ Departments of Chemical Engineering, University of Texas at Austin, Austin, Texas 78712-0231, U.S.A.

${ }^{\mathrm{b}}$ Pacific Northwest National Laboratory, Institute for Interfacial Catalysis, Fundamental Sciences Directorate, Chemical Sciences Division, Richland, WA 99352, U.S.A.

${ }^{\mathrm{c}}$ Department of Chemistry and Biochemistry, University of Texas at Austin, Austin, Texas 78712-0231, U.S.A.

\begin{abstract}
In this paper, we present the diffusion of 1-octoxy on a rutile $\mathrm{TiO}_{2}(110)$ surface employing scanning tunneling microscopy. Upon formation from dissociation of 1octanol on $\mathrm{BBO}_{\mathrm{V}}, 1$-octoxy appears as bright protrusion with four equivalent orientations indicating that 1-octoxy rotates on the surface with the $\mathrm{C}-\mathrm{O}$ bond anchored on bridgebonded oxygen vacancies. Isothermal and atomically-resolved STM images show that 1octoxy species hop along bridge-bonded oxygen atom rows. The hopping rate increases exponentially with increasing temperature with an experimental activation energy of 1.10 $\pm 0.03 \mathrm{eV}$ and a pre-exponential factor of $10^{9.2 \pm 0.3} \mathrm{~s}^{-1}$. Based on comparison of the kinetic parameters $\left(E_{b}, v\right)$ of $\mathrm{BBO}_{\mathrm{V}}$ diffusion and 1-octoxy diffusion, we propose an oxygenvacancies assisted diffusion mechanism dominate the 1-octoxy diffusion.
\end{abstract}

Keywords: 1-octanol; 1-octoxy, Scanning tunneling microscopy; Diffusion, Rotation, Oxygen vacancy; Barrier, $\mathrm{TiO}_{2}$.

\section{Introduction}

Investigations of adsorption and diffusion of molecules on metal oxides are important for better understanding of how chemical reactions proceed on the atomic scale. $^{1-3}$ Thermal excitations as well as tunneling and adsorbate assistance may provide the 
energy for reactants to diffuse to active sites and upon arrival, surmount an energy barrier to reaction. ${ }^{4,5}$ Diffusion and reaction barriers can depend on molecular orientation as well as the degree of rotational excitation. Significant contributions to the understanding of surface diffusion at the atomic/molecular scale have been made with scanning tunneling microscopy (STM) on time scales from milliseconds to days. The classic method (as we used in this study) for studying diffusion and rotation with the STM is to take snap-shots of ongoing surface processes via repeated imagines. The positions, orientations, and chemical states of molecules are monitored on a frame by frame basis until a significant number of events are recorded. Through this approach, the microscopic parameters (i.e., pre-exponential factor, diffusion energy) which determine macroscopic phenomena (diffusion rate, reaction rate) are ideally measured at the molecular level. ${ }^{1}$

Titania $\left(\mathrm{TiO}_{2}\right)$ has attracted much attention due to its wide range of applications. ${ }^{\mathbf{6 - 1 1}}$ Titania is widely used in heterogeneous catalysis, gas sensors, photolysis of water, photocatalysis, optical coatings, and pigments. In turn, such various applications of $\mathrm{TiO}_{2}$ have led to extensive fundamental and applied research with hopes to better understand the underlying physical and chemical properties on pristine and doped forms of $\mathrm{TiO}_{2}{ }^{\mathbf{6}, 12}$ For example, the thermal and photocatalytic oxidation of alcohols has been extensively studied on $\mathrm{TiO}_{2}$ surfaces as a prototype for the catalytic oxidation of organic species that model environmental contaminants. ${ }^{7,10,13}$

In recent published work, we studied the adsorption and dissociation of alcohols (i.e., methanol ${ }^{13}$ and 2-butanol ${ }^{14}$ ) on $\mathrm{TiO}_{2}(110)$ at room temperature employing in-situ scanning tunneling microscopy. Both methanol and 2-butanol prefer to adsorb on bridge bonding oxygen vacancy $\left(\mathrm{BBO}_{\mathrm{V}}\right)$ at low exposures, i.e., much less than $\mathrm{BBO}_{\mathrm{V}} \mathrm{s}$ concentration. Upon adsorption, these short-chain alcohols dissociate on $\mathrm{BBO}_{\mathrm{V}}$ via $\mathrm{O}-\mathrm{H}$ bond scission forming paired alkoxy and hydroxyl species. ${ }^{13,14}$ Additionally, with a high coverage (i.e., close to the oxygen vacancy concentration), undissociated mobile alcohol molecules adsorbed on $\mathrm{Ti}^{4+}$ interacts with alkoxy-hydroxyl pairs and facilitates the movement of hydroxyl away from the stationary alkoxy group along bridge-bonded oxygen (BBO) row. ${ }^{13}$ For 2-butanol, unlike the case for $\mathrm{CH}_{3} \mathrm{OH}$, hydrogen hopping away from the nascent 2-butoxy-hydroxyl pair formed by dissociation at $\mathrm{BBO}_{\mathrm{V}}$ 's to an adjacent anion row is tracked directly. ${ }^{14}$ 
As a continuum and an extending study of previous work, in this paper, we report results from an investigation of dynamics of the alkoxy group on $\mathrm{TiO}_{2}(110)$ at elevated temperatures using a medium long-chain alcohol, 1-octanol. Interestingly, we observed, upon formation, 1-octoxy rotate on the surface with the $\mathrm{C}-\mathrm{O}$ bond anchored on $\mathrm{BBO}_{\mathrm{V}}$. At elevated temperatures, isothermal and atomically-resolved STM images show that 1octoxy species hop along bridge-bonded oxygen atom rows. The hopping rate increases exponentially with increasing temperature. Arrhenius analysis yields an activation energy of $1.10 \pm 0.03 \mathrm{eV}$ and a pre-exponential factor of $10^{9.2 \pm 0.3} \mathrm{~s}^{-1}$.

\section{Experimental}

Experiments were performed in an ultrahigh vacuum chamber (base pressure $<8 \times$ $10^{-11}$ Torr) equipped with variable-temperature STM (Omicron), Auger electron spectroscopy (PHI), and quadrupole mass spectrometry (UTI). The $\mathrm{TiO}_{2}(110)$ substrate $\left(10 \times 3 \times 1 \mathrm{~mm}^{3}\right.$, Princeton Scientific) was mounted on a standard Omicron double plate tantalum holder and heated radiatively with a tungsten filament heater located behind the sample plate. Prior to use, commercial STM tips (Tungsten, Custom Probe Unlimited) were cleaned via $\mathrm{Ne}^{+}$sputtering and UHV annealing. The sample temperature dependence on heater power was calibrated in a separate experiment using a $\mathrm{TiO}_{2}(110)$ crystal with a chromel-alumel thermocouple (type K) glued directly to the crystal surface. Well-ordered $\mathrm{TiO}_{2}(110)$ surfaces were prepared using repeated cycles of $5 \mathrm{keV} \mathrm{Ne}$ ion sputtering and UHV annealing at 900-1000 K with the holder mounted on the preparation stage, not the STM stage. During the initial stages of sample preparation we found with Auger electron spectroscopy that the surface was contaminate with $\sim 10 \% \mathrm{Ca}$ and $\mathrm{K}$, which segregated from the bulk to the surface. After $\sim 30$ cleaning cycles the level of impurities was well below $1 \%$ confirmed by Auger spectra. The clean $\mathrm{TiO}_{2}$ sample was transferred to the STM stage where a liquid-nitrogen cooled surface was used to cryogenically pump water and eliminate the influence of background $\mathrm{H}_{2} \mathrm{O}$ (beyond maintaining a very low background pressure, $8 \times 10^{-11}$ Torr).

1-Octanol (Fisher, 99.9\%), purified by several freeze-pump-thaw cycles using liquid nitrogen, was introduced onto the $\mathrm{TiO}_{2}(110)$ surface, located at the STM stage, via a retractable tube doser containing a pinhole with a $2 \mu \mathrm{m}$ aperture. Prior to dosing, the STM 
tip was retracted $\sim 2 \mathrm{~mm}$ from the surface to avoid shadowing the imaged area. All STM images were collected using constant current $(\sim 0.1 \mathrm{nA})$ tunneling mode with a positive sample bias voltage $(1.0-1.5 \mathrm{~V})$. At each experimental temperature, in order to determine the hoping rate of 1-octanol on $\mathrm{TiO}_{2}$, several hundred (i.e., 100-400) STM images from the same area were acquired at a constant scanning rate varied from 60 to $120 \mathrm{~s} /$ frame. Thermal drift in the scans was periodically corrected for in order to sequentially acquire STM images of the same area. Only representative subsets of data from these measurements that illustrate the observed surface processes are presented here. Images were processed using WSxM software (Nanotech, freeware). ${ }^{15}$

\section{Results and Discussion}

Figure 1 shows representative sequential STM images (atomically resolved) $(t=120$ s) from an STM movie recorded as a function of experimental time at $465 \mathrm{~K}$ after adsorption of 1-octanol on $\mathrm{TiO}_{2}(110)$ at room temperature. The surface is composed of rows of topographically low lying $\mathrm{Ti}^{4+}$ ions and rows of topographically high lying $\mathrm{BBO}$ ions running along the [001] direction. In the empty state STM images, the low lying $\mathrm{Ti}^{4+}$ ions are imaged as protrusions while the rows of $\mathrm{BBO}$ ions are imaged as depressions due to the inverse electronic contrast of these two ions. ${ }^{6}$ Additionally, $\mathrm{BBO}_{\mathrm{V}}$ 's appear on images as bright spots on dark rows as marked by the black circle. There are $0.1 \mathrm{ML}$ $\mathrm{BBO}_{\mathrm{V}}$ 's on this surface. Here one ML is defined in terms of the area density of fivecoordinate $\mathrm{Ti}^{4+}$ cations on a perfect $\mathrm{TiO}_{2}(110)$ surface $\left(5.2 \times 10^{14} \mathrm{~cm}^{-2}\right)$. Upon adsorption, 1- octanol appears as bright protrusion with " $\mathrm{H}$ " shape as mark in white circle. The 1octanol coverage was held at $\sim 0.01 \mathrm{ML}$. The in-situ adsorption results (not shown) reveal that, behaving similar to other short-chain alcohols (i.e., $\mathrm{CH}_{3} \mathrm{OH}$ and 2-butanol), ${ }^{\mathbf{1 3}, 14} 1$ octanol preferentially adsorbs at $\mathrm{BBO}_{\mathrm{v}}$ sites and dissociates via $\mathrm{O}-\mathrm{H}$ bond scission to form paired 1-octoxy and hydroxyl species. The " $\mathrm{H}$ " shape of the 1-octoxy suggests that 1octoxy species rotate on the surface with the $\mathrm{C}-\mathrm{O}$ bond anchored on $\mathrm{BBO}_{\mathrm{V}}$ and have four equivalent orientations. Due to fast rotation speed of 1-octoxy group and relatively slow scanning speed of the STM, while the eight-carbon backbone of 1-octoxy switches among many orientations on the time scale of gathering an STM image, the detected four angular preferences reflect four local minima in the potential energy surface. Additionally, we note 
that the nominal length of the ligand (from the oxygen to the most distant carbon) is $\sim 9.1$ $\AA$, in a good agreement with the experimentally measured STM line profiles (not shown).

Figure 1 also reveals the thermally-driven diffusion of 1-octoxy species along the BBO rows. Comparing the position of two 1-octoxy species (highlighted by green arrows) from Figure 1(a) to Figure 1(b), we notice that these 1-octoxy species diffuse along the [001] direction. Additionally, the white circle represents the stationary 1-octoxy species, while the impurity on the surface that can be used a reference to track the movement of 1octoxy species is marked by the black arrow. Based on the analysis of collected images ( $200,30 \times 30 \mathrm{~nm}^{2}$ ), 1-octoxy species diffuse exclusively along the [001] direction at this temperature $(465 \mathrm{~K})$ and all observed displacements between two consecutive images (i.e., $2 \mathrm{~min}$ ) range from 1 to 3 atom lattice spacings. About $30 \%$ of 1 -octoxy species change their position from image to image at $465 \mathrm{~K}$. Cross row hopping is rarely observed in the temperature range $(400-500 \mathrm{~K})$ explored in this study.
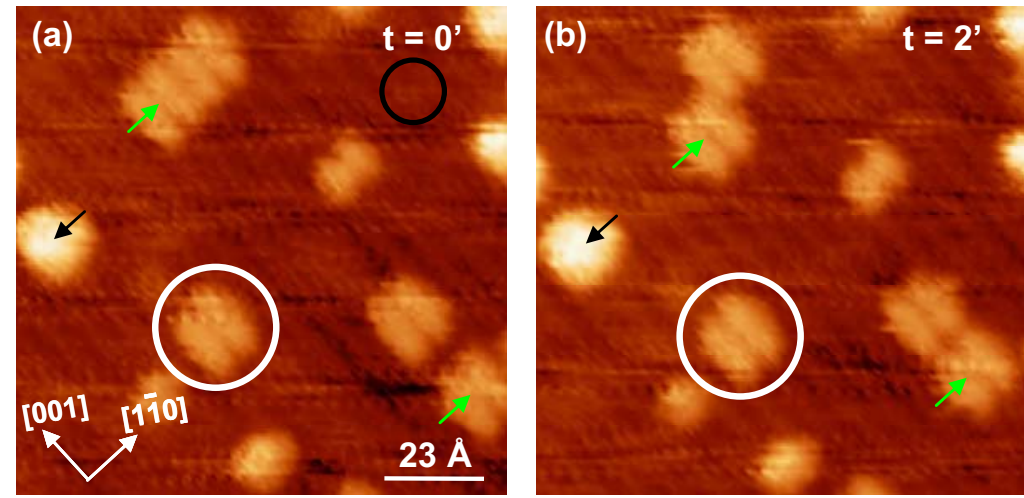

Figure 1. Two representative sequential STM images $(t=120 \mathrm{~s})$ from an STM movie recorded as a function of experimental time at $465 \mathrm{~K}$ after adsorption of 1-octanol on $\mathrm{TiO}_{2}(110)\left(\theta_{\text {l-octanol }}=0.01 \mathrm{ML}\right)$ at room temperature. Upon adsorption, 1-octanol preferentially adsorbs at bridge-bonded oxygen vacancy $\left(\mathrm{BBO}_{\mathrm{v}}\right)$ sites and dissociates via $\mathrm{O}-\mathrm{H}$ bond scission to form paired 1-octoxy and hydroxyl species. The $\mathrm{BBO}_{\mathrm{v}}$-bound 1octoxy features appear as " $\mathrm{H}$ "s. The detected angular preference indicates four local minima in the potential energy surface. The whole STM sequence is obtained on a same area $\left(115 \times 115 \AA^{2}\right)$ with a bias voltage of $+1.2 \mathrm{~V}$ and a tunneling current of $0.09 \mathrm{nA}$. The distance between adjacent $\mathrm{Ti}^{4+}$ ions along the $\mathrm{Ti}^{4+}$ row is $3.0 \AA$ and distance between the $\mathrm{Ti}^{4+}$ rows is $6.5 \AA$. The length of the ligand (from the oxygen to the most distant carbon) is $\sim 9.1 \AA$. The black circle highlights an example of $\mathrm{BBO}_{\mathrm{v}}$. The green arrows highlight the 1-octoxy species that hop along the BBO rows. The white circle marks the stationary 1octoxy species. The black arrow represents the impurity on the surface. 
Another issue that has to be mentioned here is that, as the hopping rate $(h)$ increases with increasing temperature, it turns out to be impossible to track all the hops with our relatively slow STM scanning rate $(0.5-1$ frame/min). For example, as addressed in a previous study by Zhang et al., ${ }^{16}$ a zero net 1-octoxy displacement would occur due to two sequential hops in opposite directions. To reasonably account for this, we use a mathematical analysis for a 1-dimensional (1D) random walk proposed by Ehrlich and coworkers. ${ }^{17}$ Here the probability $\left(P_{x}(h t)\right)$ of finding the diffusing entity displaced from its initial position by a displacement $(x)$ at time $(t)$ is given by expression as follows:

$$
P_{x}(h t)=\exp (-2 h t) I_{x}(2 h t),
$$

where $I_{n}$ are the modified Bessel functions of the first kind. The mean square displacement of the distribution, $<\Delta x^{2}>$, is given as: $:^{17}$

$$
<\Delta x^{2}>=2 h t
$$

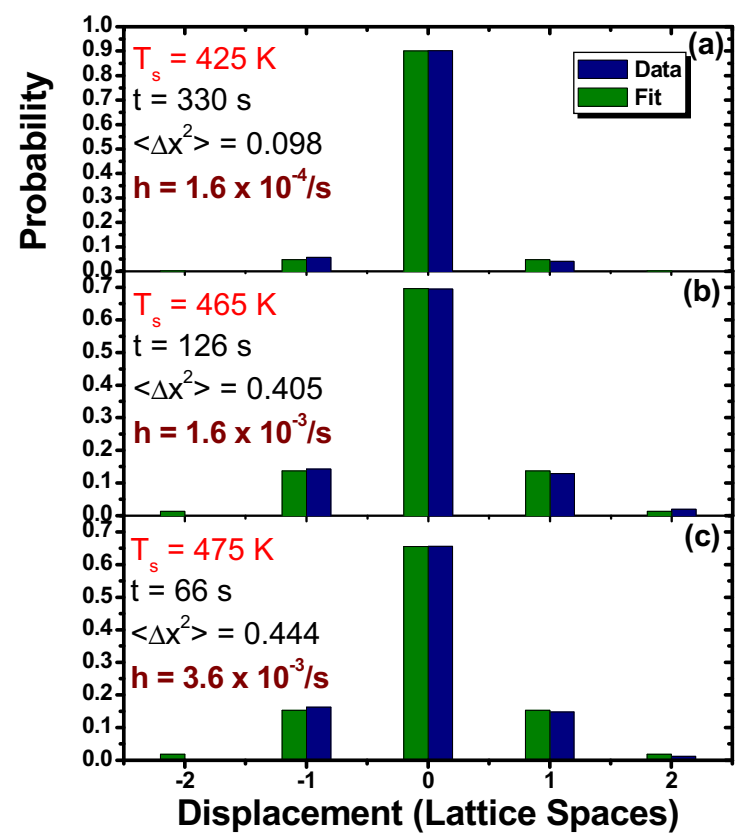

(2)

Figure 2. The displacement distribution (blue bars) for diffusion of 1-octoxy species on $\mathrm{TiO}_{2}$ (110) obtained at different temperatures of (a) $425 \mathrm{~K}$, (b) $465 \mathrm{~K}$, and (c) $475 \mathrm{~K}$. The values of the mean square displacement $\left(<\Delta x^{2}>\right)$ for a simple 1D random walk are extracted using the statistical formula $\left\langle\Delta x^{2}\right\rangle=\sum_{i} P_{i} x_{i}^{2}$ where $P_{i}$ is the probability of 
finding the diffusing 1-octoxy species at a number of lattice space displacements, $x_{i}$. The $<\Delta x^{2}>$ and hopping rate $(h)$ values are further used to calculate the probability distribution for each temperature, as shown with green bars. The good quality of the fit further shows that the motion of the 1-octoxy species can be described by a simple 1D random work. The total number of analyzed events is $\sim 200-500$ at each temperature.

Employing the mathematical analysis outlined above, we were able to determine the hopping rates of 1-octoxy and the overall distributions of 1-octoxy displacements using Equations (1) and (2) at six different temperatures between 400 and $500 \mathrm{~K}$. An example of the experimentally measured distributions determined at $424 \mathrm{~K}, 465 \mathrm{~K}$ and $475 \mathrm{~K}$ as well as the best fits obtained using Equations (1) and (2) are shown in Figure 2, respectively. The good quality of the theoretical fit further shows that the diffusion of 1-octoxy can be described by a simple $1 \mathrm{D}$ random walk.

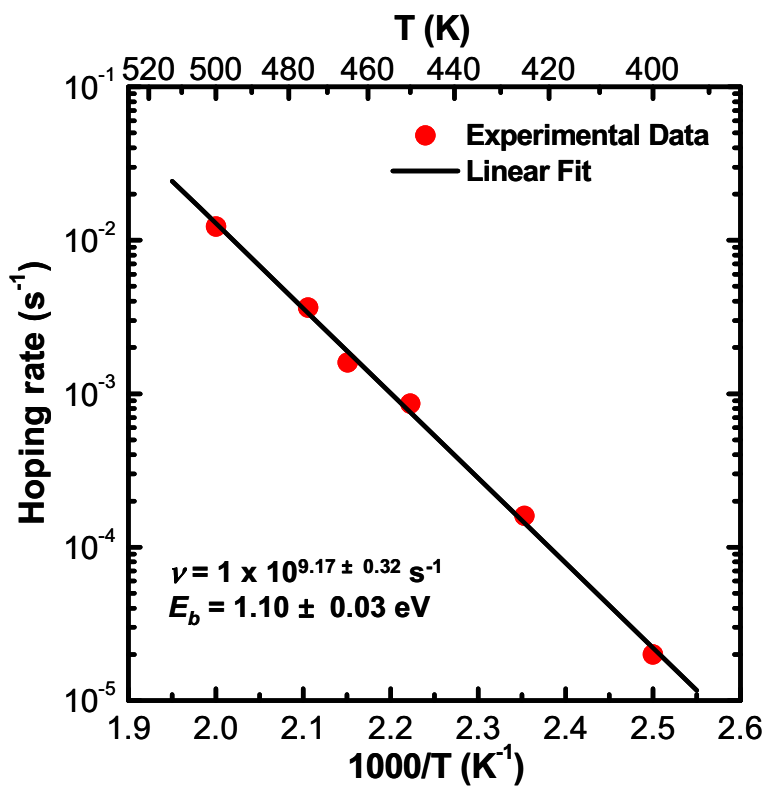

Figure 3. Arrhenius plot of the logarithm of hopping rate $(h)$ calculated from the experimentally determined mean square displacements $\left(<\Delta x^{2}>\right)$ vs $1000 / T$ for diffusion of 1-octoxy species on $\mathrm{TiO}_{2}(110)$. A fit to the rate equation $h=v \exp \left(-E_{b} / k_{B} T\right)$ gives a diffusion barrier of $1.10 \pm 0.03 \mathrm{eV}$ and pre-exponential factor of $10^{9.2 \pm 0.3} \mathrm{~s}^{-1}$. The hopping rates reported here were determined by analysis of 200 to 500 events at each temperature.

Assuming that the observed 1-octoxy diffusion is thermally activated, we can employ the Arrhenius expression for the hopping rate, $h=v \exp \left(-E_{b} / k_{B} T\right)$, where $E_{b}$ is 
the diffusion barrier, $v$ is the pre-exponential factor, and $k_{B}$ is Boltzmann's constant to determine the diffusion barrier and the pre-exponential factor. To extract such relevant kinetic parameters $\left(E_{b}, v\right)$ we perform an Arrhenius analysis and plot the logarithm of hopping rate $(h)$ as a function of reciprocal temperature $(1000 / T)$ as shown in Figure 3. This analysis yields a diffusion barrier, $E_{b}=1.10 \pm 0.03 \mathrm{eV}$, and a pre-exponential factor, $v=1 \times 10^{9.2 \pm 0.3} \mathrm{~s}^{-1}$.

In our previous work of the diffusion of $\mathrm{BBO}_{\mathrm{V}}$ 's on rutile $\mathrm{TiO}_{2}(110)$ surface we have reported a diffusion barrier of $1.15 \pm 0.05 \mathrm{eV}$ and a pre-exponential factor of $1 \times 10^{12.2 \pm 0.6}$ $\mathrm{s}^{-1} \cdot{ }^{16}$ Interestingly, the barrier for 1-octoxy diffusion is almost identical to that for $\mathrm{BBO}_{\mathrm{V}}$ diffusion. We also note that the pre-factor for 1-octoxy diffusion is three orders of magnitude lower than that for $\mathrm{BBO}_{\mathrm{V}}$ diffusion. Based on this, we propose that 1-octoxy diffusion on $\mathrm{TiO}_{2}(110)$ is assisted by $\mathrm{BBO}_{\mathrm{V}}$ 's. Shown in Figure 4 is the schematic model describing the $\mathrm{BBO}_{\mathrm{V}}$ assisted mechanism for 1-octoxy diffusion, i.e., the initial spatially separated pair of 1-octoxy species and $\mathrm{BBO}_{\mathrm{V}}$ (Figure $4 \mathrm{a}$ ), diffusion of nearby $\mathrm{BBO}_{\mathrm{V}}$ along the $\mathrm{BBO}$ row to the site adjacent to the 1-octoxy species (Figure $4 \mathrm{~b}$ ), a transition state in which the 1-octoxy diffuses into the $\mathrm{BBO}_{\mathrm{V}}($ Figure $4 \mathrm{c})$ and a final 1-octoxy species moved one lattice space with the $\mathrm{BBO}_{V}$ on the other side (Figure 4d). Since the 1-octoxy diffusion is $\mathrm{BBO}_{V}$ mediated, the diffusion barrier should be determined by $\mathrm{BBO}_{V}$ diffusion. That is what we observe; the 1-octoxy diffusion barrier $(1.10 \mathrm{eV})$ is almost identical with that for $\mathrm{BBO}_{\mathrm{V}}$ diffusion $(1.15 \mathrm{eV})$. Since the diffusion can occur only in the configurations with the $\mathrm{BBO}_{\mathrm{V}}$ 's next to the 1-octoxy the pre-factor for 1-oxtoxy diffusion can be lowered significantly (here three orders of magnitude) as compared to that for $\mathrm{BBO}_{\mathrm{V}}$ diffusion.

(a)

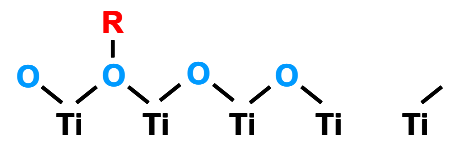

(b)

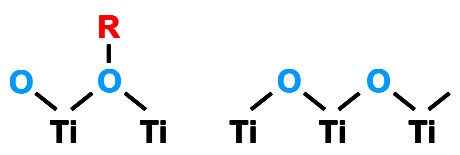

(c)

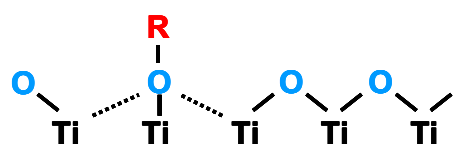

(d)

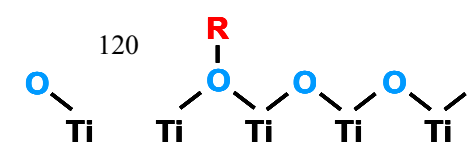


Figure 4. Schematic model of the proposed $\mathrm{BBO}_{\mathrm{v}}$-assisted along-row diffusion process of 1-octoxy on $\mathrm{TiO}_{2}$ (110): (a) a 1-octoxy species formed after adsorption and dissociation of 1-octanol on a $\mathrm{BBO}_{\mathrm{V}}$; (b) Diffusion of $\mathrm{BBO}_{\mathrm{V}}$ along the $\mathrm{BBO}$ row to the site adjacent to the 1-octoxy species; (c) the intermediate state in which the 1-octoxy diffuse into the $\mathrm{BBO}_{\mathrm{V}}$; (d) Diffusion of 1-octoxy species to the adjacent $\mathrm{BBO}_{\mathrm{v}}$ site.

\section{Conclusions}

Employing scanning tunneling microscopy, we present the first study of the diffusion of 1-octoxy species formed from the adsorption and dissociation of 1-octanol on bridge bonded oxygen vacancies on a rutile $\mathrm{TiO}_{2}(110)$ surface at elevated temperature $(400-500 \mathrm{~K})$. The 1-octoxy species appears as a bright protrusion with four equivalent orientations indicating that it can rotates on the surface with the $\mathrm{C}-\mathrm{O}$ bond anchored on the bridge-bonded oxygen vacancies. Isothermal and atomically-resolved STM images show that 1-octoxy species hop along bridge-bonded oxygen atom rows. The hopping rate increases exponentially with increasing temperature with an experimental activation energy of $1.10 \pm 0.03 \mathrm{eV}$ and a pre-exponential factor of $10^{9.2 \pm 0.3} \mathrm{~s}^{-1}$. Comparing the kinetic parameters $\left(E_{b}, v\right)$ of $\mathrm{BBO}_{\mathrm{V}}$ diffusion and 1-octoxy diffusion, we propose an oxygen-vacancies assisted mechanism for the 1-octoxy group diffusion.

\section{Acknowledgement}

This work was supported by the U.S. Department of Energy Office of Basic Energy Sciences, Chemical and Material Sciences Division, Robert A. Welch Foundation (F0032), and National Science Foundation (CHE-0412609). and it was performed at the W.R. Wiley Environmental Molecular Science Laboratory, a national scientific user facility sponsored by the Department of Energy's Office of Biological and Environmental Research located at Pacific Northwest National Laboratory. PNNL is operated for the U.S. DOE by Battelle under Contract No. DE AC06 76RLO 1830. J.L.G. would like to acknowledge the support from the Summer Research Institute at PNNL through an Alternate Sponsored Fellowship. The authors feel sad and shocked that our respectable colleague, Dr. White, had suddenly passed away from an unexpected heart problem.

\section{References}

[1] Ho, W. J. Chem. Phys 2002, 117, 11033. 
[2] Gimzewski, J. K.; Joachim, C.; Schlittler, R. R.; Langlais, V.; Tang, H.; Johannsen, I. Science 1998, 281, 531.

[3] Wintjes, N.; Bonifazi, D.; Cheng, F. Y.; Kiebele, A.; Stohr, M.; Jung, T.; Spillmann, H.; Diederich, F. Angew. Chem. Int. Ed. 2007, 46, 4089.

[4] Lauhon, L. J.; Ho, W. J. Chem. Phys 1999, 111, 5633.

[5] Mayne, A. J.; Lastapis, M.; Baffou, G.; Soukiassian, L.; Comtet, G.; Hellner, L.; Dujardin, G. Phys. Rev. B 2004, 69.

[6] Diebold, U. Surf. Sci. Rep. 2003, 48, 53.

[7] Linsebigler, A. L.; Lu, G. Q.; Yates, J. T. Chem. Rev. 1995, 95, 735.

[8] Valden, M.; Lai, X.; Goodman, D. W. Science 1998, 281, 1647.

[9] Thompson, T. L.; Yates, J. T. Chem. Rev. 2006, 106, 4428.

[10]Bikondoa, O.; Pang, C. L.; Ithnin, R.; Muryn, C. A.; Onishi, H.; Thornton, G. Nat. Mater. 2006, 5, 189.

[11]Zhang, Z.; Bondarchuk, O.; Kay, B. D.; White, J. M.; Dohnalek, Z. J. Phys. Chem. B 2006, 110, 21840.

[12] Campbell, C. T. Surf. Sci. Rep. 1997, 27, 1.

[13]Zhang, Z. R.; Bondarchuk, E.; White, J. M.; Kay, B. D.; Dohnalek, Z. J. Am. Chem. Soc. 2006, 128, 4198.

[14]Zhang, Z. R.; Bondarchuk, E.; Kay, B. D.; White, J. M.; Dohnalek, Z. J. Phys. Chem. $C$ 2007, 111, 3021.

[15] http://www.nanotec.es.

[16]Zhang, Z. R.; Ge, Q. F.; Li, S.-C.; White, J. M.; Kay, B. D.; Dohnalek, Z. Phys. Rev. Lett. 2007, In press.

[17]Wrigley, J. D.; Twigg, M. E.; Ehrlich, G. J. Chem. Phys 1990, 93, 2885. 


\author{
Shilpi Gupta \\ Portland State University \\ and \\ S. Thevuthasan \\ Pacific Northwest National Laboratory
}

\title{
Process:
}

1. Sol-gel synthesis of ceria and $\mathrm{Yb}, \mathrm{Y}, \mathrm{Sm}$ and Gd doped ceria

2. Measurement of conductivity as a function of doping concentration and processing conditions

3. Temperature dependent ceria reduction \& grain boundary mapping by XRD and SEM

\section{Goal:}

The aim of this project is to observe and study temperature dependent ceria reduction properties and possible grain boundary dopants/defects migration in sol-gel grown ceria thin films. Reduction properties of ceria are already well known in catalysis and solid oxide fuel cells. The defects migration is a major issue which governs the properties like oxygen storage and oxygen conduction in ceria. The doping of above elements in ceria are expected to create oxygen vacancies and eventually influence virtually all types of transport properties like ionic, electronic, defects migration and grain-boundary segregation etc. It is extremely complex to separate the individual contribution of each in the overall transport. Thus, it would be highly desirable to study the effects of changes in surrounding conditions such as temperature, pressure, grain-size, thickness and porosity on the transport properties. Finally investigating the scope of utilizing ceria nanoparticles for trace oxygen detection. The outcome of this research directly supports EMSL/PNNL's mission related to energy and catalysis. 
PNNL-17069 
PNNL-17069

\section{A Quasielastic Neutron Scattering Investigation of the Reorientational Motions of $\left[\mathrm{NH}_{4}\right]^{+}$and $\left[\mathrm{BH}_{4}\right]^{-}$Tetrahedra in Ammonium Borohydride}

Michael R Hartman

Intuition: Oregon State University and

Dr. Nancy Hess

Pacific Northwest National Laboratory

Socio-economic pressures, arising from a desire to move towards a carbon-neutral or carbon-free energy cycle to offset the negative environmental effects of rising levels of atmospheric carbon dioxide, combined with the increasing world-wide demand, and consequently cost, of liquid hydrocarbon fuels have created a growing interest in using hydrogen as an energy carrier. The significant technological challenges that must be overcome to successfully implement a hydrogen economy were identified in a recent workshop sponsored by the Department of Energy (DOE) Office of Basic Energy and Sciences (OBES). ${ }^{i}$ Perhaps the largest single barrier that must be surmounted is the development of a high capacity, reversible, low-cost hydrogen storage medium that operates at temperatures and pressures consistent with fuel-cell applications.

One class of complex metal hydride which shows promise for hydrogen storage is the tetrahydroborates. The tetrahydroborates consist of $\left[\mathrm{BH}_{4}\right]^{-}$anions which are combined with a cationic species to form an ionic solid. An advantage of the tetrahydroborates is that the cationic species can come from the low atomic number members of the Group IA or Group IIA columns of the periodic table (i.e. $\mathrm{Li}, \mathrm{Na}, \mathrm{K}, \mathrm{Be}, \mathrm{Mg}, \mathrm{Ca}, \ldots$ ) or other hydrogenous cations like $\mathrm{NH}_{4}{ }^{+}$, resulting in materials with inherently high volumetric and gravimetric hydrogen storage densities. Although several of these materials have been of technological importance for many decades there is still a great deal that is not well understood about their structure and in particular the dynamics of the hydrogen within the materials. Detailed information regarding the crystal structure and the dynamics of hydrogen within these materials is a prerequisite to their rational design as hydrogen storage media.

In the proposed research, we will conduct a quasielastic neutron scattering study of ammonium borohydride, $\mathrm{NH}_{4} \mathrm{BH}_{4}$, to gain further insight into the dynamical motions of the $\left[\mathrm{NH}_{4}\right]^{+}$and $\left[\mathrm{BH}_{4}\right]^{-}$tetrahedra present within the material. A prior theoretical work suggested a barrier to rotation of 0.9 and $1.6 \mathrm{kcal} / \mathrm{mole}$ for the $\left[\mathrm{NH}_{4}\right]^{+}$and $\left[\mathrm{BH}_{4}\right]^{-}$species, respectively. ${ }^{\text {ii }}$ The quasielastic neutron scattering effort in the proposed research will provide experimental validation of these barriers to rotation and permit an investigation into the geometry of the reorientations, i.e. 2-fold versus 3 -fold rotations. Insight into the dynamical motions of these tetrahedra and changes that occur concomitant with the nanoscale confinement or inclusion of catalytic material will further our fundamental physical understanding of the tetrahydroborate family of compounds, and will aid in the design of future hydrogen storage materials. 
PNNL-17069 
PNNL-17069

\title{
Ion Beam and Surface Analysis of Conductivity Suppressed Mn Doped ZnO Thin Films Grown by MOCVD
}

W.M. Hlaing Oo ${ }^{a}$, L.V. Saraf ${ }^{b}$, M.H. Engelhard ${ }^{b}$, V. Shutthanandan ${ }^{b}$, D.R. Baer ${ }^{b}$ and M.D. McCluskey ${ }^{\mathrm{a}}$

(a) Department of Physics, Washington State University, Pullman WA

(b) Pacific Northwest National Laboratory, Richland WA

\begin{abstract}
We study dopant concentration distribution and conductivity effects in $\mathrm{Mn}: \mathrm{ZnO}$ films. The ion beam, surface and microstructural properties of undoped $\mathrm{ZnO}$ films were compared with lightly $\mathrm{Mn}$-doped $\mathrm{ZnO}$ films. Suppression of $\mathrm{ZnO}$ conductivity was noticed up to 4.5 atom $\% \mathrm{Mn}$ doping. The existence of $\mathrm{Mn}^{2+}$ confirmed by X-ray photoelectron spectroscopy (XPS) reduces the conductivity by possible $\mathrm{Zn}$ interstitials replacement which is widely believed to be responsible for the n-type conductivity. No major change in the activation energy $(\sim 40 \mathrm{meV})$ and a reduction in the $\mathrm{Zn} / \mathrm{O}$ ratio as a function of $\mathrm{Mn}$ concentration in highly sensitive proton induced X-ray emission (PIXE) technique also support this hypothesis. We discuss our results from a view point of homogeneous Mn distribution, elemental XPS ratio offsets and secondary phase formations in $\mathrm{ZnO}$ films.
\end{abstract}


PNNL-17069

\section{INTRODUCTION}

Zinc oxide is a wide band gap semiconductor that has received rising attention for a variety of applications. ${ }^{1}$ Among the transition-metal dopants, manganese is considered to be a promising candidate for dilute magnetic semiconductors (DMS). ${ }^{2}$ Fukumura et al. showed that higher concentration of $\mathrm{Mn}$ (up to 35\%) can incorporate into $\mathrm{ZnO}$ without changing the wurtzite structure. ${ }^{3}$ However, there are other studies which found segregation of the $\mathrm{Mn}_{3} \mathrm{O}_{4}$ phase even at low Mn concentrations. ${ }^{4}$ Liu et al. ${ }^{5}$ studied $\mathrm{Mn}$ doped $\mathrm{ZnO}$ films by radio frequency magnetron sputtering and observed that $25 \%$ of $\mathrm{Mn}$ substitute $\mathrm{Zn}$ ions in wurtize structure. Thus, there is a clear need to understand manganese doping induced conductivity effects in $\mathrm{ZnO}$ films. Especially at low doping levels, there exists an interesting correlation between native defect states and modulation in it by dopants. Excellent correlation among surface and microstructrural properties in $\mathrm{Mn}$ doped $\mathrm{ZnO}$ films with conductivity effects as a function of dopant incorporation can shed valuable light on the band structure modification with excess defect states. In this report, we try to understand and discuss the observed conductivity suppression with correlation to ion beam and surface properties in oriented and lightly doped (up to $\sim 4$ atom \%) Mn:ZnO films.

A wide variety of thin film growth techniques have been utilized to grow oriented or epitaxial $\mathrm{ZnO}$ thin films. Metal organic chemical vapor deposition (MOCVD) has been one of the popular techniques to grow $\mathrm{ZnO}$ due to its high throwing power, scalability in operation and high purity of the precursor solutions. The challenges for CVD precursor volatility can be tackled by using appropriately designed main and dopant precursors which decompose at similar temperatures. Precursors such as Bis(2,2,6,6-tetramethyl-3,5heptanedionato)Zinc $\left[\mathrm{Zn}(\mathrm{TMHD})_{2}\right]$ provide a good compromise between appropriate 
volatility and environmental friendliness with less carbon contamination in the films ${ }^{6}$. In this work, we show with the help of unchanged activation energy in the transport properties and x-ray photoelectron spectroscopy (XPS) data for Mn that the suppressed conductivity of $\mathrm{ZnO}$ as a function of $\mathrm{Mn}$ addition is a result of $\mathrm{Mn}^{2+}$ valence state replacing $\mathrm{Zn}^{2+}$ state. Since most of the $\mathrm{n}$-type conductivity in $\mathrm{ZnO}$ is correlated to the oxygen vacancies or $\mathrm{Zn}$ interstitials, we also believe from our highly sensitive proton induced x-ray emission (PIXE) data that addition of Mn reduces Zn interstitials.

\section{EXPERIMENTAL}

A cold-wall Emcore MOCVD system at Environmental Molecular Sciences Laboratory, PNNL was used to grow the $\mathrm{ZnO}$ thin-films. The zinc $\left[\mathrm{Zn}(\mathrm{TMHD})_{2}\right]$ and manganese $\left[\mathrm{Mn}(\mathrm{TMHD})_{2}\right]$ precursors were dissolved in tetrahydrofuran (THF) solution to a molar concentration of $0.025 \mathrm{M}$. The depositions were made on $c$-plane sapphire and silicon (100) oriented substrates. The Mn concentrations were varied by adjusting $\mathrm{Zn}$ and Mn precursors flow rate during the deposition. Visually a more yellowish color appearance was observed in the films with higher Mn contents. The nitrogen was used as carrier gas. For better oxidation, oxygen gas was also injected into reactor. We note that the thickness of $\mathrm{ZnO}$ films has a linear relationship with partial deposition pressure in the range of 5-60 Torr. This situation is typically present when a feed rate limited condition during the deposition exists. We also note that changing the precursor flow rates in the range of $50-100 \mathrm{~g} / \mathrm{hr}$ does not significantly alter the film thickness at a given constant pressure. Deposition at vapor pressure 60 Torr results a growth rate about $\sim 1 \AA /$ s. Details of growth parameters are presented in Table I. 
PNNL-17069

The structural properties of the films were determined by x-ray diffraction (XRD) using $\mathrm{Cu} \mathrm{K} \alpha$ x-ray. Elemental quantification was made by PIXE. Rutherford back scattering spectrometry (RBS) measurements were made by using $2.0 \mathrm{MeV} \mathrm{He}{ }^{+}$ions at normal incidence. Thickness and chemical composition of the films were determined by fitting the experimental data using SIMNRA program. Furthermore, the chemical compositions were also examined with XPS, and the measurements were made by using a Physical Electronics Quantum 2000 Scanning ESCA Microprobe with monochromatic Al $\mathrm{K} \alpha$ x-rays $(1486.7 \mathrm{eV})$ source and a spherical section analyzer. To remove carbon contamination at the surface, $\mathrm{Ar}^{+}$ion sputtering was performed using $2 \mathrm{kV} \mathrm{Ar}^{+}$ions with a sputter rate of $2.8 \mathrm{~nm} / \mathrm{min}$. The etched thicknesses of the films were varied from $0.07 \mathrm{~nm}$ to $1.1 \mathrm{~nm}$. The charge correction was made by referencing $\mathrm{O} 1 \mathrm{~s}$ line at $530.4 \mathrm{eV}$ from known $\mathrm{ZnO}$ reference. Temperature dependent electrical conductivity measurements were made in standard 4-probe van der Pauw geometry. The films grown on single crystal sapphire substrates were used for electrical conductivity measurements.

\section{RESULTS AND DISCUSSION}

The XRD spectra of undoped and Mn doped films grown on Si (100) single crystals show dominant peaks for $\mathrm{ZnO}$ (002) plane and (004) plane (Fig. 1). The results confirm that the films are well-oriented along the c-axis. Within XRD detection limit, no secondary phase formation related to $\mathrm{Mn}-\mathrm{O}$ is detected. The as-recorded $c$-axis lattice parameter for undoped sample was $5.20 \AA$. After assuming that the films are completely relaxed due to its $\sim 100 \mathrm{~nm}$ thickness and expected defects in it, the $c$-axis lattice parameters for Mn doping of $\sim 1.5$ atom $\%$ and $\sim 4.5$ atom $\% \mathrm{ZnO}$ films are observed to be 
slightly increased to $5.21 \AA$ and $5.22 \AA$, respectively. This shift to lower angle as a function of $\mathrm{Mn}$ incorporation is shown as an inset of Figure 1. Hence, the possible substitution of $\mathrm{Mn}^{2+}$ for $\mathrm{Zn}^{2+}$ expands the lattice parameter due to the larger ionic radius of $\mathrm{Mn}^{2+}$ ion. In addition, the lack of major structural disorder in doped films was confirmed by the consistency of peak widths without further broadening. A similar increase in the $\mathrm{ZnO}$ lattice parameter with addition of $\mathrm{Mn}$ was also noticed by Chikoidze et. al. ${ }^{7,8}$

PIXE is highly sensitive to elemental analysis and thus is an excellent technique to quantify the overall concentration of host as well as dopant materials. A typical PIXE spectrum for the $\sim 3 \%$ atom $\%$. Mn doped films grown on $\mathrm{Si}(100)$ a single crystal is shown in Fig. 2. The Mn K $\alpha$ emission along with $\mathrm{Zn}$ and Si peaks, can be clearly seen in the spectrum. The inset of Figure 2 represents RBS spectra of the same $\mathrm{Mn}: \mathrm{ZnO}$ film grown on a Si (100) single crystal. The overall uniformity in the Mn distribution can be realized in the spectrum. We also use these data for the calculation of film thickness $\sim 100$ $\mathrm{nm}$. From the curve profile, no noticeable diffusion of the film into the substrate is observed. High resolution XPS spectra for the regions of Zn 2p, O 1s, Mn 2p and Mn 3p are shown in Figs. 3 and 4. The intensity ratios between $\mathrm{O}$ to $\mathrm{Zn}$ were mostly un-affected by $\mathrm{Mn}$ incorporation. Despite the lack of $\mathrm{Mn}$ dopant in undoped $\mathrm{ZnO}$ sample, there is a weak and broad peak exhibits at an energy around $640 \mathrm{eV}$, which is Auger (AES) line of $\mathrm{Zn} 2 \mathrm{p}$ state (Fig. 4) originating from Auger emission of $\mathrm{Zn}$ atoms. Hence, instead of using Mn 2p peak, we used weaker Mn 3p peak for the analysis of Mn composition, so that we can avoid the convolution of $\mathrm{Zn}$ Auger emission. The Mn 2p and Mn 3p peak positions and widths are consistent for all $\mathrm{Mn}$ contents which indicate that $\mathrm{Mn}^{2+}$ state is dominant in all doped films. 
PNNL-17069

The ratio of zinc to oxygen compositions as a function of Mn content calculated from both XPS and PIXE are presented in Fig. 5. The data are presented in four different sets as (a) from PIXE technique, (b) As recorded XPS surface scan, (c) After $\mathrm{Ar}^{+}$ion sputtering in XPS and (d) XPS corrected atomic concentration, respectively. One of the major reasons for presenting the data in such a way is to discuss the role of surface carbon, and hydrocarbons in XPS technique, adjusting it with correction and comparing with independent PIXE technique. As shown in Fig, 5(b), by calculating the ratio of $\mathrm{Zn}$ to $\mathrm{O}$ peaks in as-recorded sample, we have seen significant variation in it with Mn addition. By considering the peaks for surface hydrocarbons and correcting it in the total, we have seen that variation in the $\mathrm{Zn}$ to $\mathrm{O}$ peak ratio was somewhat reduced. $\mathrm{Ar}^{+}$ion sputtering was used to remove surface layers and XPS analysis after sputtering indicates substantial removal of the surface hydrocarbons. As seen in Fig. 5(d), the variation in $\mathrm{Zn}$ to O peak ratio as a function of $\mathrm{Mn}$ addition narrowed considerably as a result of cleaning of surface contaminants and hydrocarbons. For most part, the XPS ratio analysis indicates Zn rich films. Some of the major reasons for it can be oxygen sensitivity factor is different than $\mathrm{Zn}$ sensitivity factor. Also as noted previously oxygen is known to sputter out preferentially. ${ }^{9}$ However, even though not detected in our analysis, we can not completely rule out minor percentage of sub-stoichometric ZnO. As seen in Fig. 5(a), after comparing the data with completely independent and sensitive PIXE technique, we have seen that the ratio of $\mathrm{Zn}$ to $\mathrm{O}$ gradually decreases from near 1 as a function of $\mathrm{Mn}$ doping concentration in $\mathrm{ZnO}$ films, which should be an expected outcome. We would like to also note that the slight differences in Mn atomic concentrations calculated by PIXE and XPS techniques are due 
PNNL-17069

to differences in the sensitivity factors, usage of $3 p$ line instead of $2 p$ line, and normalization process during calculations in the case of XPS analysis.

The temperature dependent conductivity results indicate that conductivity decreases with increasing $\mathrm{Mn}$ content in $\mathrm{ZnO}$ (Fig. 6). The results are in good agreement with other reports of $\mathrm{Mn}$ doped $\mathrm{ZnO} .{ }^{10,11} \mathrm{By}$ using the relationship between conductivity of semiconductor as a function of temperature $[\sigma \propto \exp (-\Delta E / k T)]$, the trends for all films are more or less similar. The estimated activation energy for all films lies between 0.04 to $0.05 \mathrm{eV}$. However, the Arrhenius plots in Fig. 6 do not produce perfect straight lines, because we have neglected the temperature dependence of electron mobility, and possibly association of different defects states in the films. These results also support $\mathrm{Zn}$ rich films observed in XPS analysis. Similar characteristic trends between undoped and Mn doped films suggest that $\mathrm{Mn}$ acts neither donor nor acceptor in $\mathrm{ZnO}$, and only native defects contribute to the free carriers. It is not surprising, since the $\mathrm{Mn}^{2+}$ state lies within the valence band, ${ }^{12}$, thereby Mn impurities do not generate additional free carriers. Look et al. ${ }^{13}$ suggest that zinc interstitial $\mathrm{Zn}_{i}$ is most likely to be native shallow donor and experimental results also confirm that the defect level lie $0.03-0.04 \mathrm{eV}$ below conduction band ${ }^{14}$, and from XPS analysis defects in our films are presumably dominated by zinc interstitials. The possibility for increasing resisitivity with $\mathrm{Mn}$ content is due to native defects in $\mathrm{ZnO}$, such as $\mathrm{Zn}_{i}$ were suppressed by $\mathrm{Mn}$ doping. With the help of photoluminescence spectroscopy, the reduction of native defects by Mn doping was also reported by Philipose et al. ${ }^{15}$ by observing a strong suppressing of midgap emission that originates from native defects. 
PNNL-17069

\section{CONCLUSION}

In summary, we have tried to correlate the ion beam and surface properties of Mn doped $\mathrm{ZnO}$ films with observation of suppressed conductivity in $\mathrm{ZnO}$. The films were well oriented in $c$-axis direction with wurtzite structure. Within our detection limit we have not seen any secondary phases which are not surprising by considering relatively low Mn doping concentration. The RBS measurements also confirm uniform distribution of Mn dopants throughout the film. Electrical conductivity results prove the conductivity suppressing nature of $\mathrm{Mn}^{2+}$ ions in $\mathrm{ZnO}$ host. The XPS results show that $\mathrm{Mn}^{2+}$ state is most likely to be dominant state. Thus, impact of $\mathrm{Mn}$ impurities on native $\mathrm{ZnO}$ defect concentrations plays the major role in defining electrical properties of $\mathrm{ZnO}$..

\section{REFERNCES}

[1] Ü. Özgür,a_Ya. I. Alivov, C. Liu, A. Teke,b_ M. A. Reshchikov, S. Doğan,c_ V. Avrutin, S.-J. Cho, and H. Morkoçd, J. Appl. Phys. 98, 041301 (2005).

[2] T. Dietl, H. Ohno, F. Matsukura, J. Cibert, D. Ferrand, Science 287, 1019 (2000).

[3] T. Fukumura, Z. Jin, M. Kawasaki, T. Shono, T. Hasegawa, S. Koshihara and $\underline{\text { H. }}$ Koinuma, Appl. Phys. Lett. 78, 958 (2001).

[4] D. P. Norton et al. Thin Solid Films 496, 160 (2006).

[5] C. Liu, F. Yun, B. Xiao, S.-J. Cho, Y. T. Moon, H. Morkoc, K. M. Yu and W. Walukiewicz, J. Appl. Phys. 97, 126107 (2005).

[6] L.V. Saraf, M. H. Engelhard, C. M. Wang, A. S. Lea, D. E. McCready, V. Shutthanandan, D. R. Baer and S. A. Chambers, J. Materials Res. 22, 1230 (2007). 
[7] E. Chikoidze Y. Dumont F. Jomard, D. Ballutaud, P. Galtier, and O. Gorochov, and D. Ferrand, J. Appl. Phys. 97, 10D327 (2005).

[8] E. Chikoidze, Y. Dumont, H.J. von Bardeleben, J. Gleize, F. Jomard, E. Rzepka, G. Berrerar, D. Ferrand and O. Gorochov, Appl. Phys. A 88, 167 (2007).

[9] R. Kelly, Surf. Sci., 100, 85 (1980)

[11] J. Han, M. Shen, W. Cao, A.M.R. Senos and P.Q. Mantas, Appl. Phys Lett. 82, 67 (2003).

[12] W. Chen, J. Wang and M. Wang, Vacuum 81, 894 (2007).

[13] K. R. Kittilstved, W. K. Liu and D. R. Gamelin, Nature Materials 5, 291 (2006).

[13] D. C. Look, J. W. Hemsky and J. R. Sizelove, Phys. Rev. Lett. 82, 2552(1999).

[14] D. G. Thomas, J. Phys. Chem. Solids, 3, 229 (1957).

[15] U. Philipose, S. V. Nair, S. Trudel, C. F. de Souza S. Aouba, R. H. Hill and H. E. Ruda, Appl. Phys. Lett. 88, 263101 (2006). 


\section{Figure captions.}

Fig. 1. XRD diffraction patterns of $\mathrm{ZnO}$ films. (a) Undoped $\mathrm{ZnO}$, (b) 1.5 At. \% Mn, (c) 4.5 At. \% Mn. Inset: Magnified ZnO (002) scan detecting slight shift in $2 \theta$ positions.

Fig. 2. PIXE spectrum of $\mathrm{ZnO}: \mathrm{Mn}$ (4.5 At. \% Mn) sample. RBS spectrum is shown in inset. The solid lines represent the modeled spectra.

Fig. 3. XPS spectra for $\mathrm{ZnO}$ and $\mathrm{ZnO}: \mathrm{Mn}$ films. $\mathrm{Zn}$ and $\mathrm{O}$ regions.

Fig. 4. XPS spectra for $\mathrm{ZnO}$ and $\mathrm{ZnO}: \mathrm{Mn}$ films. Mn regions.

Fig. 5. The ratio of zinc to oxygen compositions as a function of Mn content calculated from both XPS and PIXE. (a) from PIXE technique, (b) As recorded XPS surface scan, (c) After $\mathrm{Ar}^{+}$ion sputtering in XPS and (d) XPS corrected atomic concentration,

Fig. 6. Temperature dependent electrical conductivity for undoped as well as $\mathrm{ZnO}: \mathrm{Mn}$ films. 
PNNL-17069

Table I. Growth parameters for un-doped and $\mathrm{ZnO}: \mathrm{Mn}$ films.

\begin{tabular}{lc}
\hline Substrate temperature $\left({ }^{\circ} \mathrm{C}\right)$ & 450 \\
Vaporization temperature $\left({ }^{\circ} \mathrm{C}\right)$ & 245 \\
Substrate rotation (rpm) & 300 \\
Vapor pressure (Torr) & 60 \\
Oxygen flow rate(sccm) & 400 \\
Argon flow rate (sccm) & 2000 \\
Nitrogen flow rate (sccm) & 100 \\
Zn(TMHD) $)_{2}$ flow rate $(\mathrm{gm} / \mathrm{min})$ & 50 \\
Mn(TMHD) $)_{2}$ flow rate $(\mathrm{gm} / \mathrm{min})$ & $5-20$ \\
Depositing time (min) & 20 \\
Growth rate & $\sim 1 \AA / \mathrm{s}$ \\
\hline \hline
\end{tabular}


Fig. 1

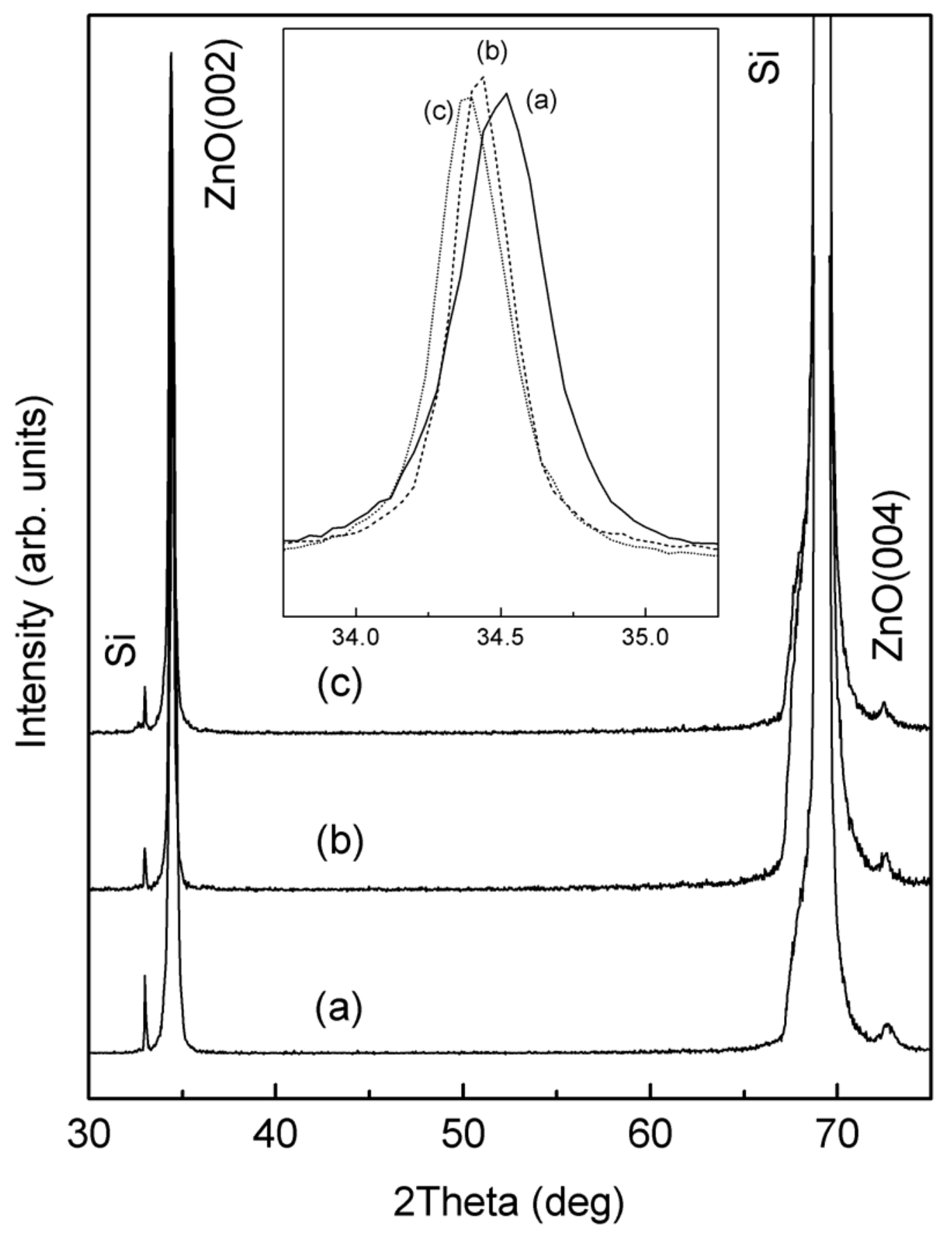


Fig. 2

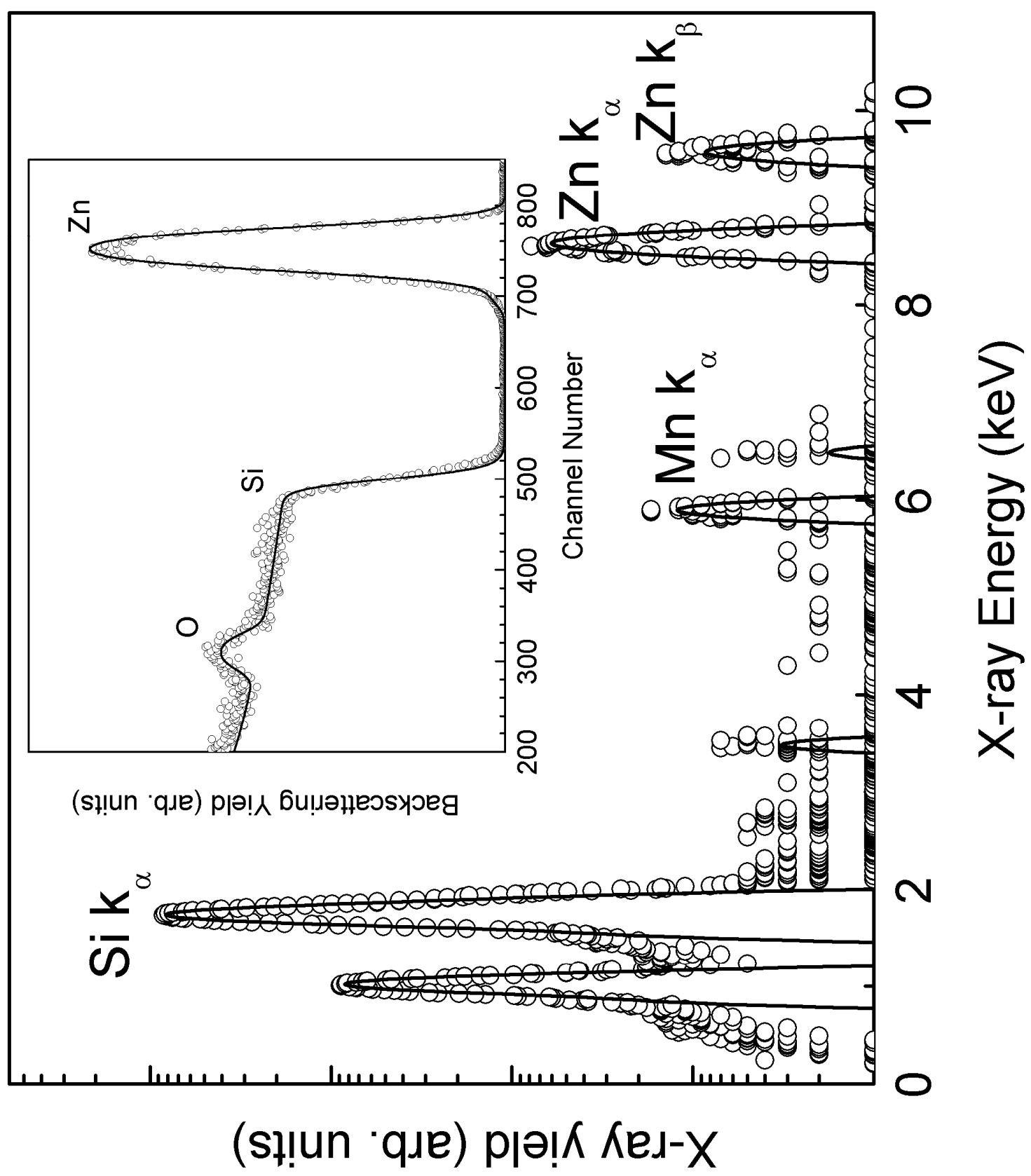


Fig. 3

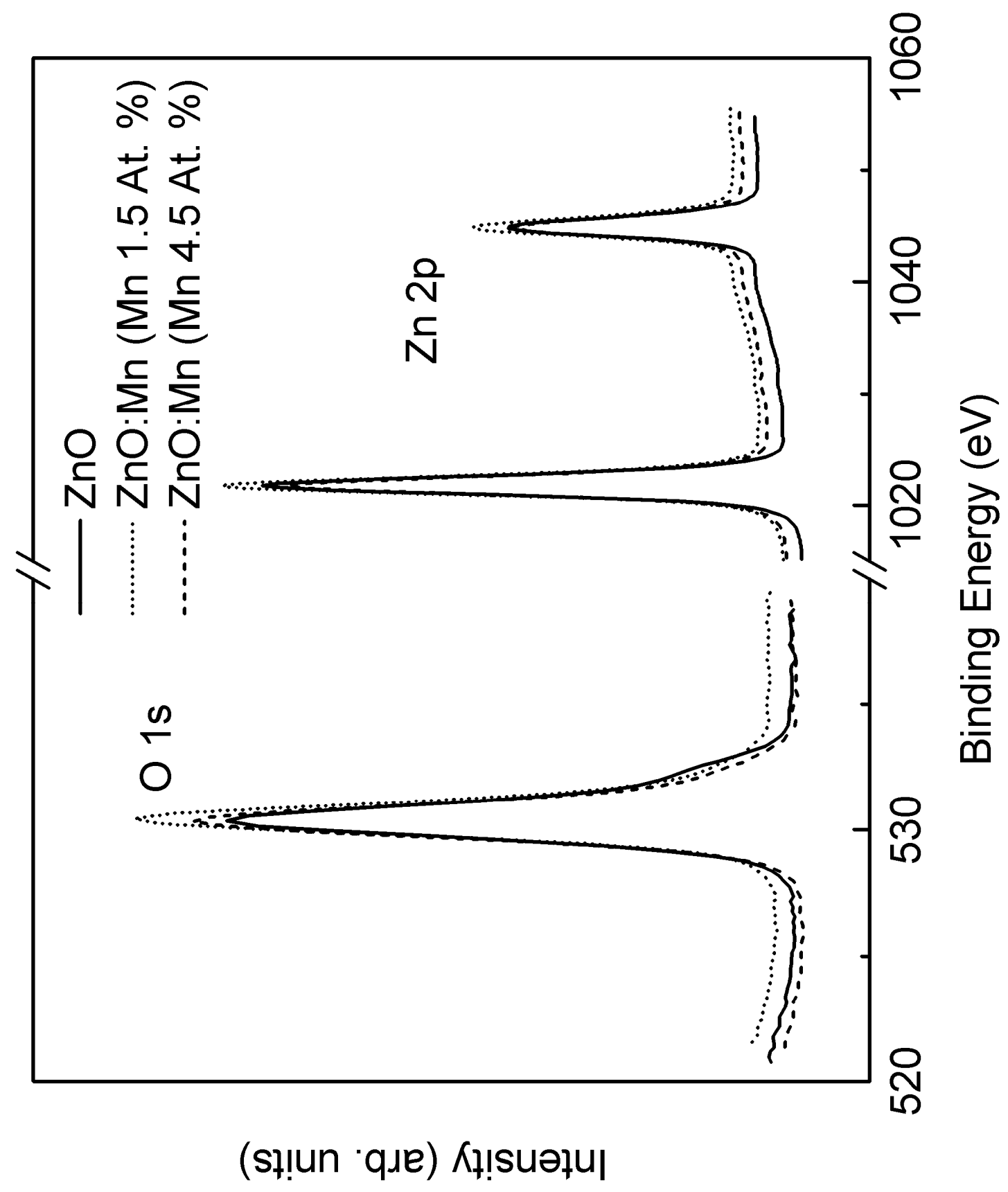


Fig. 4

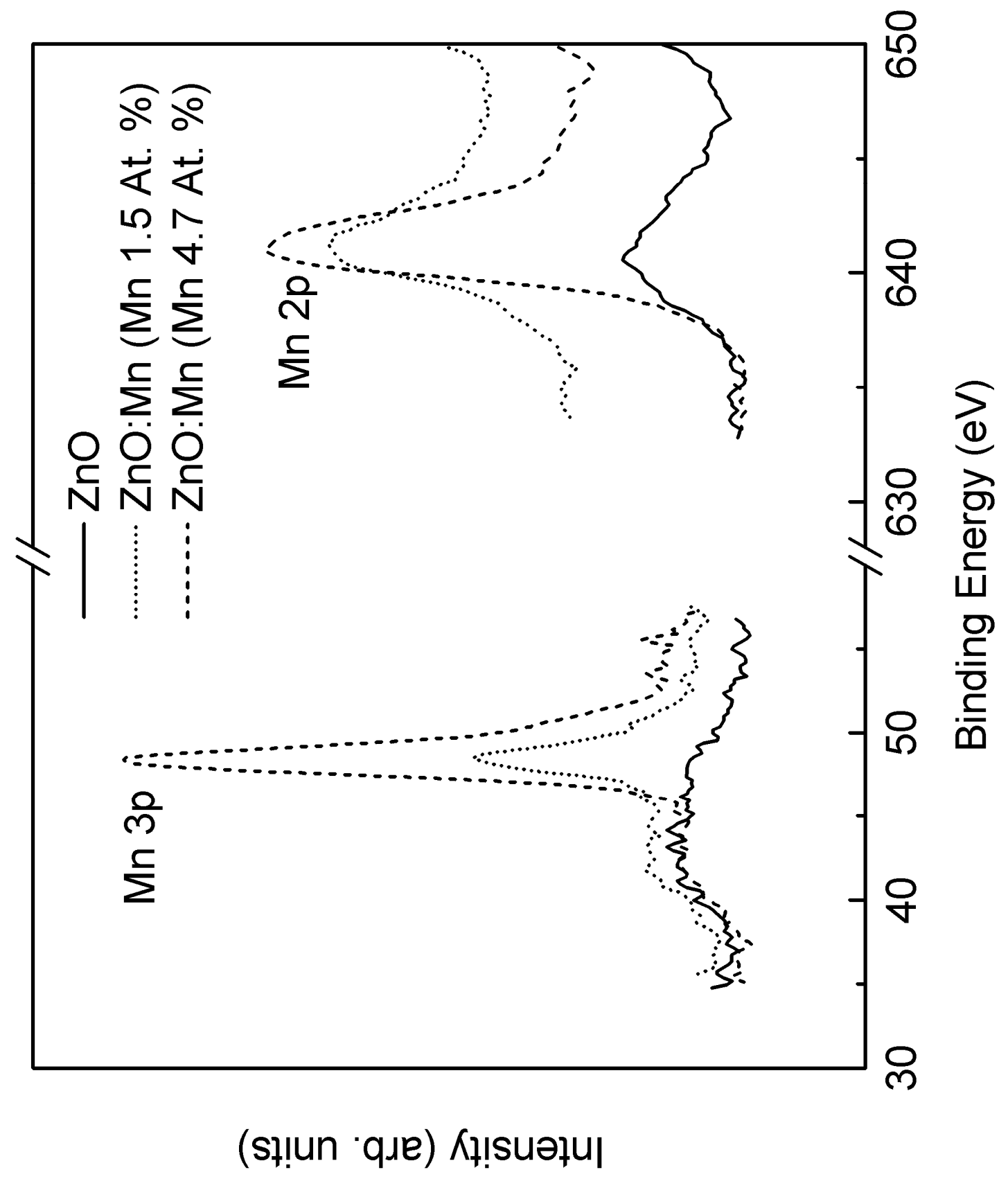


Fig. 5

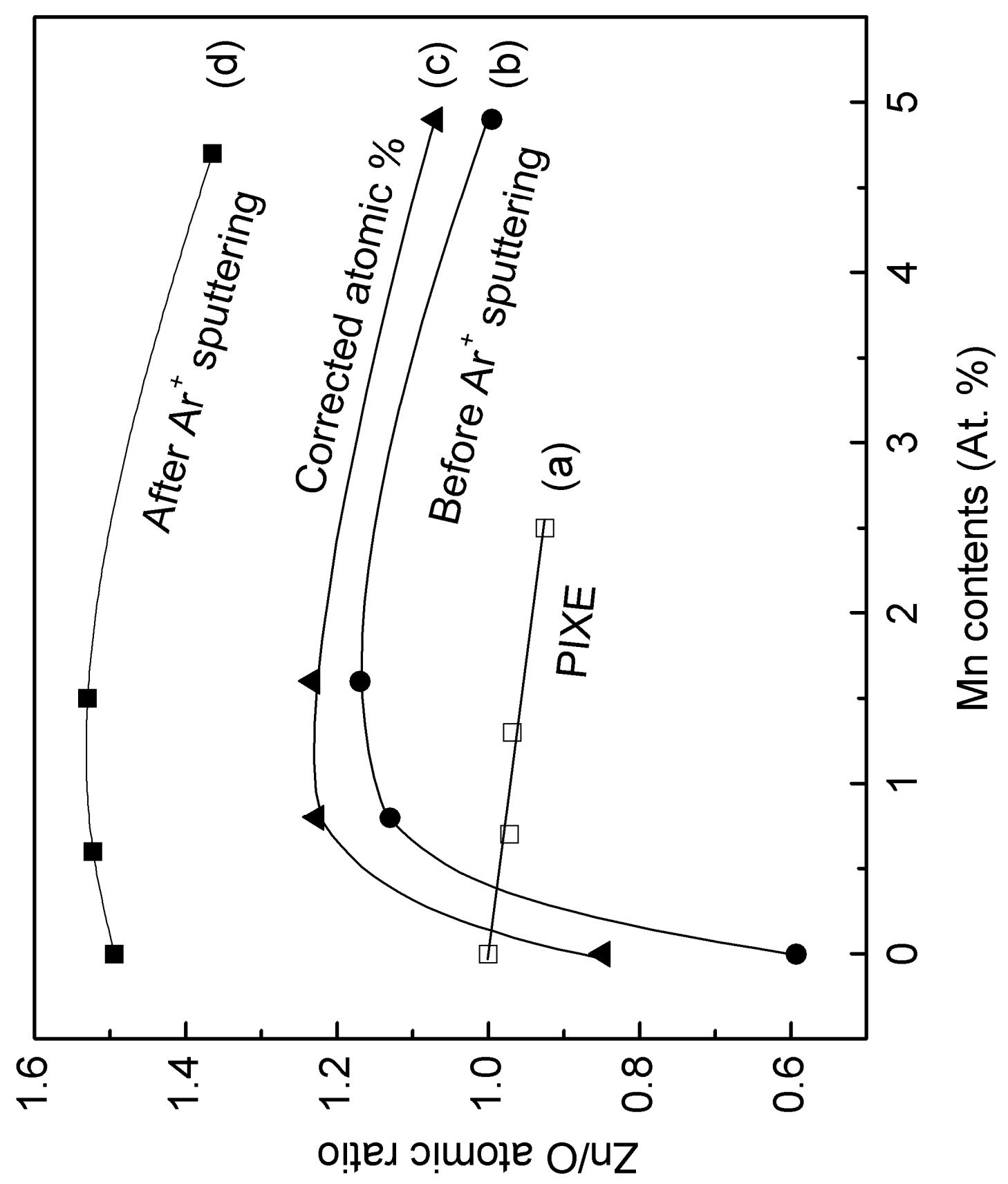


Fig. 6

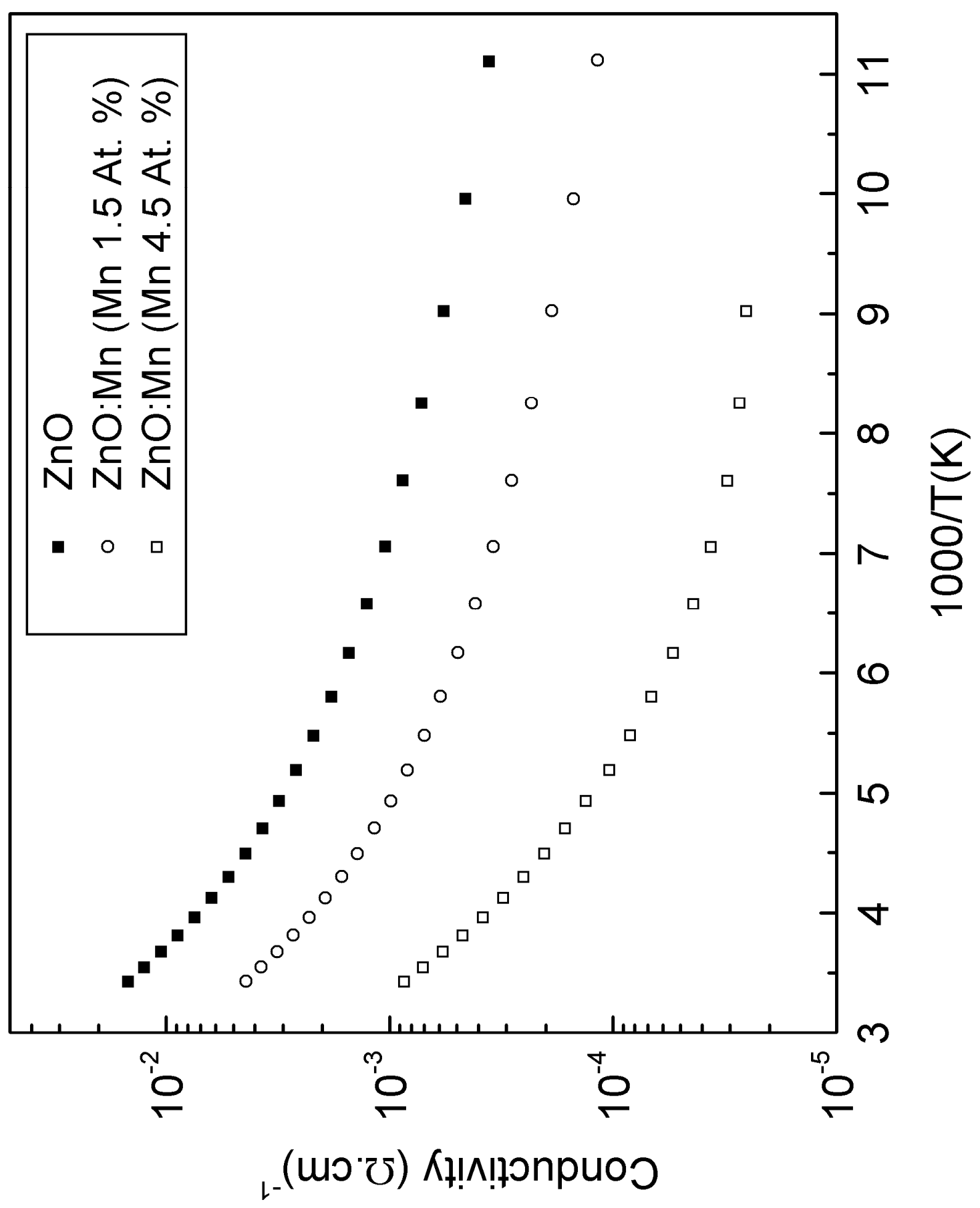


PNNL-17069 
PNNL-17069

\title{
Fundamental Studies of NOx Adsorbers
}

\author{
Adrienne C. Lukaski, Mark Barteau \\ University of Delaware
}

\author{
and \\ Chuck Peden \\ Pacific Northwest National Laboratory
}

The group of highly reactive gases that contain various amounts of nitrogen and oxygen are collectively termed nitrogen oxides (NOx). Nitrogen oxides are one of the main contributors to the formation of ground-level ozone and to global warming; react to form nitrate particles, acid aerosols, and $\mathrm{NO}_{2}$; contribute to the formation of acid rain and nutrient overload that deteriorates water quality; and contribute to global warming ("Http://Epa.Gov/Air/Urbanair/Nox/Chf.Html"). Nitrogen oxides form when fuel is burned at high temperatures, as in a combustion process. The primary man-made sources of NOx are motor vehicles, electric utilities, and other industrial, commercial, and residential sources that burn fuels ("Http://Epa.Gov/Air/Urbanair/Nox/What.Html").

Removing harmful gases, such as NOx, emitted by internal combustion engines is a central issue for the catalysis community. Operation of engines at lean conditions, rather that the normal stoichiometric air/fuel ratios, leads to improved fuel-economy and concomitant mitigation of vehicular $\mathrm{CO}_{2}$ emissions, yet creates additional obstacles for overall greenhouse gas reductions. The traditional three-way catalyst converts pollutants completely to $\mathrm{CO}_{2}, \mathrm{H}_{2} \mathrm{O}$, and $\mathrm{N}_{2}$ under stoichiometric conditions when the exhaust gas contains a mixture of oxygen and the pollutant hydrocarbons, $\mathrm{CO}$, and NOx species. The excess oxygen present in exhaust under lean conditions, however, prevents reduction of NOx species because the high oxidation efficiency decreases the concentration of reducing agents, $\mathrm{CO}$ and hydrocarbons, significantly through oxidation on the noble metal component of the three-way catalyst. Reduction of NOx emissions from lean-burn engines, therefore, requires new catalytic techniques. One promising technology under investigation is the lean-NOx trap (LNT) system (Epling et al.). The LNT catalyst is used in an engine that operates in alternating lean (excess oxygen) and rich (excess reductant) cycles. Since the inception of this technology by Toyota in the 1990s, barium oxide $(\mathrm{BaO})$ supported on high surface area alumina $\left(\mathrm{Al}_{2} \mathrm{O}_{3}\right)$ materials continues to be the most extensively studied catalytic NOx storage system $[4,5]$. Nitrogen oxides are stored on the oxide catalyst, primarily as nitrates, during lean cycles and, upon saturation, are released and reduced by precious metal sites rich operation (Takahashi et al.). $\gamma-\mathrm{Al}_{2} \mathrm{O}_{3}$ is the most widely used material for oxide metal supports. Traditional three-way catalysts employ alumina and LNT catalysis systems proposes to use high surface area $\gamma-\mathrm{Al}_{2} \mathrm{O}_{3}$ to support a basic oxide, such as $\mathrm{BaO}$ or $\mathrm{K}_{2} \mathrm{O}$, along with a noble metal component, such as $\mathrm{Pt}[3,4]$.

It is generally held that $\mathrm{NO}_{2}$ storage occurs primarily on the basic component of the catalyst, although the $\gamma-\mathrm{Al}_{2} \mathrm{O}_{3}$ support material is believed to contribute to the total NOx storage capacity (Szanyi et al.). The focus of this research, of which the current study 
was a part, is to develop a practical and fundamental understanding of the operation of LNT systems. This study investigated the relationship between surface hydroxyls and adsorbed nitrate species on the $\gamma-\mathrm{Al}_{2} \mathrm{O}_{3}$ surface because the contribution of the support to the total NOx storage capacity of these systems is not well understood. The roles of $\mathrm{H}_{2} \mathrm{O}$ and $\mathrm{CO}_{2}$ in the performance of NOx storage materials are central issues in LNT catalysis; both $\mathrm{H}_{2} \mathrm{O}$ and $\mathrm{CO}_{2}$ level in the exhaust gas are very high $(\sim 10 \%)$ under lean conditions.

Two distinct types of nitrate species have been identified on the $\mathrm{BaO}$ surface subsequent to exposure to $\mathrm{NO}_{2}$ : surface nitrates that adsorb strongly to the monolayer of $\mathrm{BaO}$ on the surface of alumina and bulk nitrates, $\mathrm{Ba}\left(\mathrm{NO}_{3}\right)_{2}$, that formed from the reaction of $\mathrm{BaO}$ particles with $\mathrm{NO}_{2}$. Recent by Peden and co-workers (Szanyi et al.) indicated that $\mathrm{H}_{2} \mathrm{O}$ exposure to a $\mathrm{NO}_{2}$-saturated $\mathrm{BaO} / \gamma-\mathrm{Al}_{2} \mathrm{O}_{3}$ sample led to conversion of surface $\mathrm{Ba}$ nitrates to the bulk-like $\mathrm{Ba}\left(\mathrm{NO}_{3}\right)_{2}$.; XRD results showed that the exposure of the sample to $\mathrm{H}_{2} \mathrm{O}$ resulted in a conversion of nanosized $\mathrm{Ba}\left(\mathrm{NO}_{3}\right)_{2}$ with an average size of $\sim 5 \mathrm{~nm}$ to large particles with an average size $>15 \mathrm{~nm}$. Temperature-programmed reactions demonstrated reformation of the surface nitrates and reestablishment of the initial surfaceto-bulk nitrate ratio upon $\mathrm{H}_{2} \mathrm{O}$ desorption, although the average crystalline size of the surface $\mathrm{Ba}\left(\mathrm{NO}_{3}\right)_{2}$ particles was different; XRD spectra showed no noticeable difference in before and after $\mathrm{H}_{2} \mathrm{O}$ desorption. The authors concluded that the presence of $\mathrm{H}_{2} \mathrm{O}$ changes the surface-bulk nitrate ratio, yet the capacity for total NOx storage remains unaffected.

Under exhaust gas conditions, however, $\mathrm{Ba}(\mathrm{OH})_{2}$ and $\mathrm{BaCO}_{3}$ are thermodynamically favored over $\mathrm{BaO}$ and $\mathrm{NOx}$ storage may take place with displacement of $\mathrm{H}_{2} \mathrm{O}$ and $\mathrm{CO}_{2}$ rather than through simple nitrate formation. Therefore, a fundamental understanding of the LNT system requires further elucidation of the effects of $\mathrm{H}_{2} \mathrm{O}$ and $\mathrm{CO}_{2}$ on NOx storage catalysts. This research used temperature-programmed desorption (TPD) and Fourier transform infrared spectroscopy (FTIR) to investigate the relationship between surface hydroxyls and nitrate species adsorbed on clean $\gamma-\mathrm{Al}_{2} \mathrm{O}_{3}$ surfaces; these surfaces were subjected to different calcinations temperatures prior to NO2 adsorption. At this time, however, the study is still ongoing. Figure 1 shows an example of the experimental data collected during my tenure on this research and illustrates the effect of annealing on the nitrate species adsorbed on $\gamma-\mathrm{Al}_{2} \mathrm{O}_{3}$. Related work also employed gas

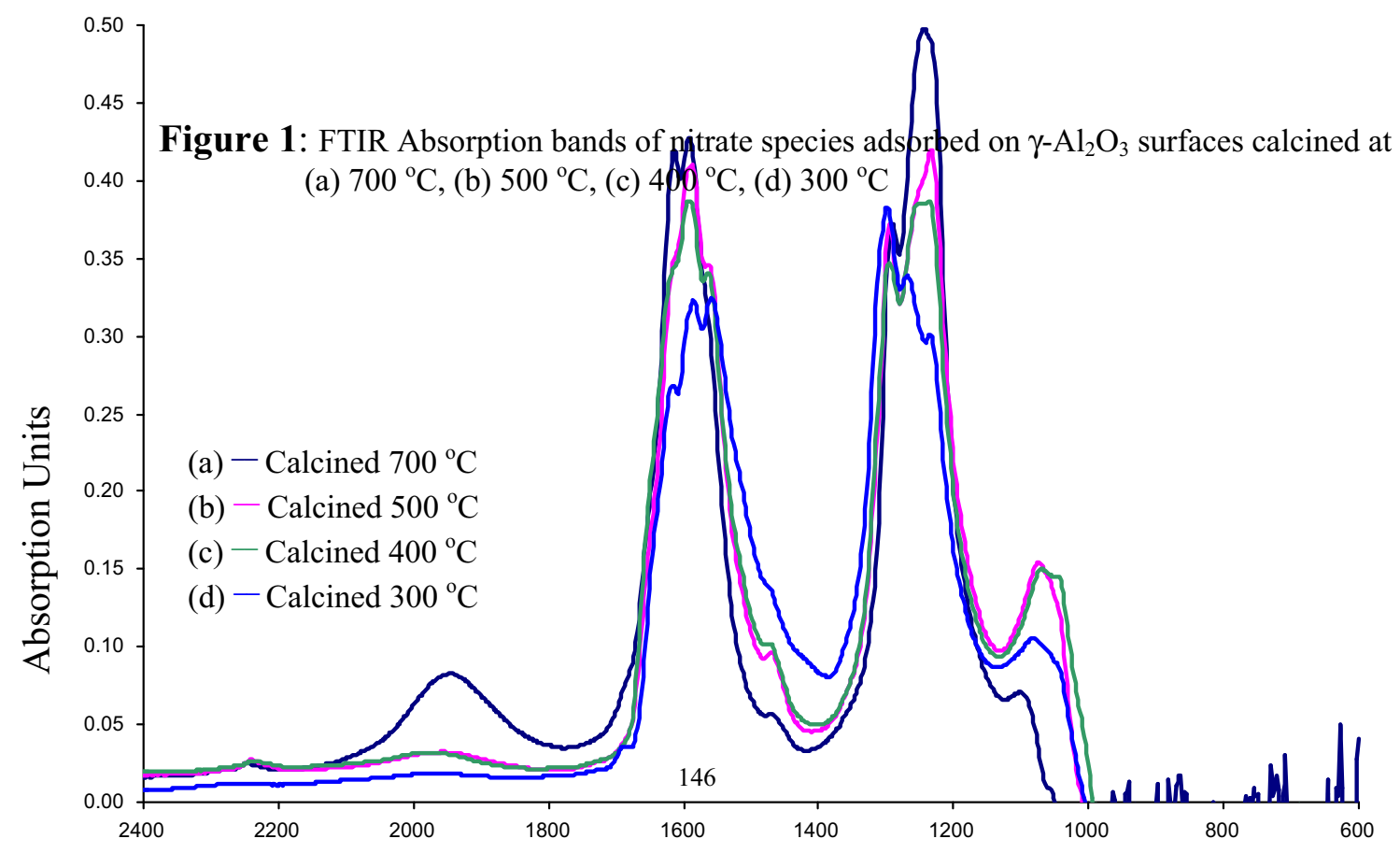


adsorption techniques (BET) and X-ray diffraction (XRD) to investigate the morphology of different $\gamma-\mathrm{Al}_{2} \mathrm{O}_{3}$ surfaces and alumina-supported basic oxides.

\section{References:}

11] http://epa.gov/air/urbanair/nox/chf.html.

]2] http://epa.gov/air/urbanair/nox/what.html.

]3] W.S. Epling, L.E. Campbell, A. Yezerets, N.W. Currier, and J.E. Parks, Catalysis Reviews-Science and Engineering 46 (2004) 163-245.

14] S. Masumoto, Cattech 4 (2000) 102.

15] N. Takahashi, H. Shinjoh, T. Iijima, T. Suzuki, K. Yamazaki, K. Yokota, H. Suzuki, N. Miyoshi, S. Matsumoto, T. Tanizawa, T. Tanaka, S. Tateishi, and K. Kasahara, Catalysis Today 27 (1996) 63-69.

]6] J. Szanyi, J.H. Kwak, D.H. Kim, X.Q. Wang, R. Chimentao, J. Hanson, W.S. Epling, and C.H.F. Peden, Journal of Physical Chemistry C 111 (2007) 4678-4687.

Frequency $\left(\mathrm{cm}^{-1}\right)$ 
PNNL-17069 


\title{
Modeling of the Effective Elastic and Thermal Properties of Glass-Ceramic Solid Oxide Fuel Cell Seal Materials
}

\author{
J. Milhans ${ }^{1}$, S. Ahzi ${ }^{2}$, H. Garmestani ${ }^{1}$, M.A. Khaleel ${ }^{3}$, X. Sun ${ }^{3}$ and B.J. Koeppel ${ }^{3}$ !!!! \\ ${ }^{1}$ Department of Materials Sci. \& Eng. Georgia Institute of Technology, Atlanta, GA xxxxx, USA \\ ${ }^{2}$ University Louis Pasteur, IMFS-UMR7507, 2 Rue Boussingault, 67000 Strasbourg, France \\ ${ }^{3}$ Pacific Northwest National Laboratory, Computational Science and Mathematics Division, \\ Richland, WA 99354, USA
}

\begin{abstract}
In this study, the effective elastic properties and coefficients of thermal expansion (CTE) of a glass-ceramic were predicted using homogenization techniques. Using G18, a glass-ceramic solid oxide fuel cell seal material as an initial reference, the models were tested for a two-phase glass-ceramic. The elastic properties and CTEs of the G18 amorphous phase are currently unknown. Thus, estimated values were used as an input to the models. The predictive model results offer accurate macroscopic values on both the elastic modulus and the CTE of glass-ceramic materials, providing the estimated amorphous values are reasonable.
\end{abstract}

Key words: effective properties, elasticity, CTE, glass ceramic, homogenization 
PNNL-17069

\section{Introduction}

Glass-ceramic seals for solid oxide fuel cells (SOFCs) have been commonly used due to their low cost and ease of manufacturing(B. J. K. Ba Nghiep Nguyen, Said Ahzi, Mohammad A Khaleel, and Prabhakar Singh; B. J. K. Ba Nghiep Nguyen, John S. Vetrano, and Mohammad A Khaleel). Glass-ceramics are resistant to degradation and provide reliable hermetic seals. Unfortunately, these glass-ceramic seals can also be vulnerable to damage and failure due to their brittle nature, unwanted chemical reactions, or porosity. The reliability of the seal is important, since it separates the chambers of the fuel cell and prevents chemicals and gases from mixing. Replacing the seal is largely costly and problematic, since it is inside of the fuel cell and bonded to several parts of the cell. A dependable, durable seal prolongs the life of the fuel cell, decreasing replacement and repair costs.

The elastic modulus and CTE are major contributors to the stresses that can lead to cracking of the seal. If the difference in the CTEs of surrounding components is large, the seal may crack during thermal cycling. Previous work has shown that it is possible to tailor a microstructure based on volume fractions and desired elastic or thermal properties. This requires a relationship between the phase volume fractions and the phase properties.

Property measurements of the appearing phases in seal materials can be difficult to obtain, and in general, not many results are available. It is, however, necessary to have some data points, in order to verify and compare theoretical results. In this study, we apply homogenization techniques, described below, to G18, a glass-ceramic SOFC seal, developed by the Pacific Northwest National Laboratory (PNNL) [1, 3-5]. The elastic moduli for the phases present can be obtained from nano- and micro-indentation. The CTEs of the phases were taken from data obtained by PNNL using a Unitherm model 1161 dilometer (K. Scott Weil).

Homogenization techniques have been widely used to predict elastic properties of heterogeneous materials. For the elastic properties, the self-consistent method (A. Molinari) and Mori-Tanaka methods are well-known, along with the Voigt (Voigt), Reuss (Reuss) and Hashin-Shtrikman bounds (Z. S. Hashin, S.; Shtrikman). Homogenization methods of the CTEs are less familiar, but there are well-studied models and bounds, including Levin, Hashin-Rosen (B. W. R. Z. Hashin), Turner, and Kerner. In this study, 
we have implemented several models for the elastic modulus and coefficient of thermal expansion for G18.

The elastic models we have employed are the Voigt-Reuss bounds, Mori-Tanaka, and a composite inclusion self-consistent method, developed by Ahzi et al(S. Ahzi). This composite self-consistent method considers a sandwich inclusion, and has been previously applied to semi-crystalline polymers. We have explored several CTE models, in order to determine which best fits the experimental data. These models include the models mentioned above and in addition, the effective Levin and self-consistent models.

\section{Experimental Procedure}

\subsection{Material}

The Pacific Northwest National Laboratory (PNNL) has developed a glass-ceramic for this application, called G18. G18 is a barium-calcium-aluminosilicate (BCAS)-based glass, with boron oxide added for better control over the coefficient of thermal expansion and viscosity. After the initial sintering of the glass, PNNL has observed a crystallization of approximately $55 \%$ barium silicate $\left(\mathrm{BaSiO}_{3}\right)$. There are also small amounts of other phases, including hexacelsian $\left(\mathrm{BaAl}_{2} \mathrm{Si}_{2} \mathrm{O}_{8}\right.$ with a hexagonal structure) and an unknown solid solution phase. The rest of the material stays as glassy phase. This glass-ceramic has shown increasing crystallization after thermal cycling. Unfortunately, monoclinic celsian begins to form, causing the CTE to decrease. This low CTE leads cracking in the seal, because the seal cannot expand with the rest of the materials in the cell. When fuel cell is heated, the sealant sticks to the neighboring materials, but cracks, since it cannot expand at the same rate $[1,2,13-15]$.

\subsection{Preparation of G18}

The glass is made in a powder form. The G18 was pressed into disks and heat-treated. The G18 powder was heated to $850^{\circ} \mathrm{C}$ and held for an hour to sinter, then cooled $750^{\circ} \mathrm{C}$ and held for 4 hours. It is finally cooled to room temperature. The 4 hours allows for a short aging time, to allow some crystallization. Finally, samples were aged for 5, 10, 25, 50,75 , or 100 hours at $750^{\circ} \mathrm{C}$ or $850^{\circ} \mathrm{C}$. 
PNNL-17069

\subsection{Testing}

Experimental procedures were used to characterize the microstructure and mechanical properties. EDS and SEM images were taken to determine the microstructure composition and morphology using a Zeiss Gemini DSM 982 (Centre des Matériaux de l'École des Mines de Paris, Evry, France). The EDS allows us to see the chemical composition and volume fractions of the present phases.
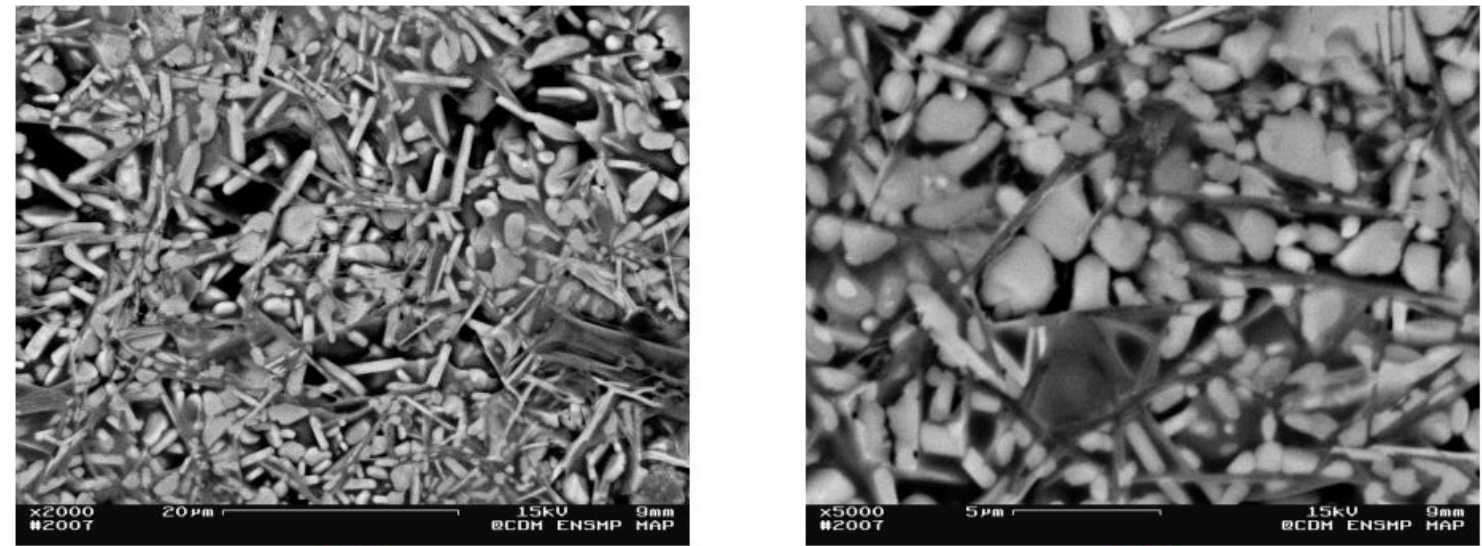

Fig 1. SEM backscattered images of G18. The white phases represent the barium silicate needles, while the dark phase is the amorphous matrix. The darker needles are hexacelsian.

Table 1. Atomic percent EDS results for G18 phases aged at $750^{\circ} \mathrm{C}$ for 4 hours

\begin{tabular}{|c|c|c|c|c|c|c|c|c|}
\hline \multirow[b]{2}{*}{ Label } & \multicolumn{8}{|c|}{ phase atomic \% } \\
\hline & B & $\mathbf{O}$ & $\mathbf{N a}$ & Al & Si & $\mathbf{K}$ & $\mathbf{C a}$ & Ba \\
\hline 401 (precipitate) & 0 & 53.87 & 0.19 & 1.22 & 11.51 & 0.04 & 6.23 & 26.95 \\
\hline 402 (precipitate) & 0.78 & 59.89 & 0.12 & 1.38 & 13.49 & 0.02 & 2.64 & 21.68 \\
\hline 3 (matrix) & 0.88 & 60.71 & 0.03 & 1.16 & 15.61 & 0.02 & 9.55 & 12.05 \\
\hline 4 (precipita & 0.47 & 74.5 & 0.05 & 1.03 & 6.48 & 0.01 & 2.69 & 14.76 \\
\hline glass matrix & 1.13 & 63.83 & 0.16 & 3.45 & 9.19 & 0.03 & 7.36 & 14.86 \\
\hline Mean (Sigma \#: 2.0) & 0.65 & 62.56 & 0.11 & 1.65 & 11.25 & 0.02 & 5.69 & 18.06 \\
\hline Std Dev (Sigma \#: 2.0) & 0.43 & 7.59 & 0.07 & 1.01 & 3.58 & 0.01 & 3.01 & 6.11 \\
\hline
\end{tabular}

Table 2. Weight percent EDS results for G18 phases aged at $750^{\circ} \mathrm{C}$ for 4 hours

\begin{tabular}{|c|c|c|c|c|c|c|c|c|c|}
\hline \multirow[b]{2}{*}{ Label } & \multicolumn{9}{|c|}{ phase weight \% } \\
\hline & B & $\mathbf{O}$ & $\mathrm{Na}$ & Al & Si & $\mathbf{K}$ & $\mathbf{C a}$ & Ba & Sum wt \% \\
\hline 401 (precipitate) & 0 & 22.52 & 0.11 & 0.86 & 8.44 & 0.04 & 6.53 & 96.7 & 135.2 \\
\hline 402 (precipitate) & 0.25 & 28.56 & 0.08 & 1.11 & 11.29 & 0.03 & 3.15 & 88.75 & 133.22 \\
\hline 3 (matrix) & 0.33 & 34.33 & 0.02 & 1.1 & 15.5 & 0.03 & 13.52 & 58.49 & 123.34 \\
\hline 4 (precipitate) & 0.19 & 44.26 & 0.04 & 1.03 & 6.75 & 0.02 & 4.01 & 75.28 & 131.58 \\
\hline glass matrix & 0.41 & 34.48 & 0.12 & 3.14 & 8.71 & 0.04 & 9.96 & 68.91 & 125.78 \\
\hline Mean (Sigma \#: 2.0) & 0.24 & 32.83 & 0.08 & 1.45 & 10.14 & 0.03 & 7.43 & 77.63 & 129.83 \\
\hline
\end{tabular}


Table 3. G18 bend bar results where aged is 1000 hours and unmarked is 4 hours at $750^{\circ} \mathrm{C}$.

\begin{tabular}{|r|r|}
\hline \multicolumn{1}{|c|}{$\begin{array}{c}\text { Temperature } \\
\text { (C) }\end{array}$} & \multicolumn{1}{|c|}{$\begin{array}{c}\text { Flexural } \\
\text { Modulus } \\
\text { (GPa) }\end{array}$} \\
\hline 25 & 89 \\
\hline 600 & 26 \\
\hline 700 & 30 \\
\hline 750 & 17 \\
\hline 800 & 12 \\
\hline 25 (aged) & 64 \\
\hline 600 (aged) & 56 \\
\hline 700 (aged) & 33 \\
\hline 750 (aged) & 25 \\
\hline 800 (aged) & 20 \\
\hline & \\
\hline
\end{tabular}

Fig 2. $\mathrm{E}$ and $\mathrm{G}$ as a function of Temperature for the unaged and aged G18 glass as measured using dynamic resonance.

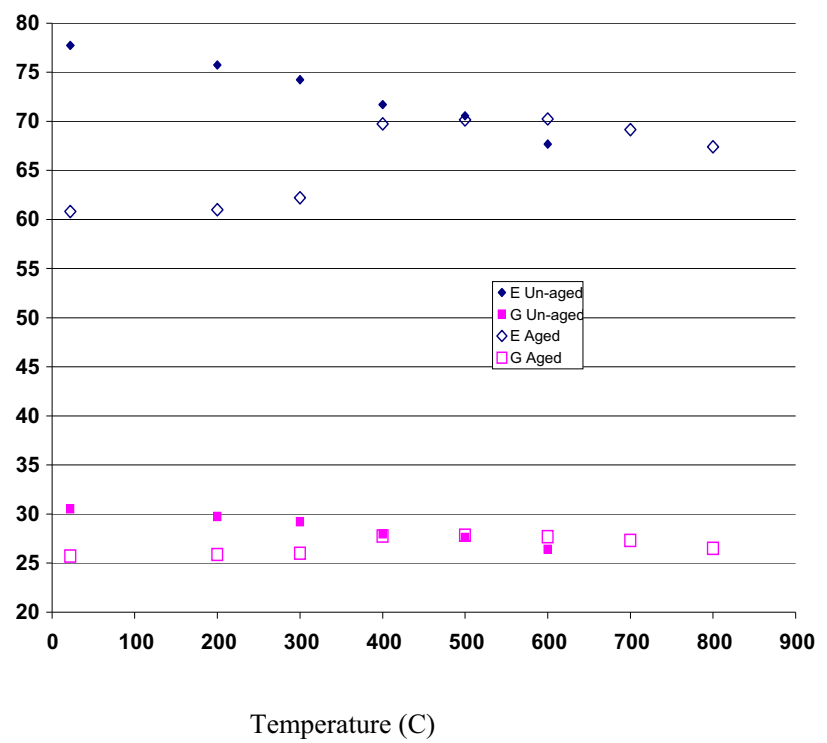

\subsection{PNNL G18 Data}

Table 3 displays the elastic modulus, as a flexural modulus, found by bend bar testing. This data has been provided by PNNL. Bend tests were performed for G18 at $25,600,700,750$, and $800^{\circ} \mathrm{C}$. The samples were reported as $3 \times 4 \times 45 \mathrm{~mm}$ and were heat treated in the same manner as described earlier. The aging temperature for these samples was $750^{\circ} \mathrm{C}$. The 4 -point bend test used a $40 \mathrm{~mm}$ outer span and $20 \mathrm{~mm}$ outer span (ASTM C1161). The crosshead speed was $0.5 \mathrm{~mm} / \mathrm{min}$, and the strain rate was $0.0001 \mathrm{~s}^{-1}$. The flexural modulus and stress-strain curves were calculated using elastic beam flexure equations and are not suitable for inelastic responses.

Fig. 2 displays the elastic modulus found by dynamic resonance (ASTM C1198) at Pennsylvania State University, conducted by Professor David Green and Dr. David Shelleman. This technique involves passing vibrations through the sample and measuring the resonance frequencies.

The CTE of each crystalline phase that may appear in G18 has been found by PNNL(K. Scott Weil). The CTE of $\mathrm{BaSiO}_{3}$ has been measured by PNNL, and has been 
found as $12.5 \times 10^{-6} \mathrm{~K}^{-1}$ for the range of $20-550^{\circ} \mathrm{C}$ and $9.4 \times 10^{-6} \mathrm{~K}^{-1}$ for the range of 20$1000^{\circ} \mathrm{C}$. We will only be using an estimated CTE for the amorphous phase and the barium silicate for our model. The rest of the crystalline phase values and more details on how these values were obtained may be found in the article by Weil et al (K. Scott Weil). The overall CTE of G18 has been found by PNNL as $11.8 \times 10^{-6} \mathrm{~K}^{-1}$ for the range of $20-813^{\circ} \mathrm{C}$ (K. Scott Weil).

\subsection{Theoretical Model Input Data}

\subsubsection{Elastic Modulus}

Because there is missing information on the stiffness constants of the barium silicate and amorphous phase, we have decided to show two different inputs for the models. For the amorphous phase, the following isotropic stiffness tensor was used:

$$
\mathbf{C}^{\mathrm{a}}=\left[\begin{array}{cccccc}
4.16 & 2.24 & 2.24 & 0.0 & 0.0 & 0.0 \\
2.24 & 4.16 & 2.24 & 0.0 & 0.0 & 0.0 \\
2.24 & 2.24 & 4.16 & 0.0 & 0.0 & 0.0 \\
0.0 & 0.0 & 0.0 & 0.96 & 0.0 & 0.0 \\
0.0 & 0.0 & 0.0 & 0.0 & 0.96 & 0.0 \\
0.0 & 0.0 & 0.0 & 0.0 & 0.0 & 0.96
\end{array}\right] \mathrm{GPa}
$$

For the crystalline phase, a Poisson ratio of 0.25 was used. Two inputs are shown here represent and isotropic phases with elastic moduli of $25 \mathrm{GPa}$ and $50 \mathrm{GPa}$, respectively. These values were chosen in regards of the reported elastic modulus of G18 at operating temperatures.

$$
\mathbf{C}^{\mathrm{c}}=\left[\begin{array}{cccccc}
30.0 & 10.0 & 10.0 & 0.0 & 0.0 & 0.0 \\
10.0 & 30.0 & 10.0 & 0.0 & 0.0 & 0.0 \\
10.0 & 10.0 & 30.0 & 0.0 & 0.0 & 0.0 \\
0.0 & 0.0 & 0.0 & 10.0 & 0.0 & 0.0 \\
0.0 & 0.0 & 0.0 & 0.0 & 10.0 & 0.0 \\
0.0 & 0.0 & 0.0 & 0.0 & 0.0 & 10.0
\end{array}\right] \mathrm{GPa}
$$


PNNL-17069

$$
\mathbf{C}^{\mathrm{c}}=\left[\begin{array}{cccccc}
60.0 & 20.0 & 20.0 & 0.0 & 0.0 & 0.0 \\
20.0 & 60.0 & 20.0 & 0.0 & 0.0 & 0.0 \\
20.0 & 20.0 & 60.0 & 0.0 & 0.0 & 0.0 \\
0.0 & 0.0 & 0.0 & 20.0 & 0.0 & 0.0 \\
0.0 & 0.0 & 0.0 & 0.0 & 20.0 & 0.0 \\
0.0 & 0.0 & 0.0 & 0.0 & 0.0 & 20.0
\end{array}\right] \mathrm{GPa}
$$

\subsubsection{Coefficient of Thermal Expansion}

The inputs for the CTE are linear, and isotropy is assumed for these models. In regards to the previous data from PNNL, this study considers the situation at approximately $500^{\circ} \mathrm{C}$. The value of $12.5 \times 10^{-6} \mathrm{~K}^{-1}$ was used for the crystalline phase, and taking into consideration the overall CTE of G18 at $11.8 \times 10^{-6} \mathrm{~K}^{-1}$, the value of $9.0 \mathrm{x}$ $10^{-6} \mathrm{~K}^{-1}$ was approximated for the amorphous phase.

\section{Elastic Modulus Theoretical Models}

The models used to predict the elastic modulus of the glass-ceramic are two-phase composite models. They are based on the Eshelby ellipsoidal inclusion (Eshelby). The models used are the Mori-Tanaka (Mori), generalized self-consistent (Budiansky), and the self-consistent composite-inclusion model more recently developed by Ahzi et al (S. Ahzi). We have also employed the Voigt and Reuss bounds.

\subsection{General Background}

In these models, we calculate the overall elasticity tensor $\mathbf{C}^{\text {eff, }}$ by using Hooke's Law to relate the macroscopic stress tensor $\boldsymbol{\Sigma}$ to the macroscopic strain tensor $\mathbf{E}$. The local strain tensor $\varepsilon$ and stress tensor $\sigma$ of both the inclusion and matrix phases are similarly related using Hooke's Law:

$$
\boldsymbol{\Sigma}=\mathbf{C}^{e f f} \mathbf{E}
$$

These results in the following relations, where the superscripts $\mathrm{M}$ and I denote matrix and inclusion respectively, and $\mathbf{A}^{I}$ and $\mathbf{B}^{I}$ are respectively the strain and stress concentration tensors, which depend on the Eshelby tensor: 


$$
\begin{aligned}
& \boldsymbol{\varepsilon}_{I}=\mathbf{A}^{I} \mathbf{E} \\
& \boldsymbol{\sigma}_{I}=\mathbf{B}^{I} \boldsymbol{\Sigma}
\end{aligned}
$$

After combining these relations and comparing with equation (1), we end up with the following equations:

$$
\begin{aligned}
& \mathbf{C}^{e f f}=\mathbf{C}^{M}+\sum_{I=1}^{N} f_{I}\left(\mathbf{C}^{I}-\mathbf{C}^{M}\right): \mathbf{A}^{I} \\
& \mathbf{S}^{e f f}=\mathbf{S}^{M}+\sum_{I=1}^{N} f_{I}\left(\mathbf{S}^{I}-\mathbf{S}^{M}\right): \mathbf{B}^{I}
\end{aligned}
$$

And

$$
\mathbf{B}^{I}=\mathbf{C}^{I}: \mathbf{A}^{I}: \mathbf{S}^{e f f}
$$

Where $N$ is the number of inclusions, and $f_{I}$ is volume fraction of the inclusion.

\subsection{Voigt-Reuss Bounds}

The Voigt upper bound (Voigt) and Reuss (Reuss) lower bound are well-known and commonly used. The Voigt bound may be thought of as taking the elastic constants of the inclusion and matrix phases in parallel, or assuming uniform strain, where the Reuss bound takes the inclusion and matrix elastic constants in series, assuming uniform stress. The phases are represented by their volume fractions. These bounds are generally far apart, especially when the crystalline volume fraction is quite high. The upper and lower bounds were calculated by setting $\mathbf{A}^{I}$ and $\mathbf{B}^{I}$ equal to the identity tensor.

\subsection{Mori-Tanaka Model (MT)}

The Mori-Tanaka method (Mori) extends Eshelby's solution (Eshelby) to include a large number of inclusions aligned. Mori-Tanaka method can also consider three-phase materials, which may be useful when including the other crystalline phases that appear in G18. In the model implemented we consider a two-phase heterogeneous material. Here, the generalized Mori-Tanaka approach, proposed by Benveniste formulation (Benveniste) is used where the second phase inclusions may be randomly oriented (not aligned), which is the case of G18. This formulation was previously used for semi-crystalline polymers and is expressed as follows (S. Ahzi): 


$$
\mathbf{A}^{I}=\mathbf{T}^{I}\left\langle\mathbf{T}^{I}\right\rangle_{V}^{-1} ; \quad \mathbf{T}^{I}=\left[\mathbf{I}+\mathbf{S}: \mathbf{S}^{M}:\left(\mathbf{C}^{I}-\mathbf{C}^{M}\right)\right]^{-1}
$$

\subsection{Self-Consistent Composite Inclusion Model (SCCI)}

The final model implemented for G18 in this work is the two-phase composite inclusion model, developed by Ahzi et al. (S. Ahzi). This model was developed for semicrystalline polymers, where the morphology of the polymer is considered as several twophase inclusions. Each inclusion is represented by a planar sandwich, consisting of the amorphous phase adjacent to the crystalline phase, with an infinite planar interface. The inclusion stiffness and compliance tensors are express as (S. Ahzi):

$$
\begin{aligned}
& \mathbf{C}^{I}=f_{a} \mathbf{C}^{a} \mathbf{Q}^{a}+\left(1-f_{a}\right) \mathbf{C}^{c} \mathbf{Q}^{c} \\
& \mathbf{S}^{I}=f_{a} \mathbf{S}^{a} \mathbf{R}^{a}+\left(1-f_{a}\right) \mathbf{S}^{c} \mathbf{R}^{c}
\end{aligned}
$$

The notations $a$ and $c$ refer to amorphous and crystalline respectively. Tensors $\mathbf{Q}$ and $\mathbf{R}$

are mapping tensors, related to the elastic moduli of the corresponding phase, and $f_{a}$ refers to the volume fraction of the amorphous phase. The effective elastic constants may be obtained by:

$$
\mathbf{C}^{e f f}=\left\langle\mathbf{C}^{I} \mathbf{A}^{I}\right\rangle_{V}=\sum_{I=0}^{N} f_{I} \mathbf{C}^{I} \mathbf{A}^{I}
$$

\section{Coefficient of Thermal Expansion Theoretical Models}

In this study, several models of the linear CTE were explored. Until further data on the CTE of the amorphous phase of G18 is obtained, we cannot determine which CTE homogenization model is best suited for the glass-ceramic. The models implemented are the Voigt (Voigt) and Reuss (Reuss) bounds, Levin model (Levin), Rosen-Hashin bounds (Z. S. Hashin, S.), Turner model (Turner), Kerner model (Kerner), and the self-consistent model (Budiansky). There are also other popular models, such as the Schapery (Schapery) model, which may be later implemented if needed. In following equations, the inclusion denotation has been changed to crystalline, and matrix to amorphous.

The input data to our calculations is the stiffness. In the case of isotropy, the bulk and shear moduli are needed for most of the CTE models, knowing that:

$$
G=\frac{E}{2(1+v)} ; \quad K=\frac{E}{3(1-2 v)}
$$


Where $G$ represents the shear modulus, $E$ is the elastic modulus, $K$ is the bulk modulus, and $v$ is simply the Poisson's ratio.

\subsection{Voigt and Reuss Bounds}

Here, $\bar{\alpha}$ represents the effective CTE of the composite, $C$ is stiffness, $f$ is volume fraction, and $\alpha_{i}$ is the CTE of a single phase, where $a$ and $c$ denote amorphous and crystalline respectively. The Voigt upper bound yields:

$$
\bar{\alpha}=\frac{f_{a} C^{a} \alpha^{a}+f_{c} C^{c} \alpha^{c}}{f_{a} C^{a}+f_{c} C^{c}}
$$

The Reuss theory of uniform stress in the material results in the rule of mixtures:

$$
\bar{\alpha}=f_{a} \alpha^{a}+f_{c} \alpha^{c}
$$

\subsection{Turner}

Turner model takes into account the mechanical interaction between the phases in the composite and generally can serve as a lower bound. The expression given below by the Turner model is similar to that derived by the Voigt upper bound, using the bulk modulus, instead of the stiffness, giving:

$$
\bar{\alpha}=\frac{f_{a} K^{a} \alpha^{a}+f_{c} K^{c} \alpha^{c}}{f_{a} K^{a}+f_{c} K^{c}}
$$

\subsection{Kerner}

The Kerner model assumes spherical inclusions, and wetted by a homogeneous, isotropic matrix. This model is often used as an upper bound with the Turner as the lower bound. Kerner leads to the effective linear CTE as:

$$
\bar{\alpha}=f_{a} \alpha^{a}+f_{c} \alpha^{c}+f_{a} f_{c}\left(\alpha^{c}-\alpha^{a}\right) \frac{K^{c}-K^{a}}{f_{a} K^{a}+f_{c} K^{c}+3 K^{a} K^{c} / 4 G^{a}}
$$

\subsection{Rosen-Hashin bounds (RH)}

Rosen and Hashin gave bounds that applied to an isotropic composite with anisotropic inclusions. Here, we consider the local properties to be isotropic. The RH model equations assume an interface, similar to Kerner's assumption, and are written as follows: 


$$
\begin{aligned}
& \bar{\alpha}^{u}=f_{a} \alpha^{a}+f_{c} \alpha^{c}+\frac{4 f_{a} f_{c} G^{c}\left(K^{a}-K^{c}\right)\left(\alpha^{a}-\alpha^{c}\right)}{3 K^{a} K^{c}+4 G^{c} \bar{K}} \\
& \bar{\alpha}^{l}=f_{a} \alpha^{a}+f_{c} \alpha^{c}+\frac{4 f_{a} f_{c} G^{a}\left(K^{a}-K^{c}\right)\left(\alpha^{a}-\alpha^{c}\right)}{3 K^{a} K^{c}+4 G^{a} \bar{K}}
\end{aligned}
$$

Here, the superscripts $u$ and $l$ correspond to upper and lower bound, and $\bar{K}$ is the effective composite bulk modulus, which may be found by elastic homogenization relations, such as the models discussed in the previous section, or experimental results may be used.

\subsection{Levin Model}

The Levin model, like the Rosen-Hashin bounds, allows us to use a computed bulk modulus from above. This model assumes that both phases are isotropic, and is given below:

$$
\bar{\alpha}=f_{a} \alpha^{a}+f_{c} \alpha^{c}+\frac{\alpha^{a}-\alpha^{c}}{\frac{1}{K^{a}}-\frac{1}{K^{c}}}\left[\frac{1}{\bar{K}}-\left(\frac{f_{a}}{K^{a}}+\frac{f_{c}}{K^{c}}\right)\right]
$$

It is possible to use this equation for bounds, instead of an effective CTE, by using an elastic modulus model that gives bounds, such as the Voigt-Reuss or Hashin-Shtrikman.

\subsection{Self-Consistent Method}

The self-consistent model considers random mixtures $\mathrm{N}$ isotropic phases. Budiansky (Budiansky) has used the following equations to express the CTE using the selfconsistent approach:

$$
\begin{aligned}
& \sum_{i=1}^{N} f_{i}\left[1-a+a\left(K^{i} / \bar{K}\right)\right]^{-1}=1 \\
& \sum_{i=1}^{N} f_{i}\left[1-b+b\left(G^{i} / \bar{G}\right)\right]^{-1}=1
\end{aligned}
$$

Where

$$
\begin{aligned}
& a=\frac{1}{3}\left(\frac{1+v}{1-v}\right) \\
& b=\frac{2}{15}\left(\frac{4-5 v}{1-v}\right)
\end{aligned}
$$


PNNL-17069

And

$$
v=\frac{3 \bar{K}-2 \bar{G}}{6 \bar{K}+2 \bar{G}}
$$

These equations are used to give the CTE in terms of phase properties as follows:

$$
\bar{\alpha}=\sum_{i=1}^{N} f_{i}\left(K^{i} / \bar{K}\right)\left(\alpha^{i}\right)\left[1-a+a\left(K^{i} / \bar{K}\right)\right]^{-1}
$$

In our model, we have used the $\bar{K}$ found by the Self-Consistent Composite Inclusion model, rather than the $\bar{K}$ found using eq. $15 \mathrm{a}$.

\section{Results and Discussion}

\subsection{Elastic Modulus Modeling}

The computed effective elastic modulus of he composite is plotted in Figure 2 as function of he volume fraction of the crystalline phase for two cases to illustrate the effect of the ration of the phase moduli. This figure shows results for the classical bounds, the composite self-consistent and the Mori-Tanaka models.

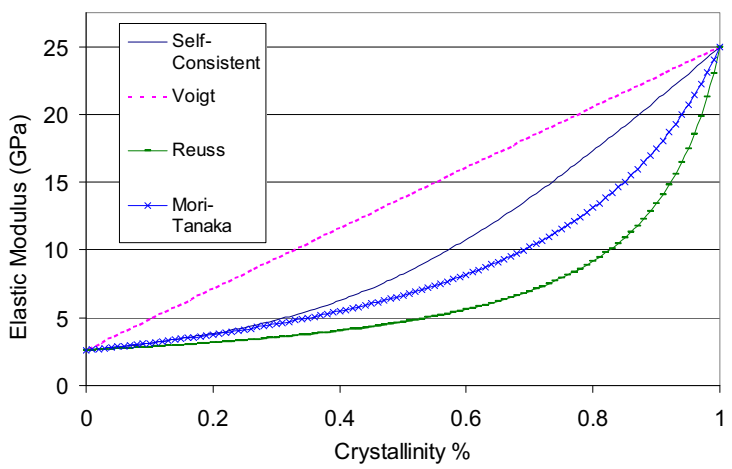

(a)

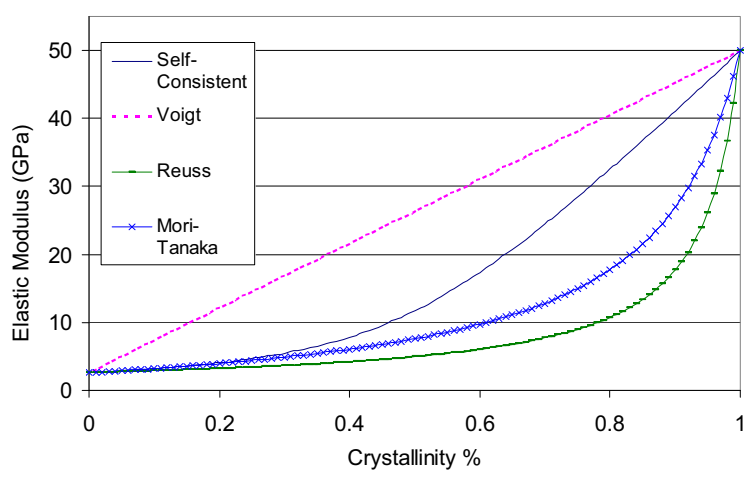

(b) 
Fig 3. Elastic modulus predictions for the case (a) $E^{c} / E^{a}=10$ and (b) $E^{c} / E^{a}=20$

Until we are able to know the elastic constants at operating temperatures of each phase, we cannot determine which model is best suited for G18. The presented results simply illustrate that the self-consistent composite inclusion and Mori-Tanaka models fall within the Voigt and Reuss bounds. One can see that it would be desirable to confirm that either the self-consistent composite inclusion model or Mori-Tanaka model follow the trend of experimental data, because the bounds can grow quite far apart. There are other closer bounds available, such as the previously mentioned Hashin-Shtrikman bounds, but for this particular case, an effective modulus value is needed.

\subsection{CTEs}

The effective CTE of the composite is given as function of the volume fraction of the crystalline phase in Figure 3. This figure illustrates the differences between the used models and shows similarly to the elastic constants, an important gap between the Voigt and Reuss bounds.

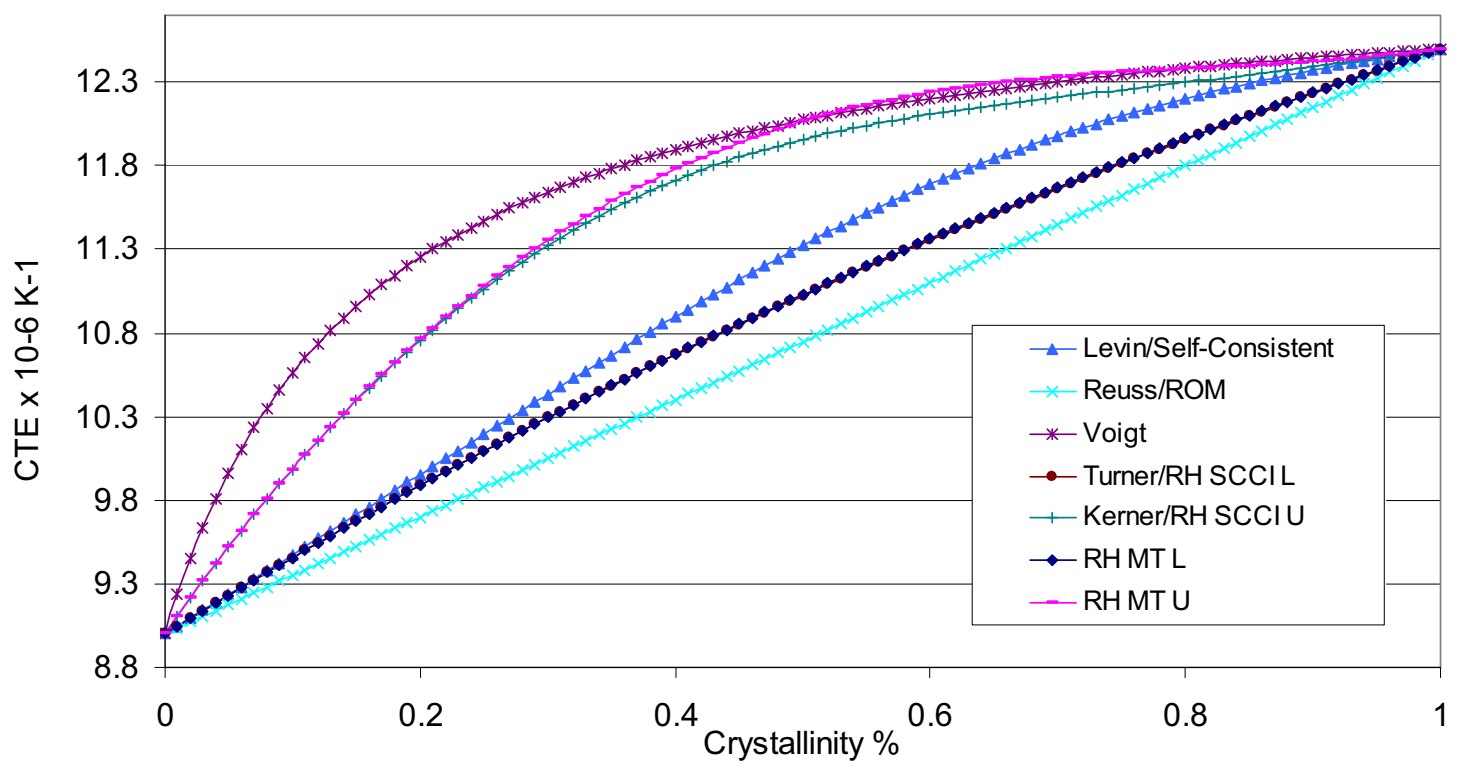

Fig 4. Coefficient of thermal expansions predictions

For the models using effective elastic properties found from previous models, the values corresponding to a crystalline phase with an elastic modulus of $25 \mathrm{GPa}$ and $\mathrm{E}^{\mathrm{c}} / \mathrm{E}^{\mathrm{a}}=$ 10, in Fig. 3a, were used. In this particular case, the Levin and self-consistent model 
overlapped. This is not surprising, since Levin based his model on Hill's self-consistent model [hill] and only two phases were used in the self-consistent model. Also, because of the SCCI result for the effective modulus, there is an overlap with the Turner and RH lower bound, and respectively, the Kerner and RH upper bound. Therefore, the RH bounds were also computed here using the modulus found by the Mori-Tanaka model. The RH bounds calculated using the Mori-Tanaka modulus still shows much overlap with those found using the SCCI model, but there is a noticeable change, especially in the upper bound.

Most of the models fit between the Voigt and Reuss bounds. The RH upper bound, calculated with the Mori-Tanaka modulus goes slightly above the Voigt bound, which shows that the SCCI would mostly like be a better choice in selecting an effective modulus. Until we are able to compare data, knowing the CTE of the amorphous phase, we will not be able to conclude which model is appropriate for G18. If the estimated amorphous CTE is reasonable, the Levin/Self-Consistent gives a similar result at 55\% crystallization, in comparison to the $11.8 \times 10^{-6} \mathrm{~K}^{-1}$ experimental results. We can however see that the closer RH SCCI bounds are most likely a better choice than the Voigt and Reuss bounds. In choosing an effective CTE, the G18 will most likely follow an intermediate model, such as the Levin and Self-Consistent model.

\section{Conclusion}

Two effective models, the Mori-Tanaka and the SCCI models were used to predict the effective elastic properties of a glass-ceramic. Both phases were assumed isotropic and different hypothetical elastic constants were tested. By looking at the predicted elastic modulus results, it seems that using the SCCI model will be the more suitable of the two effective elastic modulus models. The Mori-Tanaka model may be applicable for glassceramics with a lower amount of crystallization, but otherwise seems to underestimate the actual value. In our case, G18 generally has a crystallization of $55 \%$ or more; therefore the SCCI model will most likely be more appropriate.

Several models were used to predict the CTE of a two-phase composite. The upper and lower bounds contain the effective CTE models. The models used a measured CTE for the crystalline phase and a hypothetical CTE for the amorphous phase. It seems that 
the effective Levin and Self-Consistent models, using the SCCI moduli, will be an accurate prediction of the CTE of G18. The Mori-Tanaka model gave an overestimation when used in the RH upper bound, and high values in the elastic modulus, therefore, would probably not be a good model. The lower bounds also display values that seem reasonable and may be used. The appropriate model will be clearer when we can compare the predicted results with the experimental results, using a measured amorphous phase CTE.

1. Ba Nghiep Nguyen, B.J.K., Said Ahzi, Mohammad A Khaleel, and Prabhakar Singh, Crack Growth in Solid Oxide Fuel Cell Materials: From Discrete to Continuum Damage Modeling. The American Ceramic Society, 2006. 89(4): p. 1358-1368.

2. Ba Nghiep Nguyen, B.J.K., John S. Vetrano, and Mohammad A Khaleel, On the Nonlinear Behavior of a Glass-Ceramic Seal and Its Application in Planar SOFC Systems. The 4th International Conference on FUEL CELL SCIENCE ENGINEERING and TECHNOLOGY, 2006.

3. Zhenguo Yang, J.W.S., Kerry D. Meinhardt, Chemical interactions of bariumcalcium-aluminosilicate-based sealing glasses with oxidation resistant alloys. Solid State Ionics, 2003. 160(3-4): p. 213-225.

4. Zhenguo Yang, K.D.M., and Jeff W. Stevenson, Chemical Compatibility of Barium-Calcium-Aluminosilicate-Based Sealing Glasses with the Ferritic Stainless Steel Interconnect in SOFCs. Journal of The Electrochemical Society, 2003. 150(8): p. A1095-A1101.

5. K. Scott Weil, J.E.D., John S. Hardy, Dong Sang Kim, Guan-Guang Xia, L.A. Chick, and Chris A. Coyle, Rupture Testing as a Tool for Developing Planar Solid Oxide Fuel Cell Seals. ASM Internation, 2004. 13(3): p. 316-326.

6. A. Molinari, S.A., and R. Koouddane, On the self-consistent modeling of elasticplastic behavior of polycrystals. Mech. Mat., 1997. 26(1): p. 43-62.

7. Voigt, W., Wied. Ann., 1889. 38.

8. $\quad$ Reuss, A., Math. Mech., 1929.9.

9. Hashin, Z.S., S., A Variational Approach to the Theory of the Elastic Behaviour of Polycrystals. J. Mech. Phys. Solids, 1962. 10: p. 343-352.

10. Shtrikman, Z.H.S., A variational approad to the theory of the elastic behaviour of multiphase materials. J. Mech. Phys. Solids, 1963. 11: p. 127-150.

11. Hashin, B.W.R.Z., Effective thermal expansion coefficients and specific heats of composite materials. Int. J. Eng. Sci., 1970. 8: p. 157-173.

12. S. Ahzi, N.B., A. Makradi, S. Belouettar, Composite modelling for the effective elastic properties of semi-crystalline polymers. Journal of Mechanics of Materials and Structures, 2006. in press.

13. JW Stevenson, L.C., MA Khaleel, DL King, LR and S.S. Pederson, ZG Yang, and P Singh, SOFC Development at Pacific Northwest National Laboratory. 2005 Fuel Cell Seminar, Palm Springs, CA, 2005. 
14. Brian J. Koeppel, J.S.V., Ba Nghiep Nguyen, Xin Sun, and Moe A. Khaleel, Mechanical Property Characterization and Performance Modeling of SOFC Seals. 30th Internation Conference on Advanced Ceramics and Composites, 2006. S3.

15. Fergus, J.W., Sealants for solid oxide fuel cells. Journal of Power Sources, 2005. 147(1-2): p. 46-57.

16. Eshelby, J.D., The determination of the elastic field of an ellipsoidal inclusion, and related problems. Proc. R. Soc. London, 1957. A241.

17. Mori, T.T., K., Average stress in matrix and average elastic energy of materials with misfitting inclusions. Acta Metallurgica, 1973. 21: p. 571-574.

18. Budiansky, B., Thermal and Thermoelastic Properties of Isotropic Composites. Journal of Composite Materials, 1970. 4.

19. Benveniste, Y., A new approach to the application of Mori-Tanaka's theory in composite materials. Mechanics of Materials, 1987. 6.

20. Levin, V.M., On the coefficients of thermal expansion of heterogeneous materials. Mekhanika Tverdogo Tela, 1967. 2(1): p. 88-94.

21. Turner, P.S., Thermal-expansion stresses in reinforced plastics. Journal of Research of the National Bureau of Standards, 1946. 37: p. 239-260.

22. Kerner, E.H., The elastic and thermo-elastic properties of composite media. The Proceedings of the Physical Society, 1956. 69(8): p. 808-813.

23. Schapery, R.A., Thermal expansion coefficients of composite materials based on energy principles. J. Comp. Mat., 1968. 2: p. 380-404. 
PNNL-17069

\title{
Surface Induced Dissociation of Multiply Charged Peptides in a Fourier Transform Ion Cyclotron Resonance Mass Spectrometer: Effect of Target Orientation
}

\author{
Leonard Nyadong $^{1}$, Facundo M. Fernandez ${ }^{1}$, Julia Laskin ${ }^{2}$
}

1. Georgia Institute of Technology, School of Chemistry and Biochemistry

2. Pacific Northwest National Laboratory, Chemical and Materials Science Division

\section{Introduction}

Tandem mass spectrometry (MS/MS) is a well established analytical technique for the characterization of biomolecules and for the investigation of gas phase ion chemistry(Hoffmann E. de). The deposition of large amounts of internal energy is required to observe fragmentation of biomolecules in the gas phase. This is primarily because biomolecules have a large number of vibrational degrees of freedom which allows the storage of significant amounts of internal energy. Accurate determination of product ion masses achieved by performing mass analysis using mass spectrometers with high resolving power facilitates the elucidation of the structure of biomolecules.

The ultrahigh resolving power and the capability to perform multiple stages of mass analysis distinguish Fourier transform ion cyclotron resonance mass spectrometry (FTICR-MS) as one of the most powerful tools in the study of gas phase ion chemistry of biomolecules. Several gas-free ion activation techniques amenable to the ultra high vacuum of the FTICR have been reported. These include surface induced dissociation (SID)(Laskin J et al.; Schey K. et al.), infrared multiphoton dissociation (IRMPD)(Little D. P. et al.; Price W. D., Schier P. D. and William E. R.), and electron capture dissociation(Tsybin Y. O. et al.; Zubarev R. A. et al.). Of all these ion activation techniques SID has a unique advantage in that; large amounts of internal energy can be deposited in a molecule in a very short time frame, thus making accessible dissociation channels that are not favored in most collisional activation methods. When implemented in an FTICR, SID provides the added advantage of long and variable post collision reaction times (milliseconds to seconds)(Laskin $\mathrm{J}$ et al.), thus enabling access to both low and high-energy dissociation pathways for large molecules such as proteins. This advantage increases sequence coverage allowing reliable protein identification capabilities from this type of tandem MS data.

In these studies, SID on an FTICR was achieved using the set-up implemented by Laskin et al(Laskin $J$ et al.). In this set-up the collision energy is defined as the potential difference between the dc offset of the accumulation octopole and the voltage applied to the SID target and varied by changing the voltage applied to the SID target. This set-up allows a controlled definition of collision energy and impact angle. It is also advantageous in that, the ion current on the surface and quality of the ion beam are independent of collision energy.

Electrospray ionization (ESI) and the more recent desorption electrospray ionization (DESI) are efficient means of generating multiply charged biomolecule ions. Multiple charging allows to obtain tandem mass spectrometry data of biomolecules with the aim of elucidating their structure without enzymatic digestion(McCormack A. L., ones J. L. and Wysocki V. H.). It was the objective of these studies to assess the performance of 
this SID set-up for dissociating large multiply-charged peptides and proteins under experimental conditions where the precursor ion beam collided normal to the target. As it is very well recognized that the SID signal is affected by neutralization of the precursor ions due to soft landing on the target, it was also investigated if perturbing the orientation of the target had a significant effect on the SID signal. The implementation of DESI for the SID analysis of multiply charged peptides was also explored.

\section{Experimental}

Samples for electrospray ionization were dissolved in a 1:1 methanol:0.1\% aqueous acetic acid to a final concentration of 0.05-0.5 $\mathrm{mg} / \mathrm{mL}$. Samples were sprayed with a syringe pump through a fused silica capillary (with the solution charged to $2 \mathrm{kV}$ ) towards a metallic capillary (held at a temperature of $120^{\circ} \mathrm{C}$ and voltage of $250 \mathrm{~V}$ ) at a rate of $21 \mu \mathrm{L} / \mathrm{hr}$. SID spectra of mass-selected multiply-charged peptides were obtained using a dodecanethiol SAM on gold as the collision target, which was mounted at the rear trapping plate of the ICR cell. Product ion analysis was done in this same ICR cell after collision. The collision energy is determined by the potential difference between the octopole dc offset and the voltage applied to the back trapping plate of the ICR and the SID target, $\Delta \mathrm{V}$; the kinetic energy of the collision was determined by multiplying $\Delta \mathrm{V}$ by the charge state. DESI was performed by spotting $20 \mu \mathrm{L}, 1 \mathrm{mg} / \mathrm{mL}$ peptide onto PTFE substrates. After samples were allowed to air dry, the spots were interrogated using a DESI spray solution of 50:50 MeOH:0.1\% aqueous acetic acid charged to $5 \mathrm{kV}$ at a flow rate of $5 \mu \mathrm{L} / \mathrm{min}$. SID spectra for electrospray generated ions were acquired in the pulsed mode and for DESI in the continuous mode(Laskin J et al.).

\section{Results/discussions}

Figure 1 shows SID spectra obtained for three different peptides at three different charge states: doubly protonated substance $\mathrm{P}$, triply protonated renin substrate, and quadruply protonated melittin, for which the precursor ion beam was directed at $0^{\circ}$ with respect to the target normal.

The SID spectrum obtained for doubly protonated substance $\mathrm{P}(\mathrm{m} / \mathrm{z} 674.6 ; \Delta \mathrm{V}$ $54.5 \mathrm{~V}$ ) is shown in Figure 1 a. Extensive fragmentation of the precursor ion upon SID resulting mainly in singly charged product ions was observed. The spectrum is dominated by immonium ions of various amino acids including leucine, phenylalanine etc. and internal fragments. This is indicative of the high-energy deposition associated with SID. Immonium ions were generally the most abundant ions observable even at lower SID energies. Figure $1 \mathrm{~b}$ shows the SID spectrum of the triply charged state of renin substrate

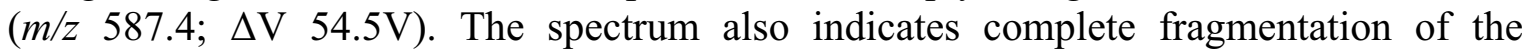
precursor ion generating predominantly singly protonated immonium ions, internal fragments and $b$-type ion series which allow the assignment of residues 3-6. Figure $1 \mathrm{c}$

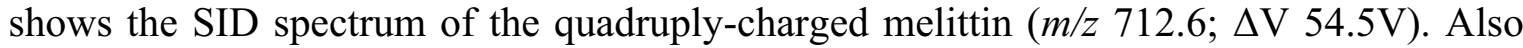
the precursor ion could not be observed in this spectrum which could also be due to the high collision energies required to get an appreciable SID signal. Singly protonated immonium, internal and a $b$-type ion series (which allow assignment of residue 3-5) were the predominant species identified in this spectrum.

The precursor ion peak was not observed in the SID spectra of all the peptides that were analyzed in this study even at low SID energies. This could be due to the large 
amount of collision energy that is required to observe measurable SID signal. Loss of the scattered ion signal at low values of $\Delta \mathrm{V}$ is attributed to precursor ion soft landing. These effects could potentially be mitigated by changing the orientation of the target with respect to the precursor ion beam. This introduces a velocity component of the ions that is parallel to the surface of the SID target which could have the effect of dragging ions from the surface resulting in an increase product ion intensity and/or detection of precursor ions during SID. Figure 2(i)a and 2(ii)a shows the intensity of the mass selected precursor ion beam for the triply protonated charge state of renin substrate that was used to obtain SID for two different orientations of the collision target. Figures 2(i)b-f and 2(ii)b-f show the SID spectra for each of these orientations of the SID surface normal $\left(0^{\circ}\right.$ and $30^{\circ}$ respectively) with respect to the precursor ion beam. The SID spectra shown in Figure 2 (i) were obtained by directing the precursor ion beam at $0^{\circ}$ to the surface normal which defines a circular collision cross section. In Figure 2 (ii), the precursor ion beam is at $30^{\circ}$ to the surface normal and this defines an elliptical collision cross section and introduces a new velocity component of the ion that is parallel to the surface of the SID target. The introduction of this new velocity component in the later should thus potentially lead to an increase SID signal and/or detection of the precursor ion intensity in the SID spectrum. However, from Figure 2 b-f (ii) it can be observed that even though the SID signal increases with collision energies up to $193.5 \mathrm{eV}$, the precursor ion peak was not observed. Also no obvious increase in the SID signal could be determined. The spectra in both case is dominated by singly protonated immonium ions, internal fragments and $b$-type ions which indicates appreciably high energy deposition.

This SID studies were then extended to the analysis of an intact protein, in this case cytochrome $\mathrm{C}$ generated by ESI. SID was obtained in the pulsed mode using a target oriented $0^{\circ}$ to the direction of the precursor ion beam. Figure 3 shows the results of this analysis. Figure 3 (i) a and $b$ shows the composition of the precursor ion beam that was employed to obtain the SID spectra shown in Figure 3 (i) c and d respectively. A very similar SID spectrum is obtained for a mixture of cytochrome $\mathrm{C}$ charge states ranging from $[\mathrm{M}+17 \mathrm{H}]^{17+}$ to $[\mathrm{M}+13 \mathrm{H}]^{13+}$ to that for the mass selected $[\mathrm{M}+14 \mathrm{H}]^{14+}$ charge state. A reliable SID spectrum is only obtained at a collision energy of $924 \mathrm{eV}$. This generates predominantly singly protonated immonium ions because of the high amounts of energy that has to be deposited unto the molecules in order to observe SID. Figure 3 (i) a, shows the mass selected precursor ion spectrum of the $[\mathrm{M}+14 \mathrm{H}]^{14+}$ charge state of cytochrome $\mathrm{C}$, Figure 3(ii) b-f shows the SID spectra generated from this ion at increasing collision energies. Even though similar SID spectra are observed, the SID signal increases with collision energy.

The implementation of DESI for the rapid analysis of biomolecules by SID was also explored in this set-up(Laskin $\mathrm{J}$ et al.). Figure 4 shows the mass-selected precursor ion of the doubly protonated peptide, substance P $(\mathrm{m} / \mathrm{z}$ 674.6) and its corresponding SID spectrum obtained in the continuous mode (for an acquisition time of 3 seconds) as insert. The SID spectrum consists predominantly of immonium ions and an internal fragment. A $b_{2}$ ion could also be seen in the spectrum. The rapid analysis time offered by both DESI and this continuous acquisition mode should results in a very high throughput approach for biomolecule analysis. 


\section{Conclusions}

Surface induced dissociation of multiply charged peptide ion in an FTICR generates predominantly singly charged peptide ions which allow some assignment of peptide sequence. The precursor ion peak could not be observed in the SID spectra even at lowest collision energies for which a reliable SID spectrum could be obtained. Changing the orientation of the SID target in order to introduce a velocity component of the ion parallel to the target upon collision and thus mitigating the effects of peptide soft landing indicate that, the collision energy plays a predominant role in the determination of the SID signal. Coupling desorption electrospray ionization with rapid continuous SID acquisition modes could be employed as a very high throughput approach for biomolecule analysis. 
PNNL-17069

\section{Figure Captions}

Figure 1: ESI-SID-FTICR spectra of various multiply charged peptides.

(a) Substance $\mathrm{P}[\mathrm{M}+2 \mathrm{H}]^{2+}$, (b) Renin substrate tetradecapeptide porcine $[\mathrm{M}+3 \mathrm{H}]^{3+}$ and (c) Mellitin $[\mathrm{M}+4 \mathrm{H}]^{4+}$.

Figure 2: (a) Mass selected precursor ion spectrum of triply protonated renin substrate. (bf) ESI-SID-FTICR spectra of the triply charged state of renin substrate at various acceleration potentials with the precursor ion beam oriented at (i) $0^{\circ}$, (ii) $30^{\circ}$ to the surface normal.

Figure 3: (i) Precursor ion spectrum for cytochrome $\mathrm{C}$ with the resolving quadrupole operating in (a) rf only and (b) rf/dc (isolation of $[\mathrm{M}+14 \mathrm{H}]^{14+}$ ions). (i)c and (i)d are the respective ESI-SID-FTICR spectra generated from these precursor ion beams at an acceleration potential of $106 \mathrm{~V}$. (ii) (a) Mass selected precursor ion spectrum of cytochrome C $\left([\mathrm{M}+14 \mathrm{H}]^{14+}\right.$ ions). (b-f) ESI-SID-FTICR spectra of the $[\mathrm{M}+14 \mathrm{H}]^{14+}$ ion of cytochrome $\mathrm{C}$ at various acceleration potentials.

Figure 4: DESI-FTICR spectrum of the mass selected double charged state of the peptide, Substance $\mathrm{P}$ and its corresponding SID spectrum as insert. 
Figures

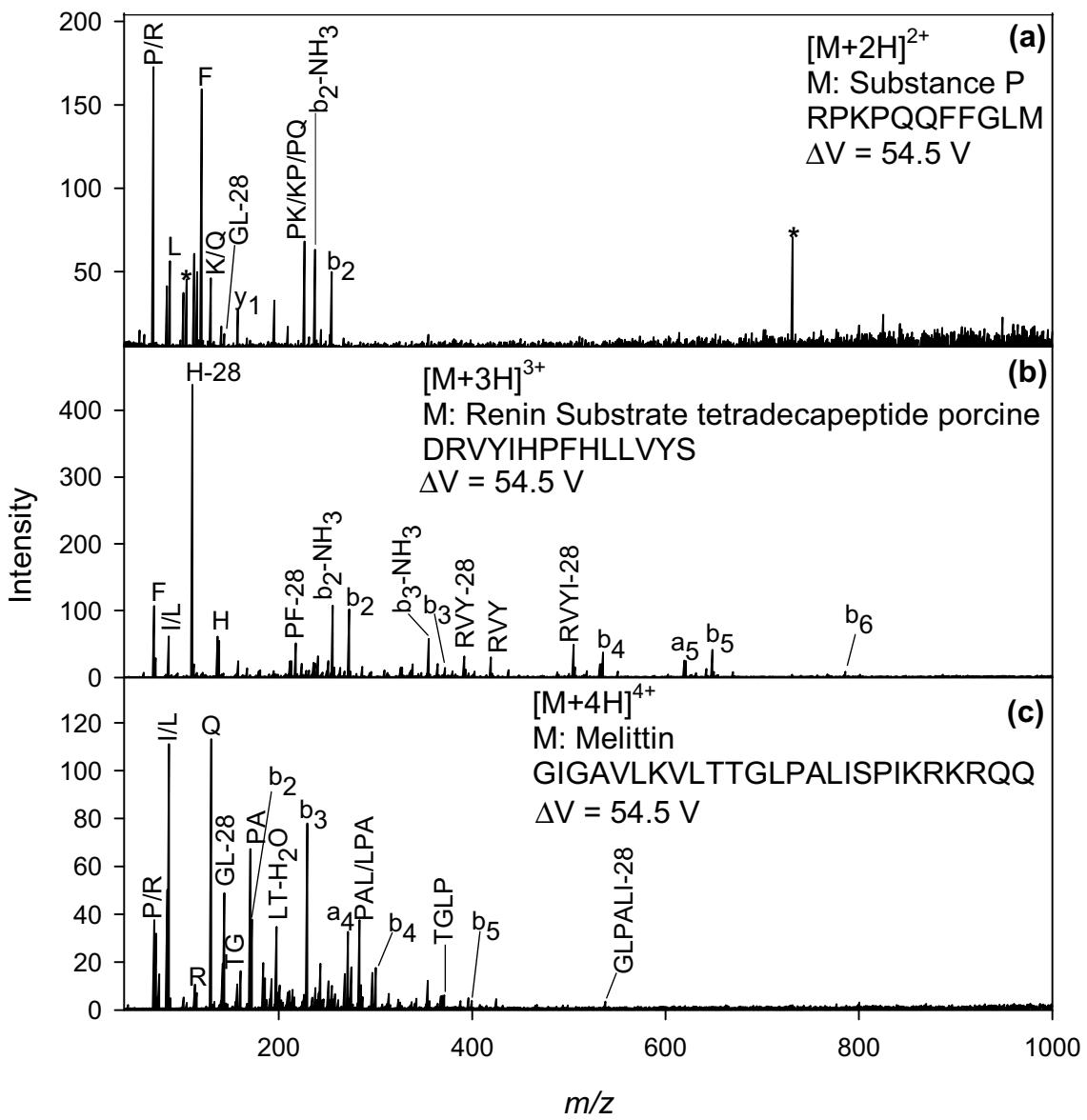

Figure 1 
PNNL-17069
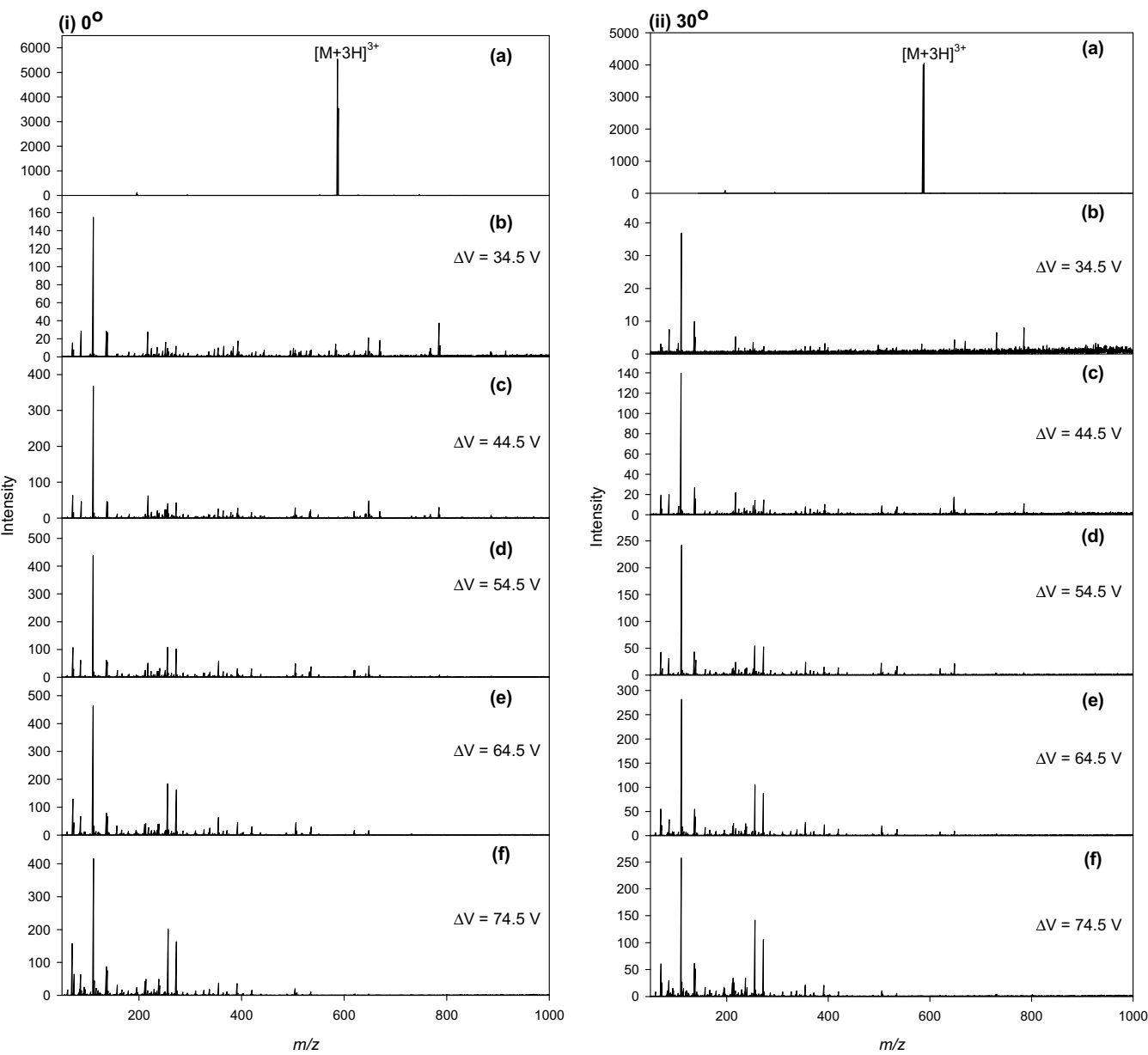

Figure 2 
PNNL-17069
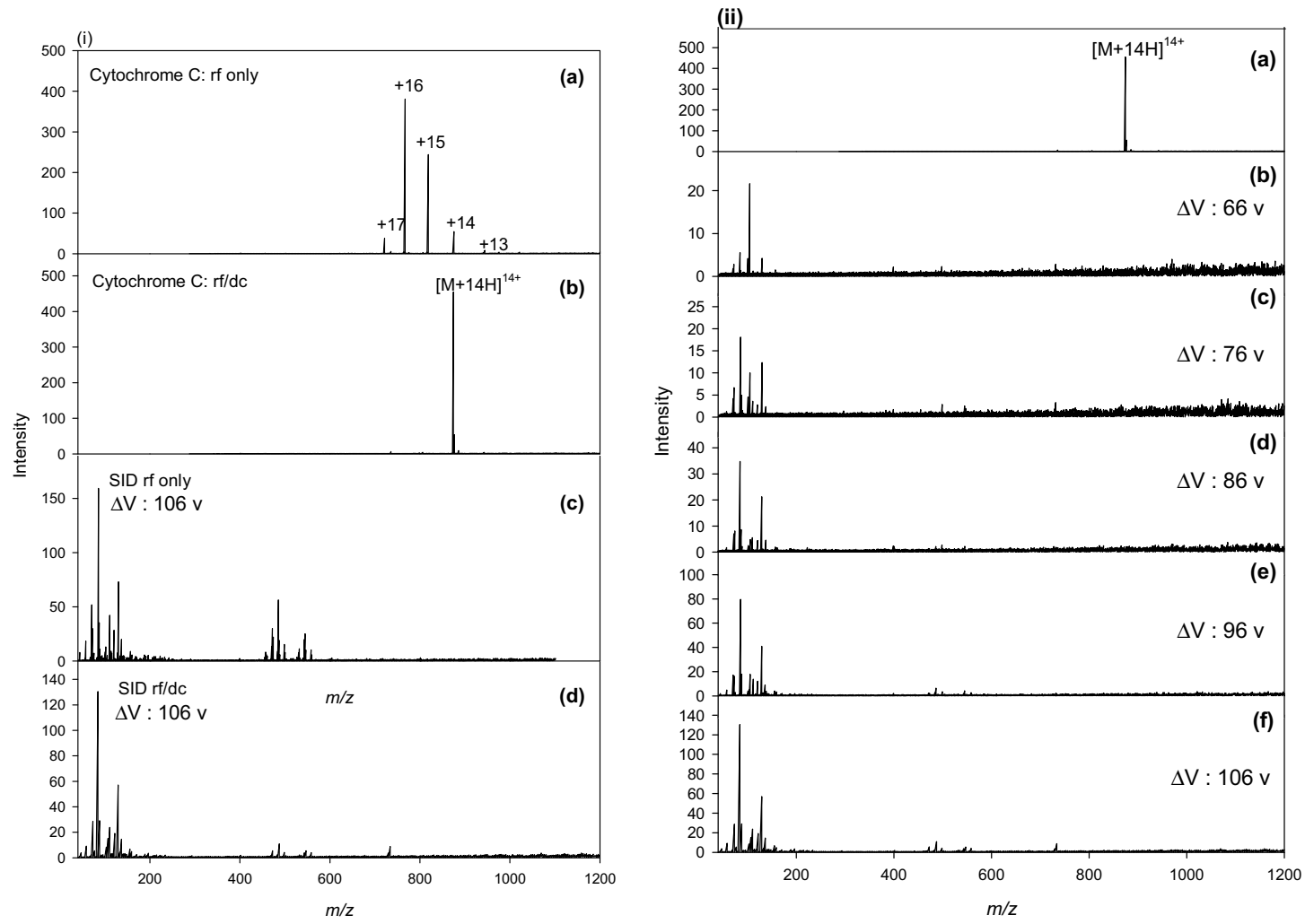

Figure 3

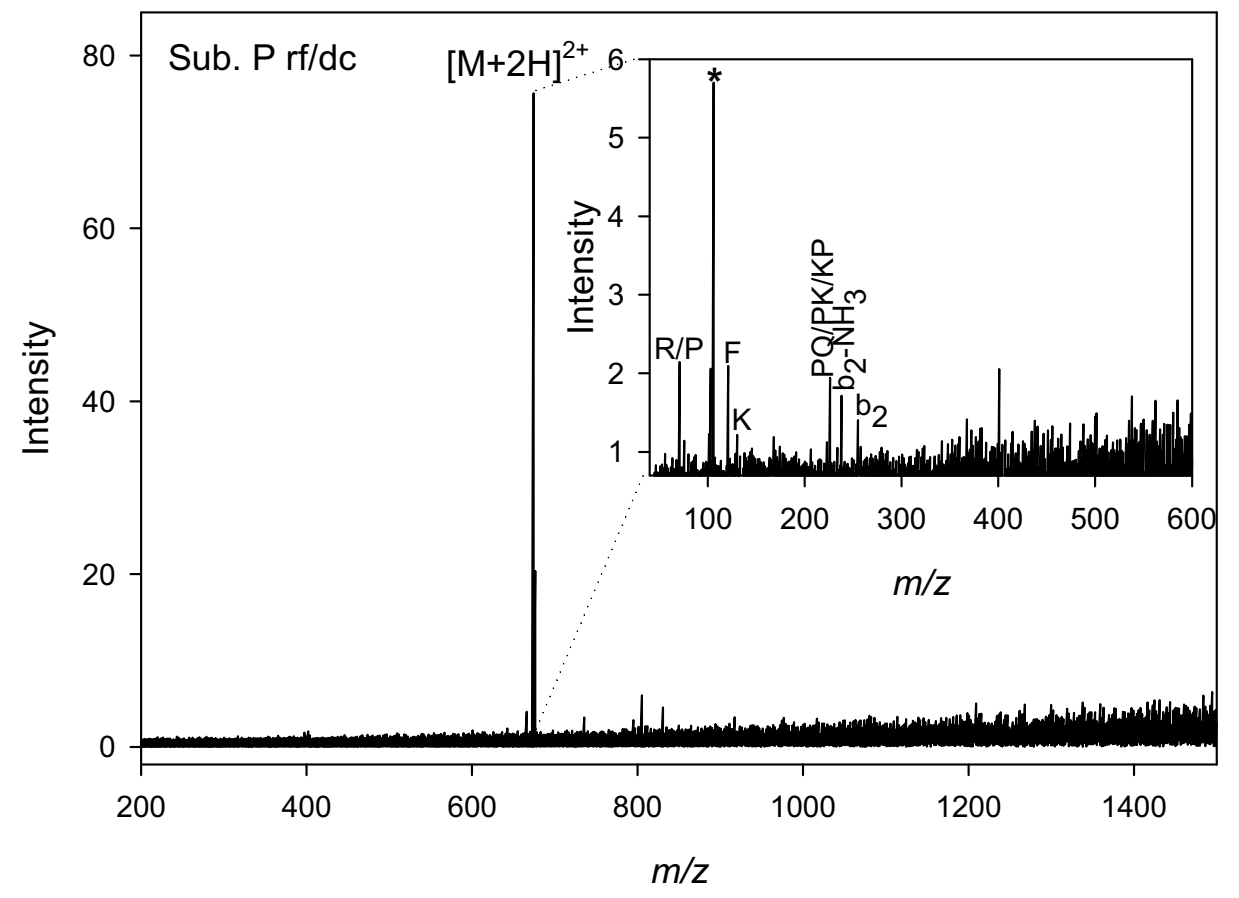

Figure 4 
PNNL-17069

\section{References}

(1) Hoffmann E. de J. Mass Spectrom. 1996, 31, 129.

(2) Laskin J; Denisov E.; Shukla A. K.; Barlow S. E.; Futrell J. H. Anal. Chem. 2002, $74,3255$.

(3) Schey K.; Cooks R. G.; Grix R.; Woellnik H. A. Int. J. Mass Spectrom. Ion Processes 1987, 77, 49.

(4) Little D. P.; Speir J. P.; Senko M. W.; O'Connor P. B.; McLafferty F. W. Anal. Chem. 1994, 66, 2809.

(5) Price W. D.; Schier P. D.; William E. R. Anal. Chem. 1996, 68, 859.

(6) Tsybin Y. O.; Hakansson P.; Budnik B. A.; Haselmann K. F.; Kjeldsen F.; Gorshkov M.; Zubarev R. A. Rapid Commmun. Mass Spectrom. 2001, 15, 1849.

(7) Zubarev R. A.; Horon D. M.; Fridriksson E. K.; Kelleher N. L.; Kruger N. A.; Lewis M. A.; Carpenter B. K.; McLafferty F. W. Anal. Chem. 2000, 72, 563.

(8) McCormack A. L., J.; ones J. L.; Wysocki V. H. J. Am. Soc. Mass Spectrom. 1992, 3,859 . 
PNNL-17069 


\title{
Using AFM to Study Biological Processes on a Single-Molecules Level
}

\author{
Zachery Oestreicher $^{1 *}$, Brian H. Lower ${ }^{2}$, and Steven K. Lower ${ }^{1}$
}

${ }^{1}$ The Ohio State University, 125 S. Oval Mall, 275 Mendenhall Laboratory

Columbus, Ohio 43210

Email for Prof. Steven K. Lower: lower.9@osu.edu

${ }^{2}$ Environmental Molecular Sciences Laboratory, Pacific Northwest National Laboratory, P.O. Box 999, K8-96, Richland, Washington 99352

Email for Dr. Brian H. Lower: brian.lower@pnl.gov

*Corresponding author: Zachery Oestreicher, PhD student

Email for Mr. Zachery Oestreicher: oestreicher.6@osu.edu

\begin{abstract}
Atomic force microscopy (AFM) is a high-resolution threedimensional imaging technique that can achieve nanometer resolution in the $\mathrm{X}, \mathrm{Y}$, and $\mathrm{Z}$ directions. Because of its ability to obtain high-resolution images, single molecules can be imaged using AFM. The significance of this is that individual molecules of cells, such as proteins and DNA, can be identified. Another advantage of AFM is that sample preparation is considerably more rapid than other techniques that give similar resolution (i.e. TEM). Unlike SEM or TEM, cellular processes may be examined under physiological conditions, such as changes in protein conformation. In this study we used the AFM to image pUC 19 plasmid DNA from E. coli. The images that were acquired clearly illustrated individual plasmids. The consequence of this work will be to further develop the imaging technique in order to examine other single molecules, primarily protein molecules inside bacterial cells and in artificial membranes.
\end{abstract}

Introduction 
The technique of atomic force microscopy (AFM) was first developed in 1986 by Binnig (Binnig, Quate and Gerber). The AFM operates by using a very fine cantilever, which possesses a very fine tip at the end of the lever and is perpendicular to the lever. This tip rasters over a very small portion of the surface of the sample. The information from the tip is then used to generate a three dimensional image of the sample.

There are many different uses for AFM such as measuring nanonewton forces which bind molecules(Hansma, Revenko et al.), for characterizing the morphological and thermodynamic properties of proteins (Yang, Wang and Erie), and to image single molecules (Hansma and Pietrasanta). One important characteristic of AFM is that it can give true three-dimensional images of samples. Imaging DNA with the AFM was initially conducted in the early 1990's (Erie et al.; Hansma, Bezanilla et al.; Rees et al.; Wyman et al.).

The work done for the Pacific Northwest National Lab Science and Engineering Education Summer Research Internship during the summer 2007 was to develop the AFM technique of imaging single molecules in fluid. This was accomplished by imaging pUC 19 plasmid DNA from E. coli in a buffered solution.

Experimental

DNA was imaged using an Asylum MFP-3D Atomic Force Microscope using Igor Pro 5.03 software in two different environments, air and fluid. Two different cantilevers were used depending on the conditions of the sample. For the air samples the Olympus AC160TS cantilever was used and for the fluid samples the Olympus RC150VB Biolever was used.

It has been demonstrated that the most effective way to image DNA is to use a buffer containing divalent cations, particularly $\mathrm{Ni}^{2+}$ (Hansma and Pietrasanta). This cation acts as a bridge to bind the negatively charged DNA to a negatively charged surface such as mica. Mica is used because it is atomically flat which limits the surface topography of the substrate so that only the sample placed on the mica contributes to changes in the Zaxis.

The DNA was pUC19 plasmid DNA (Sigma cat. \# D3404) buffered in 5mM $\mathrm{NiCl}_{2}$. The DNA was deposited onto a freshly cleaved mica (V-1) grade surface. Two different depositional methods were used depending on conditions of the sample. For the air sample, $50 \mathrm{~L} 1 \mathrm{mg} / \mathrm{mL}$ solution of pUC19 DNA in $5 \mathrm{mM} \mathrm{NiCl}_{2}$ buffer was pipetted onto a freshly cleaved mica surface and incubated at room temperature for approximately10 minutes. The solution was then wicked off using a Kim wipe and analyzed in the AFM. For the fluid samples, $200 \mathrm{~L}$ of $1 \mathrm{mg} / \mathrm{mL}$ pUC19 DNA in $5 \mathrm{mM}$ $\mathrm{NiCl}_{2}$ buffer was pipetted onto a freshly cleaved surface of mica and incubated at room temperature for 10 minutes, followed by an addition of $200 \mathrm{~L}$ of $5 \mathrm{mM} \mathrm{NiCl}_{2}$ buffer. The samples were then analyzed in the AFM.

Results \& Discussion 
DNA was imaged in the AFM under two different environmental conditions, in air and in fluid (Figure 13 \& Figure 14 respectively). Both conditions exhibited single DNA molecules that were on the order on several hundred nanometers in the $\mathrm{X}$ and $\mathrm{Y}$-axes and approximately 1 nanometer in the $\mathrm{Z}$ direction. This is equivalent to the resolution of transmission electron microscopy (TEM); however, AFM gives three dimension data (Figure 15) and has much greater depth of field.

However, there are artifacts associated with the imaging technique. In both conditions the images illustrated similar morphologies of DNA, but the fluid images appeared to have more circular DNA. Whereas the DNA imaged in air appeared to have several morphologies other than circular. The number of plasmids on the mica and the morphology of the plasmids is dependent on the procedures, i.e. the initial concentration and the incubation time of the deposited plasmids (Hansma and Laney).

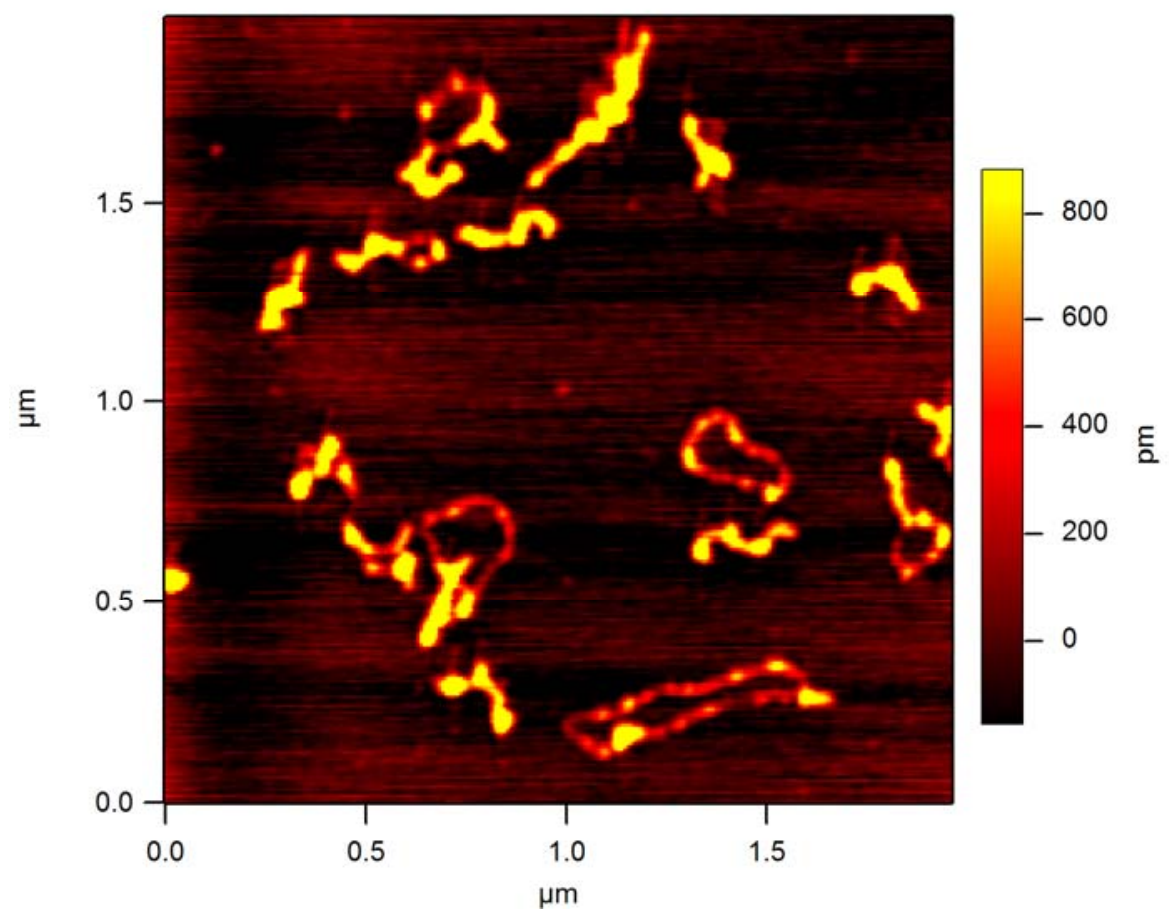

Figure 13 pUC19 plasmid DNA imaged in air using tapping mode in the AFM. The $X$ and $Y$ scale of the image is located on bottom and left side of the image and the $Z$ scale is located on the right side of the image represented by a color scale. 
PNNL-17069

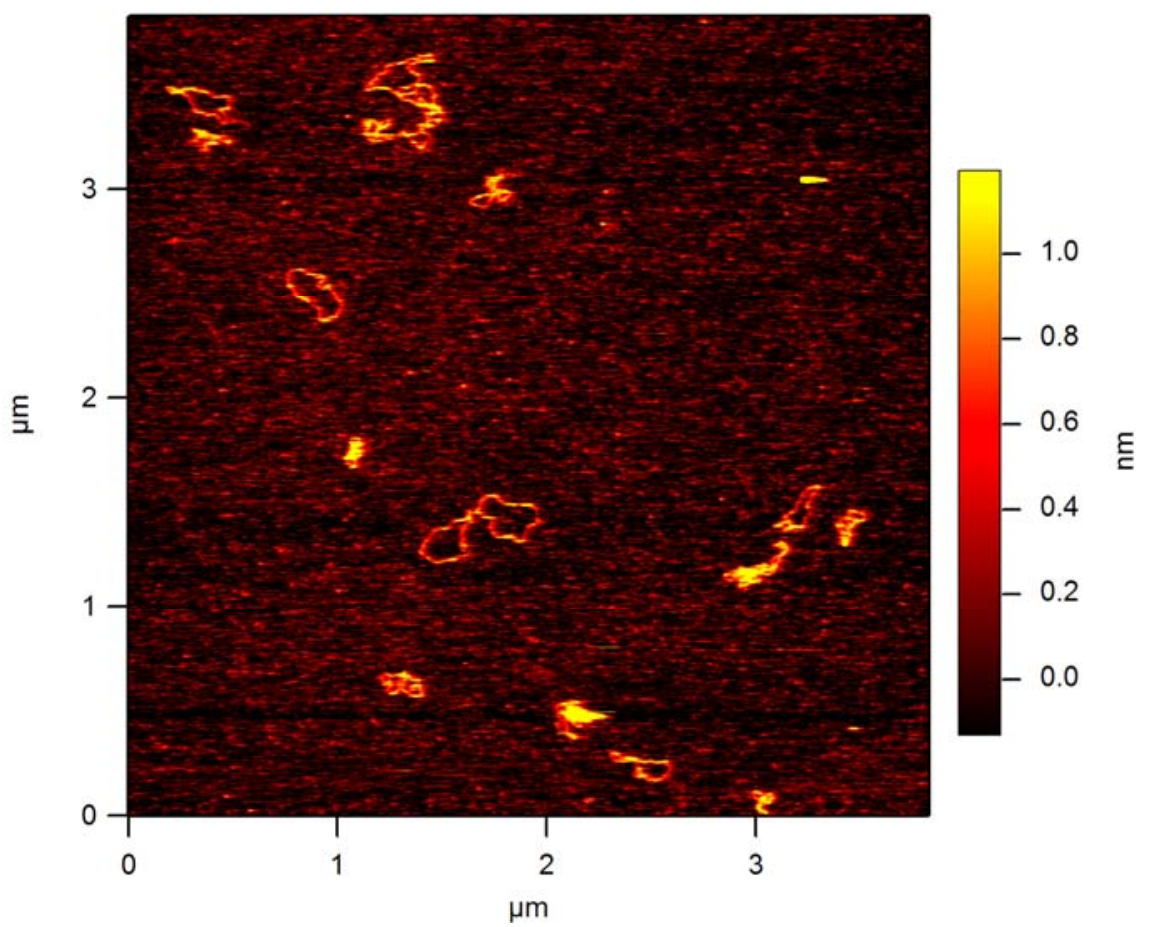

Figure 14 pUC19 plasmid DNA imaged in buffer using tapping mode in the AFM. The $X$ and $Y$ scale of the image is located on bottom and left side of the image and the $\mathrm{Z}$ scale is located on the right side of the image represented by a color scale. 


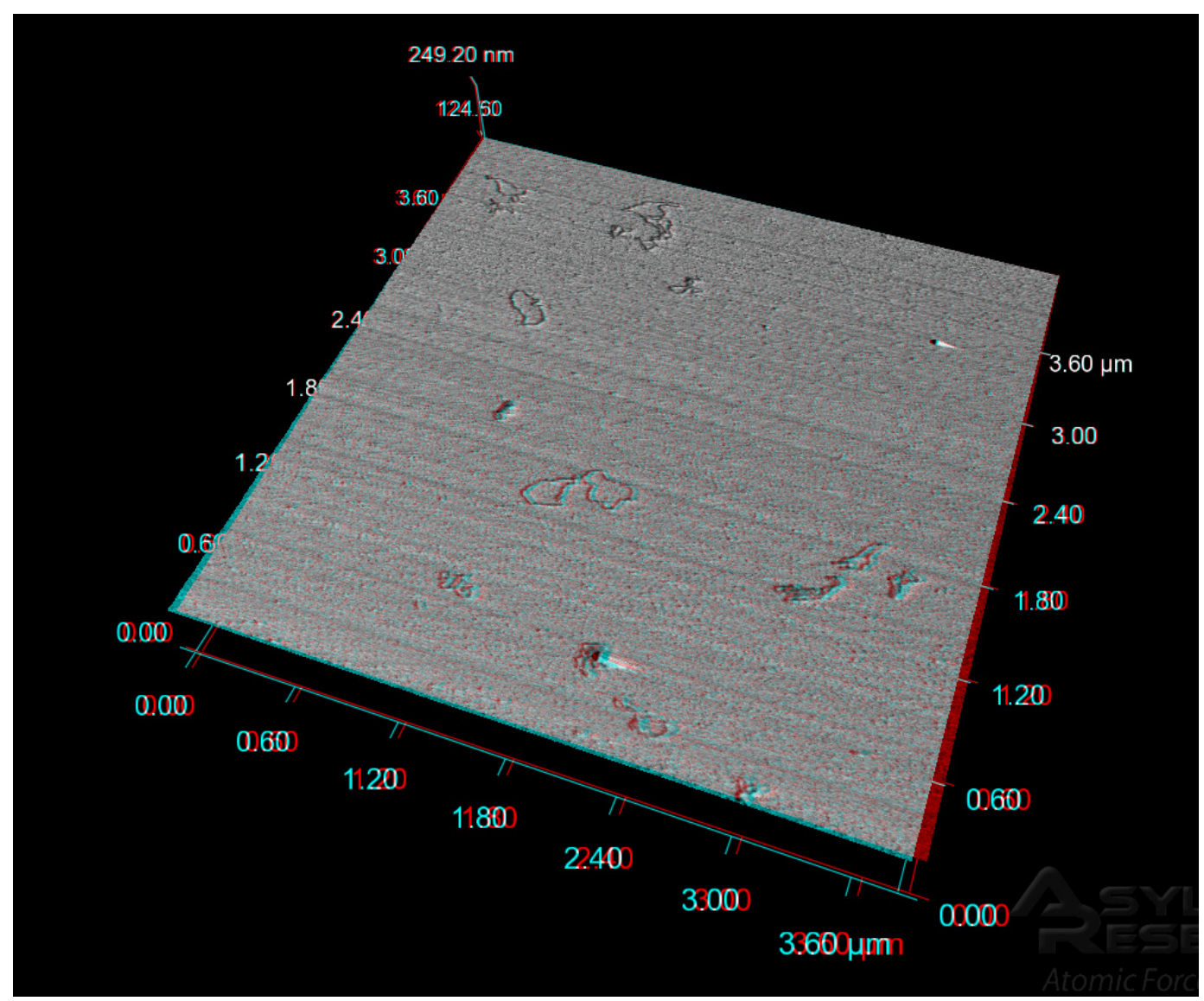

Figure 15 Three-dimensional view of pUC19 plasmid DNA imaged in buffer using tapping mode in the AFM. The $X$ and $Y$ scale of the image is located on the sides of the image and the $Z$ scale is located in the upper middle portion of the image. 
PNNL-17069

Conclusion

During my 2007 Summer Research Internship for the Science Engineering Education I was able to learn the technique of single molecule imaging using the Atomic Force Microscope (AFM). The images of single DNA molecules were acquired under physiological conditions in buffered media. This is an important technique because it is the only way to image single molecules in three dimensions (Roiter and Minko). The technique of imaging single molecules under physiological conditions is important because single molecules can be investigated inside cells, rather than spread out on a substrate such as mica. For instance, images of specific cellular proteins under various experimental conditions can be acquired and the different conformations of the protein can be correlated with specific actions of the protein (Yang, Wang and Erie).

Future Work

Cells are very complex; they consist of many proteins along with other molecules, packed into a small compartment bound by a plasma membrane. In order to identify specific molecules within this slurry of molecules, a probe needs to be used. It is possible to tether antibodies to AFM cantilever tips and use this to identify a molecule of interest (Stroh et al.). However, imaging single molecules using the AFM is possible only if the cantilever can touch the molecule. Therefore it is not possible to image single molecules inside living cells without severely damaging the cell's integrity.

One way to get inside cells is to fix the cells, embed them in resin, and cut the cells into transverse section. This is conventionally done for cells in the transmission electron microscope; however, sectioned cells have been imaged with the AFM (Matsko and Mueller). These sections will give the cantilever tip access to the proteins inside the cells. The AFM tip can be functionalized with a probe such as an antibody and then individual proteins of interest can be probed. From this data, a high-resolution three-dimensional image could be produced of proteins of interest inside of cells. This data could be combined with fluorescent data from confocal microscopy images to create a comprehensive high-resolution picture of proteins inside a cell. 
PNNL-17069

References

1. Binnig, G., C.F. Quate, and C. Gerber, Atomic Force Microscope. Physical Review Letters, 1986. 56(9): p. 930.

2. Hansma, H.G., et al., Atomic force microscopy of long and short double-stranded, single-stranded and triple-stranded nucleic acids. Nucleic Acids Research, 1996. 24(4): p. 713-720.

3. Yang, Y., H. Wang, and D.A. Erie, Quantitative characterization of biomolecular assemblies and interactions using atomic force microscopy. 2003.

4. Hansma, H.G. and L. Pietrasanta, Atomic force microscopy and other scanning probe microscopies. Current Opinion in Chemical Biology, 1998. 2(5): p. 579-584.

5. Erie, D.A., et al., DNA bending by Cro protein in specific and nonspecific complexes: Implications for protein site recognition and specificity. Science (Washington D C), 1994. 266(5190): p. 1562 1566.

6. Hansma, H.G., et al., Atomic force microscopy of DNA in aqueous solutions. Nucleic Acids Research, 1993. 21(3): p. 505-512.

7. Rees, W.A., et al., Evidence of DNA bending in transcription complexes imaged by scanning force microscopy. Science (Washington D C), 1993. 260(5114): p. 1646-1649.

8. Wyman, $C$., et al., Determination of heat-shock transcription factor 2 stoichiometry at looped DNA complexes using scanning force microscopy. EMBO (European Molecular Biology Organization) Journal, 1995. 14(1): p. 117-123.

9. Hansma, H.G. and D.E. Laney, DNA binding to mica correlates with cationic radius: Assay by atomic force microscopy. Biophysical Journal, 1996. 70(4): p. 1933-1939.

10. Roiter, Y. and S. Minko, AFM Single Molecule Experiments at the Solid-Liquid Interface: In Situ Conformation of Adsorbed Flexible Polyelectrolyte Chains. J. Am. Chem. Soc., 2005. 127(45): p. 15688-15689.

11. Stroh, C., et al., Single-molecule recognition imaging microscopy. Proceedings of the National Academy of Sciences, 2004. 101(34): p. 12503-12507.

12. Matsko, N. and M. Mueller, AFM of biological material embedded in epoxy resin. Journal of Structural Biology, 2004. 146(3): p. 334-343. 
PNNL-17069 
PNNL-17069

\title{
Interface Studies of CdS Nanoparticle/Polymer Composites
}

\author{
Saida Ortiz \\ University of Akron \\ and \\ Sarah Burton \\ Pacific Northwest National Laboratory
}

\section{Introduction}

Cadmium sulfide (CdS) nanoparticles have been synthesized using two different capping agents, 1-thioglycerol and 4-bromophenylethenyl phosphonic acid (4BrEPPA). These are being studied to determine the impact of the capping agent on the final structure and physical properties of the nanoparticles. These systems are also being used as a model to study how a polymer will interact with the nanoparticles. The technique used to characterize these materials was solid-state nuclear magnetic resonance (SSNMR), as the materials are rich in NMR active nuclei $\left({ }^{113} \mathrm{Cd},{ }^{13} \mathrm{C},{ }^{1} \mathrm{H}\right)$. The results from these studies will be used to gain a molecular level understanding of the mechanism of how the organicinorganic interface impacts the materials physical properties.

\section{Experimental}

CdS nanoparticles were prepared by dissolving $0.002 \mathrm{~mol}$ of $\mathrm{CdSO}_{4} 8 / 3 \mathrm{H}_{2} \mathrm{O}$ to $1 \mathrm{~L}$ of nanopure water. This was followed by the addition of $0.018 \mathrm{~mol}$ of 1-thioglycerol (structure 1) and the mixture was stirred for 5 minutes, followed by the addition of 0.03 mol of $\left(\mathrm{NH}_{4}\right)_{2} \mathrm{~S}$. A white cloudy solution was formed, followed by the formation of a cloudy yellow solution. The mixture was stirred for 2 hours until the solution was clear yellow. The solution was roto-evaporated at $\sim 40{ }^{\circ} \mathrm{C}$, and the remaining slurry was vacuum dried for $\sim 24$ hours. These particles are referred to as the as-synthesized $\mathrm{CdS} / 1$ thioglycerol nanoparticles. 
PNNL-17069

\section{Structure 1}

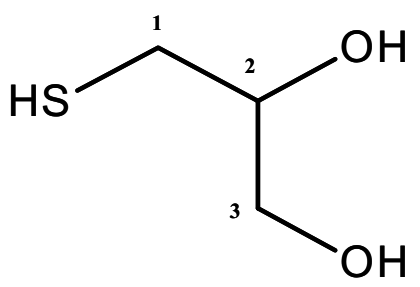

1-thioglycerol

$\mathrm{CdS} / 1$-thioglycerol precipitated with ethanol (EtOH) nanoparticles were synthesized as described above and then $1 \mathrm{~L}$ of ethanol was added to the mixture and the solution was left overnight without stirring. The sample was centrifuged and the residue was rinsed with nanopure water, followed by centrifugation. The precipitate was dried under vacuum for $\sim 24$ hours.

CdS particles were also prepared using 4-bromophenylethenyl phosphonic acid (4BrEPPA) (structure 2) as the capping agent. Two solutions were prepared in order to synthesize these nanoparticles, one by dissolving $0.0012 \mathrm{~mol}$ of $\mathrm{CdSO}_{4} 8 / 3 \mathrm{H}_{2} \mathrm{O}$ in 300 $\mathrm{mL}$ of nanopure water, and the other solution was prepared by dissolving $0.0121 \mathrm{~mol}$ of 4BrEPPA in $300 \mathrm{~mL}$ of ethanol. The 4BrEPPA solution was added to the $\mathrm{CdSO}_{4} 8 / 3 \mathrm{H}_{2} \mathrm{O}$ solution, and a white precipitate was formed after $\sim 2$ minutes of stirring the solution. This precipitate is referred to as the $\mathrm{Cd}^{+2}-4 \mathrm{BrEPPA}$ salt. $1.2 \mathrm{~mL}$ of $6 \mathrm{M} \mathrm{H}_{2} \mathrm{SO}_{4}(0.0072 \mathrm{~mol})$ were added to the $\mathrm{Cd}^{+2}-4 \mathrm{BrEPPA}$ solution and the precipitate re-dissolved completely in solution. $0.18 \mathrm{~mol}$ of $\left(\mathrm{NH}_{4}\right)_{2} \mathrm{~S}$ were added to the mixture and a yellow precipitate was formed. The solution was stirred for 2 hours and centrifuged. The yellow precipitate was collected and dried under vacuum for $\sim 24$ hours.

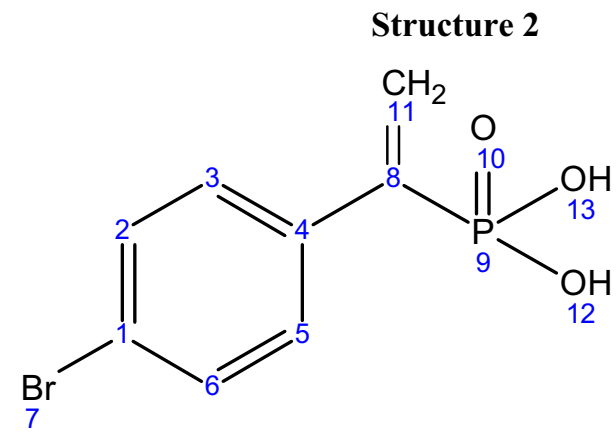

\section{4-bromophenylethenyl phosphonic acid (4BrEPPA)}


PNNL-17069

\section{Results and Discussion}

\section{a. CdS / 1-thioglycerol nanoparticles}

The absorption spectrum can be used to determine the nanoparticle diameter and distribution of particle size. Based on the absorption spectrum from the CdS/1thioglycerol as synthesized nanoparticles, Figure 1, the average diameter is $\sim 4 \mathrm{~nm}$ with a moderate distribution in particle diameter.

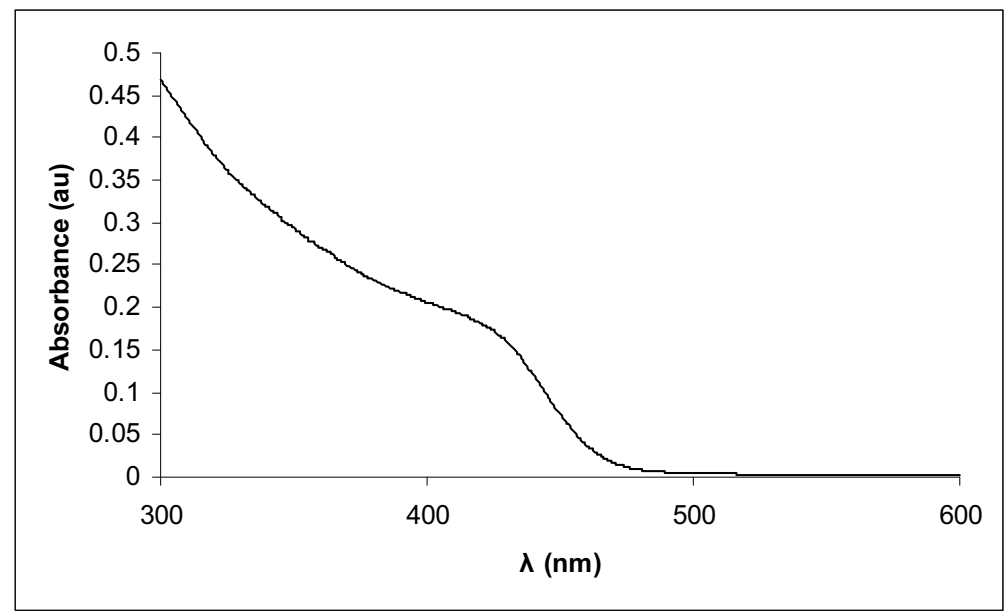

Figure 1: Absorption spectrum of $\mathrm{CdS} / 1$-thioglycerol as synthesized nanoparticles

The ${ }^{13} \mathrm{C}$ NMR spectra from the $\mathrm{CdS} / 1$-thioglycerol nanoparticles and neat 1 thioglycerol are shown in Figure 2. Based on Structure 1, C1, C2 and C3 of 1-thioglycerol were identified to be at $\sim 34 \mathrm{ppm}, \sim 75 \mathrm{ppm}$, and $\sim 68 \mathrm{ppm}$, respectively. The CdS/1thioglycerol as-synthesized nanoparticles show two components in the ${ }^{13} \mathrm{C}$ NMR spectrum, a broad and a narrow component. The broad component is assigned to the carbons of the 1-thioglycerol attached to the CdS nanoparticles, and the narrower component arises from 1-thioglycerol that is not attached to the nanoparticles and is more mobile. The ${ }^{13} \mathrm{C}$ NMR spectrum from the CdS/1-thioglycerol nanoparticles precipitated with EtOH shows only the broad component. The excess 1-thioglycerol has been removed by washing with EtOH due to its solubility in this solvent. 


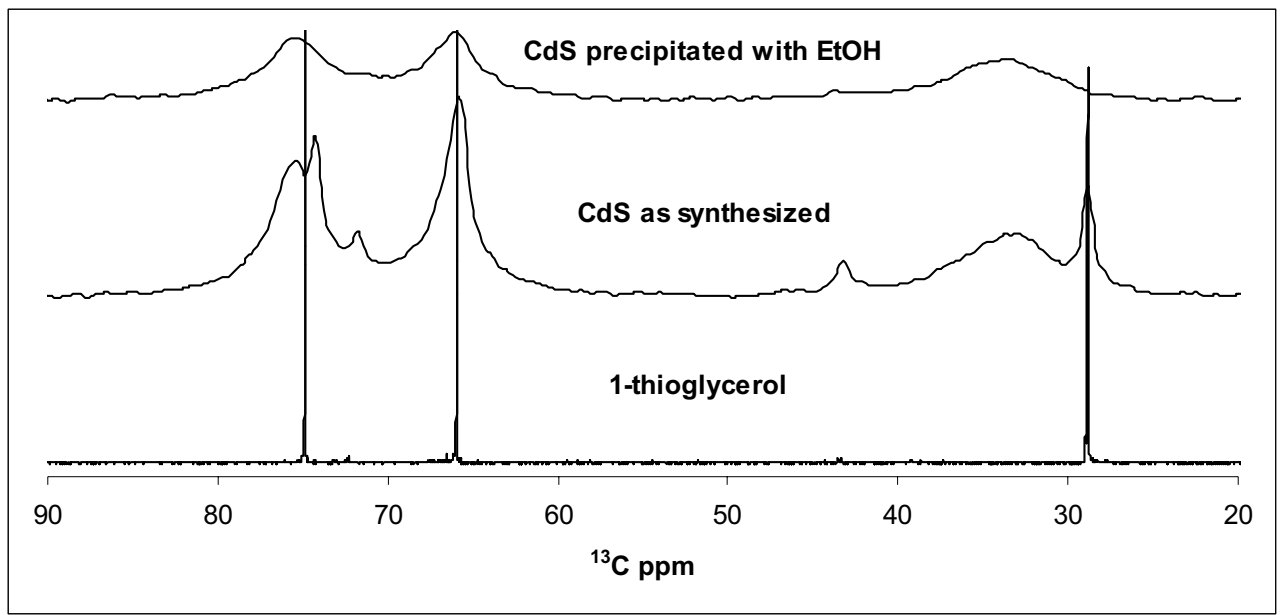

Figure 2: ${ }^{13} \mathrm{C} \mathrm{CP} / \mathrm{MAS}$ from 1-thioglycerol in $\mathrm{D}_{2} \mathrm{O}$ (bottom), $\mathrm{CdS} / 1$-thioglycerol as synthesized (middle), and CdS/1-thioglycerol precipitated with Ethanol (top). These data were collected in a 400 MHz instrument with 1 second recycle delay for 1-thioglycerol, and $200 \mathrm{MHz}$ instrument for CdS/1thioglycerol as synthesized and precipitated with ethanol nanoparticles, with recycle delays and contact times of 2 seconds and $1 \mathrm{~ms}$, respectively, spinning speed of $5 \mathrm{KHz}$ and 32760 transients.

The ${ }^{13} \mathrm{C}$ signal also has been recorded as a function of the cross-polarization (CP) time, Figure 3. We observe that when the particles are precipitated with $\mathrm{EtOH}$, the maximum intensity is reached with a shorter $\mathrm{CP}$ time than for the as-synthesized nanoparticles. The as-synthesized nanoparticles show evidence of two different populations. In one case the signal intensity rises fast $(0-1 \mathrm{~ms})$, while the other signal increases more slowly (1-12 ms). In the case of the $\mathrm{CdS}$ precipitated with EtOH nanoparticles, a single rise time is observed where the maximum is reached at $1 \mathrm{~ms}$.

The CdS nanoparticles precipitated with EtOH also show a single exponential decrease in the signal intensity versus the $\mathrm{CP}$ time. The rate of decay is a measure of the proton signal relaxation, $T_{1 p}\left({ }^{1} H\right)$. The relaxation rate for the $\mathrm{CdS}$ as-synthesized nanoparticles is observed to be much slower than for the CdS precipitated with EtOH. The differences observed in these two samples are the result of the two type of 1-thioglycerol present, bound and free. The free 1-thioglycerol is more mobile, therefore it will show a longer time for intensity increase and for proton relaxation. 
PNNL-17069

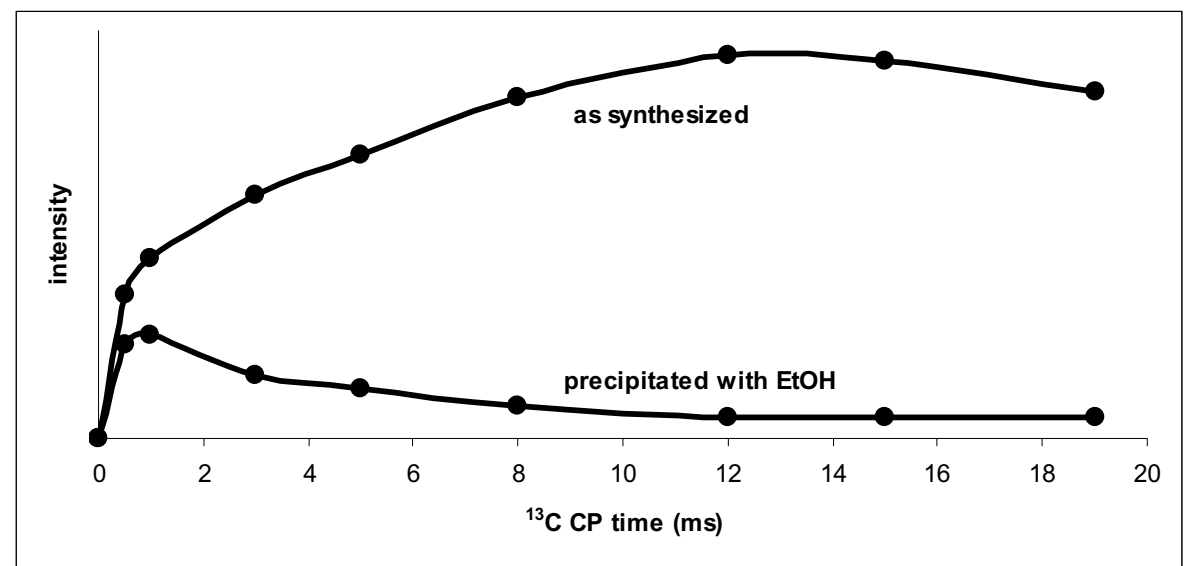

Figure 3: ${ }^{13} \mathrm{C}$ Signal Intensity vs. Cross-Polarization (CP) time

Figure 4 shows the ${ }^{1} \mathrm{H}$ NMR from CdS/1-thioglycerol as-synthesized nanoparticles and from CdS/1-thioglycerol precipitated with EtOH. We observed narrower lines that arise from more mobile species of the as-synthesized nanoparticles and are assigned to the free 1-thioglycerol. In the sample precipitated with EtOH the spectrum is broader due to the restricted motion of the protons which increases the linewidth from larger ${ }^{1} \mathrm{H}-{ }^{1} \mathrm{H}$ dipolar couplings. The assignment of each resonance in Figure 4 is presented in tables 1 and 2. The narrower peak at $\sim 1-2 \mathrm{ppm}$ was assigned to the $\mathrm{SH}$ group of 1-thioglycerol. Further studies are in progress to confirm this assignment.

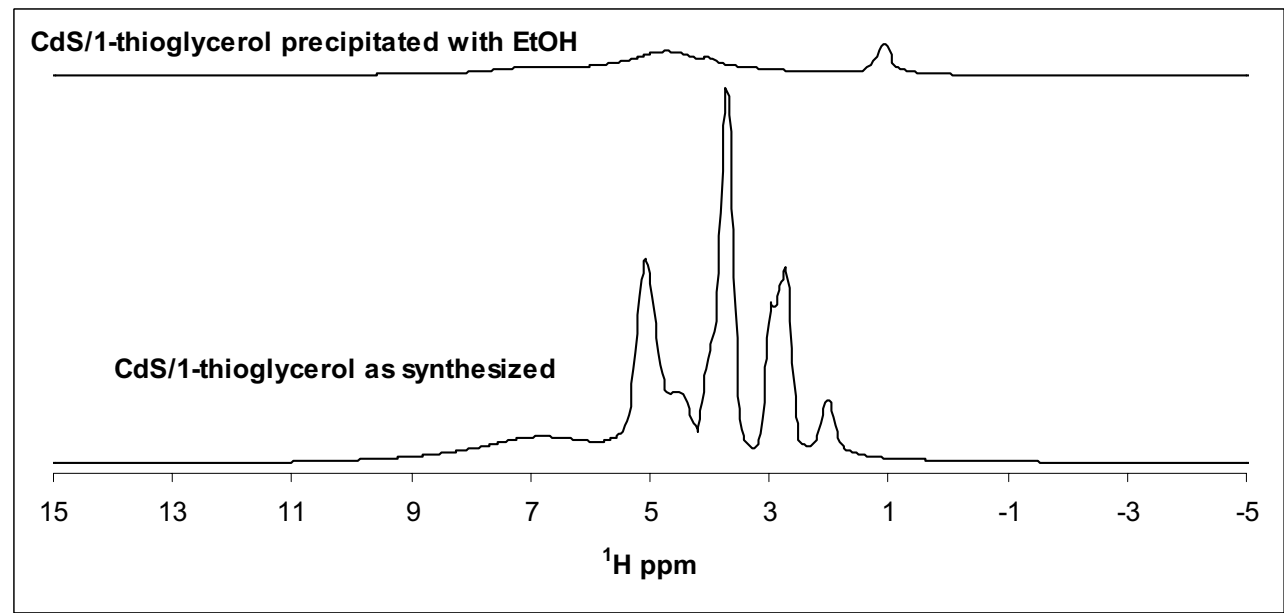

Figure 4: ${ }^{1} \mathrm{H}$ DP/MAS of CdS/1-thioglycerol as synthesized (bottom), and CdS/1-thioglycerol precipitated with EtOH (top). These data was collected in a $500 \mathrm{MHZ}$ instrument using a one pulse sequence and a spinning speed of $10 \mathrm{KHz}$. The recycle delay of these two samples was of 5 and 2 seconds, respectively. 
Table 1: Chemical shift assignment of CdS/1-thioglycerol as synthesized

\begin{tabular}{|c|c|}
\hline $\begin{array}{c}\text { Chemical } \\
\text { shift } \\
\text { (ppm) }\end{array}$ & $\begin{array}{c}\text { CdS as } \\
\text { synthesized }\end{array}$ \\
\hline 2.0 & SH \\
\hline 2.7 & HS-CH \\
\hline 2.9 & HS-CH \\
\hline 3.7 & HO-CH \\
\hline 4.0 & HO-CH \\
\hline 4.5 & H2O \\
\hline 5.0 & H2O \\
\hline 6.8 & OH \\
\hline
\end{tabular}

Table 2: Chemical shift assignment of

CdS/1-thioglycerol precipitated with EtOH

\begin{tabular}{|c|c|}
\hline $\begin{array}{c}\text { Chemical } \\
\text { shift } \\
\delta(p p m)\end{array}$ & $\begin{array}{c}\text { CdS } \\
\text { precipitated } \\
\text { with EtOH }\end{array}$ \\
\hline 1.0 & SH \\
\hline & HS-CH CH $_{2}$ \\
& HO-CH \\
$4.0-4.7$ & HO-CH \\
& H2O \\
\hline 6.8 & OH \\
\hline
\end{tabular}

The ${ }^{113} \mathrm{Cd}$ direct polarization magic angle spinning (DP/MAS) and CP/MAS spectra from CdS/1-thioglycerol as-synthesized nanoparticles is shown in Figure 5. The resonance at $\sim 700 \mathrm{ppm}$ in the ${ }^{113} \mathrm{Cd}$ spectra proves that $\mathrm{CdS}$ particles have been synthesized, as this is the same chemical shift observed for commercially available, bulk CdS. The DP/MAS spectrum of Figure 5 and Figure 6 arise from all the cadmium present in the sample, while the CP/MAS spectra are from the cadmium at the surface of the nanoparticles. The fraction of cadmium at the surface is very small compared to the entire particle, and is consistent with a particle diameter of $\sim 4 \mathrm{~nm}$. 
PNNL-17069

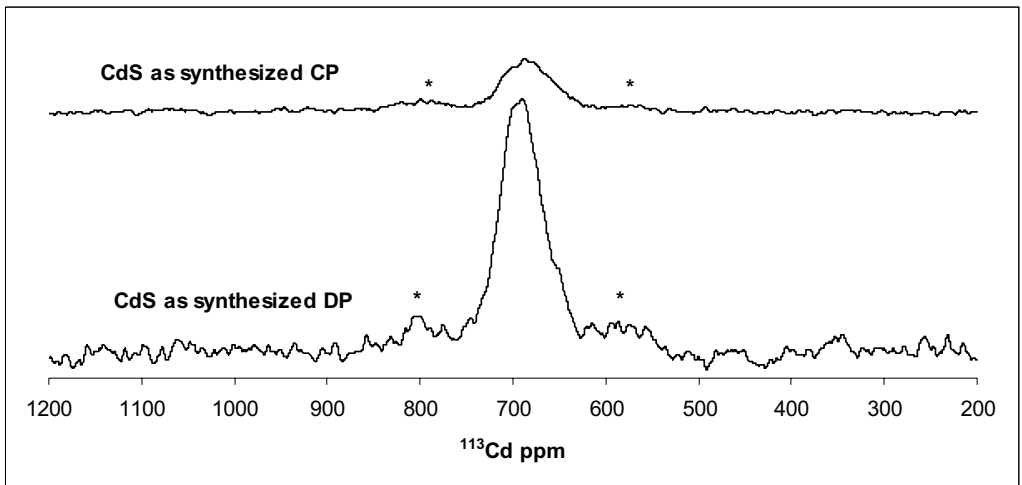

Figure $5{ }^{113} \mathrm{Cd}$ DP/MAS (bottom) and ${ }^{113} \mathrm{Cd} \mathrm{CP} / \mathrm{MAS}$ (top) of CdS/1-thioglycerol as synthesized. These data were collected in a $200 \mathrm{MHz}$ instrument using a spinning speed of 5KHz. The recycle delay for the DP/MAS was 60 seconds with 1146 transients collected, while fore the CP/MAS, a recycle delay of 2 seconds was used wit, cp time of $1 \mathrm{~ms}$ and 13,660 transients were collected. Line broadening of 200 was used to process these data.

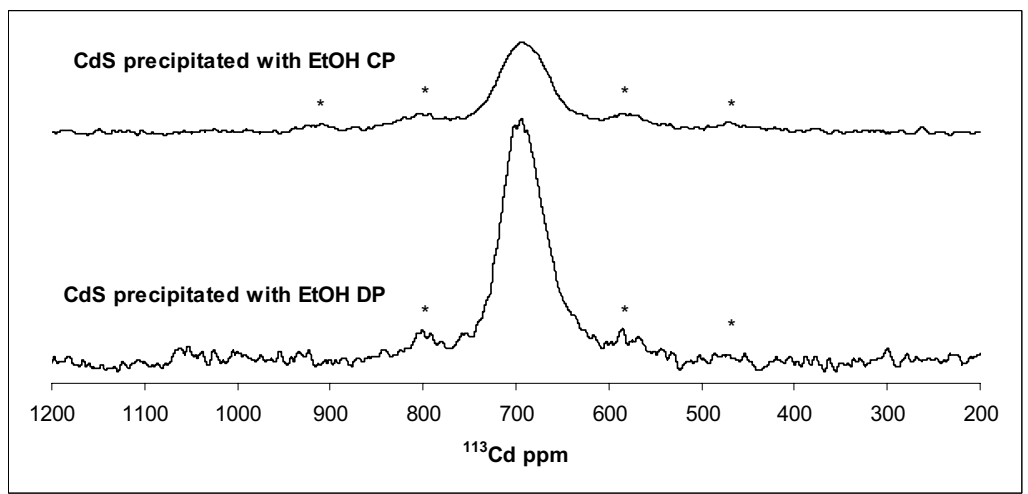

Figure $6{ }^{113} \mathrm{Cd} \mathrm{DP} / \mathrm{MAS}$ (bottom) and ${ }^{113} \mathrm{Cd} \mathrm{CP} / \mathrm{MAS}$ (top) of $\mathrm{CdS} / 1$-thioglycerol as synthesized. These data were collected in a $200 \mathrm{MHz}$ instrument using a spinning speed of $5 \mathrm{KHz}$. The recycle delay for the DP/MAS was 60 seconds with 1146 transients collected, while fore the CP/MAS, a recycle delay of 2 seconds was used wit, cp time of $1 \mathrm{~ms}$ and 13,660 transients were collected. Line broadening of 200 was used to process these data. 
A two dimensional experiment, heteronuclear correlation (HETCOR), was performed to the CdS/1-thioglycerol precipitated with EtOH nanoparticles, Figure 7. In this experiment, the spatial correlation due to dipolar coupling between the protons (F1 dimension) and the cadmium (F2 dimension) in the sample can be observed. Two proton signals were observed to have a strong correlation with the cadmium of the $\mathrm{CdS}$ nanoparticles, one at $\sim 4 \mathrm{ppm}$ arising from the protons on carbons $\mathrm{C} 1$ and $\mathrm{C} 2$, structure 1 , and the other one at $\sim 8 \mathrm{ppm}$ from possible $\mathrm{OH}$ protons at the surface of the $\mathrm{CdS}$ nanoparticles. These correlations indicate the proximity in space of the two nuclei.

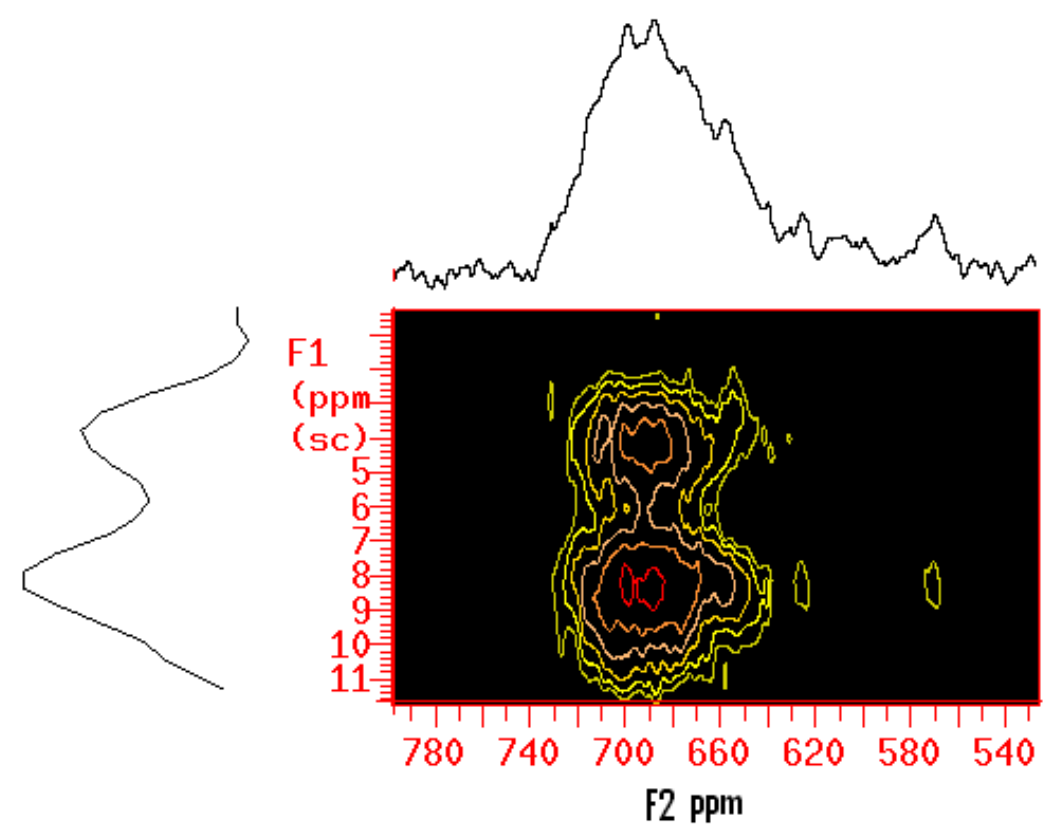

Figure 7: ${ }^{1} \mathrm{H}^{113} \mathrm{Cd}$ HETCOR from CdS/1-thioglycerol precipitated with EtOH nanoparticles. This data was collected in a $500 \mathrm{MHz}$ instrument using a spinning speed of 12,200 $\mathrm{KHz}$ 
PNNL-17069

\section{b. CdS synthesized with 4-bromophenyl ethenyl phosphonic acid (4BrEPPA)}

Figure 8 shows the ${ }^{113} \mathrm{Cd}$ DP/MAS spectra of $\mathrm{Cd}^{+2}-4 \mathrm{BrEPPA}$ and CdS-4BrEPPA, where $\mathrm{Cd}^{+2}-4 \mathrm{BrEPPA}$ is the salt produced as intermediate in the synthesis of the CdS4BrEPPA. The characteristic resonance of $\mathrm{CdS}$ at $\sim 700 \mathrm{ppm}$ is observed in Figure 8, indicative of the formation of $\mathrm{CdS}$ particles. The $\mathrm{Cd}^{+2}-4 \mathrm{BrEPPA}$ spectrum shows two resonances at $\sim 20 \mathrm{ppm}$. These resonances are not observed at the CdS-4BrEPPA spectrum, indicating the complete conversion of $\mathrm{Cd}^{+2}$ to $\mathrm{CdS}$.

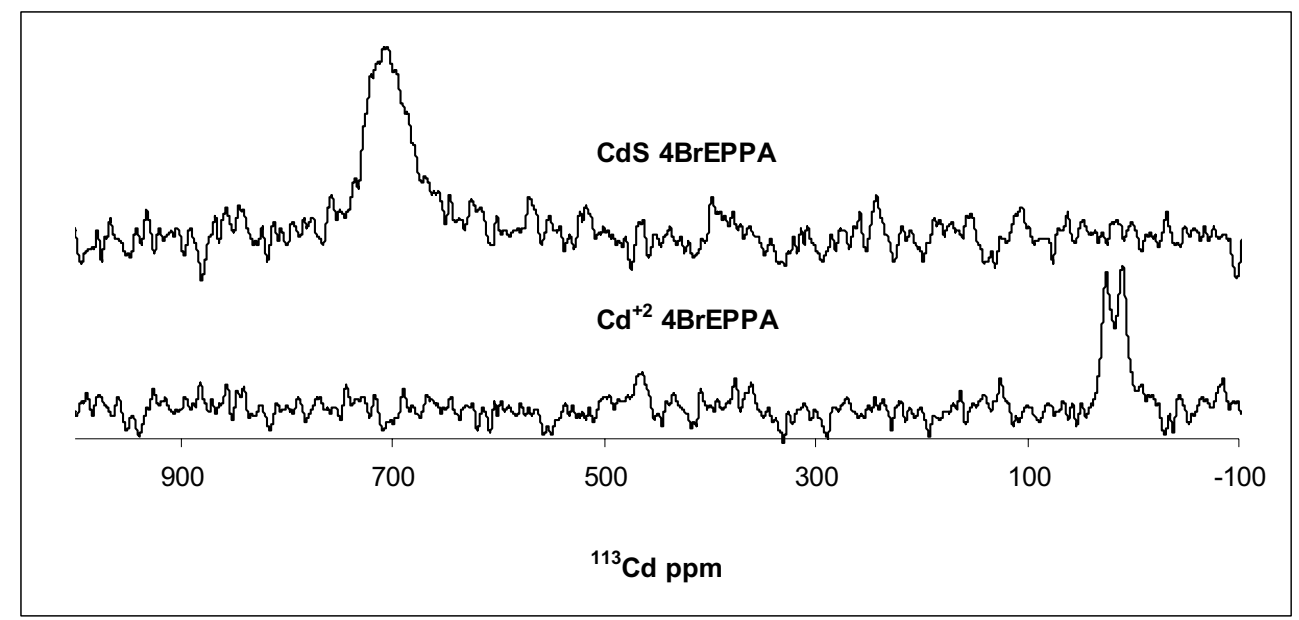

Figure 8: DP/MAS echo of $\mathrm{Cd}^{+2}$ 4BrEPPA (bottom), and CdS 4BrEPPA (top). This data was collected in a $200 \mathrm{MHz}$ instrument using a spinning speed of $5 \mathrm{KHz}$ and a recycle delay of 30 seconds for both samples.

The CdS-4BrEPPA sample was analyzed $11.7 \mathrm{~T}$ and the results are shown in Figure 9. Again, ${ }^{113} \mathrm{Cd} \mathrm{DP} / \mathrm{MAS}$ spectrum shows all the cadmium present in the sample and the ${ }^{113} \mathrm{Cd} \mathrm{CP} / \mathrm{MAS}$ spectrum shows only that cadmium present at the surface of the CdS particles. The dipolar coupling between the cadmium at the surface and the protons leads to the small signal observed for the particles. The presence of particles with bigger size and less surface area impede the interaction of the CdS particles surface with protons of 4BrEPPA. 


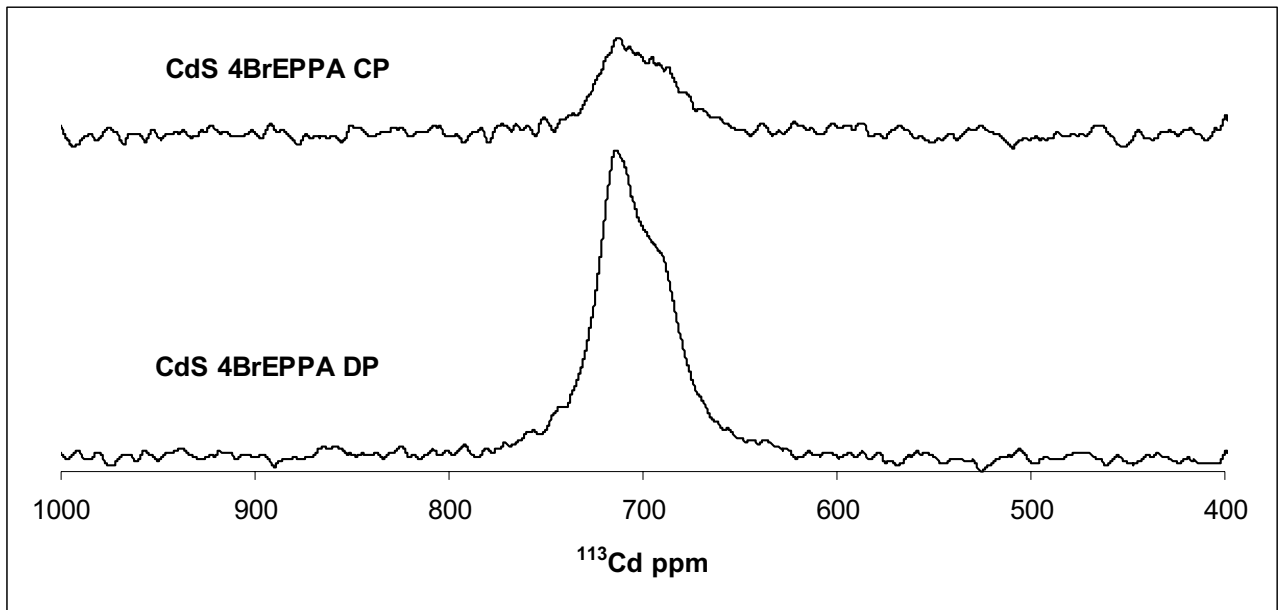

Figure 9: DP/MAS with proton decoupling (bottom) and CP/MAS (top) of CdS-4BrEPPA. This data was collected in a $500 \mathrm{MHz}$ instrument using a spinning speed of $10 \mathrm{KHz}$. The recycle delay used for the DP/MAS was 30 seconds, with 2048 transients collected. For the CP/MAS, a recycle delay of 3 seconds and contact time of $3 \mathrm{~ms}$ was used with 110,216 transients collected.

The ${ }^{1} \mathrm{H}$ NMR spectra from 4BrEPPA (structure 2), $\mathrm{Cd}^{+2}-4 \mathrm{BrEPPA}$, and CdS4BrEPPA are shown in figure 10. Narrower lines are observed from 4BrEPPA indicating more mobile species, whereas for $\mathrm{Cd}^{+2}-4 \mathrm{BrEPPA}$ and CdS-4BrEPPA broader lines arise from large ${ }^{1} \mathrm{H}-{ }^{1} \mathrm{H}$ dipolar coupling. The ${ }^{1} \mathrm{H}-{ }^{1} \mathrm{H}$ dipolar coupling increases when the protons are very close to each other and this is a consequence of limited motion. Table 3 summarizes the assignments of the resonances in figure 10.

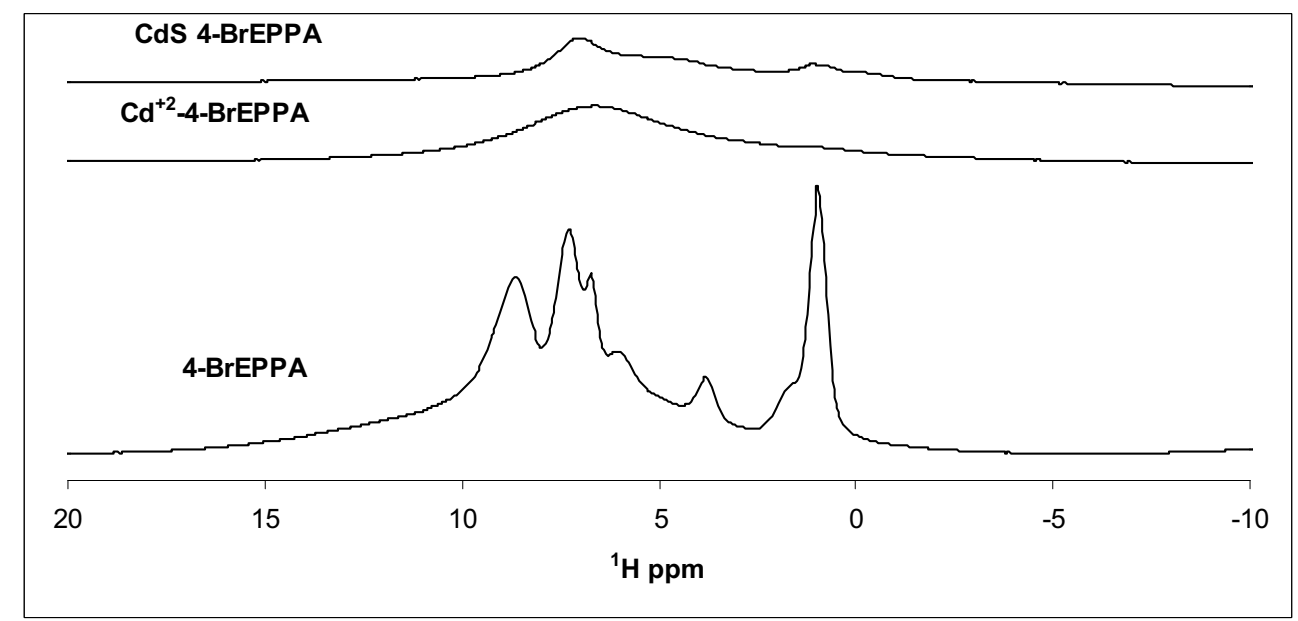

Figure 10: ${ }^{1} \mathrm{H}$ DP/MAS of 4Br-EPPA (bottom), Cd ${ }^{+2}$-4BrEPPA (middle), and CdS-4BrEPPA (top). These data was collected in a $500 \mathrm{MHZ}$ instrument using a one pulse sequence and a spinning speed of $10 \mathrm{KHz}$. The recycle delay of these samples was of 30,60 , and 2 seconds, respectively. 


\begin{tabular}{|c|c|}
\hline Chemical shift (ppm) & Type of proton \\
\hline $0.9,1.6,3.7$ & $\mathrm{H}_{2} \mathrm{O}$ present \\
\hline 5.8 and 6.7 & $\mathrm{CH}_{2}$ of $\mathrm{C11}$ \\
\hline 7.2 & $\mathrm{CH}$ of $\mathrm{C3}$ and $\mathrm{C5}$ \\
\hline 8.6 & $\mathrm{CH}$ of $\mathrm{C} 2$ and $\mathrm{C6}, \mathrm{OH}$ \\
\hline
\end{tabular}

Table 3: Chemical shift assignment of 4BrEPPA, $\mathrm{Cd}^{+2}-4 \mathrm{BrEPPA}$, and CdS-4BrEPPA

Using the $500 \mathrm{MHz}$ instrument, a double cross-polarization (DCP) experiment was performed to the CdS-4BrEPPA sample to determine the amount of phosphorus close to the cadmium at the surface of the particles. In the DCP experiment, polarization is transferred from protons $\left({ }^{1} \mathrm{H}\right)$ to phosphorus $\left({ }^{31} \mathrm{P}\right)$ followed by polarization transfer from the phosphorus to cadmium $\left({ }^{113} \mathrm{Cd}\right)$. We were successful with this technique using the standard sample, cadmium orthophosphate. The small amount of phosphorus on the surface of the CdS-4BrEPPA particles did not permit the identification of any resonance after three days of data aquisition.

\section{Conclusion}

$\mathrm{CdS}$ nanoparticles of $\sim 4 \mathrm{~nm}$ in diameter and a moderate particle distribution have been synthesized in the presence of 1-thioglycerol and characterized by ${ }^{113} \mathrm{Cd},{ }^{13} \mathrm{C}$ and ${ }^{1} \mathrm{H}$ SSNMR. Excess 1-thioglycerol was observed in the CdS/1-thioglycerol as synthesized nanoparticles, this narrowed the linewidths of the SSNMR spectra. The excess of 1thioglycerol can be easily removed by precipitating the particles with EtOH. This restricted the motion of the protons in the nanoparticles. Surface cadmium has been identified to be $\sim 1 / 4$ of the total particles. The correlations in the two dimensional experiment (HETCOR), prove the close proximity of the surface cadmium and the protons of the 1-thioglycerol.

CdS particles were also synthesized in the presence of 4BrEPPA. Traces of the intermediate salt, $\mathrm{Cd}^{+2}-4 \mathrm{BrEPPA}$ were not observed in the CdS-4BrEPPA particles. It was found that the presence of $4 \mathrm{BrEPPA}$ in the intermediate or CdS-4BrEPPA particles increases the ${ }^{1} \mathrm{H}-{ }^{1} \mathrm{H}$ dipolar coupling leading to the broadening of the ${ }^{13} \mathrm{C}$ and ${ }^{1} \mathrm{H}$ spectra. Further studies are in progress to establish the molecular structure of these two systems under study. 
PNNL-17069 
PNNL-17069

\title{
The study of gold nanocluster with thiolate ligands using electrospray ionization and photoelectron spectroscopy
}

\author{
Narendra Singh Parmar \\ Washington State University \\ and \\ Prof Lai-Sheng Wang \\ Washington State University and Pacific Northwest National Laboratory
}

Instead of stable molecules, positive and negative ions and radicals play important roles in many fields, such as particles in solutions or interstellar space. So the study on the fundamental properties of anions and radicals, such as the EAs(electron affinity) and electronic-state structures, became a hot topic in recent years in chemical physics field. The importance and utility of these information are even beyond the region of gas-phase ion chemistry. PES(photoelectron spectroscopy) is the most useful and the widest used method to observe the electronic structure of matters experimentally.

Wang's group combined the electrospray technique and PES to investigate the anion species, which exist in solutions, in the gas phase.

The chemistry of gold has great potential applications in material science, medicine and catalysis. Many theoretical research works had been done on the Au-S bond about its stability, bond energy, relativistic effect and so on. So the experimental data are very important for understanding the nature and developing of theory.

My work in this summer institute will focus on studying the PES of gold nanoclusters with some ligands, typical lignads are $\mathrm{CH} 3 \mathrm{~S}, \mathrm{CF} 3 \mathrm{~S}, \mathrm{SPh}$ and $\mathrm{SCN}$, and characterizing the electronic structures of gold nanoclusters and $\mathrm{Au}-\mathrm{S}$ bond in different anions. 
PNNL-17069 
Analysis of MHC class I peptide dissociation by molecular dynamics simulation

Florian Sieker ${ }^{1}$, Tjerk P Straatsma ${ }^{2}$, Sebastian Springer $^{1}$, and Martin Zacharias ${ }^{1 *}$ ${ }^{1}$ Jacobs University Bremen,

Campus Ring 6, 28759 Bremen, Germany.

E-mail: m.zacharias@jacobs-university.de,

Telephone: +49-421-2003541, Fax: +49-421-2003249.

${ }^{2}$ Pacific Northwest National Laboratory,

Richland, WA 99352, United States of America 


\section{Introduction}

Understanding the molecular mechanisms responsible for high affinity binding of antigenic peptides to major histocompatibility (MHC) class I molecules plays a key role in the design of peptide based vaccines. MHC class I molecules are membrane bound glycoproteins consisting of three distinct domains $\left(\alpha_{1-3}\right)$ in complex with $\beta_{2^{-}}$ microglobulin. The first two of these domains form the peptide binding groove composed of two $\alpha$-helices $\left(\alpha_{1}, \alpha_{2}\right)$ on top of an extended, anti-parallel $\beta$-sheet(Madden). Peptide loading to MHC class I molecules takes place in the peptide loading complex (PLC). The PLC is an integral part of the peptide processing pathway responsible for transporting peptides from the lumen into the endoplasmatic reticulum (ER) through the transporter associated with antigen processing (TAP)(Uebel and Tampe), stabilizing the fold of MHC molecules by the chaperone calreticulin, the protein disulfide isomerases ERp57, and PDI(Park et al.) as well as directly linking the TAP transporter and the MHC class I molecule through tapasin(Bouvier; Ellgaard and Helenius; Wright et al.; Lehner, Surman and Cresswell). In addition, tapasin has been shown to have further functions: it facilitates peptide binding to class I molecules and therefore initially allows more diverse peptides to form a MHC peptide complex by stabilizing a peptide receptive conformation as well as editing the repertoire of bound peptides, i.e. removing peptides from the repertoire that cannot meet a certain minimum energy threshold(Howarth et al.; Williams et al.; Zarling et al.; Chen and Bouvier). Once a class I molecule is loaded with a high affinity peptide it is released from the PLC and transported to the cell surface where its cargo can be expected by CD8+ T-cells. In case the peptide cargo of the MHC molecule is recognized to be antigenic the T-cell responds by initializing apoptosis of the infected 
cell(Doherty; Harty, Tvinnereim and White). MHC class I molecules are not limited to just 1 binding peptide but are able to form a complex with a well defined set of ligands(Zhang, Anderson and DeLisi). Thus, high polymorphism especially in human class I subtypes HLA-A and HLA-B, respectively allows for recognition of a broader spectrum of antigenic peptides. Nevertheless analysis of MHC class I crystal structures reveals that the protein peptide interface located within the binding groove surrounded by $\alpha$-helices $\alpha_{1}$ and $\alpha_{2}$ is well conserved(Madden). It can be separated into distinct binding pockets termed Pocket A to F that bury specific amino acid side chains of the bound peptide(Garrett et al.). Interactions between the side chains and these pockets as well as the establishment of hydrogen bond networks incorporating the peptide backbone and residues located within the surrounding $\alpha$-helices are responsible for tight binding of the peptide ligand to the class I molecule. Variations in the pocket nature are responsible for altering the binding specificity of different MHC molecules. Among the 6 available pockets the B-, D-, and F-Pocket play dominant roles since they bury the side chains of the most frequent anchor residues located at position 2, 5, and 9 of the peptide (P2, P5, and $\mathrm{P}$ 9, respectively). A fact that is often employed to define binding motifs which can be used to predict whether a candidate peptide will bind to a particular MHC class I molecule or not(Sieker, May and Zacharias).

Here, we analyze the peptide binding characteristics of 2 class I molecules HLA-B*4402 and HLA-B*4405 that differ in just 1 amino acid at position 116 (ASP in B*4402 and TYR in $\mathrm{B} * 4405$, respectively) which is located at the bottom of the F-Pocket burying the side chain of the C-terminal anchor residue. Crystal structures of both proteins bound to the same antigenic peptide have recently been determined(Macdonald et al.; Zernich et 
al.). Interestingly, despite their high sequence similarity both alleles differ significantly in their dependence on tapasin for effective peptide presentation at the cell surface(Williams et al.; Zernich et al.). While HLA-B*4402 shows a strongly reduced ability to present peptides at the cell surface of cells lacking tapasin. No influence of the tapasin availability on the peptide presentation ability of cells carrying HLA-B*4405 class I molecules could be observed(Williams et al.). Additionally, the location of the point mutation at position 116 is distant from the proposed tapasin binding regions of class I molecules. Residues 128 to 134 in the MHC heavy chain have been shown to be crucial for effective class I tapasin complex formation(Lewis et al.; Zernich et al.). Moreover, positions 222 to 229 play a major role in non-covalently binding MHC and tapasin(Suh et al.). In a previous study we have shown how the difference in the F-Pocket between these two alleles lead to significantly changed dynamics of the surrounding $\alpha$-helical parts in absence of a peptide ligand(Sieker, Springer and Zacharias). While in presence of a high affinity peptide almost no differences could be observed. The most remarkably discrepancy was found within the $\alpha_{2-1}$-helix consisting of residues 138 to 149 of the $\alpha_{2}$ helix which forms the wall of the binding groove located between the peptide $\mathrm{C}$-terminus and the proposed tapasin binding region (residues 128 to 134). Employing molecular dynamics (MD) simulations we showed that the $\alpha_{2-1}$-helix has a high tendency to roll out leading to an opening of the binding groove by approximately 1 helix diameter in case of the tapasin dependent allele B*4402 in the absence of the peptide ligand. Contrary, the peptide "bound" forms of both alleles as well as the peptide free form of $B * 4405$ presented no such tendency. We reasoned that the facilitating function of tapasin consists in stabilizing a conformation of the MHC class molecule close to the bound form. This 
finding was just recently experimentally confirmed by Chen et al.(Chen and Bouvier). In another study focusing on closely related alleles HLA-B*2705 and HLA-B*2709 which also differ at position 116 from each other it was reported that this single amino acid mutation has a major influence on the dynamics of the bound peptide(Pohlmann et al.). They reasoned that increased flexibility of the peptide C-Terminus is due to the inability to firm anchoring the terminal side chain within the F-Pocket which also leads to an increased movement of the $\alpha_{2-1}$-helix. Our previous studies did not reveal such correlations in case of the MHC class I molecules HLA-B*4402 and HLA-B*4405. Enhanced mobility of the $\alpha_{2-1}$ helix in absence of a peptide ligand has also been reported for a HLA-A allele(Zacharias and Springer).

In the present study we used MD simulations of HLA-B*4402 and HLA-B*4405, respectively to analyze the peptide binding characteristics in more detail. Simulations were restricted to the $\alpha_{1} / \alpha_{2}$-binding domain of both alleles since it has already been shown that the $\alpha_{1} / \alpha_{2}$ - domain efficiently binds peptides in the absence of the remainder of the MHC class I molecule(Rigney et al.). Although, there might be some sort of influence of the missing parts on peptide binding it should be identical for both alleles as their only difference is located within the F-Pocket which is distant from the $\alpha_{3}$-domain as well as the $\beta_{2}$-microglobulin MHC interface. In order to increase the sampling rate of conformations during peptide dissociation different simulation series with various distance restraints between the peptide and the class I protein were performed. 
PNNL-17069

\section{Materials and Methods}

Crystals of human class I alleles HLA-B*4402 (protein data bank entry: 1M6O(Macdonald et al.)) and HLA-B*4405 (1SYV(Zernich et al.)), respectively were taken as start structures for the restrained molecular dynamics simulations. Simulations were restricted to the $\alpha_{1} / \alpha_{2}$ binding domain (residues 1 to 182 ) in complex with a high affinity peptide ligand (sequence: EEFGRAFSF) derived from HLA-DPA*0201, residues 46 to 54(Macdonald et al.). Both MHC molecules were crystallized in the presence of the aforementioned peptide and differ only by a single amino acid substitution at position 116 of the heavy chain (HLA-B*4402: ASP, HLA-B*4405: TYR). All simulations on either protein were performed using the Amber software package version 9.0(Case et al.) together with the parm03 force field(Duan et al.). Before the restraints were introduced into the simulation run following procedure was used to obtain solvated and equilibrated structures. The proteins were placed into a rectangular box with periodic boundary conditions containing about 9,000 TIP3P water molecules(Jorgensen et al.), 24 additional sodium and chloride ions, and a number of $\mathrm{NA}^{+}$ions to compensate the negative charge of the MHC molecules. Non-bonded interactions up to a cut-off value of $0.9 \mathrm{~nm}$ were taken into account while long-range electrostatic interactions were treated employing the particle mesh Ewald option(Darden, York and Pedersen) with a grid spacing of 0.09nm. After energy minimization the solvated structures were gradually heated up from 50 to $300 \mathrm{~K}$ within $0.15 \mathrm{~ns}$ while reducing initially defined positional restraints from 50.0 to 0.7

kcal $\mathrm{mol}^{-1} \AA^{-2}$. Temperature and pressure (1 bar) was controlled for all simulations using a relaxation time of 5.0ps. Coordinates were extracted every $2.0 \mathrm{ps}$ and saved for later 
analysis. Trajectories were graphically prepared and figures prepared using the visual molecular dynamics software package(Humphrey, Dalke and Schulten) (VMD).

Restraint simulations on the equilibrated systems were formed to force partial peptide dissociation from the MHC class I molecule according to the following umbrella sampling scheme(Adcock and McCammon). The reaction coordinate was defined as the distance between the backbone atoms center of gravity of reference residues (residues 6 , $7,8,9,26,27,28,29,97,98,99,116,117,118)$ located within the $\beta$-sheet at the bottom of the binding groove and the center of gravity of the peptide backbone atoms (Fig.1). The distance restraint consisting in a harmonic potential (force constant $2.0 \mathrm{kcal} \mathrm{mol}^{-1} \AA^{-}$ ${ }^{2}$ ) starting at $1.225 \mathrm{~nm}$ was stepwise increased by $0.05 \mathrm{~nm}$ after $1 \mathrm{~ns}$ of simulation time to produce a new simulation window. This procedure was repeated until 17 windows were produced and a distance restraint of $2.075 \mathrm{~nm}$ was reached. In total each window was simulated for $8 \mathrm{~ns}$. The weighted histogram analysis method(Kumar et al.) (WHAM, implemented by Grossfield, http://dasher.wustl.edu/alan/) was used to create free energy profiles from the recorded distance probabilities for each window.

In addition to simulations incorporating a distance restraint on the complete backbone of the peptide further simulation series were performed with distance restraints on either the backbone atoms of the anchor residue next to the N-Terminus (P2) or the C-terminal anchor residue (P9). Changing the center of gravity within the peptide group to be located within just residue required to redefine the reference residues located within the $\beta$-sheet. In case of the residue next to the N-Terminus backbone atoms of amino acids 7, 8, 9 were used to define the center of gravity. Starting at $0.925 \mathrm{~nm} 16$ windows with a gradually increasing distance restraint of $0.05 \mathrm{~nm}$ per window were created. Simulations on each 
PNNL-17069

window were performed for $4 \mathrm{~ns}$ in total. In case of the C-terminal anchor residue backbone atoms of positions 116 and 117 were taken to define the distance restraint. The first restraint was initialized at a distance of $1.025 \mathrm{~nm} 14$ windows were produced and simulated for $6 \mathrm{~ns}$ in total. During all these simulations the force constant for the distance restraint was kept at $2.0 \mathrm{kcal} \mathrm{mol}^{-1} \AA^{-2}$.

To analyze the influence of $\beta$-sheet fluctuations on the obtained free energy profiles one further simulation series was performed. This series in principal identical to the simulations focusing on the $\mathrm{P} 2$ anchor residue contained an additional positional restraint on the whole $\beta$-sheet (residues 3 to 12,20 to 28,32 to 37,94 to 104,110 to 119,122 to 126) to reduce its flexibility. The positional restraining constant added up to $10.0 \mathrm{kcal}$ $\mathrm{mol}^{-1} \AA^{-2}$. Simulations within this series were run for 3 ns per window.

Analysis of molecular dynamics trajectories with respect to root mean square deviation and fluctuation, respectively were performed employing a new module of the NWChem(Kendall et al.; Bylaska et al.) software package developed at the pacific northwest national laboratory particularly suited to perform data intensive analysis (DIANA) of large trajectories. In contrast to former sequential implementations of analysis software the current DIANA implementation divides the trajectory according to the number of processors and causes each processor to read in only the assigned frames. Thus, even fairly long trajectories can be held in the aggregate memory of large parallel computers and calculations can be done in parallel. Additionally, since all data is kept in memory only one pass through the trajectory is needed which reduces the I/O operations and further increases the performance. Taken together, the performance increase with 
PNNL-17069

respect to time requirements sums up to more than one order of magnitude on standard systems compared to previous sequential implementations. 
PNNL-17069

\section{Results}

Since no dissociation effects could be observed in a previous studies of class I molecules targeted molecular dynamics simulations of the $\alpha_{1} / \alpha_{2}$-binding domain (residues 1 to 182 ) of MHC class I allele HLA-B*4402 in presence of a high affinity peptide ligand (sequence: EEFGRAFSF) were performed in order to force the peptide to dissociate from the class I binding groove. Using a high resolution crystal structure(Macdonald et al.) as a reference start structure a distance restraint was introduced and gradually increased. Starting at a distance of $1.225 \mathrm{~nm}$ the restraint was increased after $1 \mathrm{~ns}$ of simulation time by a step length of $0.05 \mathrm{~nm}$ until a final distance of $2.075 \mathrm{~nm}$ was reached. Center of gravity of backbone atoms of residues located within the class I $\beta$-sheet as well as all peptide backbone atoms were used to define reference points to which the distant restraint was then applied. All simulations were run at a temperature of $300 \mathrm{~K}$ and each window was simulated for $8 \mathrm{~ns}$ in total (see Materials and Methods for more details). Interestingly, analyzing the root-mean square deviation (Rmsd) revealed strong differences in the time courses of the different windows (Fig.2). While the first 10 windows up to a distance restraint of $1.675 \mathrm{~nm}$ reached a relatively stable Rmsd value around 0.15 to $0.22 \mathrm{~nm}$ with respect to the start structure. Simulations incorporating a larger distance restraint led to fairly higher values of up to $0.5 \mathrm{~nm}$. In fact 2 distinct clusters could be observed with very limited overlap between 0.22 and $0.24 \mathrm{~nm}$. Despite this finding a correlation with peptide dissociation or structural deformation of whole domains could not be observed. The jump in the Rmsd value occurring within the $10^{\text {th }}$ window (distance restraint $1.725 \mathrm{~nm}$ ) accompanies slight movements within the Nterminal part of the $\alpha_{1}$ helix and the $\alpha_{2-1}$ helix, respectively while the major contribution 
derives from large motions of the C-terminal part of the $\alpha_{1} / \alpha_{2}$-binding domain as well as loops connecting $\beta$-sheet strands (data not shown). In fact no complete dissociation of the peptide from the HLA-B*4402 binding groove could be observed within the limits of simulations presented here. Instead individual dissociations of either the peptide $\mathrm{N}$ - or CTerminus could be observed in the $16^{\text {th }}$ and $17^{\text {th }}$ window, respectively (Fig. 3 A and B). Despite the differential release of peptide termini both windows present a stable $\beta$-sheet with just slight changes in the $\beta_{2}$-microglobulin interface. Additionally, both windows have a partial structural dissolving of the $\alpha_{2-2}$ helix in common. In contrast to these similarities they present large differences with respect to helical parts surrounding either of the peptide termini and binding pockets $\mathrm{B}$ and $\mathrm{F}$ accomodating the respective side chains. In case of the release of the peptide N-Terminus occurring within the $16^{\text {th }}$ window (distance restraint: $2.025 \mathrm{~nm}$ ) fluctuations in the N-terminal part of the $\alpha_{1}$-helix as well as the passage from the $\alpha_{2-2}$ to the $\alpha_{2-3}$ helix could be observed (Fig. 3A). While the $\alpha_{1}$-helix on top of the B-Pocket (residues 62 to 67) covering the P2 anchor residue tends to loose its helical structure and moves away from the binding groove the $\alpha_{2-2} / \alpha_{2-3}$ helical part (residues 160 to 165 ) on the opposite site shifts outwards on the whole. Interestingly, the outwards directed movement of both helices occurs in a chronology comparable to the dissociation of the N-Terminus. Moreover, both helices show no tendency to move back in during the limits of these simulations. To investigate a possible correlation of the just described movements in more detail we calculated the Pearson correlation coefficient(Hartung) between the distance of the center of gravity of the N-terminal anchor residue backbone atoms and the center of gravity of backbone atoms located at the bottom of the B-Pocket and all other distances of atoms involved in the described helical 
movements. As shown in figure 4 a high positive correlation exists between the distance of the N-terminal anchor residue to the B-Pocket and the distance between the backbone atoms of helical parts flanking this pocket. This implies that the dissociation of the peptide N-Terminus is accompanied by an opening of the binding pocket. Interestingly, all depicted side chains show a comparable movement except for the side chain of residue 62 which presents no correlation with the dissociation of the $\mathrm{N}$-terminal anchor residue. Despite the large movements in and around the B-Pocket almost no fluctuation could be observed at the F-Pocket of the binding groove (Fig. 3A). The C-Terminus of the peptide remains bound to the binding groove and its side chain stays deeply buried within the FPocket. Additionally, the C-terminal part of the $\alpha_{1}$-helix and the $\alpha_{2-1}$ helix remain in almost the same conformation during the whole simulation time of the $16^{\text {th }}$ window close to the crystal structure.

In contrast, the $17^{\text {th }}$ window (distance restraint $2.075 \mathrm{~nm}$ ) presents a completely different picture (compare figure $3 \mathrm{~A}$ and $\mathrm{B}$ ). Instead of the peptide $\mathrm{N}$-Terminus the $\mathrm{C}$-Terminus dissociates from the binding pocket while the first 5 amino acids of the peptide remain in a conformation similar to the bound state found in crystal structures (Fig. 3B). Dissolving of the C-terminal anchor residue is accompanied by large fluctuations in the $\alpha_{2-1}$-helix and the beginning of the $\alpha_{2-2}$-helix while the $\alpha_{1}$-helix presents only slight movements. Even the C-terminal part of the $\alpha_{1}$-helix (residues 74 to 85 ) flanking the F-Pocket shows almost no movement. A contrary observation could be made for the $\alpha_{2-1}$-helix. During the $8 \mathrm{~ns}$ of simulation time the helix shifts away leading to an opening of the binding grove by approximately one helix diameter. In agreement with the chronological snap shots we find a high correlation between the distance of the peptide C-Terminus to the bottom of 
the F-Pocket and the distance from the C-terminal part of the $\alpha_{1}$-helix to the $\alpha_{2-1}$-helix (Fig. 5). Interestingly, the distance between the $\alpha_{1}$ helix and residues 116 and 117 at the bottom of the F-Pocket and the distance of the C-Terminus to residues 116 and 117 is negatively correlated which indicates that an opening of the binding pocket is primarily achieved by a movement of the $\alpha_{2-1}$-helix. Moreover, motion of the side chains is less correlated compared to the dissociation of the peptide N-Terminus.

Defining the distance between the center of gravity of peptide backbone atoms and the center of gravity of selected HLA-B*4402 $\beta$-sheet backbone atoms as a reaction coordinate the work or free energy necessary to extract the peptide from the binding groove could be obtained. The free energy was calculated using the WHAM method based on distance distributions recorded during targeted MD simulations (see materials and methods for more details). The free energy minimum was found at a distance of approximately $1.25 \mathrm{~nm}$ (Fig. 6) which is fairly close to the distance found in the crystal structure $(1.225 \mathrm{~nm})$. However, increasing the distance restraint is accompanied by an increase in free energy. During the first 7 windows up to a distance of $1.525 \mathrm{~nm}$ and a free energy of about $20.0 \mathrm{kcal} \mathrm{mol}^{-1}$ the energy function has a progressive shape which changes to a linear increase afterwards ending at 45 to $50 \mathrm{kcal} \mathrm{mol}^{-1}$ within the $17^{\text {th }}$ window (distance restraint set to $2.075 \mathrm{~nm}$ ). A remarkable difference between the windows before and after this change is that helical structures especially in the $\alpha_{2-2}$-helix are breaking up in the latter while they are still intact in the former (data not shown). This suggests that the dissociation of the peptide requires more flexibility in particular side chains which are part of the binding groove walls. This increase in flexibility can only be achieved to the disadvantage of secondary structure elements. Thus, once the helical 
structure is broken up less work is needed to push side chains away witch hinder the peptide from leaving the binding groove.

Since both the peptide N-Terminus as well as the peptide C-Terminus dissociate during the original MD simulation series we set up another run of simulations but with different distance restraints to investigate whether there exists a discrepancy between the dissociation free energies of both termini. In case of the peptide $\mathrm{N}$-terminal anchor residue the restraint was applied to the distance of the center of mass of residues 7 to 9 backbone atoms to the center of gravity of $\mathrm{P} 2$ backbone atoms. In contrast, the center of mass of backbone atoms of residues 116 and 117 to the center of gravity of the Cterminal backbone atoms was used to calculate the free energy during dissociation of P9. Despite the fact that both series did not reach full convergence within limits of simulations presented here a significant discrepancy between both runs could already be observed (Figure $7 \mathrm{~A}$ and B). A movement of the peptide C-Terminus of $0.05 \mathrm{~nm}$ away from the F-Pocket requires about 2.0 to $2.5 \mathrm{kcal} \mathrm{mol}^{-1}$ while the free energy necessary to shift P2 the same distance away from the B-Pocket is about 4 to 5 times higher. The difference in the initial distances of each termini to the respective binding pocket arises from the fact that the side chains of both anchor residues have a different length as well as a different binding geometry. While the side chain of P9 lies perpendicular to the plane spanned by the $\beta$-sheet the side chain of P2 presents a somewhat smaller degree and the according backbone atoms are therefore closer to the bottom of the B-Pocket. Another significant difference between these two simulation series was found within the $\beta$-sheet itself. While only small fluctuations $(<0.1 \mathrm{~nm})$ could be observed in simulations focusing on the C-Terminus larger movements $(>0.2 \mathrm{~nm})$ especially of backbone atoms in and 
around the B-Pocket occurred within runs aiming at extracting the N-Terminus from the binding groove. To analyze the influence of these fluctuations on the free energy another simulation series similar to the former one focusing on the N-Terminus was conducted but this time all $\beta$-sheet backbone atoms were subject to a positional restraint of $10.0 \mathrm{kcal}$ $\mathrm{mol}^{-1} \AA^{-2}$ limiting the flexibility of the $\beta$-sheet. As a result a slight shift of the free energy minimum from about 1.025 to $1.075 \mathrm{~nm}$ could be observed while the overall shape of the energy function remains unchanged. Still, the free energy necessary for moving the peptide N-Terminus $0.5 \mathrm{~nm}$ away from its minimum was about $10.0 \mathrm{kcal} \mathrm{mol}^{-1}$ (data not shown). In contrast to the almost linear increase in free energy found in simulation runs focusing on the peptide N-Terminus, the shape of the free energy function calculated for the C-Terminus shows a short exponential increase between its minimum at $1.125 \mathrm{~nm}$ and $1.225 \mathrm{~nm}$ followed by a linear increase up about $1.4 \mathrm{~nm}$ where a energy barrier could be observed (Fig.7 B). After this energy barrier from $1.5 \mathrm{~nm}$ on the free energy stays almost constant at $2.0 \mathrm{kcal} \mathrm{mol}^{-1}$. Interestingly, this energy barrier can directly be related to a significant change of the peptide conformation. In those windows that operate on a smaller distance restraint than $1.45 \mathrm{~nm}$ (maximum of the free energy) the peptide stays bound to the HLA-B*4402 binding groove in a similar manner as can be found in the crystal structure (Fig. 8A). Especially the side chain of the C-terminal anchor residue is still buried within the F-Pocket although shifted a small amount away from the bottom of the pocket (Fig. 8B). In contrast, the P9 side chain in simulations after the energy barrier windows 19 and upwards (distance restraint $>1.45 \mathrm{~nm}$ ) the side chain of the peptide Cterminus is released from the F-Pocket and can move unrestricted (Fig. 8B). Regarding the peptide N-Terminus both windows compared here are in good agreement with the 
crystal structure. The backbone of the peptide N-Terminus of both average conformations (windows 18 and 19, respectively) stays within $0.1 \mathrm{~nm}$ Rmsd of the crystal structure and the side chain of P2 remains buried in the B-Pocket (Fig. 8A).

In order to analyze the influence of the physiochemical properties of the F-Pocket on the peptide C-Terminus dissociation a further simulation series was started using the crystal structure of HLA-B*4405 as start conformation. HLA-B*4402 and HLA-B*4405 share a high sequence similarity differing only at position 116 (ASP in B*4402 and TYR in B*4405, respectively) located at the bottom of the F-Pocket which buries the peptide CTerminus. Despite their almost identical structure both alleles present a high discrepancy regarding their dependence on tapasin for successful peptide presentation at the cell surface. While tapasin seems to have no influence on $B * 4405$ it is crucial for $B * 4402$ (see introduction). Simulations and recording of the corresponding distances in case of $B^{*} 4405$ are identical to series performed on $B^{*} 4402$. As shown in figure 9 a significant difference between both alleles with respect to the free energy could be observed. Starting from the energetic minimum at $1.025 \mathrm{~nm}$ the free energy increases almost linearly. Shifting the peptide C-Terminus $0.5 \mathrm{~nm}$ from its equilibrium position takes about $7.0 \mathrm{kcal} \mathrm{mol}^{-1}$ which is about 3 times higher compared to $\mathrm{B} * 4402$. Additionally, the $\mathrm{C}$ terminal part of the $\alpha_{1}$ helix as well as the $\alpha_{2-1}$-helix stay closer together in case of B*4405, forming a more narrow binding groove and F-Pocket, respectively (data not shown). 
PNNL-17069

\section{Discussion}

In this study we have used targeted MD simulations on the binding groove of HLAB*4402 and HLA-B*4405, respectively bound to the same antigenic peptide (sequence: EEFGRFSF) to examine the peptide dissociation process. Both alleles share a high sequence similarity differing only at position 116 which is located at the bottom of the binding groove within the F-Pocket which accommodates the C-Terminus of the peptide(Garrett et al.). Despite their high structural agreement both molecules show a high discrepancy regarding their dependence on tapasin for effective peptide loading and presentation on the cell surface(Williams et al.; Zernich et al.). While B*4402 is highly dependent on the availability of tapasin for peptide loading it has almost no effect on the peptide presentation capability of $\mathrm{B} * 4405$ (Williams et al.). In a previous study we concluded that this discrepancy might arises from different tendencies of both molecules to remain in particular states(Sieker, Springer and Zacharias). The dependent molecule B*4402 presents a high tendency of helical parts surrounding the F-Pocket to open up. In contrast, this region in B*4402 stays closer together similar to the "bound" state found in the crystal structures. We termed this particular conformation receptive state and reasoned that tapasin stabilizes this structure in order to allow MHC class I molecules to bind peptides. The hypothesis that class I molecules can exist in several forms and that tapasin may stabilize a peptide receptive conformation were in good agreement with

previous studies(Cabrera; Gakamsky, Boyd et al.; Gakamsky, Davis et al.; Springer et al.). In the present study we analyzed the difference in the F-Pocket of HLA-B*4402 and HLA-B*4405, respectively in order to examine the influence on peptide dissociation. Since the difference is locally restricted we assumed that both alleles would present 
similar behavior regarding the peptide N-Terminus and limited simulations in case of B*4405 to the C-Terminus. Comparing the free energy curves obtained from analyzing differences in distance distributions using the WHAM method it could be observed that the free energy increase for extracting the N-Terminus from the B*4402 binding groove is about 4 to 5 times higher as was found for the C-Terminus. This suggests that the peptide C-Terminus is weaker bound within the binding groove and furthermore that the dissociation process starts at the $\mathrm{C}$-terminal end of the peptide. This is in good agreement with recent reports that came to similar conclusions when analyzing the peptide binding properties of HLA-B*2705(Dedier et al.; Pohlmann et al.; Winkler et al.). In contrast, the free energy increase when moving the $\mathrm{C}$-Terminus along the reaction coordinate is about 3 times higher in case of $\mathrm{B} * 4405$ indicating a stronger binding. But still the free energy difference found at the peptide N-Terminus in simulations on $\mathrm{B}^{*} 4402$ is higher. Taken together this suggests that the effect of exchanging aspartate for tyrosine at the bottom of the F-Pocket is twofold. First it increases the hydrophobic interactions between the peptide C-Terminus and the binding groove. Second in agreement with our previous study(Sieker, Springer and Zacharias) it stabilizes the position of the $\alpha_{2-1}$ helix which partially hinders residues at the C-Terminal end of the peptide to dissociate from the binding groove. Both effects add up to a higher free energy for the dissociation of the peptide $\mathrm{C}$-Terminus in case of $\mathrm{B} * 4405$. Taking the differential dependence of both alleles on tapasin into account we hypothesize that tapasin also stabilizes the $\alpha_{2-1}$ helix leading to higher dissociation free energy and therefore a stronger binding of the MHC class I molecule and its ligand. 


\section{Acknowledgements}

We thank A. May, C. Schneeweiß, and Dr. R. Lins for helpful discussions. This work was performed using the computational resources of the CLAMV (Computational Laboratories for Animation, Modeling and Visualization) at Jacobs University and supercomputer resources of the EMSL (Environmental Molecular Science Laboratories) at the PNNL (Pacific Northwest National Laboratories; grant gc11-2002). 
A. Molinari, SA, and R. Koouddane. 1997, "On the Self-Consistent Modeling of ElasticPlastic Behavior of Polycrystals." Mech. Mat. 26:43-62.

Adcock, SA, and JA McCammon. 2006, "Molecular Dynamics: Survey of Methods for Simulating the Activity of Proteins." Chem Rev 106:1589-615.

Aiga, F, H Iwanaga, and A Amano. 2005, J. Phys. Chem. A 109:11312.

Autrey, T, et al. 2004, "Thermochemistry of Aqueous Hydroxyl Radical from Advances

in Photoacoustic Calorimetry and Ab Initio Continuum Solvation Theory." Journal of the American Chemical Society 126:3680-81.

Ba Nghiep Nguyen, BJK, John S. Vetrano, and Mohammad A Khaleel. 2006, "On the Nonlinear Behavior of a Glass-Ceramic Seal and Its Application in Planar Sofc Systems." The 4th International Conference on FUEL CELL SCIENCE ENGINEERING and TECHNOLOGY.

Ba Nghiep Nguyen, BJK, Said Ahzi, Mohammad A Khaleel, and Prabhakar Singh. 2006, "Crack Growth in Solid Oxide Fuel Cell Materials: From Discrete to Continuum Damage Modeling." The American Ceramic Society 89:1358-68.

Becke, AD. 1993, J. Chem. Phys. 98:5648.

Ben-Naim, A, and Y Marcus. 1984, Journal of Chemical Physics 81:2016.

Benveniste, Y. 1987, " A New Approach to the Application of Mori-Tanaka's Theory in Composite Materials." Mechanics of Materials 6.

Binnig, G, CF Quate, and C Gerber. 1986, "Atomic Force Microscope." Physical Review Letters 56:930.

Bouvier, M. 2003, "Accessory Proteins and the Assembly of Human Class I Mhc Molecules: A Molecular and Structural Perspective." Mol Immunol 39:697-706. Boys, SF, and F Bernardi. 1970, "Calculation of Small Molecular Interactions by Differences of Separate Total Energies - Some Procedures with Reduced Errors." Molecular Physics 19:553-\&.

Budiansky, B. 1970, "Thermal and Thermoelastic Properties of Isotropic Composites." Journal of Composite Materials 4.

Bunzli, JG. 2006, Acc. Chem. Res. 39:53. Bylaska, EJ. 2006. Et Al, Nwchem, a Computational Chemistry Package for Parallel Computers. version 5.0, Pacific Northwest National Laboratory, Richland, WA. Bylaska, EJ, et al. 2006, "Nwchem, a Computational Chemistry Package for Parallel Computers, Version 5.0." Pacific Northwest National Laboratory, Richland, Washington 99352-0999, USA.

Cabrera, CM. 2007, "The Double Role of the Endoplasmic Reticulum Chaperone Tapasin in Peptide Optimization of Hla Class I Molecules." Scand J Immunol 65:487-93.

Case, DA, et al. 2005, "The Amber Biomolecular Simulation Programs." J Comput Chem 26:1668-88.

Chen, M, and M Bouvier. 2007, "Analysis of Interactions in a Tapasin/Class I Complex Provides a Mechanism for Peptide Selection." Embo J 26:1681-90.

Darden, T, D York, and L Pedersen. 1993, "Particle Mesh Ewald - an N.Log(N) Method for Ewald Sums in Large Systems." Journal of Chemical Physics 98:10089-92. de Bettencourt-Dias, A. 2007, Dalton Trans. 22:2229.

De Silva, CR, et al. 2007, Inorg. Chim. Acta 360:3543.

Dedier, S, et al. 2001, "Use of Fluorescence Polarization to Monitor Mhc-Peptide Interactions in Solution." J Immunol Methods 255:57-66. 
Doherty, PC. 1998, "Immunology: Update: The Numbers Game for Virus-Specific Cd8+ T Cells." Science 280:227-.

Dolg, M, et al. 1991, I. Chem. Phys. 94:3011.

---. 1993, Theor. Chim. Acta 85:441.

--- 1989, Theor. Chim. Acta 75:173.

Du, S, et al. 2006, "The Oh Radical - $\mathrm{H}_{2} \mathrm{O}$ Molecular Interaction Potential." Journal of Chemical Physics 124:224318.

Duan, Y, et al. 2003, "A Point-Charge Force Field for Molecular Mechanics Simulations of Proteins Based on Condensed-Phase Quantum Mechanical Calculations." J Comput Chem 24:1999-2012.

Dunning, TH. 2000, "A Road Map for the Calculation of Molecular Binding Energies." Journal of Physical Chemistry A 104:9062-80.

Ellgaard, L, and A Helenius. 2003, "Quality Control in the Endoplasmic Reticulum." Nat Rev Mol Cell Biol 4:181-91.

Epling, WS, et al. 2004, "Overview of the Fundamental Reactions and Degradation Mechanisms of Nox Storage/Reduction Catalysts." Catalysis Reviews-Science and Engineering 46:163-245.

Erie, DA, et al. 1994, "DNA Bending by Cro Protein in Specific and Nonspecific Complexes: Implications for Protein Site Recognition and Specificity." Science (Washington D C) 266:1562-66.

Eshelby, JD. 1957, "The Determination of the Elastic Field of an Ellipsoidal Inclusion, and Related Problems." Proc. R. Soc. London A241.

Finlayson-Pitts, BJ, and JN Pitts, Jr. 1999. Chemistry of the Upper and Lower Atmosphere. Academic Press, San Diego.

Gakamsky, DM, et al. 1999, "An Allosteric Mechanism Controls Antigen Presentation by the H-2k(B) Complex." Biochemistry 38:12165-73.

---. 2000, "Assembly and Dissociation of Human Leukocyte Antigen (Hla)-A2 Studied by Real-Time Fluorescence Resonance Energy Transfer." Biochemistry 39:11163-9. Garrett, TP, et al. 1989, "Specificity Pockets for the Side Chains of Peptide Antigens in Hla-Aw68." Nature 342:692-6.

Guillaumont, D, et al. 2007, Chem. Phys. Chem. 8:480. Hansma, HG, et al. 1993, "Atomic Force Microscopy of DNA in Aqueous Solutions." Nucleic Acids Research 21:505-12.

Hansma, HG, and DE Laney. 1996, "DNA Binding to Mica Correlates with Cationic Radius: Assay by Atomic Force Microscopy." Biophysical Journal 70:1933-39.

Hansma, HG, and L Pietrasanta. 1998, "Atomic Force Microscopy and Other Scanning Probe Microscopies." Current Opinion in Chemical Biology 2:579-84.

Hansma, HG, et al. 1996, "Atomic Force Microscopy of Long and Short DoubleStranded, Single-Stranded and Triple-Stranded Nucleic Acids." Nucleic Acids Research 24:713-20.

Hartung, J. 1999. Statistik. 12 ed., Oldenbourg Verlag. Harty, JT, AR Tvinnereim, and DW White. 2000, "Cd8+ T Cell Effector Mechanisms in Resistance to Infection." Annu Rev Immunol 18:275-308.

Hashin, BWRZ. 1970, "Effective Thermal Expansion Coefficients and Specific Heats of Composite Materials." Int. J. Eng. Sci. 8:157-73. 
Hashin, ZS, S. 1962, "A Variational Approach to the Theory of the Elastic Behaviour of Polycrystals." J. Mech. Phys. Solids 10:343-52.

Hodges, MP, AJ Stone, and SS Xantheas. 1997, "Contribution of Many-Body Terms to the Energy for Small Water Clusters: A Comparison of Ab Initio Calculations and Accurate Model Potentials." Journal of Physical Chemistry A 101:9163-68.

Hoffmann E. de. 1996. " " J. Mass Spectrom. 31:129.

Howarth, M, et al. 2004, "Tapasin Enhances Mhc Class I Peptide Presentation According to Peptide Half-Life." Proc Natl Acad Sci U S A 101:11737-42. "Http://Epa.Gov/Air/Urbanair/Nox/Chf.Html." Vol March 2. "Http://Epa.Gov/Air/Urbanair/Nox/What.Html." Vol 2007. Humphrey, W, A Dalke, and K Schulten. 1996, "Vmd: Visual Molecular Dynamics." J Mol Graph 14:33-8, 27-8.

Jorgensen, WL, et al. 1983, "Comparison of Simple Potential Functions for Simulating Liquid Water." Journal of Chemical Physics 79:926-35.

K. Scott Weil, JED, John S. Hardy, Dong Sang Kim, Guan-Guang Xia, L.A. Chick, and Chris A. Coyle. 2004, "Rupture Testing as a Tool for Developing Planar Solid Oxide Fuel Cell Seals." ASM Internation 13:316-26.

Kendall, RA, et al. 2000, "High Performance Computational Chemistry: An Overview of Nwchem a Distributed Parallel Application." Computer Physics Communications 128:260-83.

Kerner, EH. 1956, "The Elastic and Thermo-Elastic Properties of Composite Media." The Proceedings of the Physical Society 69:808-13.

Kido, J, and Y Okamoto. 2002, Chem. rev. 102:2357.

Kumar, S, et al. 1992, "The Weighted Histogram Analysis Method for Free-Energy Calculations on Biomolecules .1. The Method." Journal of Computational Chemistry 13:1011-21.

Laskin J, et al. 2002, Anal. Chem. 74:3255.

Latva, M, et al. 1997, J. Luminescence 75:149.

Lee, C, W Yang, and RG Parr. 1988, Phys. Rev. B 37:785.

Lehner, PJ, MJ Surman, and P Cresswell. 1998, "Soluble Tapasin Restores Mhc Class I

Expression and Function in the Tapasin-Negative Cell Line .220." Immunity 8:221-31. Levin, VM. 1967, "On the Coefficients of Thermal Expansion of Heterogeneous Materials." Mekhanika Tverdogo Tela 2:88-94.

Lewis, JW, et al. 1996, "Point Mutations in the Alpha 2 Domain of Hla-A2.1 Define a Functionally Relevant Interaction with Tap." Curr Biol 6:873-83.

Little D. P., et al. 1994, Anal. Chem. 66:2809.

Liu, B, and AD McLean. 1973, "Accurate Calculation of Attractive Interaction of Two Ground-State Helium-Atoms." Journal of Chemical Physics 59:4557-58.

Macdonald, WA, et al. 2003, "A Naturally Selected Dimorphism within the Hla-B44

Supertype Alters Class I Structure, Peptide Repertoire, and T Cell Recognition." J Exp Med 198:679-91.

Madden, DR. 1995, "The Three-Dimensional Structure of Peptide-Mhc Complexes." Annu Rev Immunol 13:587-622.

Maron, L, and O Eisenstein. 2000, J. Phys. Chem. A 104:7140.

Matsko, N, and M Mueller. 2004, "Afm of Biological Material Embedded in Epoxy

Resin." Journal of Structural Biology 146:334-43. 
McCormack A. L., J, ones J. L., and Wysocki V. H. 1992, J. Am. Soc. Mass Spectrom. 3:859.

Milet, A, et al. 1999, "Hydrogen Bonding in Water Clusters: Pair and Many-Body Interactions from Symmetry-Adapted Perturbation Theory." Journal of Physical Chemistry A 103:6811-19.

Møller, C, and MS Plesset. 1934, "Note on an Approximation Treatment for ManyElectron Systems." Physical Review 46:0618-22.

Mori, TT, K. 1973, "Average Stress in Matrix and Average Elastic Energy of Materials with Misfitting Inclusions." Acta Metallurgica 21:571-74.

Park, B, et al. 2006, "Redox Regulation Facilitates Optimal Peptide Selection by Mhc Class I During Antigen Processing." Cell 127:369-82.

Parsons, AF. 2000. An Introduction to Free Radical Chemistry. Blackwell Science Ltd., Oxford.

Petrik, NG, AG Kavetsky, and GA Kimmel. 2006, "Electron-Stimulated Production of Molecular Oxygen in Amorphous Solid Water." Journal of Physical Chemistry B 110:2723-31.

Pohlmann, T, et al. 2004, "Differential Peptide Dynamics Is Linked to Major Histocompatibility Complex Polymorphism." J Biol Chem 279:28197-201.

Price W. D., Schier P. D., and William E. R. 1996, Anal. Chem. 68:859.

Rees, WA, et al. 1993, "Evidence of DNA Bending in Transcription Complexes Imaged by Scanning Force Microscopy." Science (Washington D C) 260:1646-49.

Reuss, A. 1929, Math. Mech. 9.

Richardson, FS. 1982, Chem. rev. 82:541.

Rigney, E, et al. 1998, "A Soluble Major Histocompatibility Complex Class I PeptideBinding Platform Undergoes a Conformational Change in Response to Peptide Epitopes." J Biol Chem 273:14200-4.

Roiter, Y, and S Minko. 2005, "Afm Single Molecule Experiments at the Solid-Liquid Interface: In Situ Conformation of Adsorbed Flexible Polyelectrolyte Chains." J. Am. Chem. Soc. 127:15688-89.

S. Ahzi, NB, A. Makradi, S. Belouettar. 2006, "Composite Modelling for the Effective Elastic Properties of Semi-Crystalline Polymers." Journal of Mechanics of Materials and Structures in press.

Schapery, RA. 1968, "Thermal Expansion Coefficients of Composite Materials Based on Energy Principles." J. Comp. Mat. 2:380-404.

Schey K., et al. 1987, Int. J. Mass Spectrom. Ion Processes 77:49.

Seinfeld, JH, and SN Pandis. 2006. Atmospheric Chemistry and Physics: From Air Pollution to Climate Change. Second ed., John Wiley \& Sons, New York.

Shtrikman, ZHS. 1963, "A Variational Approad to the Theory of the Elastic Behaviour of Multiphase Materials." J. Mech. Phys. Solids 11:127-50.

Sieker, F, A May, and M Zacharias. 2007, "Predicting Affinity and Specificity of Antigenic Peptide Binding to Major Histocompatibility Class I Molecules." In preparation.

Sieker, F, S Springer, and M Zacharias. 2007, "Comparative Molecular Dynamics Analysis of Tapasin-Dependent and -Independent Mhc Class I Alleles." Protein Sci 16:299-308. 
Springer, S, et al. 1998, "Fast Association Rates Suggest a Conformational Change in the Mhc Class I Molecule H-2db Upon Peptide Binding." Biochemistry 37:3001-12.

Stroh, C, et al. 2004, "Single-Molecule Recognition Imaging Microscopy." Proceedings of the National Academy of Sciences 101:12503-07.

Stumm, W, and JJ Morgan. 1995. Aquatic Chemistry: Chemical Equilibria and Rates in Natural Waters. Third ed., John Wiley \& Sons, Inc., New York.

Suh, WK, et al. 1999, "Interaction of Murine Mhc Class I Molecules with Tapasin and Tap Enhances Peptide Loading and Involves the Heavy Chain Alpha3 Domain." J Immunol 162:1530-40.

Szanyi, J, et al. 2007, "Water-Induced Morphology Changes in Bao/Gamma-Al2o3 Nox

Storage Materials: An Ftir, Tpd, and Time-Resolved Synchrotron Xrd Study." Journal of Physical Chemistry C 111:4678-87.

Takahashi, N, et al. 1996, "The New Concept 3-Way Catalyst for Automotive Lean-Burn Engine: Nox Storage and Reduction Catalyst." Catalysis Today 27:63-69.

Tsybin Y. O., et al. 2001, Rapid Commmun. Mass Spectrom. 15:1849.

Turner, PS. 1946, "Thermal-Expansion Stresses in Reinforced Plastics." Journal of

Research of the National Bureau of Standards 37:239-60.

Uebel, S, and R Tampe. 1999, "Specificity of the Proteasome and the Tap Transporter."

Curr Opin Immunol 11:203-8.

Voigt, W. 1889, Wied. Ann. 38.

Wayne, RP. 2000. Chemistry of Atmospheres: An Introduction to the Chemistry of the Atmospheres of Earth, the Planets, and Their Satellites. Third ed., Oxford University Press, Oxford.

Werner, H-J, et al. 2006, "Molpro." Cardiff, UK.

Williams, AP, et al. 2002, "Optimization of the Mhc Class I Peptide Cargo Is Dependent on Tapasin." Immunity 16:509-20.

Winkler, K, et al. 2007, "Natural Mhc Class I Polymorphism Controls the Pathway of Peptide Dissociation from Hla-B27 Complexes." Biophys J.

Wright, CA, et al. 2004, "Tapasin and Other Chaperones: Models of the Mhc Class I Loading Complex." Biol Chem 385:763-78.

Wyman, C, et al. 1995, "Determination of Heat-Shock Transcription Factor 2

Stoichiometry at Looped DNA Complexes Using Scanning Force Microscopy." EMBO (European Molecular Biology Organization) Journal 14:117-23.

Xantheas, SS. 1994, "Ab-Initio Studies of Cyclic Water Clusters (H2o)(N), N=1-6 .2.

Analysis of Many-Body Interactions." Journal of Chemical Physics 100:7523-34.

Xantheas, SS, CJ Burnham, and RJ Harrison. 2002, "Development of Transferable Interaction Models for Water. Ii. Accurate Energetics of the First Few Water Clusters from First Principles." Journal of Chemical Physics 116:1493-99.

Yang, Y, H Wang, and DA Erie. 2003, "Quantitative Characterization of Biomolecular Assemblies and Interactions Using Atomic Force Microscopy."

You, H, et al. 2006, Mater. Sci. Eng. B131:252.

Zacharias, M, and S Springer. 2004, "Conformational Flexibility of the Mhc Class I Alpha1-Alpha2 Domain in Peptide Bound and Free States: A Molecular Dynamics Simulation Study." Biophys J 87:2203-14.

Zarling, AL, et al. 2003, "Tapasin Is a Facilitator, Not an Editor, of Class I Mhc Peptide Binding." J Immunol 171:5287-95. 
Zernich, D, et al. 2004, "Natural Hla Class I Polymorphism Controls the Pathway of Antigen Presentation and Susceptibility to Viral Evasion." J Exp Med 200:13-24.

Zhang, C, A Anderson, and C DeLisi. 1998, "Structural Principles That Govern the Peptide-Binding Motifs of Class I Mhc Molecules." J Mol Biol 281:929-47.

Zubarev R. A., et al. 2000, Anal. Chem. 72:563. 
Figure legends

\section{Figure 1}

New cartoon representation of the HLA-B*4402 $\alpha_{1} / \alpha_{2}$-binding domain (protein data bank entry: 1M6O) in complex with a high affinity ligand (sequence: EEFGRAFSF). Peptide backbone atoms as well as backbone atoms of residues $6,7,8,9,26,27,28,29,97,98$, $99,116,117,118$ used to calculate center of gravities as reference for the distance restraints are given in van der Waals representation. Helical segments as well as the proposed tapasin binding region are indicated.

\section{Figure 2}

Moving average of the root mean square deviation time course for backbone atoms of the HLA-B*4402 $\alpha_{1} / \alpha_{2}$-binding domain with respect to the crystal structure. Time courses are shown for all 17 windows. The first window represents a distance restraint of $1.225 \mathrm{~nm}$ which is increased in further windows by $0.05 \mathrm{~nm}$ per window up to a maximal distance of $2.075 \mathrm{~nm}$.

\section{Figure 3}

Top view of the $\alpha_{1} / \alpha_{2}$ peptide binding domain of HLA-B*4402 bound to a high affinity ligand shown in tube representation. Presented are in each case 8 snapshots taken during simulations of the $16^{\text {th }}(\mathrm{A})$ and $17^{\text {th }}(\mathrm{B})$ window, respectively with a time interval of $1 \mathrm{~ns}$. The color scheme represents the chronology of time points at which the snapshots were taken. Starting from red and changing via light red to white to light blue and ending in blue. 
PNNL-17069

Figure 4

Correlation map displaying the Pearson correlation coefficients between distance vectors recorded during $8 \mathrm{~ns}$ of molecular dynamics simulations of the $16^{\text {th }}$ window. One of the vectors is always the distance between the center of gravity of backbone atoms of the Nterminal anchor residue (P2) and the center of gravity of backbone atoms located at the bottom of the B-Pocket (residues 7 to 9). The other vectors are defined as distances between atoms marked at the $\mathrm{x}$ and $\mathrm{y}$ axis. Red cells represent high positive correlation while blue cells mark high negative correlation. Black cells display no correlation or not calculated distances, respectively. Only $\mathrm{C}_{\alpha}$ atoms and $\mathrm{C}_{\gamma}$ if applicable are depicted.

\section{Figure 5}

Correlations of distances recorded during the $17^{\text {th }}$ window (see figure 4 for a description of the methodology). Distances were calculated for the peptide C-Terminus to the FPocket and surrounding helical segments. Atoms between which distances are calculated are depicted at axis marks.

\section{Figure 6}

Cumulated averages of free energy vs. distance of the center of gravity of selected $\beta$ sheet backbone atoms (residues $6,7,8,9,26,27,28,29,97,98,99,116,117,118$ ) to the center of gravity of all peptide backbone atoms calculated using the weighted histogram analysis method based on distances recorded during 17 windows of targeted MD simulation. Each window consists of $8 \mathrm{~ns}$ of simulation time on HLA-B*4402 bound to a 
high affinity peptide ligand (sequence: EEFGRAFSF). The distance restraint is represented by a harmonic potential with a force constant of $2.0 \mathrm{kcal} \mathrm{mol}{ }^{-1} \AA^{-2}$.

\section{Figure 7}

Cumulated averages of free energy vs. distance of the center of gravity of backbone atoms of either the $\mathrm{N}$-terminal (A) or the C-terminal (B) anchor residue (P2 or P9) to the center of mass of backbone atoms located at the bottom of the respective binding pocket $\mathrm{B}$ and $\mathrm{F}$, respectively. In case of the peptide $\mathrm{N}-$ Terminus (C-Terminus) the free energy is based on distance distributions obtained from 4ns (6ns) of targeted MD simulations on 16 (14) windows incorporating a harmonic potential starting at $0.925 \mathrm{~nm}(1.025 \mathrm{~nm})$ increased by $0.05 \mathrm{~nm}$ in each consecutive window.

\section{Figure 8}

Top view (A) on the HLA-B*4402 binding groove (backbone atoms) bound to a high affinity ligand (all heavy atoms) in licorice representation. Presented here are the crystal structure (blue colors) as well as average structures of $5 \mathrm{~ns}$ simulations each within the $18^{\text {th }}$ (green colors) and $19^{\text {th }}$ (red colors) window (center of distance restraint potential set to $1.425 \mathrm{~nm}$ and $1,475 \mathrm{~nm}$, respectively) of the simulation series focusing on the dissociation of the peptide C-Terminus. Side view of the peptide in licorice representation (all heavy atoms) with the C-Terminus depicted on the right side (color scheme as in panel A). 
PNNL-17069

\section{Figure 9}

Cumulated averages of free energy vs. distance of the center of mass of the peptide CTerminus backbone atoms to the center of gravity of backbone atoms located within the F-Pocket (residues 116 and 117). Calculation based on simulations of HLA-B*4405; 16 windows with a stepwise increase of $0.05 \mathrm{~nm}$ starting at $0.925 \mathrm{~nm}$, force constant $2.0 \mathrm{kcal}$ $\mathrm{mol}^{-1} \AA^{-2}$. 


\section{Figures}

Figure 1

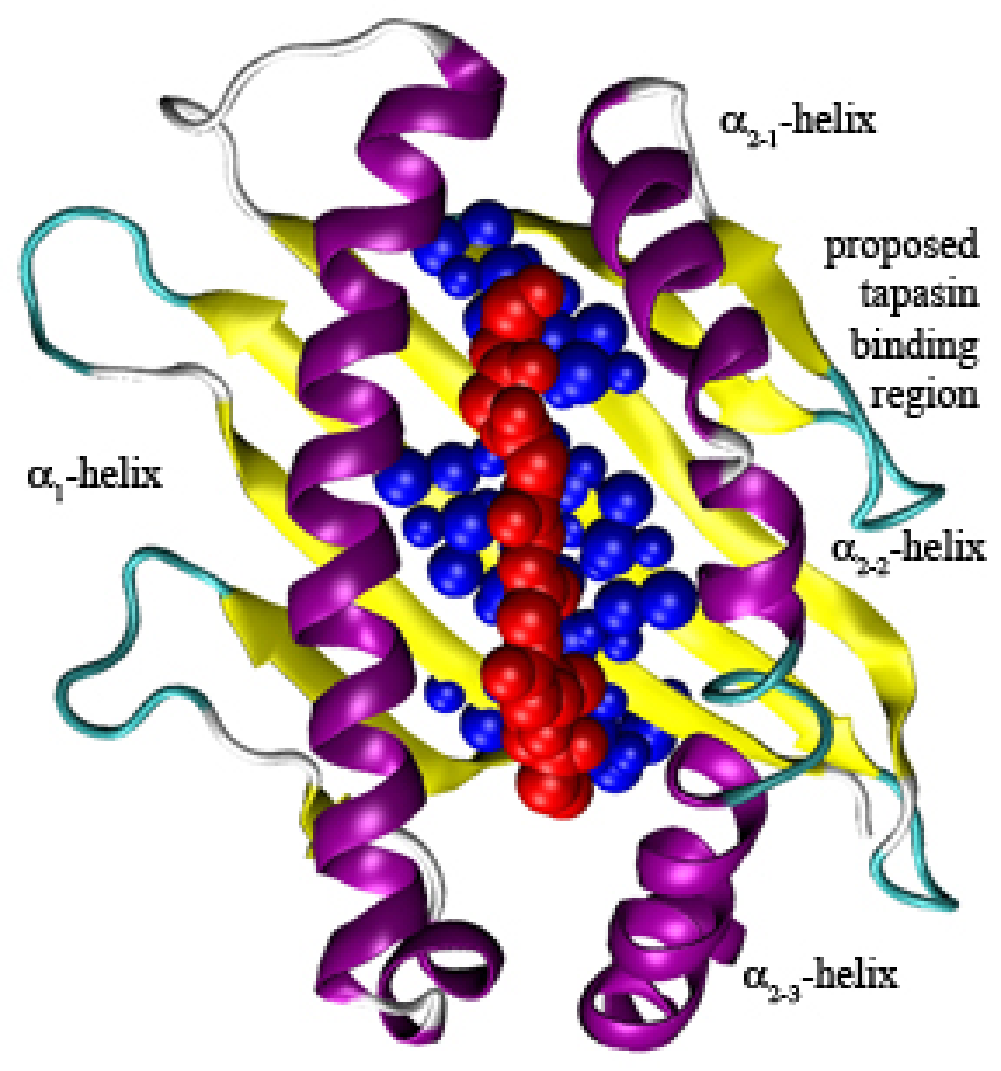


PNNL-17069

Figure 2

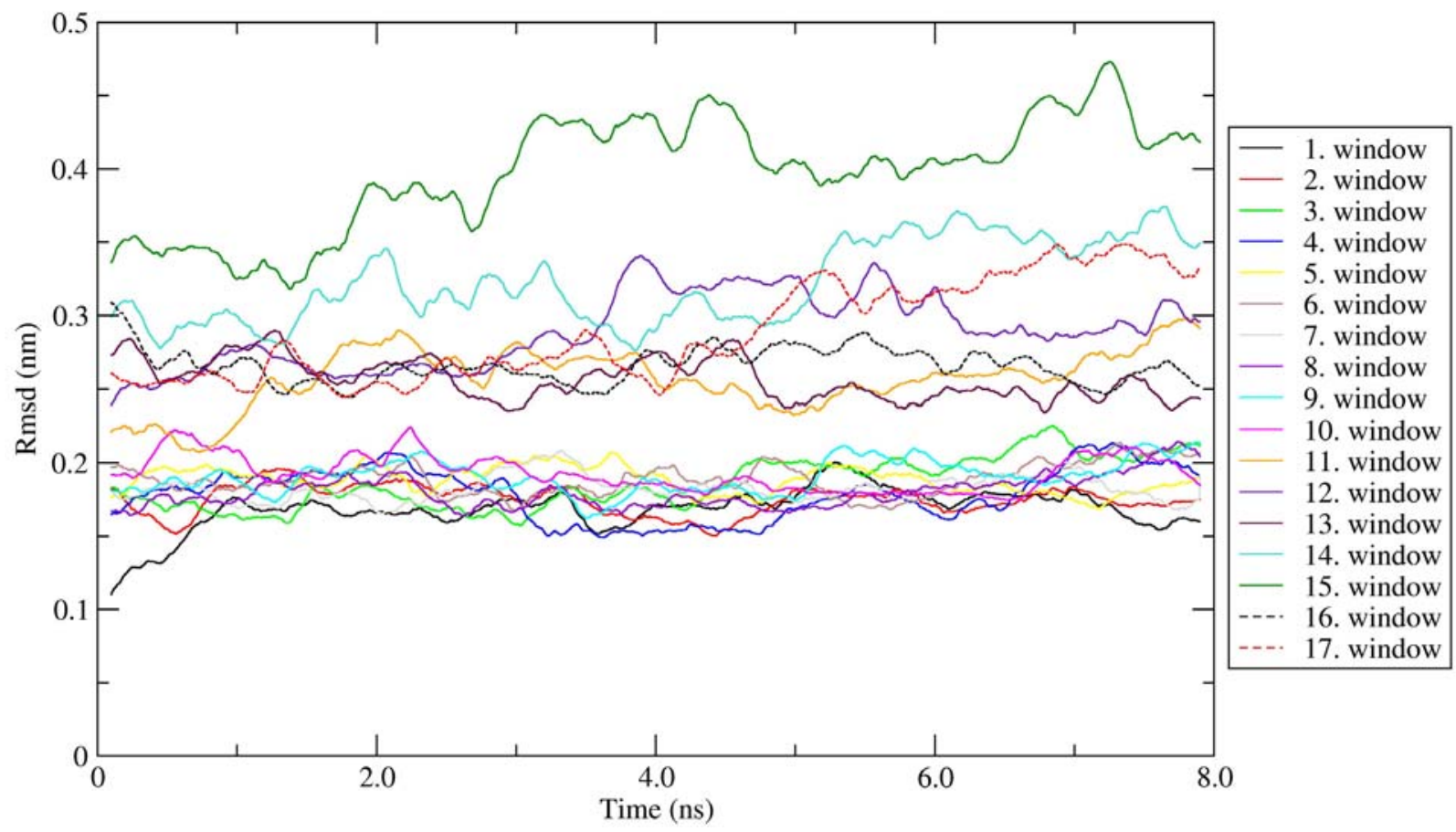


PNNL-17069

Figure 3
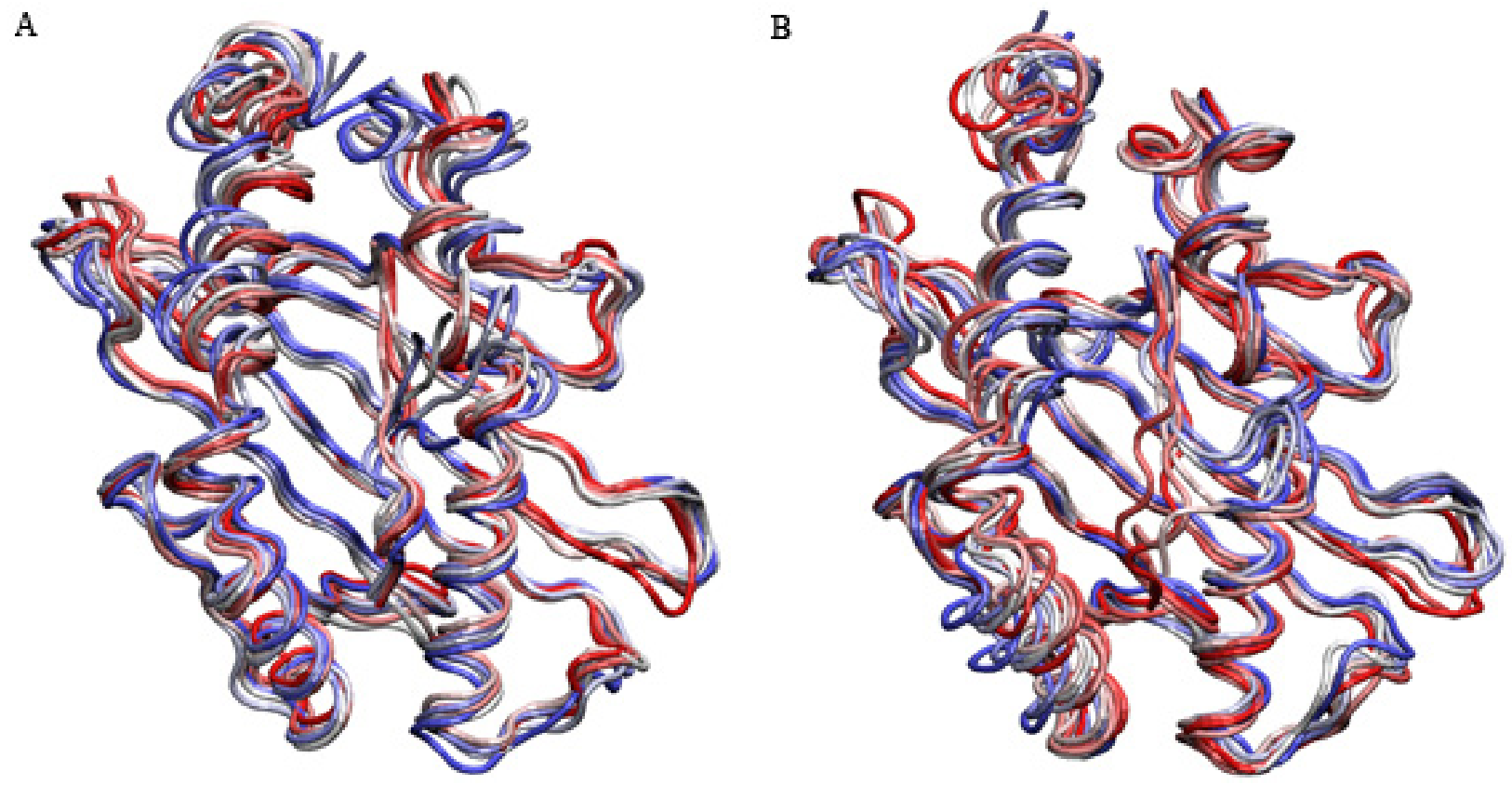
Figure 4

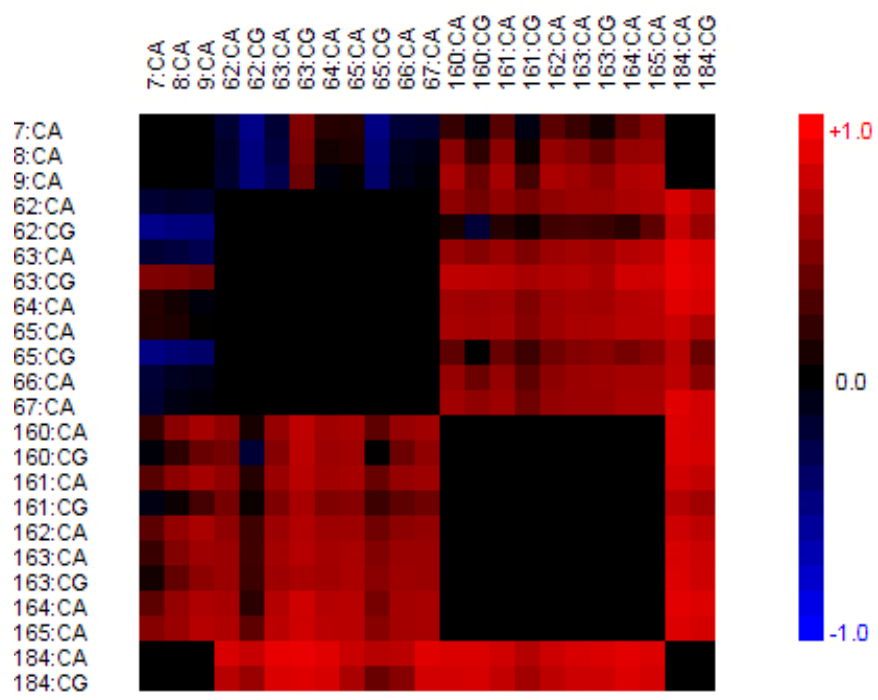


Figure 5

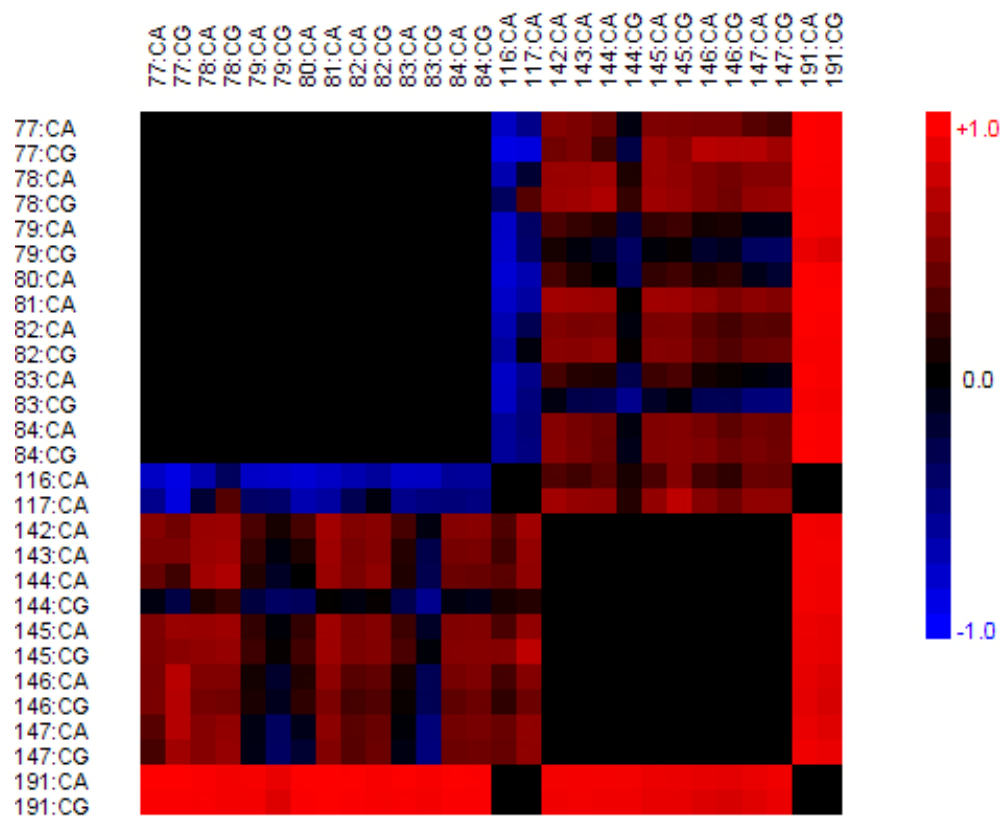


PNNL-17069

Figure 6

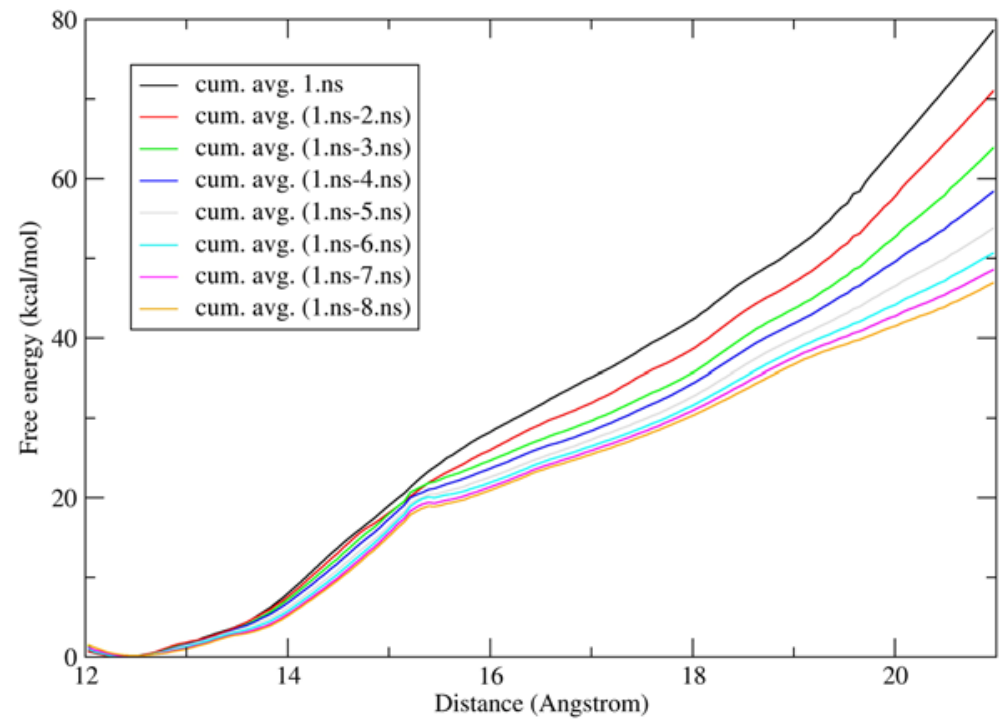


PNNL-17069

Figure 7
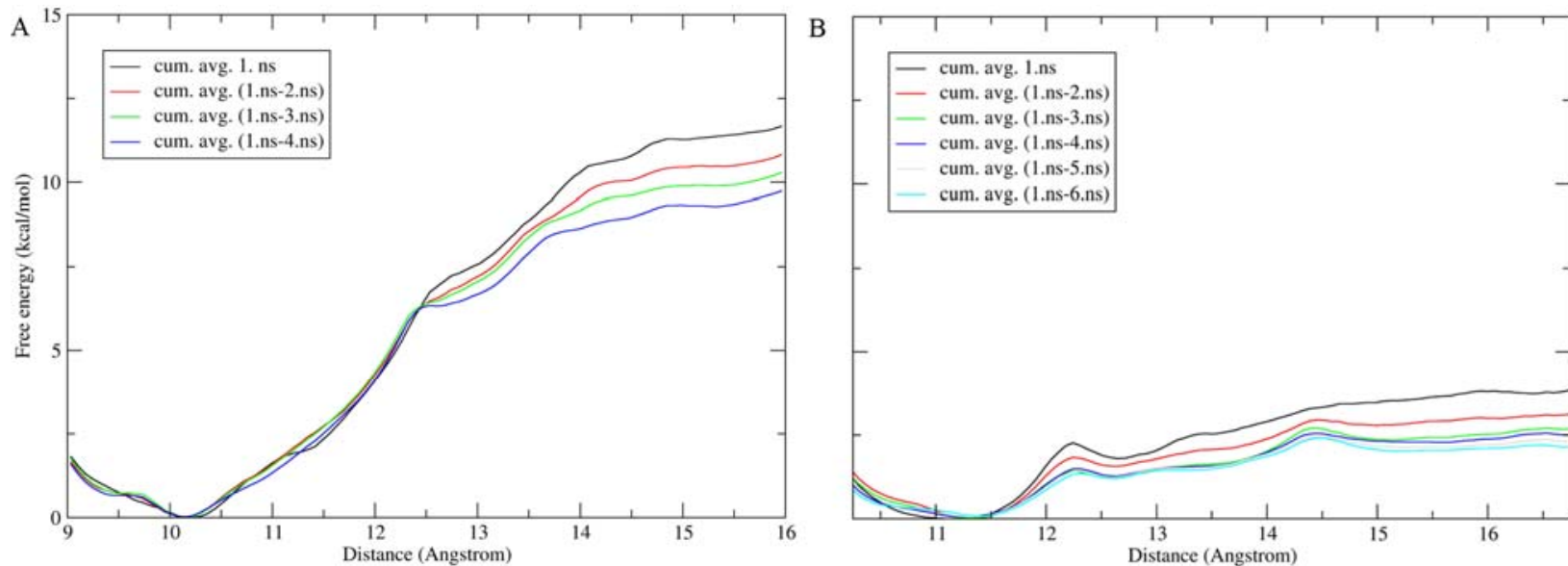
PNNL-17069

Figure 8

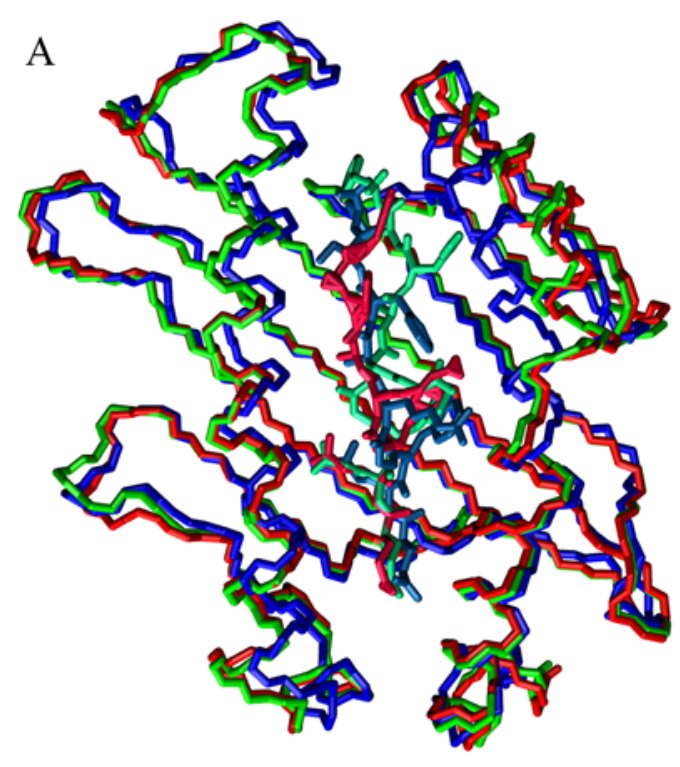

B

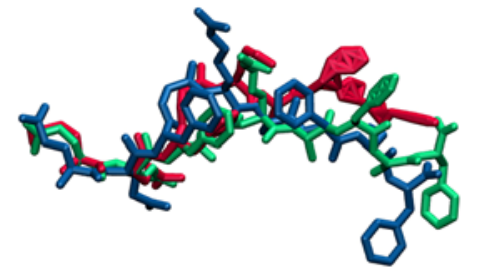


PNNL-17069

Figure 9

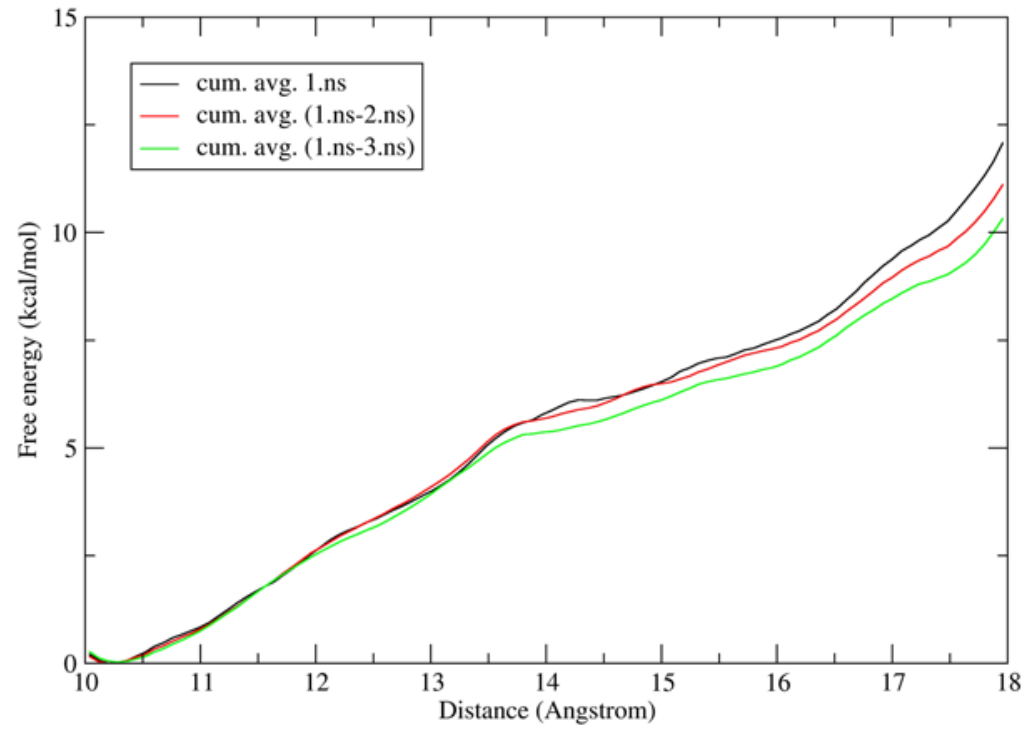


PNNL-17069

\title{
Dopant concentration and incorporation in doped metal oxide powders studied with XPS
}

\author{
Aaron Thurber and Dr. Alex Punnoose \\ Department of Physics \\ Boise State University \\ Boise, ID 83725 \\ and
}

Dr. P. Nachimuthu and Dr. M. H. Engelhard

Environmental Molecular Sciences Laboratory

Pacific Northwest National Laboratory

Richland, WA, 99354

\begin{abstract}
$\mathrm{Ni}$ doped $\mathrm{CeO}_{2}$ and $\mathrm{Cr}$ doped $\mathrm{SnO}_{2}$ have been synthesized in powder form for study as potential spintronics materials. The powders are comprised of nanocrystals in the size range $<50 \mathrm{~nm}$. Concentration of $\mathrm{Ni}$ in $\mathrm{CeO}_{2}$ is varied between 0 and $20 \%$ while the concentration of $\mathrm{Cr}$ in $\mathrm{SnO}_{2}$ varies from 0 to $10 \%$, with both systems showing weak ferromagnetism up to a certain dopant concentration $x_{\mathrm{p}}$, above which the magnetism disappears. X-ray photoelectron spectroscopy (XPS) has been used to verify the dopant concentrations as well as being used as a method to verify dopant incorporation.
\end{abstract}




\section{Introduction}

Recently, it has been shown that transition metal (TM) doped metal oxides (MO) are an interesting candidate for spin electronics, or spintronics, applications because of their interesting magnetic properties. ${ }^{1-3} \mathrm{Sn}_{1-\mathrm{x}} \mathrm{Fe}_{\mathrm{x}} \mathrm{O}_{2}$ has been specifically shown to have a novel application as a magnetic gas sensor. ${ }^{4}$ Other $\mathrm{M}_{\mathrm{x}} \mathrm{TM}_{1-\mathrm{x}} \mathrm{O}_{\mathrm{y}}$ materials have recently garnered interest for applications as well, including TM doped $\mathrm{SnO}_{2}$ and $\mathrm{CeO}_{2} \cdot{ }^{5-6}$ For this work, nanocrystalline powders of $\mathrm{Sn}_{1-\mathrm{x}} \mathrm{Cr}_{\mathrm{x}} \mathrm{O}_{2}$ and $\mathrm{Ce}_{1-\mathrm{x}} \mathrm{Ni}_{\mathrm{x}} \mathrm{O}_{2}$ have been synthesized for study.

\section{Experimental}

Synthesis of $\mathrm{Sn}_{1-\mathrm{x}} \mathrm{Cr}_{\mathrm{x}} \mathrm{O}_{2}$ was accomplished following a previously reported procedure ${ }^{3}$ that differed by using $\mathrm{CrCl}_{3}$ as a precursor in place of $\mathrm{FeCl}_{2}$. The $\mathrm{Ce}_{1-\mathrm{x}} \mathrm{Ni}_{\mathrm{x}} \mathrm{O}_{2}$ powder was also synthesized following another procedure ${ }^{7}$. Some of the $\mathrm{Ni}$ doped $\mathrm{CeO}_{2}$ samples were prepared at room temperature and some at an elevated temperature. In the cases of both doped systems, $x$ represents the molar ratio $\frac{[T M]}{[T M]+[M]}$ where $[T M]$ is the atomic concentration of the dopant $(\mathrm{Cr}$ or $\mathrm{Ni})$ and $[M]$ is the atomic concentration of the host metal ( $\mathrm{Sn}$ or $\mathrm{Ce}$ ). The dopant concentration is controlled by using carefully measured amounts of each precursor chemical. Some of the $\mathrm{Ni}$ doped $\mathrm{CeO}_{2}$ samples have undergone additional treatment following synthesis which has resulted in drastic changes in the magnetic properties ${ }^{7}$.

X-ray photoelectron spectroscopy (XPS) studies were carried out on a Kratos AXIS 165 spectrometer equipped with a monochromatic $\mathrm{Al} \mathrm{K}_{\alpha}$ source $(1486.6 \mathrm{eV})$. The binding energy scale was calibrated using an $\mathrm{Ag}$ standard referencing the $\mathrm{Ag} 3 \mathrm{~d}_{5 / 2}$ peak. The system uses a hemispherical analyzer containing a channeltron detector with 8 
channels, which was operated with pass energy of $80 \mathrm{eV}$. The x-ray source was operated at $200 \mathrm{~W}$. The samples studied were insulating and would undergo charging as a result of the photoemission process. To minimize this effect, the AXIS 165 system uses low energy electrons from an electron flood gun. The flood gun current was kept constant at $1.95 \mathrm{~A}$. The $\mathrm{Cr}$ doped $\mathrm{SnO}_{2}$ samples were then charge referenced to the $\mathrm{Sn} 3 \mathrm{~d}_{5 / 2}$ feature of $\mathrm{SnO}_{2}$ at $486.7 \mathrm{eV}$. The $\mathrm{Ni}$ doped $\mathrm{CeO}_{2}$ samples were also charge referenced using the Ce $3 \mathrm{~d}_{5 / 2}$ feature of $\mathrm{CeO}_{2}$ at $882.0 \mathrm{eV}$. Cr doped $\mathrm{SnO}_{2}$ spectra are shown in Fig. 1, while Ni doped $\mathrm{CeO}_{2}$ spectra are shown in Fig. 2. The $\mathrm{Cr} 2 \mathrm{p}$ region of the $\mathrm{Cr}$ doped $\mathrm{SnO}_{2}$ samples shows a shift towards higher binding energy compared to the $\mathrm{Cr}_{2} \mathrm{O}_{3}$. This indicates that the $\mathrm{Cr}$ in the doped sample is not $\mathrm{Cr}_{2} \mathrm{O}_{3}$. Also, since the energy shift is toward higher binding energy, the formation of $\mathrm{Cr}$ metal is ruled out. The $\mathrm{Ni}$ doped $\mathrm{CeO}_{2}$ samples show different binding energy of the Ni $2 p$ region than NiO. Furthermore, similar to the $\mathrm{Cr}$ doped $\mathrm{SnO}_{2}$, the Ni 2p binding energies are not shifted to the lower end of the scale, indicating the $\mathrm{Ni}$ is not present in its metallic form.

\section{Dopant concentration}

The concentrations were studied using quantitative XPS analysis. XPS is inherently quantitative since the flux of the emitted photoelectrons is directly proportional to the atomic concentrations of the emitting species. All of the quantitative results are outlined in Table 1.

For the $\mathrm{Cr}$ doped $\mathrm{SnO}_{2}$ samples, the $\mathrm{Cr}$ concentration is consistently above the expected dopant concentration. It has been previously shown in $\mathrm{Fe}$ doped $\mathrm{SnO}_{2}$ that the Fe dopants segregate to the surface of the particles. ${ }^{3}$ Since XPS is a surface sensitive technique, it may be explained by presuming that the $\mathrm{Cr}$ dopants are segregating in a 
similar fashion, although further studies are reuired to verify this. All of the dopant concentrations determined from the $\mathrm{Ni}$ doped $\mathrm{CeO}_{2}$ samples were within $\pm 2 \%$ of the expected concentrations.

\section{Dopant incorporation}

Previously, XPS has been used to aid in demonstrating dopant incorporation into the host system. ${ }^{2-4,7}$ This is an important step, since the weak ferromagnetism displayed by the powders studied here could easily be explained by suggesting the dopant is not incorporated into the host system but rather forms its own metal oxide or precipitates in its elemental form. Pure $\mathrm{Cr}_{2} \mathrm{O}_{3}$ and $\mathrm{NiO}$ samples were prepared under identical conditions to $\mathrm{Sn}_{1-\mathrm{x}} \mathrm{Cr}_{\mathrm{x}} \mathrm{O}_{2}$ and $\mathrm{Ce}_{1-\mathrm{x}} \mathrm{Ni}_{\mathrm{x}} \mathrm{O}_{2}$, respectively, for comparison to the doped samples. High resolution XPS of the $\mathrm{Cr} 2 \mathrm{p}$ and Ni $2 \mathrm{p}$ regions, shown in Figs. 1 and 2, demonstrate reasonably well that the binding energies of the dopants in $\mathrm{Sn}_{1-\mathrm{x}} \mathrm{Cr}_{\mathrm{x}} \mathrm{O}_{2}$ and $\mathrm{Ce}_{1-\mathrm{x}} \mathrm{Ni}_{\mathrm{x}} \mathrm{O}_{2}$ are different from that of the pure oxides. For the $\mathrm{Cr}$ doped $\mathrm{SnO}_{2}$ samples, the binding energy shifts toward higher values than that of the pure oxide, which indicates that the dopant has not formed $\mathrm{Cr}_{2} \mathrm{O}_{3}$ or $\mathrm{Cr}$ metal. ${ }^{3}$ For the Ni doped $\mathrm{CeO}_{2}$ samples, the binding energy of the Ni $2 p_{3 / 2}$ peak is also shifted to higher binding energy,

which also indicates the dopant has not formed $\mathrm{NiO}$ or Ni metal. ${ }^{3}$ As can also be seen in Fig. 2, additional processing of the $\mathrm{Ni}$ doped $\mathrm{CeO}_{2}$ samples (Activated and Heated samples) does not result in changes to the Ni $2 p$ binding energies.

\section{Conclusions}

XPS has been utilized to study the dopant concentrations and binding energies of TMs in TM doped MOs. For $\mathrm{Cr}$ doped $\mathrm{SnO}_{2}$, the dopant concentration was higher than expected which may indicated the dopant has a tendency to diffuse toward the surface of 
PNNL-17069

particles, while for $\mathrm{Ni}$ doped $\mathrm{CeO}_{2}$ the dopant concentrations were within close agreement of the expected values. The binding energies of the $\mathrm{Cr}$ and $\mathrm{Ni}$ in the respective systems demonstrate reasonably well that the dopant is indeed incorporated into the host $\mathrm{MO}$ systems. The additional processing of $\mathrm{Ni}$ doped $\mathrm{CeO}_{2}$ that result in drastic changes in magnetic properties does not indicate any change in the binding energies or concentration of the incorporated $\mathrm{Ni}$.

\section{Acknowledgements}

Thanks go to Drs. P. Nachimuthu, M. H. Engelhard and S. Thevuthasan for their guidance and assistance during these studies. Thanks also go to Dr. S. ThevuthasaN This research was supported by the SRI program at Pacific Northwest National Laboratory and was conducted in the Environmental Molecular Sciences Laboratory at PNNL. Support was also provided by the following grants:

\section{Tables}

\begin{tabular}{|r|l|r|r|}
\hline \multicolumn{4}{|c|}{ Dopant concentrations (\%) } \\
\hline Ni doped $\mathrm{CeO}_{2}$ samples & \multicolumn{2}{c|}{ Cr doped $\mathrm{SnO}_{2}$ samples } \\
\hline Nominal & $\begin{array}{l}\text { XPS } \\
\text { measured }\end{array}$ & Nominal & $\begin{array}{l}\text { XPS } \\
\text { measured }\end{array}$ \\
\hline 5 & 5.3 & 1 & 6.40 \\
\hline 10 & 11.7 & 2 & 11.6 \\
\hline 20 & 20.7 & 2.5 & 10.3 \\
\hline & & 3 & 14.7 \\
\hline & & 5 & 15.7 \\
\hline & & 10 & 15 \\
\hline
\end{tabular}

Table 1: Nominal and measured dopant concentrations of $\mathrm{Ni}$ doped $\mathrm{CeO}_{2}$ and $\mathrm{Cr}$ doped $\mathrm{SnO}_{2}$.

\section{Figures}


PNNL-17069

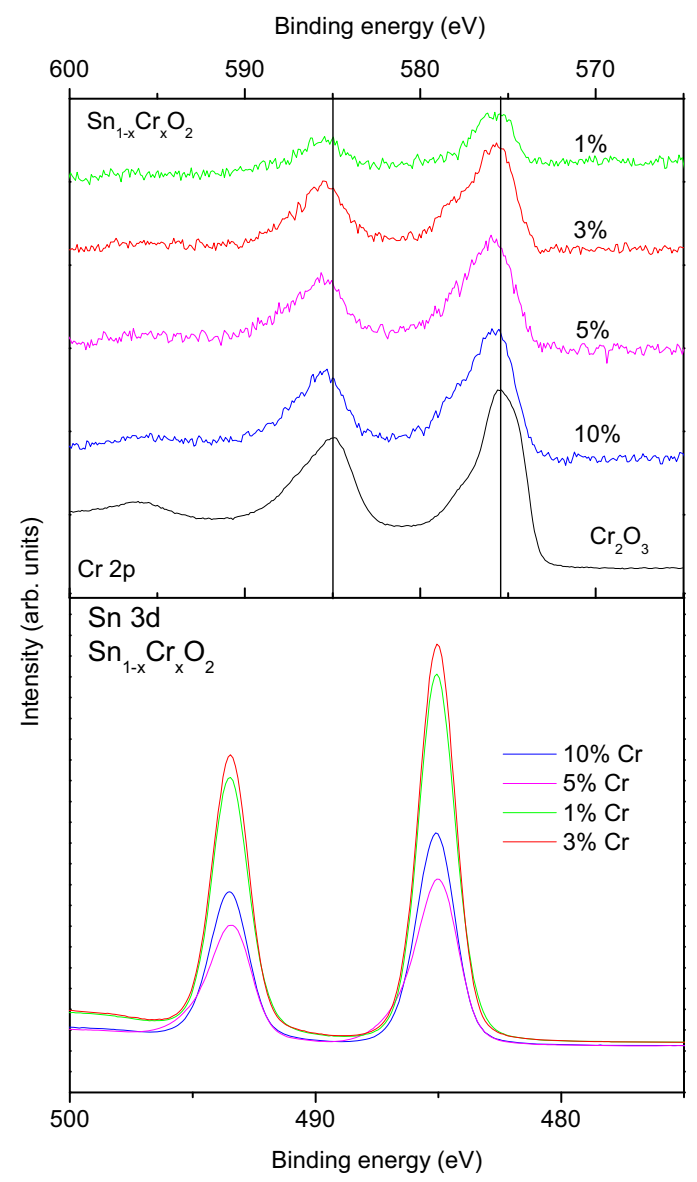

Figure 1: $\mathrm{Cr} 2 \mathrm{p}$ (top) and $\mathrm{Sn} 3 \mathrm{~d}$ (bottom) regions of $\mathrm{Cr}$ doped $\mathrm{SnO}_{2}$ samples. For comparison, $\mathrm{Cr}_{2} \mathrm{O}_{3}$ is also shown in the top panel. 
PNNL-17069

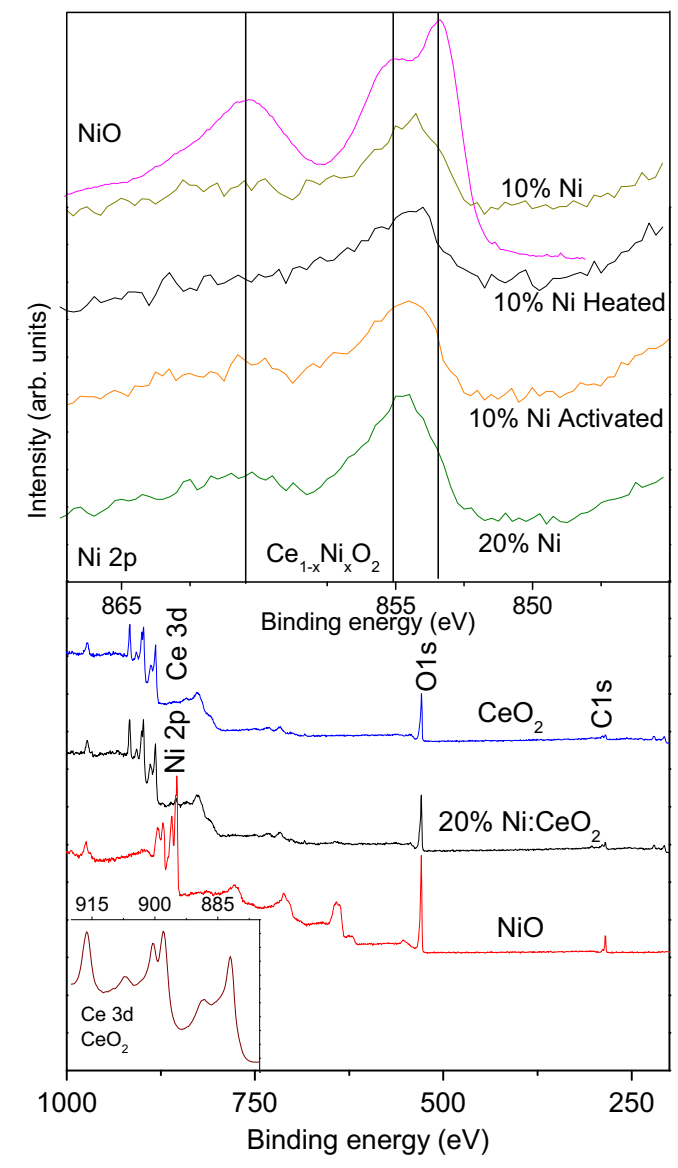

Figure 2: Ni $2 p$ region (top) and survey spectra (bottom) collected on $\mathrm{Ni}$ doped $\mathrm{CeO}_{2}$ samples. For comparison, a sample of $\mathrm{NiO}$ is also shown in both panels. Inset shows the $\mathrm{Ce} 3 \mathrm{~d}$ region of pure $\mathrm{CeO}_{2}$ powder.

\section{References}

1. J. M. D. Coey, M. Venkatesan and C. B. Fitzgerald, Nature 4, 173 (2005) 
2. J. Hays, A. Thurber, K. M. Reddy, M. H. Engelhard and A. Punnoose, J. Appl. Phys. 99, 08M123 (2006)

3. A. Punnoose, J. Hays, A. Thurber, M. H. Engelhard, R. K. Kukkadapu, C. Wang, V. Shutthanandan and S. Thevuthasan, Phys. Rev. B 72, 054402 (2005)

4. A. Punnoose, K. M. Reddy, J. Hays, A. Thurber and M. H. Engelhard, Appl. Phys. Lett. 89, 112509 (2006)

5. C. B. Fitzgerald et al., Phys. Rev. B 74, 115307 (2006)

6. A. Tiwari, V. M. Bhosle, S. Ramachandran, N. Sudhakar, J. Narayan, S. Budak and A. Gupta, Appl. Phys. Lett. 88, 142511 (2006)

7. A. Thurber, K. M. Reddy and A. Punnoose, J. Appl. Phys. 101, 09N506 (2007) 


\section{Measuring electron transfer across the nanoscale space between bacterial cytochromes and oxide surfaces}

Nicholas S. Wigginton (Student) Michael F. Hochella Jr. (Ph.D. Advisor) Virginia Tech
Kevin M. Rosso (Mentor) EMSL

Some species of Bacteria are able to control natural geochemical processes by exchanging electrons with inorganic mineral phases by either oxidizing or reducing the mineral surface. One such bacterium, Shewanella oneidensis, reduces polyvalent metal-oxide minerals by transferring metabolically-generated electrons to reducible cites on the crystal (e.g. Fe(III) atoms on a hematite surface). Adsorbed metals and/or radionuclides (e.g. U(VI)) can also be reduced in a similar fashion which is why $S$. oneidensis is highly considered a model microorganism for use in the environmental remediation of DOE's many hazardous waste sites. Although much is known about how $S$. oneidensis respires on metal oxides and adsorbed metal species, much more remains shrouded in complexity. One such poorly characterized component of this system is the molecular mechanism(s) of how redox-active proteins called cytochromes expressed on the cell's outer membrane are able to transfer electrons efficiently to reducible cites on the oxide surface. For example, it is unknown how/why in certain conditions the cells can only transfer electrons when in direct contact with the oxide while in other cases 'long-range' extracellular electron transfer is possible or even preferred.

Our initial work towards addressing this problem using scanning tunneling microscopy (STM) showed that the two primary metal-reducing cytochromes expressed on the cell surface of $S$. oneidensis (OmcA and $\mathrm{MtrC}$ ) possess the unique abilities to mediate tunneling current when in direct contact to a $\mathrm{Au}(111)$ (Wigginton et al., 2007a). This result was surprising considering the similarities these two decaheme cytochromes share in their molecular size, primary protein sequence, and presumed physiological function. To further understand these results, we interpreted the single-molecule tunneling spectra in a theoretical context and showed that indeed OmcA and MtrC facilitate electron transfer to a solid surface through two different fundamental tunneling mechanisms (Wigginton et al., 2007b).

For the first half of my SRI appointment, I did a similar set of experiments as above using a cytochrome with a known crystal structure: the small tetraheme cytochrome (STC) from S. oneidensis (Fig. 1a). This protein has already been examined computationally in regards to metal reduction by scientists at PNNL (Kerisit et al., 2007). Using STM, I was able to provide an experimental component to the computational work, and show that STC transfers electrons to $\mathrm{Au}(111)$ in a way similar to OmcA (above). Moreover, with an understanding of the structure of the protein and/or molecular monolayer on Au(111) from STM images (Fig. 1b), 
we can compare results to ongoing Molecular Dynamics simulations in order to get a more detailed understanding of how proteins transfer electrons to solid substrates. Further experiments using X-ray Reflectivity (XRR) at the Stanford Synchrotron Radiation Laboratory (SSRL) were also conducted during my appointment to resolve additional detailed molecular scale information about the structure of STC on Au(111). Interpretation of the XRR data is currently underway.
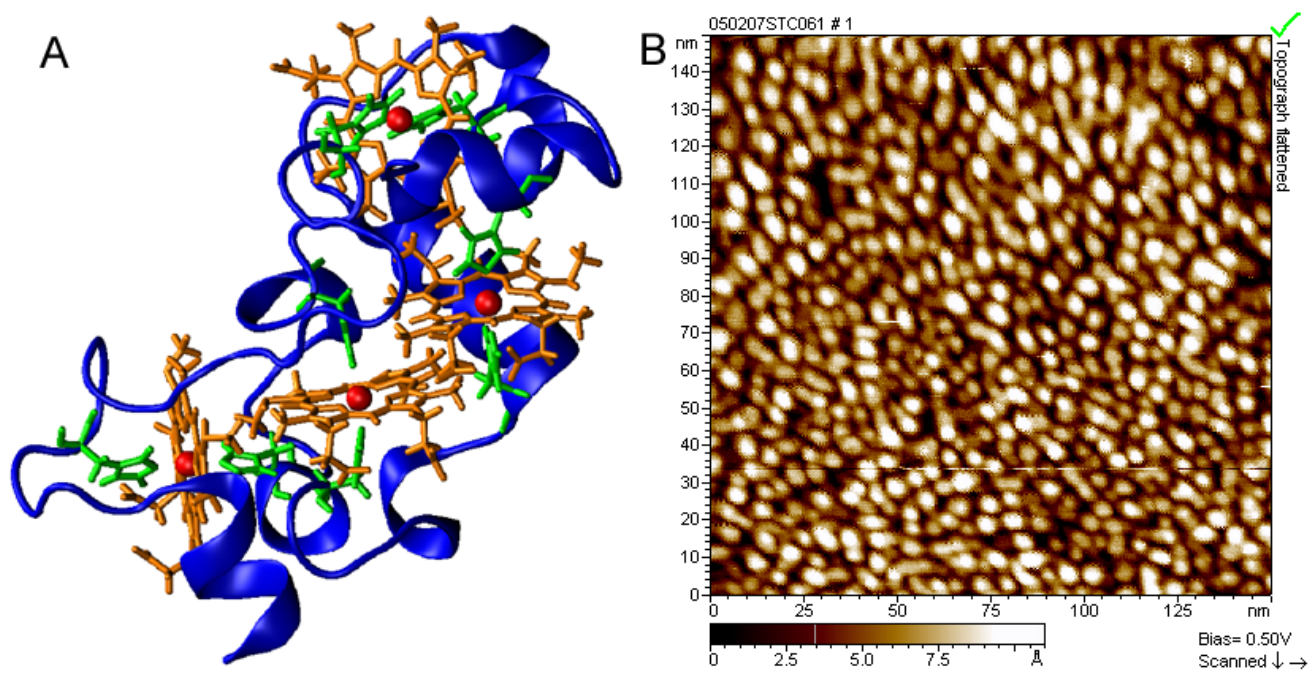

Figure 1: The small tetraheme cytochrome (STC) from S. oneidensis. (A) crystal structure, and (B) corresponding STM image of STC molecules on a Au(111) surface.

The second half of my proposal was spent addressing the aforementioned 'long-range' extracellular electron transfer scenario when proteins are not in direct contact with mineral surfaces. For these experiments, STM was used to control the sub-nanometer separation distance between proteins and hematite $\left(\mathrm{Fe}_{2} \mathrm{O}_{3}\right)$ in an aqueous solution. Preliminary currentdistance spectra show that the electrical double layer, which is controlled in part by the biasvoltage between tip and sample, can have a significant effect on electron tunneling to natural hematite surfaces in solution without proteins (Fig. 2). In addition to controlling the electrical double layer thickness with the bias voltage, experiments were done in an electrochemical cell with solutions of varying $\mathrm{pH}$ and electrolyte concentrations. Depending on the value of $\mathrm{pH}$, the hematite surface will undergo protonation/deprotonation reactions that may influence electron transfer. Varying the salt concentration-in this case, we used $\mathrm{KCl}$-controls the thickness of the electrical double layer independently of the applied bias voltage and provides another control for the bare hematite case. We also characterized two synthetic hematite surfaces grown at PNNL (by Tim Droubay, EMSL) to understand the effects of mineral surface structure, particle size, and dopant concentration on electronic tunneling to hematite surfaces. A rigorous study of this nature will builds upon our previous knowledge by providing information about facile 'long-range' electron transfer channels to the oxide surface. 

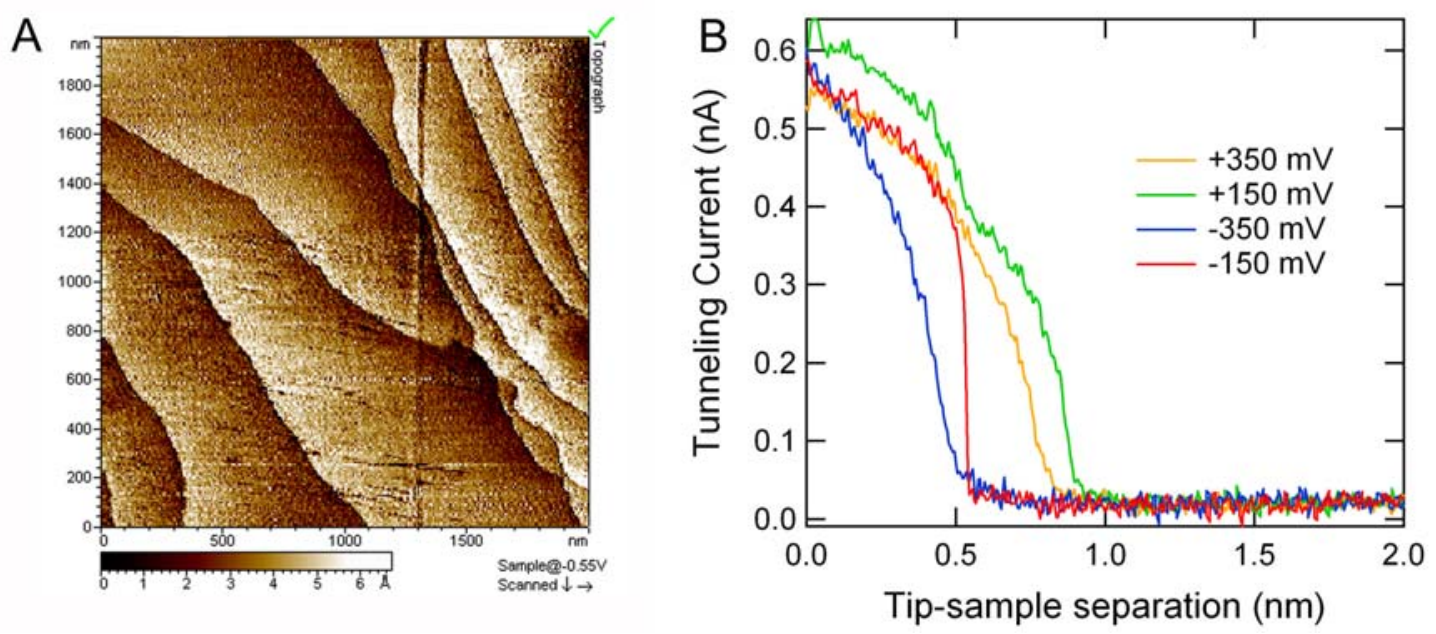

Figure 2: (A) STM image of natural hematite [001] surface. (B) Current-distance profile at the same surface for different bias voltage set-points.

Future experiments using cytochromes chemically adsorbed to homemade Au STM tips are planned as an extension of this collaboration through an EMSL User Proposal. Hopefully, these experiments coupled with the preliminary data on bare hematite (above) will test the maximum distance that proteins can transfer electrons in solution. This, in turn, has significant implications for determining the mechanisms of electron transfer at the mineralmicrobe interface.

\section{References}

Kerisit, S., and Rosso, K. M., Dupuis, M., and Valiev, M., 2007, Molecular computational investigation of electron transfer kinetics across cytochrome-iron oxide interfaces. J. Phys. Chem. C, 111, 11363-11375.

Wigginton, N. S., Rosso, K. M., Lower, B. H., Shi, L., and Hochella, M. F., Jr., 2007a, Electron tunneling properties of outer membrane decaheme cytochromes from Shewanella oneidensis, Geochimica et Cosmochimica Acta, 71, 543-555.

Wigginton, N. S., Rosso, K. M., and Hochella, M. F., Jr., 2007b, Mechanisms of electron transfer in two decaheme cytochromes from a metal-reducing bacterium, Journal of Physical Chemistry $B$, in press. 
PNNL-17069 


\title{
Micro-structural and optical properties of $\mathrm{Sn}$ and $\mathrm{SnO}_{2}$ nanoparticles in $\mathrm{Al}_{2} \mathrm{O}_{3}$ by ion implantation and annealing
}

\author{
X. Xiang ${ }^{1}$, Y. Zhang ${ }^{2}$, S. Zhu ${ }^{1}$, L.M. Wang ${ }^{1}$, V. Shutthanandan ${ }^{2}$, P. Nachimuthu ${ }^{2}$ \\ ${ }^{1}$ Department of Nuclear Engineering and Radiological Sciences, University of \\ Michigan, Ann Arbor, MI48109, USA; \\ ${ }^{2}$ Pacific Northwest National Laboratory, P.O. Box 999, Richland, Washington \\ 99352
}

\begin{abstract}
Nearly spherical metallic tetragonal Sn nanoparticles with size of $\sim 15 \mathrm{~nm}$ in diameter are produced in $\mathrm{Al}_{2} \mathrm{O}_{3}$ by direct $\mathrm{Sn}$ implantation at room temperature. After thermal annealing at $1000{ }^{\circ} \mathrm{C}$ in oxygen, $\mathrm{SnO}_{2}$ nanoparticles are formed. As the $\mathrm{Sn}$ atoms migrates $\sim 10 \mathrm{~nm}$ towards the surface during the annealing, the total content of Sn decreases slightly. Furthermore, the implantation-induced amorphous region recrystallized and the Sn nanoparticles turned into $\mathrm{SnO}_{2}$ nanoparticles with a lager size of $\sim 30 \mathrm{~nm}$ in diameter. While, none absorption and photoluminescence are observed for the metallic $\mathrm{Sn}$ nanoparticles. $\mathrm{SnO}_{2}$ nanoparticles exhibit an absorption edge at $\sim 280 \mathrm{~nm}$ and three emission bands at 410, 520 and $700 \mathrm{~nm}$, respectively. Except the blue and green emission reported before, a red photoluminescence band of $\mathrm{SnO}_{2}$ nanoparticles was observed for the first time due to the new trapped states within the band gap that are introduced by ion implantation.
\end{abstract}

\section{Introduction}

Nanostructured oxides have attracted great interests due to their unique properties and novel applications. In recently years, oxides have become the basis of smart and 
functional materials. As a n-type semiconductor with a wide band gap $3.6 \mathrm{eV}$ at room temperature, excellent photoelectric properties and gas sensitivities, $\mathrm{SnO}_{2}$ is one of the promising materials for optoelectronic devices, transparent conductor, gas sensors, etc. ${ }^{1-3}$ A variety of methods, such as chemical vapor deposition, vapor-liquid-solid approach, rapid thermal evaporation, sol-gel were used to prepare various $\mathrm{SnO}_{2}$ nanostructures, including nanowires, nanobelts, nanorods, nanoribbons, nanopowders. ${ }^{4-9}$

As a versatile and powerful technique for forming nanoparticles, ion implantation was utilized to prepare dispersed metallic and oxide nanoparticles in insulator substrates. To date, $\mathrm{NiO}, \mathrm{ZnO}, \mathrm{CuO}, \mathrm{Cu}_{2} \mathrm{O}$, and $\mathrm{VO}_{2}$ nanoparticles have been prepared in $\mathrm{SiO}_{2}$, sapphire or $\mathrm{CaF}_{2}$ substrates by ion implantation and subsequent annealing. ${ }^{10-16} \mathrm{In}$ contrast, there are few reports on $\mathrm{SnO}_{2}$ nanoparticles prepared by ion implantation and annealing. Moreover, ion implantation is essentially a brute force (athermal) process involving individual atoms, which is not restricted by the laws of thermodynamics governing equilibrium processes. For example, the implanted ions can be placed at any desirable location and to any desired concentration in a solid material (within the limitations of available ion energy) without being restricted by diffusivity constants or solubility constants. Therefore, ion implantation will introduce a large amount of point defects, e.g., $\mathrm{O}$ vacancies, in the substrates. The point defects will probably change the optical properties of the materials and even create new luminescence.

In this work, we reported the fabrication and characterization of metallic $\mathrm{Sn}$ and $\mathrm{SnO}_{2}$ nanoparticles by room-temperature ion implantation and subsequent thermal annealing. Optical absorption and photoluminescence of $\mathrm{SnO}_{2}$ nanoparticles embedded in sapphire were studied. The emission of $\mathrm{SnO}_{2}$ had been reported form $\mathrm{UV}$ to orange wavelength 
PNNL-17069

region. In this study, the red emission was observed for the $\mathrm{SnO}_{2}$ nanoparticles fabricated in sapphire by ion implantation and annealing.

\section{Experimental}

Optical polished (0001) $\alpha-\mathrm{Al}_{2} \mathrm{O}_{3}$ single crystals (sapphire), $10 \times 10 \times 0.5 \mathrm{~mm}$ in dimensions, were implanted with $\mathrm{Sn}$ ions of $60 \mathrm{keV}$ at a fluence of $1 \times 10^{17} \mathrm{~cm}^{-2}$ in a vacuum chamber of $1.8 \times 10^{-3} \mathrm{~Pa}$. The samples were kept at room temperature with the circulation of cooling water during ion implantation. The ion flux was limited at $\sim 5$ $\mu \mathrm{A} / \mathrm{cm}^{2}$ in order to avoid over heating the samples. The samples were tilted off-axis by about $7^{\circ}$ to avoid the channeling implantation. After that, the as-implanted samples were annealed for $1 \mathrm{hr}$ in a quartz tube furnace at $1000{ }^{\circ} \mathrm{C}$ under flowing $\mathrm{O}_{2}$ atmosphere. The heating rate was controlled at $10{ }^{\circ} \mathrm{C} / \mathrm{min}$.

Rutherford backscattering spectrometry (RBS) studies were performed with a $2.0 \mathrm{MeV}$ $\mathrm{He}^{+}$beam for the as-implanted and annealed samples. The spectra were collected using a Si surface barrier detector positioned at $165^{\circ}$ relative to the beam direction. Grazing incidence X-ray diffraction (GIXRD) measurements were conducted with a Philips X'Pert diffractometer with a $\mathrm{Cu} K_{\alpha}$ line of $1.5406 \AA$. The A JEM $2010 \mathrm{~F}$ field emission gun electron microscope operating at $200 \mathrm{keV}$ was used for bright-field TEM, selected area electron diffraction (SAED) and high-resolution electron microscopy (HREM). TEM samples were prepared in cross-section to allow observation of depth distribution of nanoparticles and radiation damage. Optical absorption measurements were performed in the 200 to $800 \mathrm{~nm}$ wavelength range at room temperature, with a SHIMADZU UV-2550 double beam spectrophotometer. Room temperature photoluminescence (PL) was excited 
by the $325 \mathrm{~nm}$ line $(3.81 \mathrm{eV})$ from a $\mathrm{He}-\mathrm{Cd}$ laser with the excitation power of $65 \mathrm{~mW}$. The spectra were detected by a SPEX 1403 double grating monochromator and a CCD array and recorded in the range from 350 to $900 \mathrm{~nm}$.

\section{Results}

In order to determine the success of incorporation of $\mathrm{Sn}$ ions implanted into $\mathrm{Al}_{2} \mathrm{O}_{3}$, as

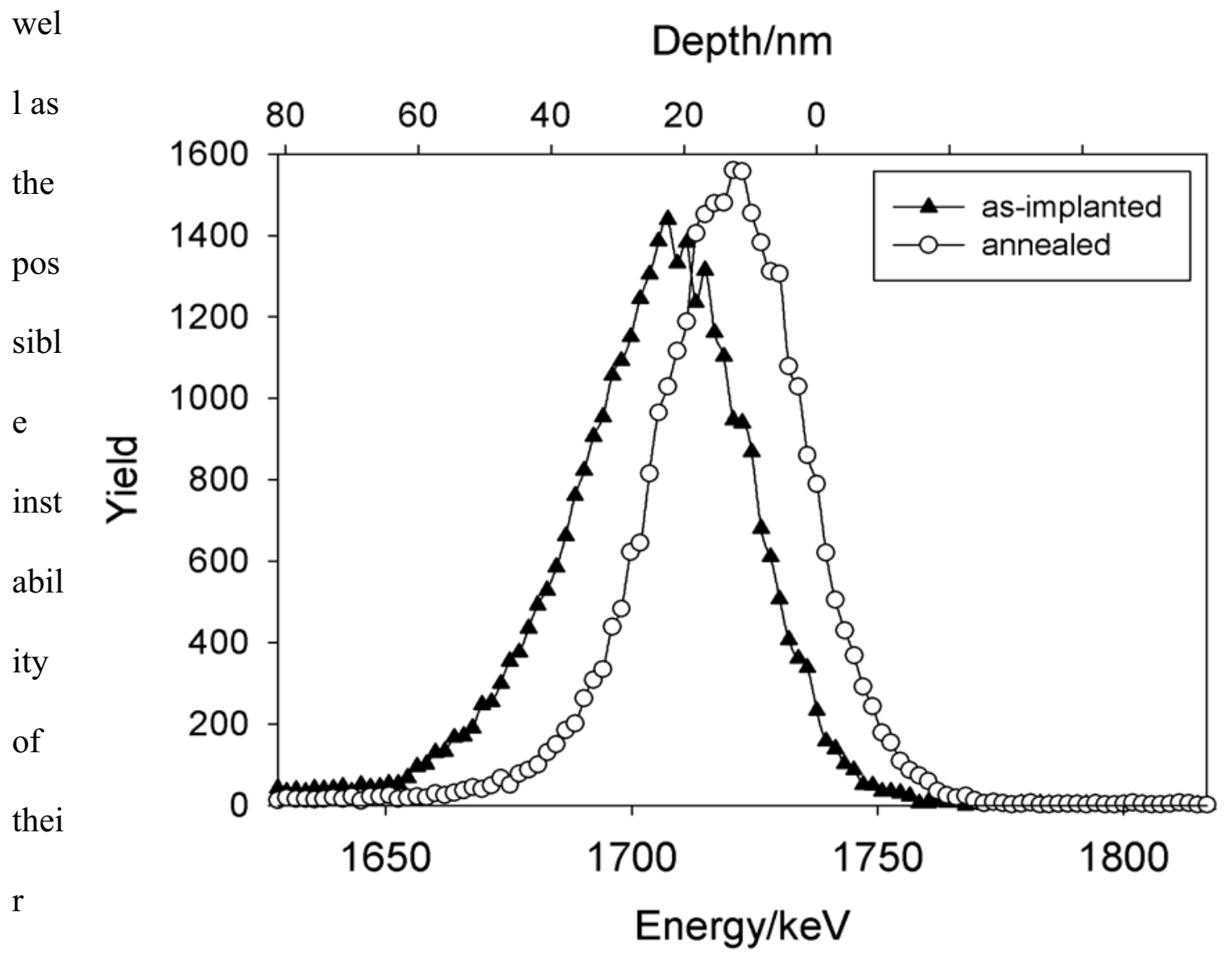

pos FIG. 1. Rutherford backscattering spectra of the Sn ion-implanted and itio annealed $\mathrm{Al}_{2} \mathrm{O}_{3}$ crystals showing the edge of Sn shifting towards the surface $\mathrm{n}$ or even loss from the implanted layer due to the thermal annealing, the RBS measurements were performed. The RBS spectra of the as-implanted and annealed 
samples are shown in Fig. 1. It shows that the implanted ions were indeed incorporated into the $\mathrm{Al}_{2} \mathrm{O}_{3}$ substrates even at a high fluence of $1 \times 10^{17} \mathrm{~cm}^{-2}$. After thermal annealing, the implanted $\mathrm{Sn}$ atoms shifted towards the surface of the $\mathrm{Al}_{2} \mathrm{O}_{3}$ substrate by $\sim 10 \mathrm{~nm}$. From the calculation of the integrated area of Sn element peak, the content of tin decreased slightly after annealing, showing a small amount of tin $(\sim 4.7 \%)$ was lost during the thermal annealing at $1000{ }^{\circ} \mathrm{C}$.

Grazing incidence XRD is a useful method to characterize the crystalline structure in the thin implanted layers. The GIXRD patterns of the as-implanted and annealed samples are shown in Fig. 2. From the patterns, tetragonal metallic tin crystals formed in the Sn ion implanted sample. After thermal annealing, metallic tin crystals were oxidized into

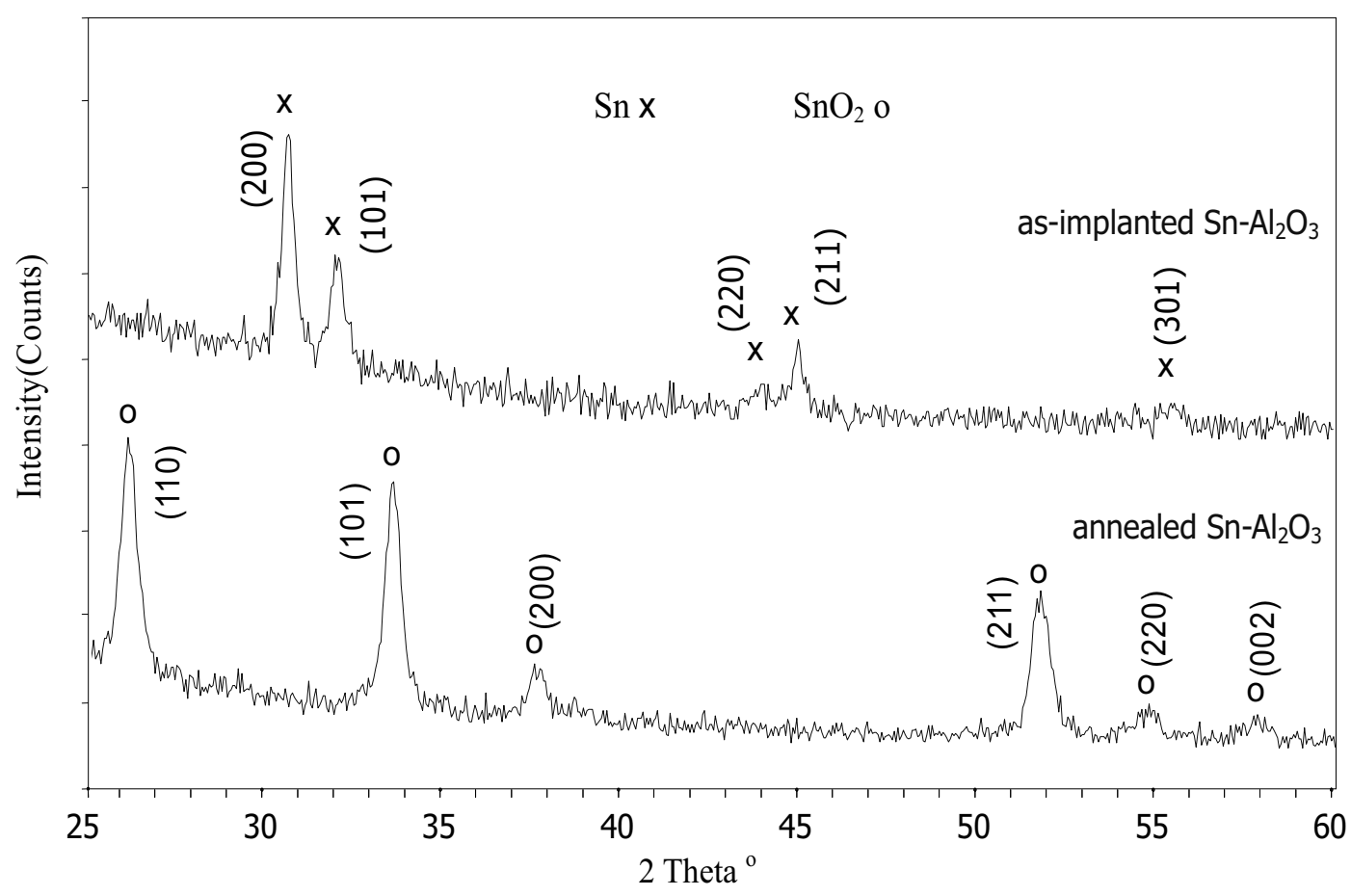

FIG. 2. GIXRD patterns of the as-implanted and annealed samples indicating the formation of tetragonal metallic tin and $\mathrm{SnO}_{2}$ crystals, respectively. 
tetragonal rutile-structured $\mathrm{SnO}_{2}$ crystals, which agree well with the reported values from $^{17}$.

Figure 3(a) shows a bright-field cross-sectional image of the as-implanted sample. The results indicate size and distribution of the embedded metallic Sn nanoparticles. Nearly spherical nanoparticles are distributed from the surface to $\sim 40 \mathrm{~nm}$ below the surface. The depth distribution of Sn from the RBS results is consistent with the predicted range $22.4 \mathrm{~nm}$ by SRIM 2006 code. ${ }^{18}$ This indicates that there is no distinct sputtering effect on the surface of the substrate during ion implantation. The size of nanoparticles, as shown in Fig. 3(a), ranges from a few nanometer to $15 \mathrm{~nm}$ in diameter. The selected area electron diffraction (SAED) pattern (inset) confirms that the nanoparticles are in metallic form. A HREM image (not shown) indicated the implanted area is amorphized. Figure 3(b) is a bright-field cross-sectional image and a SAED pattern (inset) of the annealed sample. Irregular-shape $\mathrm{SnO}_{2}$ nanoparticles with a larger size of $\sim 30 \mathrm{~nm}$ in diameter are observed after annealing. This is consistent with the GIXRD results. The Furthermore, the nanoparticles migrate towards the surface of the substrate during the high temperature annealing. This result is consistent with the RBS data (not shown), which indicated that the implanted Sn atoms move towards the surface of the sapphire substrate by $\sim 10 \mathrm{~nm}$. HREM image (not shown) indicates that the amorphous layer is recrystallized after annealing. 
PNNL-17069

Room-temperature optical absorption (a) and photoluminescence (b) spectra of as- 
PNNL-17069

implanted and annealed $\mathrm{Al}_{2} \mathrm{O}_{3}$ crystals are shown in Fig. 4. The absorption spectrum of 
the as-implanted sample, the background absorption drastically increased with increasing

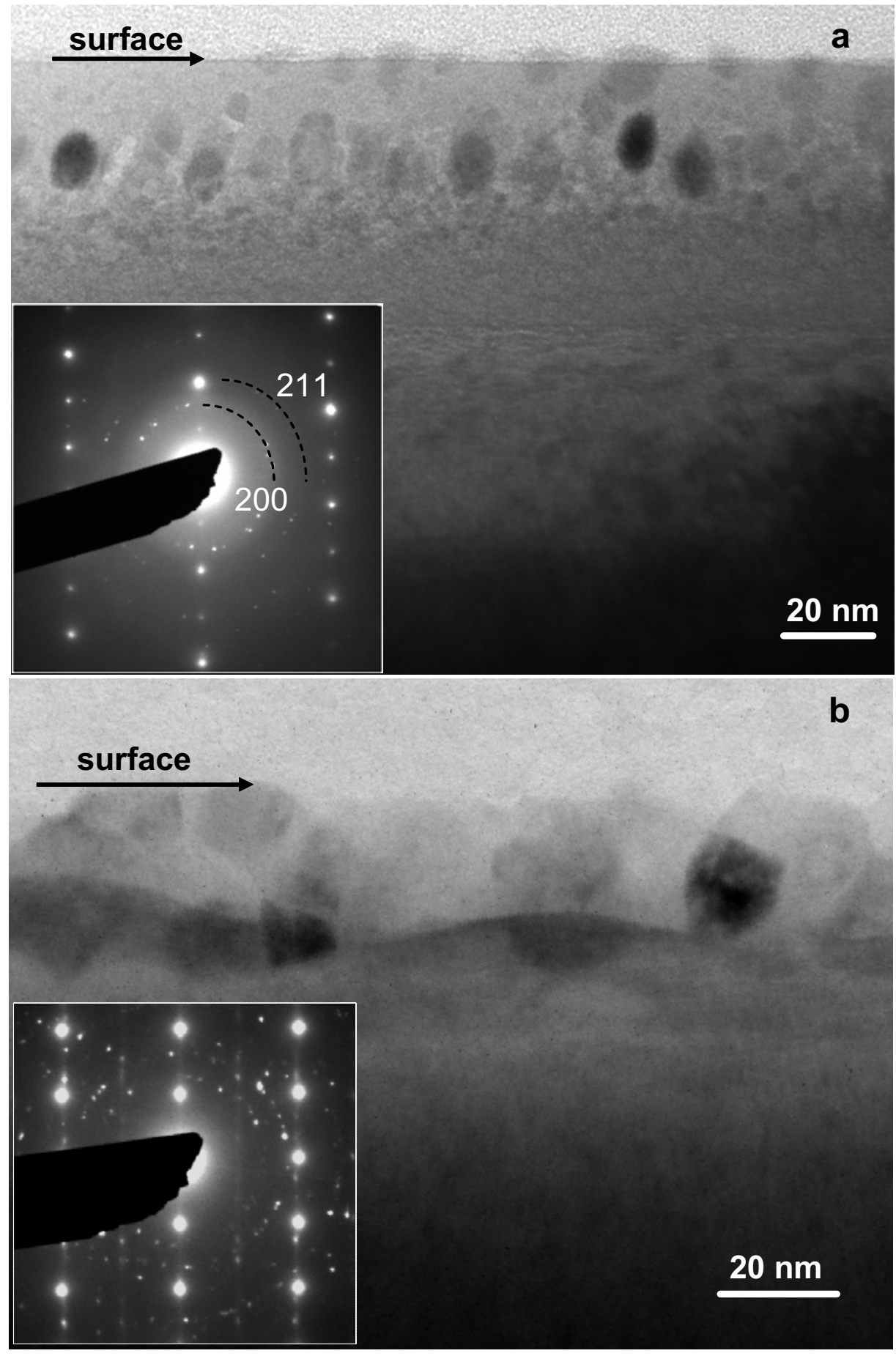

FIG. 3. Bright-field cross-sectional images of as-implanted (a) and annealed (b) samples showing the size and distribution of nanoparticles. The inset ones are selected area electron diffraction patterns of metallic $\mathrm{Sn}$ and $\mathrm{SnO}_{2}$ nanoparticles in $\mathrm{Al}_{2} \mathrm{O}_{3}$ single crystals. 
energy in the UV waveband. In addition, a weak absorption edge appeared at $\sim 400 \mathrm{~nm}$ and a weaker edge at $\sim 280 \mathrm{~nm}$, which are attributed to the small amount of $\mathrm{SnO}$ and $\mathrm{SnO}_{2}$ formed during ion implantation, respectively. This is consistent with the absorption feature of the $\mathrm{SnO}$ and $\mathrm{SnO}_{2}$ nanocrystalline powders. ${ }^{19} \mathrm{SnO}$ and $\mathrm{SnO}_{2}$ peaks are not observed in GIXRD measurements, which may due to low concentration or amorphous nature of the materials. The optical absorption spectra of as-implanted sample did not show any absorption band of metallic tin. This is different from the optical absorption spectra of $\mathrm{Ni}$ and $\mathrm{Zn}$ ions implanted $\mathrm{Al}_{2} \mathrm{O}_{3}$ samples, in which the surface plasmon resonance (SPR) absorption bands had been observed at $\sim 400$ and $\sim 285 \mathrm{~nm}$, respectively. ${ }^{12,20}$ However, such bands have not been observed in Sn-implanted $\mathrm{SiO}_{2}$ samples. ${ }^{21-22}$ It is well known that the Mie scattering theory can predict the wavelength of SPR absorption peak by the formula: $\varepsilon_{1}+2 n_{d}{ }^{2}=0$, where $\varepsilon_{1}$ is the real part of dielectric function of nanoparticles and $n_{d}$ is the refractive index of the surrounding dielectric matrix. However, because $\varepsilon_{1}$ of $\mathrm{Sn}$ is larger than zero in the visible and IR regions, it is impossible to observe the SPR absorption band of Sn nanoparticles. ${ }^{21}$ After annealing at $1000{ }^{\circ} \mathrm{C}$ in $\mathrm{O}_{2}$, the metallic $\mathrm{Sn}$ and $\mathrm{SnO}$ were oxidized to $\mathrm{SnO}_{2}$ nanocrystals and its absorption edge at $\sim 280 \mathrm{~nm}$ became clear, as shown in Fig. 4(a). The absorption intensity of the annealed sample is smaller than that of the as-implanted one. The content of Sn decreases slightly with a small amount of tin ( 4.7\%) lost after annealing at $1000{ }^{\circ} \mathrm{C}$. Such small loss can not account for the significant drop of the intensity. The decrease of intensity should be due to the decrease of background absorption.

As shown in Fig. 4(b), the PL spectra of the as-implanted and annealed samples are similar except for intensities. There are three emission bands peaked at 410, 520 and 700 
PNNL-17069
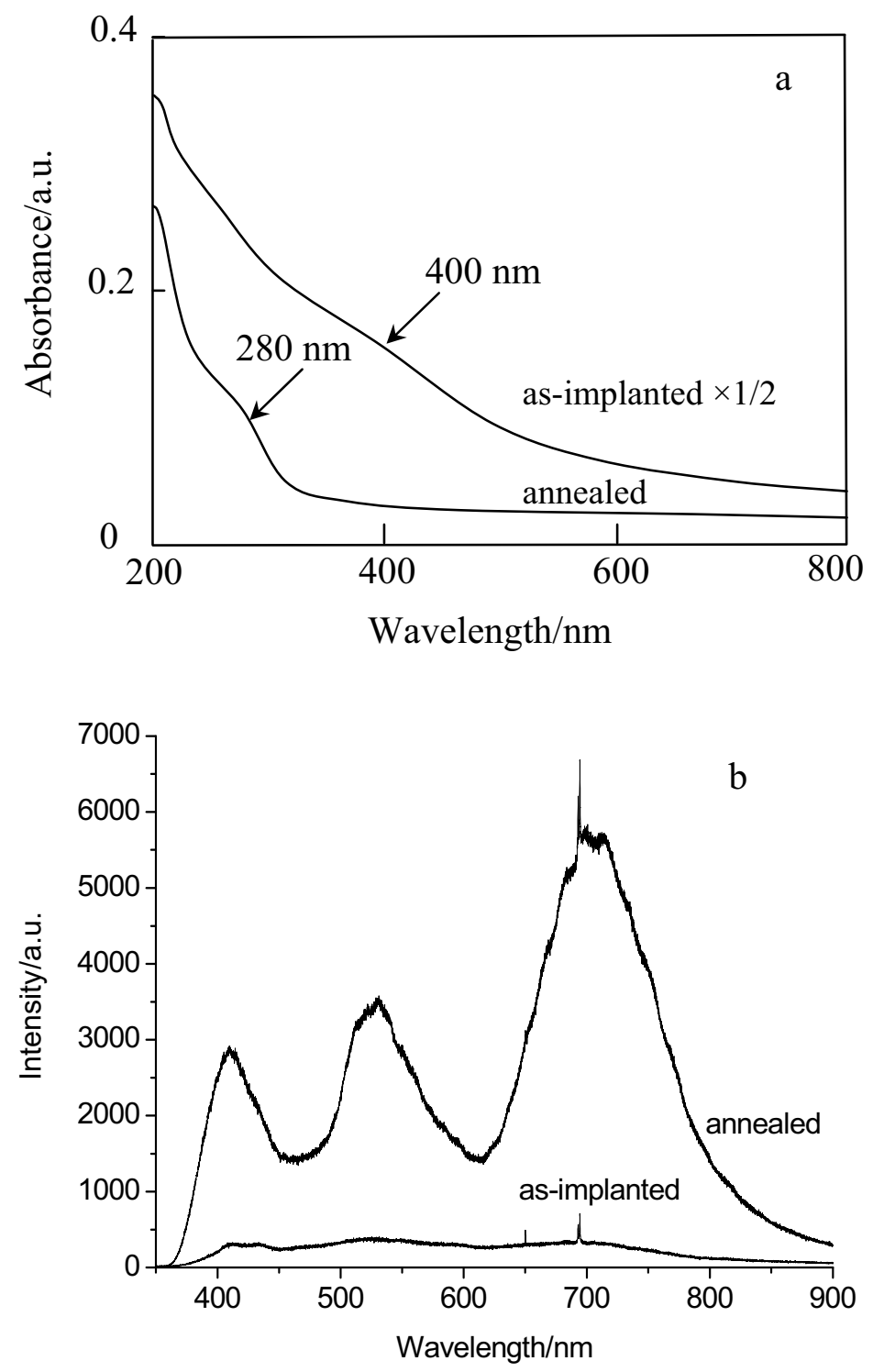

FIG. 4. Optical absorption (a) and photoluminescence (b) spectra of as-implanted and annealed samples. $\mathrm{SnO}_{2}$ nanoparticles exhibit an absorption edge at $\sim 280 \mathrm{~nm}$ and three emission bands at 410, 520 and $700 \mathrm{~nm}$, respectively.

$\mathrm{nm}$ in the both spectra. It should be pointed out that the sharp and small emission peak at $\sim 690 \mathrm{~nm}$ is due to the intrinsic impurity $\mathrm{Cr}^{3+}$ ions present in as-grown $\mathrm{Al}_{2} \mathrm{O}_{3}$ single crystals. In our earlier work, a very weak PL band peaked at $\sim 470 \mathrm{~nm}$ was reported in the $\mathrm{Zn}$ ion implanted crystal, which is attributed to the PL combination of both $\mathrm{F}$ and $\mathrm{F}_{2}$ 
centers coexisted in $\mathrm{Al}_{2} \mathrm{O}_{3}$ induced by ion implantation. ${ }^{12}$ However, this PL band of color centers did not appeared in the Sn ion implanted sample in this work. It is reported that $\mathrm{Sn}$ and $\mathrm{SnO}$ could completely form pure $\mathrm{SnO}_{2}$ after annealing at temperatures higher than 550 or $600{ }^{\circ} \mathrm{C}$ in an oxidized atmosphere. ${ }^{23-24}$ In this study, the absorption edge at $\sim 400$ $\mathrm{nm}$ resulted from $\mathrm{SnO}$ disappeared after annealing at $500{ }^{\circ} \mathrm{C}$ in $\mathrm{O}_{2}$ (not shown), showing that the $\mathrm{SnO}$ nanoparticles had been oxidized into $\mathrm{SnO}_{2}$ at this temperature. Therefore, the emission bands are most likely related to $\mathrm{SnO}_{2}$ nanoparticles. The three weak emission bands, as well as the absorption spectra, have also confirmed that there was a small amount of $\mathrm{SnO}_{2}$ formed in the as-implanted sample that is below the detection limit though of the GIXRD measurements.

In the past several decades, the luminescence mechanisms of $\mathrm{SnO}_{2}$ have been studied. Literature results have shown complex emission bands ranging from 318 to $640 \mathrm{~nm}^{4-9}$ Among of them, S. Brovelli et al. reported that the $318 \mathrm{~nm}(3.9 \mathrm{eV})$ emission was the evidence of free-exciton decay in $\mathrm{SnO}_{2}$, with a energy shift of $0.3 \mathrm{eV}$ with respect to the bulk gap energy $(3.6 \mathrm{eV}) .{ }^{8}$ This emission is not observed in our work because of the limit of the PL detection range with a He-Cd $325 \mathrm{~nm}$ excitation resource. In general, except the sharp excitonic emission, semiconductor has another broad trapped emission, which often contains multiple luminescent centers. As for $\mathrm{SnO}_{2}$, the trapped emission is complicated. For example, $\mathrm{SnO}_{2}$ nanopowders has showed two distinct PL emissions at 400 and 430 nm. ${ }^{9}$ Three emission peaks at 439,486 , and $496 \mathrm{~nm}$ were observed in the as-synthesized $\mathrm{SnO}_{2}$ nanoribbons. ${ }^{6}$ Two main optical emissions at 452 and $560 \mathrm{~nm}$ were found by $\mathrm{CL}$ spectroscopy for the $\mathrm{SnO}_{2}$ nanowires and nanobelts grown onto $\mathrm{Al}_{2} \mathrm{O}_{3}, \mathrm{SiO}_{2}$ and $\mathrm{Si}$ substrates. ${ }^{4}$ The beaklike nanorods exhibited a strong emission peak at $602 \mathrm{~nm}$ and the 
PNNL-17069

field-emission properties. ${ }^{5}$ A broad yellow emission at a wavelength of around $597 \mathrm{~nm}$ as well as a small orange emission shoulder at $640 \mathrm{~nm}$ were reported in the nanostructured fishbone-like $\mathrm{SnO}_{2}{ }^{7} \mathrm{Up}$ to now, the mechanism of observed emissions is not yet clear. However, it should be associated with defect energy levels within the band gap of $\mathrm{SnO}_{2}$. Oxygen vacancies are well known to be the most common defects and usually act as radiative centers in luminescence processes. Thus, the nature of the transition is tentatively ascribed to oxygen vacancies, tin vacancies or $\mathrm{Sn}$ interstitials, which form a considerable amount of trapped states within the band gap. ${ }^{4-9}$ These trapped states contribute to the emission bands above. In this work, the two emission bands at $410 \mathrm{~nm}$ (blue) and $520 \mathrm{~nm}$ (green) should also be ascribed to the similar luminescence centers as discussed above. The newly observed one at $700 \mathrm{~nm}$ (red) exhibited a red shift in comparison with those of previous studies. The red shift should be related to the new trapped states within the band gap induced by ion implantation. Moreover, ion implantation introduced a large amount of point defects in substrates. The point defects formed defect levels located in the band gap, trapping electrons from the valence band to make contribution to the luminescence. The energy level of the point defects induced by implantation should be different from those of defects induced by other synthesis methods. In this study, the defects induced by implantation have smaller transition energy from the valence band than those induced by other methods. Further systematic study on luminescence centers and trapped states are needed to reveal the mechanism of observed emissions.

\section{Conclusion}


PNNL-17069

Tetragonal Sn nanoparticles with size of $\sim 15 \mathrm{~nm}$ in diameter were successfully fabricated in $\alpha-\mathrm{Al}_{2} \mathrm{O}_{3}$ single crystals after ion implantation at room temperature and tetragonal $\mathrm{SnO}_{2}$ nanoparticles with a lager size of $\sim 30 \mathrm{~nm}$ formed after thermal annealing in oxygen atmosphere. Nanoparticles migrated towards the surface and the content of tin decreased slightly after annealing. $\mathrm{SnO}_{2}$ nanoparticles exhibited an absorption edge at $\sim 280 \mathrm{~nm}$ and three emission bands at 410, 520 and $700 \mathrm{~nm}$, respectively. The emission of $\mathrm{SnO}_{2}$ had been reported form UV to orange wavelength region. In this study, the red emission was observed for the $\mathrm{SnO}_{2}$ nanoparticles fabricated in sapphire by ion implantation and annealing.

This study was supported by the U.S. Department of Energy under Grant No. DEFG0202ER46005 and by the operational support for the EMSL accelerator by the Office of Biological and Environmental Research, US Department of Energy.

\section{References:}

${ }^{1}$ J. S. Lee, S. K. Sim, B. Min, K. Cho, S. W. Kim, S. Kim, J. Crystal Growth, 267, 145 (2004).

${ }^{2}$ A. Benshaloma, L. Kaplan, R. L. Boxman, S. Goldsmith, M. Nathan, Thin Solid Films, 236, 20 (1993).

${ }^{3}$ S. Choudhury, C. A. Betty, K. G. Girija, S. K. Kulshreshtha, Appl. Phys. Lett., 89, 071914 (2006).

${ }^{4}$ D. Calestani, L. Lazzarini, G. Salviati, and M. Zha, Cryst. Res. Technol. 40, 937 (2005). 
${ }^{5}$ Jr H. He, Te H. Wu, Cheng L. Hsin, Kun M. Li, Lih J. Chen, Yu L. Chueh, Li J. Chou, and Zhong L. Wang, Small, 2, 116 (2006).

${ }^{6}$ J. Q. Hu, X. L. Ma, N. G. Shang, Z. Y. Xie, N. B. Wong, C. S. Lee, and S. T. Lee, J. Phys. Chem. B, 106, 3823 (2002).

${ }^{7}$ H. W. Kim, N. H. Kim, J. H. Myung, and S. H. Shim, Phys. Stat. Sol. A, 202, 1758 (2005).

${ }^{8}$ S. Brovelli, N. Chiodini, F. Meinardi, A. Lauria, and A. Paleari, Appl. Phys. Lett., 89, 153126 (2006).

${ }^{9}$ F. Gu, S. F. Wang, C. F. Song, M. K. Lv, Y. X. Qi, G. J. Zhou, D. Xu, D. R. Yuan, Chem. Phys. Lett., 372, 451 (2003).

${ }^{10}$ H. Amekura, N. Umeda, Y. Takeda, J. Lu, and N. Kishimoto, Appl. Phys. Lett. 85, 1015 (2004).

${ }^{11}$ H. Amekura, N. Umeda, Y. Sakuma, N. Kishimoto, and Ch. Buchal, Appl. Phys. Lett. 87, 013109 (2005).

${ }^{12}$ X. Xiang, X. T. Zu, S. Zhu, Q. M. Wei, C. F. Zhang, K. Sun, L. M. Wang, Nanotech, 17, 2636 (2006).

${ }^{13}$ Y. C. Liu, H. Y. Xu, R. Mu, D. O. Henderson, Y. M. Lu, J. Y. Zhang, D. Z. Shen, X. W. Fan, and C. W. White, Appl. Phys. Lett. 83, 1210 (2003).

${ }^{14}$ M. Ikeyama, S. Nakao, M. Tazawa, Surf. and Coat. Tech. 158-159, 720 (2002).

${ }^{15}$ S. Nakao, S. X. Wang, L. M. Wang, M. Ikeyama, Y. Miyagawa, S, Miyagawa, Nucl. Instr. and Meth. in Phys. Res. B 175-177, 202 (2001).

${ }^{16}$ R. Lopez, L. A. Boatner, T. E. Haynes, L. C. Feldman and R. F. Haglund, Jr., J. Appl. Phys. 92, 4031 (2002). 
${ }^{17} \mathrm{Sn}$ : JCPDF card 04-0673; $\mathrm{SnO}_{2}$ : JCPDS card 41-1445.

${ }^{18}$ J. F. Ziegler, J. P. Biersack, U. Littmark, The Stopping and Range of Ions in Solids, Pergamon Press, New York, 1985; http://www.srim.org/.

${ }^{19}$ H. M. Deng and J. M. Hossenlopp, J. Phys. Chem. B, 109, 66 (2005).

${ }^{20}$ X. Xiang, X. T. Zu, S. Zhu and L. M. Wang, Appl. Phys. Lett. 84, 52 (2004).

${ }^{21}$ J. P. Zhao, Y. Meng, D. X. Huang, and W. K. Chu, J. Vac. Sci. Technol. B, 25, 796 (2007).

${ }^{22}$ D. Ila, E. K. Williams, S. Sarkisov, C. C. Smith, D. B. Poker, D. K. Hensley, Nucl. Instr. and Meth. in Phys. Res. B 141, 289 (1998).

${ }^{23}$ L. Sangaletti, L. E. Depero, B. Allieri, F. Pioselli, E. Comini, G. Sberveglieri, and M. Zocchi, J. Mater. Res., 13, 2457 (1998).

${ }^{24}$ W. K. Choi, H. Sung, K. H. Kim, J. S. Cho, S. C. Choi, H.-J. Jung, S. K. Koh, C. M. Lee, and K. Jeong, J. Mater. Sci. Lett., 16, 1551 (1997). 
PNNL-17069

\title{
Conductivity Studies in Oriented Samaria-Doped Ceria Thin Films Grown
}

\section{by Oxygen-plasma-assisted Molecular Beam Epitaxy}

\author{
Z.Q. Yu ${ }^{\text {a }}$, L.V. Saraf ${ }^{\mathrm{b}}$, O.A. Marina ${ }^{\mathrm{b}}$, C.M. Wang ${ }^{\mathrm{b}}$, M.H. Engelhard ${ }^{\mathrm{b}}$, V. \\ Shutthanandan $^{\mathrm{b}}$, P. Nachimuthu ${ }^{\mathrm{b}}$ and S. Thevuthasan ${ }^{\mathrm{b}}$
}

(a) Department of Chemistry, Nanjing Normal University, Nanjing 210097, China

(b) Pacific Northwest National Laboratory, Richland, WA 99352, USA

\begin{abstract}
We used oxygen-plasma-assisted molecular beam epitaxy (OPA-MBE) to grow highly oriented $\mathrm{Ce}_{1-\mathrm{x}} \mathrm{Sm}_{\mathrm{x}} \mathrm{O}_{2-\delta}$ films on single crystal c- $\mathrm{Al}_{2} \mathrm{O}_{3}$. The samarium concentration, $\mathrm{x}$, was varied in the range $1-33$ atom $\%$. It was observed that dominant (111) orientation in $\mathrm{Ce}_{1-\mathrm{x}} \mathrm{Sm}_{\mathrm{x}} \mathrm{O}_{2-\delta}$ films can be maintained up to about 10 samarium atom\% concentration. Films higher than 10 atom $\%$ Sm concentration started to show polycrystalline features. The highest conductivity of $0.04 \mathrm{~S} . \mathrm{cm}^{-1}$ at $600{ }^{0} \mathrm{C}$ was observed for films with 5 atom\% Sm concentration. A loss of orientation triggering an enhanced grain boundary scattering appears to be responsible for the decrease in conductivity at higher dopant concentrations.
\end{abstract}


PNNL-17069

\section{Key Words: Samaria doped ceria; Ionic Conductivity; MBE, Thin film electrolyte}

\section{Introduction}

State-of-the-art solid oxide fuel cells (SOFCs) are based upon oxygen ion conducting zirconia based electrolytes like yttria-stabilized zirconia (YSZ) operating at $750-1000{ }^{\circ} \mathrm{C}$. High operating temperatures impose severe limitations on a use of other SOFC constituents, in particular, the interconnect materials. The inexpensive metal interconnect is susceptible to oxidation at temperatures above $600^{\circ} \mathrm{C}$, and complex ceramic coatings

are required to protect metals from oxidation. At temperatures above $800{ }^{0} \mathrm{C}$, most metals (except the noble ones) are unstable and only relatively pricey conductive ceramics can be applied in SOFCs. Development of electrolyte materials that possess high oxygen ion conductance at lower temperatures would broaden the materials selection and possibly expand the applications. It would potentially have a positive effect on the SOFC lifetime as high temperatures significantly contribute to the materials degradation and detrimental interfacial reactions. Doped $\mathrm{CeO}_{2}$ have been considered for use as an SOFC electrolyte due to its high ionic conductivity at intermediate operating temperatures.[1-3] Various dopants like samaria and gadolinia have been used in bulk as well as thin films and samaria-doped ceria showed slightly higher ionic conductivity compared to others.

Since ways of preparing polycrystalline samples in different techniques partly affect conductivity, the discrepancy in the data produced by different growth techniques can be minimized by growing oriented or epitaxial films. Oriented or epitaxial films reduce the grain boundary density and thus reduce the scattering across them increasing 
the oxygen ionic conductivity. [4] Although molecular beam epitaxy (MBE) is an expensive and time consuming growth technique, it is ideally suited to grow high quality complex oxide films with highly oriented single crystal structures needed for fundamental science investigations. Since most of the data in the literature is focused on the polycrystalline $\mathrm{Gd}_{2} \mathrm{O}_{3}$-doped $\mathrm{CeO}_{2}, \mathrm{Sm}_{2} \mathrm{O}_{3}$-doped $\mathrm{CeO}_{2}$ and pure ceria, the aim of this study was to study highly oriented $\mathrm{Sm}_{2} \mathrm{O}_{3}$-doped $\mathrm{CeO}_{2}$ films on the c-plane single crystal sapphire substrates grown by oxygen plasma assisted MBE (OPA-MBE).[5-15] Other substrates such as single crystal YSZ, which assist in achieving better epitaxial growth of these materials can not be used due to their own ionic conductivity contribution in the measurements. We have found that the conductivity value peaks at $\sim 5$ atom $\%$ samarium dopant concentration with a total conductivity of $0.04 \mathrm{~S} / \mathrm{cm}$ at $600{ }^{0} \mathrm{C}$. Since the oxygen vacancy concentration increases as a function of dopant concentration, for dopant concentration less than 5 atom\%, conductivity appears to be increasing as a function of samarium concentration. Also the loss of structural orientation associated with the high concentration of samaria increases the population of grain boundaries and reduces the conductivity of these films.

\section{Experimental Procedure}

The films were grown in a dual-chamber ultrahigh vacuum (UHV) system equipped with an electron cyclotron resonance (ECR) oxygen plasma source. Ultrasonically cleaned $\mathrm{Al}_{2} \mathrm{O}_{3}(0001)$ single crystals in acetone and methanol were used to grow films. After the surface plasma cleaning at $600^{\circ} \mathrm{C}$, films were grown at simultaneous growth rates of 0.2 and $0.01 \mathrm{~nm} / \mathrm{s}$ for ceria and samaria, respectively in an oxygen partial pressure of $\sim 2.0 \times 10^{-5}$ Torr and at a substrate temperature of $650^{\circ} \mathrm{C}$. Cerium $(99.98 \%$ purity) and 
samarium (99.98\% purity) were evaporated from an e-bam source and an effusion cell, respectively. The growth rates of the films were monitored by quartz crystal oscillators (QCOs). The in-situ film growth was monitored using reflection high energy electron diffraction (RHEED). The details of the OPA-MBE system along with growth capabilities are discussed elsewhere.[16-18]. X-ray photoelectron spectroscopy (XPS) measurements were performed to determine the oxidation state of elements and the elemental distribution throughout the film using sputter depth profiling. The ion beam sputter rate was calibrated $\sim 4.6 \mathrm{~nm} / \mathrm{min}$ by using a known thickness of $\mathrm{SiO}_{2} / \mathrm{Si}$ reference material.

The conductivity in these films was determined using the four-terminal Van der Pauw technique. [19] Four identical Au electrodes-terminals were spring-loaded to the ceria film. Probe tips were polished to reduce the Ohmic contact resistance. The separation between the probes was kept nearly even and significantly larger than the thickness of the film. Characteristic resistances $R_{1}, R_{2}, R_{3}, R_{4}$, associated with the corresponding terminals $1,2,3$ and 4 were measured in the temperature range $300-900^{\circ} \mathrm{C}$ using an ac electrochemical impedance spectroscopy technique. Each $\mathrm{R}$ was found as the distance from the low frequency intercept and the origin (high frequency intercept) of the real part of the corresponding impedance spectra. The difference between all four resistances was within $10-15 \%$. Thus, the assumption for symmetrical geometry was made and the electrical conductivity $\sigma$, was calculated using the van der Pauw equation:

$$
1 / \sigma=\pi \mathrm{dR}_{\mathrm{s}} / \ln (2)
$$

where $R_{s}$ is sheet resistance, $d$ is the thickness of the film, $\pi=3.14$. It has been shown that the use of the ac impedance spectroscopy technique may cause the parasitic inductive 
PNNL-17069

effects in both low and high frequencies. [20] Indeed; small inductive loops were periodically observed in the high frequency part. However, the size of these loops was negligible compared to the rest of the impedance spectra and those contributions were not taken into account.

\section{Results and discussion}

The structural characterizations of samaria-doped ceria films were analyzed by $\mathrm{x}$-ray diffraction (XRD, Phillips X'pert $\theta-2 \theta$ diffractometer) and high-resolution transmission electron microscopy (HRTEM, JEOL 2010 microscope). Rutherford backscattering spectrometry (RBS) measurements were carried out to investigate the interfacial diffusion along with the film thickness and stoichiometry. XRD measurements indicated that the film was predominantly oriented with the $\mathrm{CeO}_{2}(111)$ plane parallel to the substrate basal plane. This is typically revealed by the $2 \theta$ scan for samaria-doped ceria film with $5 \mathrm{Sm}^{3+}$ atom $\%$ concentrations as shown in Figure 1. The inset in Figure 1 represents the selected area electron diffraction pattern obtained from the cross-sectional TEM specimen. In this diffraction pattern, the zone axes for the fluorite structured samariadoped $\mathrm{CeO}_{2}$ film and the sapphire substrate are [110] and [11-20], respectively. Selected area electron diffraction pattern shows the orientation relationship: $\mathrm{CeO}_{2}[110] / / \mathrm{Al}_{2} \mathrm{O}_{3}[11-$ 20] and $\mathrm{CeO}_{2}(111) / / \mathrm{Al}_{2} \mathrm{O}_{3}(0001)$, which is consistent with the XRD results. No apparent hkl reflections related to Sm-O phase were observed. At Sm concentrations above 10 atom $\%$, hkl reflections related to (200) and (400) were apparent indicating loss of orientation and transformation to polycrystalline samaria-doped ceria phase. This is mostly due to the large lattice mismatch of $13.5 \%$ between samaria-doped ceria and 
$\mathrm{Al}_{2} \mathrm{O}_{3}$ knowing that samaria-doped $\mathrm{CeO}_{2}$ has a cubic structure and c-plane of $\mathrm{Al}_{2} \mathrm{O}_{3}$ is hexagonal.

XPS depth profile gives an excellent overview of atomic elemental concentrations of $\mathrm{Ce}, \mathrm{Sm}, \mathrm{O}$ and $\mathrm{Al}$ as a function of film depth. The qualitative variation in dopants and associated oxygen vacancies can be realized and applied in conjunction with film conductivity. Figure 2 shows the XPS depth profile in the case of 5 atom\% samariadoped $\mathrm{CeO}_{2}$ film. A uniform concentration of samaria as a function of film depth was observed and the stoichiometry of the film was determined to be $\mathrm{Ce}_{0.95} \mathrm{Sm}_{0.05} \mathrm{O}_{2-\mathrm{x}}$. In addition, fairly sharp interface between samaria doped $\mathrm{CeO}_{2}$ and $\mathrm{Al}_{2} \mathrm{O}_{3}$ is also realized from the spectra indicating minimum diffusion. As expected, some preferential oxygen sputtering was observed during XPS depth profile measurements [21].

Conductivity of samaria-doped ceria films with different amount of samarium dopant was measured in the temperature range of $250-900{ }^{0} \mathrm{C}$ (Figure 3 ). As seen, the 5 at $\%$ samaria-doped $\mathrm{CeO}_{2}$ sample exhibited the highest conductivity in the whole temperature range when $\mathrm{Sm}^{3+}$ concentration was varied from 1 to 33 atom\%. The activation energy appears to be constant over the temperature range of conductivity measurements for each Sm concentration. These results indicate that the films grown at $650^{\circ} \mathrm{C}$ consist of mostly single domain and there were no major changes in the domain size over these conductivity measurements.

Total conductivity values determined as a function of $\mathrm{Sm}$ concentration from Figure 3 at different temperatures are presented in Figure 4. Total conductivity increases as a function of $\mathrm{Sm}$ concentration, peaks around 5 atom $\% \mathrm{Sm}$ and decreases for higher Sm concentrations. The peaks associated with polycrystalline features in the XRD spectra 
(not shown in Figure 1) from heavily samaria doped samples clearly show that the crystalline quality of the films was significantly affected by the incorporation of $\mathrm{Sm}$ in the ceria lattice. As a result, the total conductivity is decreasing as a function of samaria doping beyond the optimum value of 5 atom $\%$ of Sm. As seen by the number of points in Figure 4, we have studied nine samaria doping concentrations. Due to the complexity of overlapping curves, the Arrhenius plots of only six representative doped samples are shown in Figure 3.

A loss of (111) orientation enhances the grain boundary scattering reducing the conductivity.[4] Nonetheless, a conductivity of $0.04 \mathrm{Scm}^{-1}$ at $600^{0} \mathrm{C}$ is higher than those measured on polycrystalline materials [22-25]. Eguchi et. al [22] reported that samariaand galodonia-doped ceria exhibit higher electrical conductivities than other rare-earthdoped ceria because of a close ionic radii match among $\mathrm{Sm}^{3+}, \mathrm{Gd}^{3+}$ and $\mathrm{Ce}^{4+}$. We have also noticed that conductivity much higher than ours was reported by Zhan et.al. They have reported a lattice conductivity of $2 \mathrm{~S} / \mathrm{cm}$ at $600{ }^{0} \mathrm{C}$ for $\mathrm{Ce}_{0.9} \mathrm{Sm}_{0.1} \mathrm{O}_{1.95}$. However, they claim that the opposite effects of grain boundary grain interior conductivity leads to the net conductivity of $1 \mathrm{~S} / \mathrm{cm}$ at $600{ }^{0} \mathrm{C}$ for $\mathrm{x}=0.2$. These values are unusually high and may need more explanations.

It is important to realize that conductivity measured consists of electronic as well as ionic contribution in it. We assume that electronic conductivity in cerium oxide in air is negligible and there by contribution of ionic conductivity in total conductivity is significant.[26] However that may not be the case all the time and thus interpretation of unusually high total conductivity becomes very complex. Also, the conductivity maxima observed in our case for samaria doped samples is for much lower doping concentrations 
PNNL-17069

than doping concentration peak observed in the literature. One of the possible explanations would be the oriented nature of our crystals as oppose to purely polycrystalline doped samples in the literature. A good orientation may help long range oxygen vacancy transport ultimately contributing to a good conductivity. The activation energy $E_{a}$, derived from the slope of the Arrhenius plot for the 5 atom $\%$ doped sample is observed at $0.6 \mathrm{eV}$ for the as-grown films. Typically lower activation energy refers to lower barrier for the oxygen transport throughout the $\mathrm{Ce}_{1-\mathrm{x}} \mathrm{Sm}_{\mathrm{x}} \mathrm{O}_{2-\delta}$ crystal.

\section{Conclusion}

In conclusion, samaria-doped ceria thin films were grown on c- $\mathrm{Al}_{2} \mathrm{O}_{3}$ using oxygenplasma-assisted molecular beam epitaxy. Samarium dopant concentration varied from 1 to 33 atom $\%$. Conductivity of these films was measured in the temperature range $250-900$

${ }^{0} \mathrm{C}$ and the highest conductivity was observed for the $\mathrm{Ce}_{0.95} \mathrm{Sm}_{0.05} \mathrm{O}_{2-\delta}$. Films with higher samarium concentrations showed lower conductivities due to a rise in other than c-axis orientations that could increase grain-boundary scattering.

\section{Acknowledgments}

The work was conducted in the Environmental Molecular Sciences Laboratory (EMSL) and Materials Division at Pacific Northwest National Laboratory (PNNL). PNNL is operated by Battelle for the US Department of Energy. EMSL is a national scientific user facility for DOE-BER. EMSL is operated by the office of Biological and Environmental Research (BER) under the contract DE-AC06-76RL01830. 
PNNL-17069

\section{References:}

[1] Steele B C, 2000 Solid State Ionics 129, 95.

[2] Yahiro H, Eguchi Y, and Arai H, 1988, J. Appl. Electrochem. 18, 527.

[3] Chen L, Chen C L, Huang D X, and Jacobson A J, 2003 Appl. Phys. Lett. 83, 4737.

[4] Tuller H L, 2000 Solid State Ionics, 131, 143.

[5] Yahiro H, Eguchi Y, Eguchi K, and Arai H, 1988 J. Appl. Electrochem. 18, 527.

[6] Mori T, Wang Y, Drennan J, Auchterlonie G, Li J, Ikegami T, 2004 Solid State Ionics, 175, 641.

[7] Suzuki T, Jasinski P, and Anderson H U, 2003Ceram. Engin. and Sci. Proceedings, 24, 323.

[8] Suzuki T, Kosacki I, Anderson H U, 2002 Solid State Ionics, 151, 111.

[9] Hong S J, Mehta K and Virkar A V, 1998 J. Electrochem. Soc. 145, 638.

[10] Zhan Z L, Wen T L, Tu H Y, Lu Z Y, 2000 J. Electrochem. Soc. 148, A427.

[11] Wang Y, Mori T, Li J, Yajima Y, 2003 Sci. \& Technol. Advan. Material. 4, 229.

[12] Tschöpe A, Sommer E, Birringer R, 2001 Solid State Ionics, 139, 255.

[13] A.Tschöpe, E. Sommer, R. Birringer, Solid State Ionics, 139, (2001) 267.

[14] Sata N, Eberman K, Eberl K, and Mailer J, 2000 Nature, 408, 946. 
[15] Yu Z Q, Wang C M, Engelhard M H, McCready D E, Shutthanandan V, Shao R, Nachimuthu P, Marina O A, Lyubinetsky I V, Saraf L V and Thevuthasan S, AVS 53rd International Symposium in San Francisco, CA, Nov.12-17,2006.

[16] Gao Y, Herman G S, Thevuthasan S, Peden C H F, and Chambers S A, 1999 J. Vac. Sci, Technol. A17, 961.

[17] Azad S, Thevuthasan S, Shutthanandan V, Wang C M, McCready D E, and Peden C H F, Conference Proceeding, Nanotechnology Symposium, 225th ACS National Meeting (2003).

[18] S. Thevuthasan, S. Azad, O.A. Marina, V. Shutthanandan, D.E. McCready, L. Saraf, C.M. Wang, I. Lyubinetsky, C.H. F. Peden, and V. Petrovsky, Proceedings of the IEEE Nano (2003).

[19] Pauw L J van der, 1958 Philips Res. Rep. 13,1.

[20] Poulsen F W and Bonanos N, in 'Abstracts of Electrochem' 95, Bangor, Wales, UK10-14 Sept 1995.

[21] Kelly R, 1980 Surf. Sci., 100, 85.

[22] Eguchi K, Setoguchi T, Inoue T and Arai A, 1992 Solid State Ionics, 52, 165.

[23] Duncan H, Lasia A, 2005 Solid State Ionics,176, 1429.

[24] Wang S, Kobayashi T, Dokiya M, and Hashimoto T, 2000 J. Electrochem. Soc. $147,3606$. 
PNNL-17069

[25] Kim N, Kim B, Lee D, 2000 J. Power Sources,90, 139.

[26] Minh N Q and Takahashi T, 1995 Science and Technology of Ceramic Fuel Cells Elsevier, Amsterdam, p. 94. 
PNNL-17069

\section{Figure Captions:}

1. A typical $2 \theta$ scan for oriented $\mathrm{Ce}_{0.95} \mathrm{Sm}_{0.05} \mathrm{O}_{2-\delta}$ film on c- $\mathrm{Al}_{2} \mathrm{O}_{3}$. Inset: diffraction pattern obtained from TEM indicating (111), (222) and (333) orientation of $\mathrm{Ce}_{0.95} \mathrm{Sm}_{0.05} \mathrm{O}_{2-\delta}$ films in the form of cubic fluorite structure. Selected area electron diffraction pattern shows the orientation relationship: $\mathrm{CeO}_{2}[110] / / \mathrm{Al}_{2} \mathrm{O}_{3}[11-20]$ and $\mathrm{CeO}_{2}(111) / / \mathrm{Al}_{2} \mathrm{O}_{3}(0001)$.

2. The XPS depth profile of $\mathrm{Ce}_{0.95} \mathrm{Sm}_{0.05} \mathrm{O}_{2-\delta}$ film on c- $\mathrm{Al}_{2} \mathrm{O}_{3}$. A uniform $\mathrm{Sm}$ concentration of 5 atom $\%$ throughout the film can be seen in the data.

3. Arrhenius plots for $\mathrm{Ce}_{1-\mathrm{x}} \mathrm{Sm}_{\mathrm{x}} \mathrm{O}_{2-\delta}$ films with various $\mathrm{Sm}$ atomic concentrations (x) in the temperature range $250-900{ }^{0} \mathrm{C}$. The highest conductivity is seen in the samples with $\mathrm{Ce}_{0.95} \mathrm{Sm}_{0.05} \mathrm{O}_{2-\delta}$.

4. The conductivity of $\mathrm{Ce}_{1-\mathrm{x}} \mathrm{Sm}_{\mathrm{x}} \mathrm{O}_{2-\delta}$ as a function of $\mathrm{Sm}$ concentration for the temperature range of $500-900{ }^{0} \mathrm{C}$. At all measurement temperatures, highest conductivity is seen at $5 \mathrm{Sm}^{3+}$ atomic \% concentrations $\left(\mathrm{Ce}_{0.95} \mathrm{Sm}_{0.05} \mathrm{O}_{2-\delta}\right)$. 


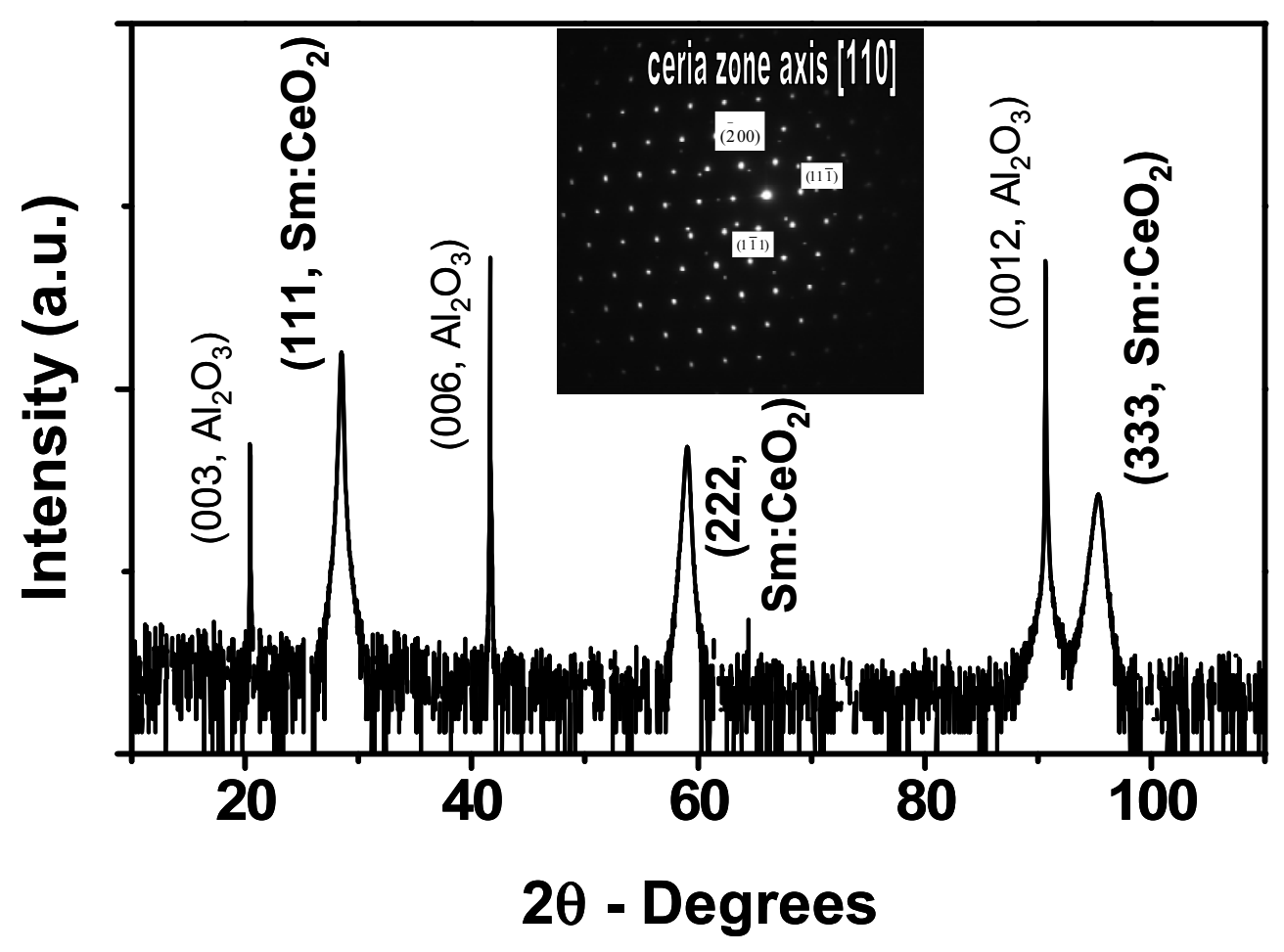

Fig. 1 
PNNL-17069

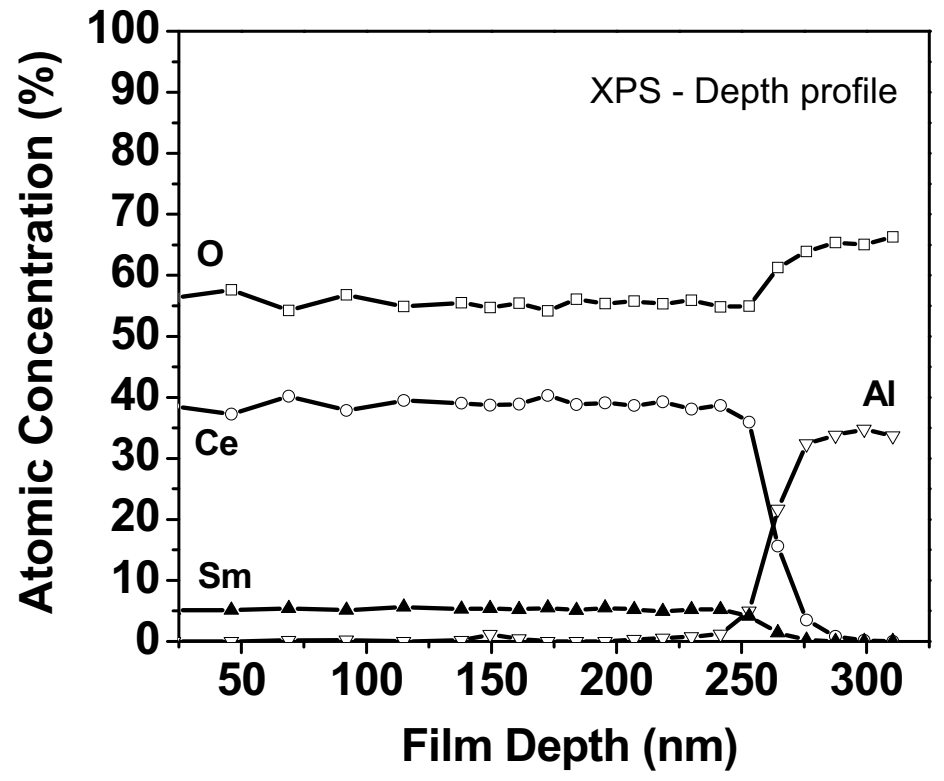

Fig. 2 
PNNL-17069

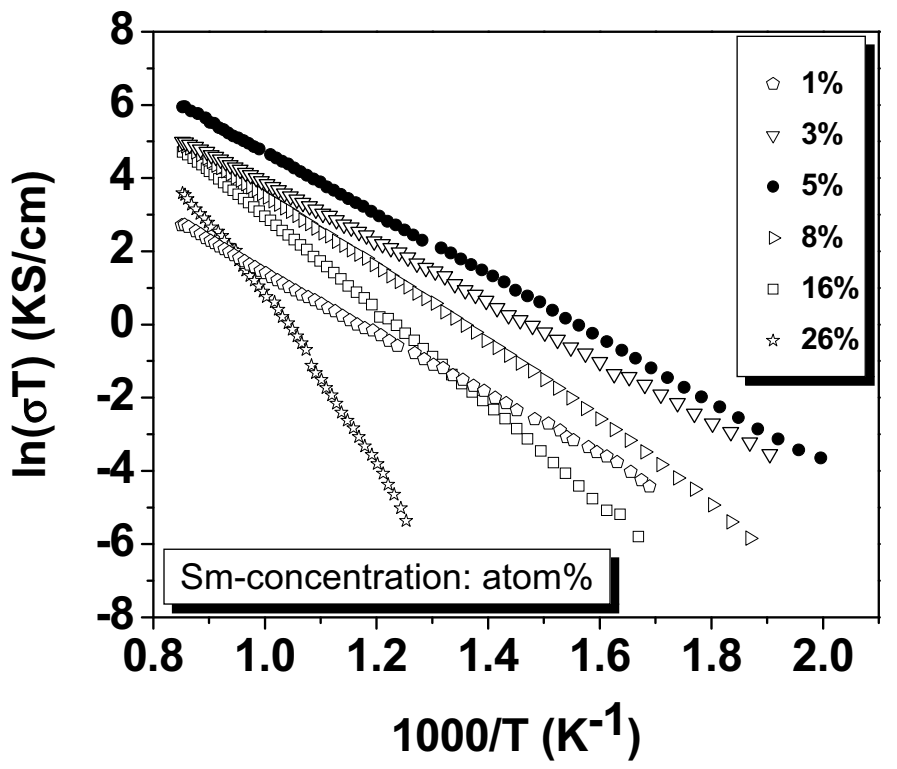

Fig. 3 
PNNL-17069

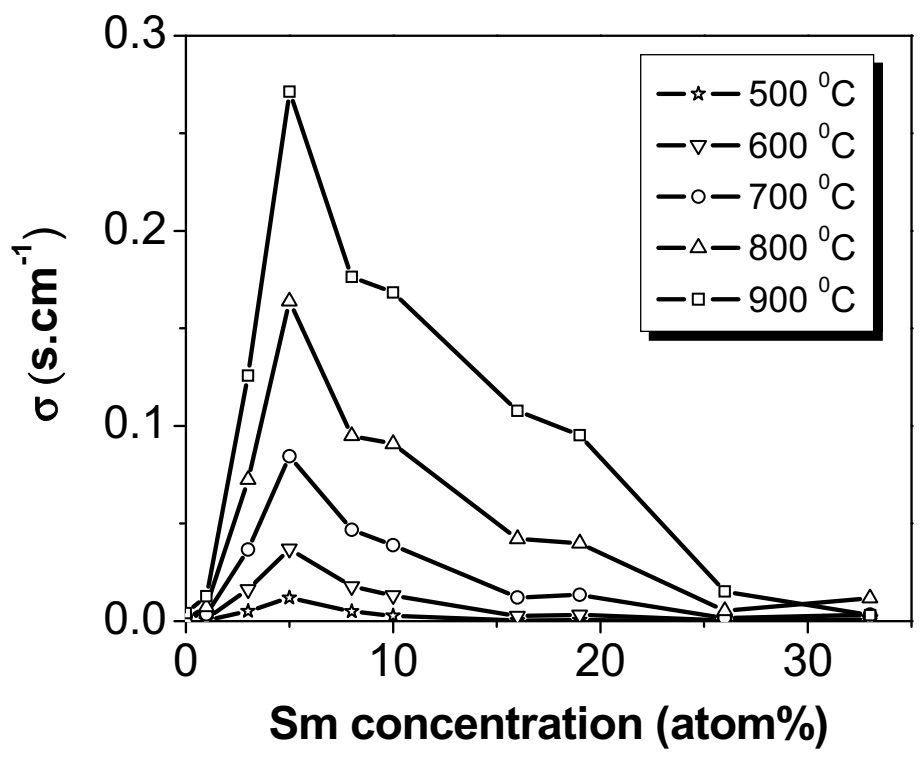

Fig. 4 
PNNL-17069

\title{
Growth and structure of epitaxial $\mathrm{Ce}_{0.8} \mathrm{Sm}_{0.2} \mathrm{O}_{1.9}$ by oxygen-plasma- assisted molecular beam epitaxy
}

\author{
Z. Q. Yu ${ }^{a}$, S. V.N.T. Kuchibhatla ${ }^{\text {b, }}$, C. M. Wang ${ }^{\mathrm{b}}$, L. V. Saraf ${ }^{\mathrm{b}}$, M. H. Engelhard ${ }^{\mathrm{b}}$, V. \\ Shutthanandan ${ }^{\mathrm{b}}$, S. Thevuthasan ${ }^{\mathrm{b}}$ and S.Seal ${ }^{\mathrm{c}}$
}

(c) Department of Chemistry, Nanjing Normal University, Nanjing 210097, China

(d) Pacific Northwest National Laboratory, Richland, WA 99352, USA

(e) Advanced Materials Processing and Analysis Center, University of Central

Florida, Orlando, FL 32816, USA

\begin{abstract}
The epitaxial growth of $\mathrm{Ce}_{0.8} \mathrm{Sm}_{0.2} \mathrm{O}_{1.9}$ films on sapphire (0001) substrate by oxygenplasma-assisted MBE has been characterized using RHEED, XPS, XRD, AFM, HRTEM and RBS in order to determine their structure and compositions. The composition of the films was determined to be 0.8:0.2:1.9 for Ce: Sm: O by RBS. The film/substrate epitaxial relationship can be written as $\mathrm{CeO}_{2}(111) / / \alpha-\mathrm{Al}_{2} \mathrm{O}_{3}(0001)$ and $\mathrm{CeO}_{2}[110] / / \alpha-$ $\mathrm{Al}_{2} \mathrm{O}_{3}[2110]$. The Ce has only $4+$ oxidation state in the films and $\mathrm{Sm}$ is fully oxidized in the films with formal oxidation of $3+$. Cubic $\mathrm{CeO}_{2}$ films have a preferred (111) preferred orientation.
\end{abstract}

Keywords: $\mathrm{CeO}_{2}$; doping; thin films; sapphire; MBE;XPS; XRD; HRTEM; RBS

\section{Introduction}

The solid-oxide fuel cell (SOFC) offers an environmentally benign alternative to current heat engines as a result of high conversion efficiency (40 to 60\%) of chemical energy to electric power [1]. Ceria-based electrolytes have been extensively studied, because of their application in SOFCs $[2,3]$. They have a higher ionic conductivity than yttria-stabilized zirconia (YSZ), generally used as the electrolyte material for SOFCs, at lower and intermediate temperature range. Thus, ceria based electrolytes are noteworthy as candidates for electrolyte materials of low-temperature $\left(700-800^{\circ} \mathrm{C}\right)$ SOFCs [4]. Replacing $\mathrm{Ce}^{4+}$ with divalent or trivalent cations results in the creation of oxygen vacancies and high oxygen ionic conductivity over an extended temperature and oxygen partial pressure range. Different types of doped ceria electrolytes were extensively studied, which include the niobia-doped [5], $\mathrm{Mn}$, Gd co-doped, [6] $\mathrm{Dy}_{2} \mathrm{O}_{3}$-doped [7], gadolinia and samaria - co-doped [8-12] gadolinia-doped [13-18], samaria-doped [19-28] etc. Among the various dopants studied, $\mathrm{Gd} 3+$ and $\mathrm{Sm} 3+$ singly or co-doped ceria have been reported to have excellent conductivity and to be relatively stable in the reducing environment. As per the optimal compositions of doped ceria, giving the highest conductivities, different literatures report completely different results [9-11]. This disagreement probably results from divergences in sample preparation and ion conductivity measurement method. Especially, major research was focused on the polycrystalline ceramics. It is probably not helpful to further understand or distinguish 
the formation of vacancies (grain interior) and grain boundary contributions to the total conductivity. Generally, molecular beam epitaxy (MBE) is a good technique for the preparation of complex oxides as epitaxial films and highly oriented structures. It could largely reduce the grain boundary contributions to the total conductivity and simplify the process to explore the role of dopant or the grain boundary to the ionic conductivity. The growth of samaria-doped ceria single crystal thin films on the sapphire (0001) substrate can be a significant addition to the existing understanding of the thin film electrolyte materials.

The immediate goal of this work has been to synthesize well-ordered epitaxial samaria doped ceria thin films to better understand the relationship between the composition, structure as well as the growth conditions and the ion conductivity.

Figure 1 shows the crystal structures of $\mathrm{CeO}_{2}(111)$ and $\mathrm{Al}_{2} \mathrm{O}_{3}(0001)$ in plan view. $\mathrm{CeO}_{2}$ has a cubic fluorite structure with the lattice constant of $5.411 \AA$, whereas sapphire has a rhombohedral primitive cell and is usually described using the simpler hexagonal unit with $\mathrm{a}=4.759 \AA$ and $\mathrm{c}=12.991 \AA$. The lattice mismatch is larger than $10 \%$. In a previous publication, our group has shown that the oxygen sublattice matching is more important than that of the cation sublattices for growing high quality epitaxial oxide films on oxide substrates [29]. The distances between oxygen atoms in $\mathrm{Al}_{2} \mathrm{O}_{3}$ (0001) plane are 2.526 and $2.8663 \AA$, respectively. The distance between cerium atoms is $3.8263 \AA$. However, based on the symmetry between the (0001) orientation of sapphire and the (111) of the ceria, we expect that high quality epitaxial samaria-doped ceria film growth should be possible on $\mathrm{Al}_{2} \mathrm{O}_{3}(0001)$ under the appropriate conditions. We discuss the growth conditions and structural characterization of $\mathrm{CeO}_{2}$ films by means of x-ray diffraction (XRD), Rutherford backscattering spectrometry (RBS), reflection high-energy electron diffraction (RHEED), x-ray photoelectron spectroscopy (XPS) and atomic force microscopy (AFM). 

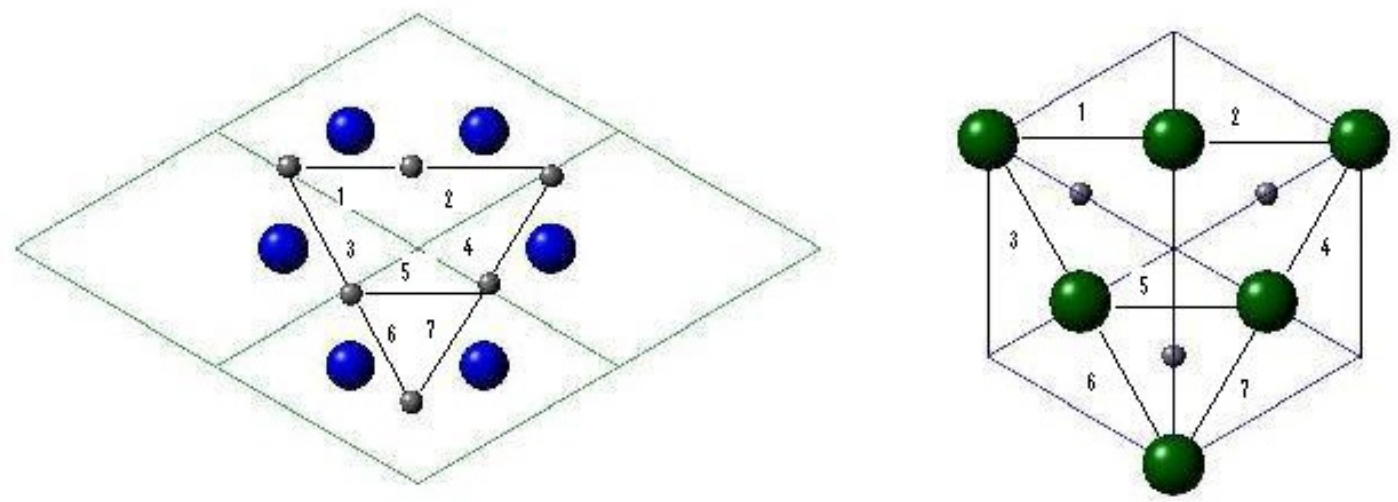

$\begin{array}{ll}\mathrm{Al}_{2} \mathrm{O}_{3}(001) & \text { 1) } 25260 \AA \mathrm{A} \\ & \text { 2) } 2.8663 \mathrm{~A} \\ \text { 3) } 2.8663 \AA \\ \text { 4) } 25260 \AA \\ \text { 5) } 2.8663 \overline{\mathrm{A}} \\ \text { 6) } 25260 \mathrm{~A} \\ \text { 7) } 2.8663 \AA\end{array}$
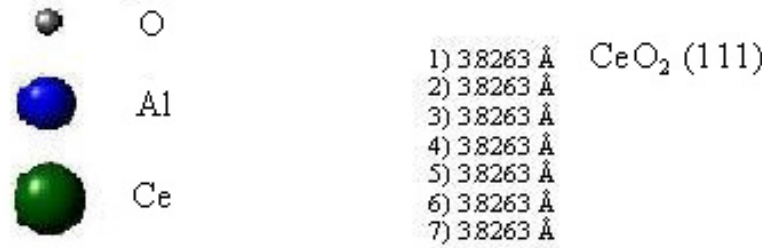

Fig.1. Crystal structures of $\mathrm{CeO}_{2}(111)$ and $\mathrm{Al}_{2} \mathrm{O}_{3}(0001)$.

\section{Experiment}

\section{A. MBE growth and in situ characterization}

All growth and in situ characterization measurements were carried out in a dualchamber ultrahigh vacuum (UHV) system described in detail elsewhere [30]. The MBE chamber used for this investigation was configured specifically for oxide epitaxy. It consists of five metal evaporation sources and a UHV compatible electron cyclotron resonance (ECR) oxygen plasma source, as well as RHEED for real-time characterization of epitaxial film growth. Ce rods of $99.9 \%$ purity were used as the metal evaporation source in an electron beam evaporator. Samarium (99.9\% purity) was evaporated from an effusion cell. The growth rates of the films were monitored by quartz crystal oscillators (QCO). The rates of cerium and samarium metal evaporation were maintained between 0.01-0.1 and $0.01 \mathrm{~nm} / \mathrm{s}$, respectively. In particular, the substrate temperature and oxygen partial pressure were kept about $873-973 \mathrm{~K}$ and $2.0 \times 10^{-5}$ Torr during growth of these films.

$\mathrm{Al}_{2} \mathrm{O}_{3}$ (0001) substrates were ultrasonically cleaned in acetone and methanol prior to insertion into the dual-chamber UHV system through a load lock. Once in the MBE chamber, the substrates were cleaned by annealing for several minutes at $650{ }^{\circ} \mathrm{C}$ in the oxygen plasma source operating at $200 \mathrm{~W}$ at a chamber pressure of $2 \times 10^{-5}$ Torr of oxygen. This treatment left the surfaces well ordered, as judged by RHEED.

A Ce metal source from an electron beam evaporator was directed at the substrate along with a beam of activated oxygen created by the ECR plasma source. The substrate temperature, Sm and Ce deposition rate, oxygen partial pressure, and ECR plasma power level were systematically varied and the resulting films were characterized to obtain the best crystalline Samria doped $\mathrm{CeO}_{2}$ films possible. The total film thickness varied from 
1000 to $2000 \AA$ from sample to sample. The resulting epitaxial films were characterized during growth by RHEED at incident electron beam energy of $15 \mathrm{keV}$.

\section{B. Ex-situ characterization}

RBS and channeling experiments were performed on samaria doped ceria / $\mathrm{Al}_{2} \mathrm{O}_{3}$ (0001) samples at the Environmental Molecular Sciences Laboratory (EMSL) accelerator facility at PNNL. The details of the accelerator facility and the end stations were described previously [31]. The standard dose of helium ions for one spectrum was $4.43 \times 10^{15}$ ions $/ \mathrm{cm}^{2}$. The backscattering spectrum was collected using a silicon surface barrier detector at a scattering angle of $150^{\circ}$. The SIMNRA simulation program was used to model the experimental RBS. The thickness and composition of the thin films were measured by RBS.

XPS measurements were performed using a Physical Electronics Quantum 2000 Scanning ESCA Microprobe. This system uses a focused monochromatic Al Ka X-rays $(1486.7 \mathrm{eV})$ source and a spherical section analyzer. The instrument has a 16 element multichannel detector. Two different analysis modes, "large area" and "point mode" were used in collecting the photoemission spectra. For the large area analysis mode we used a $99 \mathrm{~W}, 100 \mu \mathrm{m}$ diameter X-ray beam that was rastered over a $1.4 \mathrm{~mm}$ by $0.2 \mathrm{~mm}$ rectangle on the sample. The point analysis mode used a $40 \mathrm{~W}, 200 \mu \mathrm{m}$ diameter spot on the sample. The X-ray beam was incident normal to the sample and the photoelectron detector was at $45^{\circ}$ off-normal. Wide scan data was collected using pass energy of 117.4 $\mathrm{eV}$. For the $\mathrm{Ag}_{3} \mathrm{~d}_{5 / 2}$ line, these conditions produce $\mathrm{FWHM}$ of better than $1.6 \mathrm{eV}$. Narrow scan data was collected using pass energy of $46.95 \mathrm{eV}$. For the $\mathrm{Ag} 3 \mathrm{~d}_{5 / 2}$ line, these conditions produced FWHM of better than $0.98 \mathrm{eV}$. Although the binding energy (BE) scale was calibrated using the $\mathrm{Cu} 2 \mathrm{p}_{3 / 2}$ feature at $932.62 \pm 0.05 \mathrm{eV}$ and Au4f feature at $83.96 \pm 0.05 \mathrm{eV}$ for known standards, the sample experienced variable degrees of charging. Low energy electrons at $\sim 1 \mathrm{eV}, 21 \mu \mathrm{A}$ and low energy $\mathrm{Ar}^{+}$ions were used to minimize this charging. The vacuum chamber pressure during analysis was $<6.6 \times 10^{-7} \mathrm{~Pa}$, and the sample temperature was $\sim 30^{\circ} \mathrm{C}$ or $303 \mathrm{~K}$. The profile data was collected using 2 $\mathrm{kV}, \mathrm{Ar}^{+}$ions rastered over a $3 \mathrm{~mm} \times 3 \mathrm{~mm}$ area of the sample. The ion beam sputter rate was calibrated as $4.6 \mathrm{~nm} / \mathrm{min}$ using a known thickness of $\mathrm{SiO}_{2} / \mathrm{Si}$ as reference material.

Tapping mode AFM images were obtained in air using a Digital Nanoscope III and XRD patterns were collected with a Philips X'Pert materials research diffractometer using $\mathrm{Cu} \mathrm{Ka} \mathrm{X}$-ray.

\section{Results and Discussion}

Data from RBS was used to confirm the amount of Sm predicted by the XPS depth profile. The arrows in the figure 2 indicate the characteristic positions expected for backscattering from $\mathrm{Sm}, \mathrm{Ce}, \mathrm{Al}$ and $\mathrm{O}$ atoms. SIMNRA was used to simulate the random spectra shown in Fig. 2 and the simulated spectra are also shown in the figure (solid line).Based on this simulation, the amount of samarium in the thin films was determined to be 20 atomic $\%$, the stoichiometry and the thickness of the film were determined to be Ce: Sm: $\mathrm{O}$ of 0.8:0.2:1.9 and $183 \mathrm{~nm}$, respectively. 
PNNL-17069

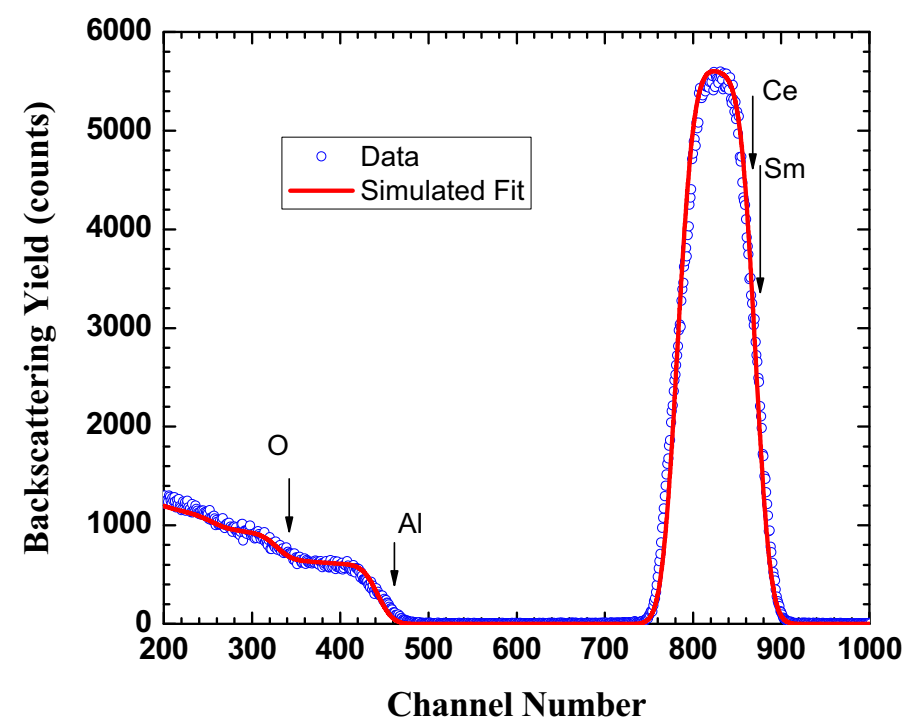

Fig. 2. Random RBS spectra along with SIMNRA simulated results for epitaxially grown $\mathrm{Ce}_{0.8} \mathrm{Sm}_{0.2} \mathrm{O}_{1.9}$ (111) on $\mathrm{Al}_{2} \mathrm{O}_{3}$ (0001) substrate. The incident energy of the $\mathrm{He}^{+}$ beam was $2.04 \mathrm{MeV}$ and the scattering angle was $150^{\circ}$.

It is shown in Fig. 3(a) that $\mathrm{Al}_{2} \mathrm{O}_{3}$ (0001) substrate RHEED pattern is of good quality and well ordered, showing characteristic streaks. A good quality substrate always helps to epitaxially grow thin films. Fig. 3(b), (c) and (d) show the typical RHEED patterns of $\mathrm{Ce}_{0.8} \mathrm{Sm}_{0.2} \mathrm{O}_{1.9}$ epitaxial thin films, predominantly oriented along the (111) direction after growing for different times. The primary beam alignments along [ $\overline{1} 10]$ are shown, and the primary beam voltage was $15 \mathrm{kV}$. After growth for $15 \mathrm{~min}$., the RHEED pattern obtained from the films in fig.3(b) indicate reasonably well ordered surface showing RHEED pattern with low background, homogeneous intensity along the streaks. With the increase of growth time, the arrays of spots are gradually appeared among the streak patterns in fig.3(c) and (d). This suggested that the Ceria thin film structures on $\mathrm{Al}_{2} \mathrm{O}_{3}$ are highly oriented. It indicates that the morphology of surface was changing during the growth from a smooth surface to a rough surface as the spots on RHEED streaks are due to the transmission diffraction of the incident beam through prominent material. It is verified by the AFM image (shown in Fig. 5) of sample with root mean square (RMS) roughness of $3.22 \mathrm{~nm}$.

As observed from the XRD patterns in Fig.4, the obtained thin film was aligned on $\mathrm{Al}_{2} \mathrm{O}_{3}$ (006) and produced Kiessig fringes around ceria (111) reflection, indicating high-quality growth. Also (111), (222) and (333) reflections of $\mathrm{Ce}_{0.8} \mathrm{Sm}_{0.2} \mathrm{O}_{1.9}$ thin films appearing in the diffraction pattern indicate that (111) is preferred orientation and the thin films are cubic phases. Figure 6(a) shows a low magnification TEM image of the sample in cross section. The cross sectional TEM image reveals a film thickness of $218 \mathrm{~nm}$, which is comparable to that measured by RBS. The interface between the films and substrate is very sharp and clear. The film/substrate epitaxial relationship can be written 
as $\mathrm{CeO}_{2}(111) / / \alpha-\mathrm{Al}_{2} \mathrm{O}_{3}(0001)$ and $\mathrm{CeO}_{2}[110] / / \alpha-\mathrm{Al}_{2} \mathrm{O}_{3}$ [2110] The HRTEM image of thin films in Fig.6 (b) confirms the single domain structure.

(a)

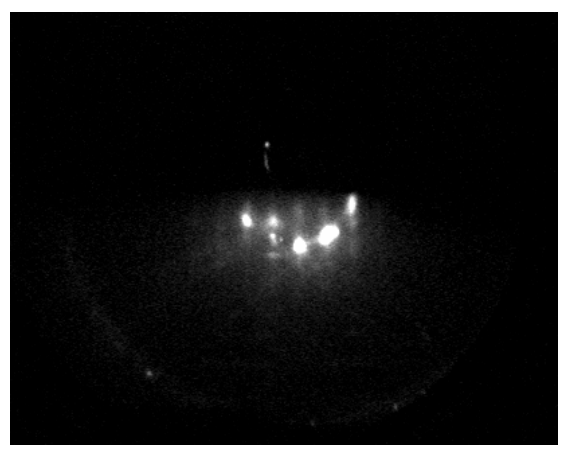

(b)

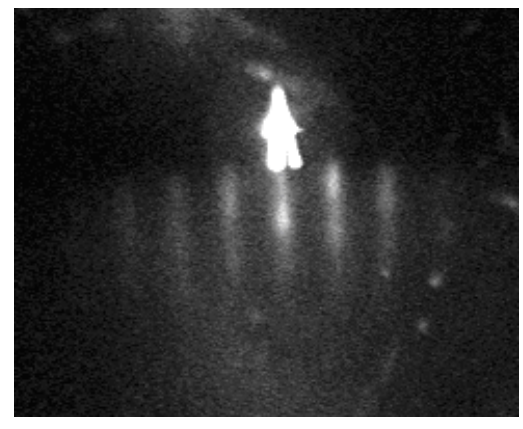

(c)

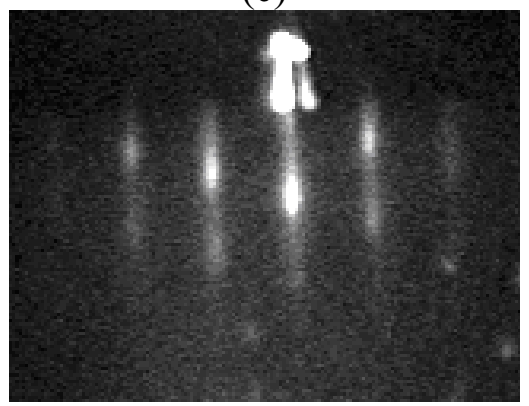

(d) 
PNNL-17069

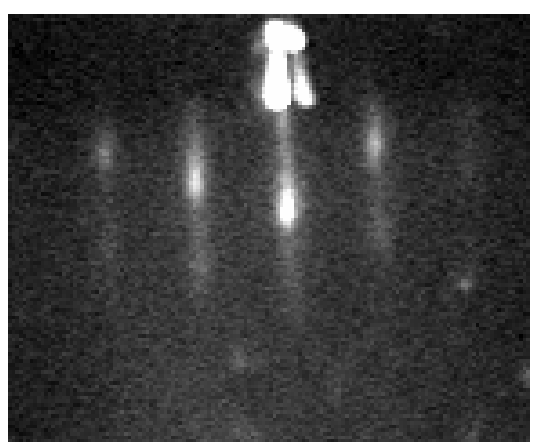

Fig.3 Typical RHEED patterns obtained from an $\mathrm{Al}_{2} \mathrm{O}_{3}$ (0001) substrate in (a) and $\mathrm{Ce}_{0.8} \mathrm{Sm}_{0.2} \mathrm{O}_{1.9}$ thin films after growing at different time in (b) $15 \mathrm{~min}$, in (c) $60 \mathrm{~min}$ and in (d) after finishing the growth along $\langle 1 \overline{1} 1\rangle$ directions. The e-beam incidence direction is along $\mathrm{Al}_{2} \mathrm{O}_{3}$ [2110]. The primary beam energy was $15 \mathrm{keV}$.

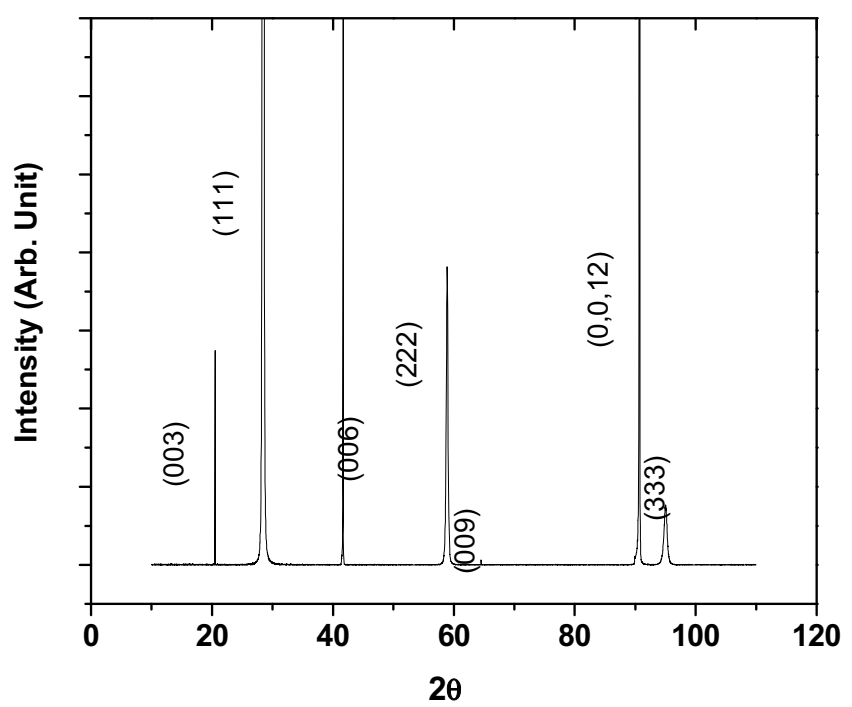

Fig. 4: Representative XRD patterns of $\mathrm{Ce}_{0.8} \mathrm{Sm}_{0.2} \mathrm{O}_{1.9}$ thin films on $\mathrm{Al}_{2} \mathrm{O}_{3}(0001)$. 
PNNL-17069

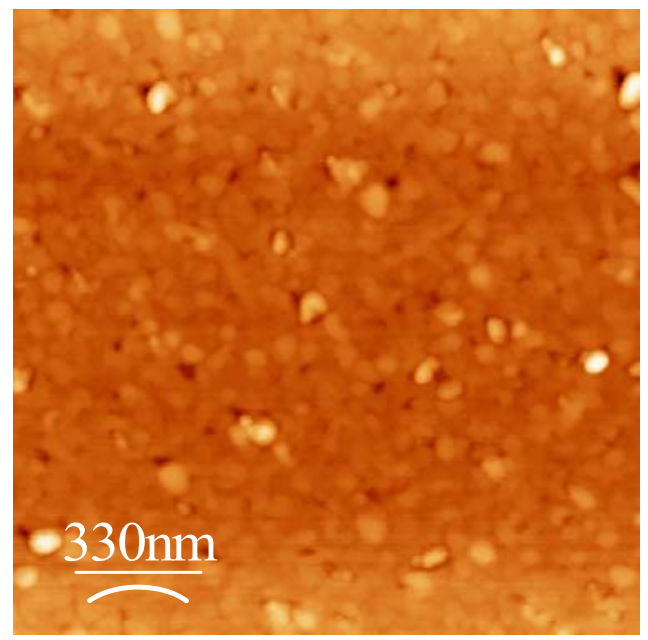

Fig. 5 Representative AFM topographic image of $\mathrm{Ce}_{0.8} \mathrm{Sm}_{0.2} \mathrm{O}_{1.9}$ thin films on $\mathrm{Al}_{2} \mathrm{O}_{3}$ (0001).

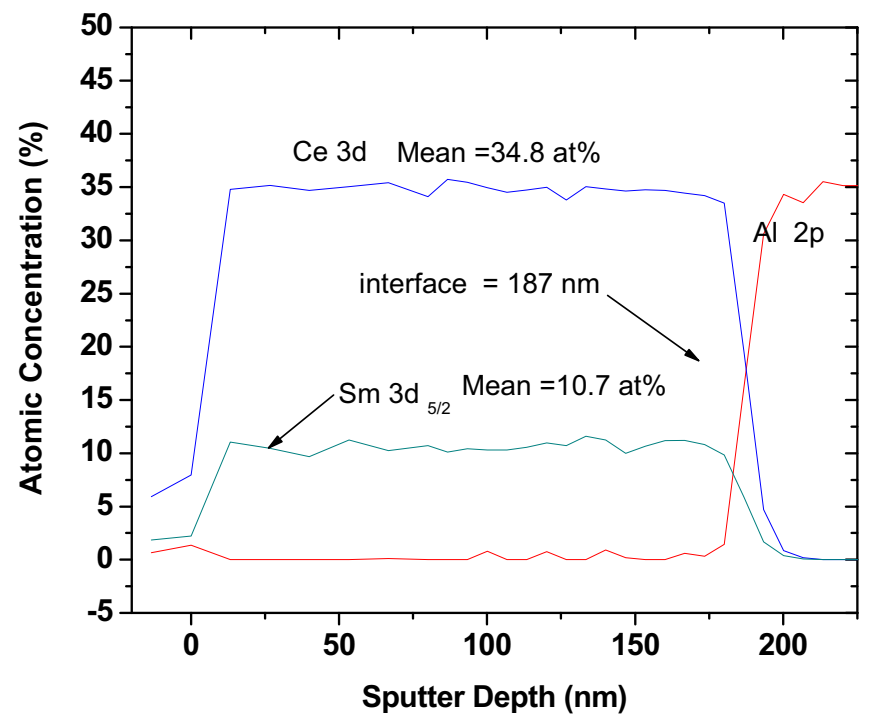

Fig. 7 XPS depth profile of $\mathrm{Ce}_{0.8} \mathrm{Sm}_{0.2} \mathrm{O}_{1.9}$ thin film. 
PNNL-17069
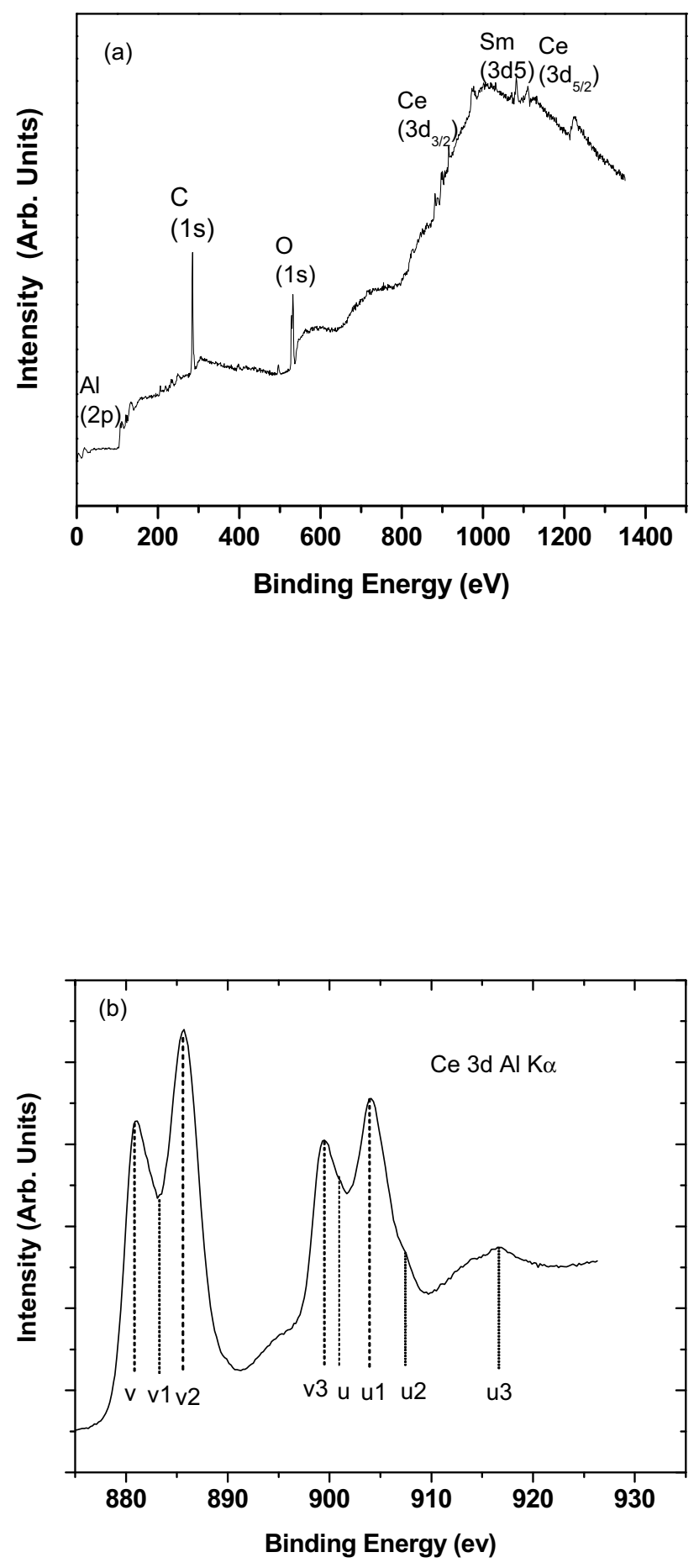
PNNL-17069

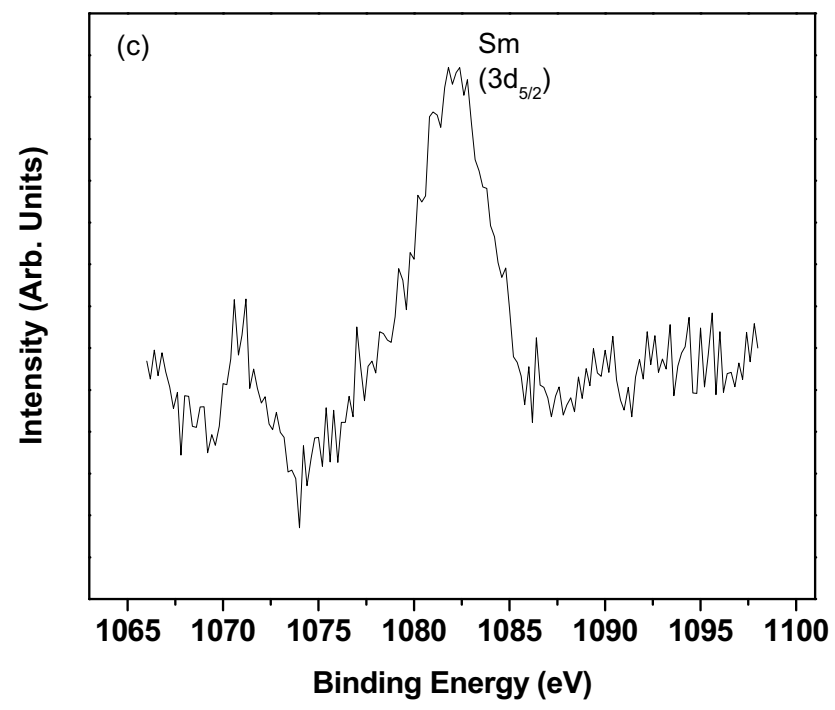

Fig. 8 (a) XPS spectra of $\mathrm{Ce}_{0.8} \mathrm{Sm}_{0.2} \mathrm{O}_{1.9}$ thin film on single crystal $\mathrm{Al}_{2} \mathrm{O}_{3}(0001)$ substrate; Narrow region scan for Ce (3D) (b), and Sm (3d5) (c) peaks on single crystal $\mathrm{Al}_{2} \mathrm{O}_{3}$ (0001) substrate. Features V1 and $\mathrm{U} 1$ are $\mathrm{Ce}^{3+} 3 \mathrm{~d}_{5 / 2}$ and $3 \mathrm{~d}_{3 / 2}$ states, respectively. The feature labeled as V3 and $\mathrm{U} 3$ are $\mathrm{Ce}^{4+} 3 \mathrm{~d}_{5 / 2}$ and $3 \mathrm{~d}_{3 / 2}$ states, respectively. V, V2, $\mathrm{U}$ and $\mathrm{U} 2$ are $\mathrm{Ce}^{4+}$ 'shake down' states.

To determine the elements ratio and oxidation states in the $\mathrm{Ce}_{0.8} \mathrm{Sm}_{0.2} \mathrm{O}_{1.9}$ thin films, the sample was investigated by XPS depth profile analysis. Fig. 7 shows the atomic distribution of $\mathrm{Ce}$ and $\mathrm{Sm}$ in the films. The mean atomic ratios of $\mathrm{Ce}$ and $\mathrm{Sm}$ in thin films are 34.8 and $10.7 \%$, respectively. The ratio of $\mathrm{Sm} /(\mathrm{Sm}+\mathrm{Ce})$ is about 0.235 , which is larger than that obtained by RBS. This preliminary result shows that the obtained thin films have uniform composition over about $187 \mathrm{~nm}$ (using calibration carried out with $\mathrm{SiO}_{2}$ thin films), which is slightly less than that obtained by TEM. From the results shown in the fig.8 (a), it can be seen that as -deposited films contain mainly $\mathrm{C}$, $\mathrm{Ce}, \mathrm{O}$ and $\mathrm{Sm}$. The presence of carbon in the XPS spectra can be attributed to the surface hydrocarbons etc., which can be removed by sputtering. There is no trace of carbon in the XPS depth profile of these films, Fig. 7. The 3d spectra of Ce in fig. 8(b) exhibited complicated features, which are consistent with the results of literature [33]. Six peaks corresponding to three pairs of spin -obit doublets are labeled using the convention established by Burroughs et al. [34]. The symbols $U$ and $V$ refer to the $C e 3 d_{3 / 2}$ and $3 d_{5 / 2}$ spin-orbit components, respectively. In particular, there is small amount of $\mathrm{Ce}^{3+}$ existed in the films on the base of Ce $3 \mathrm{~d}$ spectra in fig.8 (b). However, this could be a consequence of the sputtering process. It was shown by researchers that the oxidation states can be easily changed during sputtering or annealing under vacuum. [35] It is therefore suggested that the Ce only has a +4 oxidation state in our films. The spectra of $\mathrm{Sm}^{3+} 3 \mathrm{~d}_{5 / 2}$ in fig.8(c) indicate that $\mathrm{Sm}$ is fully oxidized in the films with formal oxidation state of +3 . 
PNNL-17069

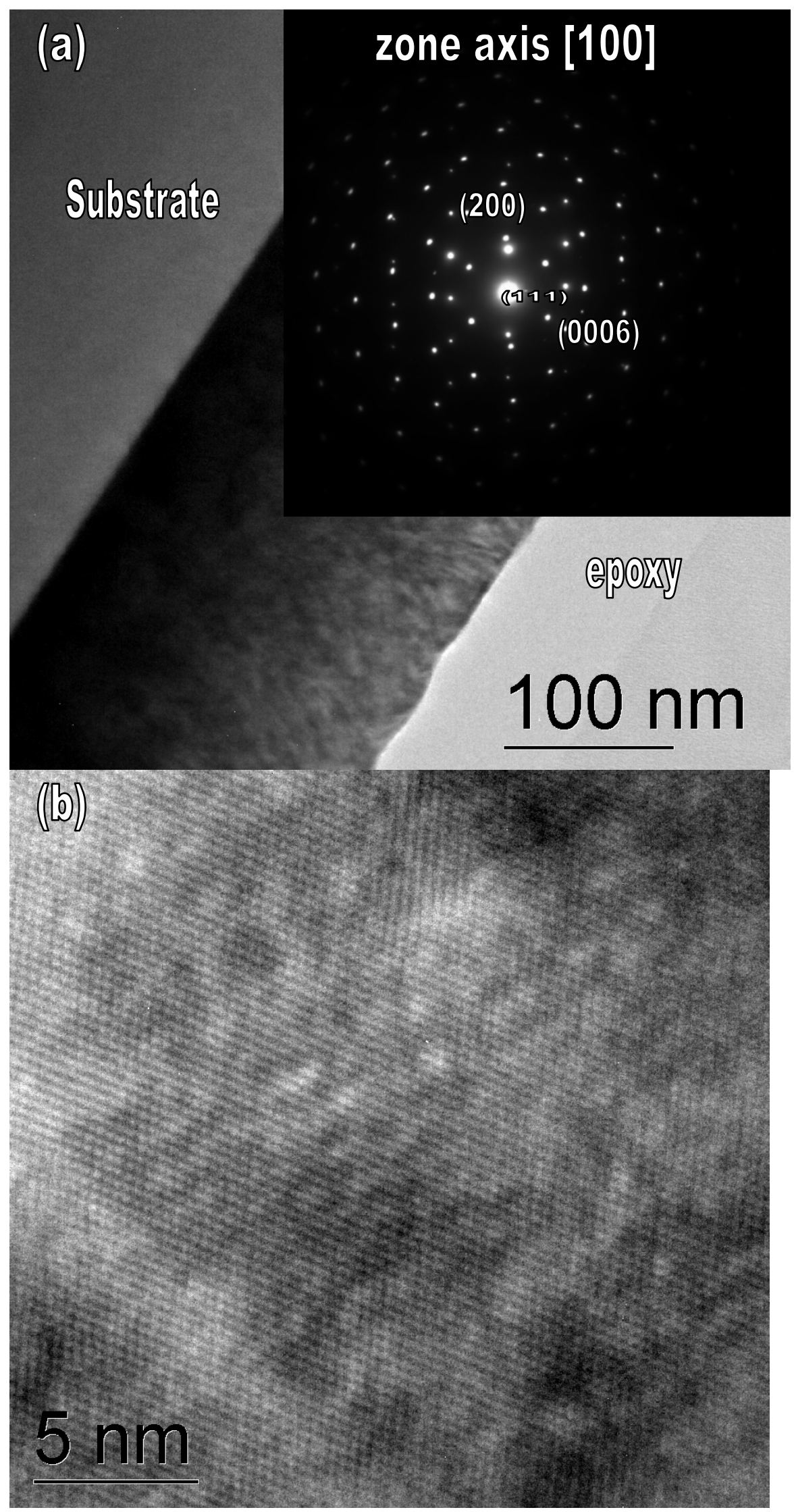


Fig. 6 TEM micrograph (a) showing a cross-sectional view of $\mathrm{Ce}_{0.8} \mathrm{Sm}_{0.2} \mathrm{O}_{1.9}$ film grown on sapphire substrate. Inset is the selected area electron diffraction pattern, revealing an epitaxial orientation relationship between the grown films and sapphire substrate. HRTEM micrograph (b) showing that there is no domain structure in the films.

\section{Conclusion}

The epitaxial growth of $\mathrm{Ce}_{0.8} \mathrm{Sm}_{0.2} \mathrm{O}_{1.9}$ films by oxygen-plasma-assisted MBE on sapphire(0001) substrate has been characterized by RHEED, XPS, XRD, AFM, HRTEM and RBS in order to determine their structure and composition. The stoichiometry of films was determined to be Ce: Sm: $\mathrm{O}$ of $0.8: 0.2: 1.9$ by RBS. The film/substrate epitaxial relationship can be written as $\mathrm{CeO}_{2}(111) / / \alpha-\mathrm{Al}_{2} \mathrm{O}_{3}(0001)$ and $\mathrm{CeO}_{2}[110] / / \alpha-$ $\mathrm{Al}_{2} \mathrm{O}_{3}[2110]$. The films have single domain in-plane along with some point defects and misfit dislocations at the interface. The Ce only has a +4 oxidation state in the films and $\mathrm{Sm}$ is fully oxidized in the films with formal oxidation of +3 .

\section{Acknowledgements}

A portion of the research described in this paper was performed in the Environmental Molecular Sciences Laboratory, a national scientific user facility sponsored by the Department of Energy's Office of Biological and Environmental Research and located at Pacific Northwest National Laboratory.

References

[1] R. Maric, S. Ohara, T. Fukui, H. Yoshida, M. Nishimur, T. Inagaki, and K. Miura Journal of the Electrochemical Society, 146 (1999) 2006.

[2] H. Inaba and H. Tagawa, Solid State Ionics, 83 (1996) 1.

[3] K. Eguchi, T. Setoguchi, T. Inoue, and H. Arai, Solid State Ionics, 52 (1992) 165.

[4] H. Yoshida, K. Miura, J. Fujita, and T. Inagaki, J. Am. Ceram. Soc. 82 (1999) 219.

[5] K. Yashiro, T. Suzuki, A. Kaimai, H. Matsumoto, Y. Nigara, T. Kawada, J. Mizusaki, J. Sfeir, J. Van herle, Solid State Ionics 175 (2004) 341.

[6] S. H. Park, H.Yoo, Solid State Ionics 176 (2005) 1485.

[7] Y. Wang, T. Mori, J. Li, J. Drennan, Journal of the European Ceramic Society 25 (2005) 949.

[8] F. Y. Wang, S. Chen, S. Cheng, Electrochemistry Communications 6 (2004) 743.

[9] F. Y. Wang, B. Z. Wan, S. Cheng, J. Solid State Electrochem. 9 (2005)168.

[10] N. Kim, B. H. Kim, D. Lee, J. Power Sources, 90(2000)139.

[11] J. van Herle, D. Seneviratne, A. J. McEvoy, Journal of the European Ceramic Society, 19 (1999) 837.

[12] J. G. Li, Y. R. Wang, T. Ikegami, T. Mori, T. Ishigaki, Mater. Sci. \& Engin. B 121 (2005)54.

[13] N. Oishi, A. Atkinson, N. P. Brandon, J. A. Kilner, and B, C. H. Steele, J. Am.

Ceram. Soc. 88 (2005)1394.

[14] L. Chen, C.L. Chen, D.X. Huang, Y. Lin, X. Chen, A.J. Jacobson, Solid State Ionics 175 (2004) 103. 
[15] D. X. Huang, C. L. Chen, L. Chen and A. J. Jacobson, Appl. Phys. Lett. 84 (2004) 708.

[16] S. Azad, O. A. Marina, C. M. Wang, L. Saraf, V. Shutthanandan, D. E. McCready, A. El-Azab, J. E. Jaffe, M. H. Engelhard, C. H. F. Peden, and S. Thevuthasan, Appl. Phys. Lett. 86(2005)131906.

[17] E. Gourba, P. Briois, A. Ringuedé, M. Cassir1 and A. Billard, J Solid State Electrochem. 8 (2004)633.

[18] H. J. Park, G. M. Choi, Journal of the European Ceramic Society 24 (2004) 1313.

[19] D. S. Bae, E. J. Kim, S. W. Park and K.S. Han, J. ceramic Processing Res. 5 (2004) 244.

[20] T. Suzuki, P. Jasinski, and H. U. Anderson, Ceram. Engin. and Sci. Proceedings, 24 (2003)323.

[21] G. B. Jung, T. J. Huang, C. L. Chang, J. Solid State Electrochem. 6(2002)225.

[22] J. E. Shemilt and H. M. Williams, J. Mater. Lett. 18(1999)1735.

[23] J. G. Li, T. Ikegami, T. Mori, Acta Materialia 52 (2004) 2221.

[24] D. X. Huang, C. L. Chen, and A. J. Jacobson, J. Appl. Phys. 97(2005)043506 .

[25] F. Y. Wang, B. Z. Wan, S. Cheng, J. Solid State Electrochem. 9(2005)168.

[26] T. Mori, Y. Wang, J. Drennan, G. Auchterlonie, J. Li, T. Ikegami, Solid State Ionics, $175(2004) 641$.

[28] J. E. Shemilt, C. L. Stanway, and H. M. Williams, Solid State Ionics 134(2000)111. [29] Y. J. Kim, Y. Gao, G. S. Herman, S. Thevuthasan, W. Jiang, D. E. McCready, and S. A. Chambers J. Vac. Sci. Technol. A 17(1999)926.

[30] S. A. Chambers, T. T. Tran, and T. A. Hileman, J. Mater. Res. 9(1994)2944.

[31] S. Thevuthasan, C. H. F. Peden, M. H. Engelhard, D. R. Baer, G. S. Herman, W. Jiang, Y. Liang, and W. J. Weber, Nucl. Instrum. Methods Phys. Res. A 420 (1999) 81.

[32] M. Pan, G. Y. Meng, H. W. Xin, C. S. Chen, D. K. Peng, Y.S. Lin, Thin Solid Films (1998)89.

[33] Y. J. Kim, , S. Thevuthasan, V. Shuttananadan, C. L. Perkins, D. E. McCready, G. S. Herman,Y. Gao, T. T. Tran, S. A. Chambers, and C. H. F. Peden, J. electron Spectroscopy and Related Phenomena 126 (2002)177.

[34] P. Burroughs, A. Hamnett, A. F. Orchard, G. Thornton, J. Chem. Soc. Dalton Trans.17(1976)1686.

[35] V. S. Smentkowski, Progress in Surface Science, 64(2000)1. 
PNNL-17069 


\title{
Study of Calcium Doped Lanthanum Ferrite in Single-Step Co-Fired Solid Oxide Fuel Cells
}

\author{
Peter A. Zink ${ }^{\mathrm{a}}$, Larry R. Pederson ${ }^{\mathrm{b}}$, Uday B. Pal ${ }^{\mathrm{a}}$, Srikanth Gopalan ${ }^{\mathrm{a}}$ \\ a Department of Manufacturing Engineering, Boston University, 15 Saint Mary's Street, \\ Brookline, MA, 02446, USA \\ b Pacific Northwest National Laboratory, Materials Synthesis and Modification Group, \\ Richland, Washington 99352, USA
}

\begin{abstract}
A-site deficient calcium doped lanthanum ferrite (LCF) cathode materials were synthesized and tested to determine their electrochemical and phase stability for use in single-step co-fired solid oxide fuel cells (SOFC). A gadolinium doped-ceria (GDC) barrier layer is used to prevent reaction between the LCF cathode and the YSZ electrolyte. Analysis shows evidence of formation of a liquid phase in LCF-20 at approximately $1220^{\circ} \mathrm{C}$ at the grain boundaries. Symmetrical cells were fabricated and tested yielding reasonable electrochemical performance and fine microstructure. In the fabricated cells the liquid phase migrated through the ceria barrier layer and formed a distinct thin layer between the YSZ and GDC layers. Cathode thickness and porosity were optimized to increase electrochemical performance.
\end{abstract}




\section{Introduction}

Single-step co-firing requires a sintering temperature of approximately $1300^{\circ} \mathrm{C}$ in order to ensure complete densification of the electrolyte, and therefore requires refractory cathode materials to preserve porosity and high three-phase boundary length. Doped lanthanum ferrites are promising candidate cathode materials for use in single-step co-fired SOFCs, due to their relatively high electrochemical activity in the intermediate temperature $\left(600-800^{\circ} \mathrm{C}\right)$ range. A-site deficient lanthanum ferrite cathode materials doped with calcium and cerium were synthesized and analyzed to determine their potential applicability and phase stability during high temperature processing. Reaction between the lanthanum ferrite cathode and YSZ electrolyte, as seen by Anderson et al [3] was prevented by the use of a thin gadolinium doped-ceria (GDC) barrier layer. 


\section{Experiment}

Calcium doped lanthanum ferrite $\mathrm{La}_{0.8} \mathrm{Ca}_{0.2} \mathrm{FeO}_{3 \pm \delta}(\mathrm{LCF}-20)$ and $\mathrm{La}_{0.85} \mathrm{Ca}_{0.15} \mathrm{FeO}_{3 \pm \delta}$ (LCF-15) were prepared by solid-state reaction of $\mathrm{La}_{2}\left(\mathrm{CO}_{3}\right)_{3} \cdot \mathrm{XH}_{2} \mathrm{O}(99.99 \%), \mathrm{CaO}(99 \%)$, and $\mathrm{Fe}_{2} \mathrm{O}_{3}(99.945 \%)$. The powders were mixed by ball milling in ethanol, dried in air, and then calcined at $1300^{\circ} \mathrm{C}$. Calcined powders were ground with an alumina mortar and pestle, and then ball-milled until a desired particle size distribution was obtained as measured with a Horiba LA-910 Laser Scattering Particle Size Distribution Analyzer.

Inductively Coupled Plasma Mass Spectrometry (ICMPS) was performed on the LCF-20 calcined powder. The crystal structure of the manufactured powders was analyzed by x-ray diffraction (XRD), using a $\mathrm{Cu}-\mathrm{K} \alpha$ radiation source operated at $40 \mathrm{kV}$ and $40 \mathrm{~mA}$ to verify the solid-state reaction was complete.

LCF-20 bar samples ( $4 \mathrm{~mm} \times 4 \mathrm{~mm} \times 32 \mathrm{~mm}$ ) were prepared by uniaxial pressing at approximately $14 \mathrm{MPa}$ and isostatic pressing at $\sim 400 \mathrm{MPa}$ and sintered at $1330^{\circ} \mathrm{C}$ with a thin layer of platinum foil (Alfa Aesar, 99.99\%) between the samples and the alumina plate to prevent any reactions between LCF and alumina. Four-probe DC conductivity tests were performed at 25 degree intervals from $\sim 180^{\circ} \mathrm{C}$ to $900^{\circ} \mathrm{C}$ on a thin sintered bar $(35 \mathrm{~mm} \mathrm{x}$ $3 \mathrm{~mm} \times 2.5 \mathrm{~mm})$. Tests were performed in conditions of both ramping the furnace up and down, and measurements were performed at each temperature until no change was detected, indicating the bar had reached equilibrium. Seebeck analysis was performed simultaneously with the 4-probe testing.

Half cells were manufactured using a tape-cast YSZ electrolyte, approximately 100-130 $\mu \mathrm{m}$ thick and sintered at $1500^{\circ} \mathrm{C}$ for 2 hours. One layer of GDC-20 (Praxair) 5-10 $\mu \mathrm{m}$ thick and three layers of LCF-20 slurry $25-30 \mu \mathrm{m}$ thick were applied. The cell was co-fired at $1330^{\circ} \mathrm{C}$ for 2 hours (though in this case the YSZ was pre-sintered), and gold contact ink was applied to the cell for electrical contact (figure 1). Gold meshes were used on each side of the cell as current collectors. 


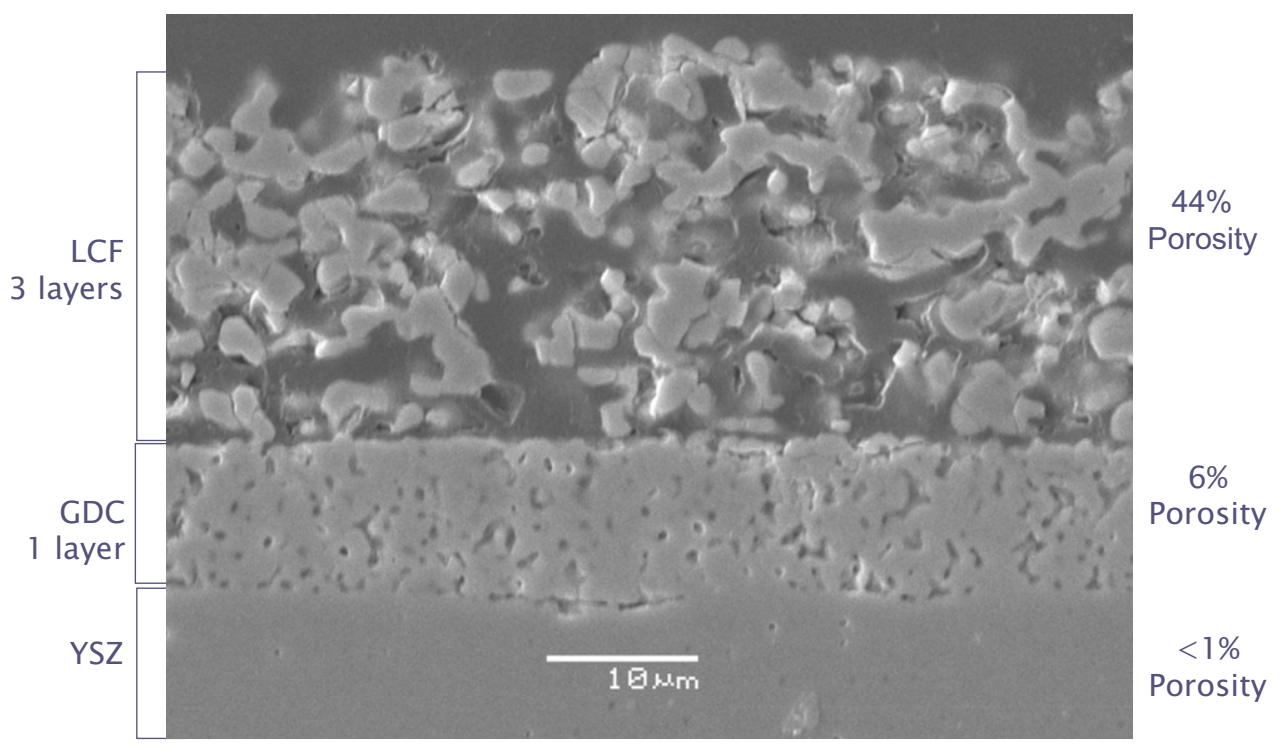

Figure 1. Cell microstructure cross-section

Three different LCF cells were tested, with variations in the thickness controlled by changing the number of LCF layers and variations in porosity controlled by the amount of pore former added to the LCF slurries. An LCM cell was also tested to provide a baseline comparison.

For each half-cell tested, two-electrode DC current-interrupt and EIS measurements were performed. The cell was tested in a two-electrode (total electrode polarization) and threeelectrode configuration. In the three-electrode configuration, the cell is tested cathodically (with a reference electrode) and anodically (with a reference electrode), and the current is applied so that the polarization direction is held constant across the cell, to prevent hysteresis. The distinction of an anodic vs. cathodic side of the cell is chosen arbitrarily as the cell is manufactured symmetrically (figure 2). 
PNNL-17069

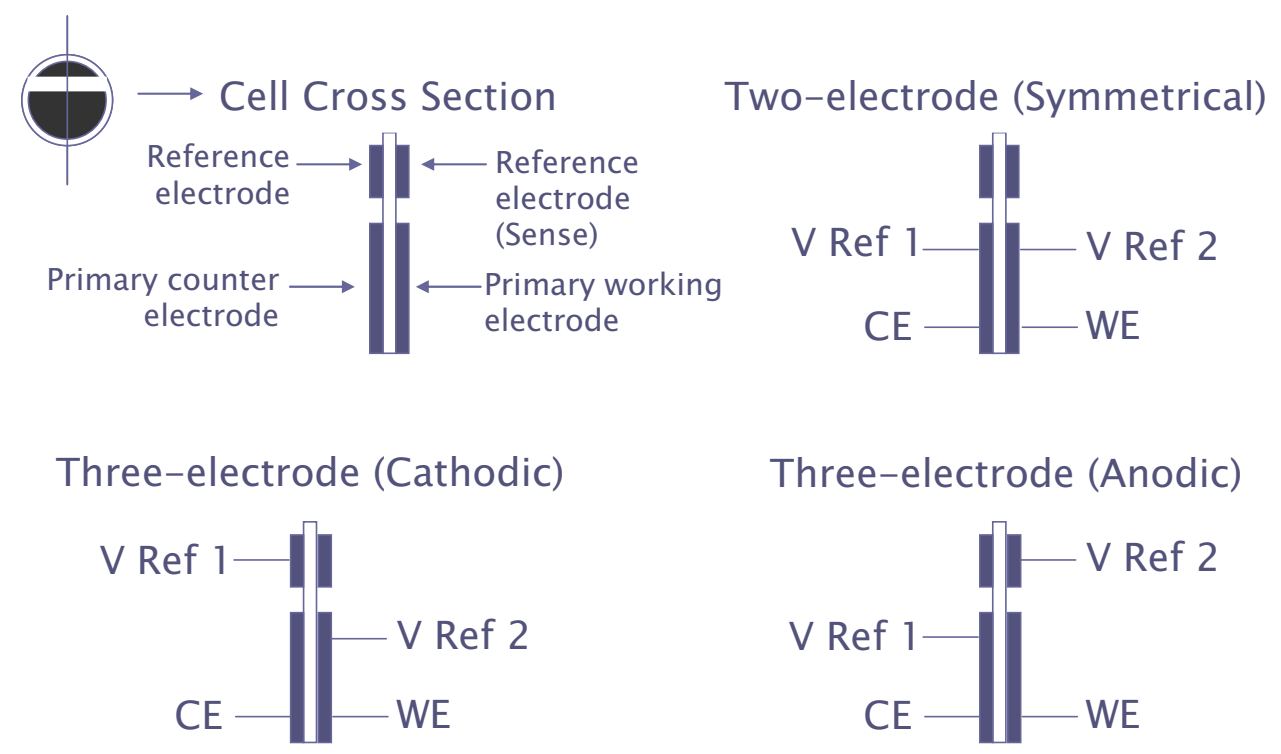

${ }^{*}$ Anodic and cathodic distinction is assigned arbitrarily, since cell is symmetric

Figure 2. Half Cell Electrode Test Configurations

EIS measurements were performed at open circuit voltage (OCV), and with applied 100 and $250 \mathrm{mV}$ polarizations in symmetric, cathodic and anodic configurations for both current interrupt and EIS measurements. The sum of the anodic and cathodic measurements was compared with the two-electrode value to verify that the cell partitioned properly and was truly symmetrical. Measurements were performed over a range of temperatures at 50 degree intervals from $650^{\circ} \mathrm{C}$ to $800^{\circ} \mathrm{C}$.

Oxygen permeation analysis was performed on a dense 1" diameter pellet. The pellet was isostatically pressed at $60,000 \mathrm{psi}$, and ground to 0.720 " $(18.3 \mathrm{~mm})$ diameter, and one face was machine ground flat. The final thickness was $0.0725 "(1.84 \mathrm{~mm})$. The pellet was mounted between the ends of two alumina tubes with gold O-rings, and heated to $950^{\circ} \mathrm{C}$. Data was collected while the pellet was cooled to room T, heated to 900 , and cooled to room temperature again. 
PNNL-17069

\section{Results and Discussion}

ICPMS found the synthesized LCF-20 to be $8 \%$ A-site deficient, with a non-stoichiometry of $\mathrm{La}_{0.74} \mathrm{Ca}_{0.18} \mathrm{FeO}_{3 \pm \delta}$ and a La:Ca ratio of 4.1:1. XRD analysis did not show any evidence of a second phase, as was the case for Anderson et al. [3], and Hung et al [4]. Lattice parameters were obtained by fitting the reflected peaks to a published PDF data file for an orthorhombic cell.

XRD analysis did not show any evidence of a second phase. Lattice parameters were obtained by fitting the reflected peaks to a published PDF data file for an orthorhombic cell.

4-probe conductivity tests yielded $\sim 93 \mathrm{~S} / \mathrm{cm}$ at $800^{\circ} \mathrm{C}$, a value slightly higher than earlier reported results $\left(71 \mathrm{~S} / \mathrm{cm}\right.$ at $\left.800^{\circ} \mathrm{C}\right)$ for the same composition [7]. This disagreement is consistent with the lower porosity of this sample due to the significantly higher pressure applied during bar sample manufacture. The results of both up and down ramping are plotted in figure 3. A slight hysteresis is visible at high temperature in the lower oxygen environments. Clearly visible in the results is an increase in conductivity as $\mathrm{pO}_{2}$ increases, which indicates LCF is a p-type conductor.

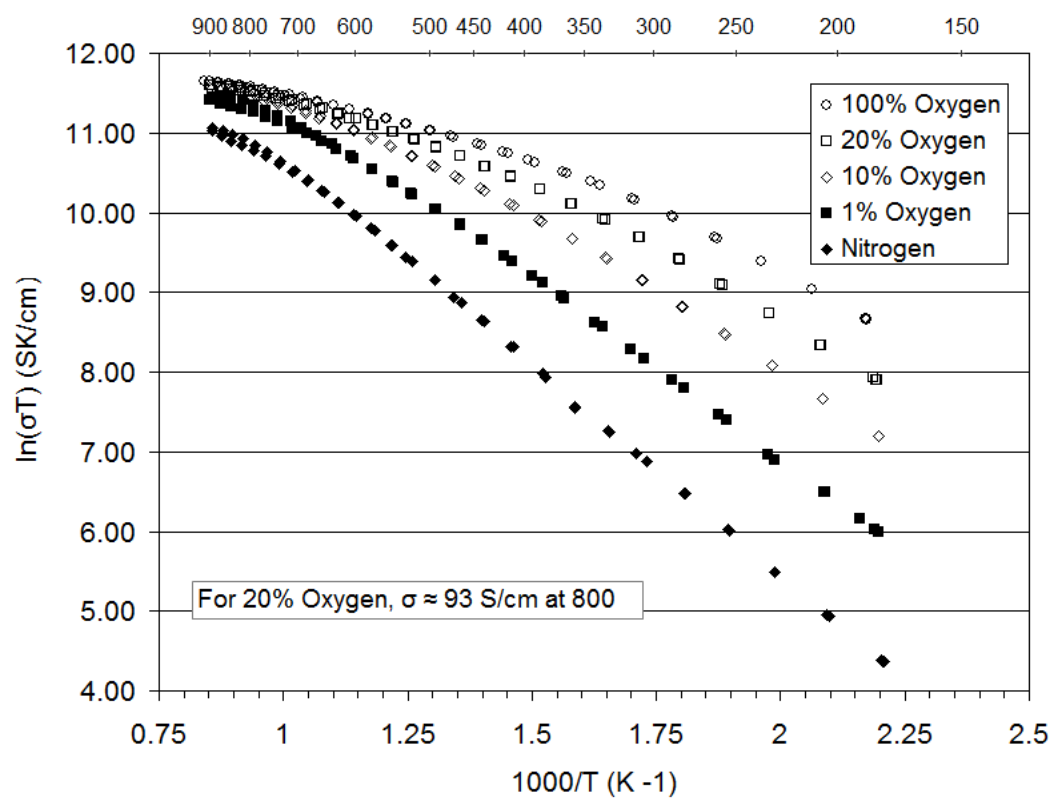

Figure 3. 4-probe conductivity results for LCF-20 
At low temperatures in 4-probe conductivity results we expect to find the same activation energy $\left(\mathrm{E}_{\mathrm{a}}\right)$ independent of $\mathrm{pO}_{2}$, because the number of oxygen vacancies should be "frozen in". However, the results show that at low temperatures, $\mathrm{E}_{\mathrm{a}}$ slightly increases as $\mathrm{pO}_{2}$ decreases.

Seebeck analysis confirmed LCF-20 is a p-type conductor (figure 4a). A plot of carrier fraction vs. temperature shows an increase in carrier fraction as $\mathrm{pO} 2$ increases, and a maximum of carriers from $350-500^{\circ} \mathrm{C}$ (figure $4 \mathrm{~b}$ ).

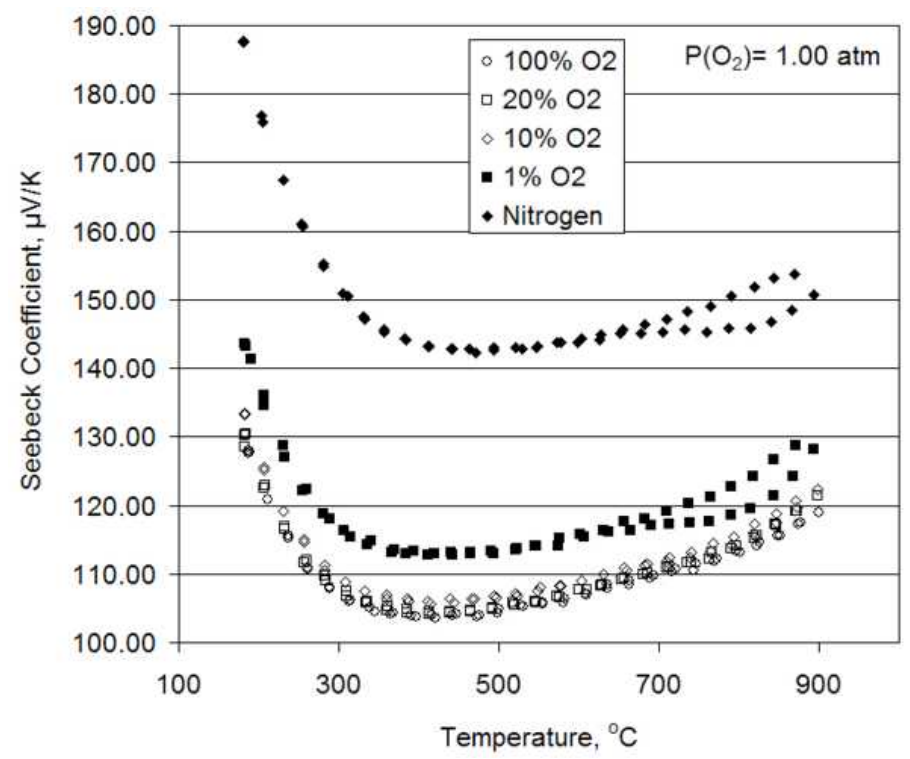

Figure 4a. LCF-20 Seebeck data

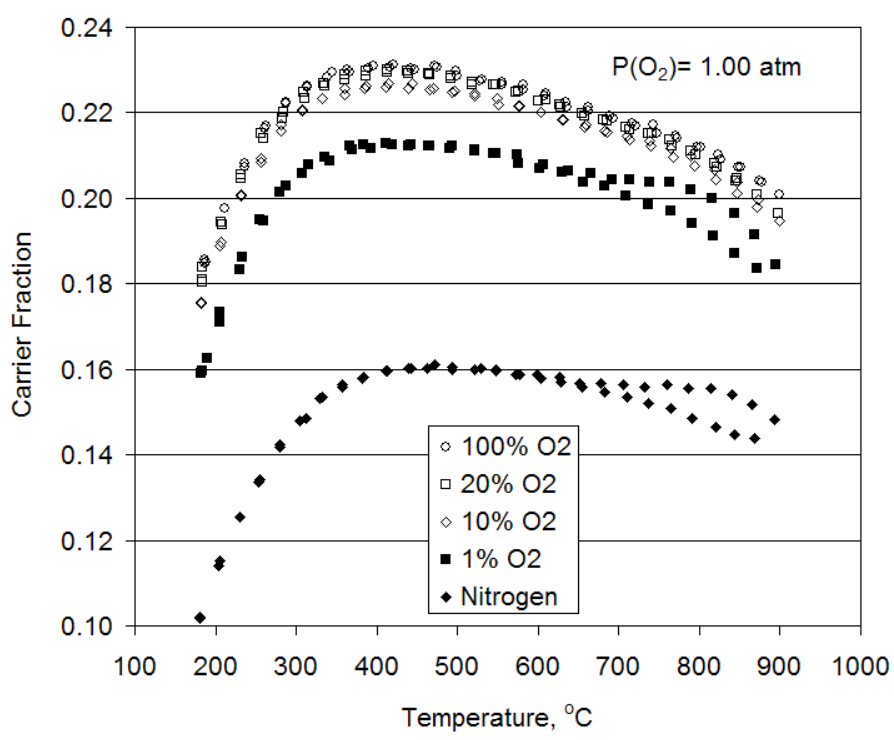

Figure4b. LCF-20 Carrier fraction 
Cyclic voltammetry of the cells showed that they performed symmetrically (figure 5).

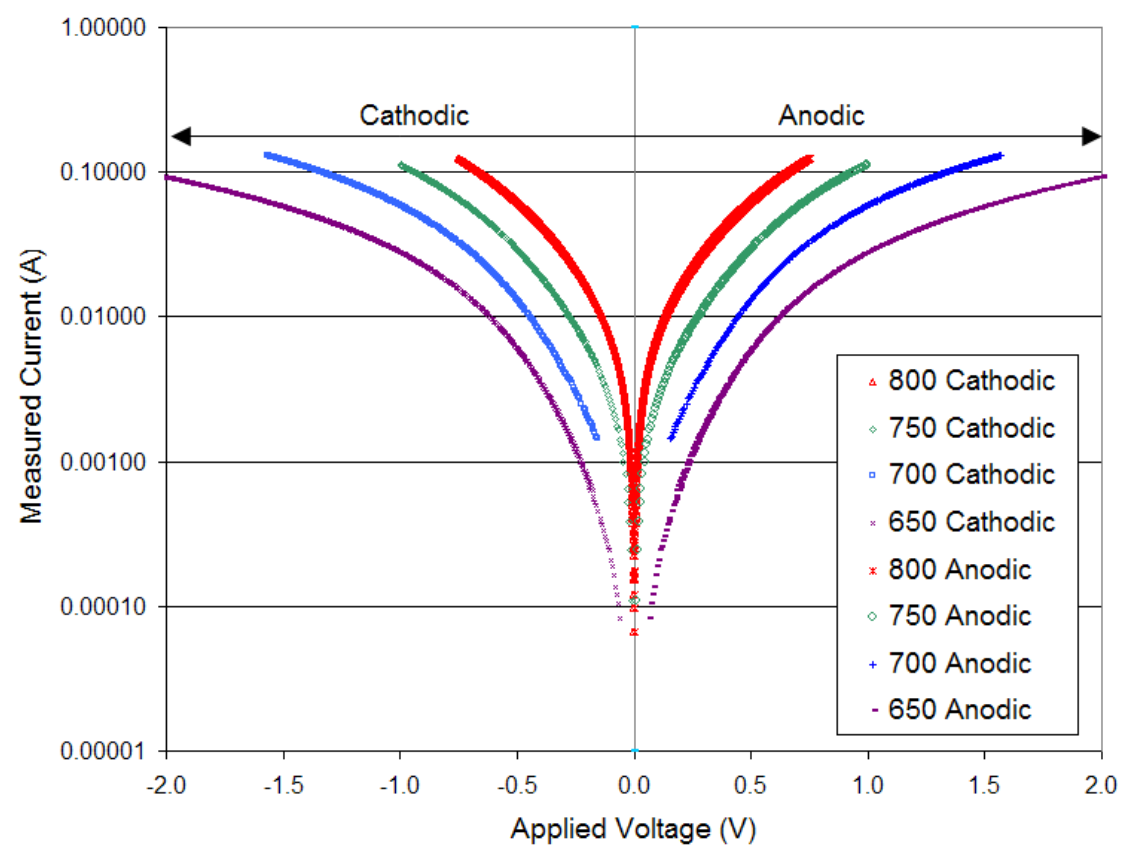

Figure 5. DC Cyclic Voltammetry

Current interrupt data shows that at high anodic potentials, the potential difference forces $\mathrm{O}^{2-}$ ions over to the anodic side of the cell, filling oxygen vacancies and causing visible roll off of the slope, indicating higher ionic resistance (figure 6). At this point, the cathode material is functioning as less of a mixed conductor, and may even be approaching stoichimetric LCF-20 (neglecting the A-site deficiency). We can also see the plot becoming steeper at high negative (cathodic) potentials. This cannot be due to resistive heating effects, as the same result is not seen on the anodic side. This suggests that the increasing slope is due to the creation of excess $\mathrm{O}^{2-}$ vacancies, thereby increasing the $\mathrm{O}^{2-}$ ionic conductivity.

Comparison of the impedance value of three cells shows that the cell with the thicker electrode and lowest porosity had the lowest polarization resistance (Rp), and also indicates that cathode thickness plays a larger role in cell performance in this case than porosity (figure 7). 
PNNL-17069

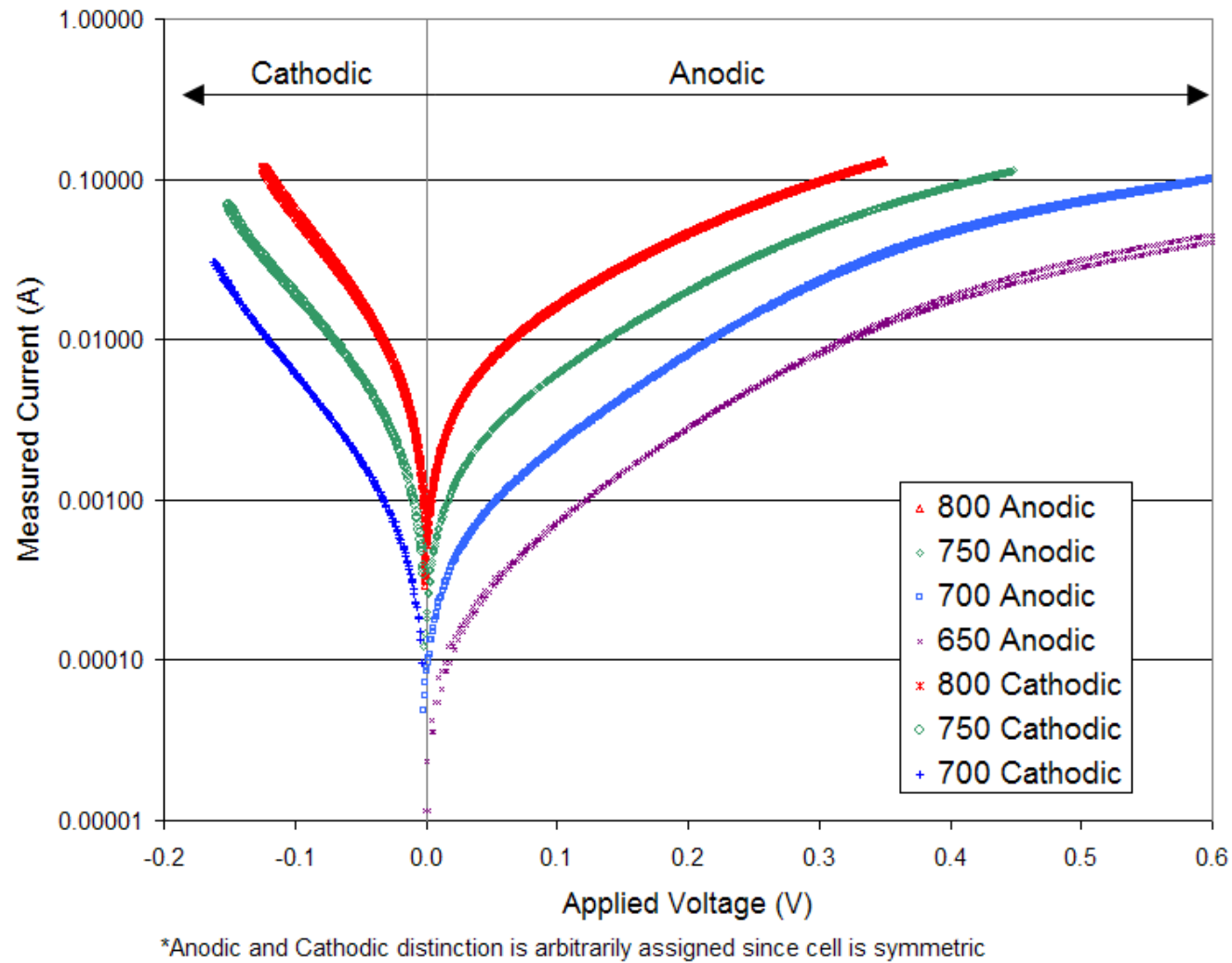

Figure 6. DC Current Interrupt

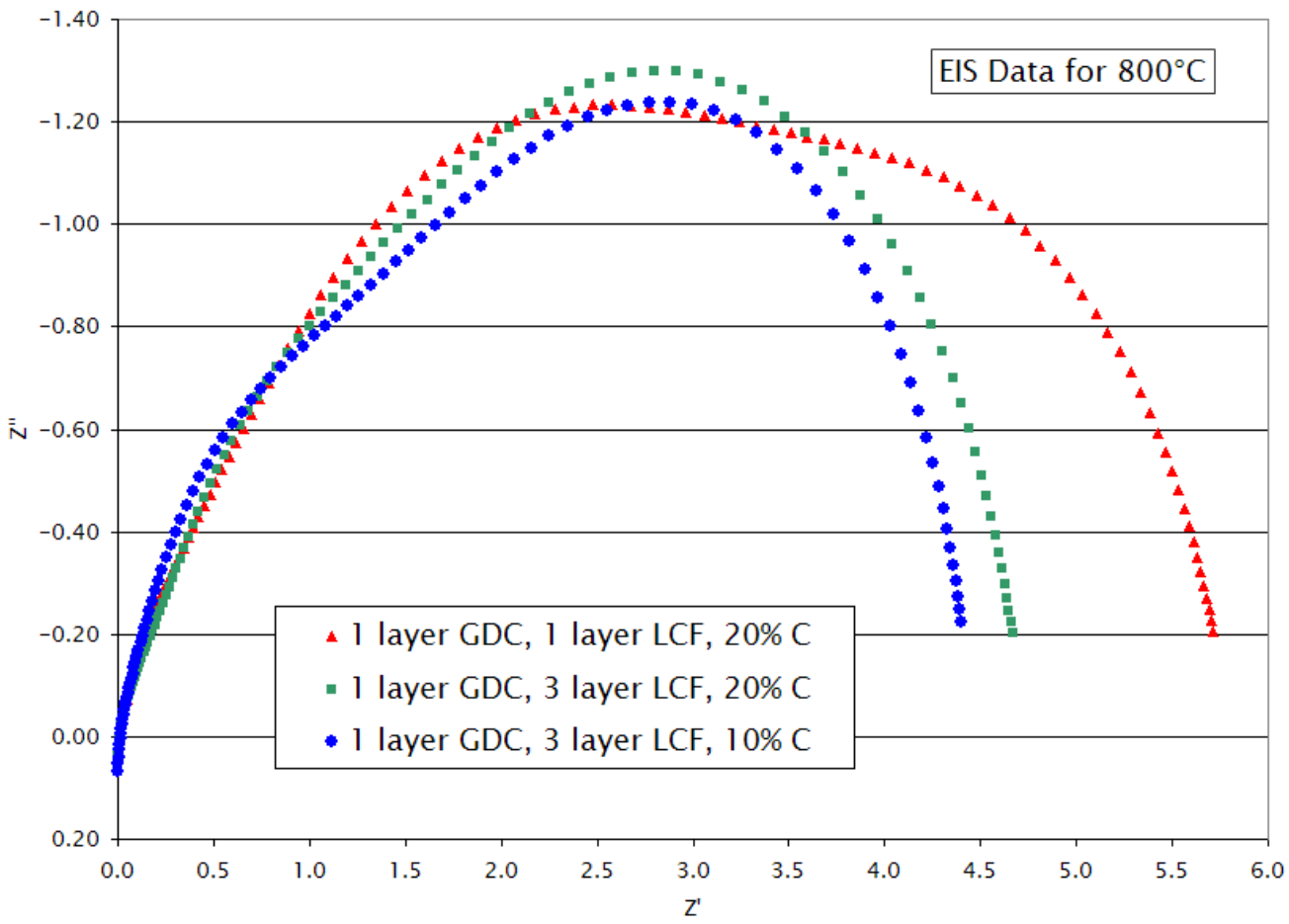

Figure 7. Cell impedance comparison 
It is also recognized that induced polarization of the cell using the DC and current interrupt may cause the measured values to change [8]. As the same procedure was used in all cases, we place emphasis on the value of these measurements to determine the relative effects of the cell variations rather than the absolute performance of each cell.

The oxygen permeation data collected during the final cooling step had the lowest observed background and is shown in figure 8 below, where it is compared to LSF-20.

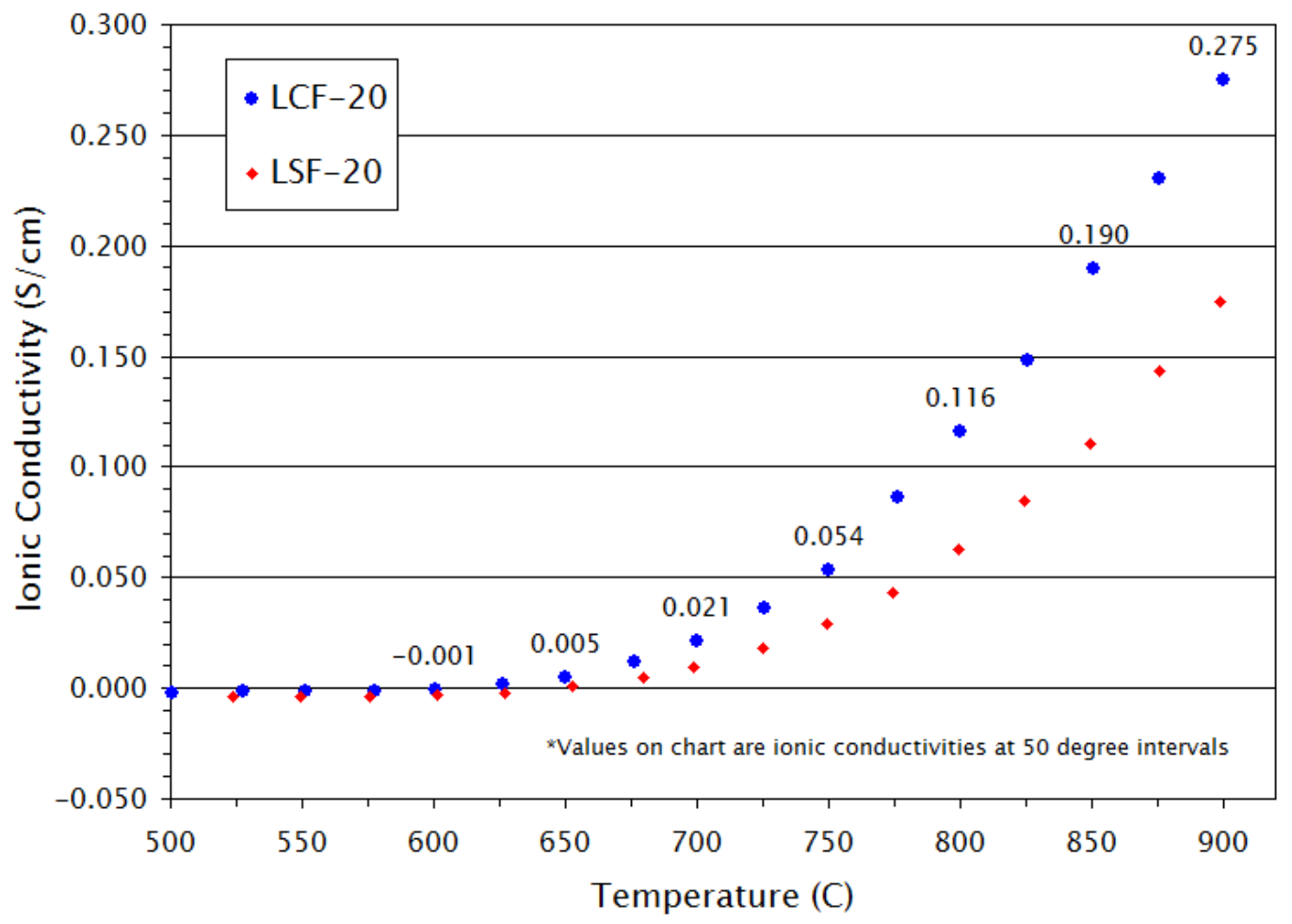

Figure 8. Oxygen permeation data of LCF-20. LSF-20 data courtesy of PNNL.

From the oxygen permeation data we are able to estimate activation energy. Inspection of the data shows that there may be two distinct regions with different activation energies, one region above $850^{\circ} \mathrm{C}$ and one below. The activation energy above $850^{\circ} \mathrm{C}$ is $0.96 \mathrm{eV}$, while below $850^{\circ} \mathrm{C}$ it is $1.18 \mathrm{eV}$ (figure 9). This suggests that there may be more than one conductivity mechanism present in each case. The ionic transference number was also calculated, found to be slightly higher than LSF-20, and increase with temperature (figure $10)$. 
PNNL-17069

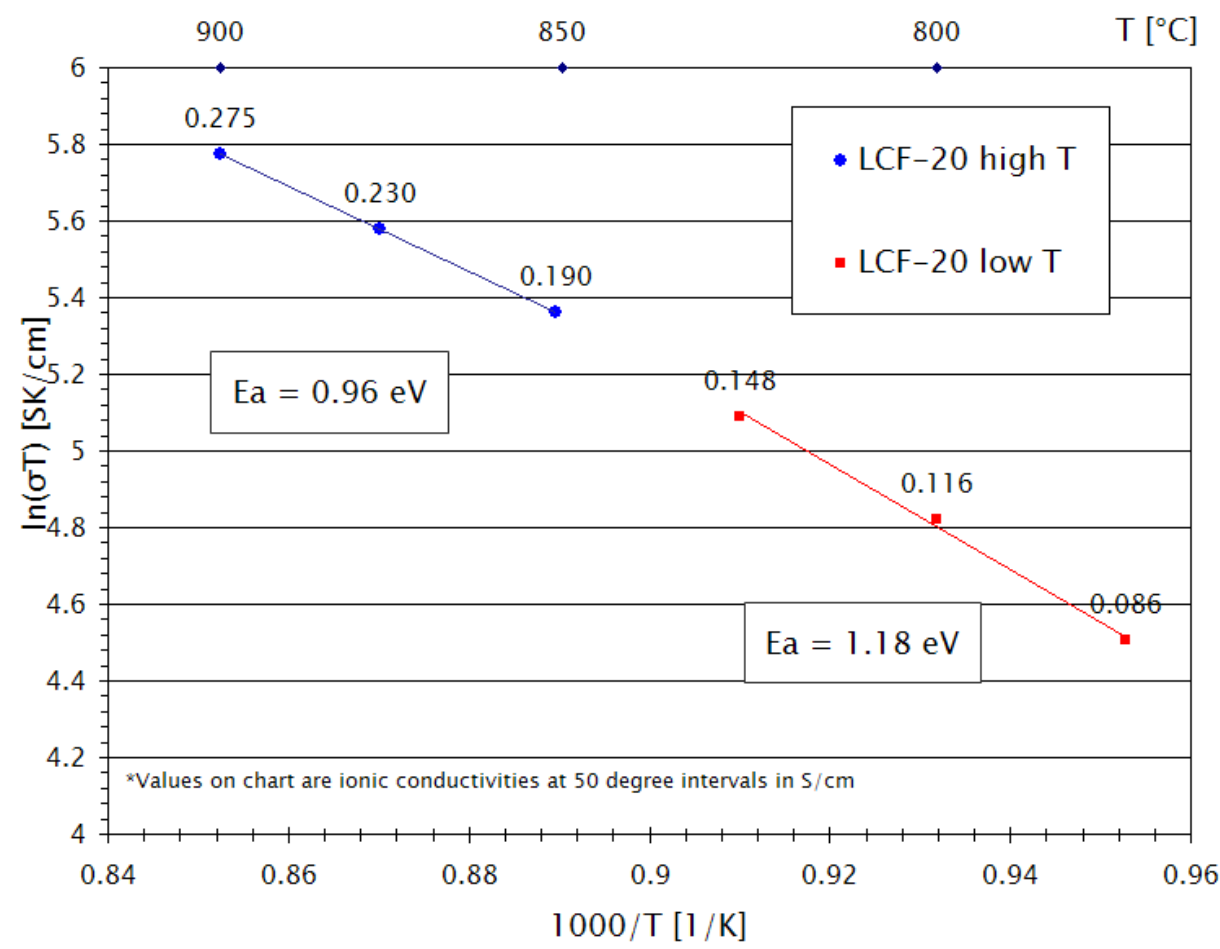

Figure 9. Ionic conductivity of LCF-20 with activation energies

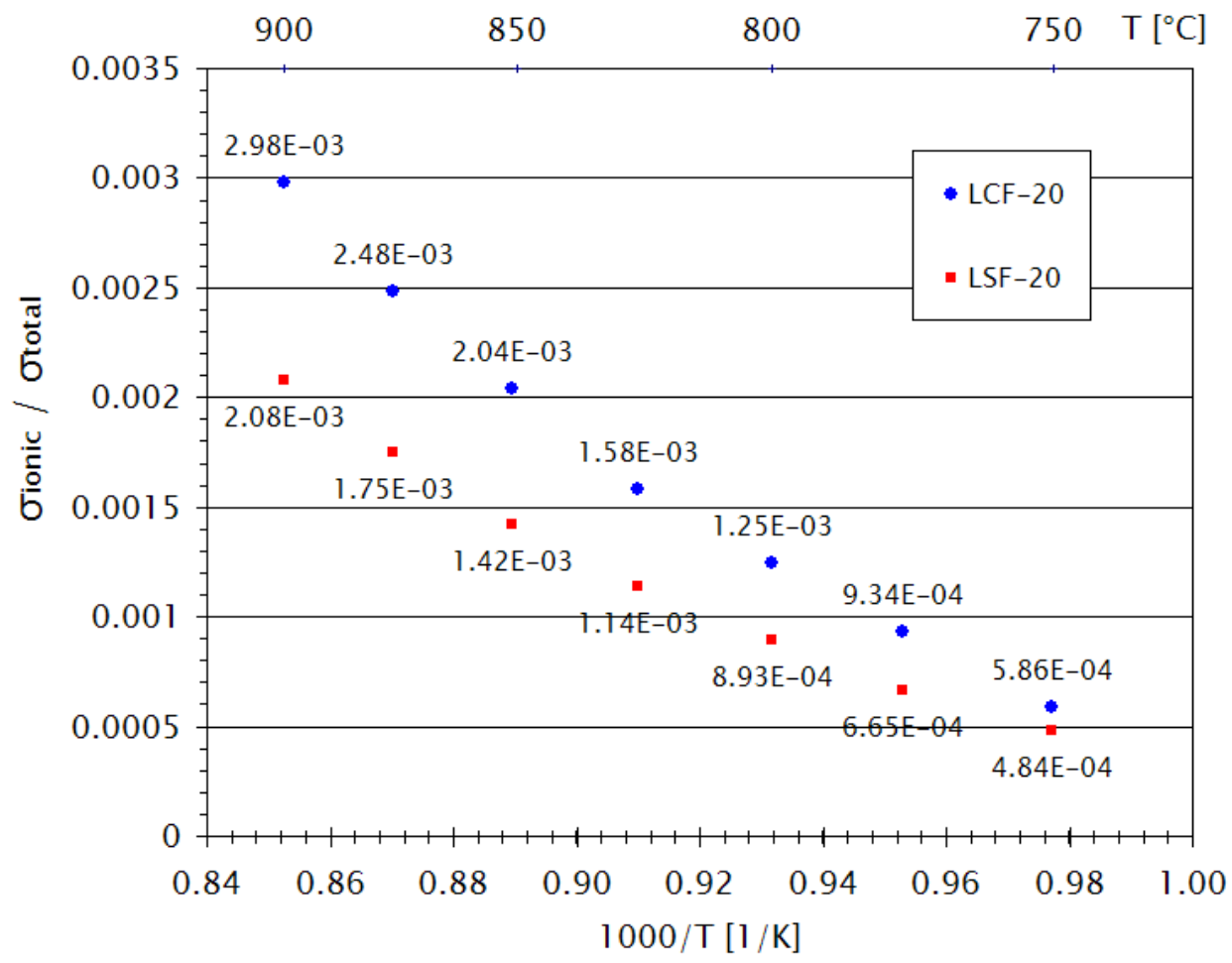

Figure 10. Ionic transference number of LCF-20 and LSF. LSF data courtesy of PNNL 
Wavelength dispersive spectroscopy (WDS) of a sectioned LCF bar sample revealed evidence of a second phase (black), poor in La and rich in Fe when compared to the bulk composition (grey), visible in figure $2 \mathrm{a}$. The composition of the dark phase was found to be $\mathrm{La}_{0.01} \mathrm{Ca}_{0.20} \mathrm{FeO}_{3}$ and was estimated from the photo below to comprise $5 \%$ of the total volume of the sample. The composition of the light (bulk) phase was $\mathrm{La}_{0.83} \mathrm{Ca}_{0.18} \mathrm{FeO}_{3}$.

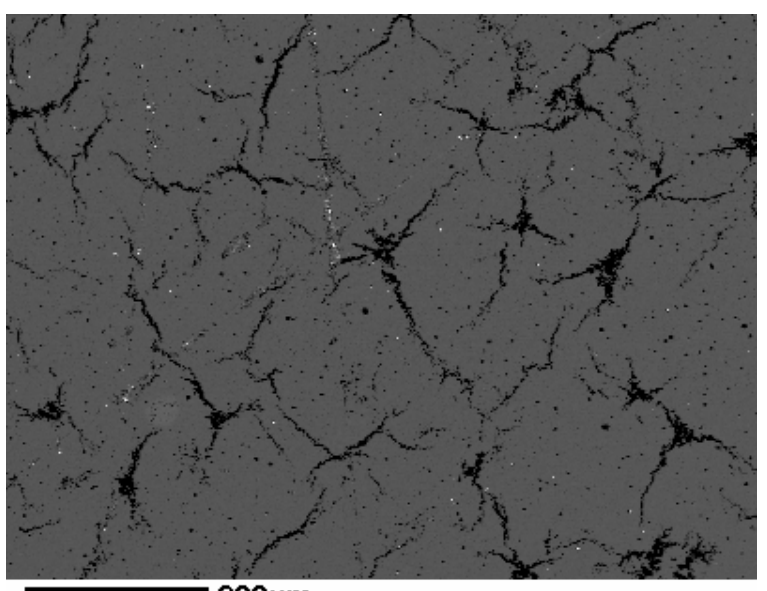

BE sample4

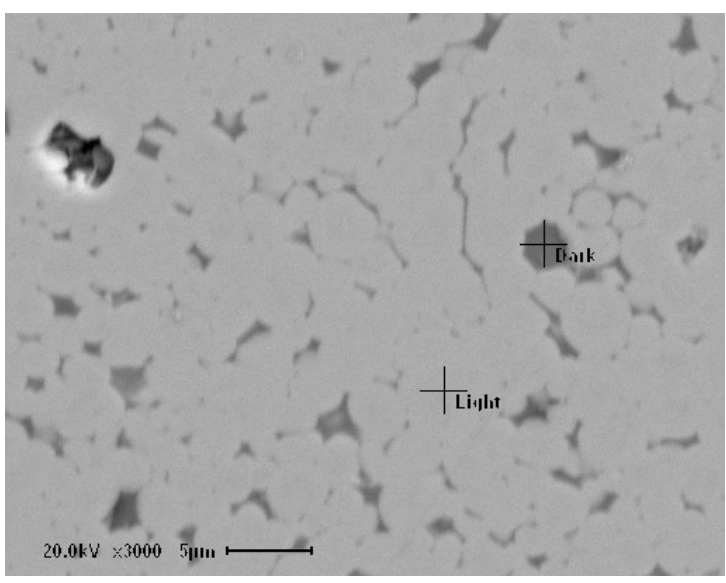

Figure 11b. SEM image of long bar

Dilatometry of a long thin bar $(35 \mathrm{~mm} \times 3 \mathrm{~mm} \times 2.5 \mathrm{~mm})$ and a short bar $(11 \mathrm{~mm} \times 3 \mathrm{~mm} \times$ $2.5 \mathrm{~mm}$ ) show a distinct mechanical failure abruptly at $1220^{\circ} \mathrm{C}$ (figure 12 ). Visual analysis of the alumina supports used in the dilatometer show evidence of diffusion into the lower support. EDX analysis of the polished cross section of the tested bar (figure 11b) showed a similar phase separation, with a dark phase composition of $\mathrm{La}_{0.06} \mathrm{Ca}_{0.21} \mathrm{FeO}_{3 \pm \delta}$ and a bulk composition of $\mathrm{La}_{0.81} \mathrm{Ca}_{0.15} \mathrm{FeO}_{3 \pm \delta}$. The compositions are both similar to the WDS results, however, the microstructure in the dilatometry sample was much finer, and the dark phase clearly formed at the grain boundaries. We hypothesize that this is due to the relatively high cooling rate experienced by the dilatometry sample, which was cooled from approximately 1300 to $400^{\circ} \mathrm{C}$ at 45 degrees per minute. SEM of quenched and non-quenched samples was performed to confirm this hypothesis. In all cases, the La: Ca ratio in the light phase was $\approx 5$ (table 1), suggesting that this may be a more stable composition than the originally 
synthesized composition. As well, the A-site deficiency of the resulting light phase was lower, suggesting that compositions closer to stoichimetric values may be more stable.

\begin{tabular}{|c|c|c|c|c|}
\hline & Dark1 & Dark2 & Light1 & Light2 \\
\hline $\mathrm{La}$ & 0.01 & 0.06 & 0.83 & 0.81 \\
\hline $\mathrm{Ca}$ & 0.2 & 0.21 & 0.18 & 0.15 \\
\hline La:Ca & 0.05 & 0.29 & 4.61 & 5.40 \\
\hline
\end{tabular}

Table 1. La:Ca ratios in light and dark phases of WDS (1) and EDX (2) analyzed samples.

Other studies have found phase separation in LCF. Isupova et al [6] show that LCF $(20 \%$ Ca) samples calcined at $1100^{\circ} \mathrm{C}$ in air form solid solutions with components of $\mathrm{LaFeO}_{3}$ and $\mathrm{Ca}_{2} \mathrm{Fe}_{2} \mathrm{O}_{5}$.
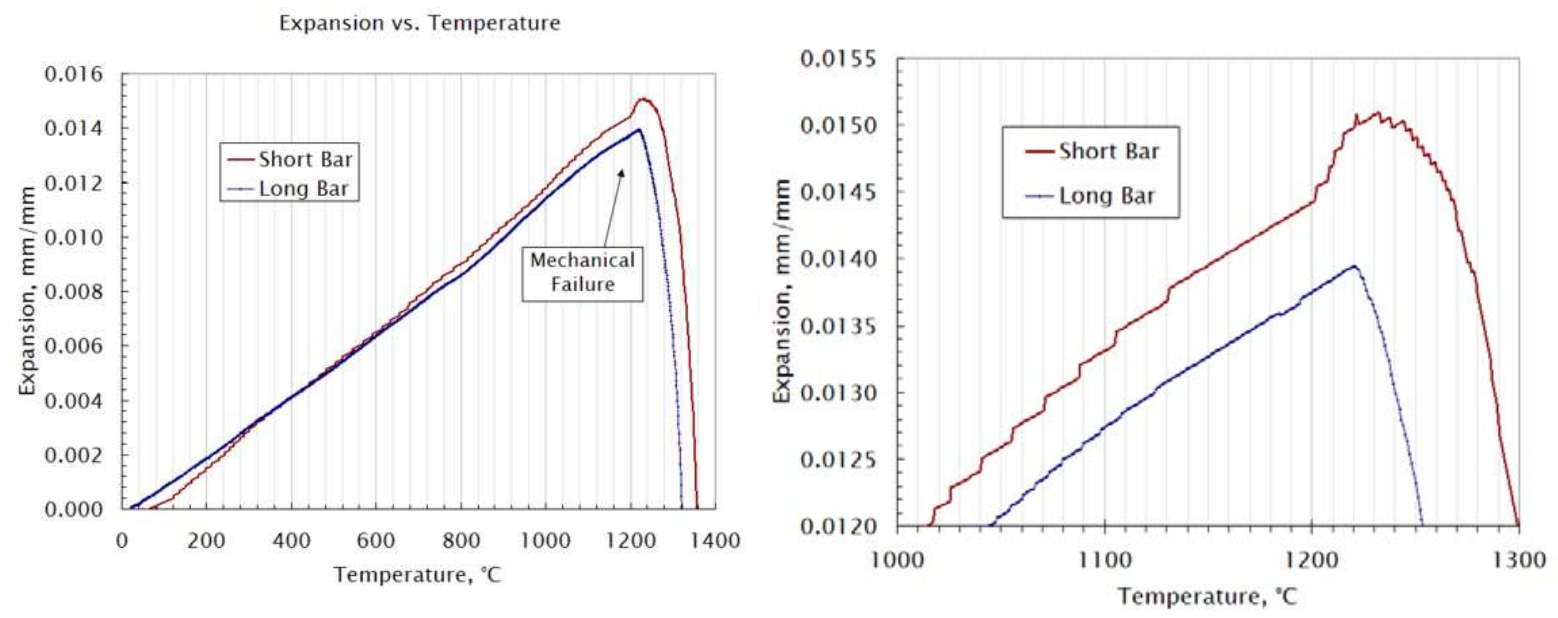

Figure 12. Dilatometry of LCF-20 showing mechanical failure of both samples at $\sim 1220 \mathrm{C}$.

Dilatometry data indicated different values for the thermal expansion coefficient (TEC), although both values are close to the reported value. A lower range of temperatures was used to calculate the TEC to avoid including the effects of any phase transformations in the TEC calculation. 
PNNL-17069

\begin{tabular}{|c|c|c|}
\hline Sample & TEC $\left({ }^{\circ} \mathrm{C}-1 \times 10-6\right)$ & Range \\
\hline LCF-20 (long bar) & 11.3 & {$\left[200-800^{\circ} \mathrm{C}\right]$} \\
\hline LCF-20 (short bar) & 12.4 & {$\left[200-800^{\circ} \mathrm{C}\right]$} \\
\hline \hline LCF-20 [4] & 11.7 & {$\left[30-1000^{\circ} \mathrm{C}\right]$} \\
\hline LSF-20 $[5]$ & 12.0 & {$\left[30-1300^{\circ} \mathrm{C}\right]$} \\
\hline
\end{tabular}

Table 2. TEC values

The Ca-Fe-O phase diagram (figure 13) shows a liquid phase emerges for a range of compositions approximately equal to the detected dark phase composition at temperatures as low as $1205^{\circ} \mathrm{C}$, with several partial liquid binary phases emerging between $1205^{\circ} \mathrm{C}$ and $1226^{\circ} \mathrm{C}$. The Ca:Fe ratio in the detected dark phase of both samples was 1:5. Examination of the phase diagram shows that this composition is not present, and suggests that the dark phase is actually a mixture of two phases. A simple mixture that leads to a 1:5 Ca:Fe ratio is a 2:1 mixture of $\mathrm{CaO} \cdot 2 \mathrm{Fe}_{2} \mathrm{O}_{3}$ and pure $\mathrm{Fe}_{2} \mathrm{O}_{3}$.

\section{$\mathrm{Ca}-\mathrm{Fe}-\mathrm{O}$ (cont.)}

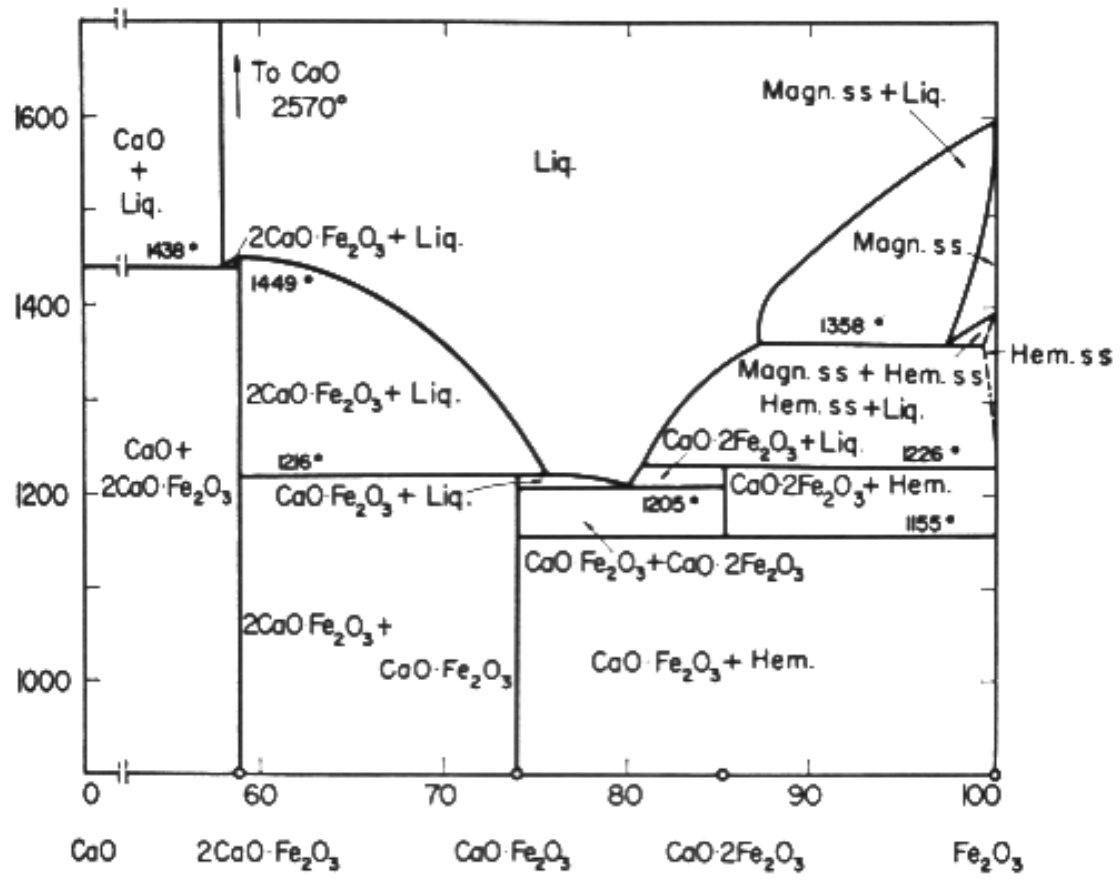

Figure 13. $\mathrm{CaO}-\mathrm{Fe}_{2} \mathrm{O}_{3}$ Phase Diagram - Bert Phillips and Arnulf Muan, J. Am Ceram. Soc., $41[11] 448(1958)$ 
Thermogravimetric analysis also shows evidence of possible phase change beginning at $1220^{\circ} \mathrm{C}$. Figure 14 shows data from TG/DTA of a powdered sample of LCF-20.

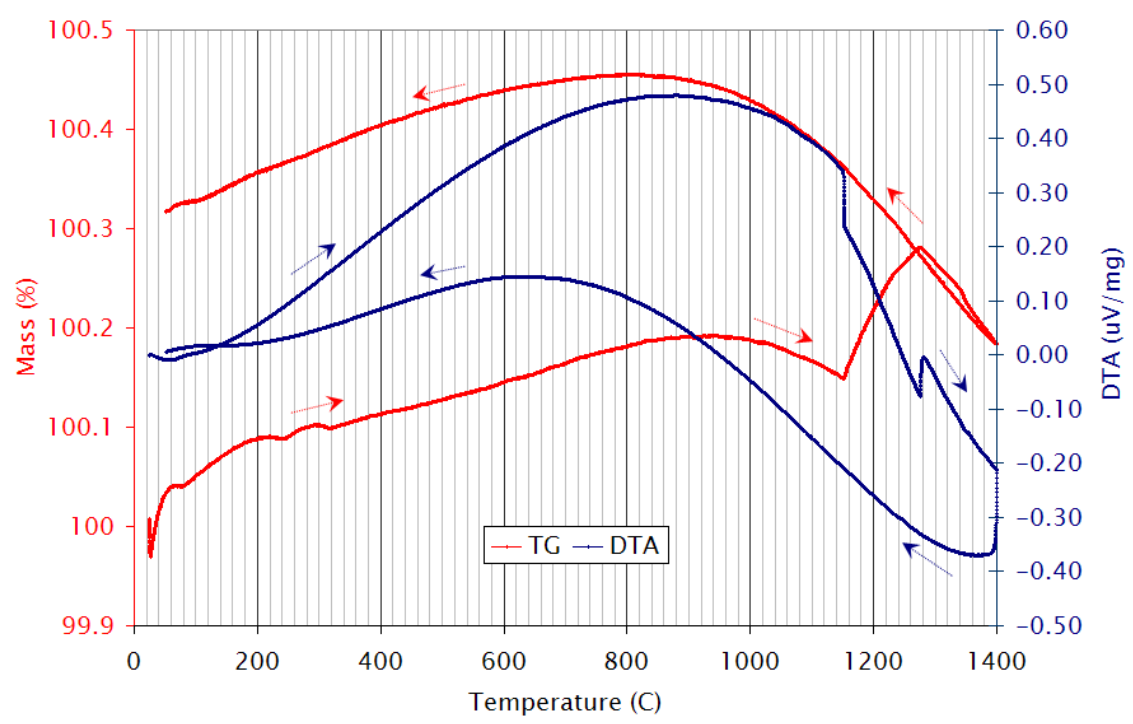

Figure 14. TG/DTA of LCF-20

Although we expect that the liquid phase is likely to be present in the half cell microstructure, it is not readily visible in SEM as seen in dense bulk samples. This may be due to use of pore former in cell manufacture, creating high (44\%) porosity, allowing the liquid phase to collect on the pore surfaces. In a few regions of the cell, the liquid phase was observed to have migrated through the GDC barrier and formed a thin layer in between the GDC and YSZ layers (figure 15).

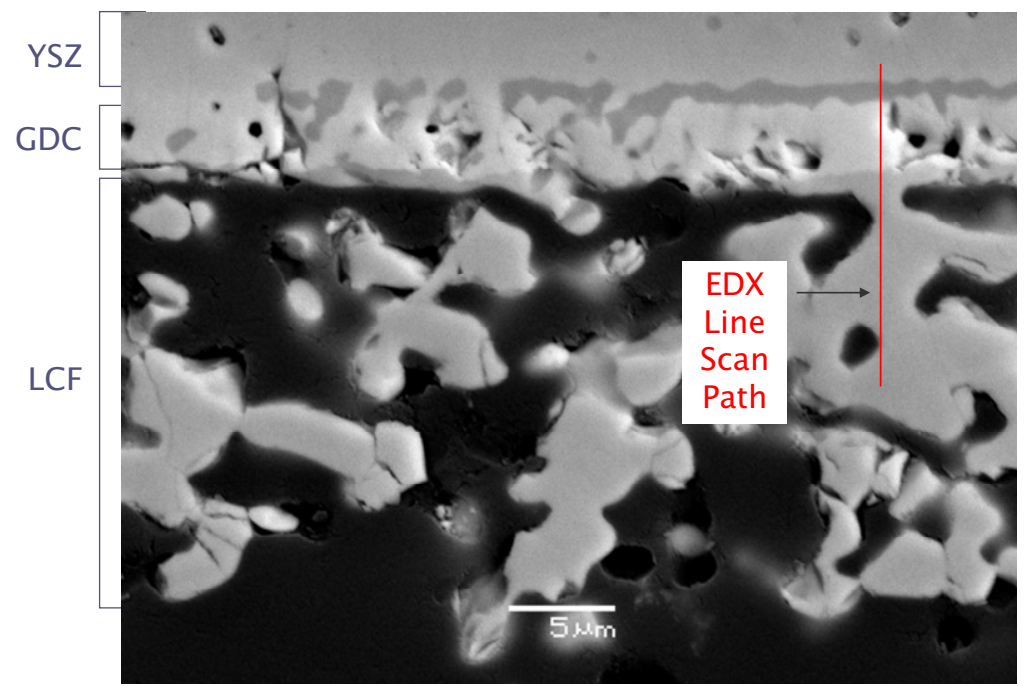

Figure15. Cell cross-section showing liquid phase migration through GDC 
PNNL-17069
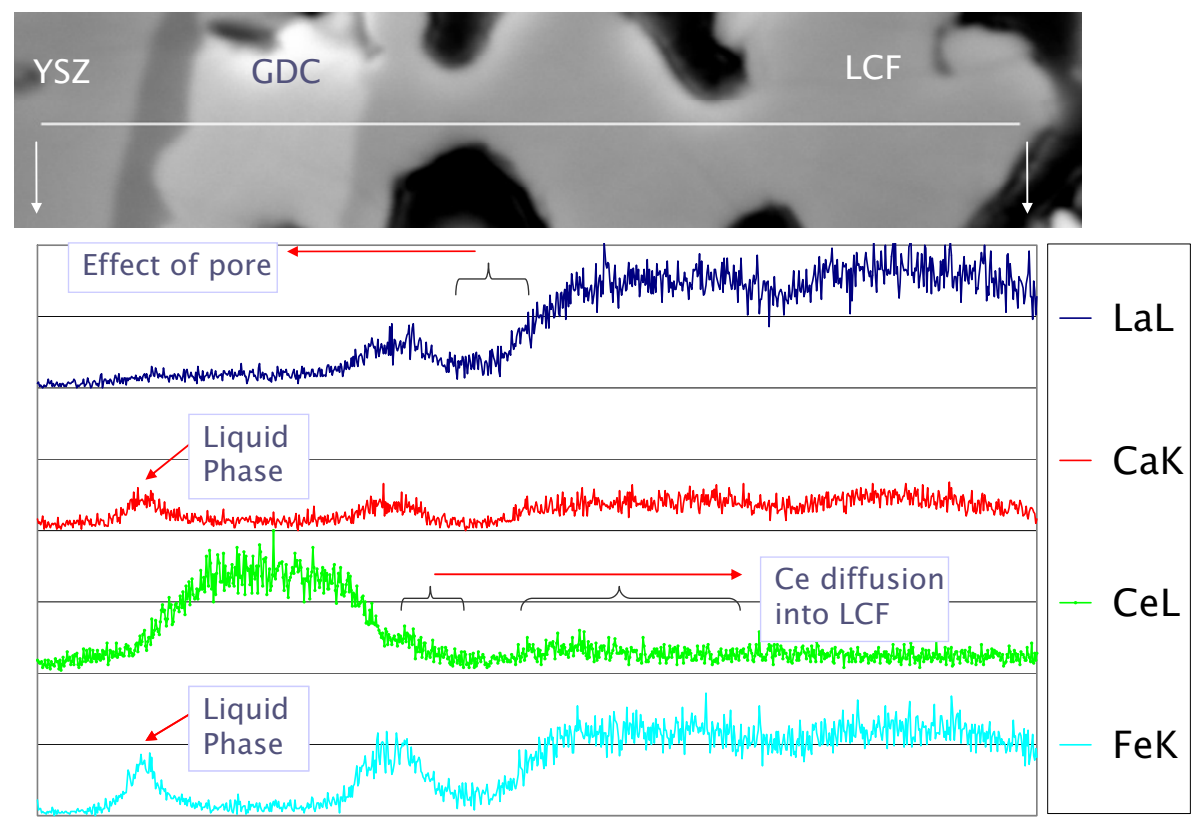

Figure 16. Cell cross-section showing $\mathrm{Ca}$, Fe rich liquid phase migration through GDC

An EDX line scan of the region (figure 16) indicates that the liquid phase penetrated the GDC layer and is $\mathrm{Ca}$ and Fe rich, as would be expected if it were the same liquid phase detected in the bulk samples. The migration through GDC was not observed in most of the cell, suggesting that it may have occurred here due to connected cracks or pores in this region caused by imperfections in cell manufacturing.

Evidence of Ce diffusion into the LCF microstructure is visible in the EDX scan, and can be seen more clearly in figure 17. 


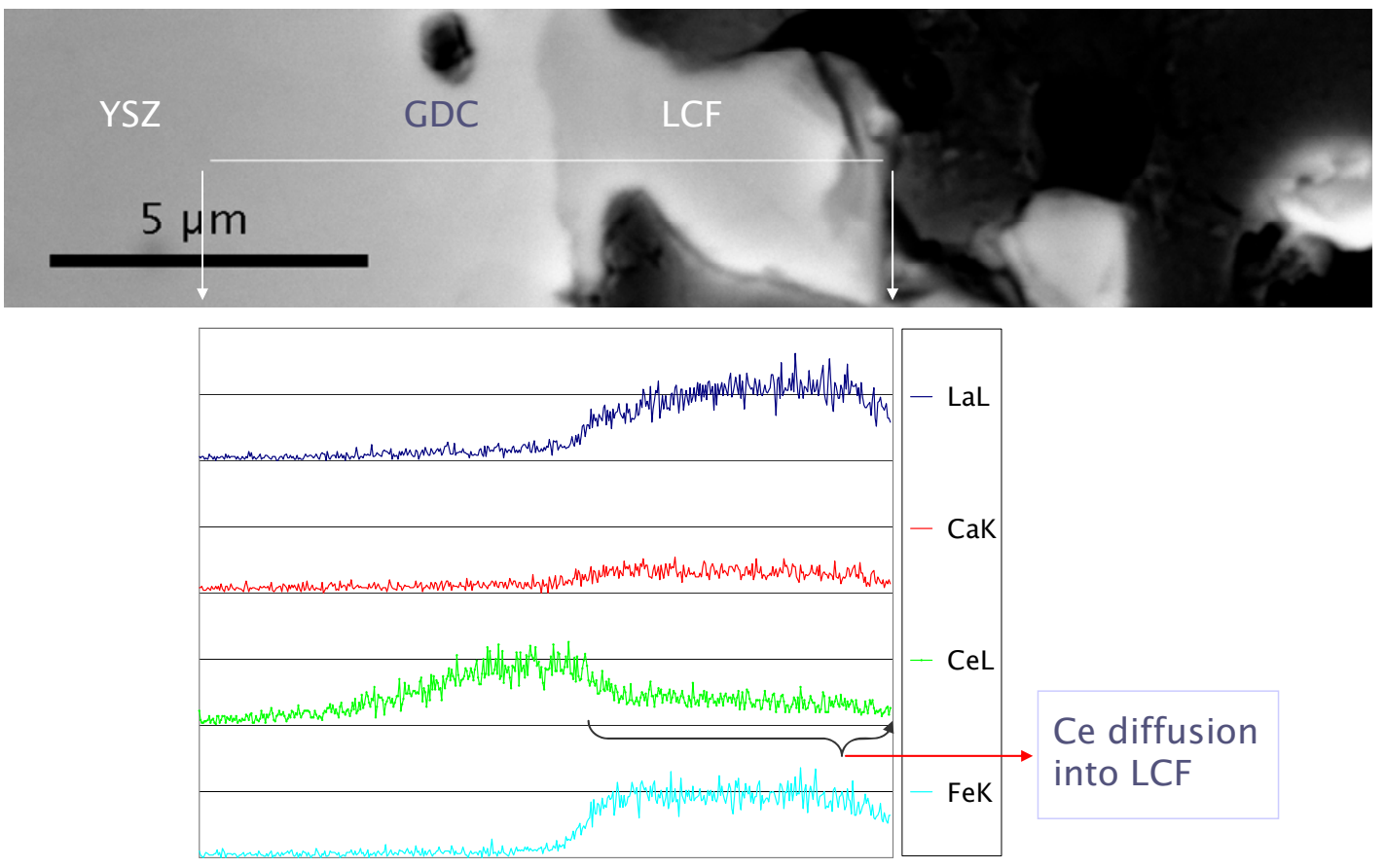

Figure 17. Cell cross-section showing Ce diffusion into LCF

Based on the evidence that Ce might be diffusing into the LCF lattice, calcium and cerium doped lanthanum ferrite $\mathrm{La}_{0.75} \mathrm{Ca}_{0.2} \mathrm{Ce}_{0.05} \mathrm{FeO}_{3 \pm \delta}$ (LCCF-2005), and $\mathrm{La}_{0.8} \mathrm{Ca}_{0.15} \mathrm{Ce}_{0.05} \mathrm{FeO}_{3 \pm \delta}$ (LCCF-1505) were prepared using the same procedures employed for the LCF compositions with the addition of $\mathrm{CeO} 2(99 \%)$. Powders and pressed bar samples were prepared and described in the LCF procedure, and examined to determine the effects, if any of cerium on the overall phase stability. Calcium and cerium doped samples were found to be less prone to sintering shrinkage, that is, they are more refractory than the samples only doped with calcium.

SEM analysis of LCCF-1505 shows a secondary phase, though the morphology of the phase is different from LCF-20. Both samples were sintered at $1300^{\circ} \mathrm{C}$ and cooled at $5^{\circ} \mathrm{C} / \mathrm{min}$, however, the secondary (liquid) phase in LCF-20 forms a much larger and more connected feature (figure 18a and 18b). 


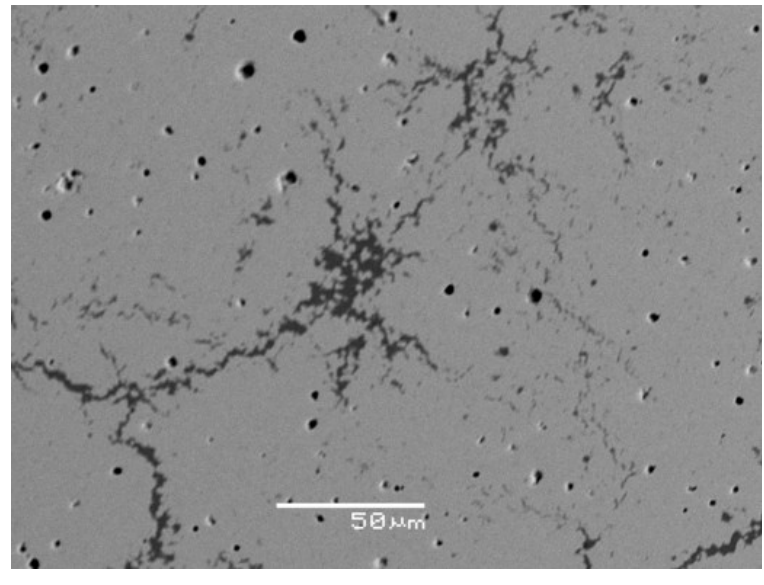

Figure 18a. LCF-20 microstructure

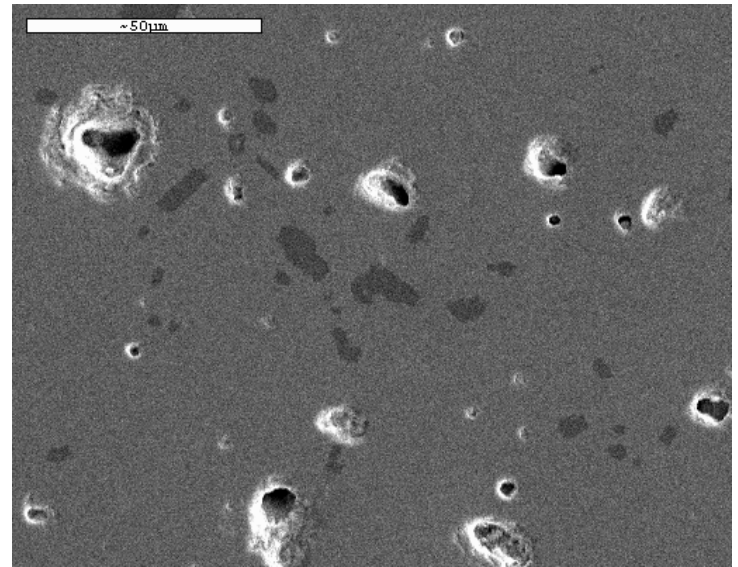

Figure 18b. LCCF-1505 microstructure

\section{Conclusions}

The results clearly show the formation of a liquid phase, though it is unknown exactly at what temperature the phase begins to form, and on cooling, at what temperature it is reabsorbed into the perovskite lattice, if at all. The liquid phase is seen in all LCF and LCCF compositions manufactured to date. It is not clear what the effect of the liquid phase has on the symmetrical cell performance, though it is generally agreed that the formation and inherent mobility of liquid phases suggests long term instability. However, current results show that reasonable symmetrical cell performance can be attained using cells with ample liquid phase present.

In an effort to reduce this effect, a post-phase separation bulk composition (for ex: $\mathrm{La}_{0.82} \mathrm{Ca}_{0.16} \mathrm{FeO}_{3}$ ) will be manufactured and microstructural analysis performed to detect any phase separation. Symmetrical cells will continue to be tested to optimize performance as a function of thickness and porosity. 
PNNL-17069

\section{References}

1. Kyung Joong Yoon, Peter Zink, Srikanth Gopalan, and Uday B. Pal, Polarization Analysis in Single-Step Co-fired Solid Oxide Fuel Cells (SOFCs), Vol. 972, p. AA 10, Materials Research Society Symposium Proceedings of the Fall 2006 Meeting, (2007)

2. Kyung Joong Yoon, Peter Zink, Srikanth Gopalan, and Uday B. Pal, Polarization Measurements on Single-Step Co-fired Solid Oxide Fuel Cells (SOFCs), Journal of Power Sources, Submitted 10/06

3. Michael D. Anderson, Jeffry W. Stevenson, Steven P. Simner; Journal of Power Sources, 129 188-192 (2004)

4. M.-H. Hung et al./Materials chemistry and Physics 101 (2007) p.300

5. S. P. Simner, J. F. Bonnett, N. L. Canfield, K. D. Meinhardt, V. L. Sprenkle, and J. W. Stevenson; Electrochemical and Solid-State Letters, 5 7, A173-A175 (2002)

6. Mater. Res. Soc. Symp. Proc. Vol. 848 C 2005 Materials Research Society

7. P. Zink, K. J. Yoon, W. Huang, S. Gopalan, U. B. Pal, In: ECS Transactions - Solid Oxide Fuel Cells, Volume 7, (2007)

8. Steven McIntosh, Stuart B. Adler, John M. Vohs, and Raymond J. Gortea, Electrochemical and Solid-State Letters, 7 (5) A111-A114 (2004) 
PNNL-17069 


\section{Appendix: The Survey and Responses}

\section{Four Years of the Summer Research Institute}

The Summer Research Institute (SRI) in interfacial and condensed matter physics as a BES-funded stretch goal project will end this fiscal year. However, your perspectives are important and can play a role in determining if a similar program can be maintained at PNNL and what form that program might take as a self-funded vehicle. I encourage you to take a few minutes to answer the following questions and to append any additional materials (publication citations, proposal summaries, etc.) that arose out of research and collaborations fostered by the SRI. Every question may not apply to you. We may wish to use your comments, so please indicate whether you would prefer to remain anonymous. Our aim is to demonstrate both the impact and positive material effect of the SRI over its successful four-year lifespan at PNNL. I would appreciate a reply by September 14th. Thanks.

---* Ken Beck, Coordinator of the SRI

\section{Section I. Contact Information}

Please provide me with current contact information

Name

Address 1

Address 2

City, ST Zipcode

E-mail

Phone

Are you willing to be contacted for further follow-up questions? Yes

\section{Section II: Measures of success}

1. Has your SRI activity been part of an on-going collaboration?

2. Will the SRI experience contribute to future collaboration outside the summer program?

3. Did the work contribute to your research or project aims? How?

4. Did the work lead to publication(s) and presentation(s) with SRI participants as coauthors? Please cite. 
5. Was the visit to PNNL supported by the NSF? Yes

6. Was the visit to PNNL partially or fully funded by the SRI mentor?

7. If you are a PNNL staff member, would you fund the travel and housing costs of an SRI participant for your research in following years, after the BES-funded project ends?

8. If you are a graduate student, did SRI-related work contribute to your M.S./Ph.D. Thesis?

9. Were any new avenues of research opened?

10. Did your work here produce any intellectual property (IP) development? (If yes, please cite only publicly available, non-business sensitive, information only)

11. Would you recommend others to apply to or participate in this program?

Please add any additional comments you wish on the intellectual, technical or scientific success of the program.

\section{Section III. The experience}

1. What aspects of the program did you feel were particularly good?

2. What can we do to improve the program?

3. What difficulties did you encounter coming here or during your stay at PNNL? 


\section{Survey Responses}

The following responses to the survey were elicited from our participants. Certain questions gave very little information and so are not included here. For example, two or three people indicated that the summer's work might lead to intellectual property; however, nothing specific was reported, so those answers are omitted here. Some visitors asked to remain anonymous and another reported some difficulties so that we judged it best to grant anonymity. In some case, obvious spelling or grammatical errors have been corrected as well. The designation N/A here means "No Answer."

\begin{tabular}{|l|l|}
\hline Participant & $\begin{array}{l}\text { Section II: Measures of success } \\
\text { II.1. Has your SRI activity been part of an on-going } \\
\text { collaboration? }\end{array}$ \\
\hline Adam Bateman & $\begin{array}{l}\text { Yes, My Ph.D. advisor, Dr. Nizkorodov, has worked with my } \\
\text { mentor here, Dr. Laskin, before. }\end{array}$ \\
\hline Sara Chamberlin & No \\
\hline Justin Cleary & No \\
\hline Shiyu Du & Yes \\
\hline Jinlong Gong & Yes \\
\hline $\begin{array}{l}\text { Win Maw Hlaing } \\
\text { Oo }\end{array}$ & Yes, it was part of EMSL proposal \#22290 \\
\hline Kirsten Johnson & Yes \\
\hline Christos Kefalidis & Yes \\
\hline $\begin{array}{l}\text { Anita } \\
\text { Lagutschenkov }\end{array}$ & Yes \\
\hline Christopher Lane & $\begin{array}{l}\text { Although we have had collaborative efforts with Greg Kimmel } \\
\text { and Nick Petrik in the past (Thomas Orlando is my advisor), our } \\
\text { collaborative project that I worked on under SRI was new. }\end{array}$ \\
\hline Chan-Woo Lee & Yes \\
\hline Jiangyu Li & Yes \\
\hline Suiqiong Li & Yes \\
\hline Jacqueline Milhans & Yes \\
\hline Leonard Nyadong & No \\
\hline Saida Y. Ortiz & No \\
\hline Florian Sieker & Yes \\
\hline Steven Tait & No \\
\hline Xia Xiang & Yes \\
\hline Zhenrong Zhang & Yes \\
\hline Peter Zink & No \\
\hline II.2. Will the SRI experience contribute to future \\
collaboration outside the summer program?
\end{tabular}




\begin{tabular}{|c|c|}
\hline Justin Cleary & Possible but I'm not sure. \\
\hline Shiyu Du & Yes \\
\hline Jinlong Gong & Yes \\
\hline $\begin{array}{l}\text { Win Maw Hlaing } \\
\text { Oo }\end{array}$ & Yes \\
\hline Kirsten Johnson & Yes \\
\hline Christos Kefalidis & Yes \\
\hline $\begin{array}{l}\text { Anita } \\
\text { Lagutschenkov }\end{array}$ & Yes \\
\hline Christopher Lane & $\begin{array}{l}\text { My laboratory at Georgia Tech is not currently working on the } \\
\text { same project, however, I have been involved with the } \\
\text { collaborative writing process since I was there a year ago. }\end{array}$ \\
\hline Chan-Woo Lee & Yes \\
\hline Jiangyu Li & Yes \\
\hline Suiqiong Li & Yes \\
\hline Jacqueline Milhans & Yes \\
\hline Leonard Nyadong & Hopefully Yes \\
\hline Saida Y. Ortiz & Yes \\
\hline Florian Sieker & Yes \\
\hline Steven Tait & Yes \\
\hline Xia Xiang & Yes \\
\hline Zhenrong Zhang & Yes \\
\hline \multirow[t]{2}{*}{ Peter Zink } & Probably \\
\hline & $\begin{array}{l}\text { II.3. Did the work contribute to your research or project } \\
\text { aims? How? }\end{array}$ \\
\hline Adam Bateman & $\begin{array}{l}\text { Yes. It allowed us to verify that some of our aerosols were being } \\
\text { chemically altered by the solvent used to extract them. }\end{array}$ \\
\hline Sara Chamberlin & $\begin{array}{l}\text { Yes; My work this summer has led to many suitable samples for } \\
\text { me to continue research on at my university. This work was key } \\
\text { in producing/obtaining such samples as well as their initial } \\
\text { characterization. }\end{array}$ \\
\hline Justin Cleary & Yes. This is the beginning of my $\mathrm{PhD}$. dissertation work. \\
\hline Shiyu Du & $\begin{array}{l}\text { Yes. I am interested in the study of the atmospherically important } \\
\text { free radicals. One of the most important way to do this type of } \\
\text { research is the theoretical calculations including quantum } \\
\text { chemical calculations and molecular dynamics simulations. }\end{array}$ \\
\hline Jinlong Gong & $\begin{array}{l}\text { Yes. The research I conducted at PNNL will be a part of my Ph.D } \\
\text { dissertation. }\end{array}$ \\
\hline $\begin{array}{l}\text { Win Maw Hlaing } \\
\text { Oo }\end{array}$ & $\begin{array}{l}\text { Yes. Growth parameters for } \mathrm{ZnO} \text { thin-film were determined } \\
\text { during the SRI. Those values can be used for the future work. }\end{array}$ \\
\hline Kirsten Johnson & $\begin{array}{l}\text { Yes - on-going research into the chemical characterization of } \\
\text { particulate matter in the Mexico City Metropolitan Area } \\
\text { (MCMA), including several journal publications and PhD thesis }\end{array}$ \\
\hline Christos Kefalidis & Yes \\
\hline Anita & Yes \\
\hline
\end{tabular}




\begin{tabular}{|c|c|}
\hline Lagutschenkov & \\
\hline Christopher Lane & $\begin{array}{l}\text { Yes, the work constituted half of my doctoral dissertation and has } \\
\text { lead to two journal publications. }\end{array}$ \\
\hline Chan-Woo Lee & $\begin{array}{l}\text { Yes. I learned many things including fundamental knowledge } \\
\text { about my research topic, effective approaches that I need to take, } \\
\text { etc. }\end{array}$ \\
\hline Jiangyu Li & Yes, by strengthening and initiating collaborations \\
\hline Suiqiong Li & $\begin{array}{l}\text { Yes. Dr. Wang has been collaborating with us on the } \\
\text { characterization of nano-scale magnetostrictive materials. }\end{array}$ \\
\hline Jacqueline Milhans & $\begin{array}{l}\text { Yes. I was able to begin the modeling in my research. I was also } \\
\text { able to do preliminary homogenization models of two phase } \\
\text { glass-ceramic materials. }\end{array}$ \\
\hline Leonard Nyadong & Yes not to a very big extent \\
\hline Saida Y. Ortiz & $\begin{array}{l}\text { Yes, I had the opportunity to use instrumentation that is not } \\
\text { available at school yet. }\end{array}$ \\
\hline Florian Sieker & $\begin{array}{l}\text { Yes. Analysis performed during my time at PNNL will be part of } \\
\text { my next publication as well as be integrated into my PhD thesis. }\end{array}$ \\
\hline Steven Tait & $\begin{array}{l}\text { Yes. The work during my SRI was a part of my Ph.D. dissertation } \\
\text { and resulted in publications. }\end{array}$ \\
\hline Xia Xiang & Yes, very helpful. \\
\hline Zhenrong Zhang & $\begin{array}{l}\text { Yes. The work ended with two publications and leads to new } \\
\text { projects that we are working on. }\end{array}$ \\
\hline Peter Zink & $\begin{array}{l}\text { Yes. I was able to directly work on my } \mathrm{PhD} \text { research during my } \\
\text { SRI experience. It was an opportunity to perform several } \\
\text { experiments I don't have access to at my home institution, and to } \\
\text { learn from experts in my field. }\end{array}$ \\
\hline & $\begin{array}{l}\text { II.4. Did the work lead to publication(s) and presentation(s) } \\
\text { with SRI participants as co-authors? Please cite. }\end{array}$ \\
\hline Adam Bateman & It will \\
\hline Sara Chamberlin & $\begin{array}{l}\text { Yes; "TiO2 Anatase(001): Initial Steps Towards Surface } \\
\text { Structure," Laboratory for Surface Studies Symposium } \\
\text { Contributed Talk, Milwaukee, August } 2007\end{array}$ \\
\hline Justin Cleary & It will lead to publications but not yet. \\
\hline Shiyu Du & $\begin{array}{l}\mathrm{Ab} \text { initio and analytical intermolecular potential for } \mathrm{ClO}-\mathrm{H} 2 \mathrm{O} \\
\text { J. Chem. Phys. 126, } 114304 \text { (2007) } \\
\text { Shiyu Du, Joseph S. Francisco, Gregory K. Schenter, and Bruce } \\
\text { C. Garrett } \\
\text { The OH radical-H2O molecular interaction potential } \\
\text { J. Chem. Phys. 124, } 224318 \text { (2006) } \\
\text { Shiyu Du, Joseph S. Francisco, Gregory K. Schenter, Tzvetelin } \\
\text { D. Iordanov, Bruce C. Garrett, Michel Dupuis, and Jun Li }\end{array}$ \\
\hline & $\begin{array}{l}\text { We also have done some other studies and are preparing these for } \\
\text { publications. We will submit this new work soon: }\end{array}$ \\
\hline
\end{tabular}




\begin{tabular}{|c|c|}
\hline & $\begin{array}{l}\text { Shiyu Du and Joseph S. Francisco, Gregory K. Schenter and } \\
\text { Bruce C. Garrett } \\
\text { Many-Body Decomposition of the Binding Energies for } \\
\mathrm{OH} \mathrm{(H2O)2} \mathrm{and} \mathrm{OH}(\mathrm{H} 2 \mathrm{O}) 3 \text { Complexes (submitted to J. } \\
\text { Chem. Phys.) }\end{array}$ \\
\hline Jinlong Gong & Yes but still in preparation. \\
\hline $\begin{array}{l}\text { Win Maw Hlaing } \\
\text { Oo }\end{array}$ & A manuscript is under preparation \\
\hline Kirsten Johnson & $\begin{array}{l}\text { Yes } \\
\text { PUBLICATIONS } \\
\text { Johnson, K.S., B. de Foy, B. Zuberi, L.T. Molina, M.J. Molina, } \\
\text { A. Laskin, Y. Xie, V. Shutthanandan, "Aerosol composition and } \\
\text { source apportionment in the Mexico City Metropolitan Area with } \\
\text { PIXE/PESA/STIM and multivariate analysis", Atmos. Chem. } \\
\text { Phys., 6, 4591-4600, } 2006 . \\
\text { Johnson, K.S., B. Zuberi, L.T. Molina, M.J. Molina, A. Laskin, } \\
\text { J.P. Cowin, "Processing of soot in an urban environment: case } \\
\text { study from the Mexico City Metropolitan Area" Atmos. Chem. } \\
\text { Phys., 5, 3033-3043, 2005. } \\
\text { Johnson, K.S. "Chemistry of carbonaceous aerosols: studies of } \\
\text { atmospheric processing and OH-initiated oxidation", MIT thesis, } \\
\text { 2007. } \\
\text { INVITED PRESENTATION } \\
\text { Johnson, K.S., PIXE-2007 (Proton-Induced X-Ray Emission) } \\
\text { International Conference, May 25-29, 2007, Puebla, Mexico. } \\
\text { OTHER PRESENTATION } \\
\text { Johnson, K.S., B. Zuberi, L.T. Molina, M.J. Molina, A. Laskin, } \\
\text { M.J. Iedema, J.P. Cowin, D.J. Gaspar, C. Wang, } \\
\text { "Characterization and atmospheric processing of soot aerosols in } \\
\text { Mexico City", 2004 National Meeting of the American } \\
\text { Geophysical Union, San Francisco, CA. }\end{array}$ \\
\hline Christos Kefalidis & $\begin{array}{l}\text { A publication concerning the work I did during the SRI program } \\
\text { is on the way. } \\
\text { In addition, I gave a presentation in a Seminar which took a place } \\
\text { at Girona, Spain with the following topic "The nature of the } \\
\text { chemical bonding". The title of the presentation was "Ligand } \\
\text { effects in transition metal coordination compounds: Rendering a } \\
\text { molecular picture to electrochemical results". For further } \\
\text { information please go to http://iqc.udg.es/gsncb2006/inici.html }\end{array}$ \\
\hline Anita & Journal of Chemical Physics, (2005), 122(19), 194310/1- \\
\hline
\end{tabular}




\begin{tabular}{|c|c|}
\hline Lagutschenkov & $194310 / 9$. \\
\hline Christopher Lane & $\begin{array}{l}\text { "Low-Energy Electron Induced Processes in Molecular Thin } \\
\text { Films Condensed on Silicon and Titanium Dioxide Surfaces". } \\
\text { Christopher D. Lane, 2007. doctoral dissertation, Georgia } \\
\text { Institute of Technology } \\
\text { Christopher D. Lane, Nikolay G. Petrik, Thomas M. Orlando, and } \\
\text { Greg A. Kimmel. Electron-stimulated oxidation of thin water } \\
\text { films adsorbed on TiO2(110). J. Chem. Phys. C. (accepted). } \\
\text { Christopher D. Lane, Nikolay G. Petrik, Thomas M. Orlando, and } \\
\text { Greg A. Kimmel. Site-dependent electron-stimulated reactions in } \\
\text { water films on TiO2(110). J. Chem. Phys. C. (submitted) }\end{array}$ \\
\hline Chan-Woo Lee & $\begin{array}{l}\text { 1. "Thermodynamic/Chemical Properties of LaFeO3 from First- } \\
\text { Principles Calculations: Implications for Use as SOFC } \\
\text { Cathodes", 31st International Cocoa Beach Conference \& } \\
\text { Exposition on Advanced Ceramics \& Composites } \\
\text { 2. "Chemical Properties of LaFeO3 from First Principles } \\
\text { Calculations: Implications for Use as SOFC Cathodes", Gordon } \\
\text { conference: Ceramics, Solid State Studies In }\end{array}$ \\
\hline Jiangyu Li & Not yet \\
\hline Suiqiong Li & $\begin{array}{l}\text { The work lead to a proceeding published at MRS conference. } \\
\text { Title: Characterization of Microstructure and Composition of Fe- } \\
\text { B Nanobars as Biosensor Platform } \\
\text { Authors: Suiqiong Li, Liling Fu, Chongmin Wang, Scott Lea, } \\
\text { Bruce Arey, Mark Engelhard, Z.-Y. Cheng } \\
\text { MRS Proceedings Volume 962E, Paper \#: 0962-P09-14 }\end{array}$ \\
\hline Julie Lloyd & $\begin{array}{l}\text { Last summer's work is actually fairly unlikely to appear in a } \\
\text { publication because the quality of the data is poor. Although the } \\
\text { idea is/was novel, a shortage of time and the early stage of } \\
\text { development of the instrumentation will not allow a quality } \\
\text { publication to result. }\end{array}$ \\
\hline Jacqueline Milhans & Pending \\
\hline Leonard Nyadong & Not yet \\
\hline Saida Y. Ortiz & Not yet \\
\hline Florian Sieker & $\begin{array}{l}\text { Sieker, F., Straatsma, T. P., Zacharias, M. Analysis of MHC class } \\
\text { I peptide dissociation by molecular dynamics simulation. In } \\
\text { preparation. }\end{array}$ \\
\hline Steven Tait & $\begin{array}{l}\text { S. L. Tait, Z. Dohnálek, C. T. Campbell, B. D. Kay, } \\
\text { "n-Alkanes on Pt(111) and C(0001) / Pt(111): Chain-length } \\
\text { Scaling of Kinetic Desorption Parameters," } \\
\text { Journal of Chemical Physics, 125, 234308 (2006). } \\
\text { S. L. Tait, Z. Dohnálek, C. T. Campbell, B. D. Kay, } \\
\text { "Methane Adsorption and Dissociation and Oxygen Adsorption } \\
\text { and Reaction with CO on Pd Nanoparticles on MgO(100) and on }\end{array}$ \\
\hline
\end{tabular}




\begin{tabular}{|c|c|}
\hline & $\begin{array}{l}\text { Pd(111)," } \\
\text { Surface Science, 591, 90-107 (2005). } \\
\text { Steven L. Tait, Ph.D. Dissertation, University of Washington, } \\
2005 .\end{array}$ \\
\hline Xia Xiang & I am still drafting the manuscript. \\
\hline Zhenrong Zhang & $\begin{array}{l}\text { a. Z. Zhang, O. Bondarchuk, J. M. White, B. D. Kay, Z. } \\
\text { Dohnálek, Imaging adsorbate O-H bond cleavage: Methanol on } \\
\text { TiO2(110), J. Am. Chem. Soc. } 128 \text { (2006) } 4198 \text {. } \\
\text { b. Z. Zhang, O. Bondarchuk, B.D. Kay, J. M. White, Z. } \\
\text { Dohnálek, Direct visualization of 2-butanol adsorption and } \\
\text { dissociation on TiO2(110), J. Phys. Chem. C; 111(7) } 20073021 . \\
\text { c. Z. Zhang, O. Bondarchuk, J. M. White, B. D. Kay, Z. } \\
\text { Dohnálek, Atomically resolved imaging of alcohol adsorption on } \\
\text { TiO2(110), oral presentation in 232nd ACS National Meeting } \\
\text { (San Francisco, CA, 2006) } \\
\text { d. Z. Zhang, O. Bondarchuk, J. M. White, B. D. Kay, Z. } \\
\text { Dohnálek, Atomic resolved adsorption of alcohols on TiO2(110) } \\
\text { investigated by in situ scanning tunneling microscopy, oral } \\
\text { presentation in 2005 Symposium of the Pacific Northwest } \\
\text { Chapter of the AVS }\end{array}$ \\
\hline \multirow[t]{2}{*}{ Peter Zink } & $\begin{array}{l}\text { Yes, it likely will, two papers are in progress, but nothing to cite } \\
\text { yet. }\end{array}$ \\
\hline & II.5. Was the visit to PNNL supported by the NSF? \\
\hline Adam Bateman & No \\
\hline Sara Chamberlin & No \\
\hline Justin Cleary & No \\
\hline Shiyu Du & Yes \\
\hline Jinlong Gong & No \\
\hline $\begin{array}{l}\text { Win Maw Hlaing } \\
\text { Oo }\end{array}$ & Yes \\
\hline Kirsten Johnson & Yes \\
\hline Christos Kefalidis & Yes \\
\hline $\begin{array}{l}\text { Anita } \\
\text { Lagutschenkov }\end{array}$ & No \\
\hline Christopher Lane & Yes \\
\hline Chan-Woo Lee & Yes \\
\hline Jiangyu Li & No \\
\hline Suiqiong Li & Yes \\
\hline Jacqueline Milhans & No \\
\hline Leonard Nyadong & Yes \\
\hline Saida Y. Ortiz & No \\
\hline Florian Sieker & No \\
\hline Steven Tait & No \\
\hline Xia Xiang & No \\
\hline Zhenrong Zhang & Yes \\
\hline
\end{tabular}




\begin{tabular}{|c|c|}
\hline Peter Zink & No \\
\hline & $\begin{array}{l}\text { II.8. If you are a graduate student, did SRI-related work } \\
\text { contribute to your M.S./Ph.D. Thesis? }\end{array}$ \\
\hline Adam Bateman & $\begin{array}{l}\text { This is an important first step and will help. I do not know if I } \\
\text { will continue working on this particular aerosol project or not. }\end{array}$ \\
\hline Sara Chamberlin & Yes \\
\hline Justin Cleary & Yes \\
\hline Shiyu Du & Yes. related to my $\mathrm{Ph} . \mathrm{D}$ thesis \\
\hline Jinlong Gong & Yes \\
\hline $\begin{array}{l}\text { Win Maw Hlaing } \\
\text { Oo }\end{array}$ & Yes \\
\hline Kirsten Johnson & Yes \\
\hline Christos Kefalidis & Yes \\
\hline $\begin{array}{l}\text { Anita } \\
\text { Lagutschenkov }\end{array}$ & Yes, it will, although not as main topic. \\
\hline Christopher Lane & Yes \\
\hline Chan-Woo Lee & Yes \\
\hline Jiangyu Li & n/a, Faculty \\
\hline Suiqiong Li & $\begin{array}{l}\text { Yes. The work I have done at SRI was the main content of a } \\
\text { chapter of my } \mathrm{Ph} \text {. D. dissertation. }\end{array}$ \\
\hline Julie Lloyd & $\begin{array}{l}\text { This work will most likely be a small chapter of my Ph.D. thesis. } \\
\text { I feel that I gained more experience and general knowledge rather } \\
\text { than physical data and conclusions to contribute to my thesis. }\end{array}$ \\
\hline Leonard Nyadong & Hopefully yes \\
\hline Saida Y. Ortiz & Yes \\
\hline Florian Sieker & Yes \\
\hline Steven Tait & Yes \\
\hline Xia Xiang & Yes \\
\hline Zhenrong Zhang & n/a Postdoc \\
\hline Peter Zink & Yes \\
\hline & II.9. Were any new avenues of research opened \\
\hline Adam Bateman & $\begin{array}{l}\text { I came with the intention of studying the aerosol particles } \\
\text { themselves and ended up running tests on how representative } \\
\text { chemicals were changed by solvents used to extract the aerosols. } \\
\text { So, yes. }\end{array}$ \\
\hline Sara Chamberlin & Yes \\
\hline Justin Cleary & Not sure yet \\
\hline Shiyu Du & Yes \\
\hline Jinlong Gong & $\mathrm{n} / \mathrm{a}$ \\
\hline $\begin{array}{l}\text { Win Maw Hlaing } \\
\text { Oo }\end{array}$ & Yes \\
\hline Kirsten Johnson & Yes \\
\hline Christos Kefalidis & Yes \\
\hline $\begin{array}{l}\text { Anita } \\
\text { Lagutschenkov }\end{array}$ & Yes \\
\hline
\end{tabular}




\begin{tabular}{|c|c|}
\hline Christopher Lane & Yes \\
\hline Chan-Woo Lee & Yes \\
\hline Jiangyu Li & Yes \\
\hline Suiqiong Li & No \\
\hline Julie Lloyd & No \\
\hline Jacqueline Milhans & Yes \\
\hline Leonard Nyadong & No \\
\hline Saida Y. Ortiz & Yes \\
\hline Florian Sieker & Yes \\
\hline Steven Tait & No \\
\hline Xia Xiang & Yes \\
\hline Zhenrong Zhang & Yeah \\
\hline \multirow[t]{2}{*}{ Peter Zink } & $\begin{array}{l}\text { Not opened, but the direction changed due to some of the } \\
\text { findings. }\end{array}$ \\
\hline & $\begin{array}{l}\text { II.11. Would you recommend others to apply to or participate } \\
\text { in this program? Please add any additional comments you } \\
\text { wish on the intellectual, technical or scientific success of the } \\
\text { program. }\end{array}$ \\
\hline Adam Bateman & $\begin{array}{l}\text { Yes, I feel that the opportunity to research with high-tech tools } \\
\text { and brand-new instruments is rare in graduate school. It allows } \\
\text { becoming a scientist and not a technician. I feel that everything } \\
\text { ran very smoothly. I was initiated and oriented into the lab very } \\
\text { quickly and smoothly. I always had either my mentor or a lab } \\
\text { post-doc to help me and answer my questions. I am very excited } \\
\text { to publish my results, although still a ways away, I have had my } \\
\text { first taste of successful research, and am very appreciative of that. }\end{array}$ \\
\hline Sara Chamberlin & $\begin{array}{l}\text { Yes; I believe that anyone participating in the program can } \\
\text { benefit immensely from it. The quality of people and facilities } \\
\text { that were available is not something always found in the } \\
\text { university setting. And as a graduate student, being able to work } \\
\text { with some of the top people in your field and expanding your } \\
\text { knowledge and skills in that field are invaluable experiences. }\end{array}$ \\
\hline Justin Cleary & $\begin{array}{l}\text { Definitely. Working at a real laboratory Is an experience that all } \\
\text { students should have at some point before they get to their PhD. } \\
\text { level. }\end{array}$ \\
\hline Shiyu Du & Yes \\
\hline Jinlong Gong & Yes \\
\hline $\begin{array}{l}\text { Win Maw Hlaing } \\
\text { Oo }\end{array}$ & Yes \\
\hline Kirsten Johnson & $\begin{array}{l}\text { Yes - wonderful opportunity to collaborate with many top-notch } \\
\text { scientists with a wide variety of quality instrumentation. }\end{array}$ \\
\hline Christos Kefalidis & Yes \\
\hline $\begin{array}{l}\text { Anita } \\
\text { Lagutschenkov }\end{array}$ & Yes, definitely. \\
\hline Christopher Lane & $\begin{array}{l}\text { Of course, this program is an opportunity to interact with brilliant } \\
\text { scientists and learn/use laboratory equipment that simply is not }\end{array}$ \\
\hline
\end{tabular}




\begin{tabular}{|c|c|}
\hline & available in most university research groups. \\
\hline Chan-Woo Lee & Yes \\
\hline Jiangyu Li & Yes \\
\hline Julie Lloyd & $\begin{array}{l}\text { Yes and no. I would say yes because the program itself is very } \\
\text { well organized and provides graduate students with an excellent } \\
\text { opportunity to work in a lab outside of their university, to have } \\
\text { access to state-of-the-art facilities, and to network with scientists } \\
\text { who are well known in their respective fields. The reason that I } \\
\text { would say no relates to the relationship with the mentors in the } \\
\text { program. A student absolutely must be in contact with the } \\
\text { mentor before arriving at PNNL. There did seem to be } \\
\text { components built into the application process to ensure contact } \\
\text { with the mentor; however in reality, the program did not make } \\
\text { this a requirement. With only } 10 \text { short weeks to conduct research } \\
\text { within the walls of PNNL, the student and mentor need to set } \\
\text { realistic project goals, and the student must be better prepared on } \\
\text { background aspects of the project in order to be more productive } \\
\text { during his/her stay. }\end{array}$ \\
\hline Jacqueline Milhans & $\begin{array}{l}\text { Yes, the program was very helpful. The people I worked with } \\
\text { were very helpful in research directions and helping accomplish } \\
\text { some of my research goals. }\end{array}$ \\
\hline Leonard Nyadong & Yes \\
\hline Saida Y. Ortiz & Yes \\
\hline Florian Sieker & Yes \\
\hline Steven Tait & Yes \\
\hline Xia Xiang & $\begin{array}{l}\text { Yes. It is a good opportunity to learn technical skills and do } \\
\text { research. }\end{array}$ \\
\hline Zhenrong Zhang & Yes \\
\hline \multirow[t]{3}{*}{ Peter Zink } & $\begin{array}{l}\text { Yes. It was a great opportunity to learn new experimental } \\
\text { methods and techniques, and has significantly furthered my } \mathrm{PhD} \\
\text { research progress. }\end{array}$ \\
\hline & SECTION III. The Experience \\
\hline & $\begin{array}{l}\text { III.1. What aspects of the program did you feel were } \\
\text { particularly good? }\end{array}$ \\
\hline Adam Bateman & The ability to work in a high-class research environment. \\
\hline Sara Chamberlin & $\begin{array}{l}\text { There are so many resources at PNNL that I had access to during } \\
\text { my stay. This allowed me to not only further my research, but } \\
\text { learn and use new techniques beyond those which I use at my } \\
\text { university and in general broaden myself professionally. }\end{array}$ \\
\hline Justin Cleary & Everything in the program ran smoothly. \\
\hline Shiyu Du & Communicating with people. \\
\hline Jinlong Gong & Academia environment \\
\hline Kirsten Johnson & $\begin{array}{l}\text { Collaborations; opportunity to meet and network with other } \\
\text { participants }\end{array}$ \\
\hline Christos Kefalidis & Everything was great \\
\hline Anita & The overall organisation and help in travel arrangements. Also \\
\hline
\end{tabular}




\begin{tabular}{|c|c|}
\hline Lagutschenkov & the possibilities to visit and speak to other research groups. \\
\hline Christopher Lane & $\begin{array}{l}\text { No particular aspects come to mind, but my overall research } \\
\text { experience and visit were very rewarding and enjoyable. }\end{array}$ \\
\hline Chan-Woo Lee & Allowing students to have various experiences \\
\hline Jiangyu Li & Interacting with PNNL staff \\
\hline Suiqiong Li & $\begin{array}{l}\text { I was able to work with my mentor and other PNNL staff } \\
\text { together, discuss problems, and get advices from them. I also got } \\
\text { diversified research experience. }\end{array}$ \\
\hline Julie Lloyd & $\begin{array}{l}\text { 1) The orientation - completion of appropriate training courses, } \\
\text { office set-up, knowing who to ask about issues that may arise, } \\
\text { etc. } \\
\text { 2) Outside the lab activities (i.e. BBQ and the lecture series) }\end{array}$ \\
\hline Jacqueline Milhans & $\begin{array}{l}\text { The research environment and the support from my mentor. } \\
\text { Also, social events among the students were great to meet people. }\end{array}$ \\
\hline Leonard Nyadong & The organization \\
\hline Saida Y. Ortiz & $\begin{array}{l}\text { Two major aspect : Interacting with experts in the field and } \\
\text { gaining knowledge from their experience, and the opportunity to } \\
\text { use the instrumentation available. }\end{array}$ \\
\hline Florian Sieker & Well organized, broad spectrum of research areas. \\
\hline Steven Tait & $\begin{array}{l}\text { Opportunity to interact with PNNL scientists. Excellent support } \\
\text { from scientific and administrative staff in EMSL. }\end{array}$ \\
\hline Xia Xiang & $\begin{array}{l}\text { I have an opportunity to make use of the equipment to do } \\
\text { research in the lab. }\end{array}$ \\
\hline Zhenrong Zhang & $\begin{array}{l}\text { The state-of-art apparatus, working with the world class chemist } \\
\text { and physicists. }\end{array}$ \\
\hline Peter Zink & $\begin{array}{l}\text { I was able to work on my own research, and was largely } \\
\text { unsupervised, though there were lots of friendly people available } \\
\text { to help me when I needed assistance or guidance. }\end{array}$ \\
\hline & III.2. What can we do to improve the program? \\
\hline Adam Bateman & $\begin{array}{l}\text { T-shirts would be cool. Perhaps have a seminar series from the } \\
\text { students participants. I think it would have been cool to see what } \\
\text { others were doing, as well as share my own project. }\end{array}$ \\
\hline Sara Chamberlin & $\begin{array}{l}\text { I cannot think of any suggestions - I found it to be an excellent, } \\
\text { well organized program. }\end{array}$ \\
\hline Justin Cleary & $\begin{array}{l}\text { Only the training modules need to be Improved. The IOPS } \\
\text { website continued telling me that certain training modules or } \\
\text { forms were needed when they were already completed multiple } \\
\text { times. }\end{array}$ \\
\hline Shiyu Du & $\begin{array}{l}\text { It is a great program that has given me an opportunity to } \\
\text { collaborate with great scientist. }\end{array}$ \\
\hline Jinlong Gong & $\mathrm{n} / \mathrm{a}$ \\
\hline Kirsten Johnson & $\begin{array}{l}\text { Provide a contact list of all participants at the beginning of the } \\
\text { program to facilitate informal get-togethers }\end{array}$ \\
\hline Christos Kefalidis & I think everything is well organized and you are doing fine job. \\
\hline $\begin{array}{l}\text { Anita } \\
\text { Lagutschenkov }\end{array}$ & $\begin{array}{l}\text { Maybe the program should be more fixed to a certain time in the } \\
\text { year. Although this is good with respect to people being more }\end{array}$ \\
\hline
\end{tabular}




\begin{tabular}{|c|c|}
\hline & $\begin{array}{l}\text { flexible in choosing when to come, I was a bit sorry that there } \\
\text { were only few people left when I arrived in August. So } \\
\text { unfortunately my overlap with the other SRI participants was } \\
\text { small. }\end{array}$ \\
\hline Christopher Lane & $\begin{array}{l}\text { During the two month time that I was there, I believe we had a } \\
\text { couple social events. Increasing the frequency of these events } \\
\text { would be more beneficial for meeting people and assembling } \\
\text { groups to take excursions outside of Richland such as wine } \\
\text { tastings and Mt. Rainier. }\end{array}$ \\
\hline Julie Lloyd & $\begin{array}{l}\text { 1) Ensure that contacts are made between mentors and students } \\
\text { before arriving at PNNL. } \\
\text { 2) Hold other SRI participant activities - i.e. lunch round tables - } \\
\text { some other means of meeting the other participants in the } \\
\text { program and learning about their respective projects. }\end{array}$ \\
\hline Jacqueline Milhans & $\begin{array}{l}\text { It was difficult to meet people at first, so maybe start an e-mail } \\
\text { list when the earliest people arrive, so that the students may } \\
\text { contact each other. }\end{array}$ \\
\hline Leonard Nyadong & $\begin{array}{l}\text { Provide access to SRI participant into other labs which might be } \\
\text { the only opportunity to see some really cool instruments, may be } \\
\text { in the form of tours }\end{array}$ \\
\hline Florian Sieker & $\begin{array}{l}\text { Reduce the administrative overhead. Why does one have to deal } \\
\text { with at least } 2 \text { administrators one from SRI and the other one } \\
\text { from SEE? Set up a weekly seminar for participants to present } \\
\text { their work and get in touch with each other. }\end{array}$ \\
\hline Steven Tait & $\begin{array}{l}\text { Housing was a little tricky to coordinate - had to stay in south } \\
\text { Richland. }\end{array}$ \\
\hline Xia Xiang & Nothing so far. It is good. \\
\hline \multirow[t]{2}{*}{ Peter Zink } & $\begin{array}{l}\text { In my case, as I drove to PNNL, I was able to bring some of my } \\
\text { research materials with me, which significantly accelerated my } \\
\text { experience. It would have been even more helpful to know more } \\
\text { specifically what resources would have been available to me, so } \\
\text { that I could have brought exactly what I needed. This is } \\
\text { something that probably would have to have occurred through } \\
\text { more specific discussions with my advisor. }\end{array}$ \\
\hline & $\begin{array}{l}\text { III. 3. What difficulties did you encounter coming here or } \\
\text { during your stay at PNNL? }\end{array}$ \\
\hline Adam Bateman & Being away from home, family and friends for 8 weeks was hard. \\
\hline Sara Chamberlin & $\begin{array}{l}\text { The only minor difficulty that I had was in getting the necessary } \\
\text { paperwork/agreements returned to PNNL as quickly as they were } \\
\text { requested. One in particular required a letter/signature from my } \\
\text { department, and it can be challenging to acquire such things in } \\
\text { only a few days time. }\end{array}$ \\
\hline Justin Cleary & $\begin{array}{l}\text { The main difficulty was the lack of transportation. Maybe PNNL } \\
\text { could offer some type of shuttle service to take groups of students } \\
\text { to the grocery store at some times. The students generally had to }\end{array}$ \\
\hline
\end{tabular}




\begin{tabular}{|c|c|}
\hline & rely on other people for rides. \\
\hline Shiyu Du & None \\
\hline Jinlong Gong & $\mathrm{n} / \mathrm{a}$ \\
\hline $\begin{array}{l}\text { Win Maw Hlaing } \\
\text { Oo }\end{array}$ & I did not have any difficulties during my stay. \\
\hline Kirsten Johnson & Transportation from the housing facility \\
\hline Christos Kefalidis & Everything was really great. \\
\hline $\begin{array}{l}\text { Anita } \\
\text { Lagutschenkov }\end{array}$ & $\begin{array}{l}\text { Missing public transport from the guest house to town. } \\
\text { Without a car you are really lost at the PNNL guest house. Maybe } \\
\text { I was the only one with this problems, but coming from Europe I } \\
\text { was used to have the chance to take a bus or something. And it } \\
\text { was not affordable to rent a car for the whole two months. }\end{array}$ \\
\hline Christopher Lane & $\begin{array}{l}\text { Transportation could be a small issue specifically traveling } \\
\text { outside of Richland. If I had not brought my car, myself and two } \\
\text { other SRI participants would not have visited Mt. Rainier and Mt. } \\
\text { St. Helens. Besides research, visiting these places made the trip } \\
\text { for me. }\end{array}$ \\
\hline Chan-Woo Lee & $\begin{array}{l}\text { Renting apartment was quite expensive. This was the only } \\
\text { problem that I had. }\end{array}$ \\
\hline Julie Lloyd & $\begin{array}{l}\text { 1) Not having regular, effective contact with my mentor. } \\
\text { 2) Finding inexpensive transportation for evenings and weekends. }\end{array}$ \\
\hline e Milhans & It is difficult to live in the Tri-Cities area without a car. \\
\hline I Nyadong & Going around for shopping etc when at PNNL was not very easy \\
\hline Florian Sieker & $\begin{array}{l}\text { The most difficult aspect is the fact that PNNL is located to far } \\
\text { away from everything else. So one has to decide whether to live } \\
\text { on campus and have difficulties to get bread-and-butter or to live } \\
\text { off campus and have difficulties to get to PNNL. Unless you can } \\
\text { afford buying a car of course. }\end{array}$ \\
\hline Tait & $\begin{array}{l}\text { Long bicycle commute to apartment - not really a big problem. It } \\
\text { went very well. }\end{array}$ \\
\hline Xia Xiang & $\begin{array}{l}\text { I did not get access to the lab using my badge in the first several } \\
\text { weeks. }\end{array}$ \\
\hline Peter Zink & I wasn't used to the heat. :) \\
\hline
\end{tabular}

\begin{tabular}{|c|c|}
\hline Faculty or & Section II: Measures of success \\
\hline & $\begin{array}{l}\text { II.1. Has your SRI activity been part of an on-going } \\
\text { collaboration? }\end{array}$ \\
\hline Mark A. Barteau & No \\
\hline $\begin{array}{l}\text { Alexander I. } \\
\text { Boldyrev }\end{array}$ & $\begin{array}{l}\text { My Ph. D. graduate students Anastassia N. Alexandrova and M. } \\
\text { S. graduate student Ben Elliott participated in Summer Research } \\
\text { Institute } 2004\end{array}$ \\
\hline Anter A. El-Azab & Yes \\
\hline Facundo & Yes \\
\hline
\end{tabular}




\begin{tabular}{|c|c|}
\hline Fernandez & \\
\hline Carol Hirschmugl & No \\
\hline Kenneth D. Jordan & No \\
\hline Matt McCluskey & Yes \\
\hline Uday B Pal & No \\
\hline J.M. White & Yes and multiple very productive collaboration. \\
\hline & $\begin{array}{l}\text { II.2. Will the SRI experience contribute to future } \\
\text { collaboration outside the summer program? }\end{array}$ \\
\hline Mark A. Barteau & Possibly \\
\hline $\begin{array}{l}\text { Alexander I. } \\
\text { Boldyrev }\end{array}$ & Yes \\
\hline Anter A. El-Azab & Yes \\
\hline $\begin{array}{l}\text { Facundo } \\
\text { Fernandez }\end{array}$ & Yes \\
\hline Carol Hirschmugl & $\begin{array}{l}\text { Yes, this is I believe the beginning of a new collaboration } \\
\text { between my group at UW-Milwaukee and EMSL. }\end{array}$ \\
\hline Kenneth D. Jordan & Highly likely \\
\hline Matt McCluskey & Yes \\
\hline Uday B Pal & I hope so \\
\hline J.M. White & Yes it has and will continue to do so. \\
\hline & $\begin{array}{l}\text { II.3. Did the work contribute to your research or project } \\
\text { aims? How? }\end{array}$ \\
\hline Mark A. Barteau & $\begin{array}{l}\text { Not directly. The principal aim was to expose the student to } \\
\text { additional experimental techniques beyond those involved in her } \\
\text { thesis research. }\end{array}$ \\
\hline $\begin{array}{l}\text { Alexander I. } \\
\text { Boldyrev }\end{array}$ & $\begin{array}{l}\text { My students (theoreticians) gained important experience to work } \\
\text { with experimentalists (Prof. Lai-Sheng Wang group). That } \\
\text { experience was especially important to Ben Elliott, who decided } \\
\text { to become an experimentalist after he graduated from Utah State } \\
\text { University. Ben Elliott is currently a graduate student at Yale } \\
\text { University, where he is doing experimental work similar he was } \\
\text { able to observe at PNNL during SRI. Anastassia Alexanderova is } \\
\text { a post-doc at Yale, where established a collaboration with Prof, } \\
\text { Mark Johnson group on similar type of research she was involved } \\
\text { at SRI. }\end{array}$ \\
\hline Anter A. El-Azab & Yes \\
\hline $\begin{array}{l}\text { Facundo } \\
\text { Fernandez }\end{array}$ & Moderately. \\
\hline Carol Hirschmugl & $\begin{array}{l}\text { Yes, I have designed and commissioned a new LEED instrument } \\
\text { that works with very low current electron beams. This is } \\
\text { optimized to study the structure of insulators and oxides. The } \\
\text { samples that have been grown during this experience will be used } \\
\text { for these experiments on a difficult to obtain, but catalytically } \\
\text { important, crystal surface. }\end{array}$ \\
\hline Kenneth D. Jordan & $\begin{array}{l}\text { Yes, it gave one of my students valuable experience with MD } \\
\text { simulations of interfaces }\end{array}$ \\
\hline
\end{tabular}




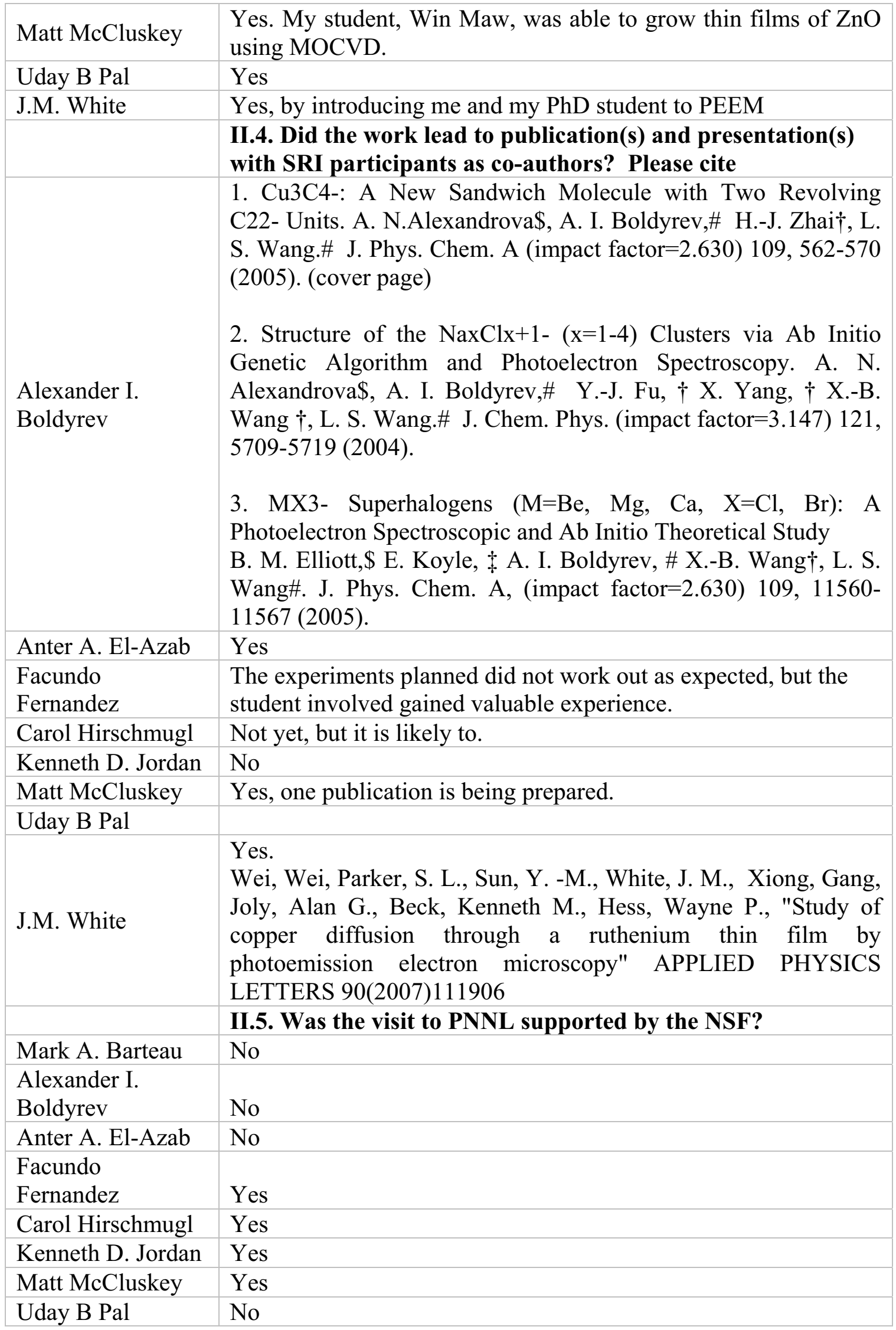




\begin{tabular}{|c|c|}
\hline J.M. White & Yes \\
\hline & $\begin{array}{l}\text { II.8. If you are a graduate student, did SRI-related work } \\
\text { contribute to your M.S./Ph.D. Thesis? }\end{array}$ \\
\hline $\begin{array}{l}\text { Alexander I. } \\
\text { Boldyrev }\end{array}$ & $\begin{array}{l}\text { The SRI-related work contributed to Ben Elliott M.S. degree and } \\
\text { Anatassia Alexandrova Ph. D. degree. }\end{array}$ \\
\hline Anter A. El-Azab & $\begin{array}{l}\text { I am not the student, but I can tell you that this SRI experience } \\
\text { contributed to my student's thesis. }\end{array}$ \\
\hline $\begin{array}{l}\text { Facundo } \\
\text { Fernandez }\end{array}$ & $\begin{array}{l}\text { My student who participated in the SRI, Leonard Nyadong, is a } \\
\text { PhD candidate and this work will contribute to his dissertation. }\end{array}$ \\
\hline Carol Hirschmugl & $\begin{array}{l}\text { Yes, the work will definitely contribute to Sara Chamberlin's PhD } \\
\text { thesis. }\end{array}$ \\
\hline Matt McCluskey & Yes, this work will contribute to Win Maw's Ph.D. thesis \\
\hline Uday B Pal & Yes \\
\hline & II.9. Were any new avenues of research opened? \\
\hline Anter A. El-Azab & Yes \\
\hline $\begin{array}{l}\text { Facundo } \\
\text { Fernandez }\end{array}$ & Several, and we plan to continue collaborating \\
\hline Kenneth D. Jordan & No \\
\hline Matt McCluskey & $\begin{array}{l}\text { Yes. We have never done MOCVD growth before, so this opens } \\
\text { up a new collaboration. }\end{array}$ \\
\hline Uday B Pal & ( \\
\hline J.M. White & Yes, PEEM in the most recent student -- David Wei \\
\hline & $\begin{array}{l}\text { II.11. Would you recommend others to apply to or participate } \\
\text { in this program? } \\
\text { Please add any additional comments you wish on the } \\
\text { intellectual, technical or scientific success of the program. }\end{array}$ \\
\hline $\begin{array}{l}\text { Alexander I. } \\
\text { Boldyrev }\end{array}$ & Yes \\
\hline Anter A. El-Azab & Yes \\
\hline $\begin{array}{l}\text { Facundo } \\
\text { Fernandez }\end{array}$ & $\begin{array}{l}\text { yes, this program is very valuable from many angles. Not only the } \\
\text { raw scientific productivity should be taken into account but most } \\
\text { importantly, the experience of a PhD to be exposed to the EMSL } \\
\text { environment }\end{array}$ \\
\hline Carol Hirschmugl & No \\
\hline Kenneth D. Jordan & Yes \\
\hline Matt McCluskey & $\begin{array}{l}\text { Yes. The link between area universities and PNNL is extremely } \\
\text { important. }\end{array}$ \\
\hline Uday B Pal & \\
\hline J.M. White & $\begin{array}{l}\text { Yes, I have done so and will continue to do so. There are two } \\
\text { students from Mullin's group at Texas participating in the } \\
\text { summer } 2007 \text { program. }\end{array}$ \\
\hline & SECTION III. The Experience \\
\hline & $\begin{array}{l}\text { III.1. What aspects of the program did you feel were } \\
\text { particularly good? }\end{array}$ \\
\hline Anter A. El-Azab & the interaction of many scientists in a multidisciplinary \\
\hline
\end{tabular}




\begin{tabular}{|c|c|}
\hline & environment \\
\hline $\begin{array}{l}\text { Facundo } \\
\text { Fernandez }\end{array}$ & The application process was very streamlined. \\
\hline Carol Hirschmugl & $\begin{array}{l}\text { The interaction with a group of scientists who have a wide } \\
\text { breadth of knowledge and expertise. }\end{array}$ \\
\hline \multicolumn{2}{|l|}{ Uday B Pal } \\
\hline \multirow[t]{2}{*}{ J.M. White } & $\begin{array}{l}\text { Very good interactions with staff and exposure to a broadening } \\
\text { research enterprise. }\end{array}$ \\
\hline & III.2. What can we do to improve the program? \\
\hline Mark A. Barteau & $\begin{array}{l}\text { Needed a clearer picture of potential advisors and projects before } \\
\text { applying. The call made it look like the projects were flexible, } \\
\text { but in fact they were highly constrained by the ongoing research } \\
\text { of PNNL staff. }\end{array}$ \\
\hline Anter A. El-Azab & $\begin{array}{l}\text { nothing - just keep it going - such programs should always exist } \\
\text { because of the high impact on widening the perspective of } \\
\text { graduate students approaching their thesis or dissertation research } \\
\text { problems. }\end{array}$ \\
\hline $\begin{array}{l}\text { Facundo } \\
\text { Fernandez }\end{array}$ & $\begin{array}{l}\text { Program works well as is. Seed grants would solidify the } \\
\text { collaborations started via the SRI7 }\end{array}$ \\
\hline \multicolumn{2}{|l|}{ Uday B Pal } \\
\hline \multirow[t]{2}{*}{ J.M. White } & $\begin{array}{l}\text { Keep it like it is now -- it works well in my opinion and is } \\
\text { organized at an appropriately flexible level -- my experience says } \\
\text { "It is easy to overorganize these summer programs." }\end{array}$ \\
\hline & $\begin{array}{l}\text { III.3. What difficulties did you encounter coming here or } \\
\text { during your stay at PNNL? }\end{array}$ \\
\hline $\begin{array}{l}\text { Alexander I. } \\
\text { Boldyrev }\end{array}$ & My students did not have any problems. \\
\hline Anter A. El-Azab & Don't know \\
\hline $\begin{array}{l}\text { Facundo } \\
\text { Fernandez }\end{array}$ & None \\
\hline Uday B Pal & None \\
\hline J.M. White & None \\
\hline
\end{tabular}



Kenneth M. Beck

Coordinator

ICPCPSRI

(509) 376-9152

Email: cpsi.pnl.gov

Website: http://www.pnl.gov/si 